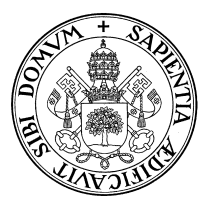

\title{
MATRICES DE CONTABILIDAD SOCIAL Y
DISTRIBUCIÓN
DE LA RENTA
}

$M^{a}$ Teresa Rubio Sanz

Valladolid, 2001 



\section{MATRICES DE CONTABILIDAD SOCIAL}

Y

\section{DISTRIBUCIÓN DE LA RENTA}

Memoria presentada para la obtención del grado de doctor por:

María Teresa RUBIO SANZ

Valladolid, 2001.

Dirigida por:

Juan VICENTE PERDIZ

Departamento de Historia e Instituciones Económicas y Economía Aplicada

Facultad de Ciencias Económicas y Empresariales

Universidad de Valladolid 

Quisiera expresar mi agradecimiento a todas aquellas personas que han hecho posible la elaboración de este trabajo. En primer lugar quiero mostrar mi más sincera gratitud al profesor Juan Vicente Perdiz, director de esta tesis y en buena parte responsable de mi interés inicial sobre el tema, por su generosidad y su dedicación así como por el apoyo y los consejos que me ha brindado en todo momento. En segundo lugar, quiero manifestar mi reconocimiento hacia mis compañeros de Departamento sin los que el resultado de esta investigación nunca hubiera sido el mismo, lo que no es óbice para que sean de mi responsabilidad todas las posibles deficiencias de este trabajo. Por último, a mis amigos y familiares que son los han tenido que soportar los mayores sinsabores que entraña la realización de un trabajo de estas características, espero saber compensarles con algo más que una cita en estas páginas. 



\section{ÍNDICE}

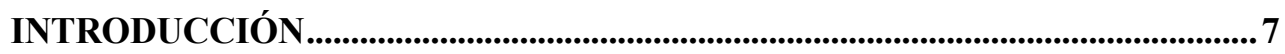

1. LOS SISTEMAS DE CUENTAS NACIONALES ....................................................17

1.1. ORÍGENES Y DESARROLLO DE LOS SISTEMAS DE CUENTAS NACIONALES .............................20

1.1.1. Las primeras estimaciones de la renta nacional y la evolución del ámbito de la actividad económica recogida en las cuentas.........................................................21

1.1.2. La Tabla Económica de Quesnay y los modelos de reproducción de Marx................25

1.1.3. Los primeros Sistemas de Cuentas Nacionales y el papel armonizador de los

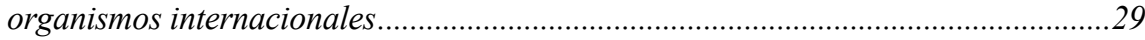

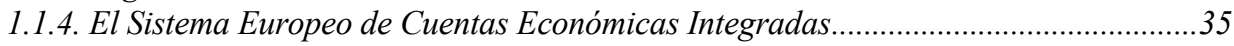

1.2. LOS SISTEMAS DE CUENTAS NACIONALES VIGENTES: SCN93 Y SEC95 ...............................38

1.2.1. La contabilidad del patrimonio y la contabilidad de flujos ...........................................42

1.2.2. Las cuentas económicas y los agregados del cuerpo central del Sistema .....................44

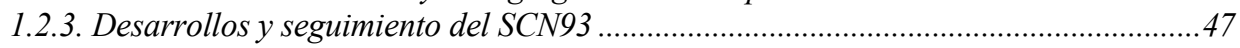

1.3. LA CONTABILIDAD NACIONAL EN ESPAÑA............................................................................55

1.3.1. Las primeras estimaciones de la renta y la riqueza nacionales......................................55

1.3.2. Hacia la elaboración de un Sistema de Cuentas ..............................................................61

1.3.3. Las distintas series de la Contabilidad Nacional de España .......................................63

1.3.4. Aplicación y seguimiento del SEC95 .........................................................................6

2. LAS MATRICES DE CONTABILIDAD SOCIAL ..............................................73

2.1. ORIGEN Y DESARROLLO DE LAS MATRICES DE CONTABILIDAD SOCIAL .................................76

2.1.1. De la Tabla Económica de Quesnay a la de Leontief ......................................................77

2.1.2. De la Tabla Input-Output a la Matriz de Contabilidad Social ......................................82

2.1.3. Matrices de contabilidad social y modelización económica .........................................87

2.2. MATRICES DE CONTABILIDAD SOCIAL Y SISTEMAS DE CUENTAS NACIONALES....................90

2.2.1. Presentación esquemática de una matriz de contabilidad social ................................90

2.2.2. Las matrices de contabilidad social en el SCN93 .......................................................96

2.2.2.1. Las matrices de contabilidad social como marco contable ................................................................97

2.2.2.2. Las matrices de contabilidad social como modelos económicos .........................................................101

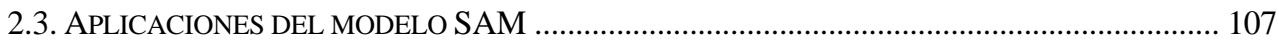

2.3.1. Descomposición de la matriz de multiplicadores SAM. ............................................. 107

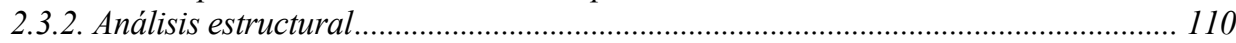

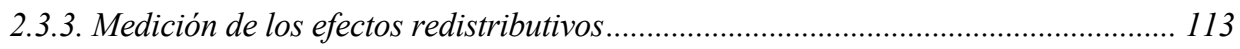

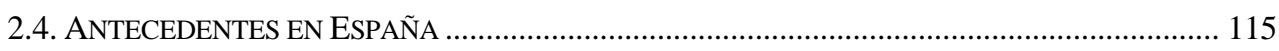

2.4.1. La Matriz de Contabilidad Social de España para 1980 (SAM-80)......................... 117

2.4.2. La Matriz de Contabilidad Social de España para 1990 (MCS-90)........................ 120 
3. LA ELABORACIÓN DE LA MCSE-90 ……...................................................... 125

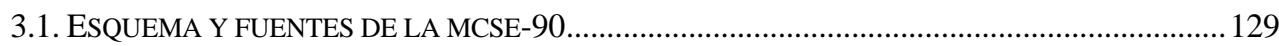

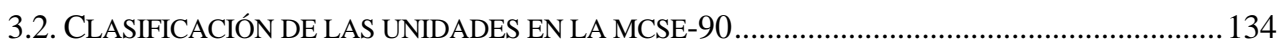

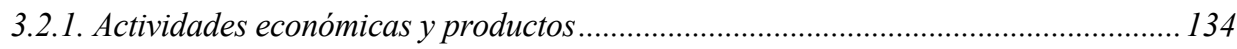

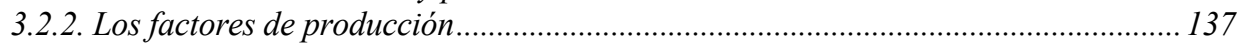

3.2.3. Las unidades institucionales ................................................................................... 141

3.2.4. Correspondencias entre las clasificaciones del consumo por funciones (PROCOME) y por categorías de productos (R.56 de la TIO90)............................ 145

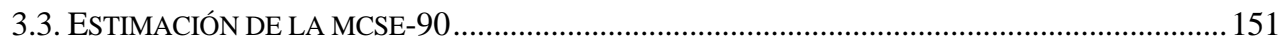

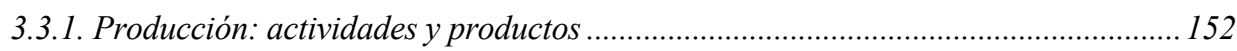

3.3.1.1. Márgenes comerciales y de transporte .................................................................................... 152

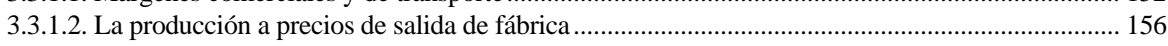

3.3.2. Distribución del valor añadido bruto .................................................................. 158

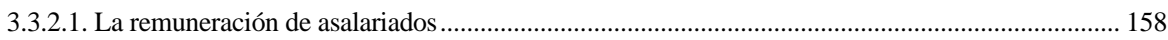

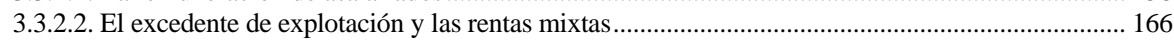

3.3.3. Asignación y redistribución de la renta ............................................................... 172

3.3.3.1. Distribución de la renta generada por factores y sectores institucionales ......................................... 172

3.3.3.2. Las rentas de la propiedad y de la empresa.............................................................................. 174

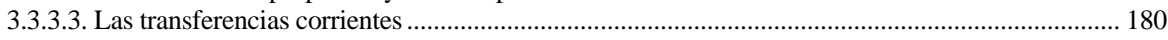

3.3.4. Utilización de la renta y otras operaciones................................................................. 189

3.3.4.1. Los gastos de consumo final clasificados por funciones PROCOME ............................................. 189

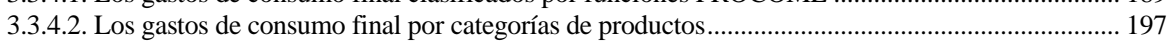

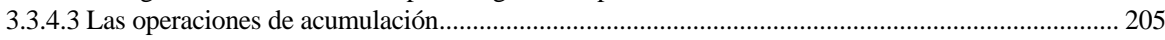

\section{LA MEDICIÓN DE LA DESIGUALDAD EN EL MARCO DE LA} CONTABILIDAD SOCIAL............................................................................................207

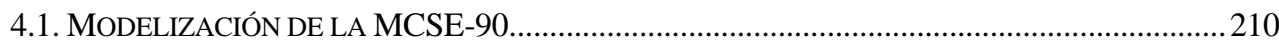

4.1.1. Agregación de operaciones y reordenación de unidades ............................................211

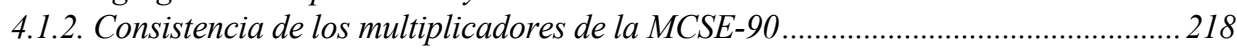

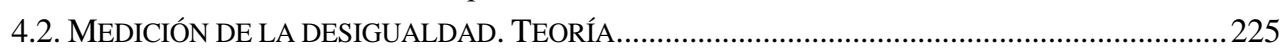

4.2.1. El espacio de las distribuciones. Representaciones geométricas ...............................228

4.2.2. Espacios normados y medidas de desigualdad. Medidas de distancia ..................... 237

4.2.3. Sensibilidad posicional. Medidas lineales y no lineales .......................................... 241

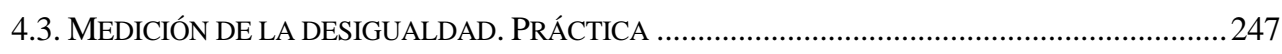

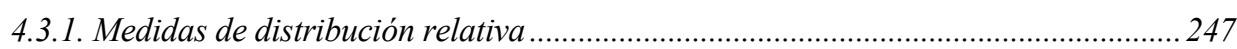

4.3.2. Medición de la desigualdad y cálculo de normas frontera ....................................... 251

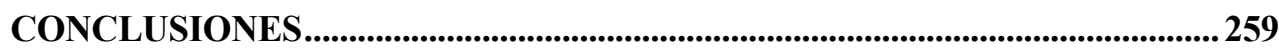

REFERENCIAS BIBLIOGRÁFICAS .................................................................269 
ANEXOS

ANEXO ESTADÍSTICO 283

PROGRAMA SAS. 311

\section{LISTA DE CUADROS}

(Salvo indicación en sentido contrario todas las cifras están expresadas en millones de pesetas)

CUADRO 1.1. Estimaciones de W. Petty, 1664. Inglaterra y Gales (millones de $£$ ) 21 CUADRO 1.2. Estimaciones de G. King. 1688-1697 .................................................22

CUADRO 1.3. Tabla Económica de Quesnay. (Francia, ₹1750) ...............................2

CUADRO 1.4. Modelos de reproducción simple y ampliada de Marx. .......................2. 28

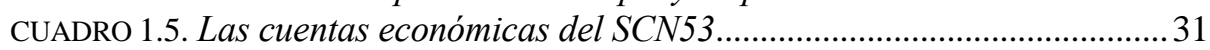

CUADRO 1.6.a. Las cuentas consolidadas de la nación (SCN68)................................33

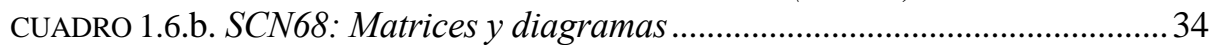

CUADRO 1.7.a. SEC70: Clasificación de las unidades institucionales ......................37

CUADRO 1.7.b. SEC70: Flujos económicos y cuentas simplificadas de la nación .37

CUADRO 1.8.a. SCN93 y SEC95: Clasificación de flujos y stocks ............................ 42

CUADRO 1.8.b. SCN93 y SEC95: Articulación de los balances con las cuentas de

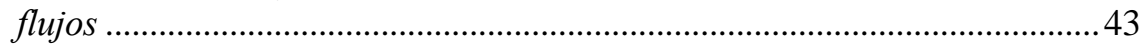

CUADRO 1.9. SCN93 y SEC95: Sucesión de cuentas y agregados ............................46

CUADRO 1.10. Reuniones de expertos en cuentas nacionales de la OCDE ..............50

CUADRO 1.11. Publicaciones oficiales sobre el SCN93 ............................................5

CUADRO 1.12. Cuadro resumen de aplicación del SCN93 .......................................53

CUADRO 1.13. Organismos participantes en la revisión continua del SCN93.........54

CUADRO 1.14. Las primeras estimaciones de la renta y la riqueza en España .......56

CUADRO 1.15. Otras estimaciones de la riqueza de España 1900-1936 ..................57

CUADRO 1.16. Otras estimaciones de la renta de España. 1900-1936 .....................58

CUADRO 1.17. La riqueza nacional de España. 1967-1971 ......................................61

CUADRO 1.18. Series oficiales de Contabilidad Nacional .........................................68

CUADRO 1.19. Programa de transmisión de datos de las cuentas nacionales ........70

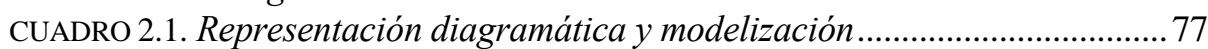

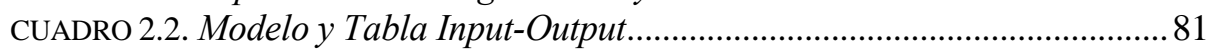

CUADRO 2.3. Generalización del modelo Input-Output ............................................. 83

CUADRO 2.4. Matriz de Contabilidad Social: del modelo I-O a los MEGAs ..........87

CUADRO 2.5. Representación matricial de la economía ................................................91

CUADRO 2.6. Elasticidad del formato matricial .......................................................92

CUADRO 2.6. Elasticidad del formato matricial (Continuación) ................................94

CUADRO 2.6. Elasticidad del formato matricial (Continuación) ...............................95

CUADRO 2.7. La matriz de contabilidad social y el flujo circular de la renta .........98

CUADRO 2.8. Equivalencia entre las matrices de contabilidad social y los SCN.101

CUADRO 2.9. SCN. Modelo de Equilibrio General ................................................104 
CUADRO 2.10. Modelización de una matriz de contabilidad social 105

CUADRO 2.11. Descomposición de la matriz de multiplicadores..

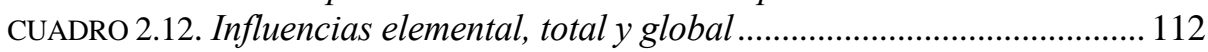

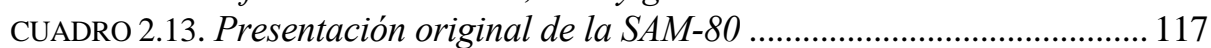

CUADRO 2.14. SAM-80b propuesta por Uriel (miles de millones de pesetas)...... 118

CUADRO 2.15. Presentación reordenada de la SAM-80 y de la SAM-80b ............ 118

CUADRO 2.16. Presentación original de la MCS-90 (miles de millones pesetas) 121

CUADRO 3.1. Matriz de Contabilidad Social de España (MCSE-90) .................... 129

CUADRO 3.2. Clasificaciones de los productos y las actividades económicas ..... 136

CUADRO 3.3. Categorías socioeconómicas ............................................................ 140

CUADRO 3.4. Clasificación de los hogares ............................................................ 145

CUADRO 3.5. Correspondencias entre las clasificaciones de los gastos de...... consumo. final (PROCOME-R.56) ............................................................. 150

CUADRO 3.6. Márgenes comerciales y de transporte de las mercancías ............... 156

CUADRO 3.7. Las rentas salariales en la EPF90-91 y la CNE90 .......................... 160

CUADRO 3.8. Sueldos y salarios brutos por categorías socioeconómicas y...... actividades.

CUADRO 3.9. Distribución del empleo asalariado (miles) .................................... 165

CUADRO 3.10. Renta mixta y excedente de explotación de los hogares .................. 169

CUADRO 3.11. Desagregación de la renta mixta por ramas de actividad .............. 171

CUADRO 3.12. Rentas de la propiedad y de la empresa por sectores ..................... 175

CUADRO 3.13. Rentas de la propiedad de los hogares en la EPF90-91 y en la...... CNE90

CUADRO 3.14. Rentas de la propiedad y de la empresa por grupos de hogares .. 179

CUADRO 3.15. Transferencias corrientes por sectores institucionales 182

CUADRO 3.16. Indicadores de distribución de las transferencias corrientes.........

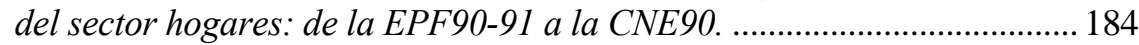

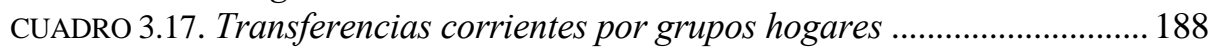

CUADRO 3.18. Consumo final de los hogares. De la EPF90-91 a la CNE90....... 193

CUADRO 3.19. Otros gastos no mencionados anteriormente .................................. 197

CUADRO 3.20. Gastos de consumo final privado por funciones y productos a...... precios de adquisición (sin ajustar a la TIO90) ............................................ 198

CUADRO 3.21. Gastos de consumo final privado por funciones y productos a...... precios de salida de fábrica (sin ajustar a la TIO90) .................................... 200

CUADRO 3.22. Gastos de consumo privado interior ajustados ............................... 202

CUADRO 3.23. Gastos de consumo de los hogares residentes............................... 204

CUADRO 4.1. Eliminación de cuentas en una matriz de contabilidad social......... 212

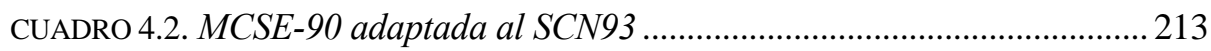

CUADRO 4.3. MCSE-90R. Sin cuenta de bienes y servicios ................................... 214

CUADRO 4.4.a. Matriz de contabilidad social reducida y reordenada ........................... 216

CUADRO 4.4.b. MCSE-90RR. Reducida, reordenada y sin PISB .......................... 217

CUADRO 4.6. Correlaciones entre las distintas series de multiplicadores ............ 221

CUADRO 4.7.a. Multiplicadores actividades-actividades, factores y hogares ...... 222

CUADRO 4.7.b. Correlaciones entre los multiplicadores $I A-I B$............................... 223

CUADRO 4.8.a. Multiplicadores actividades-actividades y hogares (47 ramas).. 224 
CUADRO 4.8.b. Multiplicadores actividades-actividades y hogares (47 ramas).. 224 CUADRO 4.9. Criterios de justicia distributiva ........................................................222 CUADRO 4.10. Distribuciones (pobres-ricos) en diferentes bases..........................2229 CUADRO 4.11. Descomposición factorial de distribuciones ...................................2231 CUADRO 4.12. Distribuciones tridimensionales (valores absolutos y...... participaciones) ....................................................................................2232

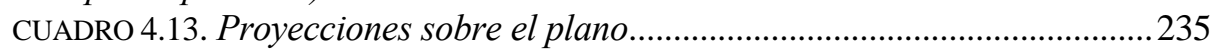

CUADRO 4.14. Curvas de nivel y medidas de distancia ..........................................240

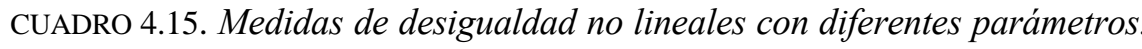
de aversión.

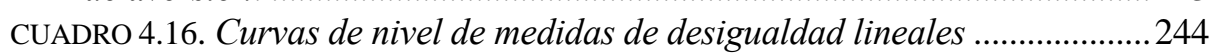
CUADRO 4.17. Efectos distributivos de un crecimiento unitario de la inversión .248 CUADRO 4.18. Efectos distributivos de un crecimiento unitario de la inversión .. 250 CUADRO 4.19. Índice de entropía generalizada ......................................................253

CUADRO 4.20. Pesos de agregación de las desigualdades intra-grupos ................255

CUADRO 4.21. Cálculo de normas frontera. (3 Ramas de actividad).....................256

CUADRO 4.22. Cálculo de normas frontera. (47 Ramas de actividad)...................257 

INTRODUCCIÓN 

En la introducción al reciente libro de lecturas sobre distribución de la renta, Atkinson y Bourguignon (2000) señalan que, a pesar del renovado interés político por la distribución de la renta, la cuestión "permanece bastante periférica en economía". Más en concreto, "echan en falta investigación que integre los aspectos distributivos en el centro del análisis sobre el funcionamiento de la economía”.

En este trabajo se mantiene la tesis de que una sólida vía para cubrir dicha laguna consiste en integrar las aportaciones más recientes en el campo de la economía de la desigualdad, especialmente sobre su medición, en el marco de los Sistemas de Cuentas Nacionales y, en particular, en el de las matrices de contabilidad social con las que definitivamente se ha roto la frontera entre la macro y la microeconomía en la investigación aplicada.

Ante todo conviene aclarar que el término nacional, como bien señala Hill (1999), constituye un desafortunado anacronismo que perpetúa el mito de que el propósito de la Contabilidad Nacional es sólo la estimación de unos pocos agregados de la economía, sin tener en cuenta que en 1984 R. Stone recibió el Premio Nobel por el diseño, ya hace más de medio siglo, de un sistema de cuentas que describe los diversos flujos que tienen lugar entre las distintas unidades de una economía, cualquiera que sea el ámbito de ésta. El Sistema de Cuentas Nacionales de 1993 (UN y otros, 1993) es ante todo "un conjunto coherente, consistente e integrado de cuentas, balances y tablas ... que proporcionan una estructura contable comprensible y diseñada para compilar la información económica en un marco adecuado a las necesidades del análisis, la predicción y la política económica”.

Tras haber dedicado los últimos años de mi vida a este trabajo, quizá sea mi obcecación con la Contabilidad Nacional la que me lleva a manifestar que los Sistemas de Cuentas Nacionales, no son sólo "una vía complementaria de introducción al estudio de la Economía”, como señala el profesor Cándido Muñoz en el prólogo del manual en castellano probablemente más clásico sobre la materia (Muñoz, 2000), ni siquiera "un procedimiento alternativo de iniciación de los estudios de economía”, como 
reconocía algo más tajante en la primera edición de su manual de 1989; sino que son la introducción a la Economía en sí misma. Economía que, sin duda alguna, habrá que aprender a analizar, a predecir y manejar, pero sólo una vez que haya sido presentada de un modo sistematizado. Como bien señalan Ruggles y Ruggles (1999), los Sistemas de Cuentas Nacionales no tratan sólo de homogeneizar e integrar las distintas estadísticas económicas y proporcionar indicadores precisos sino, sobre todo, de mostrar las relaciones entre los agentes económicos que resultan fundamentales para poder entender el funcionamiento de la economía.

Este trabajo parte de la primera descripción agregada de una economía, realizada por W. Petty en 1664 para Inglaterra y Gales (cuadro 1.1) y concluye con una ordenación de políticas alternativas en términos de sus efectos sobre la distribución de la renta disponible equivalente de los hogares españoles en 1990 (cuadro 4.22).

El primero de los cuadros mencionados recoge todos los aspectos esenciales a tener en cuenta a la hora de describir la actividad económica: las dotaciones de capital físico y humano determinan las rentas que pueden emplearse para satisfacer necesidades presentes o futuras y, en este último caso, como mostró Quesnay en 1750, demostró Marx en 1885 y formalizó Neumann en 1832, la economía se expande. Un respuesta simple a una cuestión compleja a la que la macroeconomía ha dedicado y sigue dedicando gran parte de sus esfuerzos.

El segundo de los cuadros mencionados en realidad es una aplicación del concepto de norma a efectos de ordenar el espacio de las distribuciones tridimensionales. En dicho cuadro se recogen todos los aspectos esenciales del problema económico de ¿cómo ordenar las distintas distribuciones posibles de un “euro" entre tres personas?1. De nuevo una pregunta simple sobre una cuestión compleja, cuyas respuestas en este caso hay que buscarlas en la microeconomía.

\footnotetext{
1 “Las proporciones del producto total de la tierra que son asignadas a cada una de estas tres clases ... determinar las leyes que regulan esta distribución es el principal problema de la Economía Política” (Ricardo, 1817, p.1).
} 
A lo largo de este trabajo hemos tratado de recorrer un camino coherente entre los dos cuadros. Se trata de un camino sin asfaltar en bastantes tramos, tanto si partimos de la literatura sobre los Sistemas de Cuentas Nacionales², como si lo hacemos desde la que trata la medición de la desigualdad ${ }^{3}$.

El medio elegido para recorrer dicho camino ha sido el de las matrices de contabilidad social $^{4}$ que pueden considerarse como el estado actual del permanente compromiso entre el desarrollo de la teoría y las limitaciones de la estadística, que a lo largo de la historia ha determinado la evolución de los Sistemas de Cuentas 5 .

Como bien señala el autor del capítulo sobre matrices de contabilidad social en el manual de Naciones Unidas de 1993 (Keuning, 1996), la relevancia del análisis económico y social aplicado está estrechamente vinculada, por un lado, con la solidez de las herramientas de análisis y, por otro, con la utilización de un marco contable apropiado. Mientras que una gran mayoría de investigaciones económicas se centran en las herramientas de análisis, en este trabajo el diseño del marco contable ocupa un lugar prioritario. La importancia otorgada al marco contable en ningún caso debe interpretarse como un desdén o una falta de interés por la teoría y las distintas técnicas de análisis económico, sino como un intento de resaltar la importancia que, junto con los desarrollos teóricos y las técnicas estadísticas y econométricas, tiene el diseño del marco contable en cualquier investigación económica y social.

\footnotetext{
2 "La siguiente afirmación tomada del manual de Kendrick y Carson de 1972 ... mantiene su vigencia para el presente volumen 'A pesar del rápido progreso de la contabilidad económica ... ha de enfatizarse que las cuentas económicas distan aún bastante de estar acabadas’.. la naturaleza incompleta de las cuentas económicas explica la aproximación crítica de este volumen” (Kendrick, 1995a, p. 2).

3 ، 'La idea de desigualdad ... es una noción extremadamente compleja que convierte los juicios sobre la desigualdad en altamente problemáticos ..., de ahí que haya sido objeto de amplia investigación ...’ Así es como Amartya Sen (1973) comenzaba el prefacio a su libro Sobre la Desigualdad Económica. Veinticinco años después mantiene toda su validez, a pesar de que desde entonces hayan sido publicados sobre la materia cientos de artículos y bastantes libros” (Silber, 2001, p.1).

4 "Una instantánea de las variables críticas en un modelo de equilibrio general que describe el flujo circular de las transacciones monetarias de una economía. ... una matriz cuadrada cuyas celdas representan los flujos entre las cuentas de una economía” (Zenios, 1996, p.484).

5 "La extensión en el uso de los modelos de equilibrio general ha estimulado, o incluso forzado, la mejora de las técnicas de Contabilidad Nacional, así como la integración de las cuentas nacionales y las tablas input-output en una estructura consistente, las matrices de contabilidad social” (Bergman, 1990, p.14).
} 
En el primer capítulo de este trabajo presentamos los antecedentes, las principales versiones y los desarrollos actuales de los Sistemas de Cuentas Nacionales, tanto en el ámbito internacional, como en el de nuestro país. En lugar de realizar una descripción detallada y rigurosa del Sistema y de los elementos que lo conforman (conceptos, definiciones y clasificaciones de las unidades y los flujos económicos, criterios de valoración y registro,...) hemos optado por resaltar las principales novedades que incorpora (contabilidad del patrimonio, contabilidad matricial, cuentas satélites, ...).

Más que una historia de las doctrinas sobre la contabilidad económica, lo que de por sí ya resulta de gran utilidad en un trabajo de estas características, se trata de un intento de mostrar cómo la elaboración de cuentas nacionales constituye una actividad que, como cualquier otra, depende de las leyes de la oferta y de la demanda, una leyes que están condicionadas por las características peculiares de cada bien en cuestión (Vicente y Decimavilla, 1998). El surgimiento de los estados nacionales y la atribución a los gobiernos de competencias intervensionistas, por un lado, y la genialidad de personas como F. Quesnay o R. Stone junto con la labor continuada de un sinfín de investigadores de Universidades e Institutos de todo el mundo, por otro, conforman respectivamente la demanda y la oferta del mercado de cuentas nacionales. Las Actas de los Congresos de la Asociación Internacional para la Investigación sobre la Renta y la Riqueza (IARIW) constituyen uno de los archivos más completos sobre Contabilidad Nacional y las tres grandes versiones del Sistema de Cuentas de Naciones Unidas, junto con las versiones paralelas de la OCDE y de Eurostat, son las joyas de la corona.

La implantación en cada país concreto del Sistema de Cuentas Nacionales ha sido y continúa siendo una expresión de su grado de desarrollo. La labor de formación de los organismos internacionales y las facilidades de acceso a la información hacen que hoy en día las diferencias entre los países tengan que ver más con los recursos dedicados a la construcción del sistema estadístico que con el nivel de conocimientos. En el caso de España, nuestra incorporación a Europa en 1986 y la firme decisión de la Unión Europea de crear un Sistema Estadístico Europeo han sido el espaldarazo definitivo a una Contabilidad Nacional que, en cualquier caso, mostraba ya una vitalidad, 
tanto desde el ámbito universitario como desde el propio Instituto Nacional de Estadística, acorde con la de la economía española en su conjunto.

A pesar del consenso alcanzado en la última revisión del Sistema de Cuentas, ni el Sistema de Naciones Unidas de 1993 ni el Sistema Europeo de Cuentas de 1995 pueden considerarse Sistemas acabados y, por tanto, definitivos. Ambos están sometidos a un proceso permanente de actualización. De ahí que concluyamos el capítulo primero, tanto en lo que respecta al ámbito internacional como al nacional, con las referencias que permiten el seguimiento de dicho proceso de revisión continua.

En el segundo capítulo mostramos la conexión entre la evolución de los Sistemas de Cuentas y los orígenes de las matrices de contabilidad social, describimos la arquitectura básica de una matriz de contabilidad social y comentamos los antecedentes en nuestro país, buena parte de los cuáles son coetáneos con la realización de este trabajo. La tesis mantenida en este capítulo es que las matrices de contabilidad social no sólo constituyen un método alternativo a los Sistemas de Cuentas para modelizar una economía desde el punto de vista de los modelos de equilibrio general, frente a los modelos macroeconómicos de corte keynesiano, ya subyacentes en las primeras versiones de los Sistemas de Contabilidad Nacional; o un medio para introducir aspectos sociales no considerados por las cuentas económicas tradicionales, como alegaban los pioneros en la elaboración de las matrices de contabilidad social (Pyatt y Thorbecke, 1976); o una extensión más de las cuentas en forma de T que actúan a modo de cuentas pantalla ocultando el origen de los recursos y el destino de los empleos (Archambault, 1982, p.69); a nuestro juicio, las matrices de contabilidad social son sin más el Sistema de Cuentas Nacionales en su presentación moderna.

Las matrices de contabilidad social extienden el camino abierto por Leontief con la tablas input-output. Así, mientras que una tabla input-output muestra el origen y el destino de las operaciones de bienes y servicios, y el origen de las operaciones de distribución primaria de la renta, una matriz de contabilidad social refleja el origen y el destino de todas las operaciones, incluidas las de redistribución de la renta y las financieras. Asimismo, para resaltar u obviar los distintos aspectos que componen la activi- 
dad económica, atendiendo a razones de interés y costes, y en función del tipo de análisis que pretenda realizarse en cada caso, una matriz de contabilidad social puede contraerse o extenderse sin más que agregar o desagregar cualquier conjunto de operaciones y/o unidades. En otras palabras, en una matriz de contabilidad social la frontera entre la macro y la microeconomía se diluye.

Su versatilidad permite la derivación inmediata de diversas modelizaciones, de hecho: "para cada modelo hay una matriz de contabilidad social... para cada matriz de contabilidad social hay una amplia gama de posibles modelos” (Pyatt, 1988, p.345). Una vez delimitados los flujos endógenos y exógenos de la matriz, es posible simular los efectos que cualquier modificación de un flujo o conjunto de flujos exógenos produce sobre un flujo o conjunto de flujos endógenos. Dichos efectos pueden descomponerse para dar cuenta de las diversas fases de un determinado proceso económico, o pueden compararse empleando el análisis estructural para, en una visión de conjunto, identificar los procesos con mayor influencia. Además, el método de apportionment permite reducir las matrices de contabilidad social para explicitar únicamente los medios y los fines.

Por lo que respecta a España, los primeros trabajos se remontan a poco más de una década y la mayoría de ellos han aparecido a partir de la segunda mitad de los noventa coincidiendo con el periodo de realización de este trabajo. En lo que conocemos, hasta el momento ninguno de los trabajos aparecidos ha presentado una matriz de contabilidad social que clasifique los hogares por niveles de renta que, entre otros razones que comentamos a lo largo del trabajo, ha sido el principal motivo para construir una matriz de contabilidad social propia.

En el tercer capítulo, que constituye el cuerpo central del trabajo, elaboramos de forma sistemática una matriz de contabilidad social para la economía española (MCSE-90). La elección del año 1990 como año de referencia se debe a que es el último año para el que se ha elaborado una gran Encuesta de Presupuestos Familiares. Durante el periodo de elaboración de este trabajo ha aparecido información estadística que permite actualizar algunas parcelas de la MCSE-90 que elaboramos, pero sólo a 
costa de romper su homogeneidad. Asimismo, la información estadística más reciente permite incluso elaborar una nueva matriz de contabilidad social más actualizada, aunque bastante menos detallada. A pesar de que a lo largo del periodo de realización de este trabajo nos hemos planteado en varias ocasiones la conveniencia de incorporar datos más actualizados y hemos realizado los oportunos ensayos, finalmente hemos optado por no incorporarlos para no desvirtuar el cariz marcadamente metodológico del trabajo, en el convencimiento de que la construcción de un marco sólido y exhaustivo es la base más firme para poder desarrollar un amplio programa de investigación aplicada en el futuro.

En los dos primeros apartados de este capítulo presentamos las fuentes estadísticas y las distintas clasificaciones de las unidades: productos, actividades, factores e instituciones. En ambos apartados discutimos detalladamente las distintas opciones disponibles y justificamos la elección realizada en cada caso. Una vez dispuesto todo el material y elegidos los niveles de desagregación, en el tercer apartado construimos paso a paso la MCSE-90. En lo que conocemos se trata de la primera matriz de contabilidad social de una economía real plenamente adaptada a la metodología del nuevo Sistema de Cuentas Nacionales.

El orden de presentación de las distintas submatrices que conforman la MCSE90 se basa en el flujo circular de la renta. Ésta se genera en forma de valor añadido como resultado de la actividad productiva, se asigna a los propietarios de los factores que han contribuido a generarla, se redistribuye básicamente por la acción de las administraciones publicas y, finalmente, la renta disponible es empleada por las distintas unidades institucionales, para satisfacer necesidades del ejercicio en curso, o acumulada en forma de activos reales y financieros que aumentarán su capacidad de obtención de rentas en el futuro.

En el cuarto capítulo discutimos la consistencia de diversos diseños alternativos de la matriz de contabilidad social elaborada, para posteriormente proponer un método de análisis de los efectos distributivos que incorpore las aportaciones más recientes en el campo de la medición de la desigualdad. Una de las 
principales motivaciones que impulsó la elaboración de las primeras matrices de contabilidad social fue, precisamente, la disconformidad con el tratamiento que los Sistemas de Cuentas Nacionales otorgaban a los aspectos distributivos. Sin embargo, en lo que conocemos, los análisis realizados en la literatura sobre contabilidad social no permiten obtener una valoración global de dichos efectos, a diferencia de lo que ocurre en el campo de la modelización input-output donde las políticas industriales son clasificadas por sus efectos globales sobre la producción.

La desigualdad, ciertamente, es un concepto extremadamente complejo. Ahora bien, el concepto de convergencia es de un orden de complejidad similar y, sin embargo, ello no impide que la Unión Europea disponga de una serie de criterios firmes que orientan buena parte de las políticas económicas de sus estados miembros. Estamos tan lejos de poder medir las capacidades y las necesidades de los individuos como seguros de que no están igualmente repartidas, por lo que resulta cuando menos sorprendente que todavía hoy la Contabilidad Nacional no recoja ninguna agregado alternativo al PIB, cuya norma implícita consiste en sumar unidades monetarias sin tener en cuenta ni su origen ni su destino. Para concluir el trabajo proponemos el cálculo de normas frontera que permitan elegir entre políticas económicas alternativas incorporando juicios distributivos. 


\section{CAPÍTULO 1}

\section{LOS SISTEMAS DE CUENTAS NACIONALES}

"Cuando podemos medir aquello de lo que hablamos y expresarlo en cifras, sabemos algo de ello; cuando no podemos medirlo ni expresarlo en cifras, nuestro saber es débil e insatisfactorio; quizá sea el comienzo, pero apenas cabe decir que hayamos llegado al estado científico.”

Lord Kelvin*

* Citado en Samuelson y Nordhaus (1996). 

"La actividad económica se manifiesta en una gran cantidad de flujos de muy distinta naturaleza, que se intercambian entre multitud de unidades que pertenecen a la economía del país o del resto del mundo. La tarea esencial de todo sistema de contabilidad nacional consiste en clasificar esa inmensa variedad de unidades y flujos económicos en un número limitado de categorías fundamentales e integrarlas en un marco general con el fin de obtener una representación del circuito económico que sea inteligible y adaptada a las necesidades del análisis, de la previsión y de la política económica” (INE, Eurostat, 1986, p.13) ${ }^{6}$.

El interés de los Sistemas de Cuentas radica en que permiten satisfacer nuestra curiosidad (análisis), reducir nuestra inquietud sobre el futuro (predicción) y, sobre todo, actuar con conocimiento sobre la actividad económica con el fin de alcanzar los objetivos deseados (política). De hecho, el desarrollo de los Sistemas de Cuentas Nacionales (SCN) ha estado estrechamente vinculado a la evolución de los conceptos de actividad y política económica. En el siguiente apartado mostramos cómo la evolución de las Cuentas Nacionales constituye un compromiso entre los desarrollos de la economía política y las limitaciones de la estadística aplicada. En el apartado 1.2 presentamos la arquitectura básica del Sistema de Cuentas Nacionales vigente en la actualidad y señalamos algunos de los campos en los que se centra hoy en día la investigación. Por último, en el apartado 1.3 tratamos la evolución y situación actual de la Contabilidad Nacional en nuestro país.

\footnotetext{
${ }^{6}$ Richard Stone, en su discurso de aceptación del Premio Nobel de 1984: “The Accounts of Society”, señaló que "organizando los datos en forma de cuentas puede obtenerse una representación coherente de los flujos y stocks, los ingresos y los gastos de cualquier variable que nos interese, tanto si se trata de bienes y servicios como de recursos humanos o naturales, y a partir de ellas analizar el sistema del que forman parte." (Stone, 1997, p.17). Para Samuelson y Nordhaus (1996, p.412): "De la misma manera que un satélite permite visualizar desde el espacio la situación meteorológica de todo un continente, la Contabilidad Nacional muestra un panorama global de la situación en la economía....es el faro que ayuda a las autoridades a llevar a la economía por el camino que permita alcanzar los objetivos del país” y Kendrick (1995b, p.1) define las cuentas económicas como "una herramienta indispensable para el análisis macroeconómico, la proyección y la formulación de la política económica”.
} 


\subsection{ORÍGENES Y DESARROLLO DE LOS SISTEMAS DE CUENTAS NACIONALES}

Un Sistema de Cuentas Nacionales es un bien indivisible, inapropiable e incierto. La indivisibilidad conlleva la necesidad de disponer de una gran cantidad de recursos para abordar la tarea de estimar directamente los grandes agregados macroeconómicos, de ahí que durante bastante tiempo no estuviera al alcance de la iniciativa privada. Dicha iniciativa se vio asimismo desincentivada por la incertidumbre en la utilidad de los primeros resultados y, sobre todo, por la dificultad para impedir que otros se beneficiaran de sus frutos, en caso de éxito, sin haber contribuido a su financiación. Tales razones explican porqué el desarrollo de la contabilidad privada, primero, y el de la contabilidad pública, más tarde, no se vieron sucedidos por el de la contabilidad social. Su surgimiento se demoró hasta bien entrado el siglo XX, coincidiendo con la reclamación de la intervención del Estado en la actividad económica, agente este último que sí dispone de los recursos necesarios para afrontar el problema de la indivisibilidad, que tiene intereses diversos que permiten compensar los riesgos de éxitos y fracasos, y que al representar a todos los ciudadanos no debe preocuparle, sino todo lo contrario, la difusión de la información.

Tras una dilatada historia de encomiables esfuerzos individuales para estimar los principales agregados económicos (1.1.1) y diseñar las primeras representaciones de la actividad económica (1.1.2), fue durante el periodo de entreguerras cuando se realizaron las primeras estimaciones oficiales con la finalidad de proporcionar la información necesaria para guiar la intervención del Estado a favor de la estabilidad y del crecimiento económico (1.1.3). Desde entonces, los esfuerzos se centraron en la armonización de las estadísticas nacionales a través del diseño de un Sistema de Cuentas Nacionales adaptado a las necesidades del análisis y la política económica. 


\subsubsection{Las primeras estimaciones de la renta nacional y la evolución del ámbito de la actividad económica recogida en las cuentas}

Los orígenes de la Contabilidad Nacional se remontan al siglo XVII cuando, al mismo tiempo que el pensamiento económico experimentaba un cambio radical, al apartarse de las creencias en la supremacía de la Ley Natural para centrar su atención en la investigación de los hechos económicos y sociales, surgían los Estados-Nación y con ellos la necesidad de disponer de una representación descriptiva y cuantificada de los hechos relevantes para la política pública. De este modo la ciencia económica pasó a ser, además de teoría, medición.

Un impulso decisivo en el cambio experimentado por el pensamiento económico vino de un reducido grupo de investigadores que defendieron la idea de que el conocimiento científico debía basarse en la medición de los fenómenos observados y acuñaron el término aritmética política $\mathrm{o}$ "arte de razonar con cifras sobre las cuestiones relativas al gobierno" (Davenant, 1698). La primacía en la estimación de agregados económicos se atribuye a William Petty (1665 y 1676). En el primero de sus ensayos estimaba, para 1964, el gasto en alimentación, vivienda, vestido y otras necesidades de los 6 millones de habitantes de Inglaterra y Gales, las rentas procedentes de la propiedad de la tierra y otras propiedades personales y deducía las rentas del trabajo como el saldo que equilibraba los recursos y empleos totales.

CUADRO 1.1. Estimaciones de W. Petty, 1664. Inglaterra y Gales (millones de $£$ )

\begin{tabular}{|c|c|c|c|c|}
\hline \multirow{2}{*}{$\begin{array}{c}\text { GASTOS } \\
40 \text { Alimentación, vivienda, } \\
\text { vestidos y otras necesidades }\end{array}$} & \multicolumn{2}{|l|}{ INGRESOS } & \multicolumn{2}{|c|}{ PATRIMONIO } \\
\hline & \begin{tabular}{|l} 
Rentas de la tierra \\
Rentas de otros propiedades
\end{tabular} & $\begin{array}{l}8 \\
7\end{array}$ & Capital físico & 250 \\
\hline & Remuneración del trabajo & 25 & Capital humano & 416 \\
\hline 40 Total de empleos & Total de recursos & 40 & Total Patrimo & 666 \\
\hline
\end{tabular}


Gregory King, siguiendo el esquema conceptual de Petty, presentó en $1696^{7}$ estimaciones más sistemáticas de la renta y el gasto de la nación para 1688, y del excedente de la renta sobre el gasto o aumento anual de la riqueza, desglosadas por clases sociales (26 categorías). Además, incluía estimaciones comparables para los dos rivales comerciales y políticos de Inglaterra, Holanda y Francia, cuya proyección a diez años le permitió vaticinar acertadamente el fin de la guerra de la Liga de los Ausburgo antes de $1698^{\circ}$. Acierto que no debió ser del agrado de Luis XIV que prohibió los prometedores textos de Pier le Pesant de Boisguillebert (1695) y Sébastien le Preste de Vauban (1707), introductores de la aritmética política en el continente.

CUADRO 1.2. Estimaciones de G. King. 1688-1697

\begin{tabular}{|c|c|c|c|c|c|c|}
\hline \multirow{5}{*}{ Inglaterra 1688} & & & \multirow{5}{*}{ Total } & 1688 (millones $L$ ) & Inglaterra & Francia \\
\hline & & & & RECURSOS & \multirow{3}{*}{$\begin{array}{l}13,0 \\
30,5\end{array}$} & \multirow{3}{*}{$\begin{array}{l}32,0 \\
52,0\end{array}$} \\
\hline & \multicolumn{2}{|c|}{ Categorías } & & Rentas de la propiedad & & \\
\hline & & & Rentas del trabajo & & \\
\hline & \multicolumn{2}{|c|}{$\begin{array}{ccc}1 & \ldots & <6 \\
\text { altas } & \text { bajas }\end{array}$} & & EMPLEOS & \multirow{3}{*}{$\begin{array}{r}39,7 \\
2,0\end{array}$} & \multirow[b]{2}{*}{70,0} \\
\hline $\mathrm{N}^{\circ}$ familias (miles) & 0,5 & 0,8 & 1,4 & Consumo (p.1...p.11) & & \\
\hline $\mathrm{N}^{\circ}$ miembros por familia & 5,2 & 3,3 & 4,0 & Impuestos & & 10,5 \\
\hline $\mathrm{N}^{\circ}$ personas (miles) & 2,7 & 2,8 & 5,5 & V. Patrimonio & 1,8 & 3,5 \\
\hline Renta familiar $(L)$ & 67,0 & 10,6 & \multicolumn{2}{|l|}{32,0} & & \\
\hline Renta per cápita $(L)$ & 12,9 & 3,2 & 1,6 & 1695 (millones $L$ ) & \multirow{4}{*}{$\frac{\text { Inglaterra }}{42,5}$} & Francia \\
\hline Gasto per cápita $(L)$ & 12,0 & 3,4 & 1,8 & RECURSOS & & \multirow[t]{3}{*}{74,0} \\
\hline V. Riqueza p.c. $(L)$ & 0,9 & $-0,2$ & 0,3 & Rentas de la propiedad & & \\
\hline Renta total (mill. $L$ ) & 34,5 & 9,0 & 43,5 & Rentas del trabajo & & \\
\hline Gasto total (mill. $L$ ) & 32,0 & 9,6 & 41,7 & EMPLEOS & \multirow{3}{*}{$\begin{array}{r}39,0 \\
6,5 \\
\end{array}$} & \multirow{3}{*}{$\begin{array}{l}62,5 \\
17,5\end{array}$} \\
\hline \multirow[t]{3}{*}{ V. Riqueza t. (mill. $L$ ) } & 2,4 & $-0,6$ & 1,8 & Consumo (p.1...p.11) & & \\
\hline & & & & Impuestos & & \\
\hline & & & & V. Patrimonio & $-3,0$ & $-6,0$ \\
\hline
\end{tabular}

Fuente: Elaborado a partir de Stone (1997).

El siguiente hito en la evolución de la Contabilidad Nacional cabe situarlo a mediados del siglo XVIII, fruto de la labor de los fisiócratas franceses que puede personificarse en el trabajo de François Quesnay, Tableau Économique de 1758. Más que

\footnotetext{
${ }^{7}$ Muchos de las estimaciones de G. King fueron incorporadas en los libros de su amigo y admirador Charles Davenant, pero sus escritos permanecieron en el olvido hasta que fueron redescubiertos y publicados como apéndice de la obra de G. Chalmers (1802).

${ }^{8}$ Coalición de potencias que lucharon contra Francia desde 1686 hasta que Luis XIV reconoció en 1697 a Guillermo III como rey de Inglaterra.
} 
por sus aportaciones a los conceptos de renta y riqueza, el trabajo de Quesnay sobresale por proporcionar la primera representación coherente de la actividad económica a través de un circuito de flujos (véase cuadro 1.3).

Los fisiócratas identificaron la renta nacional con el producto de la tierra, al considerar que la tierra es el único recurso capaz de generar excedente o renta por encima de sus costes y que el resto de actividades tan sólo redistribuyen la renta generada por la agricultura y otras actividades extractivas. Este estrecho concepto de renta nacional, apropiado para una época en la que la agricultura constituía la actividad predominante, fue inmediatamente contestado por quienes observaban cómo el proceso de industrialización cada vez requería una mayor cantidad de recursos para transformar los materiales extraídos de la tierra.

Surge así la teoría clásica del valor trabajo atribuible a Adam Smith (1776) y desarrollada por David Ricardo (1817), que servirá de base para las principales estimaciones de la renta nacional que se realizaron hasta bien entrado el XIX. Para los clásicos, la creación de riqueza proviene de cualquier actividad susceptible de materializarse en una nueva mercancía, y el valor de la renta que genera dicha actividad puede medirse por el valor del trabajo empleado. De este modo, el ámbito de la actividad económica, o creadora de renta, se amplía más allá del sector primario para incluir la industria transformadora y el comercio. No obstante, el concepto de producción de A. Smith está limitado al ámbito de la producción material y deja fuera la mayor parte de las actividades de servicios por considerar que, al consumirse directamente, no son generadoras de renta. Ambos conceptos, el de producción material y el de valor trabajo fueron adoptados por Marx y mantenidos acríticamente por la Contabilidad Nacional de las economías planificadas hasta fechas muy recientes.

La exclusión de los servicios en las estimaciones de la renta nacional contrastaba con su incipiente desarrollo, especialmente en las grandes urbes, y con las observaciones de los utilitaristas que desde Bentham (1789) venían insistiendo en la necesidad de tener en cuenta no sólo los costes sino sobre todo la utilidad. A principios del siglo XIX Say (1803) proporcionaba el instrumento que posibilitaba a los estadísticos 
ampliar el concepto de actividad económica, los precios de mercado como síntesis de costes y utilidades. El subtítulo de su tratado de economía política es bien significativo, sencilla exposición de la manera como se forman, se distribuyen y se consumen las riquezas. En él defendía que el valor de una actividad, se traduzca o no en bienes materiales, se determina en el mercado y, por tanto, para registrar contablemente la actividad económica deben emplearse los precios de mercado.

A pesar de la aportación de Say al concepto de actividad económica y de la teoría del equilibrio general de Walras (1874-1877) que también defendía la utilización de los precios de mercado como criterio de valoración de la actividad económica, el concepto restringido de renta de Smith, perpetuado por los escritos de D. Ricardo y de J. Stuart Mill (1848), siguió formando parte del pensamiento económico convencional hasta que a finales del siglo XIX A. Marshall (1890) le diera el golpe de gracia definitivo al identificar la producción con la creación de utilidad, para incluir tanto los bienes materiales como los servicios.

Desde entonces, la única extensión notable del ámbito de actividad económica ha sido la incorporación de la producción de no mercado. Una vez más la realidad fue por delante de la teoría. La extensión de las tareas encomendadas a las administraciones públicas a medida que transcurría el siglo XX que, además de absorber una cantidad creciente de recursos económicos, satisfacían necesidades de gran utilidad social no podían seguir siendo omitidas por la contabilidad social. Pigou (1923) definió la renta nacional como los bienes y servicios que pueden ser comprados directa e indirectamente en relación con la unidad monetaria de referencia para incluir, además de los bienes y servicios que se intercambian en el mercado, las transacciones de no mercado que tienen una contrapartida susceptible de ser valorada en el mercado o a partir de la cuál puede derivarse un valor.

De este modo, en las primeras versiones de los Sistemas de Cuentas Nacionales, el ámbito de la actividad económica quedó así delimitado: actividad socialmente organizada destinada a la obtención de bienes y servicios que son destinados al mercado, o susceptibles de serlo, y/o que utiliza inputs que han sido adquiridos en el 
mercado. En la última revisión del Sistema de Cuentas Nacionales de 1993, el ámbito de la producción se amplió a todas las actividades realizadas bajo el control y la responsabilidad de una unidad institucional que utiliza mano de obra, capital y bienes y servicios, para producir otros bienes y servicios. Por tanto, para contabilizar la renta generada por una actividad deja de ser necesario que sea legal o que figure en los registros fiscales, de la seguridad social u otros registros públicos.

La utilización de los precios de mercado, ciertamente, constituye más una necesidad que una panacea. Para representar la actividad económica de modo inteligible, los Sistemas de Cuentas Nacionales necesitan agregar multitud de flujos reales que son heterogéneos (hectolitros de leche, toneladas de carbón, kilovatios, horas de educación básica, viajeros transportados por kilómetro....), y hasta ahora no parece que ninguna alternativa a la de los precios de mercado (valor trabajo, útiles, unidades de energía, etc.) goce del consenso mínimo para su aplicación práctica.

Los responsables de la elaboración y revisión de los Sistemas de Cuentas Nacionales son conscientes de que los precios de mercado no siempre reflejan el verdadero valor de los bienes y servicios, al depender, entre otros factores, del reparto inicial de los derechos de propiedad y de la existencia de monopolios. También lo son de que hay actividades económicas y sociales, como las tareas realizadas en el seno de los hogares o de voluntariado social, que deberían incluirse en el ámbito de la producción y que se han dejado fuera por la dificultad que conlleva su valoración. De ahí la necesidad de seguir trabajando para romper las limitaciones estadísticas y continuar con la adaptación de los Sistemas de Cuentas a las nuevas realidades económicas y sociales.

\subsubsection{La Tabla Económica de Quesnay y los modelos de reproducción de Marx}

François Quesnay obtuvo celebridad entre la profesión médica por sus publicaciones sobre el sistema circulatorio. Tras varios años como médico de Luis XV accedió a una propiedad cuya gestión agraria motivó su preocupación por la economía. En 1758 presentó su célebre Tableau Économique, acompañado de una memoria titulada 
Máximas generales para el gobierno de un reino agrícola, en él se explicaba por primera vez el proceso de circulación de la renta. Aunque su interpretación de la economía, demasiado apegada a la tierra, pronto fue superada por los hechos, su idea de circuito económico se convirtió en un pilar fundamental para la representación de la actividad económica.

"Le total des cinq milliards partagé d'abord entre la classe productive et la classe des propriétaires étant dépensé annuellement dans un ordre régulier qui assure perpétuellement la même reproduction annuelle, il y a un milliard qui est dépensé par les propriétaires en achats faits à la classe productive, et un milliard en achats faits à la classe stérile: la classe productive en dépense aussi un milliard en achats quelle fait â la classe stérile; ainsi la classe stérile reçoit deux milliards qu'elle emploie à la classe productive en achats pour la subsistance de ses agents et en achats pour les matières premières de ses ouvrages.” (Quesnay, 1766).

Como fácilmente puede deducirse del párrafo anterior y del cuadro 1.3, el modelo de representación de la actividad económica de Quesnay integra todos los aspectos fundamentales que caracterizan una economía estacionaria y refleja con nitidez la idea de interdependencia general entre los diferentes sectores de un sistema económico. De ahí, que le Tableau Économique sea un precedente inequívoco de las tablas input-output, de las matrices de contabilidad social (Stone, 1985) y de la introducción en la economía de la programación lineal (E. Britannica, 2000). 
CUADRO 1.3. Tabla Económica de Quesnay. (Francia, ₹1750)

\begin{tabular}{|c|c|c|c|c|c|c|c|c|c|c|c|c|}
\hline & & & I.1 . & I.2 & II.1 & II.2 & II.3 & II.4 & II.5 & III & IV & Total \\
\hline 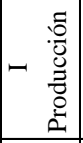 & $\begin{array}{c}1 \text { Agricultura } \\
\ldots \\
2 \text { Otras actividades } \\
\end{array}$ & $\begin{array}{l}\mathrm{I} .1 \\
\ldots \\
\mathrm{I} .2 \\
\end{array}$ & 525 & 525 & 300 & $\begin{array}{r}525 \\
525 \\
\end{array}$ & $\begin{array}{r}263 \\
263 \\
\end{array}$ & $\begin{array}{l}150 \\
150 \\
\end{array}$ & $\begin{array}{r}75 \\
75 \\
\end{array}$ & 525 & 263 & 3150 \\
\hline 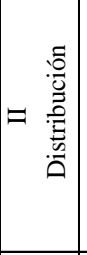 & $\begin{array}{l}1 \text { Terratenientes } \\
2 \text { Agricultores } \\
3 \text { Artesanos } \\
4 \text { Estado } \\
5 \text { Iglesia }\end{array}$ & \begin{tabular}{r|} 
II.1 \\
II.2 \\
II.3 \\
II.4 \\
II.5
\end{tabular} & $\begin{array}{l}1050 \\
1050\end{array}$ & 525 & \multicolumn{5}{|l|}{$\begin{array}{l}300 \\
150 \\
\end{array}$} & & & $\begin{array}{r}1050 \\
1050 \\
525 \\
300 \\
150\end{array}$ \\
\hline III & 1 Acumulación & III & 525 & & & & & & & & & 525 \\
\hline IV & 2 Resto del mundo & IV & & 263 & & & & & & & & 262,5 \\
\hline \multicolumn{2}{|r|}{ Total } & Total & 3150 & 1313 & 1050 & 1050 & 525 & 300 & 150 & 525 & 263 & 8325 \\
\hline
\end{tabular}

El trabajo de Quesnay permaneció en el olvido hasta que un siglo después fue rescatado por Marx, momento a partir del cuál ha sido objeto de un creciente reconocimiento. En palabras de Leontief (1941, p.7): "le Tableau es el descubrimiento más importante después de Newton”.

Karl Marx $(1885,1894)$ con el fin de profundizar en el concepto de excedente, extendió el modelo de reproducción simple (vol. II, parte. III, cap. XX) y diseñó una representación dinámica de la economía, su modelo de reproducción ampliada (vol.II, parte III, cap. XXI). Aunque Marx no conseguiría demostrar que el valor trabajo de las mercancías determina los precios, en su intento sí logró desentrañar algunas de las leyes fundamentales que rigen la dinámica del sistema: si todo el excedente, o producción que supera la necesaria para reproducir el capital y el trabajo, se emplea en consumo suntuario, la economía alcanzará un estado estacionario (reproducción simple); mientras que si una parte del excedente se emplea en acumular medios de producción (capital constante), siempre que el trabajo (capital variable) sea abundante, la economía se ampliará ilimitadamente (reproducción ampliada). 
CUADRO 1.4. Modelos de reproducción simple y ampliada de Marx.

\begin{tabular}{|c|c|c|c|c|c|c|c|c|}
\hline \multirow{2}{*}{$\begin{array}{l}\text { REPRODUCCIÓN } \\
\text { SIMPLE }\end{array}$} & \multirow{2}{*}{ Bienes de Capital } & \multirow{2}{*}{ Bienes de Consumo } & \multirow{2}{*}{$\begin{array}{c}\text { Servicios } \\
\text { improductivos }\end{array}$} & \multicolumn{2}{|c|}{ Consumo Final } & \multirow{2}{*}{\begin{tabular}{|c|} 
Acumulación \\
neta de capital \\
\end{tabular}} & \multirow{2}{*}{\begin{tabular}{|c|} 
Consumo de \\
Capital Fijo
\end{tabular}} & \multirow{2}{*}{ TOTAL EMPLEOS } \\
\hline & & & & necesario & extra & & & \\
\hline Bienes de Capital & 0 & 0 & 0 & 0 & 0 & 0 & $100 p_{c}$ & \multirow{4}{*}{$\begin{array}{c}\boldsymbol{q}_{c} \boldsymbol{p}_{c}=100 p_{c} \\
\boldsymbol{q}_{t} \boldsymbol{p}_{t}=100 p_{t} \\
\boldsymbol{q}_{s} \boldsymbol{p}_{s=}=1600 p_{s} \\
\boldsymbol{q}_{t} \boldsymbol{p}_{h}=2400 p_{t}\end{array}$} \\
\hline Bienes de Consumo & 0 & 0 & 0 & $100 p_{t}$ & 0 & 0 & 0 & \\
\hline Servicios improductivos & 0 & 0 & 0 & 0 & $1600 p_{s}$ & 0 & 0 & \\
\hline Trabajo & \multirow{3}{*}{$\begin{array}{c}100^{*} 4 p_{h} \\
g *\left(100^{*} 4 p_{h}\right) \\
0 \\
\end{array}$} & \multirow{3}{*}{$\begin{array}{c}100^{*} 4 p_{h} \\
g *\left(100 * 1 p_{c}+100^{*} 4 p_{h}\right) \\
100 * 1 p_{c}\end{array}$} & \multirow{3}{*}{$\begin{array}{c}1600 * 1 p_{h} \\
\mathrm{~g}^{*}\left(1600^{*} 1 p_{h}\right) \\
0 \\
\end{array}$} & & & & & \\
\hline Excedente Neto & & & & & & & & \multirow{2}{*}{$\begin{array}{c}g^{*}\left(100 p_{c}+2400 p_{h}\right) \\
100 p_{c}\end{array}$} \\
\hline Consumo de Capital Fijo & & & & & & & & \\
\hline TOTAL RECURSOS & \multicolumn{7}{|c|}{$\boldsymbol{q}_{c} \boldsymbol{p}_{c}=(1+g)^{*} 400 p_{h} \boldsymbol{q}_{\boldsymbol{t}} \boldsymbol{p}_{\mathbf{t}}=(1+g)^{*}\left(100 p_{c}+400 p_{h}\right) \boldsymbol{q}_{s} \boldsymbol{p}_{s}=(1+g)^{*} 1600 p_{h}$} & \\
\hline \multirow{2}{*}{$\begin{array}{l}\text { REPRODUCCIÓN } \\
\text { AMPLIADA }\end{array}$} & \multirow{2}{*}{ Bienes de Capital } & \multirow{2}{*}{ Bienes de Consumo } & \multirow{2}{*}{$\begin{array}{c}\text { Servicios } \\
\text { improductivos }\end{array}$} & \multicolumn{2}{|c|}{ Consumo Final } & \multirow{2}{*}{\begin{tabular}{|c|} 
Acumulación \\
de capital
\end{tabular}} & \multirow{2}{*}{\begin{tabular}{|c|} 
Consumo de \\
Capital Fijo
\end{tabular}} & \multirow{2}{*}{ TOTAL EMPLEOS } \\
\hline & & & & necesario & extra & & & \\
\hline Bienes de Capital & 0 & 0 & 0 & 0 & 0 & $100 p_{c}$ & $100 p_{c}$ & \multirow{4}{*}{$\begin{array}{c}\boldsymbol{q}_{c} \boldsymbol{p}_{c=200 p_{c}} \\
\boldsymbol{q}_{\boldsymbol{t}} \boldsymbol{p}_{t}=100 p_{t} \\
\boldsymbol{q}_{s} \boldsymbol{p}_{s=1200 p_{s}} \\
\boldsymbol{q}_{h} \boldsymbol{p}_{h=2400 p_{h}}\end{array}$} \\
\hline Bienes de Consumo & 0 & 0 & 0 & $100 p_{t}$ & 0 & 0 & 0 & \\
\hline Servicios improductivos & 0 & 0 & 0 & 0 & $1200 p_{s}$ & 0 & 0 & \\
\hline Trabajo & \multirow{3}{*}{$\begin{array}{c}200^{*} 4 p_{h} \\
g *\left(200^{*} 4 p_{h}\right) \\
0 \\
\end{array}$} & \multirow{3}{*}{$\begin{array}{c}100 * 4 p_{h} \\
g *\left(100 * 1 p_{c}+100^{*} 4 p_{h}\right) \\
100 * 1 p_{c} \\
\end{array}$} & \multirow{3}{*}{$\begin{array}{c}1200 * 1 p_{h} \\
\mathrm{~g}^{*}\left(1200 * 1 p_{h}\right) \\
0 \\
\end{array}$} & & & & & \\
\hline Excedente Neto & & & & & & & & \multirow{2}{*}{$\begin{array}{c}g^{*}\left(100 p_{c}+2400 p_{h}\right) \\
100 p_{c}\end{array}$} \\
\hline Consumo de Capital Fijo & & & & & & & & \\
\hline \multirow[t]{2}{*}{ TOTAL RECURSOS } & \multicolumn{6}{|c|}{$\boldsymbol{q}_{c} \boldsymbol{p}_{c}=(1+g) * 800 p_{h} \quad \boldsymbol{q}_{t} \boldsymbol{p}_{t}=(1+g) *\left(100 p_{c}+400 p_{h}\right) \boldsymbol{q}_{s} \boldsymbol{p}_{s}=(1+g) * 1200 p_{h}$} & & \\
\hline & \multicolumn{6}{|c|}{ Población ilimitada; Capital inicial $\left(q_{c}\right)=100 ; \quad$ salario de subsistencia $\left(p_{h}\right)=\left(p_{t} / 24\right)=1$} & & \\
\hline
\end{tabular}

Fuente: Elaborado a partir de Marx (1885) y Samuelson (1983).

Como el propio Marx reconocía: “dejando a un lado el sistema económico históricamente definido... la transformación del excedente en capital no es más que el empleo de una porción del exceso de trabajo para formar medios de producción adicionales”... "primero, es una falsa abstracción considerar la nación ...como un agregado que trabaja exclusivamente para la satisfacción de las necesidades nacionales” y segundo, “... la regulación del tiempo de trabajo y la distribución del trabajo social entre los distintos grupos de producción, y sobre todo la contabilidad que requiere todo ello, resulta más esencial que nunca” (vol. III, parte VII, cap. 49, últimos párrafos).

En palabras de Samuelson (1983, p.928): “cualquiera que sea el fallo último del análisis marxista maduro ..., los economistas de todas las escuelas estarán seguramente de acuerdo en que Karl Marx realizó una aportación analítica estelar a lo que hoy llamamos modelos de crecimiento input-output de Von Neumann-Leontief”. Y en palabras de Schumpeter (1942, p.2): "La mayor parte de las creaciones del intelecto o la fantasía desaparecen para siempre después de un intervalo que varía entre una hora y una generación. Con otras sin embargo, no ocurre así. Sufren eclipses, pero reaparecen de nuevo; ... , tal es indudablemente la calificación que hay que aplicar al mensaje de Marx”. De hecho entre los últimos desarrollos de los Sistemas de Cuentas Naciona- 
les destacan, precisamente, la contabilidad del patrimonio y la consideración de los aspectos distributivos, que tienen como finalidad última el análisis de la sostenibilidad económica y social del sistema.

\subsubsection{Los primeros Sistemas de Cuentas Nacionales y el papel armonizador de los organismos internacionales}

A lo largo del siglo XIX, las estimaciones de la renta nacional fueron extendiéndose por distintos países, hasta el punto de que a finales del mismo, alrededor de veinte países ya contaban con estimaciones razonables de su renta ${ }^{9}$.

La necesidad de recabar una masa ingente de recursos para afrontar las guerras mundiales (Peacock y Wiseman, 1961), al igual que siglos atrás impulsó la aritmética política, fue una de las razones del abrupto desarrollo de la Contabilidad Nacional en la primera mitad del siglo XX y de la creación de oficinas estadísticas oficiales encargadas de la estimación regular de los principales agregados económicos. La Gran Depresión de los años 30 y la respuesta keynesiana a la crisis extendieron su aplicabilidad a los periodos de paz.

El triunfo electoral de Roosvelt en 1932 y su propuesta de New Deal supuso el reconocimiento, en el país que estaba consolidándose como la nueva potencia económica mundial, de la necesidad de que los estados interviniesen para paliar las crisis y otros fallos del mercado. Previamente, dicha necesidad ya había sido reconocida en la Alemania de Bismark o la Inglaterra de Lloyce (Galbraith, 1989). Los instrumentos teóricos para la intervención fueron proporcionados por Keynes: los estados pueden corregir las fugas del circuito económico incentivando la demanda privada o comple-

\footnotetext{
${ }^{9}$ Muchas de las estimaciones fueron realizadas por G. Mulhall y publicadas en libras esterlinas en las sucesivas ediciones de su Dictionary of Statistics desde 1884. En Rusia las primeras estimaciones de la renta se remontan a finales del XVIII y a partir de los trabajos S. Prokopovitch de principios del siglo XX ya se adoptó el concepto de producción material que ha perdurado hasta fechas muy recientes. En Estados Unidos las primeras estimaciones de la renta se realizaron a mediados del XIX y se atribuyen a G. Tucker. Austria (1861), Australia (1890), Noruega (1893), Alemania (1899), Japón (1902), Holanda (1910) e Italia (1911) son a menudo citados como países precursores en este campo. No obstante, siempre es posible encontrar alguna estimación,
} 
mentándola con intervenciones directas. La realización de dicha tarea por parte de los gobiernos requiere estimaciones fiables y regulares de la producción y de las demandas de consumo, inversión y externa, entre otros agregados, y de un sistema contable para diseñar y evaluar las distintas políticas económicas.

En la Conferencia Internacional sobre Estadísticas Económicas celebrada por la Liga de las Naciones en 1928 se constató la necesidad de alentar y coordinar los esfuerzos de compilación y homogeneización de tales estadísticas en sus países miembros. En 1939 la Liga de Naciones ya publicó el primer World Economic Survey con estimaciones de renta nacional para 26 países que abarcaban todo o parte del periodo 1929-1938 y que si bien no eran del todo comparables, al menos la mitad de ellas ya tenían carácter oficial. Al finalizar la Segunda Guerra Mundial, el reparto de los gastos de los organismos internacionales hizo inminente la necesidad de disponer de medidas comparables de renta nacional. Para contribuir a dicha labor se creó el Subcomité de Estadística de Renta Nacional del Comité de Expertos en Estadísticas de la Liga de Naciones $^{10}$, que en 1947 ya publicó el informe titulado Measurement of National Income and the Construction Of Social Accounts, que es considerado como el primer Sistema Universal de Cuentas Nacionales. El testigo fue recogido por la Organización de Naciones Unidas y la Organización para la Cooperación Económica Europea (OCEE).

En 1950 la Oficina Estadística de Naciones Unidas presentó estimaciones basadas en fuentes nacionales para 41 países y varios años en la publicación National Income Statistics, 1938-1948. Ese mismo año la OCEE publicó el Sistema Simplificado de Cuentas Nacionales, que sirvió de base para el Sistema Normalizado de Cuentas Nacionales que publicaría dos años más tarde. Al año siguiente Naciones Unidas tam-

por burda que sea, para incluir otros países, y entre ellos España, dentro de la lista de los que contaban con estimaciones de renta antes de la Primera Guerra Mundial (véase, Kendrick, 1979).

${ }^{10}$ Dicho Subcomité estaba integrado por su director R. Stone (Reino Unido), H.P.Brown (Australia), J.B.D. Derksen (Holanda), C.M. Isbister (Canadá), G. Jaszi (USA), H. Kneeland Instituto de Estadística Inter.Americano), R. Ortiz Mena (México), A. Skaug (Noruega) y J. Wyler (Suiza). 
bién publicó su Sistema de Cuentas Nacionales (SCN53) ${ }^{11}$. Tras algunas adaptaciones, ambos Sistemas llegaron a ser muy similares en sus respectivas ediciones de 1958 y 1960. En 1958 Naciones Unidas publicó el primer Anuario de Estadísticas de Contabilidad Nacional que incluía, para 70 países, las nueve cuentas estándar del SCN53 (cuadro 1.5).

CUADRO 1.5. Las cuentas económicas del SCN53

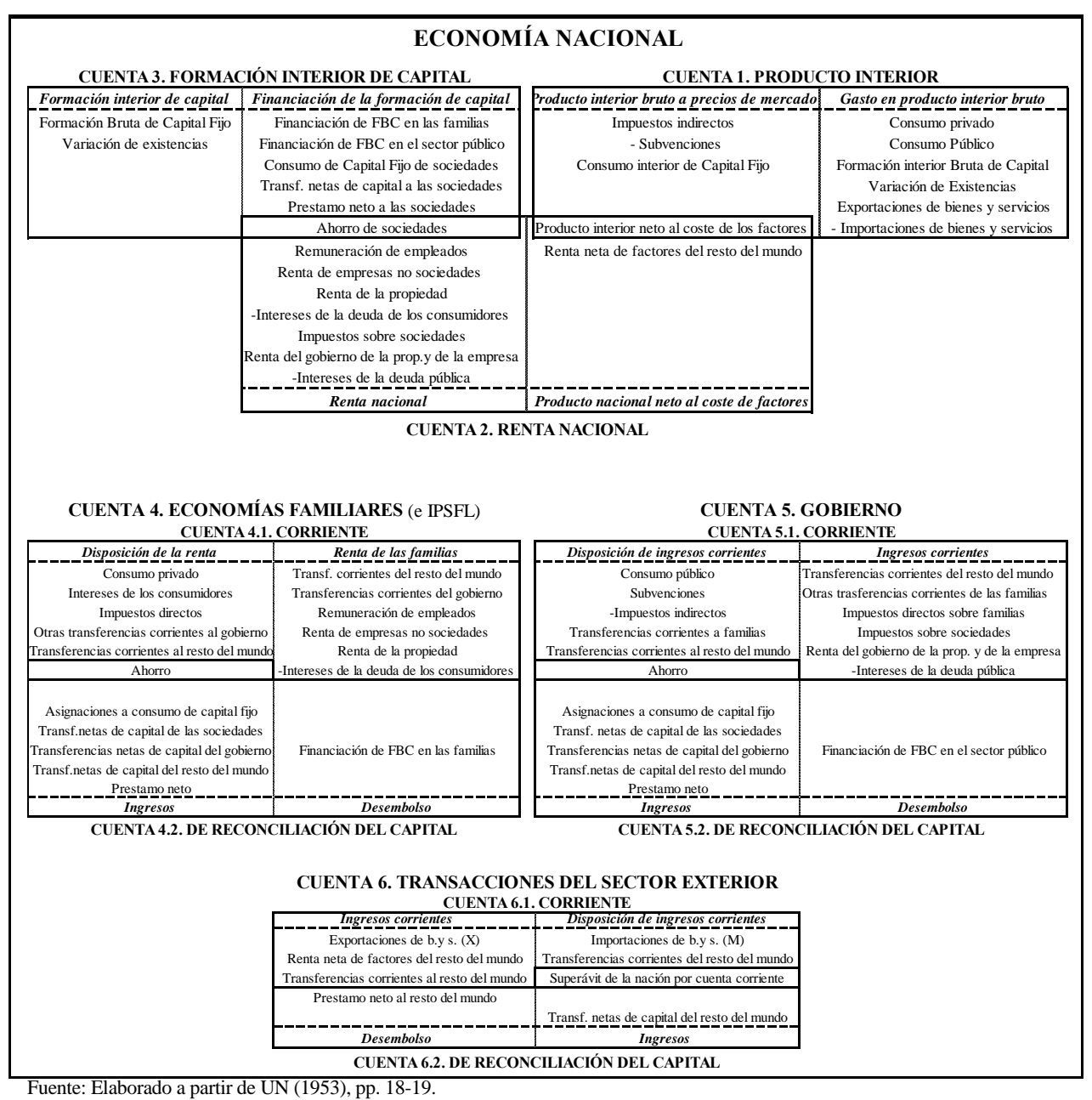

\footnotetext{
${ }^{11}$ Para los países con mayores deficiencias estadísticas, la Oficina Estadística de Naciones Unidas preparó una versión simplificada del SCN53.
} 
El capítulo I del SCN53 ya reconocía la posibilidad de "subdividir la cuenta de producción para mostrar las corrientes de productos entre industrias ... o relaciones insumo-producto, ..., introducir en el mismo sistema todas las corrientes financieras pertinentes, añadir balances para los diferentes sectores de la economía..., expresar en precios constantes las principales corrientes de productos y las existencias incluidas en este sistema”. No obstante, se pensó que era prematuro llevar a cabo el programa en su totalidad, porque aunque ya se habían hecho algunos trabajos en cada uno de los campos mencionados, éstos resultaban insuficientes para fijar normas a escala internacional, excepto en el caso de las cuentas nacionales expresadas a precios corrientes. Tal y como establecía su prefacio, "El propósito ... es establecer un sistema de cuentas nacionales estándar capaz de proporcionar una estructura para elaborar las estadísticas de producción y renta nacionales que sea de general aplicabilidad”.

En resumen, el SCN53 constituyó un paso más en el camino para establecer de forma clara y concisa un marco dentro del cuál pueda organizarse e interrelacionarse de modo coherente toda la información estadística necesaria para estudiar el proceso económico en sus múltiples aspectos.

La creciente elaboración de modelos económicos desagregados puso de manifiesto la urgente necesidad de ampliar el Sistema para poder disponer de clasificaciones adicionales e información más detallada sobre las principales magnitudes económicas. La experiencia acumulada por los países que aplicaron el SCN53 serviría de guía para el desarrollo de algunas de las cuestiones que el SCN53 dejó pendientes y para la incorporación de nuevos elementos. Un grupo de expertos en cuentas nacionales, coordinado de nuevo por R. Stone, acordó un primer documento en 1964 que fue objeto de discusión por las autoridades estadísticas nacionales y diversas asociaciones, entre las que destaca la Asociación Internacional para la Investigación de la Renta y la Riqueza (IARIW). Dicho grupo concluyó sus trabajos en 1967 y al año siguiente sus propuestas fueron aprobadas por la Comisión Estadística de Naciones Unidas, culmi- 
nando así la revisión del SCN53 y su sustitución por el nuevo Sistema de Cuentas Nacionales de 1968, SCN68, $(\mathrm{UN}, 1968)^{12}$.

Entre los avances más notables del SCN68 cabe destacar la desagregación de la cuenta de producción por ramas de actividad, que supuso la integración de las tablas input-output en el Sistema, la subdivisión de los flujos financieros entre los distintos sectores institucionales por tipos de instrumentos financieros y la estimación de los flujos de bienes y servicios a precios constantes. Otros avances dignos de mención fueron la delimitación del ámbito de la producción, un mayor detalle en las clasificaciones de las unidades productivas e institucionales y una mayor precisión en la definición de los flujos económicos. Al menos como propuesta, el SCN68 reconocía la plena correspondencia entre las cuentas de flujos tradicionales y los modelos que podían inferirse de su representación matricial o diagramática (cuadros 1.6.a y 1.6.b).

CUADRO 1.6.a. Las cuentas consolidadas de la nación (SCN68)

\begin{tabular}{|c|c|c|c|}
\hline & \multicolumn{2}{|c|}{ CUENTA 3. RENTA NACIONAL DISPONIBLE Y SU ASIGNACIÓN } & \\
\hline & Asignación del ingreso disponible & Ingreso disponible & \\
\hline & \multirow[t]{2}{*}{$\begin{array}{l}\text { Gasto de consumo final de las AA.PP. } \\
\text { Gasto privado de consumo final }\end{array}$} & $\begin{array}{l}\text { Remuneración de los empleados (netas del RDM) } \\
\text { Renta de la prop.y de la empresa (netas del RDM) } \\
\text { Otras transferencias corrientes (netas del RDM) }\end{array}$ & \\
\hline & & $\begin{array}{l}\text { Remuneración de los empleados } \\
\text { Impuestos indirectos } \\
\text { - Subvenciones }\end{array}$ & \multirow{3}{*}{$\begin{array}{c}\text { Exportaciones de bienes y servicios } \\
\text {-Importaciones de bienes y servicios } \\
\text { Gasto de consumo final de las AA.PP } \\
\text { Gasto de consumo final privado } \\
\text { Aumento de existencias } \\
\text { Formación bruta de capital fijo_. }\end{array}$} \\
\hline Variación de existencias & Ahorro & Excedente de explotación & \\
\hline \begin{tabular}{|c|} 
Formación Bruta de Capital Fijo \\
Compra de intangibles (netos del RDM) \\
Adquisición neta de activos financieros
\end{tabular} & $\begin{array}{c}\text { Consumo de Capital Fijo } \\
\text { Transferencias de capital (netas del RDM) } \\
\text { Emisión neta de pasivos }\end{array}$ & Consumo de capital fijo & \\
\hline Adquisición neta de activos & Finaciación de la Adquisición neta de activos & Producto Interior Bruto & Gasto correspondiente al PIB \\
\hline \multicolumn{2}{|c|}{ CUENTA 5. FINANCIACIÓN DECAPITAL } & \multicolumn{2}{|c|}{ CUENTA 1. PRODUCTO Y GASTO INTERNOS BRUTOS } \\
\hline \multicolumn{3}{|c|}{$\begin{array}{c}\text { CUENTA 6. TRANSACCIONES EXTERIORES } \\
\text { OPERACIONES CORRIENTES }\end{array}$} & \\
\hline & $\begin{array}{l}\text { Exportaciones de bienes y servicios } \\
\text { Gastos en el mercado interior de hogares no resid. } \\
\text { Remuneración de los empleados proc. del RDM } \\
\text { Renta de la prop. y de la empresa proc. del RDM } \\
\text { Otras Transferencias corrientes proc. del RDM }\end{array}$ & \begin{tabular}{|c|} 
Utilización de los ingresos corrientes \\
Importaciones de bienes y servicios \\
Gastos en el exterior de AA.PP. y hogares resid. \\
Remuneración de los empleados pag. al RDM \\
Renta de la prop. y de la empresa pag. al RDM \\
Otras Transferencias corrientes pag. al RDM \\
\end{tabular} & \\
\hline & \multirow[b]{2}{*}{$\begin{array}{c}\text { Compra de intangibles (netos del RDM) } \\
\text { Adquisición neta de activos financieros extranjeros }\end{array}$} & Excedente de la nación por transacciones corrientes & \\
\hline & & $\begin{array}{l}\text { Transferencias de capital (netas del RDM) } \\
\text { Emisión neta de pasivos extranjeros }\end{array}$ & \\
\hline \multicolumn{4}{|c|}{ OPERACIONES DE CAPITAL } \\
\hline
\end{tabular}

${ }^{12}$ A pesar de los esfuerzos que se realizaron para homogeneizar el nuevo Sistema de Cuentas Nacionales con el Sistema de Balances de la Economía Nacional (más conocido como Sistema de Producción Material) desde su elaboración en 1965 por el Consejo de Asistencia Económica Mutua, este último continuó siendo durante las dos décadas siguientes la base de las estadísticas presentadas a Naciones Unidas por los países con economías planificadas. 
CUADRO 1.6.b. SCN68: Matrices y diagramas

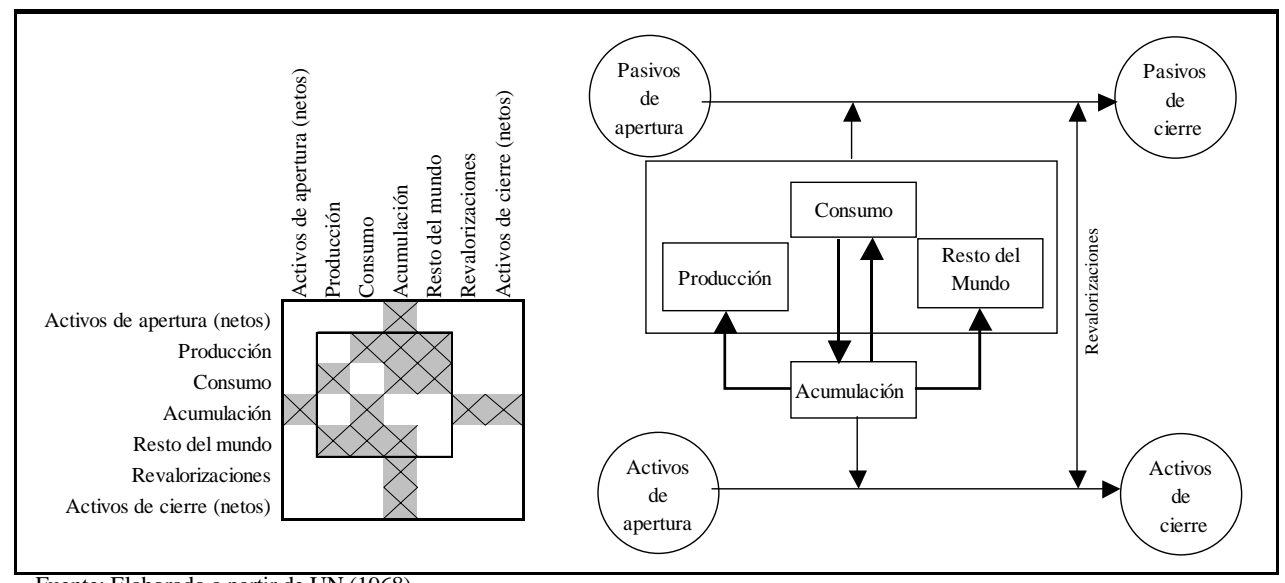

Fuente: Elaborado a partir de UN (1968)

Algunos de los avances mencionados respondían a las nuevas necesidades de una época en la que se pensaba que las políticas keynesianas de ajuste fino de los años sesenta habían vencido los peligros de la depresión económica. Así, la incorporación de la tabla input-output reflejaba el interés por identificar las actividades con mayores efectos de arrastre sobre el resto de la economía para, de este modo, posibilitar una intervención selectiva del Estado con la que lograr, no sólo el equilibrio macroeconómico, sino también el máximo crecimiento posible. El desarrollo de la contabilidad de flujos financieros y la estimación de las variaciones de los precios respondía a la preocupación latente por los riesgos inflacionistas que se derivaban del creciente intervencionismo militar norteamericano.

Otros avances, más que respuestas a intereses o problemas reales concretos, constituyeron una lista de objetivos para el desarrollo futuro de los sistemas estadísticos. Así por ejemplo: "aunque los balances son parte integrante del nuevo Sistema, este informe no contiene definiciones y clasificaciones detalladas ni cuentas y cuadros normalizados respecto a tales datos” (UN,1968, p. iv). De hecho, el conjunto de 20 cuentas y 26 cuadros suplementarios del SCN68 configuraban un sistema difícil de asimilar a primera vista, lo que quizá pudo deberse a una presentación precipitada del mismo o, más probablemente, al hecho de tener que congeniar experiencias demasiado 
dispares $^{13}$. En suma, aunque el SCN68 supuso un desarrollo importante de la Contabilidad Nacional, su aplicación no fue todo lo universal y homogénea que sus promotores desearon.

La labor desempeñada por el gran numero de investigadores que participaron en la elaboración y revisión del Sistema de Cuentas Nacionales fue reconocida y personificada por la Academia responsable de la concesión de los Premio Nobel en las figuras de Simon Kuznets y Wasily Leontief de Estados Unidos, de Richard Stone y James Meade de Reino Unido y de J. Tinbergen de Países Bajos. En dicha tarea también tuvieron un papel destacado los grupos de trabajo de Noruega, Francia, Canadá, y Australia, sin olvidar el trabajo más o menos independiente de la URSS.

\subsubsection{El Sistema Europeo de Cuentas Económicas Integradas}

Finalizada la revisión del Sistema de Cuentas de Naciones Unidas, en la que también habían participado expertos de la Oficina de Estadística de las Comunidades Europeas, esta última se puso a trabajar en la adaptación del nuevo Sistema a los países comunitarios en estrecha colaboración con las oficinas estadísticas de sus estados miembros, hasta ultimar en 1970 su propio Sistema de Cuentas Económicas Integradas, SEC70 (OSCE, 1972). A diferencia del SCN68, el SEC70 fue concebido, más que como una guía para trabajos futuros, como un sistema para ser aplicado desde el mismo momento de su aparición, de ahí que buena parte de los esfuerzos en el proceso de adaptación del SCN68 se centraran en conseguir una mayor precisión y rigor en los conceptos y definiciones.

Tal y como se señala en su introducción, el SEC70 conforma un conjunto coherente y detallado de cuentas y cuadros contables cuyo fin es dar una visión sistemática, comparable y lo más completa posible de la actividad económica de los estados miembros de la comunidad. Con ligeras modificaciones en los criterios de clasifica-

\footnotetext{
${ }^{13}$ El grupo de diez expertos que se encargó de la elaboración del informe final incluía representantes de Venezuela, Noruega, Francia, USA, Reino Unido, Hungría, Países Bajos, India, Irlanda y el FMI.
} 
ción de las unidades institucionales y en algunas operaciones económicas (cuadros 1.7.a y 1.7.b), el SEC70 después de tres décadas de existencia mantiene su vigencia.

Las cuentas de flujos del SEC70 agrupan para un conjunto concreto y homogéneo de unidades las operaciones relativas a una determinada fase del proceso económico (producción, generación, distribución o utilización de la renta y acumulación). Sus saldos, que sintetizan los desequilibrios que se producen en las distintas parcelas de la actividad económica y a los que se asigna el nombre de un agregado económico, se incorporan a la cuenta siguiente para representar de la forma más completa posible el flujo circular de la renta.

El capítulo del SEC70 dedicado a la clasificación de las unidades de producción y a la integración de sus operaciones en una tabla input-output constituye un buen ejemplo del compromiso que los Sistemas de Cuentas representan entre los desarrollos de la teoría y las limitaciones de la estadística, en este caso se sacrificó la exposición de modelos cuyo desarrollo estaba entonces en plena ebullición, en aras de una mayor precisión en la descripción de sus componentes y de los criterios de valoración y registro. Tal compromiso todavía resulta más patente en el capítulo dedicado a la población y el empleo en el marco de la Contabilidad Nacional, en el que a costa de una simplicidad exasperante se consigue introducir, por vez primera, a las personas en un Sistema que hasta entonces sólo admitía monedas. Otro ejemplo de moderación fue el aplazamiento, a su segunda edición de 1979 (Eurostat, 1980), del capítulo dedicado a las variaciones de los precios y de volumen, cuando ya se disponían de criterios compartidos para calcular en términos reales todos los flujos económicos y no sólo las operaciones de bienes y servicios. 
CUADRO 1.7.a. SEC70: Clasificación de las unidades institucionales

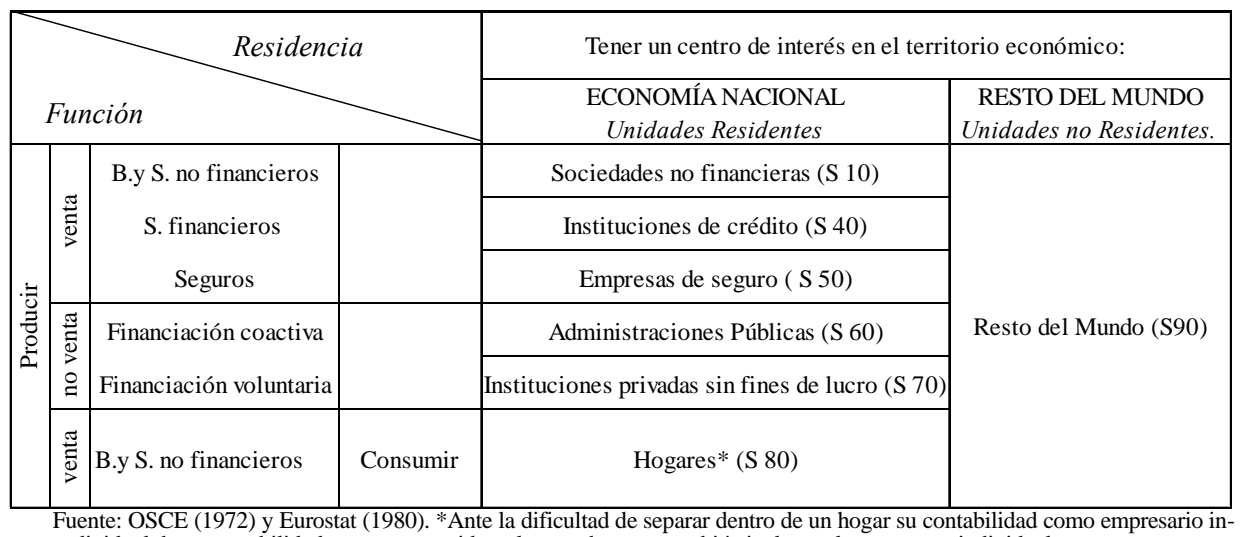
dividual de su contabilidad como consumidor, el sector hogares también incluye a las empresas individuales.

CUADRO 1.7.b. SEC70: Flujos económicos y cuentas simplificadas de la nación

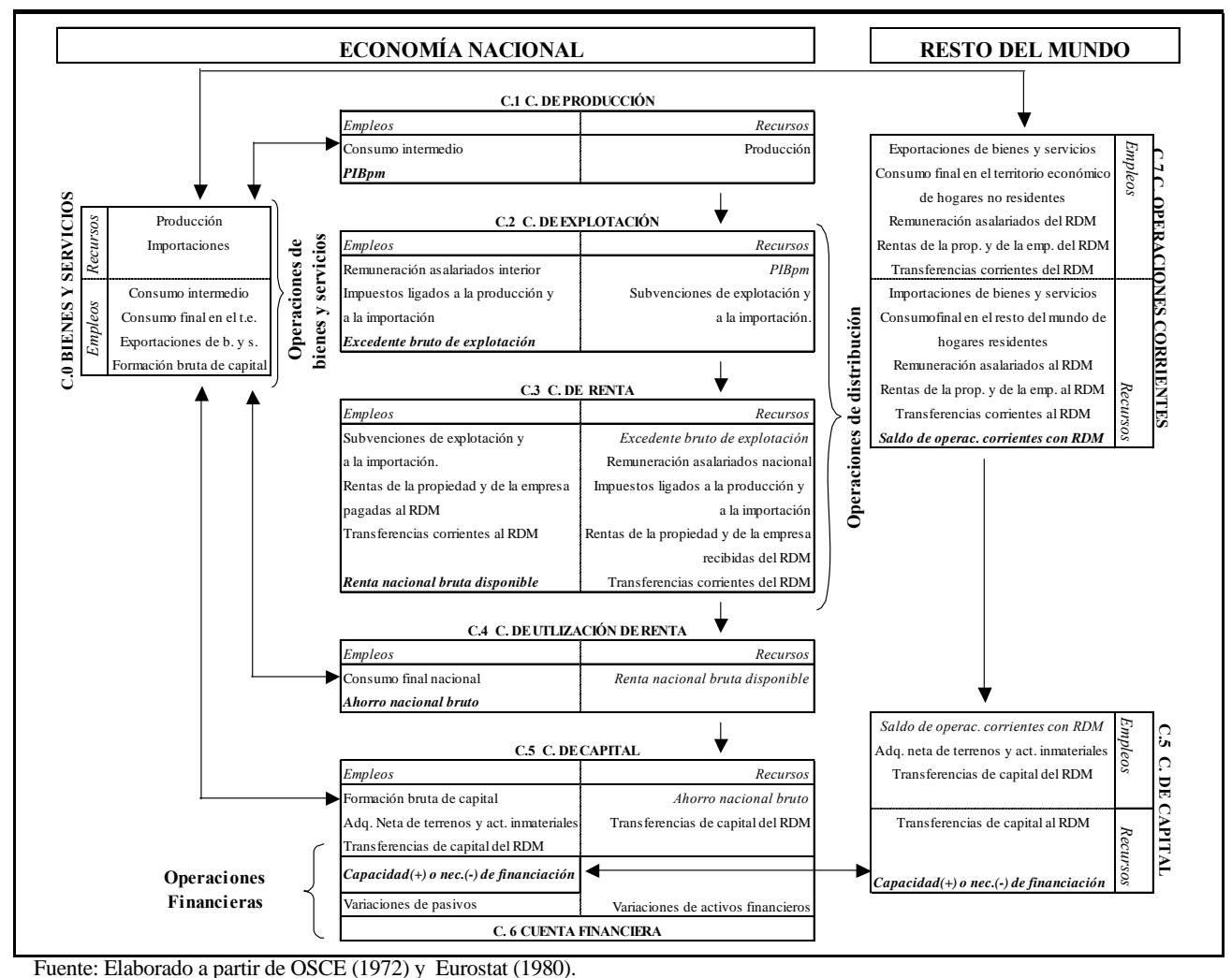




\subsection{LOS SISTEMAS DE CUENTAS NACIONALES VIGENTES: SCN93 Y SEC95}

Los diversos seminarios que los responsables estadísticos de Naciones Unidas celebraron a lo largo del quinquenio 1975-1980, para contrastar las experiencias de los distintos países que venían aplicando el SCN68, culminaron con la creación de un nuevo grupo de expertos en Cuentas Nacionales. Este grupo recomendó en 1982 la revisión del Sistema, con la finalidad de adaptarlo a las nuevas circunstancias, clarificarlo, simplificarlo y armonizarlo con otras estadísticas internacionales relacionadas, e inició la tarea de recopilación y discusión de diversos documentos de base. A diferencia de lo ocurrido con la revisión del SCN53, en esta ocasión la Comisión Estadística de Naciones Unidas, a partir de 1985, confió la planificación de los trabajos a la InterSecretaría de Cuentas Nacionales (ISWGNA) en la que participaron, además de representantes de la División Estadística de Naciones Unidas, representantes de la Oficina Estadística de la Unión Europea (Eurostat), del Fondo Monetario Internacional (FMI), de la Organización para la Cooperación y el Desarrollo Económico (OCDE) y del Banco Mundial (BM). El punto de partida de sus trabajos fueron dos documentos sobre el diseño y la estructura conceptual del nuevo Sistema de Cuentas (UN, 1986a y 1986b).

Después de numerosas reuniones en las que participaron expertos de más 40 países, el primer borrador completo del nuevo Sistema de Cuentas estuvo disponible a principios de 1991 y la aprobación de su versión definitiva se produjo en $1993^{14}$. El SCN93 incorpora la mayor parte de los avances producidos durante el último cuarto de siglo en el ámbito de la Contabilidad Nacional y, lo que es tanto o más importante, cuenta con un consenso sin precedentes entre todos los responsables de los organismos estadísticos internacionales y nacionales, y de la mayor parte de los expertos académicos en esta materia (Kendrick, 1995a).

\footnotetext{
${ }^{14}$ Para una descripción del proceso de revisión del SCN68, véase (UN y otros, 1993, pp.xxxv y xlii).
} 
Aún a riesgo de caer en cierta simplicidad, podría decirse que las dos grandes innovaciones del SCN93 son, por un lado, la incorporación de la contabilidad de balances y su integración con la contabilidad de flujos y, por otro, el desarrollo de la contabilidad matricial y de las cuentas satélites. El resto de innovaciones pueden interpretarse como soluciones técnicas a problemas específicos, aunque de indudable trascendencia práctica. Entre otros, este sería el caso de la armonización de las cuentas del resto del mundo con la balanza de pagos, o el de la diferenciación entre los gastos de consumo final y el consumo final efectivo.

El desarrollo de la contabilidad de balances ha tenido que ver, sin duda alguna, con los esfuerzos realizados para reconciliar los dos Sistemas de Cuentas vigentes, el de Naciones Unidas empleado por las economías de mercado y el Sistema de Producción Material utilizado por las economías planificadas. En cierto modo, dicho desarrollo puede considerarse como la herencia recibida del segundo de los Sistemas, después de la transición hacia el mercado de buena parte de las economías en las que venía aplicándose. Por su parte las economías de mercado, preocupadas por las crisis energéticas y por el pesimismo de informes que, como los del Club de Roma, desenterraban de nuevo la Ley de Rendimientos Decrecientes y advertían de los peligros de un crecimiento que no tuviese en cuenta el agotamiento de los recursos no renovables, sintieron la necesidad de incorporar la contabilidad de balances en su Sistema de Cuentas.

En cuanto a la contabilidad matricial y las cuentas satélites, su introducción está estrechamente ligada a los esfuerzos realizados para adaptar el sistema estadístico a las nuevas interpretaciones de la teoría económica que, ante la incapacidad de las viejas recetas para afrontar las crisis macroeconómicas, ponen en entredicho los supuestos sobre los papeles desempeñados por los distintos agentes en la economía. Hasta entonces los hogares se consideraban meros suministradores de inputs y receptores de outputs, y tanto éstos como las empresas se presumían fácilmente manipulables por unos gobiernos omniscientes y benevolentes. Sin embargo, son los individuos, o los hogares, quienes como propietarios últimos de los recursos deciden cómo emplearlos al elegir entre trabajo y ocio, o entre consumo presente y futuro. Si bien es cierto que sus 
decisiones están condicionadas por el marco institucional, también lo es que son ellos mismos quienes a través de su participación en las juntas de accionistas o en las elecciones políticas determinan dicho marco.

Los capítulos XVII a XXI del SCN93 que abordan la población y el empleo, las clasificaciones funcionales, la clasificación detallada de los hogares, las matrices de contabilidad social y las cuentas satélites constituyen un amplio reconocimiento del papel protagonista de la población en el sistema económico y social, y de que el funcionamiento de una economía no puede explicarse a través del mero análisis de los flujos económicos agregados. De este modo, el SCN93 sienta las bases para el análisis de la sostenibilidad de los sistemas, tanto desde el punto de vista económico como social, algo que durante la etapa de crecimiento anterior que culminó con la aprobación del SCN68 no fue objeto de especial preocupación.

Más allá de todos estos desarrollos, como ya hemos señalado al principio del epígrafe, el logro más trascendente del SCN93 es el consenso alcanzado en el seno de la comunidad estadística internacional. Tal consenso ha permitido la armonización de los Sistemas de Cuentas Nacionales con las directrices de otros organismos internacionales, tales como el Manual de Balanza de Pagos del FMI, las estadísticas de finanzas públicas y las estadísticas financieras, las estadísticas presupuestarias de la OCDE o las estadísticas laborales de la OIT. A pesar de que se trató de un consenso sin precedentes, en ningún caso puede interpretarse como la aceptación de que el SCN93 constituye una versión definitiva del modo de representar la actividad económica y social, sino como una voluntad compartida de introducir al unísono las adaptaciones necesarias.

La nueva versión del Sistema Europeo de Cuentas Económicas Integradas elaborada por Eurostat en 1995 (SEC95) viene a corroborar dicha voluntad, ya que al adoptarse en forma de Reglamento del Consejo de la Unión Europea en junio de 1996 se convirtió en el primer Sistema de Cuentas económicas y sociales de obligado cumplimiento para un ámbito supranacional. El SEC95 es totalmente coherente con el SCN93, si bien se centra más en las circunstancias y necesidades de información pro- 
pias de la Unión Europea. Al igual que el SCN93, está armonizado con muchas otras estadísticas sociales y económicas (de empleo, industriales, de comercio exterior,...).

A efectos de garantizar su aplicación rigurosa en los estados miembros de la Unión Europea, el SEC95 es menos generalista y más operativo que el SCN93, lo que se traduce en una mayor precisión en la descripción de los conceptos, de las definiciones y de las normas de registro. Asimismo, incluye clasificaciones específicas y referencias explícitas a disposiciones institucionales de la UE, tales como el Sistema Intrastat de registro de flujos de bienes intracomunitarios o las contribuciones de sus estados miembros. También la estructura por capítulos del SEC95 es diferente a la del SCN93, mientras que el SEC95 presenta las operaciones de bienes y servicios, las de distribución, las financieras y otros flujos económicos en cuatro capítulos sucesivos, el SCN93 las presenta en los siete capítulos correspondientes a cada una de las cuentas de flujos que integran la sucesión y a la cuenta del resto del mundo. Ambos dedican sendos capítulos a los balances, al marco input-output, a la medición de las variaciones de precio y volumen, y a la población y el empleo. En tanto que el SCN93 dedica sus últimos capítulos al desarrollo del marco central (XVIII: clasificaciones funcionales; XIX: aplicación del marco integrado a distintas circunstancias y necesidades; XX: matrices de contabilidad social y XXI: cuentas satélites), el SEC95 trata estas cuestiones en varios párrafos o un apartado ${ }^{15}$, destinando sus dos últimos capítulos a las cuentas trimestrales y regionales, cuentas que son tratadas en el SCN93 en los dos últimos apartados del capítulo XIX, circunstancia que de nuevo refleja el carácter más pragmático del SEC ${ }^{16}$.

\footnotetext{
${ }^{15}$ Flexibilidad del Sistema (párrafos 1.15 a 1.17), cuentas satélites (1.18 a 1.23) y presentación matricial del Sistema (apartado 6 del capítulo VIII)

${ }^{16}$ Para una descripción detallada de las diferencias entre el SCN93 y el SEC95, véase OCDE(1997a).
} 


\subsubsection{La contabilidad del patrimonio y la contabilidad de flujos}

Los Sistemas de Cuentas Nacionales registran dos tipos básicos de información: los stocks que reflejan la situación en un momento dado y los flujos que se refieren a las acciones y los resultados de acontecimientos acaecidos durante un periodo de tiempo. Los stocks recogen los componentes del patrimonio de una unidad económica, que está conformado por sus activos económicos, financieros y no financieros, y sus pasivos. Los activos económicos se definen como entidades que funcionan como reservas de valor sobre las que las unidades institucionales ejercen derechos de propiedad, individual o colectivamente, y de cuya posesión o utilización a lo largo de un periodo de tiempo pueden derivarse beneficios económicos para su propietario. Por su parte, los flujos económicos reflejan variaciones (creación, transformación, intercambio, transferencia o extinción) de valor económico y, por tanto, comportan un cambio en el balance patrimonial.

CUADRO 1.8.a. SCN93 y SEC95: Clasificación de flujos y stocks

\begin{tabular}{|c|c|c|}
\hline FLUJOS & \multicolumn{2}{|c|}{ STOCKS } \\
\hline OPERACIONES: interacciones voluntarias entre dos & ACTIVOS NO FINANCIEROS & ACTIVOS FINANCIEROS \\
\hline $\begin{array}{l}\text { unidades (excepcionalmente se recogen operaciones en el } \\
\text { seno de una unidad). } \\
\text { P. Operaciones de bienes y servicios } \\
\text { D. Operaciones de distribución } \\
\text { F. Operaciones financieras } \\
\text { K. Otras operaciones }\end{array}$ & $\begin{array}{l}\text { 1. } P R O D U C I D O S: \text { se originan en el } \\
\text { proceso productivo } \\
\text { 1.1 Activos fijos: } \\
\text { 1.1.1.Tangibles } \\
\text { 1.1.2. Intangibles* } \\
\text { 1.2 Existencias } \\
\text { 1.3 Objetos valioso }\end{array}$ & $\begin{array}{l}\text { Incluyen los medios de pago, los } \\
\text { derechos financieros y los activos } \\
\text { de naturaleza similar a los derechos } \\
\text { financieros. }\end{array}$ \\
\hline $\begin{array}{l}\text { K. OTROS FLUJOS } \\
\text { Otras variaciones del volumen } \\
\text { Apariciones y desapariciones económicas normales } \\
\text { Apariciones y desapariciones económicas excepcionales } \\
\text { Cambios en la clasificación y estructura } \\
\text { Variaciones de valor o ganancias y pérdidas de posesión } \\
\text { Nominales } \\
\text { Neutrales } \\
\text { Reales }\end{array}$ & $\begin{array}{l}\text { 2. NO PRODUCIDOS: originados mediante } \\
\text { procesos distintos a los de la producción. } \\
\text { 2.1. Tangibles } \\
\text { 2.1.1.Terrenos } \\
\text { 2.1.2. Activos del subsuelo } \\
\text { 2.1.3. Recursos biológicos no cultivados } \\
\text { 2.1.4. Recursos hídricos } \\
\text { 2.2 Intangibles }\end{array}$ & $\begin{array}{l}\text { instrumento financiero, de acuerdo } \\
\text { con sus características de riesgo, } \\
\text { liquidez y rentabilidad, en: oro y } \\
\text { DEG, efectivo y depósitos, valores } \\
\text { distintos de acciones, acciones y } \\
\text { otras participaciones, préstamos, } \\
\text { reservas técnicas de seguro y } \\
\text { cuentas pendientes de cobro y } \\
\text { pago. }\end{array}$ \\
\hline
\end{tabular}

Fuente: UN y otros (1993) y Eurostat (1996). * La incorporación de esta nueva categoría de activos económicos se debe a que los gastos de exploración, de adquisición y/o desarrollo de software y bases de datos, así como los gastos de producción de obras literarias y trabajos artísticos originales son tratados en el SCN93 como gastos de capital. 
CUADRO 1.8.b. SCN93 y SEC95: Articulación de los balances con las cuentas de flujos

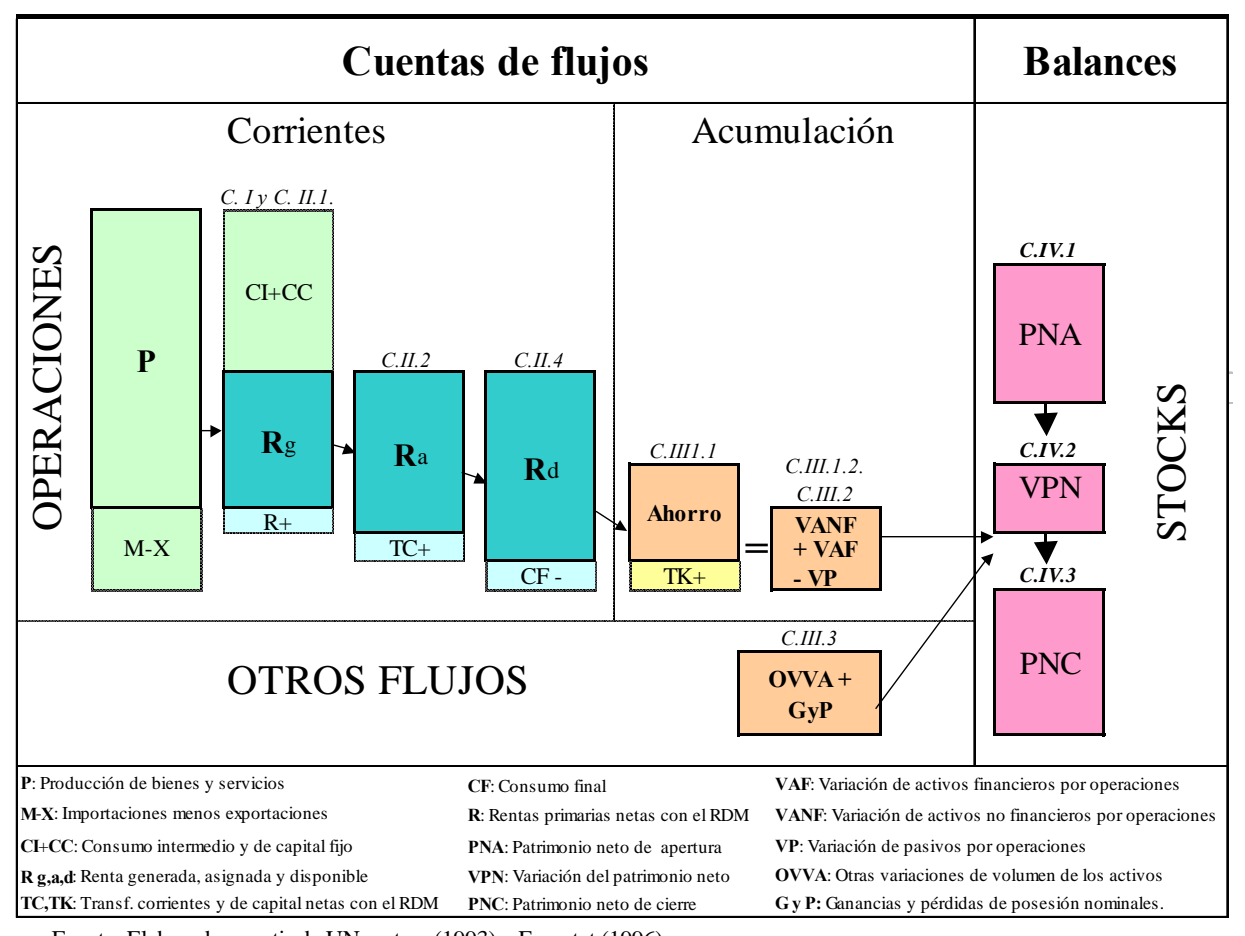

Fuente: Elaborado a partir de UN y otros (1993) y Eurostat (1996).

Toda predicción sobre una economía que esté basada exclusivamente en su contabilidad de flujos puede ser cuestionada por la información procedente de su contabilidad patrimonial. Por ejemplo, unos criterios presupuestarios estrictos que estén centrados en la contabilidad de flujos pueden incentivar a la Hacienda Pública a vender activos para aumentar los ingresos y corregir el déficit corriente, renunciando a una fuente de ingresos con la que ya no podrá corregir déficits en un futuro; también las autoridades monetarias pueden obstinarse en mantener artificialmente una paridad sin tener en cuenta el deterioro en su posición inversora internacional, lo que sin duda va a dificultar los futuros equilibrios externos. En esta misma línea, cabría situar la actuación de los planificadores en las economías del Este que seleccionaron las inversiones sin tener en cuenta sus costes de oportunidad, con el consiguiente efecto negativo que el deterioro en la calidad de los activos fijos produjo sobre la productividad. Asimismo, hoy en día, el mundo desarrollado comprende que si todos los países en desarrollo 
se embarcasen en sendas de crecimiento similares a las que ellos mismos sostuvieron en el pasado, podría producirse el agotamiento de algunos recursos vitales no reproducibles.

En suma, la introducción de la Contabilidad del Patrimonio en el marco de los Sistemas de Cuentas Nacionales permitirá analizar la sostenibilidad del crecimiento y la elaboración de programas más realistas compatibles con el largo plazo. Todavía son muy pocos los países que disponen de balances, de ahí la importancia de los esfuerzos que actualmente se están realizando para llevar a cabo su compilación, especialmente laboriosa en el caso de los activos no financieros ${ }^{17}$.

\subsubsection{Las cuentas económicas y los agregados del cuerpo central del Sistema}

El cuerpo central de los actuales Sistemas de Cuentas consiste en una sucesión de cuentas en forma de T clasificadas en cinco grandes grupos (cuadro 1.9). El grupo I muestra las operaciones relativas a las actividades productivas que generan la renta. El grupo II describe la distribución de dicha renta entre los factores productivos que han contribuido a su obtención, su asignación a los propietarios de los factores de producción (las unidades institucionales), su redistribución entre los sectores institucionales a través de transferencias corrientes y su utilización para satisfacer necesidades finales. El grupo III refleja cómo la renta que no ha sido gastada por los distintos sectores institucionales en empleos corrientes es utilizada para adquirir activos en los mercados de bienes y servicios y/o financieros, los pasivos contraídos por cada uno de ellos, así como otras variaciones en sus activos y pasivos que no se derivan de sus operaciones. El grupo IV describe la estructura de su patrimonio al inicio y final del periodo contable y su variación total (por operaciones y otros flujos) desglosada por tipos de activos

\footnotetext{
${ }^{17}$ Destacan los trabajos del grupo de Canberra sobre estadísticas de stock de capital cuyas tres reuniones anuales de 1997, 1998 y 1999 (oecd.org/std/nameet.htm) culminaron en un manual sobre la medición del stock de capital, consumo de capital fijo y servicios del capital que fue presentado en la Reunión sobre Cuentas Nacionales de la Conferencia de Estadísticos Europeos celebrada los días 25 a 28 de Abril de 2000 (unece.org/stats/documents/ces/ac.68/2000:5) Dichos trabajos también han sido presentados y debatidos en las reuniones bianuales que celebran la Asociación Internacional para la Investigación de la Renta y la Riqueza y l’Association de Comptabilité Nationale.
} 
económicos. Finalmente, en el grupo V se registran los flujos y stocks (únicamente activos financieros y pasivos) en los que participan, o afectan a, una unidad residente y una no residente.

$\mathrm{Al}$ igual que en el SEC70/79, los recursos y empleos de cada cuenta afectan al saldo de la cuenta siguiente, o agregado económico que sintetiza en una única cifra el desequilibrio de la actividad económica recogida hasta ese momento. Aún manteniendo el esquema de las versiones iniciales, la nueva sucesión de cuentas, en primer lugar, permite una integración más precisa de las cuentas de flujos y de los balances a través de la inclusión de la cuenta de otras variaciones de activos (III.3), en segundo lugar, mejora la comparabilidad internacional de los estándares de vida al asignar como consumo efectivo de los hogares los gastos de consumo individualizables de administraciones públicas e instituciones privadas sin fines de lucro (II.3 y II.4.2) y, en tercer lugar, existe una correspondencia total entre las cuentas del resto del mundo y las cuentas de la nueva balanza de pagos (V.I, V.II, V.III.1 y V.III.2) y la posición inversora internacional (V. IV y V.III). 
CUADRO 1.9. SCN93 y SEC95: Sucesión de cuentas y agregados

\begin{tabular}{|c|c|c|}
\hline \multicolumn{2}{|r|}{ CUENTAS } & \multirow[t]{2}{*}{ SALDOS } \\
\hline 1 & $0 \quad$ C. BIENES Y SERVICIOS & \\
\hline \multirow[t]{2}{*}{2} & I C. PRODUCCIÓN & Valor Añadido (PIB/PNB) \\
\hline & II C.DISTRIBUCIÓN Y UTILIZACIÓN DE LA RENTA & \\
\hline 3 & $\begin{array}{l}\text { II.1 C. Distribución primaria de la renta } \\
\text { II.1.1 C. Generación de renta (C.Explotación) } \\
\text { II.1.2 C. Asignación de la renta primaria }\end{array}$ & $\begin{array}{l}\text { Excedente de Explotación (Rentas Mixtas) } \\
\text { Renta Primaria }\end{array}$ \\
\hline \multirow{2}{*}{4} & II.2 C. Distribución secundaria de la renta & Renta disponible \\
\hline & II.3 C. Redistribución de renta en especie & Renta disponible (ajustada) \\
\hline \multirow[t]{4}{*}{5} & II.4 C. Utilización de la Renta & \\
\hline & II.4.1 C. Utilización de la renta disponible & Ahorro \\
\hline & II.4.2 C. Utilización de la renta disponible ajustada & \\
\hline & III C. ACUMULACIÓN & \\
\hline 6 & $\begin{array}{l}\text { III.1 C. Capital } \\
\text { III.1.1 C. Variaciones del patrimonio neto (por Ah.y Tran. Capital) } \\
\text { III.2.2 C. Adquisición de activos no financieros }\end{array}$ & $\begin{array}{l}\text { Var.patrimonio neto debida al ahorro y las transf. de capital } \\
\text { Capacidad o necesidad de financiación }\end{array}$ \\
\hline 7 & III.2 C. Financiera & Capacidad o necesidad de financiación \\
\hline \multirow[t]{2}{*}{8} & $\begin{array}{l}\text { III.3 C. Otras variaciones de los activos } \\
\text { III.3.1 C. Otras variaciones del volumen de activos } \\
\text { III.3.2 C. Revalorización } \\
\text { III.3.2.1 Pérdidas y ganacias de posesión (neutrales) } \\
\text { III.3.2.2 Pérdidas y ganacias de posesión (reales) }\end{array}$ & $\begin{array}{l}\text { Var.patrimonio neto debida a otras var. volumen de activos } \\
\text { Var.patrimonio neto debida a } G \text { y } P \text { de posesión nominales } \\
\text { Var.patrimonio neto debida a } G \text { y } P \text { de posesión neutrales } \\
\text { Var.patrimonio netodebida a } G \text { y } P \text { de posesión reales }\end{array}$ \\
\hline & IV HOJAS DE BALANCE & \\
\hline 9 & IV.1 Balance de apertura & Patrimonio neto de apertura \\
\hline 10 & IV.2 C. Variaciones de balance & Variaciones de patrimonio neto \\
\hline 11 & IV.3 Balance de cierre & \\
\hline \multirow[t]{2}{*}{12} & & Patrimonio neto de cierre \\
\hline & $V$ C.DEL RESTO DEL MUNDO (C.transacciones externas) & \\
\hline 13 & V.I $\quad$ C.Intercambios exteriores de bienes y servicios & Saldo exterior de bienes y servicios \\
\hline \multirow[t]{2}{*}{14} & V.II C.E. de rentas primarias y transferencias corrientes & Saldo exterior de operaciones corrientes \\
\hline & V.III C.E. de acumulación & \\
\hline \multirow{3}{*}{15} & V.III.1 C. Capital & \\
\hline & V.III.1.1 C. Variaciones de patrimonio neto (ah.y tf. capital) & Var.patrimonio neto (por ahorro y transf. capital) \\
\hline & V.III.1.2 C. Adquisición de activos no financieros & Capacidad o necesidad de financiación \\
\hline 16 & V.III.2 C. Financiera & Capacidad o necesidad de financiación \\
\hline \multirow{4}{*}{17} & V.III.3 C. Otras Variaciones de activos & \\
\hline & V.III.3.1 C. Otra variaciones del volumen de los activos & Var.patrimonio neto (otras var. volumen de activos) \\
\hline & V.III.3.2 C. Revalorización & Var.patrimonio neto (perd.y gan.de posesión nominales) \\
\hline & V.IV C.E. Activos y Pasivos & \\
\hline 18 & IV.1 Balance de apertura & Patrimonio neto de apertura (PII apertura) \\
\hline 19 & IV.2 C. Variaciones del balance & Variaciones de patrimonio neto (Variaciones de la PII) \\
\hline 20 & IV.3 Balance de cierre & \\
\hline 21 & & Patrimonio neto de cierre (PII de cierre) \\
\hline 22 & TOTAL & \\
\hline
\end{tabular}

Las cuentas anteriores se presentan para cada uno de los sectores y subsectores institucionales residentes y del resto del mundo, excepto la cuenta de bienes y servicios que sólo tiene sentido para el conjunto de la economía y por tipos de productos. Su integración en un único marco o tabla económica de conjunto (Tablas 2.8 del 
SCN93 y Tabla 8.18 del SEC95) permite mostrar dos clases de equilibrios. Por una parte, para el conjunto de todas las unidades deben coincidir los recursos (o variación de pasivos) y los empleos (o variación de activos) de todas las operaciones de bienes y servicios, y de cada una de las operaciones de distribución y financieras. Por otra parte, para cada una de las unidades y sectores institucionales, el total de sus recursos (incluida la variación de pasivos) debe coincidir con sus empleos totales (incluida la variación de activos).

La finalidad de dichas identidades contables es doble: facilitar la verificación contable para corregir posibles errores y omisiones mediante los correspondientes ajustes entre las distintas fuentes de información priorizadas de acuerdo con su grado de fiabilidad y, tal vez más importante, permitir el análisis de los desequilibrios que resultan al romper el cuadro integrado y considerar tan sólo un grupo concreto de unidades y flujos, cuyo saldo siempre tiene como contrapartida un desequilibrio de signo contrario del resto de flujos y unidades económicas.

\subsubsection{Desarrollos y seguimiento del SCN93}

El Sistema de Cuentas Nacionales, en cierto modo, puede considerarse como una especie de agujero negro que va integrando paulatinamente las diversas estadísticas económicas y sociales. En un mundo ideal, las cuentas económicas de los sectores institucionales deberían obtenerse directamente de la agregación de la información disponible en el ámbito individual, pero lo cierto es que la práctica contable de muchas de las unidades económicas difiere de los criterios teóricos que proponen los Sistemas de Cuentas Nacionales. De ahí la importancia y la necesidad de avanzar en la homogeneización de los conceptos, definiciones y clasificaciones empleados, y de elaborar sistemas intermedios que traduzcan en términos de Contabilidad Nacional la contabilidad tradicional de las distintas unidades o la información que proporcionan las Encuestas para aquellas que no disponen de contabilidad propia. 
El SCN93 (párrafos 1.64 a 1.67) reconoce la conveniencia, al tiempo que las dificultades, de compatibilizar plenamente las bases de datos microeconómicos y las cuentas macroeconómicas, y propone la utilización de dos enfoques alternativos: las matrices de contabilidad social y las cuentas satélites ${ }^{18}$.

A las matrices de contabilidad social les dedicamos el capítulo siguiente. Por lo que respecta a las cuentas satélites, su justificación obedece a que en numerosas ocasiones la información necesaria para analizar determinadas cuestiones económicas y sociales no puede traducirse en términos de Contabilidad Nacional, ya sea porque requiere la utilización de un concepto diferente, porque su valoración no resulte la más relevante o bien porque las unidades implicadas desborden sus clasificaciones sectoriales. La protección social (sanidad, pensiones, desempleo,...), el progreso técnico (educación, I+D, capital humano, ...), el medio ambiente (recursos naturales, contaminación, ...), el bienestar (distribución de la renta, pobreza, ...) constituyen algunas de las cuestiones clave cuyo análisis requiere metodologías contables propias. De ahí el interés de desarrollar cuentas satélites que amplíen la capacidad analítica del Sistema y permitan una mejor integración de las estadísticas no monetarias (flujos o stocks que no pueden observarse fácilmente en términos monetarios o que carecen de una contrapartida monetaria clara) en el marco central del Sistema.

El capítulo que el SCN93 dedica a las cuentas satélites se limita a sugerir un marco contable para que puedan elaborarse desde una perspectiva más funcional que la de los Sistemas de Cuentas y, al mismo tiempo, relevante para el análisis de temas como la cultura, la educación, la salud, la protección social, el turismo, la protección del medio ambiente o la ayuda al desarrollo. Asimismo propone distintas alternativas para ampliar el marco del Sistema que van desde la introducción de algunas cifras adicionales hasta la redefinición de sus principales conceptos. Por último, también a mo-

\footnotetext{
${ }^{18}$ Algunos expertos en la materia como R. Ruggles (1995) defienden que la separación de las operaciones imputadas o reasignadas de las operaciones de mercado y la elaboración de cuentas macroeconómicas únicamente con operaciones de mercado haría teóricamente posible y estadísticamente viable la integración de las estadísticas micro y macroeconómicas.
} 
do de propuesta, presenta la contabilidad medioambiental en el marco contable que en él se propone.

Hay otros aspectos relacionados con las estadísticas económicas y sociales, que debido a su carácter horizontal, no pueden encasillarse ni dentro del cuerpo central ni en su periferia como sistemas intermedios o cuentas satélites. Las series en volumen y en valor, las estadísticas sobre población y empleo, la estimación de la economía sumergida, las cuentas regionales o las cuentas trimestrales, son algunos de los campos difíciles de encajar dentro de la estructura del Sistema, si bien su desarrollo afecta al conjunto del Sistema de Cuentas Nacionales.

Como muestra de los trabajos que se están llevando a cabo para desarrollar el SCN93, en el cuadro 1.10 recogemos una selección de las sesiones celebradas en las últimas reuniones del grupo de expertos en cuentas nacionales de la OCDE, y como reflejo de los avances ya consolidados en el cuadro 1.11 presentamos los manuales y materiales de apoyo elaborados por las organizaciones internacionales responsables del SCN93 desde su aparición. 
CUADRO 1.10. Reuniones de expertos en cuentas nacionales de la OCDE

\begin{tabular}{|c|c|c|c|c|c|c|c|c|c|}
\hline & TEMA & (1) & (2) & & TEMA & (1) & (2) $(3$ & & \\
\hline \multirow{8}{*}{ 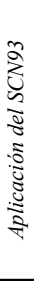 } & Aplicación del SCN 93. & 1997 & 1 & 6 & Input-output y SAM & 2000 & 2 & & \\
\hline & Aplicación del SCN 93. & 1998 & 4 & 1 & Bienestar social (indicadores) & 1998 & 11 & & $\vec{\Xi}$ \\
\hline & Aplicación del SCN 93. & 1999 & 13 & 5 & Contabilidad del medio ambiente & 1997 & 7 & & 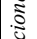 \\
\hline & SNA93 y SEC95: nuevo cuestionario . & 1997 & 10 & 3 & Cuentas de Salud & 1988 & 12 & 5 & 胥 \\
\hline & Educación de usuarios sobre cambios en el SCN93. & 1998 & 6 & 3 & Cuentas satélite (turismo) & 1998 & 3 & & $\stackrel{2}{n}$ \\
\hline & Revisión de las CN por la introducción del SCN93. & 1998 & 5 & 3 & Cuentas satélite (hogares) & 1999 & 1 & 3 & $=$ \\
\hline & Políticas de revisión de la Contabilidad Nacional. & 1998 & 9 & 4 & Estimaciones de empleo en el SCN93 & 1998 & 8 & 2 & 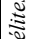 \\
\hline & Retrospectividad y enlaces del SCN93. & 1999 & 7 & 4 & Estimaciones de empleo en el SCN93 & 1999 & 9 & 3 & $\mathbb{Z}^{\pi}$ \\
\hline \multirow{4}{*}{ 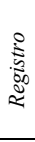 } & Criterios de registro & 2000 & 5 & 3 & Hogares y gobierno & 2000 & 1 & & ن \\
\hline & Ajuste contables & 1999 & 12 & 2 & Administraciones Publicas (productividad) & 1997 & 4 & 6 & \\
\hline & Subsidios al consumo & 1998 & 7 & 2 & Sectores institucionales (empresas) & 1999 & 10 & 2 & \\
\hline & Impuestos y subvenciones al consumo & 1999 & 3 & 2 & Sector Financiero & 1999 & 2 & & $\frac{3}{3}$ \\
\hline \multirow{3}{*}{ 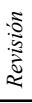 } & Clasificaciones funcionales (revisión) & 1997 & 5 & 3 & Seguros de vida & 2000 & 12 & 1 & 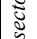 \\
\hline & Clasificaciones funcionales (revisión) & 1998 & 14 & 1 & Servicios de intermediación financiera & 1997 & 9 & 2 & $\dddot{\mho}$ \\
\hline & Clasificaciones funcionales (revisión) & 1999 & 14 & 1 & Servicios financieros & 2001 & 4 & 2 & $\cong$ \\
\hline \multirow{5}{*}{ 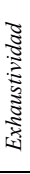 } & Economía oculta e ilegal & 1997 & 2 & 6 & Stock options & 2000 & 10 & 5 & $\vec{y}$ \\
\hline & Producción de no mercado & 1998 & 1 & 8 & Nuevas tecnologías & 2000 & 11 & I & $\sqrt[3]{2}$ \\
\hline & Producción de no mercado & 1999 & 8 & 4 & Comercio electrónico & 1999 & 11 & 2 & 站 \\
\hline & Economía sumergida & 2000 & 6 & 3 & Licencias de móviles & 2000 & 4 & 3 & \\
\hline & Calidad de las cuentas nacionales & 2001 & 7 & 3 & & & & & \\
\hline \multirow{9}{*}{ 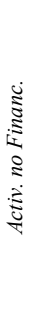 } & Formación de capital & 1999 & 6 & 5 & Medición precios y volumen & 1997 & 8 & 3 & \\
\hline & Activos fijos (consumo y servicios de) & 1997 & 3,12 & 14 & Medición precios y volumen & 1998 & 2 & 3 & $\cdot \stackrel{8}{8}$ \\
\hline & Medición deSoftware & 2001 & 9,1 & 7 & Medición de precios y volumen & 2001 & 5 & 4 & 3 \\
\hline & Medición de intangibles & 1997 & 6 & 6 & Estimaciones a precios constantes & 1999 & 4 & 3 & $\vec{\jmath}$ \\
\hline & Medición de intangibles & 2001 & 2 & 2 & Estimaciones de volumen y productividad & 2000 & 8 & 1 & हี \\
\hline & Capital humano y gastos en I+D & 2001 & 1 & 2 & Medición del interés real & 2000 & 3 & 1 & $\ddot{8}$ \\
\hline & Costes de transferencia de propiedad de activos & 2000 & 9 & 2 & Paridades de poder de compra & 1998 & 18 & 1 & 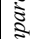 \\
\hline & Estimación de existencias & 1998 & 13 & 1 & Paridades de poder de compra & 1999 & 5 & 1 & $0^{2}$ \\
\hline & & & & & Paridades de poder de compra & 2000 & 7 & $1]$ & \\
\hline
\end{tabular}


CUADRO 1.11. Publicaciones oficiales sobre el SCN93

\begin{tabular}{|c|c|c|}
\hline $\begin{array}{l}\text { Manuales, guías y materiales para la aplicación del SCN elaborados por las } \\
\text { organizaciones miembros del Grupo de Trabajo entre Secretarias sobre } \\
\text { Cuentas Nacionales }\end{array}$ & $\begin{array}{l}\text { Organismo } \\
\text { responsable }\end{array}$ & $\begin{array}{c}\text { Fecha de } \\
\text { publicación }\end{array}$ \\
\hline \multicolumn{3}{|l|}{ CUERPO CENTRAL } \\
\hline 5. An Approach to Presenting the 1993 SNA, with an Operational Application & CESPAO & 1994 \\
\hline 6. Manual on the 1993 SNA Compared to the 1968 SNA & CESPAO & 1994 \\
\hline 10. A Systems Approach to National Accounts Compilation. & DENU & 1995 \\
\hline 15. Versión en CD- ROM del SCN de 1993 & DENU & 1996 \\
\hline 16. Traducción al árabe del SCN de 1993 & CESPAO/DENU & 1996 \\
\hline 17. Traducción al chino del SCN de 1993 & DENU & 1996 \\
\hline 18. Sistema Europeo de Cuentas Económicas de 1995 (idiomas oficiales) & Eurostat & 1996 \\
\hline 19. Versión en CD- ROM del Sistema Europeo de Cuentas Económicas de 1995 & Eurostat & 1996 \\
\hline 21. Handbook on SNA for Transition Economies & DENU & 1997 \\
\hline 22. Traducción al francés del SCN de 1993, en estrecha cooperación con el Eurostat & INSEE (Francia) & 1997 \\
\hline 23. Traducción al español del SCN de 1993, en estrecha cooperación con la CEPAL & INE (España) & 1998 \\
\hline 24. Traducción al ruso del SCN de 1993 & FMI & 1998 \\
\hline 27. Handbook on a Systems Approach to National Accounts Compilation & DENU & 2000 \\
\hline 31. Glosario del SCN de 1993 & OCDE & 2000 \\
\hline 32. Elaboración de nuevos cuestionarios internacionales basados en el SCN93 y SEC95 & Eurostat, OCDE y & 1999 \\
\hline 35. Handbook on the Use of Macro- Accounts for Policy Analysis & DENU & 2001 \\
\hline 38. Handbook on the Computerization of National Accounts & DENU & Postergado \\
\hline 39. Guide for Compiling the $1993 \mathrm{~S}$ & DENU & 2001 \\
\hline 48. Versión en CD-ROM del SCN de 1993 en español. & CEPAL/DENU & 2000 \\
\hline 50. Glosario de la CESPAO sobre cuentas nacionales & CESPAO & 2000 \\
\hline 59. Primer folleto de actualización del SCN de 1993 & $\begin{array}{l}\text { Grupo de trabajo entre } \\
\text { Secretarías de CN }\end{array}$ & 2001 \\
\hline \multicolumn{3}{|l|}{ SISTEMAS INTERMEDIOS } \\
\hline 2. Manual de balanza de pagos & FMI & 1993 \\
\hline 4. Guía de bala & FMI & 1994 \\
\hline 11. Balance of Payments Textbook & FMI & 1995 \\
\hline 25. Manual on Monetary and Financial Statistics & FMI & 2000 \\
\hline 28. Handbook on Input- Output Table Compilation and Analysis & DENU & 2000 \\
\hline 33. Handbook on Links Between Business and National Accountin & DENU & 2000 \\
\hline 34. Handbook ol & DENU & 2000 \\
\hline 36. Handbook on the Non- Profit Institutions, in Cooperation with John Hopkins University & DENU & 2002 \\
\hline 37. Manual de estadísticas de las finanzas públicas : revisión del manual de1986 & FMI & 2001 \\
\hline 43. Manual sobre la compilación de estadísticas relativas a la deuda y el déficit públicos (SEC95) & Eurostat & 2000 \\
\hline 44. Manual on the Compilation of Input-Output Tables under ESA1995 & Eurostat & En elaborac. \\
\hline 46. Foreign Trade Statistics Operational Manual & DENU & 2000 \\
\hline 52. Manual on Capital Stock Statistics & OCDE & 2001 \\
\hline 53. Manual de estadísticas de comercio internacional de servicios. & $\begin{array}{l}\text { Eurostat, FMI, OCDE, } \\
\text { DENU, UNCTAD, OMC }\end{array}$ & \\
\hline 58. Guidelines on Income Distribution & OCDE & 2001 \\
\hline \multicolumn{3}{|l|}{ CUENTAS SATELITES } \\
\hline Economic Accounting. & DENU & 1993 \\
\hline 7. Envir & DENU & 1994 \\
\hline 9. Integrated Satellite Accounting, Socio- Economic Concerns and Modelling. & DENU & 1995 \\
\hline 34. Handbook on Household Accounting: Vol. 2. Household Satellite Accountin & DENU & 2000 \\
\hline 40. Integrated Environmental and Economic Accounting: Operational Manual, with Nairobi Group. & DENU & 2000 \\
\hline 41. Integrated Environmental and Economic Accounting for Forestry, in Cooperation with FAO & DENU, Eur.y BM & 1999 \\
\hline 42. Integrated Environmental and Economic Accounting for Fisheries, with FAO and UNU & DENU & 2001 \\
\hline 51. Tourism Satellite Account (TSA): Recommended Methodological Framework & $\begin{array}{l}\text { Org. Mundial de Turismo, } \\
\text { OCDE, Eurostat, DENU }\end{array}$ & 2001 \\
\hline 54. Sistema de contabilidad ambiental y económica & $\begin{array}{c}\text { Eurostat, OCDE, DENU, } \\
\text { BM }\end{array}$ & 2001 \\
\hline 57. Manual on the Nonobseved Economy & OCDE & 2001 \\
\hline
\end{tabular}




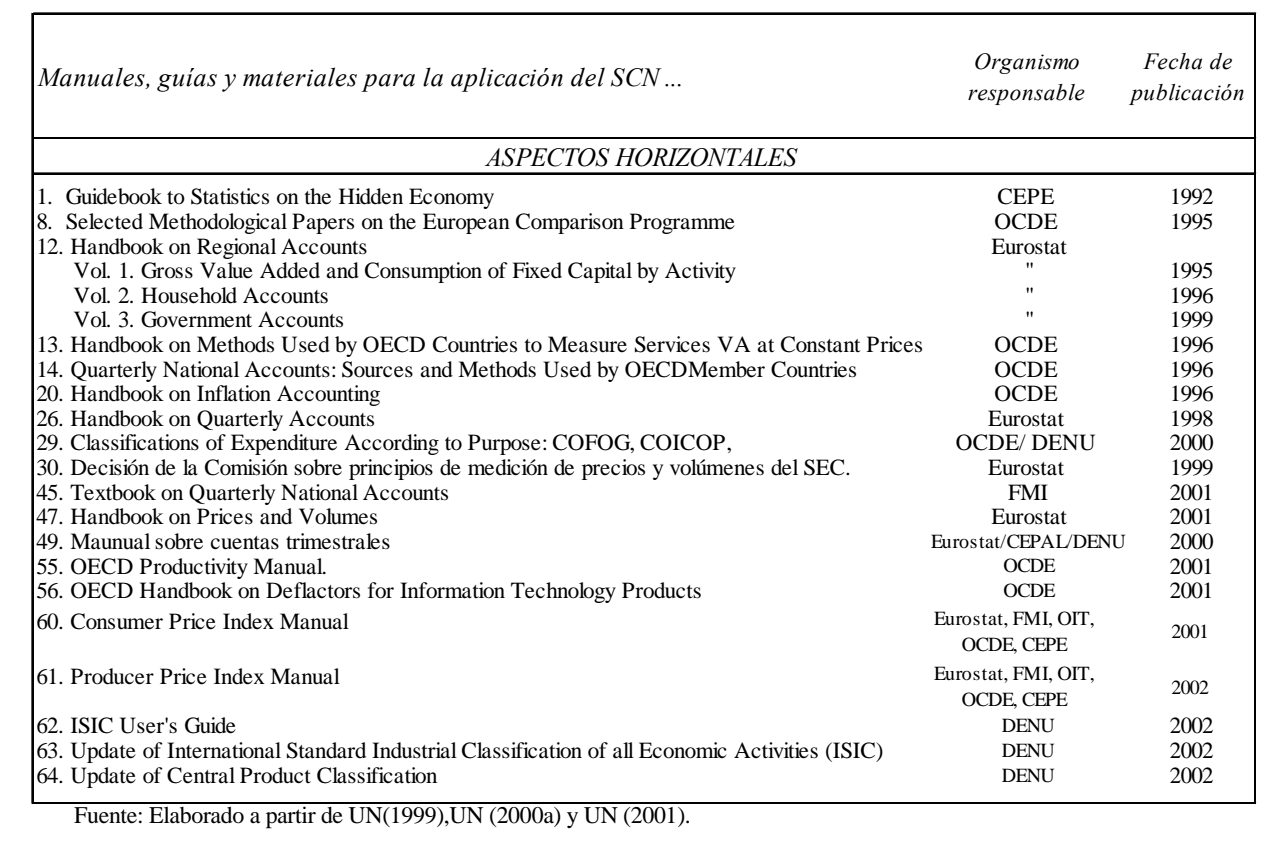

En cuanto a la implantación del Sistema de Cuentas Nacionales, en el cuadro 1.12 recogemos un resumen del grado de aplicación del SCN93 en 1998, último año para el que la Comisión Estadística ha publicado un balance para los distintos estados miembros de Naciones Unidas. Como puede observarse en dicho cuadro, tan sólo dos países disponen de una contabilidad completa que incluya los balances, un cinco por ciento más tiene integradas las cuentas financieras y otro cinco por ciento de países, entre los que se encuentra España, disponen de una contabilidad completa de cuentas no financieras. 
CUADRO 1.12. Cuadro resumen de aplicación del SCN93

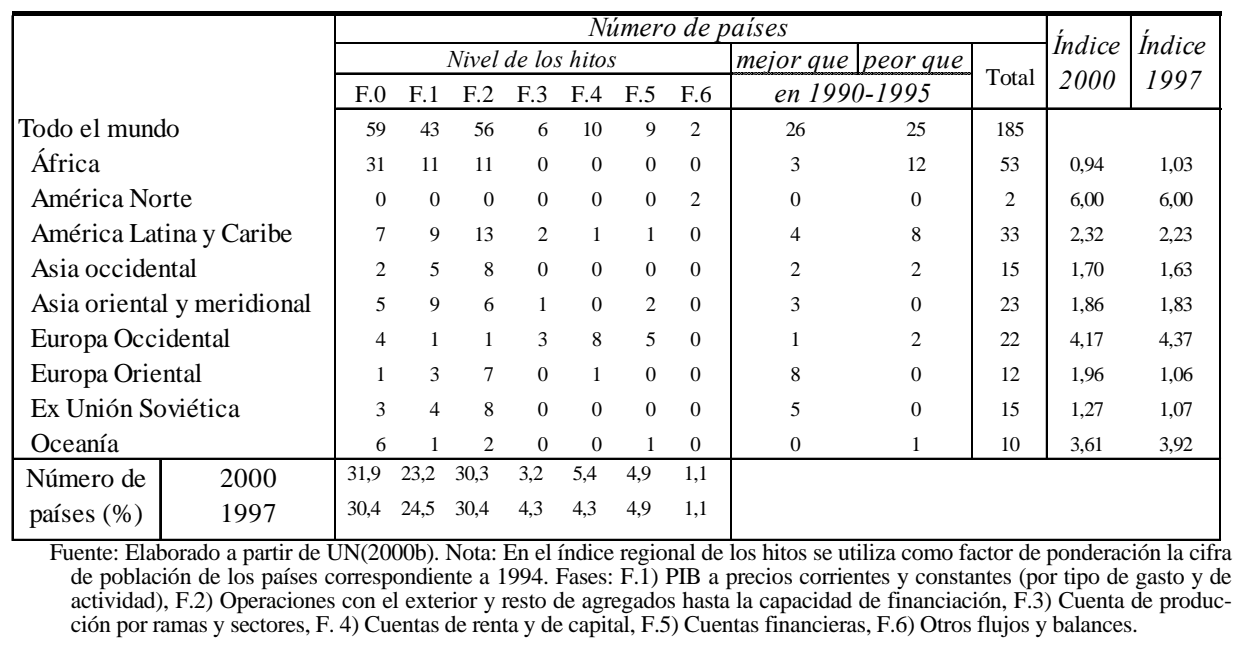

El SCN93 es un sistema vivo que cuenta con un mecanismo de revisión y actualización permanente en el que participan, con distintos grados de implicación, los organismos cuya interrelación presentamos en el cuadro 1.13. Las distintas propuestas de revisión del Sistema son examinadas por el Grupo de Trabajo entre Secretarías sobre Cuentas Nacionales (ISWGNA), aprobadas por la Comisión Estadística de Naciones Unidas (SC) y publicadas en el boletín de Noticias y Notas. Hasta la fecha los dos únicos procesos de actualización iniciados son las Clasificaciones de gastos por finalidades de los gastos de consumo individual, de los gastos de las instituciones privadas sin fines de lucro al servicio de los hogares y de los gastos de los productores que fueron aprobadas por la Comisión Estadística en el año 1999 y el Tratamiento de los instrumentos financieros derivados, aprobado en el año 2000. 
CUADRO 1.13. Organismos participantes en la revisión continua del SCN93

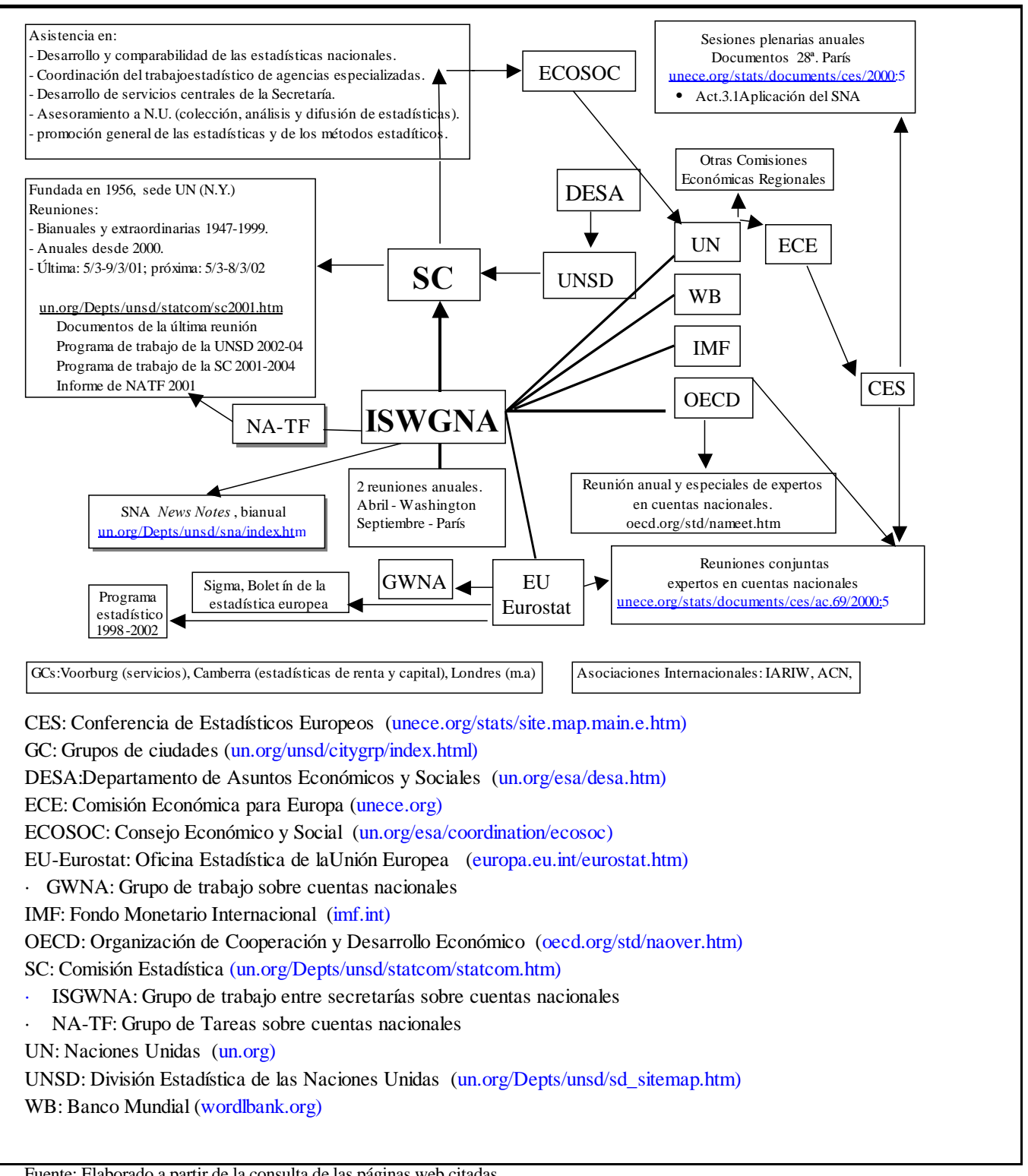

Fuente: Elaborado a partir de la consulta de las páginas web citadas. 


\subsection{LA CONTABILIDAD NACIONAL EN ESPAÑA}

Los primeros intentos de evaluación y medición de la renta nacional de España datan de finales del siglo XVIII y principios del XIX. Sin embargo, no fue hasta la década de los 60 cuando se elaboró por vez primera un sistema completo de cuentas nacionales. A partir de ese momento, la Contabilidad Nacional de España se ha ido ampliando y perfeccionando progresivamente tratando de incorporar los distintos desarrollos de los Sistemas de Cuentas Nacionales descritos en la sección anterior. La incorporación de nuestro país a las Comunidades Europeas en 1986 ligaría definitivamente la evolución de la Contabilidad Nacional de España a la del Sistema Europeo de Cuentas Económicas Integradas.

\subsubsection{Las primeras estimaciones de la renta y la riqueza nacionales}

Las primeras estimaciones sobre la riqueza y la renta nacional en España, más allá del oscurantismo de las fuentes usadas o de la omisión de actividades relevantes, se caracterizaron por la falta de una demarcación precisa entre las contabilidades de flujos y stocks. Velarde (1968, p.288) aventura que “quizá el primer cálculo ordenado y sistemático del capital de la nación sea el de la Junta de Medios” de Cádiz, publicado en 1812 y dado a conocer por José Canga Argüelles en su célebre Diccionario de Hacienda con aplicación a España, reimpreso en Madrid en 1833-1834, tras una primera edición durante su exilio en Londres en 1826-1827 que estuvo prohibida en España por considerarse que podía "causar perjuicio a las personas sensatas que lo lean sin tener en cuenta los principios de una juiciosa y sana crítica”. En el cuadro 1.14 están recogidas y reordenadas las estimaciones de la Junta de Medios en las que se mezclaban los cálculos sobre la renta y la riqueza.

En cuanto a la estimación de la renta, el propio J. Canga Argüelles (1833-1834) recoge el Censo de Frutos y Manufacturas (también llamado Censo de la riqueza territorial e industrial de España en el año de 1799) como el único documento oficial 
que se poseía en la materia, amén del Catastro de Ensenada de 1784 para las 22 provincias de Castilla y León. Por las mismas fechas Moreau de Jonnes en su Statistique de l'Espagne ofrecía dos estimaciones de la renta nacional para 1803 y 1823, que Plaza Prieto (1975, p.531) sospecha estén basadas en el citado Censo de Frutos y Manufacturas. Pascual Madoz, que había traducido el texto de Moreau, también incluyó en su célebre Diccionario geográfico, estadístico, histórico de España y sus posesiones de ultramar de 1846 algunas estimaciones de la renta nacional de España (t. I, p. 226). La infravaloración de los sectores agrario e industrial y la exclusión del sector servicios por parte del Censo de 1799 llevó a estos autores a introducir sucesivas correcciones al alza, así Canga Argüelles (1833-1834, p.180), mencionando como fuente a “un sujeto muy versado en la ciencia económica y en el cálculo” llegó a estimar el producto líquido del capital nacional en algo más de 11.000 millones de reales de vellón (Velarde 1968, p.287). De ahí que autores como Fuentes Quintana (1954) o Velarde (1957) comiencen su repaso por la Contabilidad Nacional de España con las estimaciones recogidas en el Dictionary of Statistics de Michael G. Mulhall ( $3^{\text {a }}$ edición 1892) y referidas al año1888 que, aunque toscas en su elaboración, al menos incluyen los servicios y distinguen entre las partidas que conforman la renta y la riqueza (cuadro 1.14).

CUADRO 1.14. Las primeras estimaciones de la renta y la riqueza en España

\begin{tabular}{|c|c|c|c|c|c|c|}
\hline \multicolumn{2}{|l|}{$\begin{array}{c}\text { CANGA ARGÜELLES (1833, t.I,p.443) } \\
\text { Millones de reales de vellón }\end{array}$} & \multicolumn{5}{|c|}{$\begin{array}{l}\text { MULHALL (1892, pp.320 y 592) } \\
\text { Millones de libras esterlinas }\end{array}$} \\
\hline Capitales estimados por la Junta de Medios & Año 1812 & Año 1832 & 1888 & Riqueza & Renta & Año 1888 \\
\hline Capital de objetos pertenecientes a la agricultura. & 68671 & 686 & 984 & Tierras & Agricultura & 156 \\
\hline Capital invertido en casas. & 17496 & 237 & 340 & Casas & Minería & 4 \\
\hline Capital invertido en artes, fábricas y oficios . & 6167 & 207 & & Casds & Rentas de viviendas & 18 \\
\hline Capital invertido en la industria agrícola. & 3755 & & & & Manufacturas & 51 \\
\hline Capital empleado en pesca, navegación y comercio. & 5000 & 186 & 1098 & $\begin{array}{l}\text { Bienes } \\
\text { diversos }\end{array}$ & Transportes internacionales & 27 \\
\hline Capital empleado en efectos de la Deuda Pública. & 3419 & & & & Comercio & 6 \\
\hline Ganancias de los médicos, abogados, escribanos, etc. & 258 & - & 94 & Ferrocarriles & Navegación & 2 \\
\hline Capital invertido en jornales de artesanos & 605 & 1109 & 2516 & Total & Banca & 2 \\
\hline Salarios de los criados & 96 & & & & Profesiones & 27 \\
\hline Total & 105467 & & & & Total & 293 \\
\hline
\end{tabular}

A partir de ese momento y hasta la guerra civil se suceden una serie de loables esfuerzos privados que, en general, derivan la renta a partir de una estimación previa 
de la riqueza. En el cuadro 1.15 recogemos una síntesis de algunas de las estimaciones más notables de la riqueza ${ }^{19}$. Más allá de la fiabilidad de los datos, la principal característica de estas estimaciones radica en el uso impreciso del concepto de riqueza nacional, al considerar todos los activos financieros en lugar de los activos financieros frente al resto del mundo.

CUADRO 1.15. Otras estimaciones de la riqueza de España 1900-1936

\begin{tabular}{|c|c|c|c|c|c|c|c|c|c|}
\hline $\begin{array}{c}\text { CLASES DE RIQUEZA } \\
\text { millones de pts. }\end{array}$ & $\begin{array}{l}\text { MAY } \\
1895\end{array}$ & \multicolumn{2}{|c|}{ BARTHE V. de EZA } & \multicolumn{2}{|c|}{$\begin{array}{c}\text { VANDELLÓS } \\
1913-14\end{array}$} & \multicolumn{2}{|c|}{ B.URQUIJO } & & $\begin{array}{c}\text { De MIGUEL } \\
1933 \\
\end{array}$ \\
\hline Agricultura & 27600 & 27500 & 30000 & 30000 & Agricultura & 60000 & 76675 & Agricultura & 86790 \\
\hline Ganadería & 2215 & 4000 & & 2500 & Ganadería & 7000 & 10119 & Ganadería & 20427 \\
\hline Minas & & & 2300 & 2000 & Minas & 3000 & 7093 & Minas & 9079 \\
\hline Casas & 6888 & 12500 & 15000 & 14500 & Casas & 25000 & 35700 & Casas & 52883 \\
\hline Mobiliario & & 9000 & & 5600 & Mobiliario & 13000 & & & \\
\hline Maquinaria industrial & & 1800 & & & & & 48247 & Industria & 74824 \\
\hline Ferrocarriles & 2657 & & 2000 & & & & 7000 & Ferrocarril & 6088 \\
\hline Navegación & & & 500 & 7000 & $\begin{array}{l}\text { Rıqueza } \\
\text { mobiliaria }\end{array}$ & 16000 & 3001 & Marina Mercante & 203 \\
\hline Tranvías & & & 100 & & diversa & & & & \\
\hline Gas y Electricidad & & & 150 & & & & & & \\
\hline Reservas de almacen & 3641 & 1500 & & & & & 1500 & Res. Almac. & \\
\hline Valores Industriales & & 6000 & 13000 & & Valores & 12000 & 9500 & Capital de SA & \\
\hline Capitales de bancos y reservas & & & 1500 & 6000 & Bancos y & & & & \\
\hline C/c de la Banca privada & & 200 & & & Sociedades & & 6179 & C/c Bancos & \\
\hline Metales preciosos & & 2000 & & 1600 & Moneda & 3900 & $3214 !$ & Tetales preciosos & \\
\hline Deuda pública & & 9000 & 9800 & 8300 & Deuda Pública & 13000 & 12623 & Deuda Pública & 20965 \\
\hline Ahorro & & & 420 & 500 & Depós. ahorro & 1600 & & & \\
\hline Ahorro Nacional anual & & & 700 & & & & & & \\
\hline Seguros & & & 300 & & & & & & \\
\hline Varios & 15547 & & & -1000 & Pasivos exter. & & & & \\
\hline Total & 58548 & 73500 & 75770 & & & & & & \\
\hline Correción de Vandellós & & 67300 & 61720 & 77000 & Total & 154500 & 218150 & Total & 271259 \\
\hline
\end{tabular}

Con relación a las estimaciones de la renta nacional de España anteriores a la guerra civil, si atendemos únicamente a la calidad de los datos, no hay motivos fundados para seleccionar, en lugar de las de Vandellós y el Banco Urquijo, alguna otra (Fuentes Quintana, 1954). Sin embargo, desde un punto de vista metodológico, la estimación de Ceballos Teresí y, sobre todo, la de Bernis, constituyen notables precedentes de la introducción en nuestro país del flujo circular producción-renta-gasto.

${ }^{19}$ Para un análisis más detallado véase Velarde (1968). 
CUADRO 1.16. Otras estimaciones de la renta de España. 1900-1936

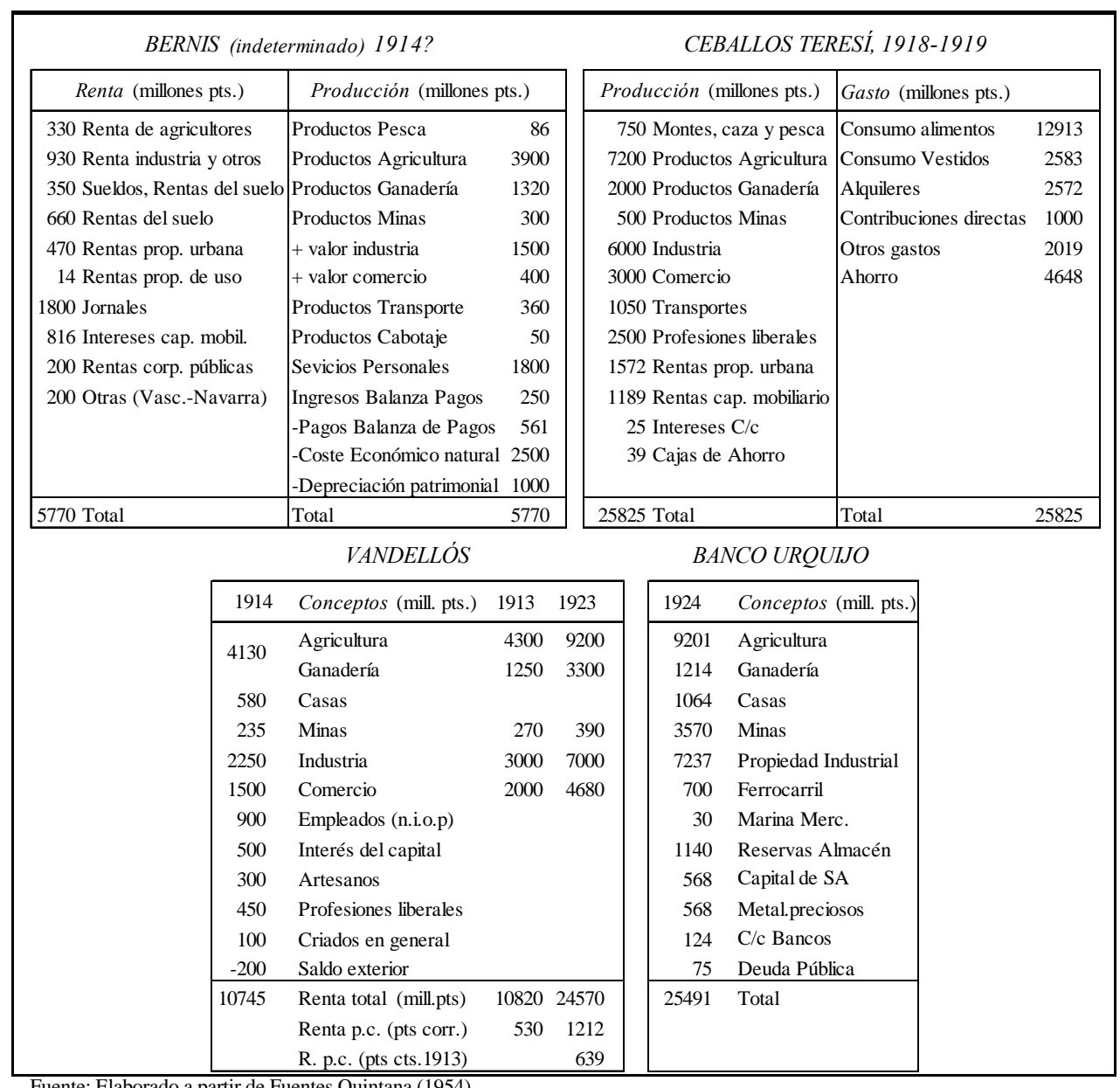

Fuente: Elaborado a partir de Fuentes Quintana (1954).

Durante la posguerra el trabajo de Bernis tuvo su continuidad en el de Gómez Orbaneja que, aun cuando no lleva a cabo ninguna aportación empírica, precisa las tres fases del circuito económico (producción, distribución y gasto) empleando la incipiente literatura existente sobre contabilidad social (Pigou, Clark, Keynes, Hicks, Meade y Stone). Sus opiniones en cuanto a que "no se puede lograr ninguna intervención estatal en ninguna de las ramas económicas, sin conocer datos lo más precisos posibles de la renta nacional. ..., de su distribución y pudiendo hacer una comparación con años anteriores ...” (Gómez Orbaneja,1943, p.40) parecen inspirar la Orden de Presidencia de 
25 de abril de 1944 (BOE 29/4/1944 convalidada un año más tarde con rango de ley, BOE de 17/5/1945), en la que por vez primera se reconoce oficialmente la necesidad del "conocimiento del volumen y distribución de la renta para la elaboración de una política económica adecuada” y por la que se crea una Comisión para garantizar la exactitud de los cálculos en el seno del Consejo de Economía Nacional.

Pasado un año, el Consejo de Economía Nacional publicó La Renta Nacional de España. Planteamiento general del problema. Estimaciones indirectas y primeras cifras (vol. I). El concepto de renta que utilizó la Comisión en sus estimaciones fue el propuesto por Colin Clark (1932): "corriente de bienes y servicios recibidos por una comunidad económica durante un período de tiempo determinado" (CEN,1945, p.20) y el método de cálculo de la misma, tal y como aparece recogido en el título del trabajo, fue indirecto. El procedimiento que siguió para realizar sus estimaciones fue el siguiente: primero calculó la renta nacional de 1923 como el promedio de las estimaciones privadas de renta que para 1923 habían realizado Vandellós y el Banco Urquijo; a continuación extrapoló con dos métodos diferentes (utilizando índices de producción, por un lado, y un índice de nupcialidad, por otro) la renta obtenida para 1923 hasta 1929, previo cambio de origen a 1913, obteniendo la renta nacional de 1929 como una media de ambas extrapolaciones. Finalmente, para calcular la renta nacional a lo largo del período 1929-1942 proyectó la renta nacional de 1929, mediante nuevos índices, más fiables al recoger una mayor cantidad de productos y ponderar los productos industriales por su valor añadido, en lugar de por el valor de su producción. Hasta 1955, el Consejo de Economía Nacional publicó dos series de renta para el periodo 19291954 sin realizar modificación alguna en su método de estimación, una a precios corrientes y otra a precios constantes de 1929, para esta última empleó el índice de precios al por mayor que elaboró el INE.

La posibilidad de calcular directamente la renta como la suma de los valores añadidos de los distintos sectores de la economía fue planteada por la Comisión en 1955. Sin embargo, escudándose en "...las dificultades de orden estadístico y la escasez de medios disponibles para la investigación directa” (CEN, 1956, p.11), optó por 
elaborar “nuevos” índices de producción con base 1953, que también ponderaban las partidas agrarias por sus valores añadidos, y reconstruir las series de renta nacional de España a precios corrientes y constantes para el período 1940-1956. A partir de 1957 y hasta 1964, año en el que la Comisión transfiere sus competencias al INE, las estimaciones de la renta ya se realizaron directamente como la suma de los valores añadidos de los distintos sectores económicos, si bien el protagonismo en la estimación de la renta nacional, como mostramos en el apartado siguiente, se encontraba ya en otro lugar.

Por lo que respecta a la riqueza nacional, aunque la Orden de 1944 creaba la Comisión de Renta del Consejo de Economía Nacional "para estudiar el volumen y la distribución tanto de la renta como del inventario de la riqueza nacional”, su única aportación fue la "Estimación de la riqueza privada de España 1913-1935” recogida en la segunda parte del vol. II de La Renta Nacional de España, publicado en 1947. Aunque sus autores iniciaron el cálculo de la riqueza a través de una compleja estimación de los capitales heredados, terminaron recurriendo a la capitalización al cinco por ciento de las rentas de capital que conformaban la renta nacional, por lo que la utilidad de la serie es bastante discutible (Velarde 1968, p.284). Desde entonces la estimación de la riqueza nacional no ha merecido la atención de la estadística oficial y el único intento de estimar la riqueza nacional de España se produjo con motivo del cincuentenario de la Universidad Comercial de Deusto en 1968. El trabajo publicado en 5 volúmenes, en el que participaron cerca de 300 investigadores bajo la dirección general de José Luis de Urquijo y la dirección técnica de Juan Velarde, fue completado en 1971 con un apéndice en el que, por una parte, se corrigen algunas deficiencias señaladas por los profesores Goldsmisth y Oomens en sendas reseñas críticas en The Economic Journal de septiembre de $1970 \mathrm{y}$ en The Review of Income and Wealth de septiembre de 1971 y, por otra parte, se actualizan los datos iniciales de 31 de diciembre de1965 a 31 de diciembre de 1967 y de 1969, y se incluye una estimación global para 1971. 
CUADRO 1.17. La riqueza nacional de España. 1967-1971

\begin{tabular}{|c|c|c|c|}
\hline & $\begin{array}{c}a 31 \\
1965 \text { (mil) } \\
\end{array}$ & $\begin{array}{c}\text { de dicie } \\
1967 \\
\text { lones pts. }\end{array}$ & $\begin{array}{l}\text { mbre de } \\
19691971 \\
\text { corrientes) }\end{array}$ \\
\hline Riqueza Agraria & 1502202 & 1556399 & 1622494 \\
\hline Flota Pesquera & 31926 & 36118 & 42420 \\
\hline Patrimonio Inmobiliario de Viviendas & 1817137 & 2038322 & 2325175 \\
\hline Patrimonio Nacional de Carreteras & 133607 & 154257 & 180126 \\
\hline Parque de Vehiculos & 116580 & 181258 & 288403 \\
\hline Transportes Urbanos Colectivos & 10470 & 13827 & 18071 \\
\hline Capital Ferroviario & 68932 & 91394 & 104089 \\
\hline Riqueza Portuaria & 25987 & 34920 & 41624 \\
\hline Flota Mercante & 25429 & 30854 & 40240 \\
\hline Aeropuertos & 8243 & 14406 & 16173 \\
\hline Flota Aerea & 5659 & 9592 & 21862 \\
\hline Comunicaciones & 55826 & 82402 & 114580 \\
\hline Riqueza Industrial & 1192729 & 1458632 & 1921624 \\
\hline $\begin{array}{l}\text { Servicios de Administración Pública, Educación y Cultura, } \\
\text { Asistencia Social y Religiosa, y Servicios profesionales }\end{array}$ & 396583 & 434100 & 506455 \\
\hline Servicios de Hostelería & 95251 & 137359 & 171874 \\
\hline Servicios de Esparcimiento & 55423 & 62628 & 72099 \\
\hline Servicios Comerciales & 359290 & 401093 & 456556 \\
\hline Servicios de Banca y Seguros & 22886 & 24480 & 28142 \\
\hline Riqueza Urbanística & 221960 & 242868 & 277789 \\
\hline Riqueza en Poder de los Particulares & 656534 & 747915 & 869051 \\
\hline Valor Total de la Riqueza Interior de España & 6802654 & 7752822 & 9118846 \\
\hline Valor de los Activos Extranjeros (netos de pasivos) & 97713 & 76307 & 62041 \\
\hline Riqueza Nacional de España & 6900367 & 7829129 & 918088710761000 \\
\hline
\end{tabular}

\subsubsection{Hacia la elaboración de un Sistema de Cuentas}

La idea de elaborar una contabilidad completa para España fue lanzada, por primera vez, por el profesor Torres en la Conferencia que pronunció en el Colegio Central de Titulares Mercantiles en 1950 bajo el título "La Contabilidad social o nacional”, en la que resaltaba la importancia y la necesidad que tiene para un país la Contabilidad Nacional:

"Calculad lo que resultaría si a un Banco se acercase un empresario a pedir un crédito y cuando el Director le dijera: "Tráigame un Balance", le contestase: "Pues no llevo Balance" y cuando le manifestara: "No llevará Balance, 
pero Contabilidad sí llevará", respondiese:" No sé que es eso de Contabilidad".

Creo que el empresario que no llevase su Contabilidad ni su Balance tendría escasas posibilidades de conseguir un préstamo." (en Schwartz, 1977, p.19)

El profesor Torres, aunque había participado de un modo destacado en los trabajos de la Comisión para el estudio de la renta nacional, consideraba muy necesario el realizar una estimación de la renta que fuera confidencial e independiente de la que venía realizándose en el seno del Consejo de Economía Nacional. La misión económica norteamericana enviada para la realización de un informe preliminar sobre la renta interior de España (Hemberg, 1955) ya había mostrado que los datos disponibles eran suficientes para realizar un cálculo directo de la renta nacional y de los principales agregados. Por encargo del Ministro de Hacienda, Mariano Navarro Rubio, un equipo de investigadores dirigido por el propio profesor Torres (V. Andrés, J.L. Sampedro, J. Fernández Castañeda, E. Fuentes Quintana, A. Alcaide y A. Santos Blanco) emprendió la ambiciosa tarea de elaborar el primer sistema completo de cuentas nacionales para España, siguiendo el Sistema Normalizado de la OCEE de 1952, que culminó con la aparición en 1958 de La Contabilidad Nacional de España (Cuentas y cuadros de 1954). A partir de dicho año se inició una serie para diez ejercicios cuya publicación corrió a cargo del Ministerio de Hacienda (1959, ..., 1965b), hasta que en 1965 (Decreto 2592 11/9/65) el Instituto Nacional de Estadística, creado por Ley de 31/12/1945 ${ }^{20}$, asumió la elaboración regular de la Contabilidad Nacional de España.

Paralelamente a la elaboración de la primera Contabilidad de España, se construyó la primera tabla input-output, referida al ejercicio de 1954, en el seno de la sección de economía del Instituto de Estudios Políticos que estaba dirigida por el profesor Valentín Andrés Álvarez (Alcaide y otros, 1958). Una buena referencia de las limitaciones que por entonces pesaban sobre los investigadores españoles es el hecho de que la matriz de consumos intermedios para 28 ramas productivas hubo de ser invertida en

\footnotetext{
${ }^{20}$ El INE tiene sus precedentes en la Comisión Estadística del Reino (Decreto de 3/11/1856), que pasa a denominarse meses después Junta de Estadística, y en el Instituto Geográfico (Decreto 12/9/1870) que tres años más tarde pasó a denominarse Instituto Geográfico y Estadístico. Actualmente, desde la aprobación de la Ley de Función Estadística Publica del 9/5/1989, es un organismo autónomo (véase www.ine.es/info/historia.htm).
} 
el Instituto de Cálculo de Roma. Aunque las tablas input-output no se integraron formalmente en el Sistema de Cuentas Nacionales de Naciones Unidas hasta 1968, la estrecha colaboración e interdependencia entre los equipos responsables de la elaboración de las tablas input-output y de la Contabilidad Nacional de España ya dejaba entrever que todos eran conscientes de la complementariedad de ambos instrumentos a la hora de representar e interpretar la actividad económica del país (Torres y otros, 1960).

\subsubsection{Las distintas series de la Contabilidad Nacional de España}

La primera serie de Contabilidad Nacional de España elaborada por el INE tomó como base el año 1964 y siguió la metodología del Sistema Normalizado de la OCDE, segunda edición de 1958. Durante los primeros años, hasta que se creó la Comisión de Cuentas Nacionales, la labor del INE se limitó a la publicación de la Contabilidad Nacional elaborada por un equipo de trabajo dirigido por Julio Alcaide (Rodríguez, 1977, p. 620). Las primeras cifras elaboradas en el seno de la Comisión del INE fueron las definitivas de 1968 y avance de 1969 (INE, 1970) y las últimas están referidas al periodo 1965-1971 y avance de 1972 (véase INE 1967, ..., 1973). Con el fin de enlazar hacia atrás la serie de Contabilidad Nacional iniciada por el INE en 1965, el Instituto de Estudios Fiscales publicó en 1969 La Contabilidad Nacional de España 1954-1964. En realidad se trataba de una recopilación de las estimaciones de Contabilidad Nacional de España realizadas por el equipo de trabajo de los profesores Manuel de Torres y Julio Alcaide, de hecho aunque esta serie utiliza como año base 1958, no existe ninguna diferencia metodológica importante con la serie elaborada por el INE con base 1964, ambas series son totalmente coincidentes a precios corrientes. La elección de los años base obedeció, entre otras razones, a la disponibilidad de nuevas tablas input-output referidas a los años 1958 y 1962-1966 (Alcaide, 1967) que, si bien no fueron de gran utilidad para la modelización por no disponerse de los medios técnicos necesarios para la inversión de la matriz de coeficientes técnicos, constituyeron un desarrollo considerable de la base estadística, tanto por el numero de ramas estimadas (207 y 160, respectivamente) como por la valoración separada de los 
inputs interiores y exteriores. En 1973, con objeto de servir de base para el IV Plan de desarrollo 1976-1979, aparecerá una nueva tabla para 1970. Sin embargo, la crisis económica e institucional de aquellos años enterró en 1975 al Ministerio de Planificación y con él las tablas de 1970.

La necesidad de un nuevo cambio de base y de un Sistema de Cuentas que se adaptase mejor a las necesidades del análisis y de la política económica del momento se hizo patente a mediados de los años 70 debido, por un lado, a los cambios económicos e institucionales acaecidos en años anteriores y, por otro, a las sensibles mejoras del sistema estadístico español, entre las que cabe destacar los Censos de locales y de edificios de 1970, la Encuesta de Presupuestos Familiares de 1973-1974 y la nueva Clasificación de Actividades Económicas de 1974 (INE, 1976b). Como respuesta a estas necesidades, a mediados de los años 70, el INE comenzó la elaboración de una nueva serie de Contabilidad Nacional de España base 1970 “con el objeto de adaptar los conceptos, definiciones y clasificaciones de las cuentas nacionales españolas a los de las últimas versiones de los sistemas normalizados de la CEE (SEC) y ONU (SCN), en función de la información estadística disponible, la organización institucional del país y las necesidades prioritarias para el análisis económico. En consecuencia, la CNE-70 no es una simple aplicación de los mismos, sino la versión española de tales sistemas, preferentemente del SEC...”(INE, 1979, p.15).

A partir de 1976, año en el que se publican las primeras estimaciones con base 1970, que a su vez fueron las primeras realizadas íntegramente por estadísticos del INE agrupados en torno a José Quevedo, Antonio Martínez y Rafael Álvarez, la serie contable se amplió regularmente hasta 1984, con la inclusión a partir de 1979 de una estimación retrospectiva desde 1964 (INE, 1976a, 1977,...1984) ${ }^{21}$.

La CNE-70 supuso un avance importante para la Contabilidad Nacional de España, tanto desde un punto de vista cuantitativo, por ofrecer una información más am-

\footnotetext{
21 Uriel (1986) elaboró una serie de Contabilidad Nacional para el periodo 1954-1980 con base 1970, enlazando la serie de Contabilidad Nacional base 70 del INE con la serie de Contabilidad Nacional 1954-64, base 1958 que había publicado el IEF en 1969.
} 
plia y detallada de la actividad económica del país que la CNE-64, como cualitativo por el mayor rigor y precisión de los conceptos y definiciones empleados, destacando como principal aportación la desagregación de las cuentas económicas por sectores institucionales. No obstante la CNE-70 todavía estaba lejos del SEC-70, por un lado, el sector instituciones privadas sin fines de lucro estaba agrupado con el sector hogares y las cuentas no financieras de éstos últimos se presentaban agregadas con las del sector empresas y, por otro, no incluía ni el cuadro de operaciones financieras, por no disponer de cuentas financieras para todos los sectores institucionales, ni la tabla inputoutput. No obstante, la omisión de esta última en parte se vio subsanada por la inclusión de un conjunto de cuadros generales en los que presentaba el PIB a coste de factor por ramas de actividad y los principales componentes de la demanda final desglosados por funciones.

En el año 1980, la Fundación FIES publicó una tabla input-output para 1975, en la que la experiencia de investigadores como Julio Alcaide se mezclaría de forma fructífera con la savia de nuevos investigadores como los que por entonces dirigía Julio Segura dentro de la Fundación Empresa Pública, y en el año 1984, último año para el que se elaboró la CNE-70, el Banco de España también publicó las cuentas financieras por sectores institucionales para el período 1970-1982. Estas últimas fueron elaboradas de acuerdo con la metodología del Sistema Europeo de Cuentas Económicas Integradas y bajo la dirección de Rafael Álvarez, miembro del equipo inicial de la CNE-70.

Coincidiendo con la incorporación de España a las Comunidades Europeas, en enero de 1986, el INE publicó una nueva Contabilidad Nacional de España con base 1980 con la que "se culmina la tarea de elaborar prácticamente el Sistema Integrado de Cuentas Nacionales de España... y finaliza el periodo de enorme esfuerzo, encaminado a la mejora de nuestro Sistema de Cuentas Nacionales, que introduce un nuevo año base y amplía sensiblemente el conjunto de operaciones y cuentas en relación, todo ello, a la anterior Contabilidad Nacional de España, base 1970” (INE,1987, p.15). La 
CNE-80 abarca el período 1980-1986 y para los principales agregados macroeconómicos se reconstruyó la serie desde 1970 (INE 1986a,...,1988).

Los desarrollos que incorporaba la nueva serie de Contabilidad Nacional fueron posibles gracias a las mejoras del sistema estadístico español; para el año 1980 ya se disponía de "grandes censos" de población, edificios, locales y viviendas, de la Encuesta de Presupuestos Familiares 1980-1981 y de las nuevas Encuestas Industriales. Información que se complementó con las Estadísticas Agrarias y de las Administraciones Públicas, que también fueron actualizadas con el nuevo año base utilizando diversos estudios sobre empresas públicas (RENFE, Telefónica, Iberia, etc...) y encuestas especiales sobre los sectores de comercio, transporte y comunicaciones.

El avance metodológico más notable de la CNE-80 fue la incorporación de la tabla input-output en el Sistema de Cuentas Nacionales de España que, además de permitir un análisis más completo de la actividad económica, dotó al Sistema de mayor coherencia debido al doble filtro (cuentas institucionales y de actividades y productos) por el que deben pasar sus estimaciones. Su principal laguna fue la no incorporación de las cuentas financieras. Aunque el INE anunció en varias ocasiones su intención de integrarlas en la CNE (INE, 1986a), todavía hoy en día son elaboradas por el Banco de España.

De acuerdo con la recomendación del SEC de cambiar de base los años terminados en 0 y 5, a partir de 1990, el INE comenzó a publicar la serie de Contabilidad Nacional base 1985 para el periodo 1985-1990 (INE 1990a, 1991a y 1991b). Aún cuando se introdujeron algunas mejoras en el sistema contable en relación con la base anterior, "la homogeneidad de ambas es notable" (INE,1990a, p.13). La introducción en 1986 del IVA en el sistema fiscal español modificó el sistema de valoración de la mayor parte de las operaciones de bienes y servicios y, por consiguiente, el del valor añadido a precios de mercado, motivo por el que se procedió a un nuevo cambio de base, tomando como referencia el año 1986. En realidad la Contabilidad Nacional de España base 1986, tiene como base estructural 1985, año para el que se estudian ex- 
haustivamente la totalidad de los flujos económicos y se construyen los correspondientes índices, y como base contable 1986.

Para solventar el problema de la diferente valoración de buena parte de las operaciones de bienes y servicios, según incluyan o no el IVA, y la consiguiente heterogeneidad de los agregados de la oferta según sean anteriores o posteriores a 1986, el INE elaboró una serie enlazada de Contabilidad Nacional de España base 1986 para el periodo 1964-1991, en la que introduce una partida de ajuste para los años anteriores a 1986 que denomina línea fiscal homogénea con el IVA (INE,1992a). La base de 1986 ha estado vigente hasta fechas muy recientes y su última serie contable está referida al periodo 1992-1997 (INE,1998). Las tablas input-output de 1985 a 1990 están incluidas en la serie de publicaciones anuales (INE, 1990a,...1995a), mientras que las correspondientes al periodo 1991-1994 tan sólo figuran parcialmente recogidas en las publicaciones anuales (INE, 1996a,...1998), si bien su versión completa puede solicitarse a la Subdirección de Cuentas Nacionales del INE. En la base de datos TEMPUS del INE (ine.es/inebase/cgi/um) están disponibles con base 1986 los principales agregados para el periodo 1971-1997 y la serie de cuentas de la economía nacional y de los sectores para el periodo 1985-1997. Asimismo, las series en precios corrientes y constantes de los componentes de la oferta y la demanda para el periodo 1964-88 pueden encontrarse en: ine.es/daco/daco42/daco4214/sbtc3.xls. 
CUADRO 1.18. Series oficiales de Contabilidad Nacional

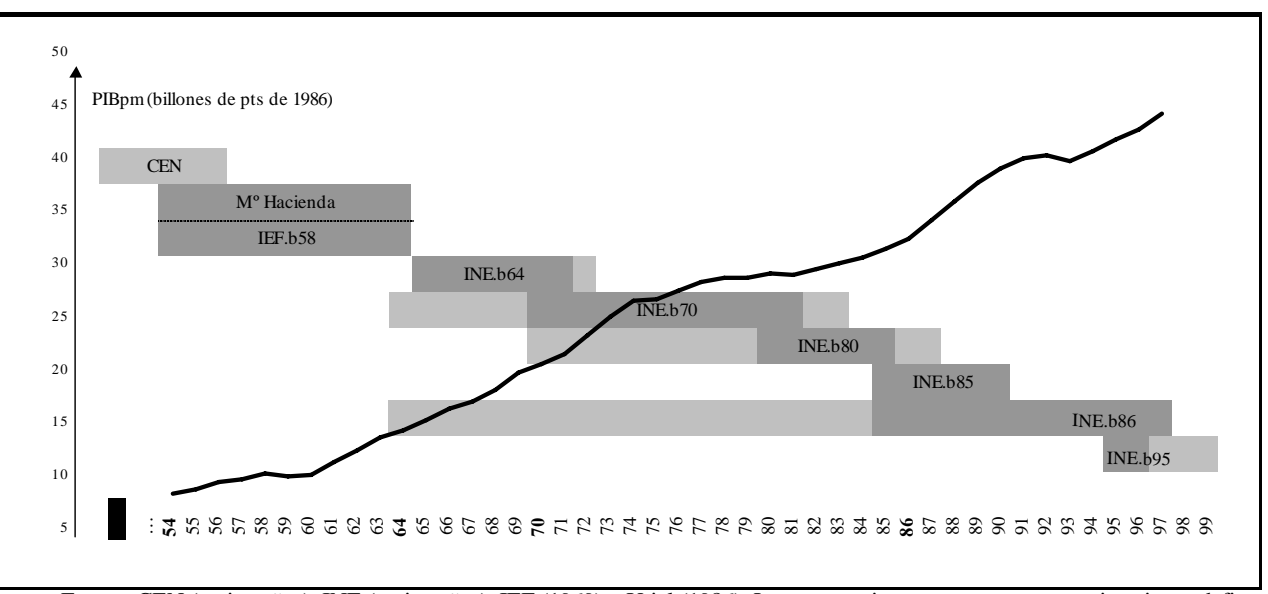

Fuente: CEN (varios años), INE (varios años), IEF (1969) y Uriel (1986). Las zonas gris oscuro representan estimaciones definitivas, las zonas gris claro situadas a su izquierda reconstrucciones retrospectivas de las series y las situadas a su derecha estimaciones provisionales o avances.

En base 1986, el INE también ha elaborado una serie de Contabilidad Trimestral que abarca desde el primer trimestre de 1970 hasta el cuarto trimestre de1998 y una serie de Contabilidad Regional para el periodo 1980-1996. Las principales características de ambas series pueden consultarse en la base de datos TEMPUS del INE, y en el caso de la serie de Contabilidad Trimestral también están detalladas en Cristóbal (1999) y Abad y otros (2000). Por su parte el Banco de España viene publicando, desde principios de los ochenta, las cuentas financieras, para las que se dispone de una serie que abarca desde 1970 y que incluye, además de las operaciones financieras, los balances financieros.

\subsubsection{Aplicación y seguimiento del SEC95}

El Sistema Europeo de Cuentas Económicas Nacionales y Regionales elaborada por el Eurostat en 1995 y adoptado como Reglamento del Consejo de la Unión Europea en junio de 1996 establece, además de la obligatoriedad para los estados miembros de seguir sus conceptos, definiciones, métodos y criterios, un calendario para la elaboración y transmisión a la Unión Europea de la información contable. En el cuadro 
1.19 recogemos el programa de transmisión de datos establecido en el Anexo B del mencionado Reglamento.

De acuerdo con dicho calendario, el Instituto Nacional de Estadística presentó en la primavera de 1999 estimaciones de los principales agregados económicos para el periodo 1995-1998 con la nueva base 1995 (INE-SGCN, 1999 y BE, 1999), el Banco de España, con anticipación al calendario previsto, presentó las cuentas y balances financieros para el periodo 1995-1999 (BE, 2000), y la Intervención General de la Administración del Estado hizo lo propio con las Cuentas de las Administraciones Públicas (Ministerio de Economía y Hacienda, 2000). La creación de grupos de trabajo formados por expertos del INE, Banco de España e IGAE ha permitido resolver satisfactoriamente alguno de los problemas tradicionales de la Contabilidad Nacional de España, como la discrepancia entre los saldos de las cuentas no financieras del INE y de las cuentas financieras del Banco de España o la disparidad de criterios entre el INE y el Banco de España, por un lado, y el IGAE, por otro, en la contabilización de la actividad financiera y no financiera de las Administraciones Públicas. 
CUADRO 1.19. Programa de transmisión de datos de las cuentas nacionales

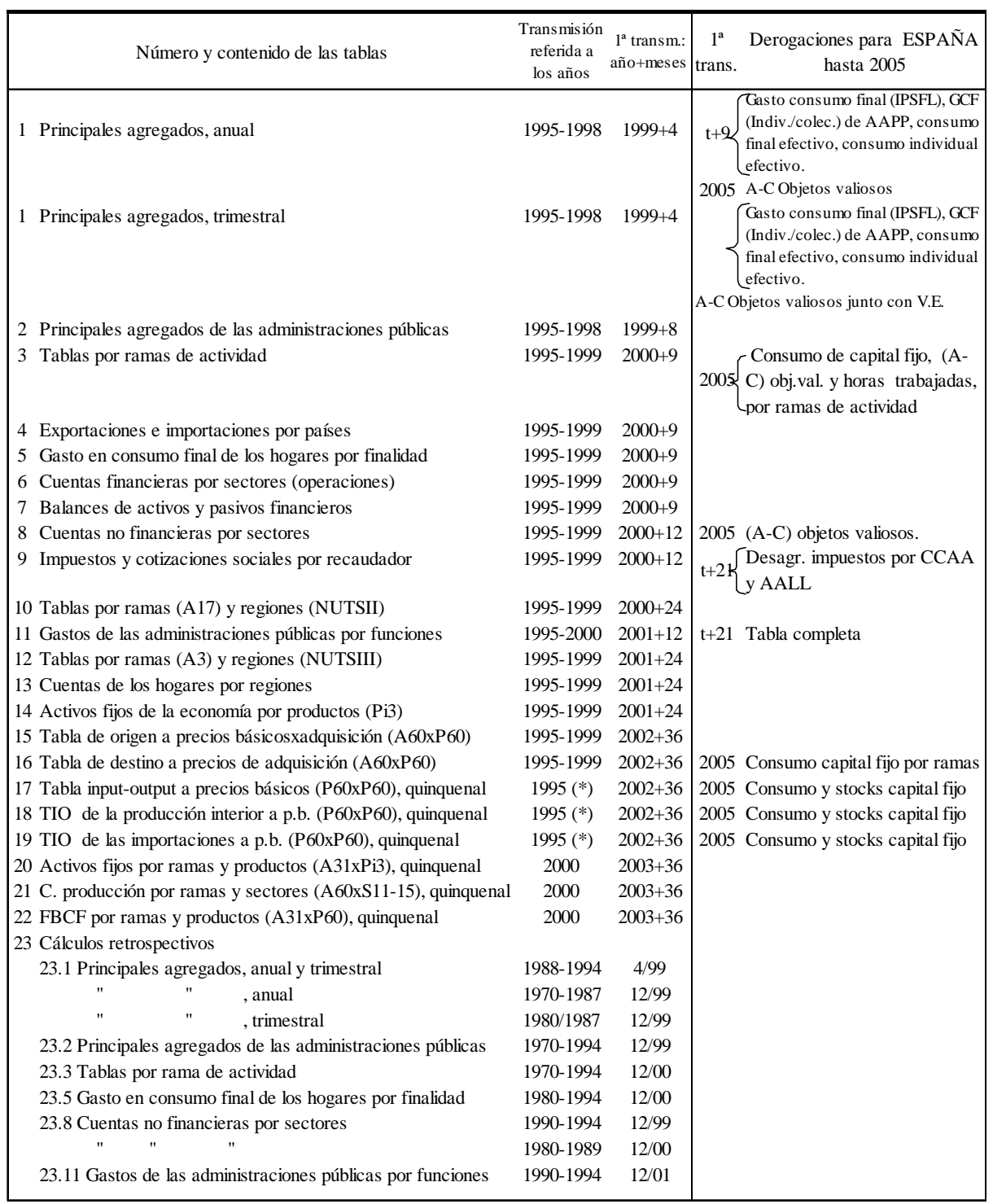

Fuente: Consejo de las CC. EE. (1996). (*)La tabla quinquenal relativa al año 2000 debe enviarse en el año 2003. (t): Año.

La primera de las publicaciones anuales de la serie prevista de Contabilidad Nacional de España, base 1995, ha aparecido en el año 2001 e incluye estimaciones definitivas para 1995 y 1996, provisionales para 1997 y 1998 y un avance para 1999, y las tablas de origen y destino para 1996. Al margen de los cambios estadísticos que 
conlleva cualquier cambio de base debido a la utilización y adaptación de nuevas fuentes estadísticas así como a la aplicación de nuevos métodos y procedimientos de estimación, como consecuencia de la implantación del SEC95, la CNE-95 incorpora importantes cambios conceptuales (véase INE, 2001, pp.15-25), y aborda dos de las tareas que todavía tenía pendientes la Contabilidad Nacional de España, la separación de los organismos privados sin fines de lucro del sector hogares y la estimación de la renta mixta.

La secuencia de cuentas de la CNE-95 abarca exclusivamente las que registran operaciones económicas no financieras: las cuentas corrientes y la cuenta de capital, por tanto, deja pendientes las cuentas de acumulación que registran las variaciones en los activos y pasivos debidas a otras variaciones del volumen de los activos y a variaciones en los precios y los balances ${ }^{22}$. Con relación al marco Input-Output de la CNE95, de las cuatro tablas básicas que lo componen: tabla de origen, tabla de destino, tabla simétrica y tabla de ramas de actividad por sectores institucionales, en esta primera publicación tan sólo se presentan las tablas de origen y destino, que incorporan clasificaciones más detalladas de los productos (110 categorías) y de las actividades (73 grupos) que las tablas input-output anteriores (56 ramas de actividad) y que las previstas en el Reglamento SEC-95 (60 productos y 60 ramas de actividad).

Asimismo, cumpliendo el calendario previsto en el Reglamento SEC-95, también se ha publicado en los años 2000 y 2001 las nuevas series de Contabilidad Regional de España, base 1995 (CRE-95), que incluyen respectivamente la serie contable 1995-1999 y 1995-2000 ambos años incluidos. Por lo que respecta a la Contabilidad Trimestral de España, base 1995, ésta viene siendo publicada regularmente en el Boletín Trimestral de Coyuntura desde junio de 1999, mes en el que se publicaron las primeras cifras en base 95 correspondientes al primer trimestre de 1999.

Para el seguimiento de la Contabilidad Nacional de España, base 1995, puede consultarse INEBASE (ine.es/inebase/cgi/um) que es un sistema de almacenamiento 
de la información estadística en Internet de todo el Sistema Estadístico Nacional y que diariamente es actualizado por el INE. Asimismo, asociada a la información numérica, INEBASE incorpora abundante información metodológica o descriptiva.

${ }^{22}$ En lo que conocemos, aparte de los Balances Financieros del Banco de España y de las series de stock de capital en España de la Fundación BBV, las únicas estimaciones de patrimonio se deben a Naredo (1997). 
CAPÍTULO 2

LAS MATRICES DE CONTABILIDAD SOCIAL 

Aunque la Tabla Económica de Quesnay se remonta a 1758, el término matriz fue utilizado, por primera vez, en 1850 por Sylvester para designar una disposición rectangular de números. Al tiempo que Neumann (1937) presentó un modelo de crecimiento de equilibrio general que aunaba las preocupaciones sobre dinámica y equilibrio de Marx y de Walras, Leontief desarrolló las primeras aplicaciones del análisis interindustrial (1928, 1936 y 1941). En 1949, Goodwing ya enlazó el multiplicador keynesiano (introducido por Khan en 1931) con la matriz inversa de Leontief; en 1960 Johansen desarrollaba el primer modelo de equilibrio general aplicado para la economía noruega y en 1962 Stone inició en Cambridge, donde Sraffa (1960) había publicado el modelo posiblemente más acabado de todos, la serie "A Programmm for Growth" (1962-1974), cuyo segundo volumen incluye la primera matriz de contabilidad social.

Las matrices de contabilidad social constituyen, en suma, una construcción hecha de materiales bien diversos pero todos ellos de contrastada calidad. De ahí su introducción en el Sistema de Cuentas Nacionales de 1968 y su definitivo reconocimiento en el Sistema de 1993. A modo de caricatura podría decirse que, mientras los Sistemas de Cuentas tradicionales otorgan el protagonismo a unas administraciones públicas que ejercen un papel de árbitro entre las empresas (oferentes) y los hogares (demandantes), las tablas input-output analizan con detalle la actividad de las empresas y las matrices de contabilidad social rescatan del olvido a los hogares, a cuyo servicio en última instancia están las empresas y las administraciones, por haber sido creadas por los hogares.

En este capítulo presentamos los fundamentos teóricos de las matrices de contabilidad social, desde sus orígenes hasta sus desarrollos más recientes (2.1) y su relación con los Sistemas de Cuentas Nacionales (2.2), señalamos algunas de sus aplicaciones más relevantes (2.3) y, por último, nos referimos a los antecedentes en nuestro país (2.4). 


\subsection{ORIGEN Y DESARROLLO DE LAS MATRICES DE CONTABILIDAD SOCIAL}

A lo largo de la historia ha existido una clara interacción entre los grandes problemas económicos que han preocupado a las sociedades y el desarrollo de la teoría y las estadísticas económicas. En la medida que las matrices de contabilidad social constituyen una extensión del Sistema de Cuentas Nacionales, su desarrollo discurre por la misma senda, aunque no al mismo paso, que el de la Contabilidad Nacional, vinculado a los avances teóricos y estadísticos, y a las cuestiones económicas que han centrado el interés de los analistas y de los responsables de la política económica.

El surgimiento de las matrices de contabilidad social tiene su justificación en la necesidad de superar algunas de las limitaciones más importantes de los Sistemas de Cuentas Nacionales. Por una parte, las cuentas económicas tradicionales actúan a modo de cuentas pantalla al ocultar las interrelaciones entre los distintos agentes que operan en la economía. Por otra parte, son cuentas excesivamente rígidas en el sentido de que son muy escasas, o prácticamente nulas, las posibilidades que ofrecen para poder adaptarlas a las necesidades y características concretas de cada economía. Y, por último, la excesiva agregación de las unidades y las operaciones económicas que confina la utilización de la Contabilidad Nacional a los modelos macroeconómicos. Si bien el desarrollo de las tablas input-output permitió superar parcialmente dichas limitaciones, al desagregar las operaciones de bienes y servicios por ramas de actividad; las matrices de contabilidad social extienden dicha desagregación al resto de operaciones y de unidades económicas, muestran los agentes o unidades económicas que participan en cada uno de los flujos que en ella se registran y, al mismo tiempo, permiten utilizar los conceptos, las unidades y las clasificaciones que mejor se adecúan a cada situación concreta. 


\subsubsection{De la Tabla Económica de Quesnay a la de Leontief}

Como ya señalamos en el capítulo anterior, el trabajo de Quesnay constituye un precedente inequívoco tanto de las tablas input-output y de las matrices de contabilidad social (Phillips, 1955; Barna, 1975 y Stone, 1985) como de la aplicación en economía de la programación lineal (E. Britannica, 2000). En el cuadro 2.1 recogemos una representación diagramática de la Tabla Económica de Quesnay con el fin de reflejar la estructura matricial que subyace en la representación que de la actividad económica realizó Quesnay.

CUADRO 2.1. Representación diagramática y modelización

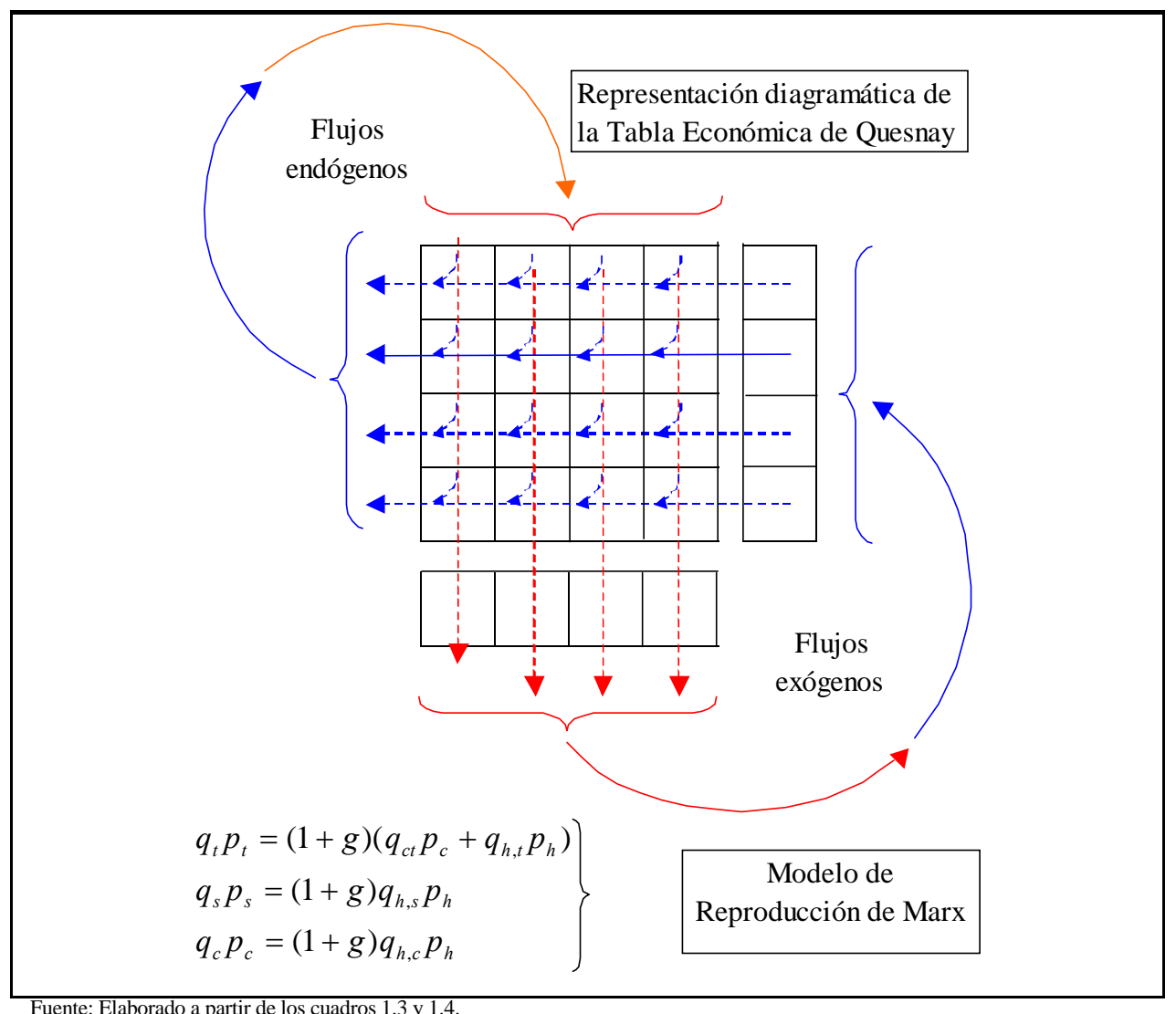


Los modelos de reproducción simple y ampliada de Marx constituyen una de las primeras modelizaciones de la Tabla Económica de Quesnay: si toda la producción que supera la estrictamente necesaria para reproducir el capital y el trabajo se emplea en consumo, la economía alcanza un estado estacionario (reproducción simple); por contra, si una parte de la misma se utiliza para acumular capital, siempre que no existan restricciones de inputs primarios, la economía se ampliará ilimitadamente (reproducción ampliada).

De las ecuaciones de los modelos de reproducción de Marx se deriva que aquellos que no necesitan emplear toda su renta en consumo necesario pueden optar por su acumulación, y de este modo aumentar sus posibilidades de consumo futuro, o por un mayor consumo presente, determinando con su conducta el sino de la sociedad: estacionaria $\left(q_{s}^{l}=1600, q_{c}^{l}=\boldsymbol{q}_{c}^{0}\right)$ o de progreso $\left(q_{s}^{l}=1200, q_{c}^{l}=2 \boldsymbol{q}_{c}^{0}\right)$. En palabras de Leontief: "El sentido de la teoría del excedente ... se entiende mejor si uno se pregunta sobre su uso. La respuesta es: si se acumula o se usa improductivamente” (1928, p.619; 1991, p.209 y 1998, p.96).

Al tiempo que Marx se preocupaba por la determinación de la tasa de ganancia ( $g$ ) y sus consecuencias sobre la dinámica del sistema, utilizando al igual que sus predecesores clásicos una teoría del valor basada únicamente en los costes de producción, Walras (1874-1877) se interesó por la determinación de los precios de equilibrio e incorporó la demanda en la explicación del valor. Bajo el supuesto de que la competencia anula los beneficios, resolvió el siguiente sistema de ecuaciones de exceso de demanda en el que los precios dependen de las preferencias de los consumidores, la tecnología y los derechos de propiedad previamente establecidos:

$$
z_{i}\left(p_{1}, p_{2}, \ldots, p_{n}\right)=0 \quad i=1,2, \ldots, \mathrm{n} .
$$

A partir de este momento, el equilibrio general se convertirá en una de las líneas de investigación más atractivas en el campo de la teoría económica. La carrera por el desarrollo y la depuración de las propuestas teóricas sobre las condiciones que garantizan la existencia, unicidad y estabilidad del equilibrio, o su carácter de óptimo 
en el sentido de Pareto y compatibilidad con cualquier sistema de derechos de propiedad alternativo (Teoremas de la Economía del Bienestar), alcanzó su cenit en la década de los cincuenta (Duffie y Sonnenshein, 1989) creándose, de este modo, una sólida base teórica para la formulación de modelos económicos que incorporen indivisibilidad, inapropiabilidad e incertidumbre.

La complejidad formal de este tipo de modelos los hizo impracticables durante un largo periodo de tiempo para una gran parte de la profesión, que se limitará a estudiar la economía en términos de las relaciones directamente observables, circunstancia esta última que no resulta sorprendente si tenemos en cuenta que las estimaciones estadísticas disponibles se circunscribían a los principales agregados económicos. El auge de la teoría proporcionada por Keynes (1936) y su clara influencia en los primeros Sistemas de Cuentas Nacionales estandarizados (OCEE, 1952; UN, 1953) hizo que, durante un tiempo, los modelos macroeconómicos de corte keynesiano fueran la mejor alternativa para la economía aplicada.

A mitad de camino entre la generalidad de la micro y la aplicabilidad de la macro surgió el análisis input-output. Leontief presentó la primera tabla input-output "como un intento de construcción, sobre la base de los materiales estadísticos disponibles, de un Tableau Economique de Estados Unidos para 1919” (Leontief, 1936, p.105). Al proponer el análisis input-output (Leontief, 1941) su objetivo no era otro que la formulación de un modelo de equilibrio general estático; de hecho, subtituló la primera edición de su libro La Estructura de la economía americana como: Una aplicación empírica del análisis de equilibrio. Más aún, el análisis input-output puede considerarse, en cierto modo, como el germen de una aproximación entre las visiones clásica y neoclásica de la economía. En palabras del propio Leontief, el análisis inputoutput constituye "una adaptación de la teoría neoclásica del equilibrio general al estudio empírico" (Leontief, 1966, p.134), al mismo tiempo que “una extensión práctica de la teoría clásica de la interdependencia general que contempla la economía en su conjunto como un sistema único ... en términos de las relaciones directamente observables” (Leontief, 1987, p.860). Las relaciones por entonces observables eran aquellas 
que muestran el origen de los bienes y servicios (la producción a partir de recursos: inputs intermedios y primarios) y su destino (empleos para satisfacer las necesidades intermedias del propio proceso productivo y las necesidades finales) ${ }^{23}$.

El cuadro 2.2 incluye, en la parte superior, una tabla input-output con $n$ actividades cuyas filas y columnas muestran, respectivamente, los empleos intermedios $\left(C_{i}\right)$ y finales $\left(B_{i}\right)$ y los recursos o inputs intermedios $\left(C_{. j}\right)$ y primarios $\left(V_{j}\right)$. En la parte inferior figura el modelo input-output, que recoge la sucesión completa de cambios en los flujos reales (o en los precios) producidos como consecuencia de una modificación exógena en los ingresos finales (o en los costes de los inputs primarios), bajo el supuesto de que todos los agentes económicos mantienen su comportamiento (coeficientes $a_{i j}$ fijos).

El modelo anterior es un modelo estático por cuanto que $A X_{t}+B_{t}=A^{T} X_{t}+V_{t}$. Si consideráramos la actividad de los hogares como una rama más cuyo output es el trabajo empleado por las demás ramas y su input es el consumo corriente, para introducir la dinámica en el modelo bastaría con establecer una función objetivo, maximizar: $\mathrm{X}_{\mathrm{t}+1}-\mathrm{X}_{\mathrm{t}} \mid \mathrm{V}_{\mathrm{o}}$ y suponer que $V_{t+1}=Y_{t} \geq V t$. O bien, siguiendo con la terminología inputoutput, el modelo se transforma en dinámico al considerar la inversión como una variable endógena, $X_{t}=A X_{t}+B\left(X_{t}-X_{t-1}\right)+\overline{B_{t}}$, siendo la producción de capital fijo, en este último caso, la que determina la expansión de la capacidad productiva de la economía.

\footnotetext{
${ }^{23}$ Para un análisis más profundo sobre la relación entre el modelo teórico de Walras y el modelo input-output de Leontief, puede consultarse Davar (2000).
} 
CUADRO 2.2. Modelo y Tabla Input-Output

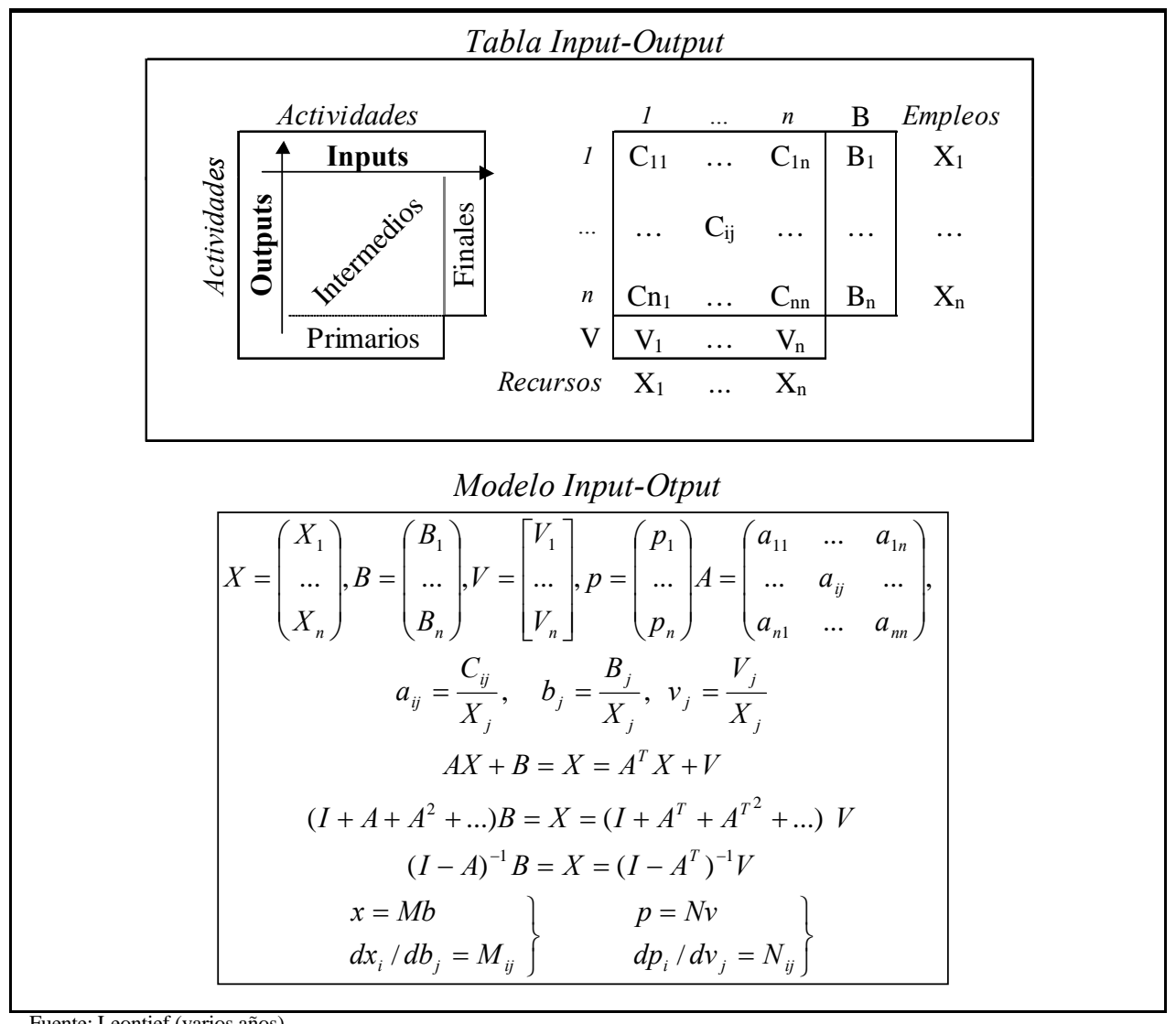

Al tiempo que Leontief publicaba sus primeros trabajos cuantificados sobre las relaciones productivas intersectoriales en la economía norteamericana, Neumann ${ }^{24}$ introdujo la programación lineal en economía al plantear el problema de la elección entre $m$ procesos alternativos para producir $n$ bienes y el de la determinación de los precios de intercambio como un problema primal de programación lineal y su dual asociado. Bajo los supuestos de rendimientos constantes a escala, inputs primarios

24 Neumann presentó en 1932 su trabajo, “A Model of General Economic Equilibrium” en el Seminario de Matemáticas de la Universidad de Princeton, fue publicado, por primera vez, en 1937 "Ubre ein ökonomisches Gleichungssystem und eine Verallgemeinerung des Brouwerschen Fixpunktsatzes”, Ergebnisse Eines Mathematischen Kolloquiums, 8, pp.73-83, y se tradujo al inglés en 1945 en Review of Economic Studies, XIII, pp. 1-9. Posteriormente ha sido objeto de diversas reimpresiones (Kurz y otros, 1998, cap. 5). 
ilimitados e inexistencia de fugas del flujo circular, Neumann demostró que la tasa de crecimiento de una economía iguala su tasa de acumulación.

\subsubsection{De la Tabla Input-Output a la Matriz de Contabilidad Social}

En el modelo input-output expuesto en la sección anterior, el consumo final es tratado como exógeno, lo que impide evaluar el impacto de una variación en la renta generada sobre dicha variable. Un primer intento de recoger las relaciones entre la producción, la generación de renta y el consumo se debe a Goodwin (1949), que consideró al sector hogares como una industria más, cuyo output es el trabajo y cuyos inputs son los bienes consumidos, para generalizar el modelo keynesiano por tipos de industrias y obtener una matriz de multiplicadores tipo Leontief.

$$
\{y\}=[I-A]^{-1}\left\{\sum_{j} b_{i j}\right\}
$$

La diferencia con el modelo input-output es que los elementos de la matriz A reflejan la propensión marginal al consumo de los hogares y los costes marginales de las industrias, por tipos de productos.

Posteriormente, Miyazawa y Masegi (1963) y Miyazawa (1976) extendieron el modelo input-output para introducir funciones de consumo tipo Kalecki, desagregadas por grupos de productos y de hogares, a efectos de poder evaluar las relaciones entre la estructura de la producción y la distribución de la renta y el gasto. Primeramente, en orden a tratar el consumo final como una variable endógena, en lugar de considerar al sector hogares como una industria más, incorporaron al modelo input-output una función de consumo keynesiana desagregada por categorías de productos y obtuvieron una matriz de multiplicadores que integra el multiplicador keynesiano con el multiplicador de Leontief (cuadro 2.3.a). Como ni la propensión al consumo ni la participación en la renta es la misma para todos los hogares, posteriormente, ampliaron el modelo anterior con funciones de consumo desglosadas por grupos de hogares. De este modo, 
la distribución de la renta generada y del gasto quedan explícitamente reflejadas, y los multiplicadores que se derivan de este segundo modelo combinan los multiplicadores de Leontief con el multiplicador de Kalecki (cuadro 2.3.b).

CUADRO 2.3. Generalización del modelo Input-Output

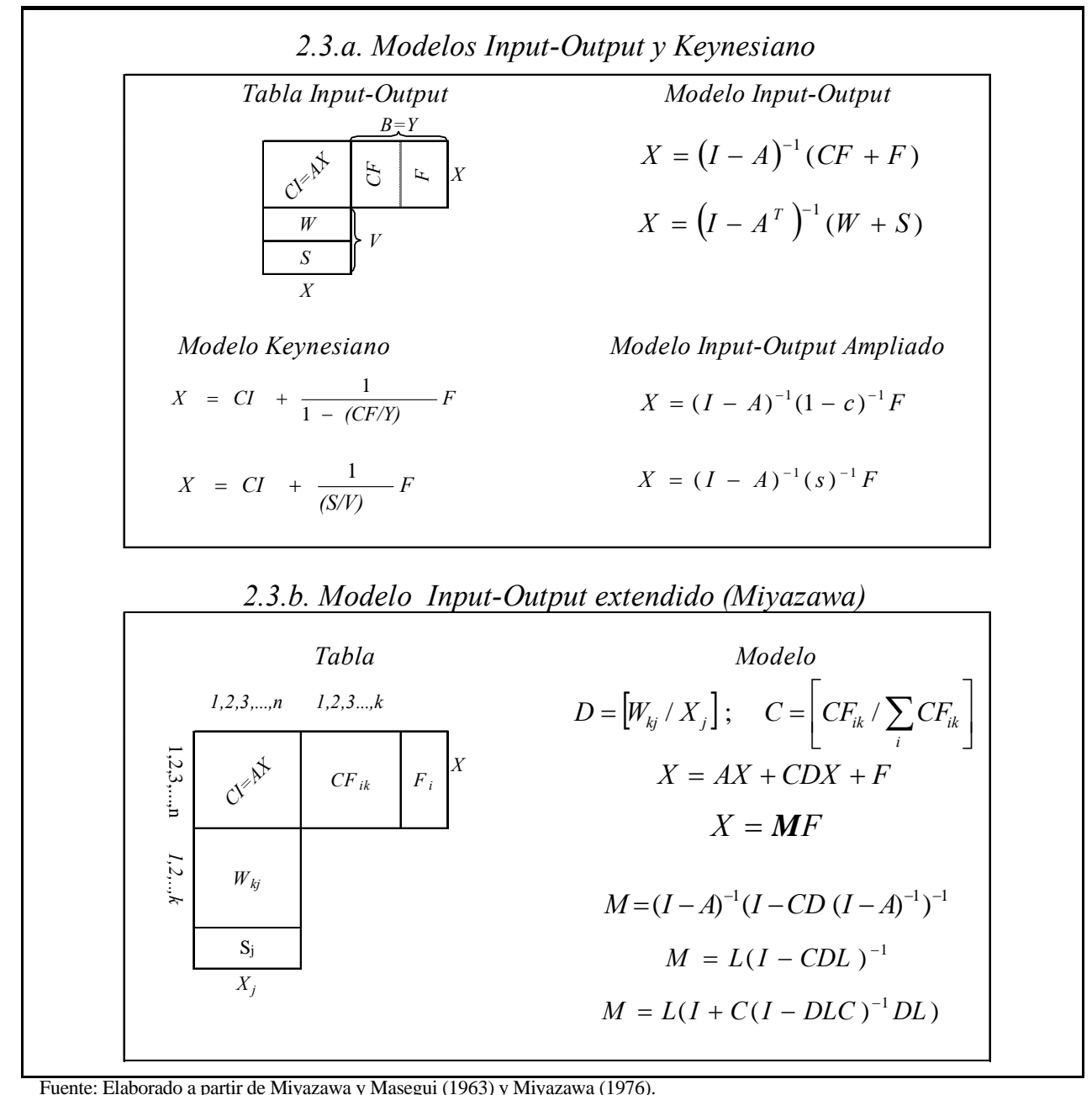

La principal aportación de este último modelo estriba en la descomposición de los procesos de generación y distribución de la renta (Rose y Miernyk, 1989). Por una parte puede definirse un multiplicador de renta multisectorial que capta el proceso de formación de renta en cada grupo de hogares $\left((I-D L C)^{-1} D L\right)$ y , por otra, un multipli- 
cador interrelacionado de distribución de la renta $(I-D L C)^{-1}$ cuyos elementos recogen los efectos directos, indirectos e inducidos del gasto de una unidad adicional de renta de un grupo de hogares sobre la renta de otro. Un análisis de distintos métodos de desagregación del sector hogares en el marco de los modelos input-output extendidos puede encontrarse en Batey y Weeks (1989).

Podemos resumir lo expuesto hasta el momento en las tres ecuaciones siguientes:

$$
\begin{gathered}
Y=k F \\
X=L k F \\
X=L K F
\end{gathered}
$$

que muestran, respectivamente, los efectos de variaciones en los flujos exógenas $(F)$ sobre la renta $(Y)$ a través del multiplicador keynesiano $(k)$ y sobre la producción total $(X)$ a través de los multiplicadores de Leontief y Keynesiano $(L k)$ y de los multiplicadores de Leontief y Kalecki $(L K)$. Estos últimos, además de las relaciones interindustriales y de la propensión marginal de consumo por grupos de productos, tienen en cuenta la distribución de la renta y el gasto por grupos de hogares.

Al tiempo que se avanzaba en la generalización del modelo input-output, Johansen (1960) y Stone (1962-74) elaboraron sendos modelos de crecimiento económico multisectorial que resultaron decisivos para el desarrollo de lo que hoy conocemos como modelos de equilibrio general aplicado.

La principal aportación de Johansen consistió, no tanto en introducir especificaciones complejas sobre las conductas de los agentes económicos, sino en incorporar especificaciones que expresaban conductas más flexibles. En palabras del propio Johansen (1960, p.1) "el modelo resulta insatisfactorio si se juzga desde un punto de vista puramente teórico". Bajo el supuesto de perfecta complementariedad de los inputs en la producción o de los outputs en el consumo, los coeficientes fijos conllevan conductas maximizadoras implícitas, de ahí que la utilización de funciones de tipo 
Cobb-Douglas, CES,... supusiera una relajación de los supuestos que recaían sobre las funciones de producción y de utilidad.

La principal contribución del modelo de Stone, The Cambridge Growth Model, se debe a la formulación input-output de los balances de mercancías y a que es el primer modelo que utiliza una matriz de contabilidad social como base de datos. "Es a partir de este momento cuando la teoría, los datos y el análisis aplicado comienzan a caminar juntos” (Pyatt, 1994, p.7).

Aunque resulte sorprendente a la vista de los desarrollos señalados, la revisión del Sistema de Cuentas Nacionales de 1968 dejó fuera del Sistema las cuestiones relacionadas con la distribución de la renta, el consumo y la riqueza entre los hogares. Aunque inicialmente se trabajó en un borrador al respecto (UNSO,1972), el desarrollo de las estadísticas sociales y demográficas (UNSO, 1975) y de comportamiento desagregado de los hogares (UNSO, 1977) discurrió por separado. Como recientemente ha señalado Pyatt (1999, p.366), tuvieron que ser los esfuerzos de investigadores individuales los que trataran de cubrir el divorcio oficial entre el Sistema de Cuentas Nacionales (UN, 1968) y el Sistema de Estadísticas Sociales y Demográficas (UNSO, 1975) y, como no podía ser de otra manera, el padre de ambas criaturas, Richard Stone, también fue el responsable de su unión a través de las matrices de contabilidad social (Stone 1962-74, vol.II).

A pesar de que a principios de los años 60 ya se había elaborado la primera matriz de contabilidad social y de los trabajos pioneros en el campo de la contabilidad social de Pyatt y otros (1972) y de Thorbecke y Sengupta (1972), la formalización del concepto y las aplicaciones de las matrices de contabilidad social no se produce hasta mediados de los años 70. El trabajo de Pyatt y Thorbecke (1976) es considerado como "la primera descripción compresiva de la estructura de una matriz de contabilidad social, incluyendo la justificación de su diseño” (Keuning y Ruijter, 1988, p.71). 
En Thorbecke (1985) puede encontrarse una comparación entre los primeros modelos económicos obtenidos a partir de una matriz de contabilidad social (Pyatt y otros, 1972; Thorbecke y Sengupta, 1972 y Ng, 1974) y los modelos de segunda generación, que algunos comienzan ya a denominar modelos de equilibrio general aplicado (Adelman y Robinson, 1978; Ahluwalia y Lysy, 1979; Taylor y otros,1980). Estos últimos se caracterizan por introducir especificaciones no lineales sobre los comportamientos de los agentes, considerar un mayor numero de operaciones y de unidades endógenas y emplear clasificaciones más desagregadas.

Como mostramos en el cuadro 2.4, una matriz de contabilidad social (2.4.b) amplía la información de la tabla input-output (2.4.a) para recoger de forma explícita las interrelaciones entre el valor añadido y la demanda final, a través de la distribución de la renta y el gasto entre los distintos grupos de unidades institucionales. En cierta medida, el modelo SAM que se deriva de la matriz de contabilidad social (2.4.c) puede considerarse como el nexo entre los trabajos aplicados en el campo del análisis inputoutput y los desarrollos teóricos en el campo del equilibrio general. La ecuación principal del modelo (2.6) constituye una generalización de los modelos recogidos en las ecuaciones (2.3 a 2.5) y permite predecir los efectos de cualquier modificación en las rentas exógenas o variables independientes $(B)$ sobre las rentas endógenas o variables dependientes $\mathrm{y}$, por ende, sobre las rentas totales (X), a través de un proceso iterativo bastante más complejo que el recogido por el modelo input-output y similar al descrito por la secuencia del modelo de equilibrio general (2.4.d). 
CUADRO 2.4. Matriz de Contabilidad Social: del modelo I-O a los MEGAs

(a) Tabla y Modelo Input-Output

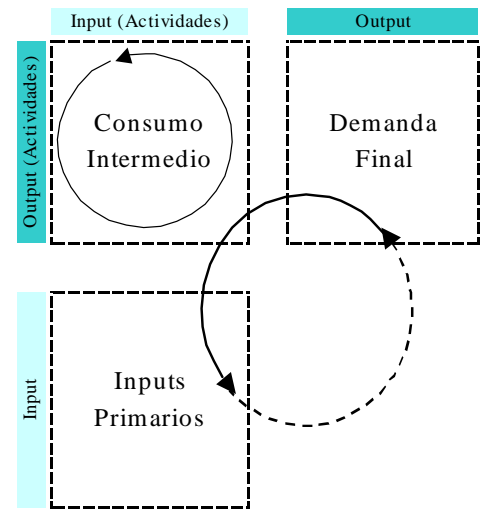

(c) Modelo SAM

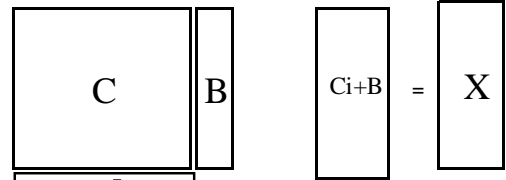

$(\mathrm{Ci}+\mathrm{B})^{\top}-\mathrm{i}^{\prime} \mathrm{C}$

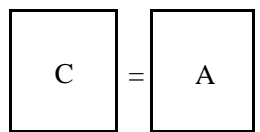

$\mathrm{X}=(\mathrm{I}-\mathrm{A})^{-1} \mathrm{~B}$

$\mathrm{X}=\mathrm{MB}(2.6)$ (b) Matriz de Contabilidad Social

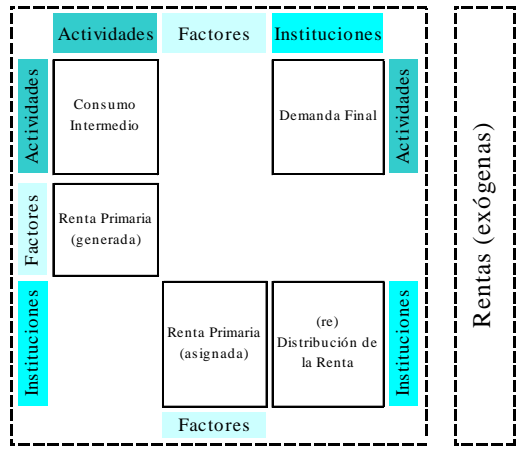

Gastos (exógenos)

(d) Modelo de Equilibrio General

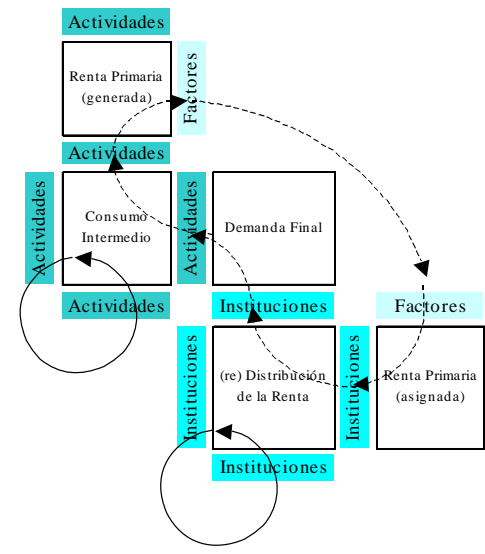

\subsubsection{Matrices de contabilidad social y modelización económica}

Curiosamente, aunque los dos primeros modelos de equilibrio general de Johansen y Stone fueron aplicados a países desarrollados (Noruega y Reino Unido), buena parte de los trabajos iniciales con matrices de contabilidad social estuvieron dirigidos a países en desarrollo, lo que se explica, entre otras razones, por la conjunción en 
estos países de unas necesidades acuciantes en materia socioeconómica y una infraestructura estadística sencilla.

A la luz de la experiencia de los países desarrollados, una de las principales preocupaciones de los organismos internacionales en los años 70 fue la de promover el desarrollo sin incurrir en los costes que, en términos de desigualdad, habían padecido los países avanzados en sus primeras fases de industrialización, y que Kuznets (1955) ya predijo para los países de nueva industrialización a menos que se adoptaran las medidas redistributivas adecuadas. De ahí el interés de los organismos internacionales $(\mathrm{BM}, \mathrm{OIT}, \ldots$.$) por los modelos basados en una matriz de contabilidad social que, ade-$ más de ser sencillos y, por tanto, poco costosos, son capaces de proporcionar información relevante con la que orientar las políticas de desarrollo, al permitir analizar conjuntamente cuestiones relacionadas con la eficiencia y la equidad. A mediados de los años 80 ya se habían elaborado modelos de este tipo para un buen número de países en desarrollo como Chipre, Egipto, Indonesia, Irán, Malasia, Filipinas, República de Corea, Arabia Saudita, Tailandia o Turquía (Pyatt y Round, 1985 y Cohen, 1989).

Por lo que respecta a las aplicaciones de modelos económicos generales en países desarrollados, en un principio éstos se centraron más en la asignación de los recursos que en las cuestiones relativas a la distribución de la renta, aunque con excepciones (Piggott y Whalley, 1977, 1985). Principalmente se utilizaron para evaluar los efectos de cambios en la estructura impositiva o en la política comercial sobre la producción, el gasto interno y los flujos con el exterior (Shoven y Walley, 1972, 1974,1984; Dixon, Parmenter, Sutton, Vicent, 1982) o para analizar los efectos de shocks externos, como los provocados por las crisis energéticas (Hudson y Jorgenson, 1978).

Hoy en día la literatura sobre los modelos de equilibrio general aplicado se ha extendido considerablemente (Bergman, 1990 y Dixon y Parmenter, 1996) debido, por una parte, a la mayor disponibilidad de datos y, por otra, a la estandarización progresiva de los programas informáticos necesarios para la resolución de este tipo de modelos (http://www.gams.com, http://www.monash.edu.au/policy/gempack.htm) en entornos 
de programación cada vez más sencillos para los investigadores (http://www.eco.edu/faculty/Kendrick/ frontpg/GrExcel.htm).

Las posibilidades que ofrecen este tipo de modelos son muy amplias, tanto desde el punto de vista de las cuestiones que pueden ser objeto de análisis (modificaciones en las políticas fiscal, comercial, energética o medioambiental, el cambio tecnológico o la formación de bloques regionales, entre otros), como desde el punto de vista de su formulación teórica, según primen más o menos los aspectos teóricos, aplicados o econométricos, o desde el punto de vista de su tipología (estáticos o dinámicos, para una economía o multiregionales). Además, cualquiera que sea su grado de complejidad, el punto de partida de la mayoría de los modelos de equilibrio general aplicado es una matriz de contabilidad social (v.gr.: Yang y Huang, 1997; Zalai, 1998; Bovenberg, Graafland y de Mooij, 1998; Abrego y Perroni, 1998; Decaluwé, Dumont y Savard, 1999; Mayeres, 1999; Rutherford y Paltsev, 1999; Karadag y Westaway, 1999 ). Como señala Pyatt (1988, p.345): "Para cada modelo hay una matriz de contabilidad social...para cada matriz de contabilidad social hay una gama de posibles modelos”. 


\subsection{MATRICES DE CONTABILIDAD SOCIAL Y SISTEMAS DE CUENTAS NACIONALES}

Como ya hemos apuntado en un principio, tradicionalmente las críticas al Sistemas de Cuentas de Naciones Unidas se han centrado en su rigidez, en que sus cuentas no reflejan las interrelaciones entre los agentes que operan en la economía y en que su campo de aplicación está limitado a la modelización macroeconómica. Precisamente, son estas tres limitaciones las que tratan de superarse con la incorporación de las matrices de contabilidad social en el capítulo XX del SCN93.

En este apartado mostramos las posibilidades que ofrecen las matrices de contabilidad social para aumentar la flexibilidad de los Sistemas de Cuentas y, con ello, su capacidad descriptiva y analítica. Dichos objetivos se alcanzan mediante la elección, para cada una de las cuentas que conforman el marco central del Sistema, de las unidades y de las clasificaciones de las unidades y operaciones que se consideren más apropiadas en función de los aspectos concretos sobre los que se pretende centrar la atención y que habrán de configurar el correspondiente modelo de equilibrio general.

\subsubsection{Presentación esquemática de una matriz de contabilidad social}

Una matriz de contabilidad social, tal y como señala Richard Stone, su creador y uno de sus principales defensores, puede definirse como una presentación ordenada de lo que está teniendo lugar en un sistema económico expresado en términos de transacciones entre los distintos agentes (Stone y Croft-Murray, 1959). Su formato matricial, al permitir la identificación de las unidades económicas que participan en los distintos flujos económicos que en ella se registran, la convierte en una herramienta sencilla, a la par que eficiente, para representar una de las leyes fundamentales de la economía: “cada ingreso se corresponde con un gasto” (Pyatt, 1988, p.329).

Una matriz de contabilidad social está estructurada de tal modo que cada unidad o grupo de unidades económicas consideradas está representado por una fila y una columna idénticamente ordenadas, en las que se registran, respectivamente, todos sus 
ingresos y todos sus gastos (cuadro 2.5). Por tanto, una matriz de contabilidad social puede representarse como:

$$
\mathrm{T}=\left[\mathrm{t}_{\mathrm{ij}}\right]
$$

donde $T$ es una matriz cuadrada, cuyo elemento genérico $t_{i j}$ expresa los pagos realizados por la unidad $j$ a la unidad $i$ a lo largo del periodo contable. La única restricción contable que debe satisfacer una matriz de contabilidad social es que para todas y cada una de las unidades o grupos de unidades considerados (por ejemplo, residentes y no residentes) el total de ingresos debe coincidir con el total de pagos $\left(T i=T^{\prime} i\right)$. En otras palabras, para cada unidad o conjunto de unidades la diferencia entre los ingresos y gastos provocados por su participación en un determinado grupo de operaciones (v.g.: corrientes) debe de ser igual a la diferencia entre los gastos e ingresos por el resto de operaciones.

CUADRO 2.5. Representación matricial de la economía

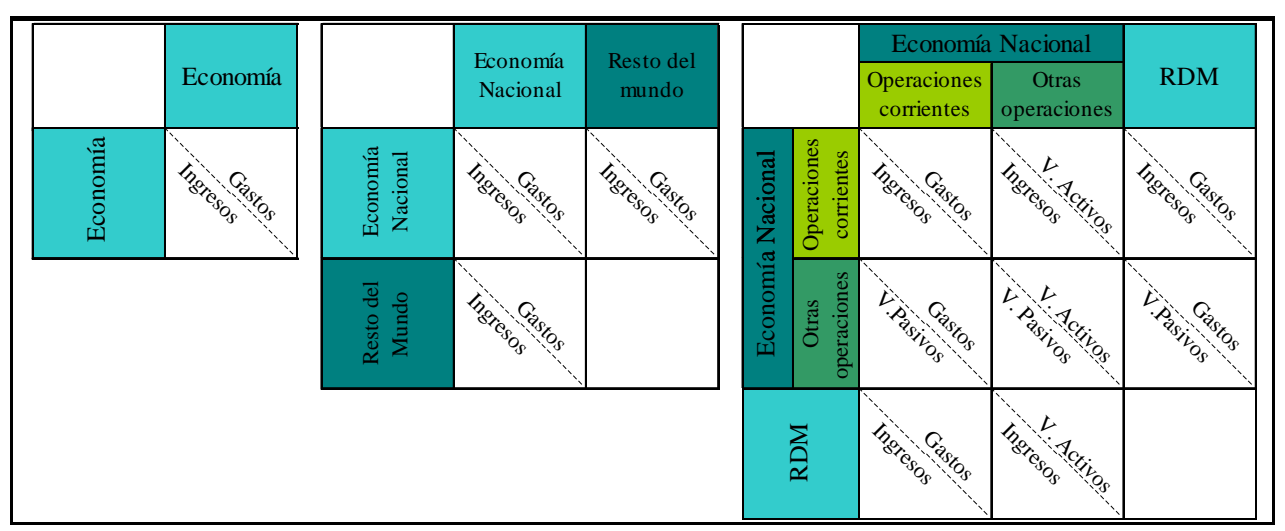

Aunque son muy diversos los rasgos que caracterizan a las matrices de contabilidad social y buena muestra de ello es la amplia gama de matrices elaboradas (véase al respecto el capítulo XX del Sistema de Cuentas Nacionales de 1993; Pyatt, 1991a; Keuning, 1991 y 1994; Keuning y Ruijter, 1988; Van Bochove y Van Tuinen, 1986; Ruggles y Ruggles, 1986 ó Pyatt y Round, 1985), a nuestro juicio hay una característica, asociada a su formato matricial, que destaca sobre las demás e incluso puede decir- 
se que engloba a muchas de ellas y ésta es su flexibilidad o capacidad para extenderse o comprimirse dentro de una misma estructura. Siempre que se satisfagan los dos requisitos señalados anteriormente, simetría de filas y columnas e igualdad en la suma de sus respectivos elementos, basta con utilizar clasificaciones con distinto grado de detalle de las unidades y de las operaciones para obtener representaciones de una misma realidad económica desde una perspectiva macro o microeconómica.

Para mostrar las posibilidades de expansión y reducción de las matrices de contabilidad social, comenzaremos con una representación de una economía sencilla, cerrada y sin AA.PP., para ir avanzando progresivamente hacia la descripción de economías cada vez más complejas y con mayor grado de detalle, utilizando siempre la misma estructura de presentación (cuadros 2.6.a, 2.6.b y 2.6.c).

CUADRO 2.6. Elasticidad del formato matricial

a) Economía cerrada sin impuestos

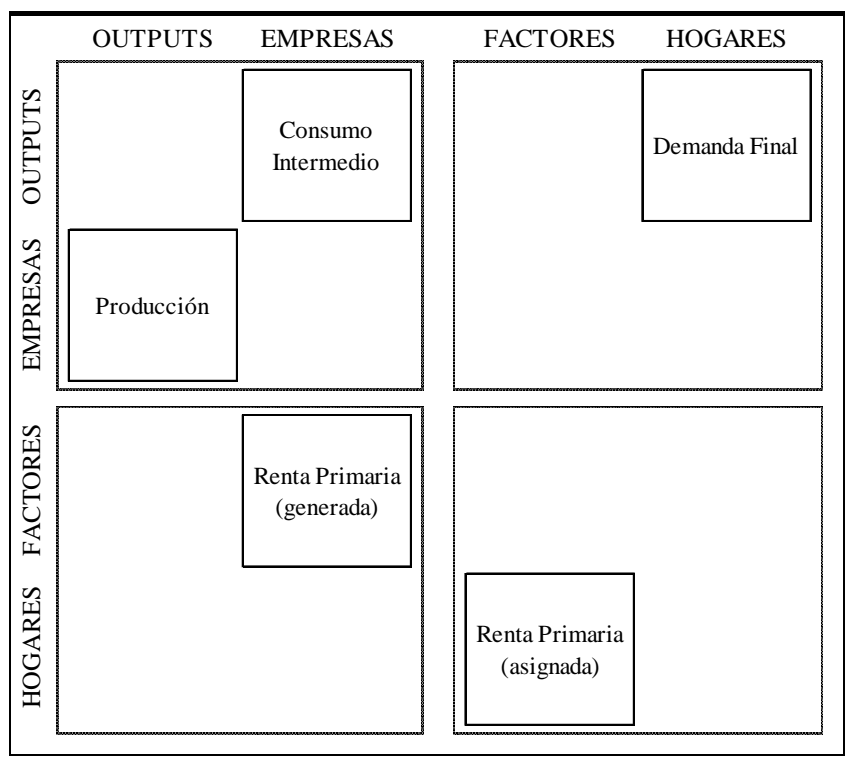


En el cuadro 2.6.a hemos representado una economía en la que únicamente hay dos tipos de unidades, los productores o empresas y los hogares que, además de ser los propietarios de los factores productivos, tienen como función principal consumir los bienes y servicios finales producidos por las empresas. Como puede apreciarse, los ingresos de las empresas proceden de la venta de su producción y coinciden con los gastos que realizan para adquirir inputs en el mercado, bienes y servicios (consumo intermedio) y factores productivos, trabajo y capital, (renta primaria generada). Los hogares, por su parte, ponen a disposición de las empresas su dotación de inputs primarios a cambio de una renta (renta primaria asignada) que utilizan para adquirir bienes y servicios en el mercado con los que satisfacer sus necesidades finales (demanda final).

Para representar ahora una economía en la que figuren, además de las empresas y de los hogares, las AA.PP. (cuadro 2.6.b) basta con ampliar la matriz anterior con una nueva fila y columna que recojan la actividad de las AA.PP., cuyas funciones son la producción y el suministro de bienes y servicios no de mercado (consumo público) y la redistribución de la renta, indirectamente mediante el establecimiento de impuestos y subvenciones a los productores y directamente a través de impuestos que gravan la renta y la riqueza de los hogares y de prestaciones sociales. 
CUADRO 2.6. Elasticidad del formato matricial (Continuación)

b) Economía cerrada con AA.PP.

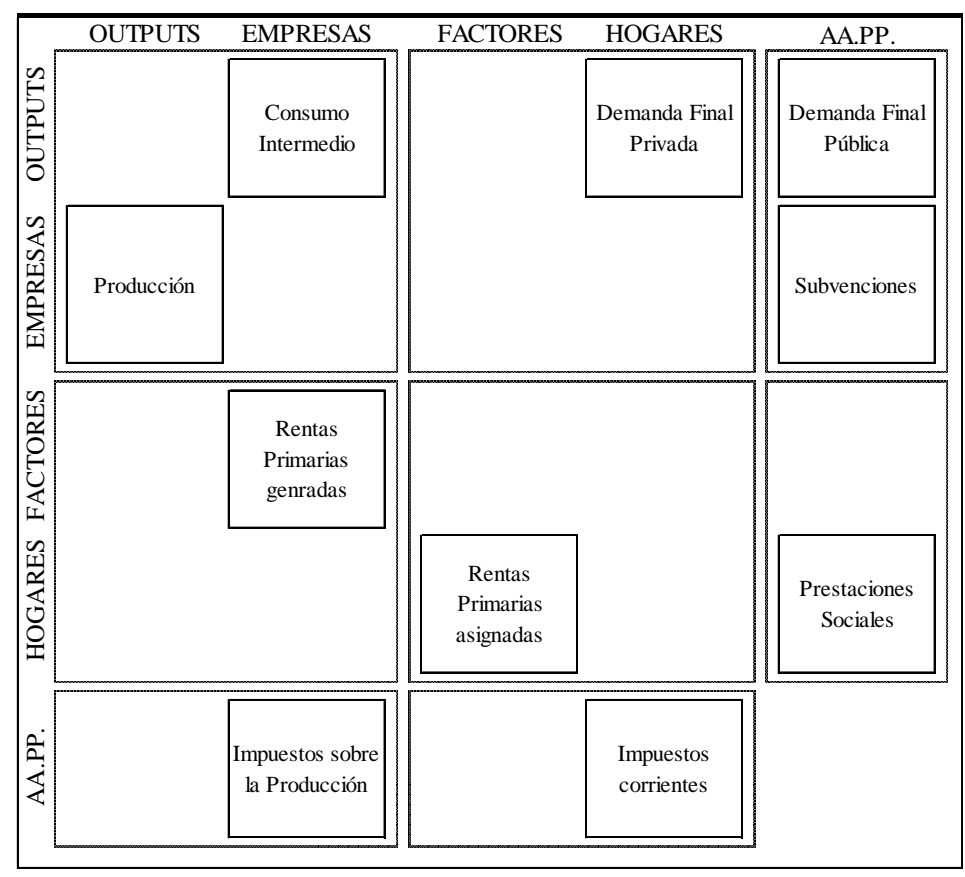

La incorporación del sector exterior permite reflejar qué parte de los bienes y servicios (ofertados o producidos), de las rentas primarias (asignadas o generadas) y de las transferencias tienen como origen o destino el resto del mundo. Y, por último, para diferenciar con mayor nitidez el equilibrio contable del equilibrio económico, separamos las operaciones corrientes de las operaciones relativas a la acumulación de capital (cuadro 2.6.c). Para ello, incorporamos cuatro nuevas filas y columnas que registran, para cada grupo de unidades con capacidad para adquirir activos y contraer pasivos en nombre propio (empresas, hogares, administraciones públicas y resto del mundo) su ahorro y las variaciones en sus activos, financieros y no financieros, y en sus pasivos.

La matriz recogida en el cuadro 2.6.c permite reflejar cómo el ahorro (o renta no utilizada para adquirir bienes y servicios destinados a satisfacer necesidades finales o intermedias) es empleado para adquirir bienes en el mercado, con el fin de acumular- 
los y utilizarlos en ejercicios venideros para producir otros bienes y servicios (formación de capital o adquisición de activos fijos), y para adquirir activos financieros. Asimismo puede apreciarse cómo las unidades económicas también contraen pasivos financieros y cómo del conjunto de sus operaciones financieras resulta su capacidad o necesidad de financiación, que para el conjunto de la economía coincide con el saldo no financiero del resto del mundo.

CUADRO 2.6. Elasticidad del formato matricial (Continuación)

c)Economía abierta y acumulación

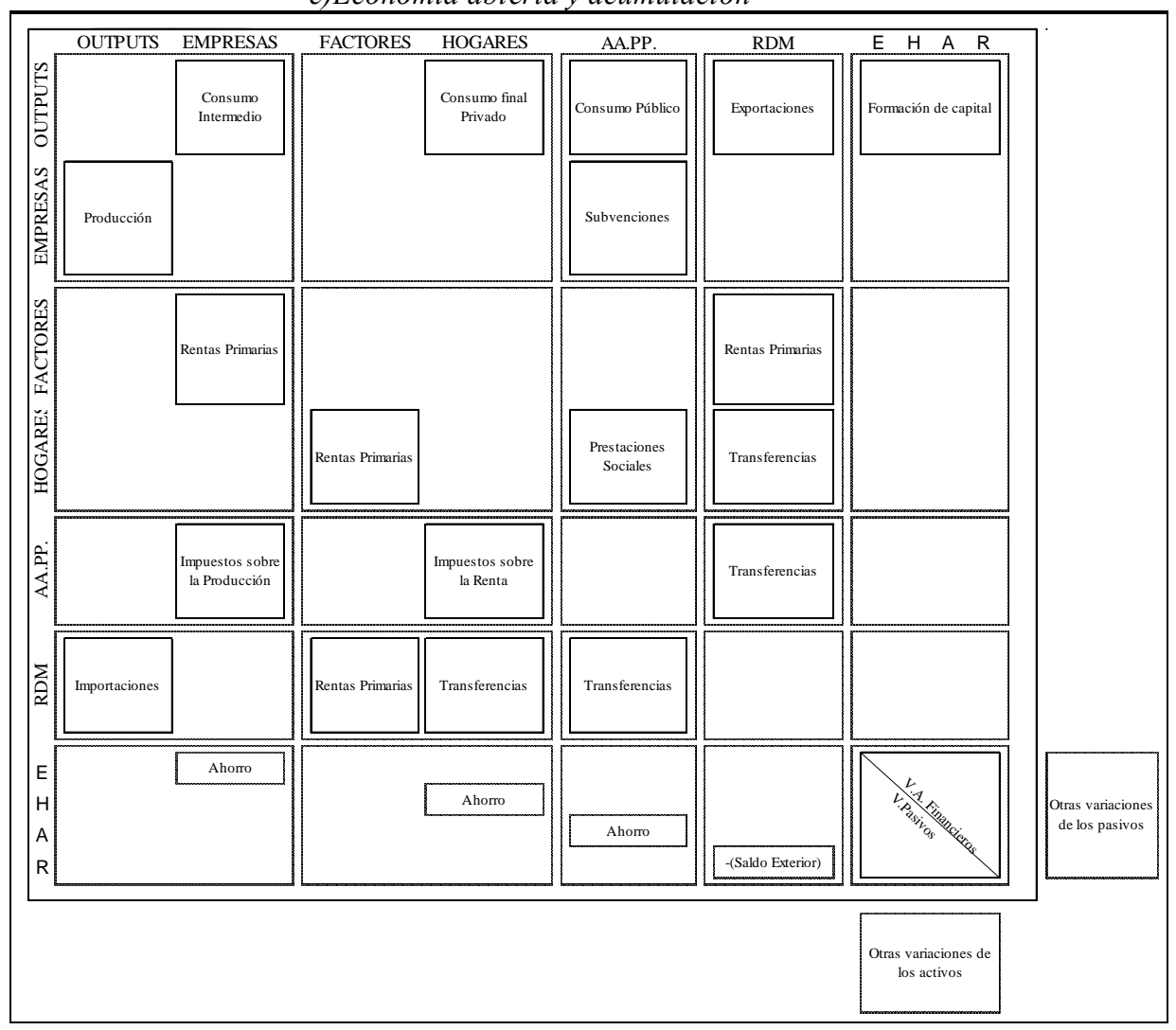


Finalmente, aquellas variaciones en el patrimonio de las unidades económicas producidas como consecuencia de variaciones en los precios o en el tipo de cambio, y por otras causas ajenas a cualquier decisión tomada por los propietarios de los activos se recogen en los dos cuadros anexos de otras variaciones de los activos y pasivos.

Todas las matrices de contabilidad social anteriores constituyen representaciones agregadas de la economía. Para pasar de representaciones macroeconómicas a representaciones microeconómicas basta con desglosar las filas y columnas correspondientes a los bienes y servicios, los productores, los factores y los consumidores empleando clasificaciones más o menos detalladas.

En resumen, las matrices de contabilidad social constituyen un marco comprensivo y consistente en el cuál pueden ser encajados, tanto los datos macroeconómicos procedentes de la Contabilidad Nacional, como los datos microeconómicos procedentes de las Encuestas. De ahí su utilidad como herramienta para la integración de las estadísticas macro y microeconómicas (Ruggles y Ruggles, 1986; Hanson y Robinson, 1991; Pyatt,1994 y Ruggles, 1995).

\subsubsection{Las matrices de contabilidad social en el SCN93}

La revisión del Sistema de Cuentas Nacionales de 1968 introdujo por primera vez el formato matricial para integrar las cuentas económicas tradicionales en forma de $\mathrm{T}$ en cuadros de doble entrada que, además de reducir el número de registros a la mitad, proporcionan más información al romper la pantalla que oculta la relación entre las unidades de origen y destino de los distintos flujos económicos. Sin embargo, es la última revisión de 1993 la que integra definitivamente las matrices de contabilidad social en el Sistema de Cuentas Nacionales. Tarea esta última a la que está dedicado en exclusiva el capítulo XX del SCN93, cuyo proceso de revisión final estuvo a cargo de Steven Keuning de la Oficina Central de Estadística de los Países Bajos (UN y otros,1993, p.xxxvi). En dicho capítulo las matrices de contabilidad social se presentan 
desde dos perspectivas diferentes: como marco contable y como modelo económico general.

\subsubsection{Las matrices de contabilidad social como marco contable}

"Ampliando una tabla input-output para mostrar de forma completa el flujo circular de la renta a escala meso-económica, se capta una de las característica esenciales de la matrices de contabilidad social", que se definen como "la presentación de las cuentas del SCN en una matriz que desarrolla las relaciones entre la tabla inputoutput y las cuentas de los sectores institucionales” (UN y otros,1993, p.461).

En una matriz de contabilidad social cada cuenta de la sucesión está representada por una fila y una columna. Por convenio, los ingresos (recursos y variación de pasivos) se anotan en las filas y los gastos (empleos y variaciones de activos) en las columnas. La sucesión completa de cuentas que figuran en las 22 filas y columnas de la matriz de contabilidad social presentada en la Tabla 2.5 del SCN93 (UN y otros,1993) figura en el cuadro 1.9 del capítulo anterior.

El objetivo de presentar la sucesión de cuentas económicas en un formato matricial no es otro que desarrollar las relaciones entre la tabla input-output y las cuentas de los sectores institucionales, aspecto al que desafortunadamente no se presta mucha atención en el esquema central del SCN93 y que, sin embargo, resulta esencial para comprender mejor el porqué de las diferencias de bienestar y de productividad, tanto entre países como a lo largo del tiempo (Keuning, 1998). La especificación de dichas relaciones en la matriz de contabilidad social se realiza a través de la desagregación de la cuenta de generación de renta por categorías de factores productivos, de modo que sus filas y columnas se correspondan, respectivamente, con la demanda y la oferta en el mercado de factores. Para ello, en las filas se registran las rentas pagadas por los distintos grupos de actividades económicas a cada una de las categorías de factores productivos y en las columnas, las rentas recibidas por los distintos sectores y subsectores institucionales de acuerdo con sus respectivas dotaciones factoriales. 
La elaboración de cuentas separadas para los factores productivos, o la desagregación de la cuenta de generación de renta, permite hacer explícita la circularidad de la renta en la economía. Para poder describir el flujo circular de la renta a través de una matriz de contabilidad social (cuadro 2.7) hay tres submatrices que resultan imprescindibles: a) la submatriz de valor añadido de las actividades económicas a los factores productivos, b) la submatriz de rentas primarias pagadas por los factores a las unidades institucionales y c) la submatriz de demanda de las unidades institucionales a las actividades económicas. Dichas submatrices, aunque necesarias, no son suficientes para completar el circuito económico, por lo que deben complementarse al menos con otras dos matrices que recojan los flujos interindustriales (consumos intermedios) y los flujos interinstitucionales (transferencias).

CUADRO 2.7. La matriz de contabilidad social y el flujo circular de la renta

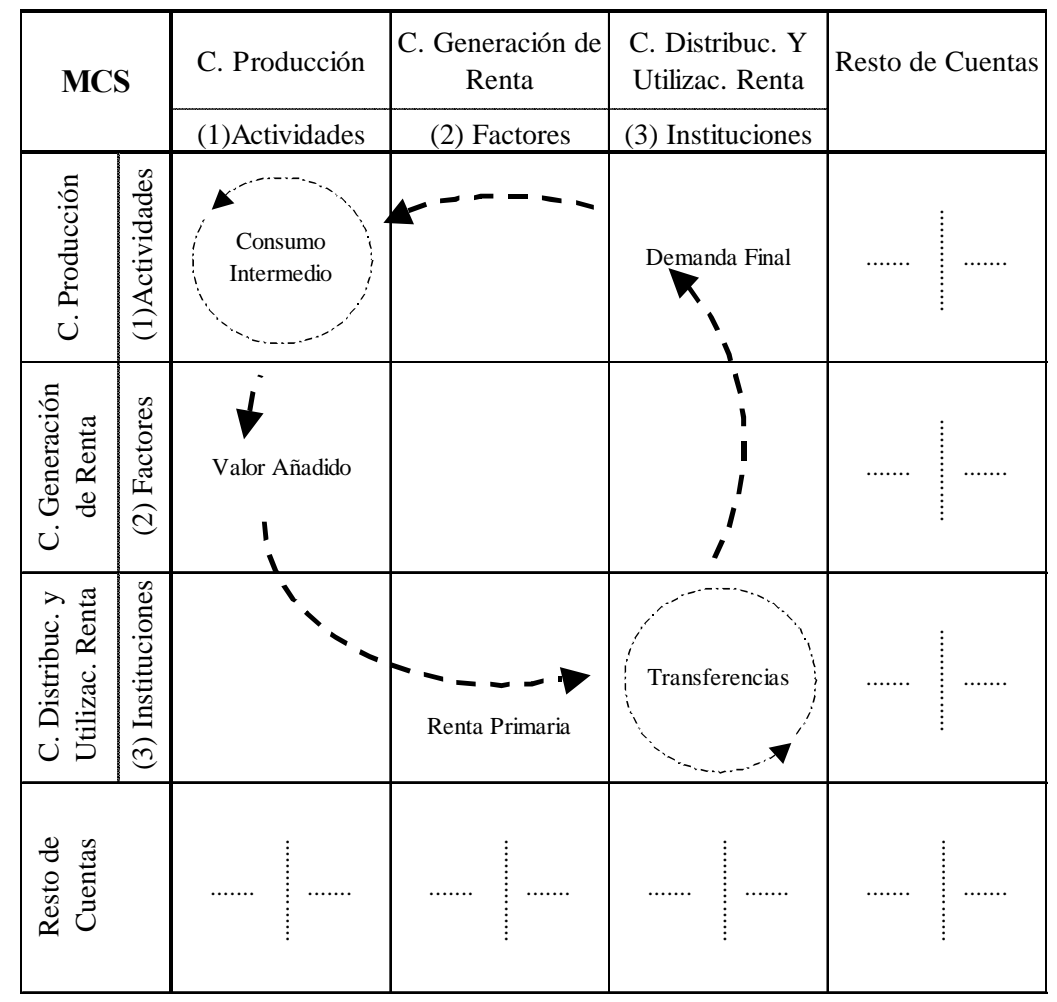


En una matriz de contabilidad social cada una de las cuentas que integran la sucesión puede presentarse para distintos niveles de desagregación, e incluso para unidades individuales (UN y otros, 1993, párrafo 1.64). Es decir, cada una de las filas y columnas de la matriz de contabilidad social propuesta por el SCN93 pueden dividirse de tal modo que sus celdas tan sólo representen el total de una gran submatriz que registraría las interrelaciones entre los agentes económicos participantes en un determinado tipo de operaciones. Además, el formato matricial permite la utilización de múltiples unidades y clasificaciones sin perder por ello la coherencia del Sistema.

Para desglosar la cuenta de bienes y servicios y la cuenta de producción, existen clasificaciones estandarizadas por tipos de productos (The Central Products Classification -CPC-, la Clasificación de Productos por Actividades del SEC -CPA- o la Clasificación Nacional de Productos -CNP-) y de actividades (The International Standard Industries Classification of all Economic Activities -ISIC-, la Clasificación de Ramas de Actividad del SEC -NACE- o la Clasificación Nacional de Actividades Económicas -CNAE-). Para las cuentas de distribución y utilización de la renta, el SCN93 propone la utilización de unidades institucionales clasificadas por sectores y subsectores institucionales (Capítulo IV), salvo para la cuenta de generación de renta que propone el empleo de categorías de valor añadido. Por último, actividades económicas y unidades institucionales es la propuesta para las cuentas de capital, y unidades institucionales para el resto de las cuentas de acumulación y para los balances.

Las únicas unidades económicas para las que no se detalla una clasificación en el marco central del Sistema son los factores productivos. Dicha omisión trata de subsanarse en el capítulo XX señalando, de forma orientativa y sin priorizar, distintos criterios de clasificación de los trabajadores, asalariados y autónomos, y del capital.

Con relación a la flexibilidad de las matrices de contabilidad social y del Sistema de Cuentas Nacionales, cabe señalar también que, dependiendo de los objetivos perseguidos con la elaboración de la matriz de contabilidad social, de las disponibilidades de datos estadísticos y de los aspectos que quieran resaltarse, las cuentas también pueden desglosarse para insertar distintas categorías de transacciones económicas 
(v.g.: distinguiendo entre transferencias monetarias corrientes y transferencias sociales en especie en la cuenta de redistribución de la renta o desglosando la cuenta financiera por tipos de activos financieros) o para incorporar aspectos económicos que no se tratan en la sucesión de cuentas (v.g.: las cuestiones medioambientales o la producción por cuenta propia de servicios domésticos y personales). Por el contrario, también hay cuentas que pueden consolidarse entre sí (v.g: la cuenta de bienes y servicios con la cuenta de producción, las cuentas de distribución de la renta con las cuentas de utilización de la renta o la cuenta de capital con la cuenta financiera). Asimismo cabe la posibilidad de añadir cuentas satélites que incorporen conceptos, definiciones y clasificaciones alternativas o variables sociodemográficas.

En el cuadro 2.8 presentamos una de las múltiples versiones consolidadas que pueden derivarse de la matriz de contabilidad social propuesta en el SCN93. Con el fin de resaltar el papel central que las matrices de contabilidad social otorgan a los hogares, dicha matriz está centrada en los aspectos distributivos y en su relación con el proceso productivo.

En relación con este último aspecto, la equivalencia entre las matrices de contabilidad social y los Sistemas de Cuentas Nacionales, a diferencia de aquellos que sostienen que las matrices de contabilidad social y los Sistemas de Cuentas Nacionales constituyen dos esquemas o marcos contables diferentes y alternativos para representar una misma realidad económica, entendemos que una matriz de contabilidad social es, simplemente, una presentación de las cuentas que conforman el cuerpo central del Sistema de Naciones Unidas en formato matricial, por lo que ambos, matrices de contabilidad social y Sistemas de Cuentas, son perfectamente asimilables. Lo que sucede es que habitualmente hay cuentas que están agrupadas y otras desglosadas por categorías de unidades económicas o de operaciones para destacar determinados aspectos de una economía u obtener representaciones con mayor o menor grado de detalle. 
CUADRO 2.8. Equivalencia entre las matrices de contabilidad social y los SCN

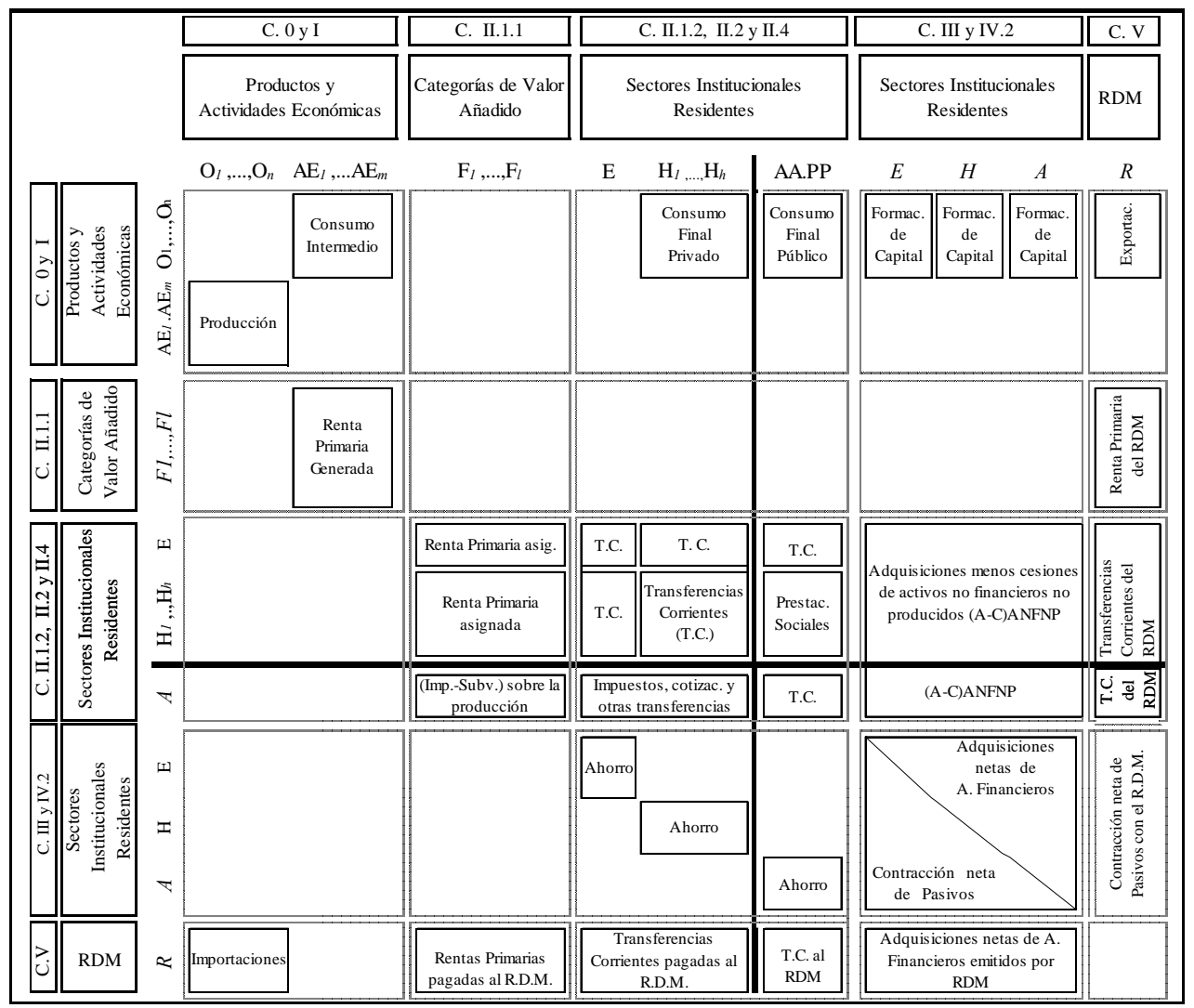

\subsubsection{Las matrices de contabilidad social como modelos económicos}

Las matrices de contabilidad social, además de ser una herramienta eficiente por su sencillez y versatilidad para representar una economía y las principales interrelaciones que en ella se producen y para integrar los datos procedentes de la Contabilidad Nacional y de las Encuestas, también lo son para suprimir las fronteras que, hasta fechas relativamente recientes, han existido entre la modelización micro y macro. De hecho, las matrices de contabilidad social recogidas en los cuadros 2.6.a, 2.6.b, 2.6.c, 2.7 y 2.8 se transforman en un modelo económico, con capacidad para predecir los efectos de cualquier operación de una unidad exógena sobre el resto de unidades y el 
conjunto de la economía, simplemente con determinar qué unidades y operaciones son endógenas y cuáles son exógenas, una vez estimada la conducta de las unidades endógenas.

De acuerdo con los objetivos específicos de cada trabajo pueden seleccionarse como exógenas todas las unidades que participen en un determinado tipo de operaciones, todas las operaciones realizadas por un grupo de unidades, o ciertas operaciones de un grupo de unidades. En concreto, la disposición y corte de la matriz de contabilidad social recogida en el cuadro 2.8 representa un modelo en el que son exógenas las operaciones de acumulación de todas las unidades, todas las operaciones del resto del mundo y las operaciones de distribución de las administraciones públicas.

Una clasificación adecuada de las unidades y operaciones permite que los requerimientos de cualquier teoría o modelo económico puedan tener acomodo en el marco de una matriz de contabilidad social. Entre otros, pueden obtenerse modelos agregados de corte keynesiano, en los que bajo el supuesto de que existen recursos sin utilizar, la renta nacional se determina a través de un proceso multiplicador de la demanda exógena (inversión, impuestos menos prestaciones y saldo exterior), para ello bastaría con agrupar a todas las empresas residentes en una sóla rama que es la que empleará todos los factores y producirá todos los bienes y servicios, y a todos los hogares residentes en un único sector que será el propietario de todos los factores de producción y el encargado de adquirir en el mercado todos los bienes y servicios finales producidos por las empresas. También pueden derivarse modelos de comercio internacional de tipo Heckscher-Ohlin (2x2x2), para dos 2 países que producen 2 tipos de bienes utilizando 2 factores productivos. La generalización de este último modelo, considerando $l$ factores empleados para producir $m$ bienes que consumen $n$ hogares 0 , de modo aún más general, $n$ instituciones (hogares que consumen, empresas que producen, administraciones que redistribuyen renta y unidades no residentes cualquiera que sea su función) conduce a los modelos de equilibrio general (MEGs).

El calificativo de general tiene que ver con el mayor o menor número de operaciones y unidades que se consideren endógenas y exógenas, entendiendo como más 
general aquel modelo que considera menos comportamientos exógenos. De hecho los más generales serían los modelos dinámicos en los que sólo el progreso técnico, como medida de nuestra ignorancia, se considera exógeno o, incluso, aún más generales serían aquellos que tratan al progreso técnico como una actividad endógena más y, por ende, las condiciones de partida o dotaciones iniciales serían sus únicos elementos exógenos. En la práctica el carácter más o menos general de los modelos depende, básicamente, de la disponibilidad o no de la información necesaria para endogeneizar los flujos. Dado que dicha disponibilidad es costosa, los modelos más generales serán preferidos siempre que las mejoras en los resultados superen la diferencia de costes asociados a la obtención de una mayor información. Sin duda alguna, el que todos los modelos puedan presentarse dentro de un mismo marco, el de una matriz de contabilidad social, supone una gran ventaja a la hora de optar por la utilización de un modelo concreto para responder a una interrogante concreta.

Aunque en el campo de la modelización económica el calificativo de equilibrio en ocasiones tiende a ser identificado con los modelos microeconómicos y el de desequilibrio con los modelos macroeconómicos, a nuestro juicio, dicha asociación no es más que una polémica estéril de carácter puramente terminológico. Como muestra el cuadro 2.9, el Sistema de Cuentas Nacionales es un modelo general equilibrado en el que subyace la ley de Walras. Los datos se recogen ex-post y los precios de las transacciones de productos y de activos son acordados entre dos unidades diferentes o por una unidad consigo misma.

Los bienes y servicios (líneas continuas) procedentes de la producción (P) o de la acumulación previa (CN) de las unidades residentes y del resto del mundo (M), se emplean para satisfacer la demanda de consumo (C) y de capital (AN) de las unidades residentes, y la demanda externa (X).

En una economía competitiva sin transferencias, las unidades institucionales reciben activos financieros (líneas discontinuas) como compensación a su contribución al proceso productivo (incremento del patrimonio neto) o por la venta de sus activos no financieros acumulados en años anteriores. Dichos activos financieros, junto con 
los acumulados previamente y los aparecidos durante el ejercicio en curso, pueden intercambiarse por otros activos financieros y no financieros, o bien utilizarse para el consumo intermedio y final (reducción del patrimonio neto).

CUADRO 2.9. SCN. Modelo de Equilibrio General

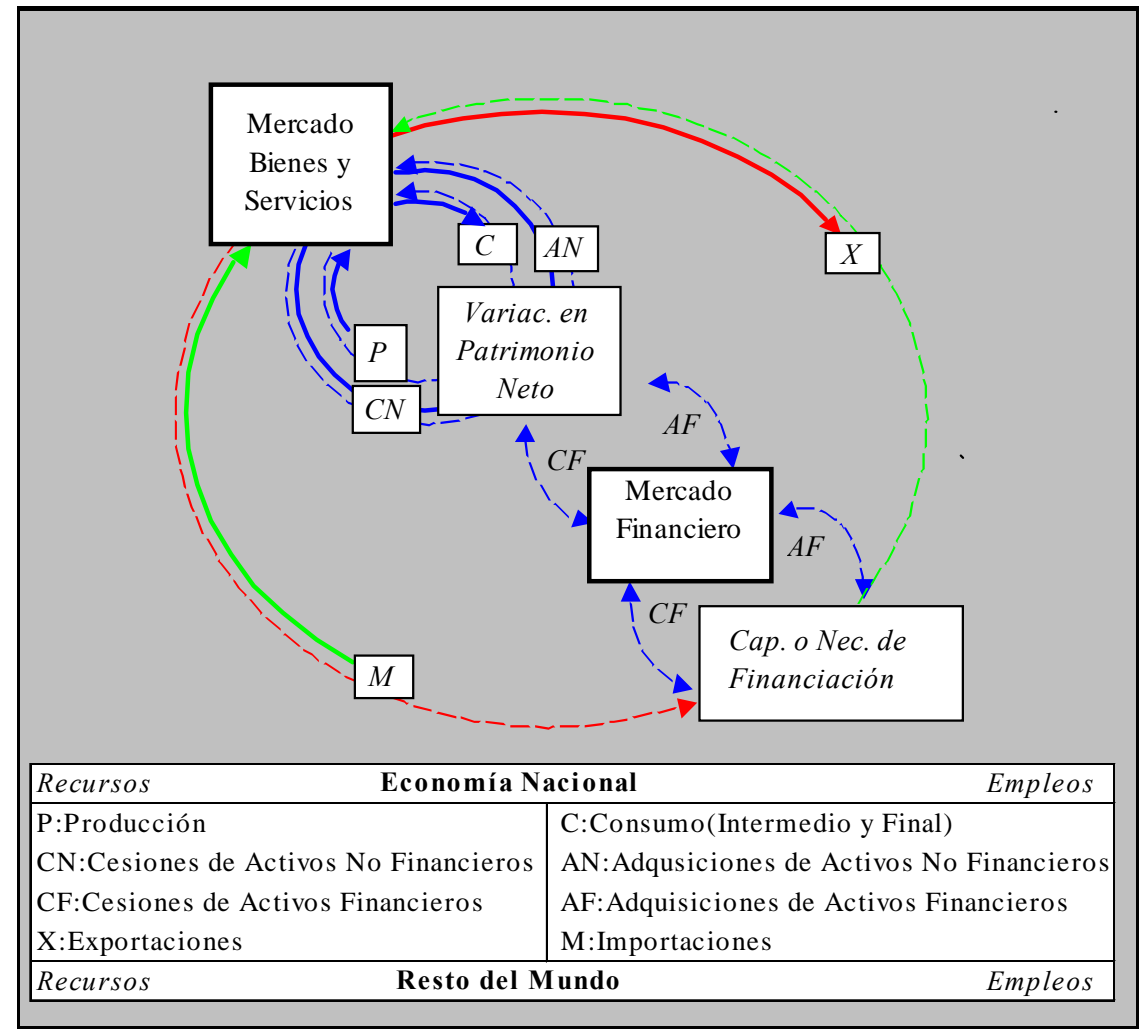

Los componentes de precio y volumen de cualquier transacción de bienes y servicios se estiman de forma más o menos directa, así como las transacciones financieras (donde el precio de la moneda es la unidad). Los activos previamente acumulados se valoran a precios de mercado homologables, distinguiendo entre cambios reales y neutrales (con relación a un índice general).

En cuanto al carácter microeconómico o macroeconómico de los modelos, éste tiene que ver con el grado de desagregación de las unidades y las operaciones. Una vez 
más, el grado de desagregación y los criterios de clasificación empleados en cada caso dependerán del tipo de análisis que se pretenda realizar y de los costes de obtener la información necesaria. Así por ejemplo, para estudiar las relaciones entre el proceso productivo y las distribuciones primaria y secundaria de la renta, además de la desagregación de las ramas de actividad, es necesaria la desagregación del sector hogares y de las categorías de valor añadido, en particular la del factor trabajo.

Con el fin de simplificar el análisis, si suponemos que no se puede predecir ningún cambio en el comportamiento de los agentes económicos y que los recursos no producidos son ilimitados, la matriz de contabilidad social que figura en el cuadro 2.8 puede modelizarse tal y como mostramos en el cuadro 2.10.

CUADRO 2.10. Modelización de una matriz de contabilidad social

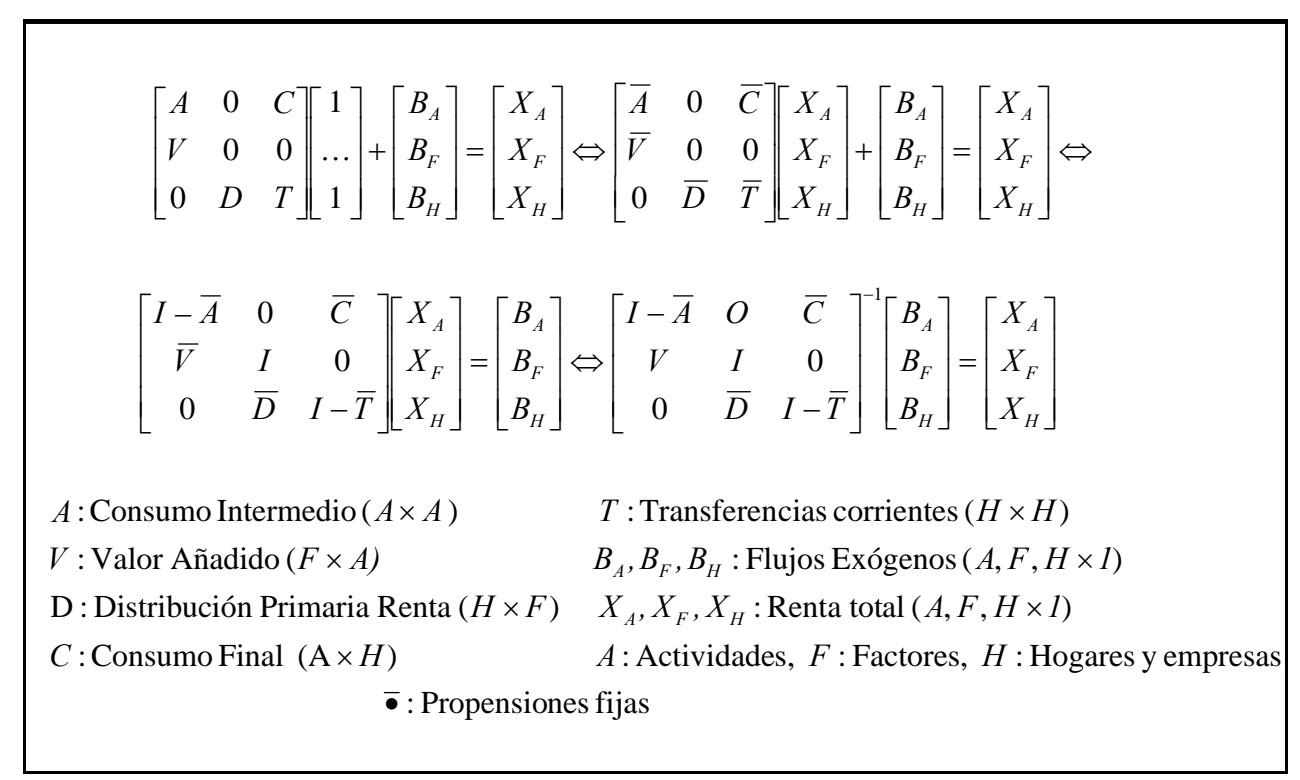

En resumen, tal y como señalan Pyatt (1991b) y Thorbecke (2000), una matriz de contabilidad social constituye un marco ideal para poder entender y analizar los efectos de variaciones exógenas en la renta de las actividades o de las instituciones sobre el crecimiento económico y la equidad, al incorporar de forma explícita las rela- 
ciones entre la estructura de la producción y la distribución de la renta. De ahí que su principal campo de aplicación sea la modelización económica.

Es más, cada una de las celdas de una matriz de contabilidad social puede rellenarse con una expresión algebraica, función de la renta y de los precios (de los bienes y servicios, de los factores y del tipo de cambio), que describa teóricamente cómo se determina el valor de la operación que en ella se registra.

$$
t_{i j}=t_{i j}(y ; p, f, e)
$$

Como en una matriz de contabilidad social la suma de cada fila $i$ coincide con la de su columna simétrica $i$,

$$
T i=y=T^{\prime} i
$$

al sustituir cada $t_{i j}$ de la ecuación (2.9) por el correspondiente en la ecuación (2.8) se obtienen las ecuaciones (2.10) y (2.11), que conforman los dos conjuntos de ecuaciones básicas de cualquier modelo de equilibrio general y que se completan con un tercer juego de ecuaciones o de reglas de cierre (Pyatt,1988) :

$$
\begin{aligned}
& p=p(y ; p, f, e) \\
& y=n+x
\end{aligned}
$$

siendo $n$ y $x$ los vectores que recogen, respectivamente, la suma de las rentas endógenas y exógenas.

En definitiva, la modelización económica no sólo es el principal campo de aplicación de las matrices de contabilidad social sino que cualquier modelo de equilibrio general aplicado, independientemente de la teoría económica que lo soporte, lleva asociada implícita o explícitamente una matriz de contabilidad social. Como ya indicamos en el apartado 2.1.3, en la práctica, el punto de partida y la base de datos utilizada por la mayor parte de los modelos de equilibrio general aplicado es una matriz de contabilidad social. 


\subsection{APLICACIONES DEL MODELO SAM}

Como el principal campo de aplicación de las matrices de contabilidad social es la modelización económica, en este apartado mostramos cuáles son las posibilidades de análisis que ofrecen los modelos SAM, que son modelos lineales de equilibrio general aplicado basados en las relaciones recogidas en una matriz de contabilidad social.

Habitualmente estos modelos se utilizan para evaluar los efectos de programas alternativos de política económica (variaciones en los flujos exógenos) sobre la producción de las distintas ramas de actividad y sobre la renta de los hogares (renta de las unidades endógenas). A efectos de profundizar en las relaciones causales y estructurales que están detrás de los efectos globales producidos por una inyección exógena, bien pueden descomponerse dichos efectos en efectos intragrupos, intergrupos o cruzados y de bucle, o bien pueden desglosarse las unidades económicas a través de las cuáles se trasmite la influencia desde la unidad de origen hasta la unidad o unidades de destino. Por último, del mismo modo que los multiplicadores input-output permiten identificar las ramas productivas con mayor capacidad de arrastre hacia delante y hacia atrás, a partir de un modelo SAM también pueden identificarse los factores productivos o los grupos de hogares que mejoran o empeoran su situación, en términos de su participación en la renta total de los factores o de los hogares.

\subsubsection{Descomposición de la matriz de multiplicadores SAM.}

Para generalizar y descomponer la ecuación básica del modelo SAM descrita en el cuadro 2.10, $A+B=X \Rightarrow \bar{A} X+B=X \Rightarrow X=(I-\bar{A})^{-1} B=M B$, utilizamos el método iterativo.

Si expresamos la matriz $(I-\bar{A})$ como una diferencia de dos matrices $\left(M_{\alpha}-M_{\beta}\right)$, tal que $M_{\alpha}$ sea una matriz invertible, cualquier solución al sistema $(I-\bar{A}) X=B$ satisfará 
que $M_{\alpha} X=M_{\beta} X+B$ y, por tanto, que $X=M_{\alpha}{ }^{-1} M_{\beta} X+M_{\alpha}{ }^{-1} B$. A partir de la expresión anterior puede definirse una sucesión por aproximaciones $X^{(\mathrm{n})}=M_{\alpha}^{-1} M_{\beta} X^{(n-1)}+M_{\alpha}^{-1} B$ que será convergente siempre que $(I-\bar{A})$ sea una matriz diagonal estrictamente dominante, $\left|M_{\mathrm{ii}}\right|>\sum_{\mathrm{j} \neq \mathrm{i}}\left|M_{\mathrm{ij}}\right|$. Simplificando la sucesión anterior, $X^{(\mathrm{n})}=M_{\delta} X^{(\mathrm{n}-1)}+C$, donde $M_{\delta}$ es la matriz de iteración, obtenemos:

$$
\begin{gathered}
M_{\delta} X^{(n-1)}+C=M_{\delta}^{2} X^{(n-2)}+\left(I+M_{\delta}\right) C=\ldots=M_{\delta}^{k} X^{(n-k)}+\left(I+M_{\delta}+M_{\delta}^{2}+\ldots+M_{\delta}^{(k-1)}\right) C \\
n \rightarrow \infty \Leftrightarrow\left(X^{(n)}-X^{(n-k)}\right) \rightarrow 0, X^{(n)} \rightarrow X \\
X=\left(I-M_{\delta}^{k}\right)^{-1}\left(I+M_{\delta}+M_{\delta}^{2}+\ldots+M_{\delta}^{k-1}\right) M_{\delta}^{-1} B
\end{gathered}
$$

Dado que el método Jacobiano construye la matriz $M_{\alpha}$ con los elementos de la diagonal principal de la matriz $(I-\bar{A})$, basta con elegir una sucesión de tres etapas $(k=3)$ para obtener la descomposición multiplicativa de la matriz de multiplicadores propuesta por Pyatt y Round (1979) y la descomposición aditiva de Stone (1978), recogidas en las dos ecuaciones siguientes:

$$
\begin{aligned}
& X=M B=M_{3} M_{2} M_{1} B=\left(I-M_{\delta}^{3}\right)^{-1}\left(I+M_{\delta}+M_{\delta}^{2}\right) M_{\delta}^{-1} B \\
& X=M B=\left(I+\left(M_{1}-I\right)+\left(M_{2}-I\right) M_{1}+\left(M_{3}-I\right) M_{2} M_{1}\right) B
\end{aligned}
$$

La elección de $k=3$ se debe a dos motivos, que el modelo SAM distingue tres grupos de unidades endógenas, actividades, factores e instituciones, y que para completar una vuelta por todo el sistema económico basta con una secuencia de tres pasos por las cuentas de las unidades endógenas. En el cuadro 2.11.a puede apreciarse cómo la renta circula de las actividades a los factores, de los factores a las instituciones, y desde estas últimas retorna de nuevo a las actividades vía demanda final. Por tanto, empezando por una esquina cualquiera del triángulo tras una secuencia de tres pasos se llega de nuevo al punto de partida. 
CUADRO 2.11. Descomposición de la matriz de multiplicadores

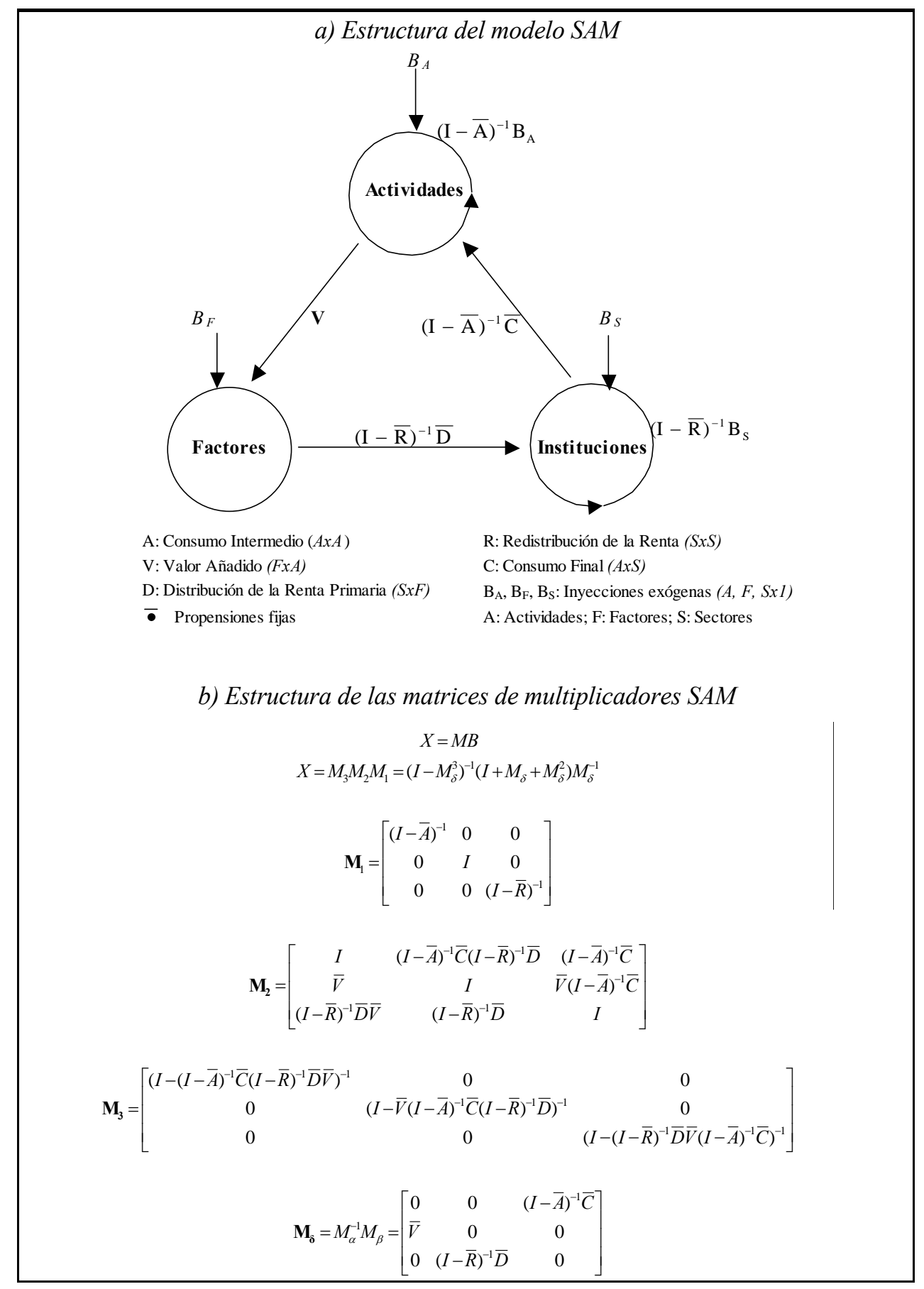


El carácter cerrado del sistema provoca que la intensidad de los efectos de una inyección exógena sobre la renta de las unidades endógenas disminuya a medida que se van completando sucesivas rondas. Precisamente, este es uno de los aspectos que se resaltan al descomponer la matriz de multiplicadores para mostrar la secuencia de interacciones que se producen entre las unidades endógenas del modelo.

Como puede observarse en el cuadro 2.11.b, la matriz $M_{1}$ es una matriz diagonal cuyos elementos capturan los efectos intragrupo de inyecciones exógenas. El primer bloque de su diagonal principal se corresponde con los multiplicadores inputoutput tradicionales que están basados en los flujos interindustriales (consumos intermedios), y el tercer bloque recoge los multiplicadores derivados de los flujos interinstitucionales (transferencias). Los elementos de la matriz $M_{2}$ miden los efectos cruzados entre las unidades endógenas, es decir, los efectos de una variación en la renta de un grupo de unidades endógenas sobre los otros dos grupos tras completar una vuelta. Por último, los elementos de la matriz $M_{3}$ recogen los efectos de bucle que se producen como consecuencia del conjunto de rondas o interacciones sucesivas entre las unidades endógenas del modelo hasta que se desvanecen todos los efectos y, por tanto, se completa el proceso; en otras palabras, representan el efecto multiplicador derivado del carácter cerrado del sistema: siempre parte de la renta generada en una cuenta endógena revierte de nuevo sobre ella misma.

\subsubsection{Análisis estructural}

Otro método para descomponer más detalladamente la matriz de multiplicadores es el análisis estructural, que tiene por objeto la identificación de la amplia red de caminos a través de la que se transmite la influencia dentro del sistema económico, desde que se produce la variación inicial en las variables exógenas hasta sus últimos efectos sobre las variables endógenas. Los conceptos de influencia económica y análisis estructural fueron formulados por Lantner (1974) y Gazon (1976 y 1979) para analizar la transmisión de la influencia dentro de la red de relaciones estructurales especi- 
ficadas en los modelos de equilibrio general con el fin de clarificar y explicar la solución a la que se llega al resolver este tipo de modelos.

La formalización matemática introducida por dichos autores permite aplicar este enfoque a cualquier sistema de ecuaciones lineales. Inicialmente se aplicó a la modelización input-output (v.g. Lantner,1974; Gazon y Nihon,1976 y Defourny,1982), posteriormente, Defourny y Thorbecke (1984) extenderan el análisis estructural a los modelos SAM.

El punto de partida del análisis estructural es la equiparación del concepto de gasto con el de influencia. Un arco $(j, i)$ está orientado en la dirección del gasto, se interpreta como la magnitud de la influencia transmitida del polo $j$ al polo $i$, y su intensidad viene dada por la propensión media de gasto $a_{i j}$. Una secuencia de arcos consecutivos conforma un camino de influencias cuya longitud se determina por el número de arcos que lo componen. Si un camino de influencias no pasa más de una vez por el mismo polo se denomina camino elemental, y si el primer polo, o polo de origen, coincide con el último, o polo de destino, se trata de un circuito. Por último, el conjunto de arcos que unen los polos de una estructura conforman su gráfico de influencia.

Para medir la influencia económica se han desarrollado tres interpretaciones cuantitativas diferentes: la influencia directa, la influencia total y la influencia global. La influencia directa de $j$ sobre $i$ transmitida a través de un camino elemental $p$ se define como la variación en la renta de $i$ ante un cambio unitario en la renta de $j$, siempre que la renta de los demás polos, excepto los que se encuentren en el camino $p$, permanezca constante. La influencia directa de $j$ sobre $i$ a través de un arco $(j, i)$ es igual a su intensidad, $\left.\mathbf{I}_{\mathbf{D}} \mathbf{( j} ! \mathbf{i}\right)=a_{i j}, \mathrm{y}$ a través de un camino elemental $p=(j, m, \ldots, n, i)$, al producto de las intensidades de los arcos que conforman el camino $\mathbf{I}_{\mathbf{D}}(\mathbf{j} ! \mathbf{i})_{\mathbf{p}}=a_{i n} \ldots a_{m j}$.

Como es habitual que exista un gran número de interacciones entre los polos de una estructura, es decir, que los polos que conforman un camino elemental a su vez estén relacionados con otros polos y otros caminos formando circuitos adyacentes que amplían la influencia económica entre los polos, Lantner introdujo el concepto de in- 
fluencia total para poder evaluar conjuntamente la influencia directa e indirecta a través de los circuitos adyacentes: $\mathbf{I}_{\mathbf{T}}(\mathbf{j} \mathbf{j} ! \mathbf{i})_{\mathbf{p}}=\mathbf{I}_{\mathbf{D}}(\mathbf{j} \mathbf{j} ! \mathbf{i})_{\mathbf{p}} \mathbf{M}_{\mathbf{p}}$, donde $M_{p}$, que es el cociente entre el determinante de la matriz que resulta al eliminar los polos que constituyen el camino $p$ de la matriz $(I-\bar{A})$ y el determinante de $(I-\bar{A})$, mide la amplificación de la influencia directa a través de los circuitos adyacentes (Defourny y Thorbecke, 1984).

Por último, la influencia global de un polo $j$ sobre un polo $i$ mide el efecto total de una variación unitaria en la renta de $j$ sobre la renta de $i$, es decir, considera todos los caminos elementales $\left(p_{i}\right)$ que unen ambos polos $\mathbf{I}_{\mathbf{G}}(\mathbf{j} ! \mathbf{i})=\mathbf{M}_{\mathbf{i j}}$, donde, $M_{i j}$ es el elemento $(i, j)$ de la matriz de multiplicadores del modelo SAM.

CUADRO 2.12. Influencias elemental, total y global

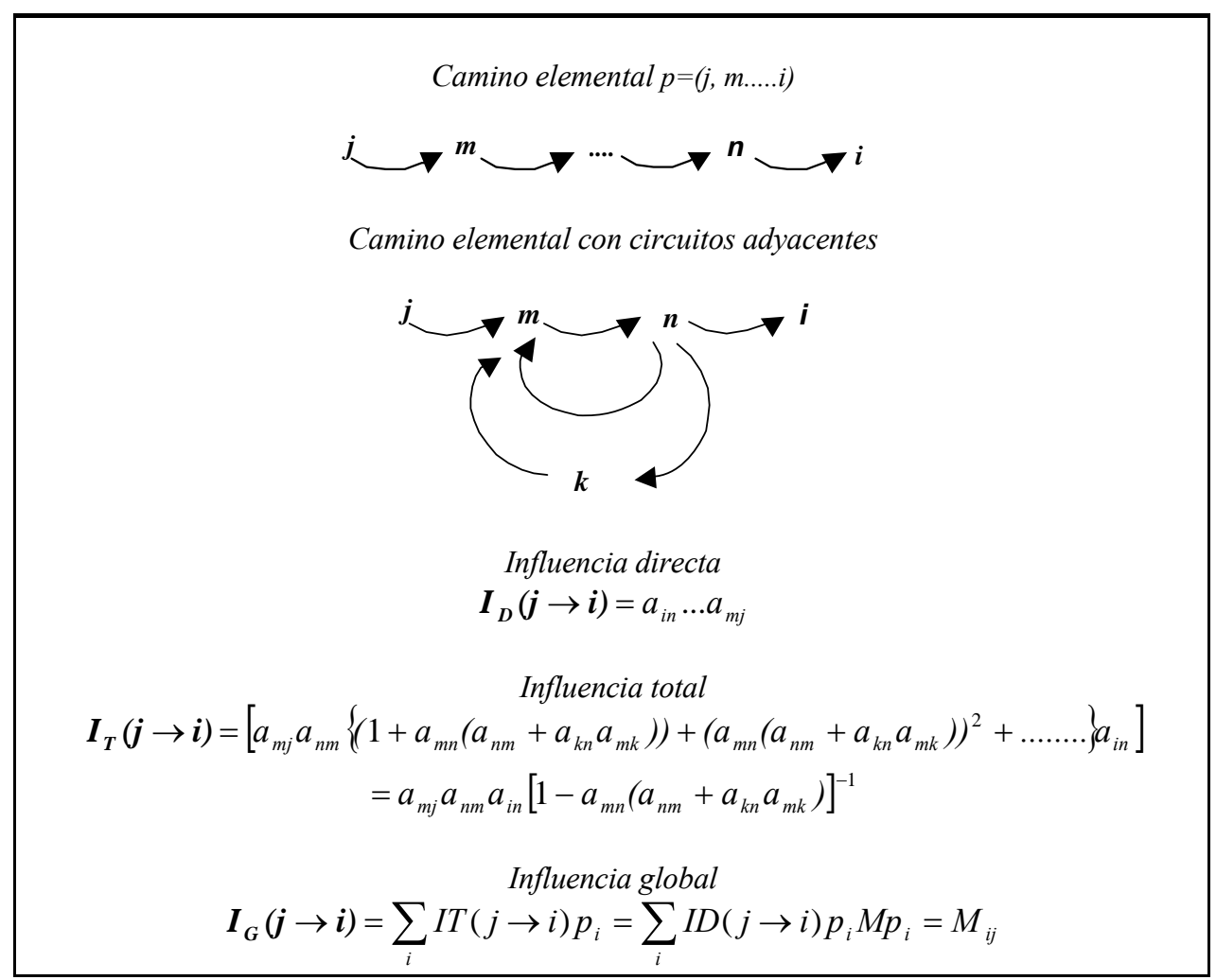




\subsubsection{Medición de los efectos redistributivos}

La matriz de multiplicadores $M$ de un modelo SAM es la matriz Jacobiana correspondiente a la transformación $B \rightarrow X$, y sus elementos ponderados pueden emplearse para describir los efectos de cambios exógenos sobre la distribución de la renta (Robinson y Roland-Host, 1988; Polo, Roland-Holst y Sancho 1990; Roland-Holst y Sancho, 1992 y Cohen y Tuyl, 1991). La ecuación siguiente recoge la expresión de los multiplicadores relativos $\left(\xi_{\mathrm{ij}}\right)$ por grupos de unidades endógenas (actividades, asalariados, trabajadores por cuenta propia, capital, hogares...), habitualmente utilizada para analizar los efectos distributivos de una variación en los flujos exógenos del modelo.

$$
\begin{gathered}
\xi_{i j}=\frac{\frac{\partial X_{i}}{X_{i}} / \frac{\partial B_{j}}{B_{j}}}{\frac{\partial \sum_{i} X_{i}}{\sum_{i} X_{i}} / \frac{\partial B_{j}}{B_{j}}}=\frac{\frac{\partial X_{i}}{\partial B_{j}} / \sum_{i} \frac{\partial X_{i}}{\partial B_{j}}}{X_{i} / \sum_{i} X_{i}}=\frac{M_{i j} / \sum_{i} M_{i j}}{X_{i} / \sum_{i} X_{i}}=\frac{m_{i j}}{x_{i}} \\
\text { Actividades: } i=1,2, \ldots . . m ; \text { Factores: } i=1,2, \ldots, l ; \text { Hogares }: i=1,2, \ldots, h
\end{gathered}
$$

La ecuación anterior puede generalizarse para simular los efectos distributivos de cambios exógenos más amplios como, por ejemplo, una variación insesgada en la renta exógena total de la economía, o de un grupo de cuentas endógenas $\left(d B_{\mathrm{j}} / \Sigma_{\mathrm{j}} d B_{\mathrm{j}}=\right.$ $\left.\mathrm{B}_{\mathrm{j}} / \Sigma_{\mathrm{j}} \mathrm{B}_{\mathrm{j}} ; \Sigma_{\mathrm{j}} d B_{\mathrm{j}}=1\right)$.

$$
\xi_{i j}=\frac{\sum_{j} M_{i j} d_{B} / \sum_{j} \sum_{i} M_{i j} d_{j}}{X_{i} / \sum_{i} X_{i}}=\frac{\sum_{j} \frac{\partial X_{i}}{\partial B_{i}} x_{j} \sum_{j} B_{j} / \sum_{j} \sum_{i} \frac{\partial X_{i}}{\partial B_{i}} x_{j} \sum_{j} B_{j}}{X_{i} / \sum_{i} X_{i}}=\frac{d X_{i} / X_{i}}{d \sum_{i} X_{i} / \sum_{i} X_{i}}
$$

Asimismo, también puede eliminarse el supuesto de cambios exógenos neutrales para analizar los efectos derivados de los cambios exógenos observados a lo largo de un periodo de tiempo. De todos modos, cualquier inyección exógena, sesgada o insesgada, provocará un aumento de la desigualdad siempre que los grupos de rentas 
elevadas incrementen su participación en la renta total $(\xi>1)$ y los grupos de menor renta reduzcan la suya $(\xi<1)$.

El análisis anterior, obviamente, es interesante a efectos de identificar los grupos de hogares que mejoran o empeoran su situación en términos de participación en la renta total, sin embargo cuando se observan aumentos y disminuciones en las participaciones en la renta total tanto de los grupos de hogares con ingresos elevados como de los grupos de hogares con menor renta, dicho análisis no es suficiente para poder inferir si la desigualdad global aumenta o disminuye. 


\subsection{ANTECEDENTES EN ESPAÑA}

Aunque existen algunos precedentes en el ámbito del análisis input-output que extienden la contabilidad matricial más allá de las operaciones de bienes y servicios para relacionar su origen y su destino a través de las operaciones de distribución de la renta (Abadía, 1979 y Abadía y otros, 1981), el primer intento de elaboración de una matriz de contabilidad social para España fue abordado por Kehoe y otros en 1986. Dos años más tarde presentaron la primera matriz de contabilidad de social para España referida a 1980 (SAM-80), año para el que ya se contaba con una Tabla InputOutput para la economía española (Kehoe, Manresa, Polo y Sancho, 1988). Un año más tarde, dicha matriz sería reformulada por Uriel (1989). Por las mismas fechas Curbelo $(1987,1988)$ elaboró la primera matriz de contabilidad social de ámbito regional, referida a la economía andaluza (SAMA-80). Todos los trabajos mencionados incorporaron las operaciones de distribución de la renta a partir de la información proporcionada por las Encuestas de Presupuestos Familiares, la de 1973-74 en el caso del trabajo de Abadía, y la de 1980-81 en el resto de estudios.

Desde entonces, en lo que conocemos, y al margen de la adaptación de la SAM-80 a los datos de 1987 por parte de sus autores (Polo y Sancho 1992), únicamente se ha elaborado una nueva matriz de contabilidad social para España, que es la publicada por el INE y el IVIE (Uriel y otros, 1997) para el año 1990 (MCS-90). También en este caso las tres fuentes estadísticas básicas utilizadas han sido la Encuesta de Presupuestos Familiares 1990-91, la Contabilidad Nacional y la Tabla Input-Output de 1990. Por contra, en el ámbito regional se cuenta con las matrices de contabilidad social elaboradas para Castilla y León (Rubio,1995), Extremadura (de Miguel y otros, 1998), Cataluña (Manresa y otros, 1998, Llop y Manresa 1999) y Andalucía (Cardenete, 1998 y Cardenete y Sancho 2000), regiones todas ellas que disponen de Contabilidad Regional y Tablas Input-Output que se combinan con las muestras regionales de las Encuestas de Presupuestos Familiares de 1980-81 y de 1990-91. 
Mas allá de los trabajos en los que se presentan las matrices de la economía española para los años 1980 y 1990, también se han abordado las tres aplicaciones clásicas de los modelos SAM sobre descomposición de multiplicadores, análisis de la influencia económica y medición de efectos distributivos: Polo, Roland-Holst y Sancho (1991a, 1991b y 1990), a partir de la SAM-80, y Ferri y Uriel (2000) a partir de la MCS-90. La SAM-80 también ha sido utilizada para construir modelos de equilibrio general aplicado, que incorporan funciones no lineales de producción, consumo y comercio exterior, con los que simular los efectos de cambios en la fiscalidad (Kehoe, Noyola, Manresa, Polo y Sancho, 1988; Manresa, Polo y Sancho, 1988; Kehoe, Manresa, Polo y Sancho, 1989; y Polo y Sancho 1990b) o en las cuotas a la seguridad social (Polo y Sancho, 1990a). Por último, para evaluar la capacidad predictiva del modelo, Polo y Sancho (1993) lo calibraron con la SAM-87. Esta ultima matriz de 1987 también ha sido empleada para elaborar un modelo de determinación de precios (Roland-Holst y Sancho,1995) y para analizar los efectos distributivos asociados a los cambios en el patrón de exportaciones e importaciones y en la imposición al consumo y a la producción producidos a raíz de la integración de España en la CE (Collado y Roland-Holst, 1993). De igual modo, la MCS-90 ha sido utilizada para calibrar un modelo de equilibrio general aplicado para evaluar los efectos derivados del descenso en los tipos de cotizaciones pagados por las empresas compensado con un aumento del IVA (Gómez, 1999).

Por lo que respecta a las aplicaciones de las matrices regionales, éstas se han limitado básicamente a la elaboración de modelos lineales con coeficientes fijos para estimar los efectos multiplicadores de inyecciones exógenas, con la excepción del trabajo de Manresa, Sancho y Vergara (1998) que proponen un modelo consistente con la teoría del valor trabajo y utilizan la matriz de contabilidad social de Cataluña como un mero instrumento para probar la factibilidad de computación del modelo teórico propuesto. 


\subsubsection{La Matriz de Contabilidad Social de España para 1980 (SAM-80)}

Tal y como destacan los comentarios a la primera publicación de la SAM-80 de Kehoe, Manresa, Polo y Sancho (KMPS) en 1988 (cuadro 2.13), "su presentación en bloques separados dificultaba la captación de las interrelaciones y consistencia última del sistema” (Rodríguez Romero, 1988).

CUADRO 2.13. Presentación original de la SAM-80 (miles de millones de pesetas)

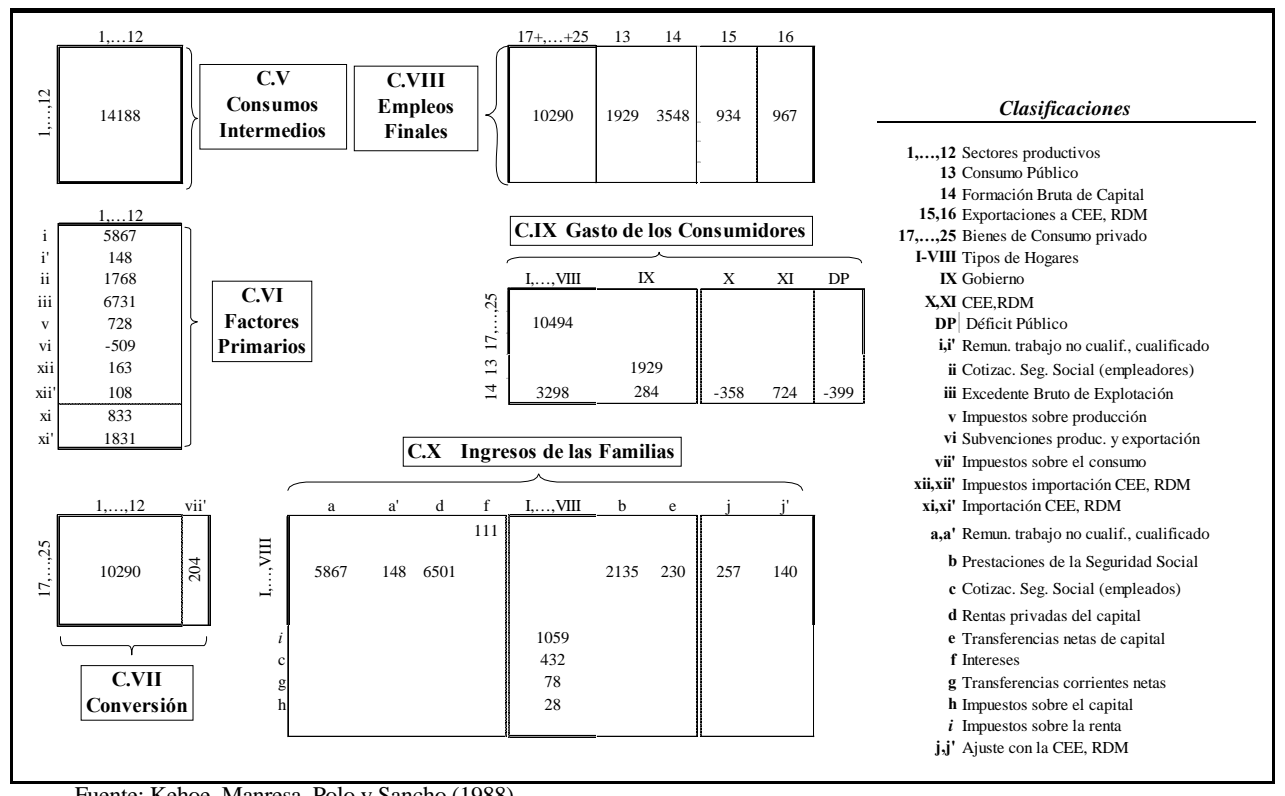

Como bien reconocían sus autores, la información disponible era insuficiente y la construcción de las matrices de contabilidad social no estaba normalizada en la literatura económica, de ahí que tanto su diseño como los supuestos adoptados para completar las lagunas de información fuesen susceptibles de interpretaciones alternativas. Uriel (1989) presentó una matriz de contabilidad social alternativa (SAM-80b) que incorporaba los nuevos desarrollos sobre el diseño de las matrices de contabilidad social propuestos por Pyatt (1988), a efectos de presentar una matriz cuadrada y equilibrada que permitiera detectar algunas inconsistencias que no resultan obvias cuando las submatrices se disponen por separado (cuadro 2.14). 
CUADRO 2.14. SAM-80b propuesta por Uriel (miles de millones de pesetas)

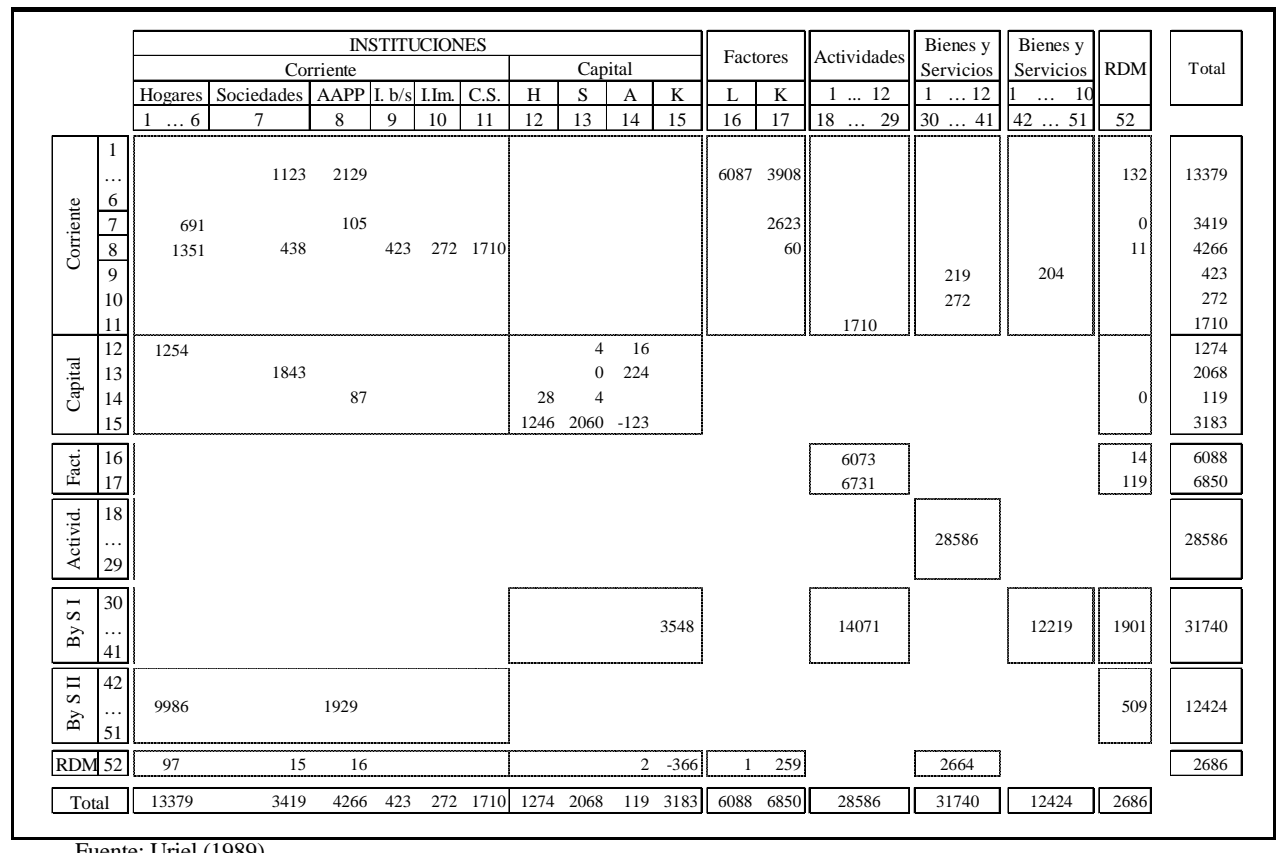

Fuente: Uriel (1989).

A nuestro juicio la SAM-80b elaborada por Uriel más que una alternativa constituye un desarrollo de la SAM-80. En el cuadro 2.15 presentamos ambas matrices en un formato más actual, que sigue las directrices propuestas por el SCN93, para reflejar el proceso de circulación de la renta desde su generación en el proceso productivo hasta su utilización para satisfacer necesidades finales, pasando por su asignación y distribución. Como puede observarse en la parte superior de dicho cuadro la SAM-80 es susceptible de ser cuadrada asignando a las AAPP, como saldo de rentas primarias, el excedente bruto de explotación que no es asignado ni a los hogares ni a las sociedades. Realizado dicho ajuste, las dos novedades más significativas de la matriz elaborada por Uriel (1989) vienen dadas por la separación de los sectores hogares y sociedades, y por la desagregación de las operaciones con el resto del mundo.

CUADRO 2.15. Presentación reordenada de la SAM-80 y de la SAM-80b

(miles de millones de pesetas) 


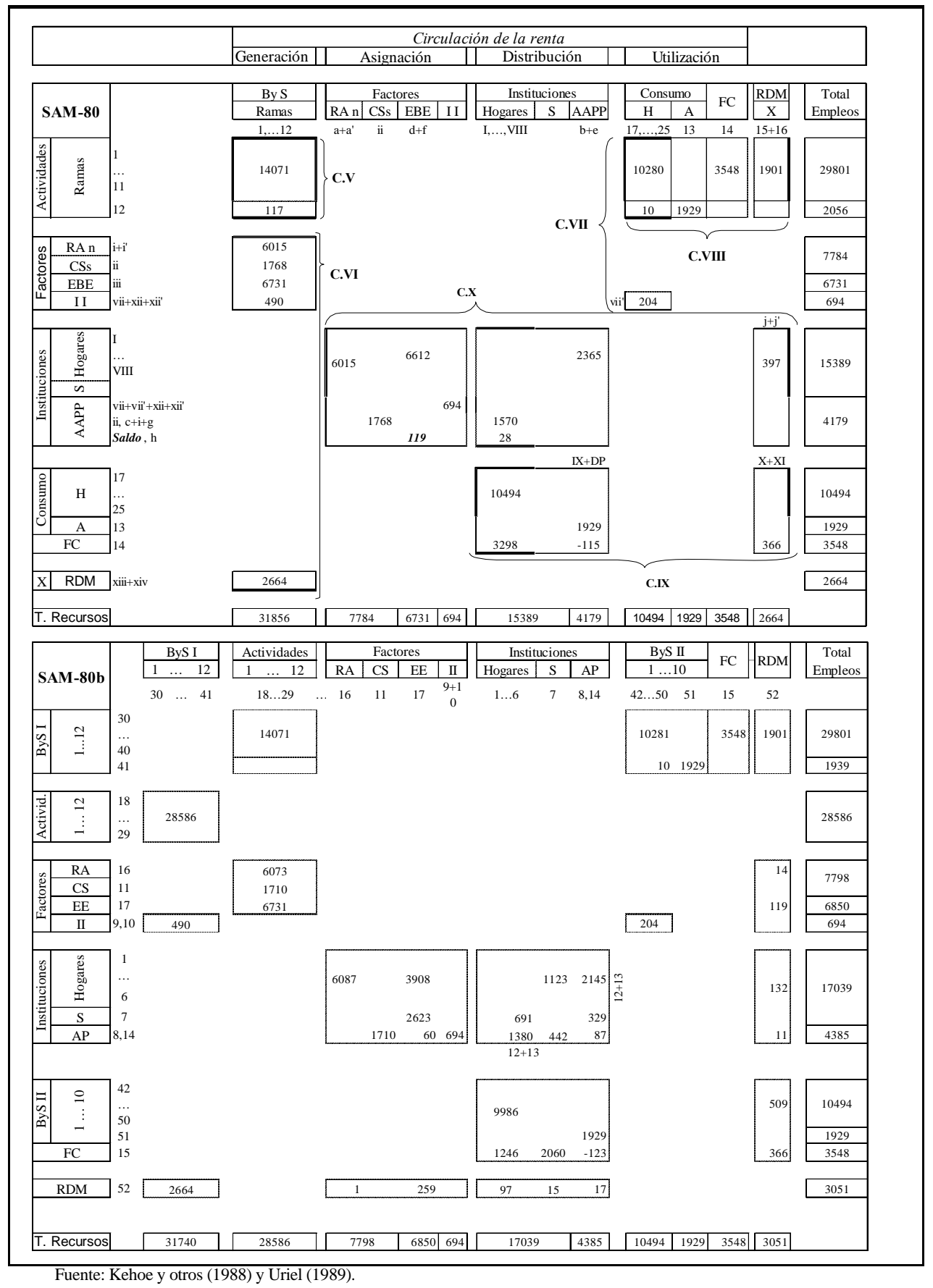


En cuanto al resto de diferencias, unas son sencillamente de formato y otras de reformulación de algunos supuestos sobre la distribución entre las unidades institucionales de algunos agregados, utilizando la información que al respecto proporcionan fuentes estadísticas adicionales. Entre las diferencias de formato destaca la desagregación, en la SAM-80b de Uriel, de las operaciones de bienes y servicios en dos cuentas para reflejar su origen y destino por tipos de actividades y por categorías de productos, y el desglose del consumo privado por funciones; en la SAM-80 de KMPS, las operaciones de bienes y servicios únicamente están desglosadas por actividades económicas. También difieren en el tratamiento de las ventas residuales de las AAPP, mientras que en la SAM-80 se consideran como una rama específica, en la matriz de Uriel se les da un tratamiento similar al de los productos fatales y vecinos. El resto de diferencias de formato se deben a la utilización de diferentes criterios de clasificación de las unidades y de las operaciones, lo que constituye una muestra de la flexibilidad de las matrices de contabilidad social. En cuanto a los supuestos adoptados para distribuir algunos agregados, en general, cabe aplicar el dicho de que cuatro ojos ven más que dos, sin detrimento del mérito que cabe atribuir al que se fija primero.

\subsubsection{La Matriz de Contabilidad Social de España para 1990 (MCS-90)}

Como se señala en la introducción de la MCS-90 (Uriel y otros, 1997), ésta "supera a las anteriores tanto en el grado de desagregación de los hogares y los factores como en los criterios metodológicos seguidos en la elaboración de cada una de las matrices que la integran”. En efecto, si comparamos la matriz de 1980 (SAM-80b) con la de 1990 (cuadros 2.14 y 2.16) puede apreciarse que, aunque sus esquemas son idénticos, la MCS-90 duplica el número de grupos de hogares (de 6 a 12), incorpora cuatro categorías de asalariados e introduce algunas variaciones en la clasificación de las actividades económicas y de los bienes y servicios de primer nivel (I). 
CUADRO 2.16. Presentación original de la MCS-90 (miles de millones pesetas)

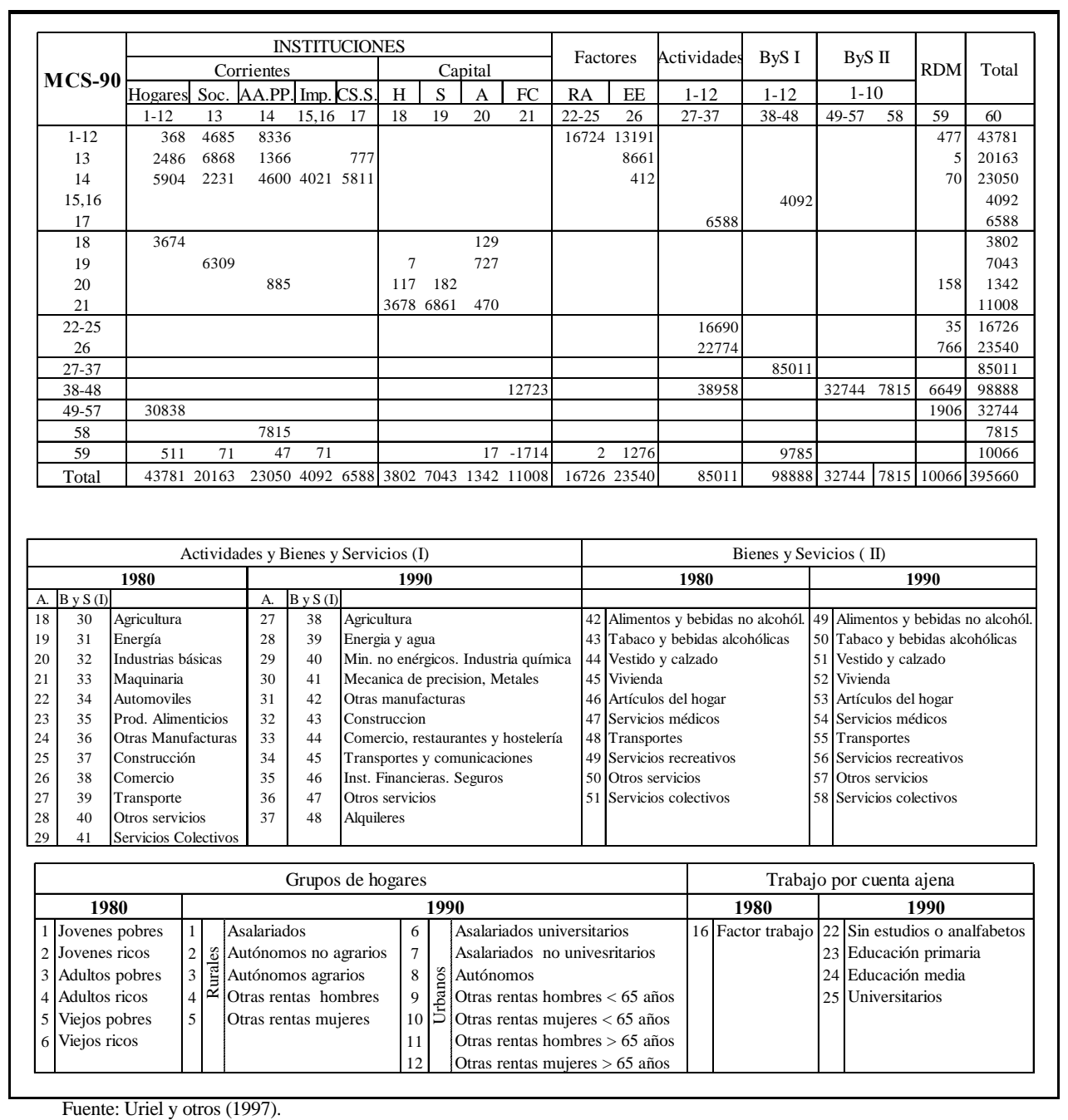

Por último, señalaremos cuáles son, a nuestro juicio, los posibles desarrollos de esta última matriz de contabilidad social ${ }^{25}$. Aunque en la elaboración de la MCS-90 los mayores esfuerzos se centraron en la desagregación de las operaciones corrientes por grupos de unidades (productos, actividades, factores e instituciones), todavía es deseable un mayor grado de detalle, especialmente, en la cuenta de los factores a efectos de

\footnotetext{
${ }^{25}$ En Gómez (2000) se proponen varias modificaciones de la MCS-90 para ampliar su uso a un mayor rango de modelos de análisis.
} 
poder diferenciar, al menos, entre renta mixta y excedente de explotación, que a su vez podrían subdividirse por categorías de trabajadores autónomos y por tipos de activos o de propietarios.

Si esa mayor desagregación de la cuenta de los factores se acompañara de una clasificación más detallada de las actividades económicas y de los bienes y servicios (v.gr.: la clasificación R.56 de la TIO90), aumentaría notablemente el potencial analítico de esta matriz de contabilidad social para el estudio de las interrelaciones entre la estructura de la producción y las distribuciones funcional y personal de la renta, un campo de investigación en el que todavía son muy escasos los trabajos realizados en nuestro país. Habitualmente, los estudios sobre la producción, la distribución funcional de la renta y su distribución personal se han abordado por separado y con enfoques diferentes.

A diferencia de lo que sucede con los bienes y servicios o con las actividades económicas, ni para factores productivos ni para hogares disponemos de clasificaciones estandarizadas, por lo que ha de ser el investigador quien, en cada caso, seleccione la variable o variables que considere más oportunas. Por lo que respecta a la clasificación del factor trabajo en la MCS-90, aunque el nivel de estudios es sin duda una variable importante y significativa en la explicación de la distribución salarial, no siempre hay una correspondencia entre la cualificación que requiere un puesto de trabajo y el nivel de estudios del trabajador. Por ello, consideramos que, en la medida de lo posible, sería deseable utilizar junto con el nivel de estudios otros criterios de clasificación tales como la ocupación, la rama de actividad, la situación profesional, el sexo o la edad del trabajador.

Uno de los aspectos básicos de las matrices de contabilidad social, o quizá el más importante, es la desagregación del sector hogares. Dicha desagregación requiere, en primer lugar, separar los organismos privados sin fines de lucro de los hogares, tarea que no siempre es posible dado que apenas existe información sobre las operaciones económicas de las instituciones privadas sin fines de lucro y en segundo lugar, tipificar a los hogares. Sobre esta última cuestión, la clasificación de los hogares, úni- 
camente apuntar que es aconsejable utilizar, entre otros criterios, su nivel de ingresos, por ser una variable necesaria para la medición de la desigualdad y del impacto que sobre la misma tienen diferentes medidas de política económica.

Por último, con relación a las cuentas de acumulación, la falta de una contabilidad del patrimonio dificulta enormemente su tratamiento dentro de las matrices de contabilidad social. Por tanto, se trata de un campo en el que prácticamente todo está por hacer. Quizá dicha tarea debería comenzar con la desagregación de las adquisiciones netas de activos fijos e incluso de los activos no producidos con clasificaciones cruzadas por instituciones, actividades económicas y tipos de activos (productos, en el caso de los activos fijos) y con la ampliación del cuadro de operaciones financieras para reflejar los sectores deudores o acreedores de los distintos activos o pasivos contraídos por cada uno de los sectores o subsectores institucionales. El último paso consistiría en incluir los balances de apertura y cierre desglosados por tipos de activos y de propietarios (instituciones).

Los trabajos anteriores, en definitiva, han abierto en nuestro país un nuevo campo de investigación de gran utilidad, como prueba su desarrollo por todo el mundo a lo largo de estas dos últimas décadas. Las matrices de contabilidad social constituyen un puente entre la modelización input-output y de equilibrio general y los estudios aplicados sobre economía industrial, economía del bienestar, comercio internacional, crecimiento, etc. En los dos capítulos siguientes trataremos de contribuir a la construcción de dicho puente en dos aspectos: el primero está relacionado con la solidez y diseño de los materiales empleados (capítulo 3) y el segundo, con la aplicación de las matrices de contabilidad social al análisis de la desigualdad, en cuyo interés está precisamente el origen de las matrices de contabilidad social (capítulo 4). 



\section{CAPÍTULO 3}

\section{LA ELABORACIÓN DE LA MCSE-90}

"Un hombre con un único reloj siempre conoce la hora; un hombre con dos relojes siempre intenta conocer cuál es el que señala la hora correcta; un hombre con diez relojes siempre está pensando en la dificultad que presenta medir el tiempo.”

Anónimo*

* Citado en Groves (1986). 

En este capítulo describimos el proceso de elaboración de una nueva matriz de contabilidad social para España referida al año 1990 (MCSE-90). La elección de 1990 como año de referencia se debe a que durante el periodo de elaboración de esta memoria dicho ejercicio es el último para el que se dispone de la información necesaria para construir una matriz de contabilidad social detallada ${ }^{26}$. Con respecto a otras matrices de contabilidad social elaboradas con anterioridad para España, incluida la elaborada para 1990 por Uriel y otros (1997), la principal novedad que incorpora la matriz que presentamos en este trabajo es su plena adaptación a los Sistemas de Cuentas Nacionales vigentes (SCN93 y SEC95). En ciertos aspectos incluso cabría afirmar que extiende el capítulo XX del manual de Naciones Unidas al estar concebida, más que como un desarrollo alternativo del Sistema de Cuentas, como una presentación más acabada y modelizable del mismo.

La elaboración de una matriz de contabilidad social propia, más allá de la formación que proporciona sobre el manejo y la articulación de las fuentes estadísticas, permite elegir las agregaciones más adecuadas de los flujos y las unidades económicas e introducir supuestos alternativos, ya sea por preferir otros o por disponer de información adicional. A este respecto, cabe destacar que ninguna de las matrices de contabilidad social publicadas con anterioridad para España desglosa los hogares por niveles de renta, aspecto éste indispensable para el análisis de las cuestiones distributivas, que constituyen la principal aplicación abordada en este trabajo. Además, todas ellas recogen de forma excesivamente resumida los procesos de armonización e integración de los datos procedentes de las distintas fuentes utilizadas y de conversión de clasificaciones que conlleva la elaboración de una matriz de contabilidad social.

En general, la información más detallada con respecto a las publicaciones previas supone un valor añadido nada desdeñable para otros investigadores que deseen

\footnotetext{
${ }^{26}$ En la fase final de elaboración de este trabajo el INE ha dado a conocer la Tabla Input-Output de 1995 y ha optado definitivamente por dejar de elaborar las grandes Encuestas de Presupuestos Familiares -conservando la Encuesta Continua que cuenta con un tamaño suficiente para la estimación de las ponderaciones del índice de precios- y sumarse al Panel de Hogares de Eurostat en el que las variables económicas forman parte de un cuestionario mucho más amplio que aborda diversos aspectos de la cohesión social.
} 
abordar nuevas aplicaciones. El núcleo de este capítulo lo constituye el apartado 3.3 en el que describimos minuciosamente las fuentes y supuestos empleados para obtener cada una de las cifras que figuran en la MCSE-90. Para aligerar la exposición y facilitar la lectura, tratamos previamente la estructura y las principales fuentes estadísticas empleadas en la elaboración de la MCSE-90 (3.1) así como los criterios de clasificación de las unidades (3.2). 


\subsection{ESQUEMA Y FUENTES DE LA MCSE-90}

La MCSE-90 elaborada en este trabajo recoge la secuencia completa de las cuentas de flujos del SCN93 que describen el proceso de circulación de la renta y la variación del patrimonio neto debida a operaciones.

CUADRO 3.1. Matriz de Contabilidad Social de España (MCSE-90)

\begin{tabular}{|c|c|c|c|c|c|c|c|c|}
\hline Cuentas & $\begin{array}{c}\text { C.1 } \\
\text { Cuenta de } \\
\text { bienes y } \\
\text { servicios } \\
\text { (Productos) } \\
1,2, \ldots ., 46 \\
\end{array}$ & $\begin{array}{c}\text { C.2 } \\
\text { Cuenta de } \\
\text { Producción } \\
\\
\text { (Actividades) } \\
1,2, \ldots, 48\end{array}$ & $\begin{array}{c}\text { C.3 } \\
\text { Cuenta de } \\
\text { generación de } \\
\text { renta } \\
\text { (Factores) } \\
1,2, \ldots, 15\end{array}$ & \begin{tabular}{|c|} 
C.4 \\
Cuenta de Asignación, \\
Distribución y utilización de \\
la renta \\
(Sectores) \\
E, A, IP, H $(1,2, \ldots, 30)$ \\
\end{tabular} & $\begin{array}{c}\text { C.5 } \\
\text { Cuenta de } \\
\text { variación del } \\
\text { patrimonio } \\
\text { (Sectores) } \\
\text { E, A, H }\end{array}$ & \begin{tabular}{|c|} 
C.6 \\
Cuenta de \\
variaciones en el \\
balance \\
(Sectores) \\
$\mathrm{E}, \mathrm{A}, \mathrm{H}$ \\
\end{tabular} & \begin{tabular}{|c|} 
C.7 \\
Cuenta del resto \\
del mundo
\end{tabular} & Total \\
\hline 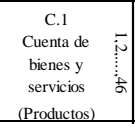 & \begin{tabular}{c|}
$\begin{array}{c}\text { Márgenes } \\
\text { comerciales y de } \\
\text { transporte }\end{array}$ \\
0
\end{tabular} & 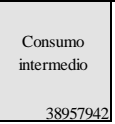 & & $\begin{array}{r}\text { Gastos de consumo final } \\
39118006 \\
\end{array}$ & & $\begin{array}{c}\begin{array}{c}\text { Formación bruta } \\
\text { de capital } \\
12722712 \\
\end{array} \\
\end{array}$ & $\begin{array}{r}\text { Exportaciones de } \\
\text { bienes y servicios } \\
8555137 \\
\end{array}$ & \\
\hline $\begin{array}{|cc|}\text { C.2 } & \\
\text { Cuenta de } & \stackrel{\sim}{N} \\
\text { Producción } & + \\
\text { (Actividades) } & \end{array}$ & $\begin{array}{l}\text { Producción } \\
85961529\end{array}$ & & & & & & & 85961529 \\
\hline \begin{tabular}{|c|c|} 
C.3. & \\
Cuenta de & $\overrightarrow{\mathrm{N}}$ \\
generación de & $\vdots$ \\
renta & $\vec{v}$ \\
(Factores) & \\
\end{tabular} & & $\begin{array}{c}\text { VALOR } \\
\text { AÑADIDO } \\
\text { BRUTO } \\
47003587\end{array}$ & & & & & \begin{tabular}{|c|} 
Remuneración de \\
asalariados \\
procedente del \\
RDM \\
35448
\end{tabular} & 47039035 \\
\hline 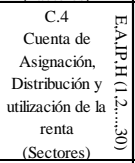 & $\begin{array}{c}\text { Impuestos netos } \\
\text { sobre los } \\
\text { productos } \\
\\
3141608\end{array}$ & & \begin{tabular}{c|} 
RENTA \\
GENERADA \\
BRUTA \\
\\
47037318
\end{tabular} & \begin{tabular}{|} 
Rentas de la propiedad, \\
Transferencias corrientes y \\
Ajustes por fondos de \\
pensiones
\end{tabular} & & & \begin{tabular}{|c|} 
Rentas de la \\
propiedad y \\
Transferencias \\
corrientes \\
procedentes del \\
RDM \\
1631199 \\
\end{tabular} & 51810125 \\
\hline 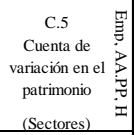 & & & & \begin{tabular}{r|} 
AHORRO BRUTO \\
\\
10867710 \\
\end{tabular} & $\begin{array}{c}\text { Transferencias de } \\
\text { capital }\end{array}$ & & 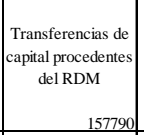 & 11025500 \\
\hline 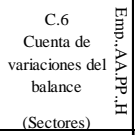 & & & & & \begin{tabular}{|} 
VARIACION EN \\
EL \\
PATRIMONIO \\
\\
11008328 \\
\end{tabular} & $\begin{array}{c}\text { Adquisición neta } \\
\text { de activos no } \\
\text { financieros no } \\
\text { producidos }\end{array}$ & \begin{tabular}{|c|}
$\begin{array}{c}\text { Contracción neta } \\
\text { de pasivos }\end{array}$ \\
23373484 \\
\end{tabular} & 34381812 \\
\hline $\begin{array}{c}\text { C.7 } \\
\text { Cuenta del } \\
\text { resto del mundo }\end{array}$ & $\begin{array}{c}\text { Importaciones de } \\
\text { bienes y } \\
\text { servicios }\end{array}$ & & \begin{tabular}{|c} 
Remuneración de \\
asalariados \\
pagada al RDM
\end{tabular} & $\begin{array}{l}\text { Rentas de la propiedad y } \\
\text { Transferencias corrientes } \\
\text { pagadas al RDM }\end{array}$ & $\begin{array}{c}\text { Transferencias de } \\
\text { capital pagadas al } \\
\text { RDM }\end{array}$ & $\begin{array}{l}\text { Adquisición neta } \\
\text { de activos } \\
\text { financieros }\end{array}$ & & \\
\hline & 10250660 & & 1717 & 1824409 & 17172 & 21659100 & & 33753058 \\
\hline Total & 99353797 & 85961529 & 47039035 & 51810125 & 11025500 & 34381812 & 33753058 & \\
\hline
\end{tabular}

Fuente: Elaborado a partir de INE (1995b).

La cuenta de bienes y servicios ${ }^{27}$ (C.1) muestra el equilibrio entre el origen y el destino de los bienes y servicios desglosados por tipos de productos. En recursos (fila 
1) figuran la producción a precios de salida de fábrica, los márgenes de distribución, los impuestos netos ligados a la importación, el IVA ${ }^{28}$ y las importaciones de bienes y servicios. En empleos (columna 1) están recogidos el consumo intermedio, el consumo final, la formación bruta de capital y las exportaciones valorados, todos ellos, a precios de mercado.

La cuenta de producción, o cuenta de actividades (C.2) muestra la creación de valor añadido por ramas de actividad. En recursos figuran la producción a precios de salida de fábrica y en empleos, el consumo intermedio y el valor añadido bruto a precios de mercado generado por cada una de las actividades económicas distinguidas en la matriz de contabilidad social.

La cuenta de generación de renta, o cuenta de factores (C.3) muestra cómo se canaliza la renta que los factores han obtenido por su contribución en el proceso productivo hacia las unidades institucionales propietarias de dichos factores. Como recursos de esta cuenta se registran la renta de las distintas categorías de trabajo, el excedente de explotación de las unidades institucionales productoras, las rentas mixtas y los impuestos netos ligados a la producción distintos del IVA. Sus empleos son la renta generada bruta de las distintas unidades institucionales residentes y la remuneración de asalariados pagada al resto del mundo.

La cuenta de asignación, distribución y utilización de la renta, o cuenta corriente de las unidades institucionales (C.4) registra, como recursos, las rentas primarias y secundarias percibidas por las distintas unidades institucionales y, como empleos, las rentas de la propiedad pagadas por cada una de ellas y el uso que hacen de su renta

\footnotetext{
${ }^{27}$ La finalidad de elaborar una cuenta de bienes y servicios y otra de actividades es obtener una valoración de las operaciones de bienes y servicios a precios de mercado y de la producción a precios de salida de fábrica (Pyatt, 1985, Keuning y Ruijter, 1988).

${ }^{28}$ El SEC distingue dos tipos de impuestos netos de subvenciones ligados a la producción, los referidos a los productos, que registra en la cuenta de bienes y servicios, y otros impuestos que gravan la producción que registra en la cuenta de producción. Debido a que sólo disponemos de datos desagregados por categorías de productos para el IVA, el resto de impuestos netos sobre los productos los hemos registrado junto con los otros impuestos netos ligados a la producción.
} 
para satisfacer sus necesidades de consumo final, para transferirla a otras unidades o para ahorrarla en previsión de necesidades futuras.

La cuenta de variación del patrimonio, o de la riqueza (C.5) muestra la variación del saldo patrimonial o acumulación de las distintas unidades institucionales como resultado de sus operaciones corrientes (ahorro) y de las posibles transferencias de capital. En tanto que la cuenta de variaciones del balance (C.6) describe las alteraciones en la estructura del patrimonio debidas al intercambio de activos reales y financieros entre las distintas unidades institucionales.

La cuenta del resto del mundo (C.7) agrupa las operaciones de todas las cuentas anteriores en las que intervienen una unidad residente y otra no residente, y las registra como recurso o empleo según supongan un ingreso o un gasto para la unidad no residente.

Por último, la fila y la columna de totales carecen de significado económico y su única finalidad es poner de manifiesto el equilibrio entre los recursos y los empleos totales de cada una de las cuentas recogidas en la MCSE-90.

Las cifras que figuran en el cuadro 3.1 están tomadas de la Contabilidad Nacional de España de 1990 (INE, 1995a y 1995b). La información desagregada que por sectores institucionales ofrece la CNE90 constituye asimismo el punto de partida para la elaboración de las cuentas de los sectores, en tanto que la Tabla Input-Output (INE, 1995a y 1995b) proporciona una parte importante de la información recogida por las cuentas de bienes y servicios y de producción. Sobre la actividad de los hogares, cuyo análisis constituye uno de los objetivos prioritarios de las matrices de contabilidad social, la fuente de información estadística más detallada es la Encuesta de Presupuestos Familiares 1990-1991 (INE, 1992c).

El que los objetivos básicos de la EPF90-91 sean, por un lado, la actualización de los bienes y servicios que integran "la cesta de la compra" y sus ponderaciones y, por otro, la estimación del consumo privado por funciones, la convierte en la fuente estadística con la información más completa sobre los gastos de consumo de los hoga- 
res (920 rúbricas y 21.155 hogares). La EPF también contiene información detallada sobre la estructura de otros gastos de los hogares, sobre sus ingresos y los de cada uno de sus miembros clasificados según su origen y naturaleza, y sobre sus características geográficas, familiares, económicas, sociales, culturales, de equipamiento, etc. La versatilidad de la EPF para seleccionar los criterios de clasificación de los hogares y para desglosar sus fuentes de renta justifica su preferencia frente a otras fuentes alternativas, como las estadísticas tributarias, de salarios o de protección social que, pese a su mayor fiabilidad al derivarse de registros administrativos, tienen una cobertura más parcial o emplean criterios de clasificación más rígidos.

La coherencia y consistencia entre las informaciones suministradas por la Contabilidad Nacional y la Tabla Input-Output las convierte en el vértice jerárquico de las fuentes estadísticas, en el sentido de que las utilizamos como punto de referencia para integrar contable y conceptualmente la información procedente de la Encuesta de Presupuestos Familiares y del resto de fuentes que puntualmente son requeridas en la elaboración de la MCSE-90.

El concepto de renta empleado por la EPF es el de renta neta, la que resulta de deducir el pago de impuestos, cotizaciones sociales y otros pagos de naturaleza similar. Respecto al consumo, la EPF sigue la definición establecida por Eurostat en su clasificación de los gastos de consumo final de los hogares por funciones (PROCOME) que, aunque no coincide plenamente con la de la $\mathrm{CNE}^{29}$, es lo suficientemente desagregada para permitir su armonización. Otras diferencias metodológicas entre la EPF y la CNE están relacionadas con el ámbito espacial y la referencia temporal. En cuanto al ámbito espacial, mientras que la EPF sólo recaba información sobre los residentes en hogares privados, la CNE incluye dentro del sector hogares a la población residente, a las unidades residentes ficticias y a las instituciones privadas sin fines de lucro y, además, para los gastos de consumo final en algunos casos agrega hogares residentes y no residentes. Con respecto a la referencia temporal, mientras que

\footnotetext{
${ }^{29}$ Algunos de los gastos recogidos por la EPF90-91 dentro del grupo 9 de gasto son tratados como transferencias corrientes en la Contabilidad Nacional de España.
} 
toda la información de la CNE está referida al año natural de 1990, en el caso de la Encuesta los hogares fueron entrevistados a lo largo del periodo comprendido entre abril de 1990 y marzo de 1991, registrándose los ingresos de los doce meses anteriores a la fecha de la entrevista y los gastos de un periodo previo que varía con el tipo de gasto considerado. Para la conversión de estos últimos a gastos anuales emplea coeficientes de elevación temporal.

El problema genérico a la hora de elaborar una matriz de contabilidad social consiste en encontrar información lo suficientemente detallada para los distintos grupos de unidades consideradas en su diseño. Los problemas aumentan en el caso de las submatrices que no están situadas sobre la diagonal principal ya que, al registrar flujos que suponen simultáneamente un recurso y un empleo de cuentas diferentes, que por su distinta finalidad pueden emplear clasificaciones e incluso unidades distintas, son necesarias una serie de correspondencias que no siempre son explícitas cuando la información proviene de varias fuentes. De ahí la conveniencia de evaluar la utilidad y viabilidad de las distintas clasificaciones y fuentes estadísticas en el momento de diseñar la desagregación de cada una de las cuentas. 


\subsection{ClasifiCACIÓN DE LAS UNIDADES EN LA MCSE-90}

Aunque las matrices de contabilidad social se caracterizan por su flexibilidad, el SCN93 (párrafo 20.69) señala los siguientes criterios generales para clasificar las unidades en las distintas cuentas que las conforman: a) homogeneidad de las categorías según los flujos a registrar en la cuenta; b) reconocimiento de los subgrupos y su relevancia para el análisis económico; c) estabilidad y mensurabilidad de las características de la clasificación; y d) necesidades estadísticas derivadas de la existencia de clasificaciones cruzadas.

En el caso concreto de una matriz de contabilidad social construida con fines no sólo descriptivos sino también analíticos, es aconsejable que exista cierto equilibrio entre el número de categorías de las cuentas que vayan a ser consideradas endógenas. En los siguientes epígrafes de este apartado analizaremos las clasificaciones de las unidades en las cuentas de bienes y servicios y de producción (3.2.1), de generación de renta primaria (3.2.2) y de asignación, distribución y utilización de la renta (3.2.3). El último de los epígrafes (3.2.4) está dedicado a las correspondencias entre las clasificaciones del consumo final por funciones y tipos de productos.

\subsubsection{Actividades económicas y productos}

En las distintas matrices de contabilidad social elaboradas en España, tanto de ámbito nacional como regional, el grado de desagregación de las clasificaciones de las ramas productivas y de los bienes y servicios es reducido, debido fundamentalmente a la escasez de información estadística y las dificultades para establecer las correspondencias entre las clasificaciones de los gastos de consumo de los hogares por categorías de productos y funciones de consumo. Sin embargo, el análisis de las interrelaciones entre la distribución funcional y personal de la renta, y entre esta última y el crecimiento económico, requieren clasificaciones más detalladas, tanto de la distribución 
de los salarios y del resto de rentas primarias, como de los patrones de consumo de los distintos tipos de hogares.

En principio consideramos que para elaborar la cuenta de bienes y servicios y la cuenta de producción de la matriz de contabilidad social de España, la clasificación R.56 de productos y actividades de la Tabla Input-Output de España de 1990 es idónea porque, por una lado, su utilización permite reducir las necesidades de información asociadas a la existencia de clasificaciones cruzadas de actividades y de productos en las submatrices de producción y de consumo intermedio y, por otro lado, su nivel de detalle se adecua perfectamente a las necesidades y características de la matriz que pretendemos construir. Sin embargo, la insuficiente información estadística para algunas de las ramas productivas de la clasificación R.56 no permite mantener el número de actividades y de productos que con ellas se identifican. En el cuadro 3.2 recogemos las correspondencias entre la clasificaciones de actividades y productos que utilizamos en la MCSE-90 con la clasificación R.56 de la TIO90 y la Clasificación Nacional de Actividades Económicas de 1974 (CNAE-74) a un dígito. En dicho cuadro puede comprobarse que, aunque hemos utilizado la misma clasificación para las actividades económicas que para los bienes y servicios, las ramas de comercio y de producción imputada de servicios bancarios no se corresponden con ninguna categoría de servicios, en la medida que los servicios comerciales están incorporados en el valor de los bienes agrarios e industriales que se adquieren en el mercado y todos los servicios bancarios en los servicios financieros y de seguros (P.38). 
CUADRO 3.2. Clasificaciones de los productos y las actividades económicas

\begin{tabular}{|c|c|c|c|c|c|}
\hline \multirow{2}{*}{ Descripción } & \multicolumn{5}{|c|}{ Códigos } \\
\hline & \multicolumn{2}{|c|}{ MCSE-90 } & TIO 90 & R.56 & CNAE-74 \\
\hline Productos de la agricultura, silvicultura y pesca & R.1 & P.1 & 1 & 10 & 00 \\
\hline Hulla y aglomerados de hulla, lignito y productos de la coquefacción & R.2 & P.2 & $2,3,4$ & $31,33,50$ & 10 \\
\hline Petróleo bruto. & R.3 & P.3 & 5 & 71 & 10 \\
\hline Productos petrolíferos refinados. & R.4 & P.4 & 6 & 73 & 10 \\
\hline Gas natural. & R.5 & P.5 & 7 & 75 & 10 \\
\hline Agua (captación, depuración, distribución), vapor, agua caliente, etc. & R.6 & P.6 & 8 & 96 & 10 \\
\hline Energía eléctrica. & R.7 & P.7 & 9 & 97 & 10 \\
\hline Gas manufacturado. & R.8 & P.8 & 10 & 98 & 10 \\
\hline Combustibles nucleares. & R.9 & P.9 & 11 & 110 & 10 \\
\hline Minerales de hierro y productos siderúrgicos. & R.10 & P.10 & 12 & 134 & 20 \\
\hline Minerales no férreos; metales no férreos. & R.11 & P.11 & 13 & 137 & 20 \\
\hline Cemento, vidrio, tierra cocida, prod. cerámicos y otr.min.no metal. & R.12 & P.12 & $\begin{array}{l}14,15 \\
16,17\end{array}$ & $\begin{array}{l}151,153 \\
155,157\end{array}$ & 20 \\
\hline Productos químicos. & R.13 & P.13 & 18 & 170 & 20 \\
\hline Productos metálicos. & R.14 & P.14 & 19 & 190 & 30 \\
\hline Máquinas agrícolas e industriales. & R.15 & P.15 & 20 & 210 & 30 \\
\hline Máquinas de oficina y tratamiento de la información. & R.16 & P.16 & 21 & 230 & 30 \\
\hline Material eléctrico. & R.17 & P.17 & 22 & 250 & 30 \\
\hline Vehículos automóviles y motores. & R.18 & P.18 & 23 & 270 & 30 \\
\hline Otros medios de transporte. & R.19 & P.19 & 24 & 290 & 30 \\
\hline Carnes y conservas. & R.20 & P.20 & 25 & 310 & 40 \\
\hline Leche y productos lácteos. & R.21 & P.21 & 26 & 330 & 40 \\
\hline Otros alimentos. & R.22 & P. 22 & 27 & 350 & 40 \\
\hline Bebidas. & R.23 & P.23 & 28 & 370 & 40 \\
\hline Tabacos. & R.24 & P.24 & 29 & 390 & 40 \\
\hline Productos textiles: vestido. & R.25 & P. 25 & 30 & 410 & 40 \\
\hline Cuero, artículos en piel y cuero, calzado. & R.26 & P. 26 & 31 & 430 & 40 \\
\hline Madera y muebles de madera. & R.27 & P.27 & 32 & 450 & 40 \\
\hline Pastas de papel, papel, cartón y artículos de papel e impresión. & R.28 & P. 28 & 33,34 & 471,473 & 40 \\
\hline Productos de caucho y plástico. & R.29 & P.29 & 35 & 490 & 40 \\
\hline Productos de otras industrias manufactureras. & R.30 & P. 30 & 36 & 510 & 40 \\
\hline Construcción & R.31 & P.31 & 37 & 530 & 50 \\
\hline Recuperación y reparación. & R.32 & P.32 & 38 & 550 & 60 \\
\hline Comercio. & R.33 & & 39 & 570 & 60 \\
\hline Restaurantes y alojamientos. & R.34 & P.34 & 40 & 590 & 60 \\
\hline Transporte terrestre, aéreo y marítimo. & R.35 & P. 35 & $\begin{array}{l}41,42 \\
43,44\end{array}$ & $\begin{array}{l}611,613 \\
631,633\end{array}$ & 70 \\
\hline Servicios anexos a los transportes. & R.36 & P.36 & 45 & 650 & 70 \\
\hline Comunicaciones. & R.37 & P.37 & 46 & 670 & 70 \\
\hline Créditos y seguros. & R.38 & P.38 & 47 & 690 & 80 \\
\hline Producción imputada de servicios bancarios. & R.39 & & 48 & & 80 \\
\hline Servicios prestados a las empresas. & R.40 & P. 40 & 49 & 710 & 80 \\
\hline Alquiler inmobiliario. & R.41 & P. 41 & 50 & 730 & 80 \\
\hline Investigación y enseñanza destinada a la venta. & R.42 & P. 42 & 51 & 750 & 90 \\
\hline Sanidad destinada a la venta. & R.43 & P.43 & 52 & 770 & 90 \\
\hline Servicios destinados a la venta n.c.o.p. & R.44 & P.44 & 53 & 790 & 90 \\
\hline Servicios generales de las Administraciones Públicas. & R.45 & P.45 & 54 & 810 & 90 \\
\hline Investigación y enseñanza no destinada a la venta. & R.46 & P.46 & 55 & 850 & 90 \\
\hline Sanidad no destinada a la venta. & R.47 & P.47 & 56 & 890 & 90 \\
\hline Servicios no destinados a la venta n.c.o.p. & R.48 & P.48 & 57 & 930 & 90 \\
\hline
\end{tabular}

Fuente: Elaborado a partir de INE (1995a). 


\subsubsection{Los factores de producción}

En una tabla input-output, las operaciones que reflejan la contribución de los distintos factores al proceso productivo se registran a modo de cuenta de explotación, en la que las rentas factoriales se contemplan como costes de producción de las actividades económicas. Sin embargo, en las matrices de contabilidad social dichas operaciones están asociadas a las cuentas de distribución de la renta; la renta fluye de las actividades hacia los factores productivos, de éstos hacia las unidades institucionales propietarias de los mismos que son las que finalmente obtienen satisfacciones por el uso de dicha renta. En una matriz de contabilidad social, por tanto, la cuenta de los factores productivos se concibe como el nexo de unión entre las cuentas de las unidades productoras en las que se genera la renta (TIO) y las cuentas de las unidades institucionales que hacen uso final de la misma (cuentas de sectores de la $\mathrm{CN}$ ).

Los cuatro grandes componentes entre los que se reparte el valor añadido son la remuneración de asalariados, el excedente bruto de explotación, las renta mixtas y los impuestos sobre la producción netos de subvenciones.

Aunque la desagregación de las rentas mixtas y del excedente bruto de explotación resulta de gran interés para el estudio tanto de los aspectos relacionados con la productividad como de algunas cuestiones básicas para el análisis de la distribución primaria de la renta (UN y otros 1993, párrafo 20.78), en la práctica dicha división difícilmente puede llevarse a cabo debido a las lagunas de información estadística. Por el momento, la información disponible en nuestro país no permite desagregar el excedente de explotación en función de los tipos de activos que generan las rentas primarias de cada uno de los sectores institucionales -empresas, AA.PP, IPSFL (instituciones privadas sin fines de lucro) y hogares-, por lo que hemos considerado una única categoría de excedente de explotación para cada sector institucional, con la excepción de los hogares productores de servicios de alquiler para los que hemos distinguido las categorías de alquileres reales y de alquileres imputados a los ocupantes de vivienda propia. En el caso de las rentas mixtas, dado que ni siquiera es posible separar las ren- 
tas del trabajo y del capital, al pertenecer ambos factores al mismo hogar y no poder determinarse sus respectivas remuneraciones de mercado, difícilmente cabe pensar en una desagregación de sus componentes, por lo que hemos considerado una única categoría de rentas mixtas. Por lo que respecta a los impuestos que gravan la producción excluido el IVA, aunque pueden considerarse diversas categorías en función del hecho gravado, en la medida en que su fijación obedece en demasiadas ocasiones más a razones de oportunidad que de mercado, también hemos optado por mantenerlos agregados.

Las rentas del trabajo por cuenta ajena se registran como una transacción entre el empleador (rama de actividad) y el empleado, y entre este último y el hogar al que pertenece (unidad institucional). La distinción entre los hogares y sus miembros es un ejercicio similar al de separar los establecimientos de la unidad institucional a la que pertenecen; en ambos casos la unidad menor es más homogénea y autónoma con respecto a la actividad económica en la que participa (UN y otros, 1993, párrafos 20.50 y 20.51). La utilización en una matriz de contabilidad social de la población ocupada, asalariados y trabajadores por cuenta propia, permite integrar el análisis del mercado de trabajo en el Sistema de Cuentas Nacionales y proporciona continuidad al análisis de las relaciones entre la estructura de la producción y la distribución factorial de la renta, y entre esta última y la distribución personal de la renta, superando el planteamiento simplista que identifica la eficiencia con el mercado y la equidad con el Estado (Caricchia, Batellini y Coli, 1997, Dagum, 1999), al considerar conjuntamente la influencia de ambas instituciones sobre los incentivos, el crecimiento y la distribución de la renta.

El SCN93 (UN y otros, 1993, párrafo 20.76), propone clasificar la población empleada a partir de una combinación de variables como género, edad, educación o lugar de residencia, por un lado, y ocupación, tipo de contrato y actividad, por otro, y diferencia hasta 18 categorías de factor trabajo en la submatriz detallada de valor añadido que recoge a modo de propuesta (Tabla 20.6, p.480). Las matrices de contabilidad social elaboradas para los países en desarrollo suelen distinguir entre trabajadores rura- 
les y urbanos, y en un segundo nivel entre trabajadores del sector público y privado, o con distinto nivel de estudios (Pyatt y Rounnd, 1985; Skountzos, 1988; Adelman y otros, 1991; Khorshid, 1991, entre otros). Sin embargo, en el caso de las economías más desarrolladas los criterios utilizados son muy heterogéneos ${ }^{30}$. Así, por ejemplo, Bottiroli y Targetti (1988) para Italia y Cohen y Tuyl (1991) para Holanda ni siquiera desagregan la población asalariada; para EE.UU Reinert y Roland-Holst (1992) clasifican los asalariados de acuerdo con su condición socioeconómica, mientras que para los Paises Bajos, Graafland, y Mooij (1998) y Reininga (2000), utilizan la cualificación o el nivel de estudios. Por lo que respecta a las matrices elaboradas para España, Kehoe y otros (1988) tan sólo distinguen entre asalariados cualificados -con titulación media o superior- y no cualificados, en tanto que Uriel y otros (1997) consideran cuatro grupos según su nivel de estudios, si bien emplean otras variables como el sexo o la dedicación a tiempo completo o parcial -menos de13 horas semanales- para asignar las rentas del factor trabajo a los distintos grupos de hogares.

En este trabajo el criterio que utilizamos para clasificar la población asalariada es su categoría o condición socioeconómica, por ser ésta "una variable que clasifica a los encuestados en grupos de población razonablemente homogéneos en cuanto a las características sociales, económicas y culturales” (INE, 1990b, p.4). Dicho criterio se basa en la metodología de la Encuesta de Población Activa (INE, 1990b), que coincide con la empleada por la EPF90-91 para definir la categoría socioeconómica de los sustentadores principales y que combina las variables ocupación, rama de actividad y situación profesional. Para la primera de las variables el INE utiliza la Clasificación Nacional de Ocupaciones de 1979 a dos dígitos, para la segunda emplea la Clasificación Nacional de Actividades Económicas de 1974, a dos dígitos para la rama agraria y a uno para el resto de actividades y, por último, para la variable situación profesional distingue entre empleador, empresario sin asalariados o trabajador independiente, miembro de una cooperativa, ayuda familiar, asalariado del sector público, asalariado

\footnotetext{
${ }^{30}$ Rowlatt y otros (2000) elaboran una propuesta de cuentas para el factor trabajo en el marco de las matrices de contabilidad social. Este estudio se encuadra dentro del programa de trabajo de Leadership Group on Social Accounting Matrix, que está conformado por representantes de Bélgica, Finlandia, Grecia, Italia, Países Bajos, Noruega, Portugal y Reino Unido.
} 
del sector privado y otros. El resultado de combinar la ocupación, situación profesional y rama de actividad de los trabajadores son 19 categorías socioeconómicas, que a efectos de este trabajo hemos reducido a algo menos de la mitad, tal y como recoge el cuadro 3.3.

CUADRO 3.3. Categorías socioeconómicas

\begin{tabular}{|c|c|}
\hline CATEGORÍA SOCIOECONÓMICA (INE) & CATEGORÍA SOCIOECONÓMICA (MCSE-90) \\
\hline $\begin{array}{ll}1 & \text { Empresarios agrarios con asalariados. } \\
2 & \text { Empresarios agrarios sin asalariados. } \\
4 & \text { Directores y jefes de empresas o explotaciones agrarias. } \\
\end{array}$ & 1 Empresarios y directivos agrarios. \\
\hline $\begin{array}{l}3 \text { Miembros de cooperativas agrarias. } \\
5 \text { Resto de trabajadores agrarios. }\end{array}$ & 2 Resto de trabajadores y miembros de cooperativas agrarias. \\
\hline $\begin{array}{ll}6 & \text { Profesionales, técnicos y asimilados, por cuenta propia } \\
7 & \text { Empresarios no agrarios con asalariados. } \\
8 & \text { Empresarios no agrarios sin asalariados. } \\
\end{array}$ & $\begin{array}{l}3 \text { Empresarios, profesionales y trabajadores independientes no } \\
\text { agrarios. }\end{array}$ \\
\hline $\begin{array}{l}10 \text { Directores de empresas no agrarias y altos funcionarios. } \\
11 \text { Profesionales, técnicos y asimilados por cuenta ajena. } \\
12 \text { Jefe de departamentos administrativos, comerciales o de servicios. }\end{array}$ & 4 Directores, profesionales y jefes administrativos por cuenta ajena. \\
\hline $\begin{array}{l}13 \text { Resto del personal administrativo y comercial. } \\
14 \text { Resto del personal de los servicios. } \\
18 \text { Profesionales de las fuerzas armadas. }\end{array}$ & $\begin{array}{l}5 \text { Resto de personal de servicios y profesionales de las fuerzas } \\
\text { armadas. }\end{array}$ \\
\hline $\begin{array}{l}9 \text { Miembros de cooperativas no agrarias. } \\
15 \text { Contramaestres y capataces no agrarios. } \\
16 \text { Operarios cualificados y especializados no agrarios. }\end{array}$ & $\begin{array}{l}6 \text { Contramaestres, operarios cualificados y miembros de cooperativas } \\
\text { no agrarias. }\end{array}$ \\
\hline 17 Operarios sin especialización no agrarios. & 7 Operarios sin especialización no agrarios. \\
\hline 19 No clasificables por condición socioeconómica. & 8 No clasificables por condición socioeconómica. \\
\hline
\end{tabular}

Fuente: Elaborado a partir de INE (1990b).

Algunas variables aparentemente excluidas de los criterios de clasificación, como el carácter rural/urbano o el nivel de estudios, están implícitamente relacionadas con la rama de actividad y el tipo de ocupación, respectivamente. En el caso de la cualificación es cuando menos discutible si ésta se refleja mejor por la ocupación o por la titulación, máxime en un mundo como el actual en el que los requerimientos de formación sufren bruscas alteraciones. Por otra parte, variables como el lugar de residencia, el género o el tipo de relación contractual, aunque están disponibles en la EPF90-91, no las consideramos con el fin de evitar un tamaño excesivo de la matriz de remuneración de asalariados. 


\subsubsection{Las unidades institucionales}

El criterio institucional resulta el más adecuado para clasificar las unidades cuando se pretende analizar la distribución de la renta y su uso final, la actividad financiera y las variaciones patrimoniales. El SCN93 agrupa a las unidades institucionales residentes, de acuerdo con su función principal y el tipo de productor, en cinco grandes sectores -sociedades no financieras, instituciones financieras, AA.PP, hogares e instituciones privadas sin fines de lucro al servicio de los hogares-, y contempla diversos criterios de subsectorización para los cuatro primeros (UN y otros, 1993, pp. 66 y ss.).

Aunque recientemente se está avanzando bastante en la metodología para la elaboración de las cuentas del sector IPSFL (Programa Johns Hopkins de comparación internacional del sector instituciones privadas sin fines de lucro, en Archaumbault, 1997), la mayoría de las contabilidades nacionales, y entre ellas la nuestra, presentan sus actividades integradas con las del sector hogares. En la matriz de contabilidad social elaborada en este trabajo, debido a la carencia de información al respecto, hemos mantenido dicha agregación para las cuentas de acumulación (variación del patrimonio debida al ahorro y las transferencias de capital y variaciones del balance), lo que no supone una limitación importante por cuanto que en todas las aplicaciones que abordamos de la MCSE-90 ambas cuentas son consideradas exógenas. Para la cuenta de asignación, distribución y utilización de la renta, dado que uno de los principales objetivos del trabajo consiste precisamente en analizar los aspectos distributivos en el marco de las matrices de contabilidad social, no sólo estimamos por separado los flujos de las instituciones privadas sin fines de lucro y de los hogares, sino que también distinguimos diversos tipos de hogares.

Las principales dificultades para clasificar a los hogares se derivan del doble papel de consumidores y productores de algunos de ellos, de la gran diversidad de 
status socioeconómicos y de la heterogeneidad de miembros de un mismo hogar ${ }^{31}$. Dado que los criterios de clasificación al respecto pueden ser muy dispares y su elección condiciona las conclusiones que puedan extraerse sobre la desigualdad, es necesario establecer grupos de hogares que sean homogéneos y relevantes para el análisis. A este respecto, el SCN93 distingue entre hogares generadores de renta (productores de mercado y para uso final propio) y hogares perceptores de renta (consumidores) y, para estos últimos, considera los siguientes criterios de clasificación: a) principal fuente de renta del hogar (rentas del trabajo por cuenta propia, rentas del trabajo por cuenta ajena, rentas de la propiedad, prestaciones de jubilación y otras transferencias corrientes); b) características económicas y sociales del miembro de referencia del hogar, como pueden ser su ocupación, rama de actividad o cualificación; y c) rasgos característicos del hogar como conjunto de individuos, tales como la renta total, el tamaño del hogar o su localización geográfica.

El SCN93 propone, a su vez, clasificaciones diferentes de acuerdo con la variable que se emplee para analizar la desigualdad. Por un lado, para analizar la distribución personal de la renta primaria aconseja tener en cuenta la principal fuente de renta, la rama de actividad y, si es renta por cuenta ajena, la cualificación del trabajador, y para el análisis de la distribución de la renta disponible propone especificar, a mayores, las transferencias recibidas por jubilación, desempleo o invalidez. Por otro lado, para analizar la distribución de los gastos de consumo final sugiere criterios relacionados con el nivel de renta, la localización geográfica y la composición del hogar.

En la práctica, los criterios empleados para clasificar a los hogares están estrechamente relacionados con las disponibilidades estadísticas, las características del país o región y la finalidad para la que se elabora la matriz de contabilidad social. Así, por ejemplo, Bottiroli y Targetti (1988) clasifican los hogares italianos por su nivel de renta para estudiar el impacto de la demanda de consumo sobre la distribución de la renta, Cohen y Tuyl (1991) clasifican los hogares de los Países Bajos de acuerdo con

\footnotetext{
${ }^{31}$ Los flujos correspondientes a las unidades residentes ficticias - unidades no residentes que se consideran residentes en cuanto a propietarias de terrenos y edificios- por limitaciones de información los repartimos entre los hogares residentes.
} 
su tamaño para analizar los efectos del cambio demográfico sobre el crecimiento y la equidad, criterio que también se utiliza en el modelo MIMIC (Micro Macro Model to Analyse the Institutional Context ${ }^{32}$; Reininga, 2000). Yang y Huang (1997) clasifican a los hogares chinos en función de su localización (urbano-rural) y su nivel de renta, a efectos de evaluar el impacto de la liberalización del comercio exterior sobre la distribución de la renta. Criterios similares emplean Karadag y Westaway (1999) para la economía turca para predecir los efectos de alteraciones en la política fiscal a través de un modelo de equilibrio general computable.

En el caso de España, Kehoe, Manresa, Polo y Sancho (1988) consideran, en la SAM-80, los ocho grupos que resultan al combinar la edad del sustentador principal (< $25<65<$ ) con su nivel de ingresos (alto o bajo, según obtengan más o menos de un millón de pesetas, para los de edad comprendida entre los 25 y 65 años, o más o menos de setecientas mil para el resto) y su cualificación profesional (educación superior o no) para los comprendidos entre los 25 y 65 años. Uriel (1989) en la matriz de contabilidad social alternativa que elabora (SAM-80b) elimina la distinción entre trabajo cualificado y no cualificado al detectar ciertas inconsistencias en los datos empleados. Por último, en la MCS-90 elaborada por Uriel, Beneito, Ferri y Moltó (1997) se combinan dos criterios básicos de clasificación de los hogares, hábitat (municipio con más o menos de 10.000 habitantes) y principal fuente de ingresos (autónomos, asalariados y perceptores de otras rentas) con tres criterios complementarios, edad (mayor o menor de 65 años) aplicable tan sólo a hogares urbanos cuya principal fuente de ingreso son otras rentas, nivel de estudios (superiores y menos que superiores) para hogares urbanos que tienen en las rentas del trabajo por cuenta ajena su principal fuente de ingresos y sexo del sustentador principal para aquellos hogares que tienen en otras rentas su principal fuente de ingresos, para conformar doce grupos de hogares.

Con respecto a las matrices de contabilidad social elaboradas para regiones españolas, los hogares sólo están desagregados en Curbelo (1988) y Rubio (1995) por

\footnotetext{
${ }^{32}$ Modelo elaborado por The Netherlands Bureau for Economic Analysis, que fue fundado en 1945 por V. Tinbergen.
} 
quintiles y deciles de renta, respectivamente, mientras que Cardenete (1998) no desagrega el sector hogares y tanto De Miguel, Manresa y Ramajo (1998) como Llop y Manresa (1999) incluyen los hogares junto con las empresas en un único sector privado.

Mas allá de la literatura sobre matrices de contabilidad social, la clasificación de los hogares también constituye un objeto de especial atención en los trabajos dedicados al estudio de la desigualdad en España. Como muestra la revisión de la literatura realizada en Alvarez, Ayala, Iriondo, Martínez, Palacio y Ruiz-Huerta (1996), el nivel de estudios y la fuente de renta del sustentador principal, son las variables con mayor influencia sobre la posición que ocupan los hogares en la distribución de la renta, en tanto que la educación, el nivel de gasto y la estructura del hogar son las más significativas para explicar las diferencias en los patrones de consumo.

Teniendo en cuenta todo lo anteriormente expuesto y considerando tanto las necesidades derivadas de las clasificaciones cruzadas de la matriz de contabilidad social como las posibilidades que ofrece la EPF90-91, en este trabajo hemos optado por una clasificación de los hogares en treinta categorías que combinan el nivel de renta (quintiles ${ }^{33}$ ), la principal fuente de ingresos (trabajo por cuenta propia, trabajo por cuenta ajena, rentas de la propiedad, pensiones de jubilación y otras transferencias) y, en el caso de que la principal fuente de ingresos sean las rentas del trabajo por cuenta ajena, el nivel de estudios (superiores o no) ${ }^{34}$.

\footnotetext{
33 Para clasificar a los hogares por quintiles de renta utilizamos la escala de equivalencia de la OCDE que pondera el primer miembro del hogar con la unidad, y el resto con 0,7 y 0,5 según tengan o no más de 14 años.

34 La principal fuente de ingresos no siempre coincide con la del sustentador principal, de ahí que no consideremos las características socioeconómicas del sustentador principal como un criterio de clasificación básico. Como señalan Keuning and Ruijter (1988), una matriz de contabilidad social debe reflejar la posible existencia de varios miembros perceptores de renta en un mismo hogar.
} 
CUADRO 3.4. Clasificación de los hogares

\begin{tabular}{|c|c|c|c|c|c|c|}
\hline \multirow{4}{*}{$\begin{array}{c}\text { Nivel de } \\
\text { renta }\end{array}$} & \multicolumn{6}{|c|}{ Principal fuente de renta } \\
\hline & \multicolumn{3}{|c|}{ Trabajo } & \multirow{3}{*}{$\begin{array}{c}\text { Rentas } \\
\text { de la } \\
\text { propiedad }\end{array}$} & \multicolumn{2}{|c|}{ Transferencias } \\
\hline & \multirow{2}{*}{$\begin{array}{l}\text { Cuenta } \\
\text { propia }\end{array}$} & \multicolumn{2}{|c|}{ Cuenta ajena } & & \multirow[b]{2}{*}{ Pensiones } & \multirow[b]{2}{*}{ Otras } \\
\hline & & $\begin{array}{c}\text { No } \\
\text { cualificado }\end{array}$ & Cualificado & & & \\
\hline Bajo & H1 & $\mathrm{H} 2$ & H3 & $\mathrm{H} 4$ & H5 & H6 \\
\hline Medio bajo & H7 & H8 & H9 & H10 & H11 & H12 \\
\hline Medio & H13 & H14 & H15 & H16 & H17 & H18 \\
\hline Medio alto & H19 & $\mathrm{H} 20$ & $\mathrm{H} 21$ & H22 & $\mathrm{H} 23$ & H24 \\
\hline Alto & H25 & H26 & H27 & $\mathrm{H} 28$ & H29 & H30 \\
\hline
\end{tabular}

\subsubsection{Correspondencias entre las clasificaciones del consumo por funciones (PROCOME) y por categorías de productos (R.56 de la TIO90)}

Las funciones de consumo agrupan bienes y servicios consumidos por los hogares de acuerdo con el tipo de necesidad que satisfacen e incluyen bienes y servicios complementarios -se utilizan conjuntamente para satisfacer una necesidad- y sustitutivos -pueden emplearse para cubrir una misma necesidad-. Por tanto, una función de consumo puede agrupar bienes y servicios producidos por diversas ramas de actividad.

Los nueve grupos de gasto recogidos en la EPF90-91 (1992b, Anexo I) están desglosados en subgrupos, clases, subclases y variedades, coincidiendo las subdivisiones por clases y variedades con la clasificación PROCOME del consumo final a tres y siete dígitos, respectivamente. Para desarrollar la tabla de correspondencias entre la clasificación PROCOME (7 dígitos) y la clasificación por productos (R.56 de la TIO90), necesaria para poder elaborar la submatriz de gastos de consumo final de la MCSE-90, utilizamos como punto de partida las correspondencias que figuran en la Contabilidad Nacional de España (INE, 1995a) entre la clasificación CNAE-74 (3 dígitos) y las clasificaciones PROCOME (3 dígitos) y R.56. 
Como puede comprobarse, son muchas las funciones de consumo PROCOME (3 dígitos) que incluyen bienes y servicios pertenecientes a varias categorías de productos de la R.56, razón por la que hemos recurrido a la Clasificación Nacional de Actividades Económicas de 1993 (CNAE-93), que incluye las correspondencias entre la nueva CNAE-93 (5 dígitos) y la antigua CNAE-74 (7 dígitos), y a la Clasificación Nacional de Productos por Actividades de 1996 (CNPA-96), que presenta un índice de la estructura completa de la CNPA-96 (8 dígitos) y sus correspondencias con la CNAE-93 (5 dígitos), para desarrollar las correspondencias anteriores hasta un nivel de 7 dígitos de la clasificación PROCOME.

En el anexo recogemos el programa SAS que hemos utilizado para clasificar las casi 900 rúbricas de gastos de consumo final de la EPF90-91 por categorías de productos homogéneos. El consumo de alimentos, bebidas y tabaco (PROCOME 1) incluye productos agrarios, carnes y pescados, leche y productos lácteos, otros alimentos, bebidas y tabaco (R.1, R.25 a R.29 de la TIO90 ${ }^{35}$ ) cuya distribución por categorías de productos al igual que la del consumo de vestido y calzado (PROCOME 2) no plantea mayores dificultades. Básicamente, este último comprende productos textiles (R.30), artículos de piel y cuero (R.31), calzado (R.31 y R.35, dependiendo de si el calzado es o no de cuero), alquileres de prendas y artículos de vestir (R.49), servicios de tintorería y lavandería (R.53) y de reparación de vestido y calzado (R.38).

En relación al consumo de vivienda, calefacción y alumbrado (PROCOME 3), son los gastos en vivienda, y más concretamente los gastos de reparación y conservación de la vivienda realizados por el inquilino (PROCOME 31013), los que plantean mayor dificultad. Cada una de las partidas incluidas en dicha subclase de gasto (31013) comprende pagos en concepto de materiales y mano de obra, por lo que cada una de ellas se corresponde con dos grupos de productos homogéneos de la clasificación R.56. Por ejemplo, los gastos de pintura de la vivienda comprenden la pintura que es un producto químico (R.18) y los trabajos de pintura, que son un servicio englobado

\footnotetext{
${ }^{35}$ Todas las ramas de actividad que figuran en este epígrafe se corresponden con la clasificación R.56 de la TIO90.
} 
en el sector de la construcción (R.37). El resto de gastos en vivienda, los alquileres brutos y la tasa de recogida de basuras y otras tasas se corresponden respectivamente con servicios de alquiler inmobiliario (R.50) y servicios destinados a la venta n.c.o.p. (R.53). Por último, los gastos de distribución de agua, con la categoría de agua vapor y agua caliente (R.8) y los gastos de calefacción y alumbrado, dependiendo del tipo de energía empleado, con energía eléctrica (R.9), productos petrolíferos refinados (R.6), gas natural (R.7), gas manufacturado (R.10), hulla y aglomerados de la hulla (R.2) o con lignito y briquetas de lignito (R.3).

El consumo de muebles y artículos para el hogar (PROCOME 4) engloba bienes y servicios producidos por una amplia gama de unidades económicas que pertenecen a diferentes ramas de actividad, lo que dificulta considerablemente el establecimiento de las correspondencias entre las clasificaciones PROCOME y R.56. Así, los gastos en muebles y accesorios fijos, alfombras y otros revestimientos de suelos (PROCOME 4.1) incluyen partidas cuantitativamente importantes, como los gastos en muebles de terraza y jardín, en artículos de decoración o en muebles especiales para bebé, que pueden ser producidos por distintas ramas de actividad. El consumo de artículos textiles para el hogar, otros artículos de mobiliario y reparaciones (PROCOME 4.2), engloba artículos textiles (R.30), artículos de mobiliario (R.19 si se trata de artículos metálicos o R.35 en el caso de que sean de plástico o caucho) y servicios de recuperación y reparación (R.38). Para el consumo de aparatos de calefacción y electrodomésticos (PROCOME 4.3) es necesario diferenciar entre gastos de adquisición de bienes (R.22 o R.19 dependiendo de si son aparatos eléctricos o mecánicos) y gastos de reparación, estos últimos al incluir el coste de los accesorios y el de la reparación se corresponden con las categorías de material eléctrico (R.22) y de servicios de recuperación y reparación (R.38). Salvo en las partidas de artículos diversos para el hogar (PROCOME 45012.06 y 45022.01), la identificación del grupo de productos al que pertenecen los bienes y servicios comprendidos en el consumo de vajilla, cristalería y utensilios de menaje (PROCOME 4.4) y de bienes y servicios para la conservación de la vivienda (PROCOME 4.5) no plantea dificultad alguna. Por último, el consumo de 
servicios domésticos (PROCOME 4.6) se corresponde con los gastos realizados por los hogares en servicios no destinados a la venta n.c.o.p.(R.57).

A diferencia de la función de consumo anterior, casi todas las clases de gastos que integran el consumo de productos y servicios sanitarios se corresponden con una única categoría de productos de la clasificación R.56. El consumo de servicios sanitarios (PROCOME 5.3 y 5.4) con la categoría de servicios sanitarios destinados a la venta (R.52) y la mayor parte del consumo de medicamentos y otros productos farmacéuticos (PROCOME 5.1) y de aparatos y material terapéutico (PROCOME 5.2) con las de productos químicos (R.18) y máquinas de oficina (R.21), respectivamente. Los gastos en otros productos farmacéuticos (PROCOME 51012.01 a 51012.03) al ser de muy diversa naturaleza, se distribuyen entre las categorías de productos químicos (R.18), máquinas de oficina (R.21), productos textiles (R.30), artículos de papel (R.34) y productos de caucho y plástico (R.35); análogamente, las compras de otros aparatos y material terapéutico (PROCOME 52011.07 y 52011.08) incluyen bienes pertenecientes a los grupos de máquinas de oficina (R.21), material eléctrico (R.22) y otros medios de transporte (R.24). Por último, en la cuota familiar de seguro médico (PROCOME 5.5) hay que diferenciar entre la parte de la cuota que sirve para remunerar los servicios prestados por la compañía aseguradora, que es consumo de servicios de seguro (R.47) y la que sirve para cubrir las prestaciones sanitarias por accidente o enfermedad, que se contabiliza como consumo de servicios sanitarios destinados a la venta (R.52).

El consumo de transporte y comunicaciones (PROCOME 6) comprende gastos de adquisición de automóviles (R.23) y de otros vehículos para transporte personal (R.24); gastos de utilización de vehículos, neumáticos (R.35), baterías y acumuladores (R.22), motores y carburadores (R.23), carburantes (R.6), autoescuelas (R.51), garajes (R.50), parking y peaje (R.45) y alquiler de vehículos sin conductor (R.49); gastos en servicios de transporte (R.41) y gastos en servicios de correos y comunicaciones (R.46). Esta función de consumo también incluye gastos de reparación y mantenimiento de vehículos para el transporte personal (PROCOME 61012), que se corresponden 
con las categorías de servicios de recuperación y reparación (R.38) y aquella a la que pertenezcan los materiales y accesorios empleados en la reparación.

La función de consumo de esparcimiento, espectáculos, enseñanza y cultura se caracteriza por la enorme diversidad de los bienes y servicios que en ella están comprendidos: artículos recreativos (aparatos de radio, televisores, videos, aparatos de reproducción y grabación, discos, cintas y accesorios, artículos y accesorios de deporte, juegos y juguetes, pequeños instrumentos musicales, aparatos y material fotográfico y cinematográfico, animales de compañía y su alimentación, y las reparaciones de los artículos recreativos), servicios recreativos (teatro, cine, conciertos, espectáculos deportivos y taurinos, salas de fiesta, entradas a instalaciones deportivas, entre otros), libros, diarios, periódicos y revistas, y enseñanza (material escolar, transporte escolar, matrículas, etc.). Por tanto, estamos ante una de las funciones de consumo que presentan mayor dificultad para desarrollar las correspondencias entre las variedades de gastos que la integran y la clasificación R.56. Además, un buen número de variedades de gasto incluyen bienes y servicios que pertenecen a dos o mas categorías de productos de la R.56, lo que aumenta la complejidad del proceso.

En último lugar, dentro de la función de consumo de otros bienes y servicios (PROCOME 8) hay que diferenciar entre el consumo de bienes y el consumo de servicios. Los gastos en servicios se clasifican en gastos de peluquería, belleza y similares (R.53), restaurantes, cafés y hoteles (R.40), viajes turísticos, todo incluido (R.45), servicios financieros (R.47) y otros servicios no declarados en otra parte (R.49, R.53 y R.57). En tanto que para el consumo de bienes las correspondencias ya no son tan claras al tener muchas de las partidas denominaciones muy genéricas que abarcan gran cantidad de artículos.

El cuadro 3.5 recoge un resumen de las correspondencias entre las clasificaciones PROCOME, R.56 de la TIO90 y la clasificación de productos que empleamos en la MCSE-90. 
CUADRO 3.5. Correspondencias entre las clasificaciones de los gastos de consumo final

(PROCOME-R.56)

\begin{tabular}{|c|c|c|c|c|c|c|c|c|c|}
\hline \multicolumn{2}{|c|}{ Productos } & \multicolumn{8}{|c|}{ Funciones de consumo PROCOME } \\
\hline & & F.1 & F. 2 & F 3 & F 4 & F 5 & F 6 & F 7 & F 8 \\
\hline R.56 TIO90 & MCSE-90 & $1,2, \ldots, 265$ & $1,2, \ldots, 95$ & $1,2, \ldots, 107$ & $1,2, \ldots, 114$ & $1,2, \ldots, 41$ & $1,2, \ldots, 54$ & $1,2, \ldots, 145$ & $1,2, \ldots, 73$ \\
\hline R.1 & P.1 & $\mathrm{xxx}$ & 0 & $\mathrm{xxx}$ & 0 & 0 & 0 & $\mathrm{xxx}$ & 0 \\
\hline R.2 a R.4 & P.2 & 0 & 0 & $\mathrm{xxx}$ & 0 & 0 & 0 & 0 & 0 \\
\hline R.5 & P.3 & 0 & 0 & 0 & 0 & 0 & 0 & 0 & 0 \\
\hline R.6 & P.4 & 0 & 0 & $\mathrm{xxx}$ & 0 & 0 & $\mathrm{xxx}$ & 0 & 0 \\
\hline R.7 & P.5 & 0 & 0 & $\mathrm{xxx}$ & 0 & 0 & 0 & 0 & 0 \\
\hline R.8 & P.6 & 0 & 0 & $\mathrm{xxx}$ & 0 & 0 & 0 & 0 & 0 \\
\hline R.9 & P.7 & 0 & 0 & $\mathrm{xxx}$ & 0 & 0 & 0 & 0 & 0 \\
\hline R.10 & P. 8 & 0 & 0 & $\mathrm{xxx}$ & 0 & 0 & 0 & 0 & 0 \\
\hline R.11 & P.9 & 0 & 0 & 0 & 0 & 0 & 0 & 0 & 0 \\
\hline R.12 & P.10 & 0 & 0 & 0 & 0 & 0 & 0 & 0 & 0 \\
\hline R.13 & P.11 & 0 & 0 & 0 & 0 & 0 & 0 & 0 & 0 \\
\hline R.14 a R.17 & P.12 & 0 & 0 & $\mathrm{xxx}$ & $\mathrm{xxx}$ & 0 & 0 & 0 & 0 \\
\hline R.18 & P.13 & 0 & 0 & $\mathrm{xxx}$ & $\mathrm{xxx}$ & $\mathrm{xxx}$ & $\mathrm{xxx}$ & $\mathrm{xxx}$ & $\mathrm{xxx}$ \\
\hline R.19 & P.14 & 0 & 0 & 0 & $\mathrm{xxx}$ & 0 & 0 & $\mathrm{xxx}$ & $\mathrm{xxx}$ \\
\hline R.20 & P.15 & 0 & 0 & 0 & $\mathrm{xxx}$ & 0 & 0 & 0 & 0 \\
\hline R.21 & P.16 & 0 & 0 & 0 & $\mathrm{xxx}$ & $\mathrm{xxx}$ & 0 & $\mathrm{xxx}$ & $\mathrm{xxx}$ \\
\hline R.22 & P.17 & 0 & 0 & $\mathrm{xxx}$ & $\mathrm{xxx}$ & $\mathrm{xxx}$ & $\mathrm{xxx}$ & $\mathrm{xxx}$ & $\mathrm{xxx}$ \\
\hline R.23 & P.18 & 0 & 0 & 0 & 0 & 0 & $\mathrm{xxx}$ & 0 & 0 \\
\hline R.24 & P.19 & 0 & 0 & 0 & 0 & $\mathrm{xxx}$ & $\mathrm{xxx}$ & $\mathrm{xxx}$ & $\mathrm{xxx}$ \\
\hline R.25 & P. 20 & $\mathrm{xxx}$ & 0 & 0 & 0 & 0 & 0 & 0 & 0 \\
\hline R.26 & P.21 & $\mathrm{xxx}$ & 0 & 0 & 0 & 0 & 0 & 0 & 0 \\
\hline R.27 & P.22 & $\mathrm{xxx}$ & 0 & 0 & 0 & 0 & 0 & $\mathrm{xxx}$ & 0 \\
\hline R.28 & P.23 & $\mathrm{xxx}$ & 0 & 0 & 0 & 0 & 0 & 0 & 0 \\
\hline R.29 & P. 24 & $\mathrm{xxx}$ & 0 & 0 & 0 & 0 & 0 & 0 & 0 \\
\hline R.30 & P.25 & 0 & $\mathrm{xxx}$ & 0 & $\mathrm{xxx}$ & $\mathrm{xxx}$ & 0 & $\mathrm{xxx}$ & $\mathrm{xxx}$ \\
\hline R.31 & P.26 & 0 & $\mathrm{xxx}$ & 0 & 0 & 0 & 0 & 0 & $\mathrm{xxx}$ \\
\hline R.32 & P.27 & 0 & 0 & $\mathrm{xxx}$ & $\mathrm{xxx}$ & 0 & 0 & 0 & $\mathrm{XXX}$ \\
\hline R.33 y R.34 & P.28 & 0 & 0 & $\mathrm{xxx}$ & $\mathrm{xxx}$ & $\mathrm{xxx}$ & 0 & $\mathrm{xxx}$ & $\mathrm{xxx}$ \\
\hline R.35 & P.29 & 0 & $\mathrm{xxx}$ & 0 & $\mathrm{xxx}$ & 0 & $\mathrm{xxx}$ & $\mathrm{xxx}$ & $\mathrm{xxx}$ \\
\hline R.36 & P.30 & 0 & $\mathrm{xxx}$ & 0 & $\mathrm{xxx}$ & 0 & 0 & $\mathrm{xxx}$ & $\mathrm{xxx}$ \\
\hline R.37 & P.31 & 0 & 0 & $\mathrm{xxx}$ & 0 & 0 & 0 & 0 & 0 \\
\hline R.38 & P.32 & 0 & $\mathrm{xxx}$ & 0 & $\mathrm{xxx}$ & 0 & $\mathrm{xxx}$ & $\mathrm{xxx}$ & $\mathrm{xxx}$ \\
\hline R.39 & & 0 & 0 & 0 & 0 & 0 & 0 & 0 & 0 \\
\hline R.40 & P.34 & 0 & 0 & 0 & 0 & 0 & $\mathrm{xxx}$ & $\mathrm{xxx}$ & $\mathrm{xxx}$ \\
\hline R.41 a R.44 & P.35 & 0 & 0 & 0 & 0 & 0 & $\mathrm{xxx}$ & $\mathrm{xxx}$ & 0 \\
\hline R.45 & P.36 & 0 & 0 & 0 & 0 & 0 & $\mathrm{xxx}$ & 0 & $\mathrm{xxx}$ \\
\hline R.46 & P.37 & 0 & 0 & 0 & 0 & 0 & $\mathrm{xxx}$ & 0 & 0 \\
\hline R.47 & P.38 & 0 & 0 & 0 & 0 & $\mathrm{xxx}$ & 0 & $\mathrm{xxx}$ & $\mathrm{xxx}$ \\
\hline R.48 & & 0 & 0 & 0 & 0 & 0 & 0 & 0 & 0 \\
\hline R.49 & P. 40 & 0 & $\mathrm{xxx}$ & 0 & $\mathrm{xxx}$ & 0 & $\mathrm{xxx}$ & $\mathrm{xxx}$ & $\mathrm{xxx}$ \\
\hline R.50 & P.41 & 0 & 0 & $\mathrm{xxx}$ & 0 & 0 & $\mathrm{xxx}$ & 0 & 0 \\
\hline R.51 & P.42 & 0 & 0 & 0 & 0 & 0 & $\mathrm{xxx}$ & $\mathrm{xxx}$ & 0 \\
\hline R.52 & P.43 & 0 & 0 & 0 & 0 & $\mathrm{xxx}$ & 0 & 0 & 0 \\
\hline R.53 & P.44 & 0 & $\mathrm{xxx}$ & $\mathrm{xxx}$ & $\mathrm{xxx}$ & 0 & 0 & $\mathrm{xxx}$ & $\mathrm{xxx}$ \\
\hline R.54 & P.45 & 0 & 0 & 0 & 0 & 0 & 0 & 0 & 0 \\
\hline R.55 & P.46 & 0 & 0 & 0 & 0 & 0 & 0 & $\mathrm{xxx}$ & 0 \\
\hline R.56 & P.47 & 0 & 0 & 0 & 0 & 0 & 0 & 0 & 0 \\
\hline R.57 & P.48 & 0 & 0 & 0 & $\mathrm{xxx}$ & 0 & 0 & 0 & 0 \\
\hline
\end{tabular}

Fuente: Elaborado a partir de INE (1995a, 1993b y 1996b). 


\subsection{ESTIMACIÓN DE LA MCSE-90}

En este apartado describimos con detalle el proceso de obtención de las cifras desagregadas de la MCSE-90 cuyo esquema presentamos en el cuadro 3.1. Las zonas sombreadas que figuran en dicho esquema se corresponden con los distintos epígrafes de este apartado. La intensidad del sombreado de cada una de ellas refleja el grado de dificultad que ha supuesto su elaboración. En el primer epígrafe (zona gris claro) utilizamos la información que proporciona la TIO90 para estimar las operaciones relativas al propio proceso de producción y los márgenes de distribución que permiten ajustar las valoraciones de los empleos y recursos de la cuenta de bienes y servicios. En el segundo epígrafe (zona gris intermedio-claro) tratamos las operaciones que describen la distribución de la renta generada bruta por las distintas ramas de actividad entre los factores de producción que han contribuido a obtenerla, siendo necesario complementar la información de la TIO90 con la de la EPA90 y la EPF90-91 para estimar la distribución de las rentas salariales y del excedente de explotación. La asignación de la renta primaria de los factores a los sectores institucionales y su posterior redistribución (zona gris intermedio-oscuro), que tratamos en el tercero de los epígrafes, requiere determinar el origen y destino de cada uno de los flujos que figuran en las cuentas de renta que la CNE90 elabora para los sectores institucionales y desagregar por tipos de hogares los flujos de renta en los que participa el sector hogares, para esta última tarea utilizamos básicamente la EPF90-91. El epígrafe cuarto (zona gris oscuro) versa sobre las operaciones de utilización de la renta, cuya estimación para el sector hogares requiere cruzar la información de la EPF90-91 previamente ajustada a la CNE90 con los datos de la TIO90. Las operaciones de acumulación y financieras (zona sin sombrear) son tratadas en el último epígrafe. Cada uno de los epígrafes anteriores contiene, asimismo, las correspondientes operaciones con el resto del mundo. 


\subsubsection{Producción: actividades y productos}

La tabla input-output presenta integradas las ramas productivas y los productos, de modo que las operaciones que conforman las cuentas de bienes y servicios y de producción deben extraerse selectivamente de las tablas de consumos intermedios, inputs primarios y empleos finales. Hacer explícita la separación de las cuentas de los productos y de los productores requiere estimar, por una parte, una matriz de márgenes de distribución que registre para los productos agrarios e industriales el valor de los servicios comerciales y de transporte que incorporan cuando se suministran en el mercado y, por otra parte, una matriz que recoja la producción de bienes y servicios a precios de salida de fábrica por ramas de actividad y categorías de productos.

\subsubsection{Márgenes comerciales y de transporte}

En la TIO90 tanto la producción efectiva de las ramas como la producción distribuida de los distintos tipos de bienes y servicios están valoradas a precios de salida de fábrica, mientras que los empleos de los bienes y servicios lo están a precios de mercado. En el caso de los servicios, la diferencia entre los precios de mercado y de salida de fábrica viene dada por el IVA, mientras que para los bienes los precios de mercado incluyen, además del IVA, los márgenes asociados a su comercialización y transporte. Para valorar, por tanto, el output por tipos de productos a precios de mercado sin alterar la valoración de sus empleos, se añade a la cuenta de bienes y servicios una fila de márgenes de distribución que registra el valor de los servicios comerciales y de transporte incorporados en las distintas categorías de bienes (columnas P.1 a P.30), cuya suma se descuenta en la misma fila, concretamente en las columnas correspondientes a servicios comerciales (P.33) y servicios de transporte (P.35) ${ }^{36}$.

\footnotetext{
${ }^{36}$ Como en la clasificación de productos no figuran los servicios comerciales, los elementos registrados en la fila y columna P.33, que hemos incluido en la cuenta de bienes y servicios para registrar los márgenes comerciales, suman cero.
} 
A pesar de existir diversas estadísticas sobre las actividades de comercio y transporte (INE, 1995c, MOPTMA, 1993 e IETC, 1993), ninguna de ellas contiene información suficiente para valorar los márgenes comerciales y de transporte por grupos de productos. De ahí que hayamos optado por estimarlos a partir de los datos de la CNE90 y de la TIO90.

En el caso de los márgenes comerciales, como la rama de comercio de la TIO90 se corresponde con las actividades de comercio al por mayor, intermediarios de comercio y comercio al por menor de productos agrarios e industriales, excluidos el agua y la energía eléctrica (CNAE-74: 61, 63 y 64, respectivamente), el total de recursos de dicha rama (7.984.652 millones de pesetas) coincide con el total de márgenes comerciales incluidos en los bienes que se consumen en el territorio económico y se exportan al resto del mundo. La distribución de dichos márgenes entre consumo intermedio (20\%), consumo privado interior (71\%), formación bruta de capital (3\%) y exportaciones (6\%) viene dada por los empleos de la rama de comercio. El montante total de márgenes comerciales que figura en la submatriz 1.1 del cuadro A.1 del anexo estadístico, lo obtenemos sumando los márgenes comerciales de los bienes consumidos por los hogares residentes en el resto del mundo a los recursos de la rama de comercio $^{37}$.

Para los márgenes de transporte no es posible utilizar directamente la información de la TIO90 sobre las actividades de transporte (R.41 a R.44) al incluir conjuntamente los servicios de transporte de mercancías y de pasajeros. Los márgenes de transporte de los bienes destinados al consumo privado los calculamos como la diferencia entre el consumo privado interior de servicios de transporte que figura en la TIO90 (965.485 millones de pesetas) y los gastos de consumo de los hogares en servicios de

\footnotetext{
${ }^{37}$ Los márgenes comerciales de los bienes consumidos en el resto del mundo ascienden a 46.315 millones pts. y los incluidos en los productos consumidos por unidades no residentes en el territorio económico a $189.670 \mathrm{mi}-$ llones pts. Estos datos los hemos calculado a partir de la Tabla Input-Output de Turismo de 1992 publicada por la Secretaría General de Turismo (1995).
} 
transporte ofrecidos por la CNE90 (555.502 millones de pesetas) ${ }^{38}$. En tanto que el consumo público al incluir básicamente servicios carece de márgenes de transporte.

De acuerdo con la TIO90, las ramas de servicios que destinan parte de sus recursos a formación bruta de capital fijo son las de comercio, transportes, recuperación y reparación, servicios producidos por las empresas y otros servicios destinados a la venta. En este trabajo hemos supuesto que los recursos destinados a formación bruta de capital fijo por las dos primeras ramas de actividad (241.265 y 60.759 millones de pesetas) se corresponden respectivamente con los márgenes comerciales y de transporte de la formación bruta de capital fijo ${ }^{39}$.

La CNE85-93 (INE, 1995b, cuadro 7.10) desglosa las exportaciones de servicios de transporte en las partidas de bienes, viajeros y otros elementos de los servicios de transporte. En este trabajo hemos considerado las exportaciones de servicios de transporte de bienes (243.254 millones de pesetas) como una medida aproximada de los márgenes de transporte que afectan a las exportaciones.

En cuanto a los márgenes de transporte de los bienes destinados al consumo intermedio carecemos de información estadística. Entre las posibles conjeturas alternativas a las que podíamos recurrir, hemos supuesto que la relación entre los márgenes comerciales y de transporte para los bienes de consumo intermedio coincide con la de los bienes destinados a capital fijo ${ }^{40}$, lo que arroja una estimación de los márgenes de

\footnotetext{
${ }^{38}$ El cuadro 7.1 de la CNE85-93 (INE,1995b) recoge los gastos de consumo privado interior por funciones PROCOME, lo que significa que los márgenes de distribución de los bienes consumidos por los hogares están incluidos en las funciones de consumo a las que afectan. El consumo de servicios de transporte de pasajeros lo hemos obtenido descontando a los gastos por servicios de transporte (PROCOME 6.3: 544.935 millones pts.) otros gastos ligados al servicio de transporte -incluidos alojamiento y restauración en transporte marítimo(PROCOME 63022.04: 7.439 millones pts.), que deben incluirse en el consumo de servicios anexos a los transportes, y añadiéndoles los gastos de los hogares en transporte escolar (PROCOME 63011.04 y 63021.05: 18.006 millones pts.) que la CNE90 considera como gastos de enseñanza (PROCOME 7).

${ }^{39}$ Tal y como señala el SEC (INE, Eurostat 1986, p.83), la formación bruta de capital fijo “representa el valor de los bienes duraderos, destinados a fines no militares y de un valor de al menos 100 UCE, adquiridos por las unidades productoras residentes con el fin de utilizarlos durante más de un año en sus procesos de producción, incluyendo el valor de los servicios incorporados a los bienes de capital fijo”. Dichos servicios tienen como finalidad mejorar los bienes de capital, aumentar su utilidad, su capacidad de producción o rendimiento, o su reparación o reconstrucción.

${ }^{40}$ Aunque por categorías de productos la estructura del consumo intermedio se asimila más a la del consumo privado que a la de la formación bruta de capital, cabe esperar que los márgenes unitarios de transporte de los
} 
transporte para los bienes intermedios de 399.874 millones de pesetas, que representan el $30 \%$ del total de empleos intermedios de las ramas de transporte ${ }^{41}$.

Por último, para completar la matriz de márgenes comerciales y de transporte, repartimos los márgenes estimados por categorías de bienes en proporción al peso de cada una de ellas en los distintos tipos de empleos -consumo intermedio, consumo privado, formación bruta de capital fijo y exportaciones- tal y como figuran en el cuadro 3.6.

bienes destinados a consumo intermedio se aproximen más a los de los bienes destinados a formación bruta de capital fijo porque en ambos casos el número de intermediarios es menor que en el de los bienes de consumo final. De hecho si aplicáramos los márgenes unitarios de transporte de los bienes de consumo final al consumo intermedio, en la mayoría de las ramas productivas los márgenes de transporte de sus inputs intermedios superarían su consumo intermedio de servicios de transporte.

${ }^{41}$ Como para las ramas productos petrolíferos refinados, combustibles nucleares y máquinas de oficina y tratamiento de la información los márgenes de transporte estimados son ligeramente superiores a su consumo intermedio de servicios de transporte, los hacemos coincidir con dicha partida. Por esta razón los gastos de estas ramas en servicios de transporte son cero en la matriz de consumos intermedios. 
CUADRO 3.6. Márgenes comerciales y de transporte de las mercancías

\begin{tabular}{|c|c|c|c|c|c|}
\hline $\begin{array}{c}\text { Productos } \\
\text { agrarios e } \\
\text { industriales }\end{array}$ & $\begin{array}{c}\text { Consumo Final } \\
\text { privado }\end{array}$ & $\begin{array}{c}\text { Formación } \\
\text { Bruta de } \\
\text { Capital Fijo }\end{array}$ & Exportaciones & $\begin{array}{l}\text { Consumo } \\
\text { Intermedio }\end{array}$ & Total \\
\hline P.1 & 406.887 & 595 & 46.543 & 224.015 & 678.040 \\
\hline P. 2 & 13.567 & 0 & 600 & 20.254 & 34.421 \\
\hline P.3 & 0 & 0 & 8 & 6.642 & 6.650 \\
\hline P.4 & 498.263 & 0 & 59.941 & 134.824 & 693.028 \\
\hline P.5 & 14.548 & 0 & 115 & 13.687 & 28.350 \\
\hline P.6 & 0 & 0 & 0 & 0 & 0 \\
\hline P.7 & 0 & 0 & 0 & 0 & 0 \\
\hline P. 8 & 9.407 & 0 & 115 & 2.711 & 12.233 \\
\hline P.9 & 0 & 0 & 47 & 4.122 & 4.169 \\
\hline P.10 & 0 & 0 & 25.930 & 104.966 & 130.896 \\
\hline P.11 & 0 & 0 & 10.199 & 44.895 & 55.094 \\
\hline P.12 & 20.758 & 1.577 & 22.386 & 161.783 & 206.505 \\
\hline P.13 & 406.796 & 0 & 49.161 & 183.558 & 639.516 \\
\hline P.14 & 108.018 & 26.575 & 25.534 & 107.658 & 267.786 \\
\hline P.15 & 4.087 & 76.156 & 36.762 & 59.342 & 176.348 \\
\hline P.16 & 51.331 & 39.041 & 17.244 & 29.415 & 137.031 \\
\hline P.17 & 219.784 & 54.585 & 34.123 & 80.395 & 388.886 \\
\hline P.18 & 613.504 & 51.810 & 116.534 & 61.186 & 843.033 \\
\hline P.19 & 42.071 & 30.709 & 32.205 & 27.099 & 132.085 \\
\hline P. 20 & 752.774 & 0 & 16.640 & 69.834 & 839.248 \\
\hline P. 21 & 336.352 & 0 & 15.059 & 18.373 & 369.783 \\
\hline P.22 & 853.050 & 0 & 44.390 & 166.486 & 1.063 .926 \\
\hline P.23 & 211.009 & 0 & 12.281 & 140.565 & 363.855 \\
\hline P. 24 & 232.636 & 0 & 4.559 & 1.007 & 238.202 \\
\hline P. 25 & 663.941 & 1.098 & 44.690 & 50.214 & 759.943 \\
\hline P. 26 & 192.168 & 47 & 27.138 & 13.520 & 232.873 \\
\hline P. 27 & 164.500 & 15.782 & 14.477 & 35.171 & 229.929 \\
\hline P.28 & 142.248 & 0 & 19.798 & 118.811 & 280.857 \\
\hline P. 29 & 53.099 & 1.660 & 20.648 & 81.365 & 156.772 \\
\hline P.30 & 137.364 & 2.389 & 10.077 & 13.029 & 162.858 \\
\hline Total & 6.148 .162 & 302.024 & 707.206 & 1.974 .926 & 9.132 .318 \\
\hline
\end{tabular}

Fuente: Elaborado a partir de INE (1992c y 1995b).

\subsubsection{La producción a precios de salida de fábrica}

En teoría una rama de actividad agrupa unidades de producción homogénea que se caracterizan por una actividad única que se identifica con los inputs empleados, el proceso de producción y el output obtenido, por lo que la submatriz que recoge la producción a precios de salida de fábrica por ramas de actividad (filas) y categorías de productos (columnas) debería ser una matriz diagonal. En la práctica, sin embargo, aparecen valores fuera de la diagonal principal porque para algunas unidades produc- 
toras no es posible aislar la producción secundaria de bienes y servicios distintos al producto principal que las identifica.

Los totales de las filas y columnas de la submatriz de producción se obtienen a partir de la TIO90 ${ }^{42}$. Para rellenar sus celdas hay que determinar la producción secundaria de las distintas ramas de actividad y su distribución por grupos de productos ${ }^{43}$. Para aquellas ramas cuyo saldo por transferencias de subproductos ordinarios, productos vecinos y producciones secundarias es cero o positivo suponemos que no tienen producción secundaria, en tanto que para el resto de actividades suponemos que el total de la producción distribuida del bien o servicio es producción efectiva de la rama de actividad con la que se identifica y repartimos sus producciones secundarias entre los bienes y servicios que presentan un saldo de transferencias positivo, en proporción al peso de cada uno de ellos en el total de transferencias de productos. En cuanto a la distribución por actividades de las ventas residuales de las AA.PP., las únicas ramas que producen de manera residual y accidental para la venta son las de servicios generales de las AA.PP. y sanidad no destinada a la venta, por lo que hemos supuestos que toda la producción secundaria de la segunda de las ramas es de servicios sanitarios destinados a la venta y que el resto de las ventas residuales proceden de los servicios generales de las AA.PP. ${ }^{44}$.

\footnotetext{
${ }^{42}$ La TIO90 proporciona información sobre la producción efectiva de las distintas ramas y la producción distribuida por tipos de bienes y servicios. Su diferencia viene dada por las transferencias de subproductos ordinarios, productos vecinos y producciones secundarias, y por las ventas residuales de las AA.PP., que en conjunto reflejan la producción secundaria de todas las ramas productivas clasificada por categorías de bienes y servicios.

${ }^{43}$ En la MCS-90 (Uriel y otros, 1997) la matriz que se corresponde con nuestra matriz de producción es la submatriz de ventas del producto interior. Dado que no aparece recogida la metodología utilizada para su estimación y además se presenta más agregada que la de este trabajo, hemos decido no utilizar los coeficientes de distribución de la producción efectiva de las distintas ramas de actividad que de ella pueden derivarse. De todas formas, consideramos que dada la escasa importancia que desde un punto de vista cuantitativo tienen las transferencias de productos, la distribución que se haga de las mismas no afecta a los resultados del trabajo.

${ }^{44}$ Como el total de ventas residuales de servicios sanitarios destinados a la venta es mayor que la producción secundaria de la rama de sanidad no destinada a la venta, la diferencia entre ambas partidas serán ventas residuales de servicios generales de las AA.PP.
} 
La matriz de producción a precios de salida de fábrica por ramas de actividad y categorías de productos que hemos obtenido está recogida en la submatriz 2.1 del cuadro A.1 del anexo estadístico.

\subsubsection{Distribución del valor añadido bruto}

La matriz de inputs primarios de una tabla input-output describe como se distribuye el valor añadido generado por las distintas ramas de actividad entre los factores productivos que han contribuido a obtenerlo. En la MCSE-90 dicha información se presenta desglosada por categorías de trabajo y capital. Para realizar dicho desglose primero calculamos la distribución de las rentas salariales por categorías socioeconómicas y después la distribución de las rentas mixtas y del excedente de explotación entre los distintos sectores institucionales. El cuarto componente del valor añadido, los impuestos sobre la producción netos de subvenciones, no requiere tratamiento alguno por corresponder íntegramente al sector AA.PP.

\subsubsection{La remuneración de asalariados}

De acuerdo con la CNE las rentas del trabajo por cuenta ajena, o remuneración de asalariados, comprenden todos los pagos en dinero y en especie realizados por los empleadores a favor de sus asalariados en concepto de remuneración del trabajo realizado a lo largo del año y se desglosan en sueldos y salarios brutos ${ }^{45}$, cotizaciones sociales reales a cargo de los empleadores ${ }^{46}$ y cotizaciones sociales ficticias ${ }^{47}$.

\footnotetext{
45 La denominación de brutos se refiere a que incluyen las cotizaciones sociales a cargo de los asalariados y las retenciones en concepto de impuestos sobre la renta. Comprenden los sueldos y salarios base, los incrementos por horas extras, trabajo nocturno o en fin de semana, los complementos por carestía de vida y desplazamientos, las primas de beneficios, de productividad, gratificaciones de Navidad, de fin de año y paga extraordinaria anual, las primas de transporte al trabajo, las remuneraciones por días festivos no laborables y vacaciones pagadas, las comisiones, propinas, primas de asistencia y porcentajes pagados a los asalariados, las acciones gratuitas distribuidas a los asalariados independientemente de los beneficios realizados, los pagos efectuados por los empleadores a los asalariados en el marco de planes de ahorro, las remuneraciones en especie suministradas gratuitamente o a precio reducido a los asalariados y las asignaciones de vivienda entregadas en dinero. No se incluye bajo esta denominación las indemnizaciones o reembolsos a los asalariados por gastos de viaje, distancia, mudanza y representación en el ejercicio de sus funciones; los gastos de acondicionamiento del lugar de trabajo, de exámenes médicos o de suministro de ropa (excepto uniformes militares). Los gastos corrientes
} 
Aunque existen diversas fuentes de información alternativas para calcular los indicadores de distribución por grupos de asalariados de los sueldos y salarios brutos pagados por las distintas ramas de actividad, hemos optado por la EPF90/91 ${ }^{48}$. Dicha fuente, a pesar de sus limitaciones ${ }^{49}$, cuenta con las ventajas de abarcar todos los sectores productivos y de ofrecer información suficiente sobre las características socioeconómicas de los trabajadores y, sobre todo, es la única que permite identificar el hogar al que pertenece cada trabajador, lo que posibilita el enlace entre las cuentas de generación y asignación de la renta primaria.

La EPF90-91 registra, por un lado, los ingresos monetarios del trabajo por cuenta ajena, ingresos percibidos como contraprestación de una actividad regular o esporádica realizada para otras personas físicas o jurídicas ${ }^{50} \mathrm{y}$, por otro, los ingresos no

de transporte al trabajo de los asalariados organizado por el empleador, las compensaciones pagadas a los asalariados por la compra de útiles, material o ropa necesaria para su actividad profesional (excepto uniformes militares) o la parte de los sueldos y salarios destinada a tales compras en virtud de obligación contractual, que se contabilizan como consumos intermedios. El montante de los sueldos y salarios que los empleadores continúan pagando temporalmente a sus asalariados en caso de enfermedades, maternidad, invalidez, despido etc., se contabiliza como una prestación social y una cotización social ficticia.

${ }^{46}$ Comprenden todos los pagos que realizan los empleadores, en beneficio de sus asalariados, a las entidades aseguradoras para cubrir las contribuciones legales, convencionales, contractuales y voluntarias en concepto de seguro contra riesgos de enfermedad, maternidad, invalidez, vejez y supervivencia, desempleo, accidentes de trabajo, enfermedades profesionales y subsidios familiares.

${ }^{47}$ Representan la contrapartida de las prestaciones sociales prestadas directamente por los empleadores a sus asalariados o antiguos asalariados y a los que tengan derecho.

${ }^{48}$ La Encuesta sobre Estrategias Empresariales del Ministerio de Industria y Energía tan sólo incluye empresas manufactureras con más de 10 trabajadores e información exigua sobre las características de los trabajadores. La Central de Balances del Banco de España apenas ofrece información sobre las características de los asalariados y, por su carácter voluntario, sobrerepresenta a las grandes empresas y las públicas. La Encuesta de Salarios en la Industria y los Servicios del INE no recoge las ganancias por categorías profesionales y deja fuera de su cobertura a la agricultura y a los servicios no destinados a la venta. La Encuesta de Costes Laborales del INE sólo recoge los centros de cotización con al menos cinco trabajadores de la industria y los servicios, excluye los trabajadores a tiempo parcial y tan sólo está disponible para los años 1988 y 1992. La Encuesta Industrial y los Salarios Agrarios son de cobertura sectorial específica y apenas recogen información sobre la cualificación de los trabajadores. En cuanto a las fuentes tributarias (La Estadística Tributaria sobre Empleo, Salarios y Pensiones, Las empresas españolas en las fuentes tributarias y Las cuentas de las sociedades en las fuentes tributarias), aunque tienen una cobertura sectorial completa, excluyen al País Vasco y Navarra y los datos que ofrecen sobre las características de los trabajadores son escasos.

${ }^{49}$ Dichas limitaciones están asociadas a la utilización del concepto de renta neta disponible, a la falta de respuesta y a la subestimación de los ingresos, si bien su incidencia sobre las rentas del trabajo por cuenta ajena es menor que en el resto de ingresos de los hogares.

${ }^{50}$ Bajo esta denominación se incluyen los sueldos, salarios y antigüedad; horas extraordinarias, trabajo nocturno, fin de semana, guardias; pagas extraordinarias, complementos de productividad, gratificaciones, complementos específicos, complementos de destino, primas de beneficio, primas de transporte al trabajo, comisiones, propinas, primas de asistencia, porcentajes pagados a los asalariados y asignaciones en dinero para vivienda entregadas por los empleadores. Se incluyen asimismo los ingresos obtenidos por la venta de productos recibi- 
monetarios del trabajo por cuenta ajena, salario en especie, comidas y alquileres ${ }^{51}$. Además registra los ingresos monetarios en términos netos, es decir, no incluye ni las cotizaciones sociales a cargo del trabajador ni las retenciones por impuestos sobre la renta. El cuadro 3.7, que recoge las estimaciones de las rentas del trabajo por cuenta ajena de la EPF90-91 y de la CNE90, permite apreciar una subestimación de los sueldos y salarios netos de las unidades residentes por parte de la EPF90-91 del 11,5\%.

CUADRO 3.7. Las rentas salariales en la EPF90-91 y la CNE90

\begin{tabular}{|lr|lr|}
\hline \multicolumn{2}{|c|}{ Encuesta de Presupuestos Familiares 1990-1991 } & \multicolumn{2}{|c|}{ Contabilidad Nacional de España 1990 } \\
\hline Ingresos monetarios netos por trabajo por cuenta ajena. & 12.280 .468 & Remuneración de asalariados residentes. & 23.317 .737 \\
Ingresos no monetarios netos por trabajo por cuenta ajena. & 102.858 & Cotizaciones sociales & 5.482 .151 \\
Salario en especie. & 5.182 & Sueldos y salarios brutos de los asalariados residentes . & 17.835 .586 \\
Comidas y cenas bonificadas. & 54.957 & Cotizaciones sociales a cargo de los asalariados. & 1.106 .619 \\
Alquileres & 42.720 & IRPF por rentas del trabajo por cuenta ajena. & 2.733 .167 \\
Sueldos y salarios netos & 12.383 .326 & Sueldos y salarios netos percibidos por los asalariados residentes. & 13.995 .800 \\
\hline \multicolumn{2}{l}{} & Sueldos y salarios brutos pagados procedentes del resto del mundo. & 35.448 \\
& & Sueldos y salarios brutos pagados pagados al resto del mundo. & 1.717 \\
& & Sueldos y salarios brutos pagados por los empleadores residentes. & 17.801 .855 \\
\hline
\end{tabular}

Para repartir los sueldos y salarios brutos de la CNE90 por categorías socioeconómicas y ramas de actividad utilizamos como indicadores de distribución los sueldos y salarios brutos de los miembros asalariados de los hogares $\left(W_{\mathrm{i}}^{*}\right)$ que estimamos a partir de la información de la EPF90-91 sobre sus ingresos monetarios $\left(I M_{\mathrm{i}}\right)$ y no monetarios $\left(I N_{\mathrm{i}}\right)$ por cuenta ajena, tal y como refleja la siguiente ecuación:

$$
\left(1-t_{\mathrm{i}}\right) W_{\mathrm{i}}^{*}-c\left(W_{\mathrm{i}}^{*}-I N_{\mathrm{i}}\right)=I M_{\mathrm{i}}+I N_{\mathrm{i}}
$$

donde $c$ es el tipo de cotización, que hemos supuesto único para todos los asalariados $^{52}$ y $t_{\mathrm{i}}$ el tipo de retención correspondiente a cada asalariado ${ }^{53}$. Como la infor-

dos como salario en especie. Sin embargo, no se incluyen las dietas (excepto la diferencia entre la dieta y el gasto efectuado a su cargo), los exámenes médicos, el suministro de ropa de trabajo y los gastos de transporte organizados por el empleador. En tanto que los pagos efectuados por las entidades aseguradoras o por los propios empleadores en situaciones de baja por enfermedad, maternidad, invalidez o despido, no tienen carácter de sueldos y salarios, sino de prestaciones sociales.” (INE, 1992b, pp. 24 y 25).

${ }^{51}$ Bonificación disfrutada por el hogar en razón de comidas y/o cenas gratuitas o semigratuitas efectuadas por los miembros del hogar en el lugar de trabajo de alguno de sus miembros asalariados y alquiler imputado de la vivienda principal o secundaria que tiene el hogar cedida gratuita o semigratuitamente por razón del trabajo actual de alguno de sus miembros.

52 Relación entre el total de cotizaciones sociales a cargo de los trabajadores por cuenta ajena y el total de sueldos y salarios monetarios brutos que se obtienen tras deducir del total de sueldos y salarios brutos de la CNE90 el porcentaje que según la EPF90-91 corresponde a los ingresos no monetarios. 
mación sobre los ingresos no monetarios por cuenta ajena tan sólo está disponible por hogares, hemos repartido el salario en especie y los ingresos por comidas y cenas bonificadas, a partes iguales, entre los miembros asalariados de cada hogar ${ }^{54} \mathrm{y}$ los ingresos por alquiler estimado de la vivienda los hemos asignado al sustentador principal siempre que éste tuviera la condición de asalariado, en caso contrario se los hemos adjudicado al cónyuge ${ }^{55}$.

Tal y como cabía esperar, el carácter progresivo del I.R.P.F. provoca que la infraestimación de los sueldos y salarios brutos calculados a partir de la EPF90-91 sea mayor que la de los sueldos y salarios netos, un $13,36 \%$ frente a un $11,5 \%{ }^{56}$

El cuadro 3.8 recoge la distribución de los sueldos y salarios brutos estimados a partir de la EPF90-91 por categorías socioeconómicas y ramas de actividad (CNAE74 , a un dígito $)^{57}$. Aunque la condición socioeconómica de los miembros de los hoga-

53 El tipo de retención correspondiente a cada asalariado lo hemos calculado a partir de las tablas de retenciones establecidas en el artículo $4^{\circ}$ del Real Decreto 1009/1990, de 27 de julio de 1990, de acuerdo con su retribución bruta, estado civil y número de hijos con derecho a deducción, transformando las retribuciones a términos netos con el fin de establecer las retenciones en función de variables sobre las que la EPF 90-91ofrece información individualizada. En la transformación de las tablas de retenciones, además del tipo de retención fijado para cada tramo de retribución bruta, también hemos considerado las cotizaciones sociales a cargo del trabajador.

${ }^{54}$ En la EPF90-91 hay 36 observaciones con ingresos no monetarios por trabajo por cuenta ajena en concepto de salario en especie, comidas y cenas bonificadas en el lugar de trabajo o alquileres estimados de las viviendas cedidas gratuita o semigratuitamente por razones de trabajo y sin ingresos monetarios por trabajo por cuenta ajena. En estos casos hemos considerado las rentas no monetarias del trabajo por cuenta ajena como una transferencia en especie recibida por los hogares y no como una ganancia salarial.

55 En la EPF90-91 hay 4 hogares con ingresos por alquileres estimados de la vivienda principal cedida gratuita o semigratuitamente por razón de trabajo en los que ni el sustentador principal ni el cónyuge son asalariados. En tres de ellos los perceptores de rentas del trabajo por cuenta ajena son hijos del sustentador principal y dicho alquiler se lo hemos asignado al hijo de mayor edad que, a su vez, es el que percibe mayores ingresos por cuenta ajena o al menos iguales a los de sus hermanos. En el cuarto de los hogares, la relación de los perceptores de ingresos monetarios por trabajo por cuenta ajena con el sustentador principal es la de padre o madre y la de otro parentesco, en este caso hemos supuesto que el alquiler imputado de la vivienda procede del padre o madre del sustentador principal, dado que ambos tienen los mismos ingresos.

${ }^{56}$ Los sueldos y salarios brutos que hemos estimado ascienden a 15.452 .087 millones pts., de los cuáles 2.113.340 corresponden a retenciones estimadas por I.R.P.F. y 958.606 a las cotizaciones sociales estimadas a cargo de los asalariados.

${ }^{57}$ Para facilitar la integración, por ramas de actividad, de los sueldos y salarios brutos obtenidos a partir de la Encuesta con los de la TIO90 incluimos los servicios agrícolas y ganaderos (CNAE-74,03) que pertenecen a la rama de agricultura, selvicultura y pesca $(\mathrm{CNAE-74,00)}$ en la rama de instituciones financieras, seguros, servicios a las empresas y alquileres (CNAE-74,80) y al resto de actividades pertenecientes al sector agrario (CNAE-74, 01,02,04,05,06) las agrupamos en una sóla rama. En la EPF90-91 (fichero tipo3) hay 389 observaciones con ingresos monetarios por trabajo por cuenta ajena que no tienen registrada información sobre su ra- 
res no está disponible en la EPF90-91, si lo están las variables ocupación, rama de actividad y situación profesional que se utilizan para su definición (INE, 1990b).

CUADRO 3.8. Sueldos y salarios brutos por categorías socioeconómicas y actividades

\begin{tabular}{|c|c|c|c|c|c|c|c|c|c|c|}
\hline \multirow{2}{*}{\begin{tabular}{l|} 
Actividades \\
CNAE-74 \\
\end{tabular}} & \multicolumn{8}{|c|}{$\begin{array}{l}\text { Sueldos y salarios brutos } \\
\text { Categorías socioeconómicas }\left(\mathbf{W}^{*}{ }_{\mathrm{ik}}\right)\end{array}$} & \multirow{2}{*}{$\begin{array}{l}\text { Recibidos por } \\
\text { residentes } \\
\text { EPF90-91 } \\
\left(\mathrm{W}^{*} \cdot \mathrm{K}\right)\end{array}$} & \multirow{2}{*}{$\begin{array}{c}\text { Recibidos y pag. } \\
\text { por residentes } \\
C N E-T I O 90 \\
\left(\mathrm{~W}_{\cdot \mathrm{k}}\right)\end{array}$} \\
\hline & CSE1 & CSE2 & CSE3 & CSE4 & CSE5 & CSE6 & CSE7 & CSE8 & & \\
\hline 00 & 18.901 & 449.780 & 0 & 13.329 & 28.336 & 0 & 0 & 16.749 & 527.094 & 543.987 \\
\hline 10 & 0 & 0 & 678 & 104.241 & 131.269 & 216.710 & 13.395 & 3.779 & 470.072 & 436.040 \\
\hline 20 & 0 & 0 & 3.373 & 121.868 & 96.730 & 393.142 & 25.926 & 10.438 & 651.477 & 875.294 \\
\hline 30 & 0 & 0 & 7.780 & 401.555 & 192.986 & 1.026 .552 & 40.479 & 24.158 & 1.693 .511 & 1.672 .364 \\
\hline 40 & 0 & 0 & 12.573 & 142.603 & 284.670 & 1.242 .160 & 63.310 & 26.489 & 1.771 .805 & 1.850 .454 \\
\hline 50 & 0 & 0 & 9.339 & 226.941 & 62.879 & 1.025 .862 & 110.677 & 27.394 & 1.463 .092 & 1.887 .552 \\
\hline 60 & 0 & 0 & 35.873 & 248.542 & 1.332 .707 & 372.394 & 20.706 & 29.848 & 2.040 .070 & 2.222 .943 \\
\hline 70 & 0 & 0 & 6.041 & 198.060 & 356.434 & 556.502 & 11.225 & 11.076 & 1.139 .338 & 942.047 \\
\hline 80 & 1.730 & 27.159 & 4.303 & 377.951 & 656.480 & 29.251 & 1.263 & 7.573 & 1.105 .710 & 1.654 .780 \\
\hline 90 & 0 & 0 & 31.606 & 2.224 .448 & 1.907.497 & 259.074 & 86.956 & 80.336 & 4.589.917 & 5.714 .679 \\
\hline$\left(\mathrm{W}_{\mathrm{i}}^{*}\right)$ & 20.631 & 476.938 & 111.567 & 4.059 .538 & 5.049 .987 & 5.121 .647 & 373.937 & 237.841 & 15.452 .086 & 17.800 .138 \\
\hline
\end{tabular}

Fuente: Elaborado a partir de INE (1992c y 1995b).

Para desagregar los salarios brutos por categorías socioeconómicas de las actividades clasificadas a un dígito de la CNAE-74 $\left(W_{\mathrm{ik}} ; k=00, \ldots, 90\right)$ entre el mayor número de ramas consideradas en la MCSE-90 (j=R.1,..., R.48) suponemos, como refleja la ecuación (3.2), que el salario medio de una categoría socioeconómica $i$ en una rama de actividad $j\left(w_{i j}\right)$ está determinado por el salario medio de dicha categoría en la rama $k\left(w_{i k}\right)$ y por el salario medio de la rama $j\left(w_{j}\right)$.

$$
\begin{gathered}
\frac{w_{i j}}{w_{j}}=\frac{w_{i k}}{\sum_{i} w_{i k} L_{i j} / L_{j}} \\
\forall j \in k \quad k=00,10, \ldots, 90 ; \quad j=1,2, \ldots 48 .
\end{gathered}
$$

A partir de la ecuación anterior:

ma de actividad. A todas ellas les hemos asignado aleatoriamente una rama de actividad con la única restricción de que la participación de las distintas ramas de actividad en el empleo asalariado no se vea alterada. 


$$
\begin{aligned}
& \mathrm{W}_{\mathrm{ij}}=\mathrm{L}_{\mathrm{ij}} \mathrm{w}_{\mathrm{ij}}=\mathrm{L}_{\mathrm{ij}} \mathrm{w}_{\mathrm{ik}} \frac{\mathrm{w}_{\mathrm{j}}}{\sum_{\mathrm{i}} \mathrm{w}_{\mathrm{ik}} \mathrm{L}_{\mathrm{ij}} / \mathrm{L}_{\mathrm{j}}} \\
& \forall \mathrm{j} \in \mathrm{k} \quad \mathrm{k}=00,10, \ldots, 90 ; \quad \mathrm{j}=1,2, \ldots .48 .
\end{aligned}
$$

Los datos de empleo asalariado $\left(L_{i j}\right)$, que presentamos en el cuadro 3.9, los hemos obtenido ajustando las cifras de empleo asalariado que proporcionan las Encuestas de Población Activa de 1990 (EPA90) ${ }^{58}$ por ramas de actividad (CNAE-74, tres dígitos) y categorías socioeconómicas al empleo asalariado por ramas de actividad (R.56) de la CNE90 59 .

Dado que en la EPA90 no figuran asalariados que pertenezcan a las categorías de empresarios, profesionales y trabajadores independientes no agrarios (CSE3) y no clasificables (CSE8), que de acuerdo con la EPF90-91 sí perciben rentas del trabajo por cuenta ajena ${ }^{60}$, hemos prorrateado sus ingresos salariales entre el resto de categorías por ramas de actividad.

Como muestra la ecuación 3.4, para calcular las ganancias salariales medias $\left(w_{i k}\right)$, hemos ajustado previamente los sueldos y salarios brutos estimados $\left(W^{*}{ }_{i k}\right)$, una vez excluidas las categorías CSE3 y CSE8, con los sueldos y salarios brutos de la CNE90 $\left(W_{k}\right)$ que figuran en el cuadro $3.8^{61}$.

\footnotetext{
${ }^{58}$ Los porcentajes de participación utilizados son la media aritmética de los cuatro trimestres de 1990.

${ }^{59}$ Cuando una actividad de la CNAE-74 (3 dígitos) se corresponde con dos ramas de la clasificación R.56, o cuando las correspondencias entre ambas clasificaciones están establecidas a cuatro dígitos, distribuimos los asalariados de las ramas de actividad de la CNAE-74 entre las correspondientes ramas de la clasificación R.56, de modo que la relación entre el empleo asalariado de estas últimas coincida con la que se obtiene al utilizar las cifras de asalariados de la CNE90. Las actividades de la CNAE-74 a las que hemos hecho referencia son: la 152, que se corresponde con las ramas R.6, R.7 y R.10 de la R.56; las actividades 931, 932, 933 y 937 que lo hacen con las ramas R.51 y R.55; las actividades 941, 942 y 946 con la R.52 y R.56; la actividad 921 con la R.53 y R.54 y, finalmente, las actividades 951,965 y 967 con la R.53, R.54 y R.57.

${ }^{60}$ La participación en los sueldos y salarios brutos de las dos categorías señaladas oscilan dependiendo de la rama de actividad, entre el 1 y el $3 \%$.

${ }^{61}$ La última columna del cuadro 3.8 recoge los sueldos y salarios brutos por ramas de actividad $\left(W_{k}\right)$ que se deriven de la TIO90 una vez descontados los pagados al resto del mundo. Tanto los sueldos y salarios brutos pagados al resto del mundo como los recibidos del resto del mundo los hemos distribuido por ramas de actividad en proporción a la participación de cada una de las ramas en los sueldos y salarios brutos totales.
} 


$$
\mathrm{w}_{\mathrm{ik}}=\frac{\mathrm{W}_{\mathrm{ik}}^{*}}{\mathrm{~L}_{\mathrm{ij}}} \times \frac{\mathrm{W}_{\mathrm{k}}}{\mathrm{W}_{\mathrm{k}}^{*}}
$$

Los resultados obtenidos están recogidos en las seis primeras filas de la submatriz de valor añadido bruto (3.2) que figura en el cuadro A.1 del anexo estadístico. La fila séptima de dicha submatriz registra los sueldos y salarios brutos de los asalariados no residentes y la fila octava, las cotizaciones sociales que completan la remuneración de asalariados ${ }^{62}$.

\footnotetext{
${ }^{62}$ La CNE registra las cotizaciones sociales reales a cargo de los empleadores y las cotizaciones ficticias, en primer lugar, como una renta primaria pagada por los empleadores a los hogares y, en segundo lugar, como una transferencia corriente de los hogares a la Seguridad Social o a las empresas de seguros, por lo que a pesar de ser rentas primarias de los hogares no afectan a su renta disponible. Este es el motivo por el que las hemos considerado como una categoría independiente del resto de rentas del factor trabajo.
} 
CUADRO 3.9. Distribución del empleo asalariado (miles)

\begin{tabular}{|c|c|c|c|c|c|c|c|c|}
\hline \multirow{2}{*}{$\begin{array}{l}\text { Ramas de } \\
\text { actividad } \\
\text { MCSE-90 }\end{array}$} & \multicolumn{6}{|c|}{ Categorías socioeconómicas $\left(\mathrm{L}_{\mathrm{ij}}\right)$} & \multirow{2}{*}{$\begin{array}{c}\text { CNE90 } \\
\text { Total } \\
\left(\mathrm{L}_{\cdot \mathrm{j}}\right)\end{array}$} & \multirow{2}{*}{$\begin{array}{l}\text { Salario relativo } \\
\mathrm{w}_{\mathrm{j}} / \sum_{\mathrm{i}} \mathrm{w}_{\mathrm{ik}} \mathrm{L}_{\mathrm{ij}} / \mathrm{L}\end{array}$} \\
\hline & CSE1 & CSE2 & CSE4 & CSE5 & CSE6 & CSE7 & & \\
\hline R.1 & 6.532 & 418.197 & 3.900 & 13.471 & 0 & 0 & 442.100 & 1,000000 \\
\hline R.2 & 0 & 0 & 3.016 & 2.871 & 39.150 & 1.363 & 46.400 & 1,007693 \\
\hline R.3 & 0 & 0 & 42 & 0 & 458 & 0 & 500 & 1,457616 \\
\hline R.4 & 0 & 0 & 3.884 & 2.454 & 6.528 & 733 & 13.600 & 1,151592 \\
\hline R. 5 & 0 & 0 & 316 & 514 & 959 & 212 & 2.000 & 1,398979 \\
\hline R. 6 & 0 & 0 & 2.037 & 7.655 & 8.770 & 5.339 & 23.800 & 0,540352 \\
\hline R.7 & 0 & 0 & 10.138 & 14.620 & 27.648 & 1.494 & 53.900 & 1,118434 \\
\hline R.8 & 0 & 0 & 237 & 341 & 696 & 126 & 1.400 & 0,773533 \\
\hline R.9 & 0 & 0 & 221 & 279 & 0 & 0 & 500 & 0,987075 \\
\hline R.10 & 0 & 0 & 6.617 & 6.884 & 44.538 & 1.662 & 59.700 & 1,140580 \\
\hline R.11 & 0 & 0 & 1.662 & 3.433 & 14.888 & 4.517 & 24.500 & 1,109457 \\
\hline R.12 & 0 & 0 & 8.861 & 17.585 & 125.402 & 25.852 & 177.700 & 0,877492 \\
\hline R.13 & 0 & 0 & 25.992 & 45.130 & 53.516 & 18.262 & 142.900 & 1,061238 \\
\hline R.14 & 0 & 0 & 9.565 & 27.563 & 191.415 & 29.157 & 257.700 & 0,928199 \\
\hline R.15 & 0 & 0 & 11.690 & 20.242 & 76.438 & 7.530 & 115.900 & 0,946181 \\
\hline R.16 & 0 & 0 & 5.139 & 6.703 & 12.803 & 3.955 & 28.600 & 0,896403 \\
\hline R.17 & 0 & 0 & 26.423 & 29.548 & 108.645 & 20.485 & 185.100 & 0,956338 \\
\hline R.18 & 0 & 0 & 11.526 & 20.318 & 118.805 & 21.050 & 171.700 & 1,233931 \\
\hline R.19 & 0 & 0 & 9.521 & 10.445 & 77.667 & 3.567 & 101.200 & 0,974977 \\
\hline R.20 & 0 & 0 & 1.516 & 9.207 & 45.732 & 4.245 & 60.700 & 1,127670 \\
\hline R.21 & 0 & 0 & 2.316 & 6.992 & 17.859 & 3.233 & 30.400 & 1,173277 \\
\hline R.22 & 0 & 0 & 8.745 & 34.257 & 137.627 & 15.771 & 196.400 & 1,057861 \\
\hline R.23 & 0 & 0 & 4.904 & 13.687 & 30.177 & 7.131 & 55.900 & 1,281177 \\
\hline R.24 & 0 & 0 & 428 & 1.427 & 8.674 & 171 & 10.700 & 1,855715 \\
\hline R.25 & 0 & 0 & 9.179 & 37.159 & 235.222 & 12.340 & 293.900 & 0,804770 \\
\hline R.26 & 0 & 0 & 1.524 & 6.577 & 75.647 & 1.752 & 85.500 & 0,885231 \\
\hline R.27 & 0 & 0 & 4.726 & 12.578 & 136.375 & 14.821 & 168.500 & 0,771588 \\
\hline R.28 & 0 & 0 & 18.019 & 35.327 & 91.566 & 15.888 & 160.800 & 1,127426 \\
\hline R.29 & 0 & 0 & 4.601 & 9.952 & 68.938 & 15.509 & 99.000 & 1,299042 \\
\hline R.30 & 0 & 0 & 1.330 & 9.084 & 30.408 & 5.777 & 46.600 & 1,090510 \\
\hline R.31 & 0 & 0 & 35.324 & 51.876 & 592.188 & 292.511 & 971.900 & 1,000000 \\
\hline R.32 & 0 & 0 & 1.424 & 12.267 & 125.314 & 6.496 & 145.500 & 1,151076 \\
\hline R.33 & 0 & 0 & 69.254 & 652.634 & 227.890 & 36.222 & 986.000 & 0,993742 \\
\hline R.34 & 0 & 0 & 12.326 & 437.866 & 14.460 & 7.548 & 472.200 & 0,972245 \\
\hline R.35 & 0 & 0 & 26.038 & 46.018 & 159.470 & 7.574 & 239.100 & 1,070357 \\
\hline R.36 & 0 & 0 & 6.992 & 36.882 & 18.573 & 4.853 & 67.300 & 0,935545 \\
\hline R.37 & 0 & 0 & 18.008 & 85.166 & 38.905 & 2.221 & 144.300 & 0,902085 \\
\hline R.38 & 0 & 0 & 66.407 & 244.215 & 3.267 & 412 & 314.300 & 1,190106 \\
\hline R.39 & 0 & 0 & 0 & 0 & 0 & 0 & 0 & 0,000000 \\
\hline R.40 & 117 & 6.060 & 62.182 & 144.206 & 9.891 & 3.343 & 225.800 & 0,755911 \\
\hline R.41 & 0 & 0 & 0 & 11.074 & 0 & 1.126 & 12.200 & 0,853001 \\
\hline R.42 & 0 & 0 & 166.792 & 35.631 & 2.950 & 1.428 & 206.800 & 0,536333 \\
\hline R.43 & 0 & 0 & 52.212 & 21.664 & 3.026 & 299 & 77.200 & 1,036914 \\
\hline R.44 & 0 & 0 & 29.978 & 249.311 & 18.278 & 8.033 & 305.600 & 0,968899 \\
\hline R.45 & 0 & 0 & 225.559 & 707.133 & 92.705 & 92.003 & 1.117 .400 & 1,249442 \\
\hline R.46 & 0 & 0 & 358.105 & 84.208 & 9.176 & 5.711 & 457.200 & 0,927945 \\
\hline R.47 & 0 & 0 & 269.579 & 101.907 & 15.371 & 2.043 & 388.900 & 1,218422 \\
\hline R.48 & 0 & 0 & 21.577 & 429.018 & 5.650 & 4.155 & 460.400 & 0,474290 \\
\hline Total & 6.649 & 424.257 & 1.619 .832 & 3.757 .376 & 3.123 .668 & 717.918 & 9.649 .700 & \\
\hline
\end{tabular}

Fuente: Elaboración propia a partir de INE (1990c y 1995b). 


\subsubsection{El excedente de explotación y las rentas mixtas}

El excedente bruto de explotación que ofrece la CNE90 en la cuenta de explotación de las AA.PP. coincide con la suma de los excedentes brutos de explotación de las ramas de servicios generales de las AA.PP., investigación y enseñanza no destinada a la venta y sanidad no destinada a la venta de la TIO90. Dicho excedente, en la MCSE-90, está recogido en la fila 14 de la submatriz de valor añadido (submatriz 3.2 del cuadro A.1 del anexo estadístico) como un pago de las ramas correspondientes (R.45 a R.47 de la MCSE-90). Por su parte, como la rama de servicios no destinados a la venta n.c.o.p de la TIO90 incluye el servicio doméstico y los servicios prestados por las instituciones privadas sin fines de lucro ${ }^{63}$, y la producción de servicios domésticos se valora por el coste del personal doméstico asalariado, su excedente de explotación cabe atribuirlo íntegramente al sector instituciones privadas sin fines de lucro ${ }^{64}$ (fila 15, columna R.48 de la submatriz de valor añadido).

El excedente de explotación de las sociedades no financieras, instituciones financieras y empresas de seguros se obtiene directamente de sus respectivas cuentas de renta de la CNE90, mientras que el excedente de explotación registrado en la cuenta de renta del sector hogares agrupa la renta mixta de los hogares y el excedente de explotación de los hogares y de las instituciones privadas sin fines de lucro. Dado que conocemos el montante de la última de las partidas incluidas, resta separar la renta mixta generada por los hogares como empresarios individuales del excedente de explotación de los hogares como propietarios de bienes inmuebles. A tal efecto utilizamos la información de la EPF90-91 que, pese a presentar serios problemas de subestimación ${ }^{65}$,

\footnotetext{
${ }^{63}$ La producción no destinada a la venta comprende los servicios producidos y suministrados por las administraciones públicas e instituciones privadas sin fines de lucro a la colectividad en su conjunto o a grupos particulares de hogares, a título gratuito o semigratuito, y los servicios domésticos producidos por los hogares como empleadores de personal doméstico asalariado (INE, Eurostat, 1986) y se corresponde con las ramas 54 a 57 de la TIO90.

${ }^{64}$ Para los productores de no mercado, AA.PP. e IPSFL, el excedente bruto de explotación coincide con el consumo de capital fijo, siendo nulo su excedente neto de explotación.

${ }^{65}$ En el trabajo de Romero Jordán (1996) se analizan los rendimientos empresariales en la EPF y se advierte del problema de la existencia de anotaciones incompletas, entendiendo por tales aquellas en las que no se consigna ningún valor (ni siquiera nulo) en la partida de ingresos de la explotación, en la de gastos o ninguna de las dos.
} 
es la única fuente que permite analizar el excedente de explotación por tipos de hogares y la renta mixta por tipos de trabajadores, tal y como recomienda el SCN93.

La renta mixta de los hogares como empresarios incluye además de los ingresos monetarios netos del trabajo por cuenta propia ${ }^{66}$, los ingresos no monetarios ${ }^{67}$, las cotizaciones sociales y retenciones por I.R.P.F., y los costes financieros. Estos últimos son tratados en la EPF90-91 como gastos deducibles y en la CNE90 como rentas de la propiedad pagadas ${ }^{68}$.

En cuanto al excedente de explotación de los hogares como productores de servicios de alquiler ${ }^{69}$, la EPF90-91 contabiliza, por un lado, los ingresos monetarios netos de los hogares por alquiler de viviendas, locales y terrenos como la diferencia entre los ingresos por alquiler y los gastos ocasionados para su mantenimiento y, por otro, los ingresos de los hogares por alquileres imputados de las viviendas, principal y se-

Las estimaciones de Sanz (1995) apuntan una infraestimación de las rentas del trabajo autónomo del orden del $50 \%$.

${ }^{66}$ Comprende todos los ingresos monetarios netos obtenidos en los doce últimos meses por trabajadores independientes, empresarios o empleadores por el ejercicio de actividades empresariales, profesionales o artísticas, con independencia de que tales ingresos procedan de trabajos realizados en periodos anteriores o sean anticipos de actividades futuras. Se calculan como la diferencia entre los ingresos brutos (por ventas efectuadas o servicios prestados y otros ingresos) y los gastos deducibles (gastos de personal, compras, gastos financieros, alquileres, luz, teléfono, agua, impuestos ligados a la actividad productiva, amortizaciones, etc.) y se registran netos de retenciones a cuenta por I.R.P.F. y cotizaciones sociales.

${ }^{67}$ Sólo están disponibles por hogares y comprenden: el autoconsumo (parte de los bienes, principalmente alimenticios, producidos en la propia explotación agraria, fábrica o taller, por alguno o algunos de los miembros del hogar, consumida o regalada durante el periodo de referencia), el autosuministro (bienes retirados, sin abono de su importe, del propio comercio por alguno o algunos de los miembros del hogar propietario) y las comidas realizadas en el establecimiento de hostelería propiedad del hogar El hecho de que la EPF90-91 no contabilice los ingresos no monetarios por cuenta propia como la diferencia entre el valor de la producción autoconsumida y la suma de los gastos de consumo intermedio y de personal no genera distorsión alguna, al menos desde un punto de vista teórico, porque se supone que dichos gastos ya están incluidos en el total de gastos deducibles que se utilizan para calcular los ingresos monetarios netos del hogar por cuenta propia.

${ }^{68}$ Ni la Contabilidad Nacional ni la Encuesta proporcionan información alguna sobre dichos costes financieros, por lo que no hemos podido considerarlos.

69 La CNE define el excedente de explotación de los hogares como la diferencia entre su producción de servicios de alquiler reales e imputados (alquileres brutos menos gastos comunitarios) y el consumo intermedio asociado (gastos de mantenimiento y reparación realizados por el propietario). En el caso de que sea el inquilino quien corra con los gastos de mantenimiento y reparación del inmueble, dichos gastos se contabilizan como consumo final si se trata de una vivienda y si se trata de un inmueble industrial, comercial o administrativo como un consumo intermedio de la actividad que se desarrolle en el inmueble. 
cundaria propiedad de los hogares con un método de valoración subjetiva ${ }^{70}$ que tiende a sobreestimar dicha partida, sobre todo en un año como 1990 de fuerte especulación en el mercado de viviendas de alquiler ${ }^{71}$.

Para corregir dicha sobreestimación, a partir de la información de la TIO90 para la rama de servicios de alquiler, recalculamos los ingresos de los hogares por alquileres imputados de las viviendas de su propiedad así como los gastos de consumo intermedio asociados a dichos ingresos. Teniendo en cuenta, por un lado, que el 95,8\% de los gastos de los hogares en alquileres corresponden a alquiler de viviendas ${ }^{72}$, que de éstos el 94,57\% son gastos en alquileres imputados y que, a su vez, el 97,82 \% de estos últimos corresponden a viviendas propiedad de los hogares ${ }^{73} \mathrm{y}$, por otro lado, la cifra de consumo privado de servicios de alquiler de la TIO90 (2.881.560 millones de pesetas), hemos obtenido un valor de 2.553.862 millones de pesetas para la producción de servicios de alquiler imputados de los hogares. Para recalcular los gastos de consumo intermedio asociados a dicha producción hemos supuesto que su peso en la producción efectiva coincide con la de la rama de servicios de alquiler de la TIO90 (un 19\%). De este modo hemos estimado en 2.069 .000 millones de pesetas el importe del excedente bruto de explotación de los hogares por alquileres imputados.

Una vez corregida a la baja la estimación de los alquileres imputados, la infravaloración del excedente de explotación de los hogares, incluidas las rentas mixtas, en la EPF es de un 50 \% con respecto a las cifras ofrecidas por la CNE90, lo que supone

\footnotetext{
${ }^{70}$ El alquiler bruto que el propietario considera que tendría que pagar, en el momento de realizarse la entrevista, por una vivienda similar a la que habita menos los gastos comunitarios. Por tanto, en términos de la CNE, los ingresos por alquileres imputados de la EPF se encuadrarían dentro del concepto de producción al no llevar descontado el consumo intermedio.

71

1 Tal y como se comprueba al comparar el consumo privado de servicios de alquiler de inmuebles que comprende todos los gastos de los hogares en alquileres de inmuebles reales e imputados (2.881.560 millones de pesetas en la TIO90) con los ingresos de los hogares por alquileres imputados de las viviendas propiedad de los hogares (3.271.944 millones de pesetas en la EPF90-91)

${ }^{72}$ Este dato lo hemos obtenido a partir del cuadro 3.23 de este capítulo que recoge los gastos de consumo final de los hogares por categorías de productos y funciones de consumo PROCOME.

${ }^{73}$ Estos porcentajes los hemos calculado a partir del fichero de gastos de la EPF90-91. En la medida que los gastos en alquileres reales se registran en términos brutos (alquileres netos más gastos comunitarios) y los gastos en alquileres imputados en términos netos, para calcular la distribución del gasto de los hogares en alquile-
} 
una infraestimación bastante mayor para las rentas mixtas y los ingresos por alquileres reales de los hogares. Ante la falta de información adicional suponemos la misma subestimación para ambas partidas y las corregimos directamente con los datos que proporciona la CNE90 netos de cotizaciones sociales y de retenciones por I.R.P.F. a cargo de los trabajadores autónomos, tal y como refleja el cuadro 3.1074.

CUADRO 3.10. Renta mixta y excedente de explotación de los hogares

\begin{tabular}{|c|c|c|c|c|}
\hline \multicolumn{2}{|l|}{ CNE90 } & & & \\
\hline Excedente bruto de explotación del sector hogares & 13.191 .170 & \multirow{4}{*}{13.175 .508} & \multirow{4}{*}{ 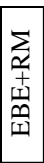 } & \\
\hline Excedente bruto de explotación de las IPSFL (TIO90, R.58)) & 15.662 & & & \\
\hline Excedente bruto de explotación de los hogares (1) & 13.175.508 & & & \\
\hline Excedente neto de explotación del sector hogares (2) & 11.584 .867 & & & \\
\hline Cotizaciones sociales pagadas por los trabajadores autónomos (3) & 414.697 & 414.697 & \multirow{10}{*}{ 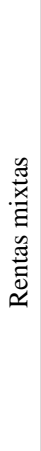 } & \\
\hline IRPF por trabajo por cuenta propia* (4) & 475.600 & 475.600 & & \\
\hline Excedente bruto de explotación excluidas cotizaciones e IRPF (1-3-4) & 12.285 .211 & & & \\
\hline Excedente neto de explotación excluidas cotizaciones e IRPF (2-3-4) & 10.694 .570 & & & \\
\hline \multicolumn{2}{|l|}{ EPF90-91 } & & & $\sqrt{3}$ \\
\hline Ingresos monetarios netos del trabajo por cuenta propia & 2.954 .489 & & & $\sqrt[5]{5}$ \\
\hline Ingresos no monetarios netos del trabajo por cuenta propia & & & & \\
\hline Autoconsumo & 138.202 & & & \\
\hline Autosuministro & 50.728 & & & \\
\hline Comidas en el establecimiento de hostelería propiedad del hogar & 34.175 & & & \\
\hline Total de ingresos del trabajo por cuenta propia (1) & 3.177.594 & 9.799 .077 & & \\
\hline Ingresos monetarios netos por alquileres de viviendas y locales (2) & 135.266 & 417.134 & 空 & \\
\hline Alquileres imputados de las viviendas propiedad de los hogares (3) & 3.964 .803 & 2.069 .000 & $\pi$ & \\
\hline Excedente de explotación, en términos CNE90 (1+2+3) & 7.277 .663 & 12.285 .211 & & \\
\hline
\end{tabular}

Fuente: Elaborado a partir de INE (1992c y 1995b). (*) Cifra estimada en Sanz (1995).

Para calcular ahora la desagregación del excedente de explotación del sector empresas y la renta mixta obtenida para el sector hogares entre las 48 ramas de actividad consideradas en la MCSE-90, determinamos la distribución de la renta mixta y residualmente obtenemos la del excedente bruto de explotación de las empresas.

res reales e imputados hemos sumado los gastos comunitarios de las viviendas en propiedad o en cesión gratuita a los alquileres imputados netos.

${ }^{74}$ El consumo de capital fijo de los hogares, que comprende tanto el que afecta a sus bienes inmuebles como a los activos fijos empleados para desarrollar su actividad empresarial, ascendió a 1.590.641 millones de pesetas. 
A partir de la información de la EPF90-91 hemos clasificado las rentas del trabajo por cuenta propia, tanto monetarias como no monetarias ${ }^{75}$, según la rama de actividad en la que han sido generadas (CNAE-74, un dígito) ${ }^{76}$. La distribución porcentual por actividades de las rentas netas del trabajo por cuenta propia así obtenida no coincide exactamente con la de la renta mixta bruta ajustada a la CNE90 que presentamos en el cuadro 3.11, al haber repartido las retenciones a cuenta por I.R.P.F. del trabajo autónomo en proporción a los ingresos brutos por trabajo por cuenta propia ${ }^{77} \mathrm{y}$ las cotizaciones sociales y el consumo de capital fijo ${ }^{78}$ en proporción a los ingresos netos.

Para repartir ahora la renta mixta entre las ramas de actividad consideradas en la MCSE-90, suponemos que la renta mixta generada depende del valor añadido bruto a coste de factor por empleado y del número de empleados por cuenta propia de cada una de ellas ( véase cuadro 3.11). Como señalamos con anterioridad, el excedente de explotación generado por el sector empresas en cada una de las ramas de actividad distinguidas lo hemos calculado residualmente ${ }^{79}$. Los resultados obtenidos para los

\footnotetext{
${ }^{75}$ Las rentas no monetarias por autosuministro y comidas y cenas en el establecimiento de hostelería propiedad del hogar las hemos asignado a partes iguales entre los miembros del hogar que perciben ingresos monetarios por trabajo por cuenta propia y desarrollan su actividad en la rama de comercio, restaurantes y hostelería. El autoconsumo, por tratarse principalmente de productos alimenticios, entre aquellos que desarrollan su actividad por cuenta propia en las ramas agraria o de otras manufacturas. Nótese que una parte importante del autoconsumo (aproximadamente un 45\%) está registrado para hogares que no cuentan entre sus miembros con ningún perceptor de rentas del trabajo por cuenta propia, circunstancia que se explica por la existencia de hogares “consumidores” que producen bienes agrarios para uso final propio.

${ }^{76}$ Alrededor de un 3\% de los perceptores de rentas del trabajo por cuenta propia no tienen asignada una rama de actividad, por ello les hemos asignado una aleatoriamente con la única restricción de que la participación de las distintas ramas de actividad en el empleo por cuenta propia antes y después de la asignación sea la misma. $\mathrm{Al}$ igual que para los sueldos y salarios brutos, hemos incluido las actividades de servicios agrarios y ganaderos que pertenecen a la rama agraria en la rama de instituciones financieras, seguros, servicios prestados a las empresas y alquileres para facilitar la comparación de los resultados con los datos de la TIO90.

${ }^{77}$ El tipo de retención aplicable a dichos ingresos según el Real Decreto 1009/1990 de 27/7/1990 es de un 15\%.

78

Aunque existen series de stock neto de capital privado y de inversión privada por ramas de actividad (Fundación BBV, 1998) que permiten calcular el consumo de capital fijo por actividades para 1990, éstas no ofrecen información sobre su distribución entre las empresas y los hogares.

${ }^{79}$ Para la rama de madera y muebles de madera (R.27), la renta mixta estimada supera la cifra conjunta de la TIO90 para las rentas mixtas y el excedente de explotación, por lo que hemos repartido el exceso de renta mixta entre el resto de ramas que pertenecen a su misma actividad en la clasificación a un dígito de la CNAE-74. En cuanto al excedente de explotación de la rama de PISB, como la CNE90 realiza los ajustes por PISB en empleos de la cuenta de explotación del sector instituciones de crédito, lo hemos asignado íntegramente al sector empresas suponiendo así que toda la PISB es un consumo intermedio de dicho sector.
} 
hogares y para el sector empresas, desglosados por ramas de actividad, están recogidos en las filas 10 a 13 de la submatriz de valor añadido (3.2) del cuadro A.1 del anexo.

CUADRO 3.11. Desagregación de la renta mixta por ramas de actividad

\begin{tabular}{|c|c|c|c|c|c|c|}
\hline $\begin{array}{l}\text { Códigos } \\
\text { CNAE-74 }\end{array}$ & $\begin{array}{l}\text { EPF90-91 } \\
(\%)\end{array}$ & \multicolumn{3}{|c|}{$\begin{array}{l}\text { MCSE-90 } \\
\text { (millones) }\end{array}$} & $\begin{array}{l}\text { Empleos por } \\
\text { cuenta propia }\end{array}$ & $\begin{array}{c}\mathrm{VAB}_{\mathrm{cf}} \text { por } \\
\text { empleado (miles) }\end{array}$ \\
\hline 00 & 17,27 & \multicolumn{2}{|c|}{1.845 .309} & R.1 & 995.800 & 1.733 \\
\hline 10 & 0,59 & $\begin{array}{l}\ddot{0} \\
\dot{0} \\
\dot{\theta}\end{array}$ & $\begin{array}{l}10.794 \\
18.587 \\
33.705 \\
\end{array}$ & $\begin{array}{l}\text { R.2 } \\
\text { R.6 } \\
\text { R.7 } \\
\end{array}$ & $\begin{array}{l}400 \\
600 \\
300 \\
\end{array}$ & $\begin{array}{r}5.166 \\
5.931 \\
21.509 \\
\end{array}$ \\
\hline 20 & 0,63 & $\begin{array}{l}\overline{8} \\
\stackrel{0}{0} \\
\widehat{6}\end{array}$ & \begin{tabular}{r|}
2.690 \\
2.475 \\
46.175 \\
15.750 \\
\end{tabular} & $\begin{array}{l}\text { R.10 } \\
\text { R.11 } \\
\text { R.12 } \\
\text { R.13 }\end{array}$ & $\begin{array}{r}500 \\
400 \\
10.200 \\
2.800\end{array}$ & $\begin{array}{l}5.703 \\
6.559 \\
4.798 \\
5.962\end{array}$ \\
\hline 30 & 4,34 & $\begin{array}{l}\mathscr{0} \\
\infty \\
\end{array}$ & $\begin{array}{r}255.954 \\
82.433 \\
39.754 \\
79.543 \\
3.359 \\
2.826 \\
\end{array}$ & $\begin{array}{l}\text { R.14 } \\
\text { R.15 } \\
\text { R.16 } \\
\text { R.17 } \\
\text { R.18 } \\
\text { R.19 } \\
\end{array}$ & $\begin{array}{r}44.600 \\
11.200 \\
3.200 \\
9.600 \\
500 \\
400\end{array}$ & $\begin{array}{l}2.827 \\
3.625 \\
6.119 \\
4.081 \\
3.309 \\
3.480 \\
\end{array}$ \\
\hline 40 & 8,95 & $\begin{array}{l}\text { Dे } \\
\text { m. } \\
\text { 以ू. }\end{array}$ & $\begin{array}{r}106.638 \\
11.472 \\
310.981 \\
44.128 \\
3.111 \\
143.612 \\
52.792 \\
153.671 \\
58.842 \\
14.659 \\
55.395 \\
\end{array}$ & $\begin{array}{l}\text { R.20 } \\
\text { R.21 } \\
\text { R.22 } \\
\text { R.23 } \\
\text { R.24 } \\
\text { R.25 } \\
\text { R.26 } \\
\text { R.27 } \\
\text { R.28 } \\
\text { R.29 } \\
\text { R.30 } \\
\end{array}$ & $\begin{array}{r}15.900 \\
1.500 \\
61.800 \\
4.900 \\
400 \\
50.500 \\
16.200 \\
74.400 \\
11.800 \\
2.400 \\
14.700 \\
\end{array}$ & $\begin{array}{l}4.981 \\
5.680 \\
3.737 \\
6.688 \\
5.776 \\
2.112 \\
2.420 \\
1.534 \\
3.703 \\
4.536 \\
2.798 \\
\end{array}$ \\
\hline 50 & 9,56 & \multicolumn{2}{|c|}{ 1.019.771 } & & 258.500 & 3.616 \\
\hline 60 & 37,51 & $\begin{array}{l}\infty \\
\infty \\
م \\
\stackrel{0}{0} \\
0 \\
\dot{+}\end{array}$ & $\begin{array}{r}331.353 \\
2.420 .354 \\
1.264 .081 \\
\end{array}$ & $\begin{array}{l}\text { R.32 } \\
\text { R.33 } \\
\text { R.34 }\end{array}$ & $\begin{array}{r}94.600 \\
852.200 \\
350.500 \\
\end{array}$ & $\begin{array}{l}3.998 \\
3.242 \\
4.116 \\
\end{array}$ \\
\hline 70 & 7,11 & $\begin{array}{l}m \\
\stackrel{2}{2} \\
\dot{0} \\
1\end{array}$ & $\begin{array}{r}728.571 \\
18.934 \\
14.197 \\
\end{array}$ & $\begin{array}{l}\text { R.35 } \\
\text { R.36 } \\
\text { R.37 }\end{array}$ & $\begin{array}{r}259.200 \\
3.300 \\
2.700 \\
\end{array}$ & $\begin{array}{l}3.156 \\
6.443 \\
5.904 \\
\end{array}$ \\
\hline 80 & 6,10 & 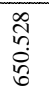 & $\begin{array}{l}408.947 \\
241.582\end{array}$ & $\begin{array}{l}\text { R. } 40 \\
\text { R. } 41\end{array}$ & $\begin{array}{r}82.200 \\
1.400\end{array}$ & $\begin{array}{r}6.200 \\
215.036\end{array}$ \\
\hline 90 & 7,92 & 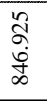 & $\begin{array}{l}118.485 \\
186.876 \\
541.564 \\
\end{array}$ & $\begin{array}{l}\text { R.42 } \\
\text { R.43 } \\
\text { R.44 } \\
\end{array}$ & $\begin{array}{r}38.500 \\
24.800 \\
125.400\end{array}$ & $\begin{array}{l}2.283 \\
5.591 \\
3.204 \\
\end{array}$ \\
\hline \multicolumn{2}{|c|}{$\mathrm{T}$ otal } & \multicolumn{3}{|c|}{10.689 .374} & 3.428 .300 & 193.777 \\
\hline
\end{tabular}

Fuente: Elaborado a partir de INE (1992c y 1995b). 


\subsubsection{Asignación y redistribución de la renta}

La renta generada por los distintos factores de producción se asigna entre las unidades institucionales propietarias de los mismos y posteriormente éstas la redistribuyen entre sí a través de transferencias corrientes. La contribución de las matrices de contabilidad social a este respecto consiste en desglosar al sector hogares en grupos relevantes para el análisis de los procesos de distribución primaria y secundaria de la renta. En este apartado describimos la metodología de elaboración de la submatriz de renta generada bruta (3.3.3.1) que describe la asignación de las rentas de los factores productivos a los sectores institucionales y grupos de hogares distinguidos en la MCSE-90 y de la submatriz de rentas de la propiedad (3.3.3.2) y transferencias corrientes (3.3.3.3) que completa la distribución primaria de la renta y refleja su posterior redistribución.

\subsubsection{Distribución de la renta generada por factores y sectores institucionales}

La renta generada bruta es un agregado macroeconómico intermedio entre el valor añadido bruto y la renta primaria bruta de un sector institucional y se define como la renta a cobrar por la participación directa en el proceso productivo. Para las empresas e IPSFL, dicho agregado coincide con sus respectivos excedentes de explotación; en el caso de las AA.PP. incluye, además del excedente de explotación, los impuestos que gravan la producción y la importación netos de subvenciones; y, por último, en el caso de los hogares comprende las rentas del trabajo percibidas, la renta mixta bruta y el excedente de explotación. De ahí que la complejidad de elaborar la submatriz de renta generada bruta radique en determinar su distribución por grupos de hogares. 
Los sueldos y salarios brutos ${ }^{80}$ percibidos por las unidades residentes y la renta mixta bruta, ajustados ambos con la CNE90 por ramas de actividad de la CNAE-74 a un dígito, los hemos distribuido respectivamente entre los preceptores de rentas del trabajo por cuenta ajena y por cuenta propia de acuerdo con su rama de actividad y sus respectivos sueldos y salarios brutos e ingresos brutos del trabajo por cuenta propia estimados en los apartados 3.3.2.1 y 3.3.2.2. A partir de los datos así obtenidos hemos calculado para cada hogar y grupos de hogares los sueldos y salarios brutos, según la categoría o categorías socioeconómicas de sus miembros ${ }^{81}$, y la renta mixta bruta correspondiente a cada uno de sus miembros.

Los excedentes brutos de explotación por la producción de servicios de alquiler reales e imputados los hemos asignado, respectivamente, a los distintos grupos de hogares según sus ingresos monetarios netos por alquileres de viviendas, locales y terrenos, y sus ingresos por alquileres imputados de las viviendas principal y secundaria propiedad del hogar ${ }^{82}$, netos de gastos de mantenimiento y conservación ${ }^{83}$.

\footnotetext{
${ }^{80}$ De acuerdo con el SCN93, las cotizaciones sociales a cargo de los empleadores forman parte de la renta generada del sector hogares. Sin embargo, para evitar los problemas derivados de la reasignación de las cotizaciones sociales a cargo de los empleadores, en este trabajo las consideramos como renta generada bruta de los sectores empresas y AA.PP. De acuerdo con la CNE85-93 (INE, 1995b), del total de cotizaciones sociales a cargo de los empleadores, el sector AA.PP. recibió 4.816 .935 millones de pesetas y los 665.216 millones restantes el sector empresas (69.217 millones correspondieron a las empresas de seguro, 346.705 a las sociedades y cuasisociedades no financieras y 249.294 a las instituciones de crédito).

81 Dado que en la EPF90-91 hay empresarios, profesionales y trabajadores independientes no agrarios (CSE3) y no clasificables (CSE8) que perciben rentas del trabajo por cuenta ajena y dichas categorías no han sido consideradas en la MCSE-90, utilizamos el método RAS para ajustar la matriz de distribución de sueldos y salarios brutos por categorías de asalariados y grupos de hogares.

${ }^{82}$ Los ingresos por alquileres imputados de las viviendas cedidas por razones de trabajo de los hogares que no cuentan entre sus miembros con ningún perceptor de rentas salariales los hemos considerado como ingresos imputados de viviendas propiedad del hogar o de viviendas cedidas por instituciones públicas o privadas, dependiendo de si dichos hogares declaran gastos de alquiler imputados en viviendas propiedad de los hogares o en cesión gratuita. Además hemos comprobado que para estos hogares coinciden los gastos e ingresos imputados que declaran por alquiler de vivienda principal y secundaria.

83

De un total de 17.946 observaciones con ingresos por alquileres imputados de viviendas propiedad de los hogares, tan sólo tres de ellas tienen registrados además ingresos por alquileres imputados de la vivienda principal cedida por razón de trabajo, por lo que hemos considerado todos sus gastos de reparación, acondicionamiento y mantenimiento de la vivienda como consumo intermedio. Asimismo hay una observación que sin tener ingresos imputados por vivienda propiedad del hogar o en cesión gratuita tiene registrados gastos de mantenimiento y conservación en ese tipo de viviendas, por ello los hemos tratado como un gasto de consumo final.
} 
Los resultados obtenidos están recogidos en la submatriz de renta generada bruta (4.3) que figura en el cuadro A.1 del anexo estadístico.

\subsubsection{Las rentas de la propiedad y de la empresa}

Todas las rentas a cobrar por los propietarios de activos financieros y de activos no financieros no producidos por poner sus activos a disposición de otras unidades conforman las rentas de la propiedad y de la empresa. Bajo esta denominación la CNE90 incluye los dividendos y otras rentas distribuidas por las sociedades, las rentas retiradas por los empresarios de cuasisociedades, las rentas de la tierra y de activos inmateriales, los intereses efectivos y los intereses imputados derivados de los contratos de seguro. Para todas ellas ofrece información por sectores institucionales ${ }^{84}$ en sus respectivas cuentas de renta que, al tratarse de cuentas pantalla, no siempre posibilitan la identificación de los sectores de origen y destino de las distintas categorías de rentas de la propiedad y de la empresa en ellas registradas, lo que explica la necesidad de introducir algunos supuestos para su determinación.

Los dividendos y otras rentas distribuidas por las sociedades (que la CNE agrupa con las rentas retiradas por los empresarios de cuasisociedades) constituyen un empleo para las empresas, residentes o del resto del mundo. Dado que conocemos la parte pagada por las empresas residentes al resto del mundo, hemos asignado el resto de dividendos y otras rentas pagadas por las empresas y todas las pagadas por el resto del mundo entre los sectores residentes en proporción a sus recursos en concepto de dividendos y otras rentas de sociedades (cuadro 3.12.a). Las rentas de la tierra y de activos inmateriales no plantean mayores problemas porque las rentas que perciben los sectores residentes (hogares y empresas) coinciden con las pagadas por el resto del mundo y viceversa (cuadro 3.12.b). Los intereses imputados derivados de los contratos de seguro tampoco plantean dificultad alguna por afectar a un sólo sector en su origen y destino (cuadro 3.12.c). Por último, para asignar los intereses

\footnotetext{
${ }^{84}$ Las rentas de la propiedad y de la empresa recibidas y pagadas por las instituciones privadas sin fines de lucro están integradas con las de los hogares.
} 
efectivos (cuadro 3.12.d), hemos supuesto que todos los intereses que pagan los hogares y las unidades no residentes son recibidos por el sector empresas, en tanto que los pagados por las AA.PP y las empresas se distribuyen entre el resto de sectores proporcionalmente a sus recursos por dicho concepto ${ }^{85}$.

CUADRO 3.12. Rentas de la propiedad y de la empresa por sectores institucionales

\begin{tabular}{|c|c|c|c|c|c|}
\hline \multicolumn{6}{|c|}{ a) Dividendos y otras rentas } \\
\hline & Hogares & Empresas & AA.PP. & RDM & Total \\
\hline Hogares & 0 & 616.896 & 0 & 20.501 & 637.397 \\
\hline Empresas & 0 & 333.043 & 0 & 11.071 & 344.114 \\
\hline AA.PP. & 0 & 271.913 & 0 & 9.043 & 280.956 \\
\hline RDM & 0 & 315.654 & 0 & 0 & 315.654 \\
\hline Total & 0 & 1.537 .506 & 0 & 40.615 & 1.578 .121 \\
\hline \multicolumn{6}{|c|}{ b) Rentas de la tierra y activos inmateriales } \\
\hline & Hogares & Empresas & AA.PP. & RDM & Total \\
\hline Hogares & 0 & 0 & 0 & 4.184 & 4.184 \\
\hline Empresas & 0 & 0 & 0 & 12.600 & 12.600 \\
\hline AA.PP. & 0 & 0 & 0 & 0 & 0 \\
\hline RDM & 0 & 124.562 & 0 & 0 & 124.562 \\
\hline Total & 0 & 124.562 & 0 & 16.784 & 141.346 \\
\hline \multicolumn{6}{|c|}{ c) Intereses imputados derivados de contratos de seguro } \\
\hline & Hogares & Empresas & AA.PP. & RDM & Total \\
\hline Hogares & 0 & 202.526 & 0 & 0 & 202.526 \\
\hline Empresas & 0 & 0 & 0 & 0 & 0 \\
\hline AA.PP. & 0 & 0 & 0 & 0 & 0 \\
\hline RDM & 0 & 0 & 0 & 0 & 0 \\
\hline Total & 0 & 202.526 & 0 & 0 & 202.526 \\
\hline \multicolumn{6}{|c|}{ d) Intereses efectivos } \\
\hline & Hogares & Empresas & AA.PP. & RDM & Total \\
\hline Hogares & 0 & 2.729 .298 & 394.817 & 0 & 3.124 .115 \\
\hline Empresas & 2.177 .776 & 6.534 .724 & 1.366 .429 & 733.361 & 10.812 .290 \\
\hline AA.PP. & 0 & 204.925 & 0 & 0 & 204.925 \\
\hline RDM & 0 & 730.381 & 105.656 & 0 & 836.037 \\
\hline Total & 2.177 .776 & 10.199 .328 & 1.866 .902 & 733.361 & 14.977 .367 \\
\hline \multicolumn{6}{|c|}{$(a+b+c+d)$ Rentas de la propiedad y de la empresa } \\
\hline & Hogares & Empresas & AA.PP. & RDM & Total \\
\hline Hogares & 0 & 3.548 .720 & 394.817 & 24.685 & 3.968 .222 \\
\hline Empresas & 2.177 .776 & 6.867 .767 & 1.366 .429 & 757.032 & 11.169 .004 \\
\hline AA.PP. & 0 & 476.838 & 0 & 9.043 & 485.881 \\
\hline RDM & 0 & 1.170 .597 & 105.656 & 0 & 1.276 .253 \\
\hline Total & 2.177 .776 & 12.063 .922 & 1.866 .902 & 790.760 & 16.899 .360 \\
\hline
\end{tabular}

Fuente: Elaborado a partir de INE (1995b)

${ }^{85}$ Criterios muy similares son empleados en Uriel y otros (1997). No obstante, como los ingresos por alquileres de los propietarios de inmuebles y terrenos situados en el territorio económico de otro país son registrados por los Sistemas de Cuentas Nacionales como intereses efectivos recibidos (o pagados) del (al) resto del mundo, una parte de los intereses recibidos por los hogares proceden del resto del mundo y viceversa. 
Para desglosar ahora las rentas de la propiedad y de la empresa entre los diversos grupos de hogares ${ }^{86}$ recurrimos a la EPF90-91 que registra, bajo la denominación de ingresos por rentas del capital y de la propiedad: los ingresos por intereses y dividendos, los rendimientos de rentas temporales o vitalicias, los ingresos por otras rentas del capital y de la propiedad, los ingresos por alquileres, los intereses pagados, los gastos generados para la producción de otras rentas del capital y los gastos en las viviendas, locales o terrenos alquilados ${ }^{87}$. Una vez descontados los ingresos netos por alquileres, las cifras recogidas por la EPF90-91 discrepan considerablemente de los datos de la CNE90 para el conjunto del sector hogares, lo que en buena medida se explica por las diferencias metodológicas entre ambas fuentes (cuadro 3.13).

CUADRO 3.13. Rentas de la propiedad de los hogares en la EPF90-91 y la CNE90

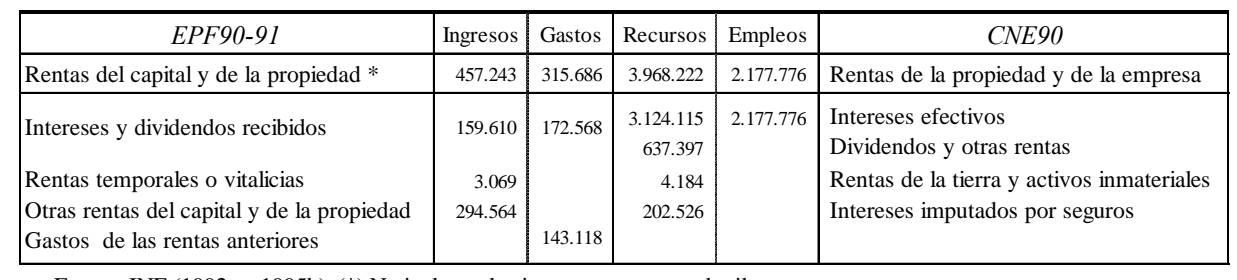

Fuente: INE (1992c y 1995b). (*) No incluyen los ingresos netos por alquileres.

Aunque a primera vista pueda parecer que la partida de intereses y dividendos de la EPF90-91 ${ }^{88}$ se asemeja a las de intereses efectivos y dividendos y otras rentas de la CNE90, entre ambas existen diferencias notables como son la inclusión por parte de la CNE90 de las instituciones privadas sin fines de lucro en el sector hogares o el tratamiento que la CNE90 otorga a las provisiones técnicas de seguros no de vida ${ }^{89}$, a las

\footnotetext{
${ }^{86}$ Ante la falta de información, hemos optado por no desglosar las rentas de la propiedad y de la empresa correspondiente al sector hogares entre hogares y organismos privados sin fines de lucro.

${ }^{87}$ En esta ocasión hemos utilizado el fichero tipo3 de la EPF90-91 de miembros del hogar en lugar del fichero de datos generales del hogar, porque en este último tan sólo figuran los ingresos de los hogares por intereses y dividendos netos y por otras rentas del capital y de la propiedad.

${ }^{88}$ Dicha partida comprende, los intereses y dividendos procedentes de obligaciones, acciones, etc, y los intereses recibidos/pagados por cuentas corrientes, cuentas de ahorro, depósitos a plazo y préstamos.

${ }^{89}$ Para mantener el equilibrio entre las primas netas de seguro e indemnizaciones para el conjunto de la economía, la Contabilidad Nacional crea un circuito ficticio para los seguros de accidentes a través del cuál las empresas aseguradoras pagan a los sectores asegurados unos intereses imputados por los rendimientos de las in-
} 
bonificaciones de intereses ${ }^{90} \mathrm{y}$ a los alquileres correspondientes a las unidades residentes ficticias ${ }^{91}$. Algunas de las diferencias anteriores son también aplicables a la partida de otras rentas del capital y de la propiedad de la $\mathrm{EPF}^{92}$. En el caso de los intereses imputados derivados de los contratos de seguro, que la CNE90 registra como una renta de la propiedad y de la empresa ${ }^{93}$, ni siquiera existe una contrapartida en la EPF90-91. Ante la falta de una correspondencia exacta entre las dos fuentes estadísticas consideradas para cada una de las partidas que componen las rentas de la propiedad y de la empresa hemos decidido ajustarlas de forma conjunta.

Dado que, por una parte, en la EPF90-91 los hogares que declaran ingresos y gastos por rentas del capital y de la propiedad tan sólo suponen, respectivamente, el $18,53 \%$ y el $12,12 \%{ }^{94} \mathrm{y}$, por otra, que la CNE90 incluye las instituciones privadas sin fines de lucro, los resultados que se obtienen al realizar el ajuste hogar por hogar no son aceptables ${ }^{95}$. La alternativa por la que hemos optado consiste en agrupar a los

versiones afectas a las provisiones técnicas. Estos intereses se incluyen en la partida de intereses efectivos de los sectores afectados.

${ }^{90}$ La CNE90 registra los intereses pagados por los hogares sin deducir las bonificaciones de intereses que en ocasiones les otorgan las AA.PP. como, por ejemplo, las que tienen como finalidad facilitar el acceso a la vivienda. Dichas bonificaciones tienen la consideración de subvenciones de explotación al sector hogares y su importe según las Cuentas de las AA.PP.(IGAE, 1993) alcanzó los 55.866 millones de pesetas en 1990.

${ }^{91}$ Los alquileres netos por inmuebles y terrenos situados fuera del país de residencia son registrados por la CNE como intereses efectivos, debido a que la compra de un inmueble o terreno por una unidad no residente se registra como un préstamo a largo plazo otorgado a unidad residente ficticia creada al efecto.

92 En dicha partida se registran las rentas obtenidas por la participación en beneficios de sociedades, fondos de inversión y otros rendimientos del capital mobiliario, las rentas que las sociedades pagan a los miembros de sus consejos de administración, siempre que no sean asalariados de la empresa, y los rendimientos de rentas temporales o vitalicias y de la propiedad intelectual o industrial, cuando no es el autor el perceptor de las ganancias.

93 Reflejan los rendimientos netos de las inversiones realizadas con las provisiones técnicas mantenidas por las entidades aseguradoras en los casos de seguros de vida y fondos de pensiones.

${ }^{94}$ Concretamente, el $11,41 \%$ de los hogares declaran ingresos por intereses y dividendos, el 0,057\% por rentas temporales o vitalicias y el 8,47\% por otras rentas del capital. Además, mientras que la EPF90-91 registra un saldo negativo por intereses y dividendos netos de 12.958 millones pts., la CNE90 registra saldos positivos para los intereses netos y para los dividendos y otras rentas de sociedades por importes de 94.639 y 637.397 millones pts., respectivamente.

${ }^{95}$ En la gran mayoría de los casos, tras el ajuste, las rentas de la propiedad y de la empresa se convierten en la principal fuente de recursos de los hogares que declaran ingresos por dicho concepto y para los que declaran pagar intereses, su renta disponible se vuelve negativa. 
hogares por deciles de renta ${ }^{96} \mathrm{y}$ ajustar las rentas del capital y de la propiedad recibidas y pagadas por cada uno de los grupos de hogares en la EPF90-91 con las rentas de la propiedad y de la empresa estimadas por la CNE9097. Una vez obtenidos los importes por deciles, hemos asignado a cada hogar los ingresos y gastos que declara más la parte que le corresponde como resultado del reparto, a partes iguales, del remanente de cada decil entre todos sus hogares independientemente de si declaran o no percibir y/o pagar rentas del capital y de la propiedad ${ }^{98}$. Finalmente, los ingresos y gastos estimados para cada hogar se agregan para conformar los de los treinta grupos de hogares distinguidos en la MCSE-90 (cuadro 3.14).

\footnotetext{
${ }^{96}$ Como todavía no es posible determinar la renta disponible de los hogares, la variable renta que utilizamos para construir los deciles con los que repartir las rentas de la propiedad y de la empresa incluyen las rentas del trabajo por cuenta propia y por cuenta ajena netas de cotizaciones, el excedente de explotación por la producción de servicios de alquiler y las prestaciones sociales.

97

Excluimos los intereses imputados derivados de los contratos de seguro y los intereses imputados por rendimientos de inversiones afectas a las provisiones técnicas de seguro de accidentes, por lo que los ingresos y gastos a repartir son 3.733.267 y 2.177.776 millones pts., respectivamente.

${ }^{98}$ Los intereses imputados derivados de los contratos de seguro (202.526 millones pts.) y los intereses imputados por rendimientos de las inversiones afectas a las provisiones técnicas de seguro de accidentes (32.429 millones pts.), excluidos con anterioridad, los hemos asignado a los hogares en proporción a sus gastos en primas brutas de seguro de "vida" y "no vida", respectivamente. Los intereses imputados los hemos calculado como la diferencia entre las indemnizaciones por seguro de accidente pagadas por las empresas de seguro a los hogares y las primas netas de seguro de accidentes. Por definición, las primas netas de seguro de accidentes representan la parte de la prima bruta destinada a cubrir las indemnizaciones que no han podido ser pagadas por las rentas netas procedentes de las inversiones mobiliarias o inmobiliarias realizadas por las empresas de seguro con las provisiones técnicas correspondientes a los seguros de accidentes.
} 
CUADRO 3.14. Rentas de la propiedad y de la empresa por grupos de hogares

\begin{tabular}{|c|c|c|c|c|c|c|c|c|c|}
\hline \multirow{2}{*}{\multicolumn{4}{|c|}{ Grupos hogares }} & \multicolumn{4}{|c|}{ Recibidas de } & \multicolumn{2}{|c|}{ Pagadas a } \\
\hline & & & & Empresas & AAPP & $\mathrm{RDM}$ & Total & Empresas & Total \\
\hline \multirow{6}{*}{ 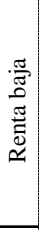 } & \multirow{3}{*}{ Trabajo } & C. propia & H.1 & 15.321 & 1.649 & 103 & 17.074 & 9.617 & 9.617 \\
\hline & & C. ajena sin cualif. & H.2 & 263.566 & 30.588 & 1.912 & 296.067 & 144.408 & 144.408 \\
\hline & & C. ajena cualif. & H.3 & 5.613 & 591 & 37 & 6.240 & 2.975 & 2.975 \\
\hline & \multicolumn{2}{|c|}{ Rentas de la propiedad } & H.4 & 23.087 & 2.739 & 171 & 25.997 & 784 & 784 \\
\hline & \multirow{2}{*}{ Transfer. } & Pensiones & H.5 & 149.510 & 17.651 & 1.104 & 168.264 & 17.790 & 17.790 \\
\hline & & Otras & H.6 & 80.237 & 9.459 & 591 & 90.288 & 30.014 & 30.014 \\
\hline \multirow{6}{*}{ 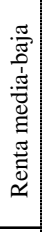 } & \multirow{3}{*}{ Trabajo } & C. propia & H.7 & 26.302 & 2.957 & 185 & 29.444 & 21.437 & 21.437 \\
\hline & & C. ajena sin cualif. & H.8 & 261.350 & 29.890 & 1.869 & 293.109 & 202.377 & 202.377 \\
\hline & & C. ajena cualif. & H.9 & 10.153 & 1.093 & 68 & 11.314 & 10.623 & 10.623 \\
\hline & \multicolumn{2}{|c|}{ Rentas de la propiedad } & H.10 & 14.437 & 1.683 & 105 & 16.225 & 1.313 & 1.313 \\
\hline & Tra & Pensiones & H.11 & 145.393 & 17.088 & 1.068 & 163.549 & 26.263 & 26.263 \\
\hline & 170 & Otras & H.12 & 88.532 & 10.420 & 651 & 99.604 & 40.833 & 40.833 \\
\hline \multirow{6}{*}{ 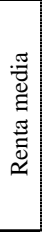 } & \multirow{3}{*}{ Trabajo } & & H.13 & 56.162 & 6.367 & 398 & 62.927 & 55.302 & 55.302 \\
\hline & & C. ajena sin cualif. & H.14 & 258.877 & 29.013 & 1.814 & 289.703 & 227.236 & 227.236 \\
\hline & & C. ajena cualif. & H.15 & 25.561 & 2.905 & 182 & 28.648 & 25.024 & 25.024 \\
\hline & \multicolumn{2}{|c|}{ Rentas de la propiedad } & H.16 & 15.111 & 1.772 & 111 & 16.995 & 2.408 & 2.408 \\
\hline & \multirow{2}{*}{ Transfer. } & Pensiones & H.17 & 96.072 & 11.040 & 690 & 107.802 & 21.987 & 21.987 \\
\hline & & Otras & H.18 & 130.057 & 15.266 & 955 & 146.278 & 51.577 & 51.577 \\
\hline \multirow{6}{*}{ 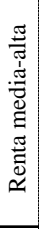 } & \multirow{3}{*}{ Trabajo } & C. propia & H.19 & 167.534 & 18.877 & 1.180 & 187.591 & 161.094 & 161.094 \\
\hline & & C. ajena sin cualif. & H.20 & 259.975 & 28.479 & 1.781 & 290.235 & 235.977 & 235.977 \\
\hline & & C. ajena cualif. & H.21 & 63.213 & 6.693 & 418 & 70.324 & 58.771 & 58.771 \\
\hline & \multicolumn{2}{|c|}{ Rentas de la propiedad } & H.22 & 13.939 & 1.635 & 102 & 15.676 & 2.534 & 2.534 \\
\hline & & & H.23 & 48.368 & 5.611 & 351 & 54.329 & 18.192 & 18.192 \\
\hline & 1 & Otras & H.24 & 106.785 & 12.399 & 775 & 119.960 & 55.759 & 55.759 \\
\hline \multirow{6}{*}{ 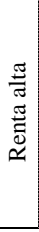 } & \multirow{3}{*}{ Trabajo } & C. propia & H.25 & 610.787 & 65.690 & 4.107 & 680.584 & 365.365 & 365.365 \\
\hline & & C. ajena sin cualif. & H.26 & 224.225 & 22.778 & 1.424 & 248.427 & 167.834 & 167.834 \\
\hline & & C. ajena cualif. & H.27 & 243.846 & 24.371 & 1.524 & 269.741 & 155.905 & 155.905 \\
\hline & \multicolumn{2}{|c|}{ Rentas de la propiedad } & H.28 & 56.056 & 5.973 & 373 & 62.402 & 17.258 & 17.258 \\
\hline & \multirow{2}{*}{ Transfer. } & Pensiones & H.29 & 26.888 & 2.990 & 187 & 30.065 & 10.550 & 10.550 \\
\hline & & Otras & H..30 & 61.762 & 7.151 & 447 & 69.360 & 36.568 & 36.568 \\
\hline & & Total & & 3.548 .720 & 394.817 & 24.685 & 3.968 .222 & 2.177 .776 & 2.177 .776 \\
\hline
\end{tabular}

Fuente: Elaborado a partir de INE (1992c) y cuadro 3.12.

Las rentas de la propiedad y de la empresa recibidas y pagadas por cada uno de los treinta grupos de hogares figuran junto con las transferencias corrientes en la submatriz 4.4 del cuadro A.1 del anexo estadístico. 


\subsubsection{Las transferencias corrientes}

Las rentas primarias de los sectores institucionales (renta generada bruta más rentas netas de la propiedad y de la empresa) se redistribuyen a través de transferencias corrientes. Las categorías de transferencias corrientes para las que la CNE90 suministra información por sectores institucionales ${ }^{99}$ son las primas netas e indemnizaciones de seguro de accidentes, las cotizaciones sociales reales y ficticias, los impuestos corrientes sobre la renta y el patrimonio, y otras transferencias corrientes, como son la cooperación internacional corriente, las transferencias privadas internaciones, las transferencias corrientes entre AA.PP. y las transferencias corrientes diversas. Para calcular el montante de los flujos de transferencias corrientes registrados en la MCSE90, en primer lugar, determinamos los sectores de origen y destino de cada uno de los distintos tipos de transferencias corrientes que figuran en las cuentas de renta de los sectores y, en segundo lugar, estimamos su distribución por grupos de hogares.

Las primas netas y las indemnizaciones por seguro de accidentes ${ }^{100}$ las hemos repartido entre los sectores institucionales residentes (cuadros 3.15.a y 3.15.b) en proporción a sus respectivos empleos y recursos por dichos conceptos. La distribución por sectores de origen y destino de las cotizaciones sociales ficticias (3.15.c) no plantea dificultad, dado que todas ellas son pagadas por los hogares residentes; en tanto que para repartir las cotizaciones sociales reales (cuadro 3.15.d) hemos supuesto que las cotizaciones pagadas por el resto del mundo se distribuyen entre las empresas y las AA.PP en proporción a sus respectivos recursos por dicho concepto. Como en la MCSE-90 las cotizaciones sociales a cargo de los empleadores son tratadas como una categoría de valor añadido, la submatriz de rentas de la propiedad y transferencias co-

\footnotetext{
${ }^{99}$ Los flujos de las instituciones privadas sin fines de lucro están integrados con los de los hogares.

${ }^{100}$ Ambas partidas forman parte de las operaciones de seguro de accidentes que agrupan todos los flujos económicos relacionados con la cobertura de riesgos como responsabilidad civil, inundación, enfermedad, siniestros y otros, salvo vida, y se clasifican en: a) primas brutas de seguro de accidentes o pagos realizados a las empresas aseguradoras en virtud de las pólizas de seguros de accidente contratadas; b) primas netas de seguro de accidente o parte de la prima bruta destinada a cubrir las indemnizaciones que las empresas de seguros no cubren con las rentas procedentes de la inversión de sus provisiones técnicas de seguros de accidentes; c) indemnizaciones por seguro de accidentes que son los pagos que las empresas de seguro realizan en favor de sus asegu-
} 
rrientes tan sólo incluye las cotizaciones sociales a cargo de los hogares cuya distribución por tipos y sectores de destino es suministrada por la CNE90 (cuadro 3.15.e). La diferencia entre las cifras que figuran en los cuadros 3.15c y 3.15d y en el cuadro 3.15.e determina la distribución por sectores de origen y destino de las cotizaciones sociales a cargo de los empleadores. Con relación a las prestaciones sociales, aunque están desglosadas específicamente en la CNE por tipos y sector de procedencia, para determinar el origen de las prestaciones sociales que tienen como destino el resto del mundo hemos supuesto que las pagan las empresas y las AA.PP. en proporción a su participación en el total de prestaciones sociales (cuadro 3.15.f) ${ }^{101}$. Las otras transferencias corrientes consideradas son la cooperación internacional corriente, que da lugar a flujos entre las AA.PP. y el resto del mundo, las transferencias privadas internacionales $^{102}$, que generan flujos de renta entre los hogares residentes y no residentes (cuadro 3.15.g) y las transferencias corrientes diversas ${ }^{103}$, para cuyo reparto suponemos que todas las transferencias realizadas por los sectores AA.PP. y resto del mundo tienen como destino el sector hogares, y que las recibidas por el resto del mundo son pagadas por las empresas y los hogares en proporción a sus respectivos empleos por dicho concepto (cuadro 3.15.h). Por ultimo, todos los impuestos corrientes sobre la renta y el patrimonio son asignados en la CNE90 a las AA.PP. ${ }^{104}$ (cuadro 3.15.i).

rados cuando se cumplen las condiciones establecidas en la póliza y; d) intereses imputados de seguro de accidentes, ya definidos al determinar la distribución de los intereses efectivos.

${ }^{101}$ El total de prestaciones sociales percibidas por el sector hogares no coincide con el publicado por la CNE90 porque están excluidas las prestaciones sanitarias en especie (545.099 millones pts.) que, de acuerdo con el SCN93, son un gasto de consumo final del sector AA.PP.

102 Aunque comprenden las transferencias de las instituciones privadas sin fines de lucro al resto del mundo y las remesas de emigrantes (INE, Eurostat, 1986), la CNE90 únicamente contabiliza en esta partida las transferencias corrientes entre hogares residentes y no residentes.

${ }^{103}$ La Contabilidad Nacional registra en esta partida las operaciones de distribución secundaria de la renta cuyo carácter no permite su clasificación en otra rúbrica y aquellas que no han podido clasificarse correctamente, bien por falta de información sobre su contenido o bien por la agregación que presentan. Por su importancia, al menos desde un punto de vista cuantitativo, destacan las transferencias ligadas a las loterías y otros juegos de azar, las tasas pagadas por los hogares a las AA.PP (las pagadas por las empresas se registran como impuestos ligados a la producción), las multas, infracciones y condenas pecuniarias y las becas y bolsas de viaje.

104 Según el SEC (INE, Eurostat, 1986, p.135), los impuestos corrientes sobre la renta y el patrimonio “comprenden todos los pagos obligatorios recaudados periódicamente por las AA.PP. y por el resto del mundo sobre la renta y el patrimonio de las unidades institucionales”. 
CUADRO 3.15. Transferencias corrientes por sectores institucionales

\begin{tabular}{|c|c|c|c|c|c|c|c|c|c|c|}
\hline \multicolumn{6}{|c|}{ a) Primas netas de seguro de accidentes } & \multicolumn{5}{|c|}{ b) Indemnizaciones de seguro de accidentes } \\
\hline & Hogares & Empresas & AA.PP. & RDM & Total & Hogares & Empresas & AA.PP. & RDM & Total \\
\hline Hogares & 0 & 0 & 0 & 0 & 0 & 0 & 502.569 & 0 & 7.781 & 510.350 \\
\hline Empresas & 477.187 & 295.812 & 0 & 4.789 & 777.788 & 0 & 269.673 & 0 & 4.175 & 273.848 \\
\hline AA.PP. & 0 & 0 & 0 & 0 & 0 & 0 & 0 & 0 & 0 & 0 \\
\hline RDM & 744 & 461 & 0 & 0 & 1.205 & 0 & 5.546 & 0 & 0 & 5.546 \\
\hline Total & 477.931 & 296.273 & 0 & 4.789 & 778.993 & 0 & 777.788 & 0 & 11.956 & 789.744 \\
\hline \multicolumn{6}{|c|}{ c) Cotizaciones sociales ficticias } & \multicolumn{5}{|c|}{ d) Cotizaciones sociales reales } \\
\hline & Hogares & Empresas & AA.PP. & RDM & Total & Hogares & Empresas & AA.PP. & RDM & Total \\
\hline Hogares & 0 & 0 & 0 & 0 & 0 & 0 & 0 & 0 & 0 & 0 \\
\hline Empresas & 595.999 & 0 & 0 & 0 & 595.999 & 181.569 & 0 & 0 & 13 & 181.582 \\
\hline AA.PP. & 426.764 & 0 & 0 & 0 & 426.764 & 6.109.656 & 0 & 0 & 428 & 6.110 .084 \\
\hline RDM & 0 & 0 & 0 & 0 & 0 & 952 & 0 & 0 & 0 & 952 \\
\hline Total & 1.022 .763 & 0 & 0 & 0 & 1.022 .763 & 6.292 .177 & 0 & 0 & 441 & 6.292 .618 \\
\hline \multicolumn{6}{|c|}{ e) Cotizaciones sociales a cargo de los hogares } & \multicolumn{5}{|c|}{ f) Prestaciones sociales } \\
\hline & Asalariados & Autónomos & Desemp & eados & Total & Hogares & Empresas & AA.PP. & RDM & Total \\
\hline Hogares & 0 & 0 & 0 & & 0 & 0 & 520.352 & 6.653 .166 & 4.451 & 7.177 .969 \\
\hline Empresas & 112.365 & 0 & 0 & & 112.365 & 0 & 0 & 0 & 0 & 0 \\
\hline AA.PP. & 994.254 & 414.697 & 310. & & 1.719 .913 & 0 & 0 & 0 & 0 & 0 \\
\hline RDM & 511 & 0 & 0 & & 511 & 0 & 1.661 & 22.978 & 0 & 24.639 \\
\hline Total & 1.107 .130 & 414.697 & 310. & & 1.832 .789 & 0 & 522.013 & 6.676 .144 & 4.451 & 7.202 .608 \\
\hline \multicolumn{6}{|c|}{ g) Cooperación y transf. privadas internacionales } & \multicolumn{5}{|c|}{ h) Transferencias corrientes diversas } \\
\hline & Hogares & Empresas & AA.PP. & RDM & Total & Hogares & Empresas & AA.PP. & RDM & Total \\
\hline Hogares & 0 & 0 & 0 & 197.093 & 197.093 & 0 & 78.978 & 737.495 & 242.832 & 1.059 .305 \\
\hline Empresas & 0 & 0 & 0 & 0 & 0 & 65.003 & 0 & 0 & 0 & 65.003 \\
\hline AA.PP. & 0 & 0 & 0 & 70.124 & 70.124 & 826.969 & 87.948 & 0 & 0 & 914.917 \\
\hline $\mathrm{RDM}$ & 21.627 & 0 & 24.463 & 0 & 46.090 & 75.624 & 14.153 & 0 & 0 & 89.777 \\
\hline Total & 21.627 & 0 & 24.463 & 267.217 & 313.307 & 967.596 & 181.079 & 737.495 & 242.832 & 2.129 .002 \\
\hline \multicolumn{6}{|c|}{ i) Impuestos que gravan la renta y el patrimonio } & \multicolumn{5}{|c|}{$(a+\ldots+i)$ Transferencias corrientes* } \\
\hline & Hogares & Empresas & AA.PP. & RDM & Total & Hogares & Empresas & AA.PP. & RDM & Total \\
\hline Hogares & 0 & 0 & 0 & 0 & 0 & 0 & 1.101 .899 & 7.390 .661 & 452.157 & 8.944 .717 \\
\hline Empresas & 0 & 0 & 0 & 0 & 0 & 654.542 & 565.485 & 0 & 8.977 & 1.229 .004 \\
\hline AA.PP. & 4.297.298 & 1.720 .751 & 0 & 0 & 6.018 .049 & 6.843 .752 & 1.808 .699 & 0 & 379.305 & 9.031 .756 \\
\hline RDM & 0 & 0 & 0 & 0 & 0 & 98.947 & 21.821 & 427.388 & 0 & 548.156 \\
\hline Total & 4.297.298 & 1.720 .751 & 0 & 0 & 6.018 .049 & 7.597.241 & 3.497.904 & 7.818 .049 & 840.439 & 19.753 .633 \\
\hline
\end{tabular}

Fuente: Elaborado a partir de INE (1995b). (*) Están incluidos los flujos con el resto del mundo en concepto de cotizaciones sociales, impuestos ligados a la producción e importación y subvenciones de explotación que, en términos de la CNE90, son transferencias corrientes con el resto del mundo.

Para desglosar los flujos de transferencias corrientes del sector hogares entre hogares e instituciones privadas sin fines de lucro y por grupos de hogares hemos empleado los indicadores de distribución recogidos en el cuadro 3.16.

Para las primas e indemnizaciones de seguro de accidentes hemos utilizado como indicador de distribución los gastos declarados por los hogares en la EPF90$91^{105}$ en concepto de seguros de accidente ${ }^{106}$.

105 La EPF no recoge las indemnizaciones por seguro de accidente porque habitualmente las compañías aseguradoras en lugar de pagar directamente la indemnización a los hogares les reponen o reparan el bien siniestra- 
En el caso de las cotizaciones sociales, como la EPF90-91 registra los ingresos monetarios de los hogares netos de cotizaciones sociales, repartimos las cotizaciones por trabajo por cuenta ajena (1.107.130 millones pts.) y por cuenta propia (414.697 millones pts.) según los criterios empleados en el apartado 3.3.2 para estimar los sueldos y salarios brutos y la renta mixta bruta de los trabajadores autónomos; el resto de cotizaciones sociales (310.962 millones pts.), que corresponden a cotizaciones por desempleo, las hemos distribuido de acuerdo con los ingresos monetarios que declaran los miembros de los hogares por prestaciones de desempleo. Las cotizaciones correspondientes a cada hogar y grupo de hogares las hemos calculado, finalmente, como la suma de las cotizaciones sociales pagadas por sus miembros.

Para las prestaciones sociales, primero hemos ajustado por tipos de prestación social los ingresos monetarios netos declarados por los hogares en la EPF90-91 con los datos proporcionados por las fuentes administrativas recogidas en el cuadro $3.16^{107}$, para luego corregirlas globalmente con la cifra que proporciona la CNE90 y calcular las prestaciones sociales percibidas por cada grupo de hogares distinguido en la MCSE-90. Este doble ajuste de las prestaciones sociales se debe a que la divergencia entre los datos de la Encuesta y del resto de fuentes administrativas varía considerablemente según el tipo de prestación considerado (véase cuadro 3.16).

do. Sin embargo, la Contabilidad Nacional supone que primero las empresas de seguros pagan a los hogares las indemnizaciones (transferencia corriente) y que luego los hogares las destinan a reponer o reparar los bienes siniestrados (gasto de consumo final).

${ }^{106}$ A los gastos de los hogares que la EPF90-91 recoge en el epígrafe de primas brutas de seguro de accidentes (PROCOME 92011.04 a 92011.10), que incluyen los gastos en seguros de incendio, robo y otros daños del mobiliario (25.949 millones pts.), de incendio del edificio o vivienda (6.566 millones pts.), los seguros obligatorio y de responsabilidad civil de vehículos (172.330 millones pts.), a todo riesgo y otros relacionados con el transporte personal (183.838 millones pts.), de viaje y equipaje (21 millones pts.), los seguros no asistenciales de enfermedad y accidente (3.516 millones pts.) y otros seguros (1.719 millones pts.), les hemos añadido los gastos en la cuota familiar de seguro médico (PROCOME 55011.01) cuyo importe es de 81.464 millones pts. No obstante, dentro de los gastos de los hogares en seguros no siempre resulta clara la distinción entre primas brutas de seguro de vida y de accidente, porque muchas de las primas pagadas por los hogares corresponden a seguros mixtos, como puede ser el caso del seguro obligatorio de vehículos.

107 Sanz (1995) analiza con detalle la información que sobre los diferentes tipos de prestaciones sociales ofrecen el Sistema Europeo de Estadísticas de Protección Social (SEEPROS), las Estadísticas del Ministerio de Trabajo y Seguridad Social, el INEM y la Contabilidad Nacional. Aunque en principio la mejor fuente de referencia es el SEEPROS, sólo la hemos utilizado para ajustar aquellos tipos de prestaciones que tienen una correspondencia exacta con los de la EPF. El salario social de la EPF90-91 inicialmente no lo hemos ajustado por carecer de fuente de contraste. 
CUADRO 3.16. Indicadores de distribución de las transferencias corrientes del sector hogares: de la EPF90-91 a la CNE90.

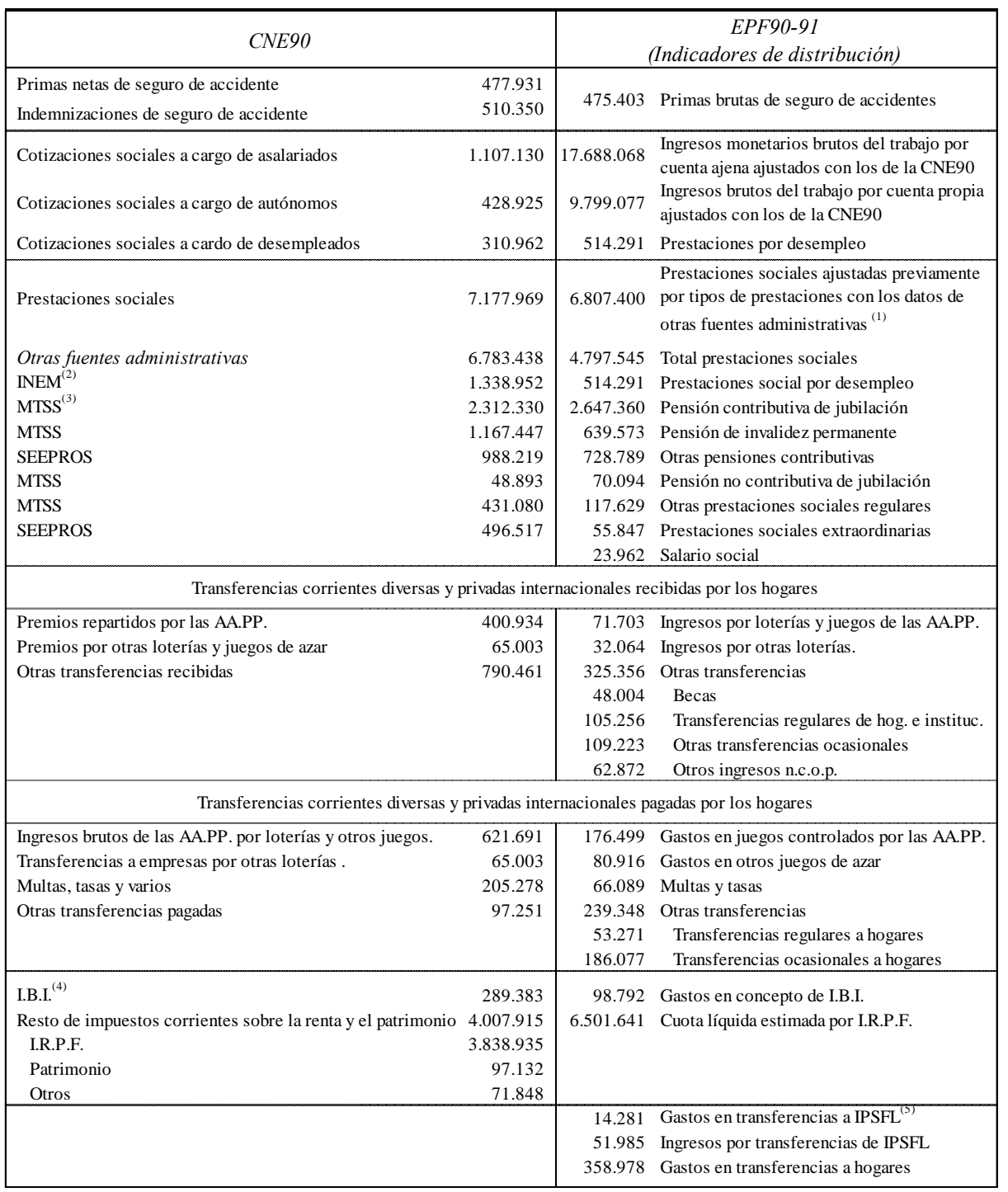

Fuente: Elaborado a partir de INE (1992c y 1995b), MTSS(1992) y Sanz (1995). (1) Incluye el salario social. (2) Incluye las cotizaciones sociales por desempleo de la CNE90. (3) Incluye las pensiones otorgadas por otras entidades de previsión social. (4) Cifra estimada por B. Sanz (1995). (5) Incluye las cuotas pagadas a las APAs.

Aunque la EPF90-91 recaba información acerca de los ingresos y gastos por transferencias entre hogares residentes y no residentes, ésta la presenta agregada a la del resto de ingresos y gastos de los hogares por transferencias regulares, por lo que 
distribuimos las transferencias privadas internacionales y las transferencias corriente diversas conjuntamente. Como puede apreciarse en el cuadro 3.16, estas transferencias se registran en la EPF90-91 en los epígrafes de otros ingresos ordinarios monetarios (becas y transferencias regulares ${ }^{108}$ de instituciones y otros hogares), ingresos extraordinarios monetarios (por loterías y juegos de las AA.PP, por otras loterías y juegos de azar y por otras transferencias ocasionales ${ }^{109}$ ) gastos en loterías y juegos de azar de las AA.PP y en otros juegos de azar (PROCOME 92031.01 y 92031.02), gastos en transferencias regulares y transferencias ocasionales a hogares residentes y no residentes (PROCOME 92031.03 y 92031.04) y gastos en impuestos de circulación y otros (PROCOME 91011.01 a 91011.06) ${ }^{110}$. Los ingresos y gastos declarados por los hogares en concepto de loterías y juegos de las AA.PP ${ }^{111}$ los utilizamos para distribuir por grupos de hogares las transferencias corrientes que la CNE90 registra por dicho concepto (400.934 y 621.691millones de pesetas, que se corresponden respectivamente con la cantidad repartida en premios y la recaudación de las AA.PP. ${ }^{112}$ ). Para el resto de juegos de azar, suponemos que todas las transferencias corrientes entre los hogares

\footnotetext{
${ }^{108}$ La EPF90-91 considera como transferencias regulares "todos los ingresos periódicos percibidos por el hogar sin mediar contraprestación laboral alguna, en concepto de donaciones de instituciones, remesas de emigrantes, rentas pagadas por las compañías aseguradoras al vencimiento de las pólizas de seguros de vida caso vida , (siempre que la entrega se realice periódicamente), así como los ingresos periódicos percibidos por el hogar sin mediar contraprestación y que no cumplen los requisitos exigidos para considerarse prestación social” (INE, 1992b, p.26)

${ }^{109}$ La partida de otras transferencias ocasionales incluye flujos "tales como capital pagado por las compañías de seguros de vida al vencimiento de las pólizas, siempre que el pago se realice de forma única; herencias monetarias y premios y regalos en metálico; transferencias ocasionales de otros hogares e instituciones" (INE, 1992b, p.27).

${ }^{110}$ La partida de otros ingresos n.c.o.p. que figura en el cuadro 3.16 no está recogida como tal en la Encuesta. Se trata de una partida que hemos creado para recoger ingresos declarados por los hogares y no contabilizados en otra parte como son los ingresos no monetarios por trabajo por cuenta ajena (366 millones pts)., y por cuenta propia (62.506 millones pts.) de los hogares que no perciben ingresos monetarios por dichos conceptos. En términos de Contabilidad Nacional, la mayor parte de los ingresos imputados a los hogares por autosuministro se consideran renta mixta generada en el sector agrario. Sin embargo, como en la matriz de rentas mixtas la unidad de análisis es el trabajador por cuenta propia y desconocemos la parte de las rentas mixtas agrarias que corresponde a los hogares como productores para uso final propio, tratamos el autosuministro como el resto de ingresos no monetarios por trabajo por cuenta propia y ajena de los hogares que no declaran ingresos monetarios por estos dos conceptos.

${ }^{111}$ Los datos sobre los ingresos de los hogares por loterías y juegos de azar controlados y no controlados por las AA.PP. los extraemos del fichero de miembros del hogar.

${ }^{112}$ La Contabilidad Nacional considera los gastos de los hogares en loterías y juegos de las AA.PP. como una transferencia de los hogares a las AA.PP. y la cantidad repartida en premios como una transferencia en sentido contrario. En el caso de las otras loterías y juegos de azar, la diferencia entre el gasto realizado por los hogares y la cantidad repartida en premios se anota como un gasto de consumo final de los hogares.
} 
y las empresas son por este concepto (65.003 millones de pesetas), y las distribuimos por grupos de hogares de acuerdo con los ingresos y gastos que declaran en la Encuesta por otras loterías y juegos de azar.

A partir de los gastos en multas y tasas de los hogares en la EPF 90-91 repartimos los recursos que, de acuerdo con la CNE90, reciben las AA.PP. de los hogares por multas, varios, y apremios (205.278 millones de pesetas). El resto de ingresos y gastos declarados por los hogares en la EPF90-91 (becas, transferencias regulares y ocasionales y otras n.c.o.p) los utilizamos, respectivamente, para repartir las restantes transferencias corrientes diversas y las transferencias privadas internaciones recibidas (593.368 y 197.093 millones de pesetas) y pagadas (97.251 millones de pesetas) por grupos de hogares.

Los impuestos corrientes sobre la renta y el patrimonio pagados por los hogares no pueden obtenerse directamente de la EPF90-91, excepto el impuesto de bienes inmuebles ${ }^{113}$. Para distribuir por grupos de hogares el resto de impuestos corrientes satisfechos por los hogares (renta, patrimonio, terrenos y otros) ${ }^{114}$ estimamos la distribución del I.R.P.F. y repartimos el resto de impuestos en proporción a este último ${ }^{115}$. De acuerdo con lo establecido en la ley de I.R.P.F para 1990 y una vez determinados el sujeto pasivo y la base de datos ${ }^{116}$, calculamos la cuota que por I.R.P.F. pagan los distintos hogares. Por tanto, una vez determinada la base imponible del impuesto (su-

\footnotetext{
${ }^{113}$ El impuesto sobre bienes inmuebles figura en la EPF90-91 como un gasto en vivienda (PROCOME 31012.22 y 31012.33) y su importe es de 98.792 millones pts.

${ }^{114}$ De acuerdo con la CNE90 de los impuestos pagados por los hogares, 3.838.935 millones pts. corresponden al impuesto sobre la renta de las personas físicas, 97.132 millones al impuesto sobre el patrimonio, y los 361.231 millones restantes a impuestos sobre terrenos y solares, varios y apremios. De acuerdo con las estimaciones de Sanz (1995, p.81) la recaudación por el impuesto sobre bienes inmuebles fue de 289.383 millones pts

${ }^{115}$ Es muy probable que al utilizar para todos los impuestos corrientes, excepto el IBI, el mismo indicador de distribución que para el I.R.P.F. estemos infravalorando los impuestos corrientes pagados por los hogares cuya principal fuente de renta son los ingresos del trabajo por cuenta ajena.

${ }^{116}$ Con relación al sujeto pasivo, aún cuando coexisten las declaraciones conjuntas e individuales, optamos por el individuo porque hemos estimado individualmente las rentas del trabajo por cuenta ajena que constituyen la principal fuente de renta de la mayor parte de la población y de ellas procede el grueso de la recaudación del I.R.P.F. Por lo que se refiere a la base de datos, hemos decidido emplear los datos de la EPF90-91corregidos partida a partida con los de la CNE90, en vez de utilizar directamente los datos de la EPF90-91, dado que esta última recoge los ingresos netos de impuestos y cotizaciones y la base imponible del impuesto se determina a
} 
ma de los rendimientos del trabajo, del capital mobiliario e inmobiliario y de las actividades por cuenta propia) basta con aplicar los tipos medios y marginales establecidos para los distintos tramos de renta para calcular la cuota íntegra. Si a dicha cuota le restamos las deducciones establecidas por gastos de enfermedad, adquisición de viviendas, primas de seguro de vida y rendimientos del trabajo dependiente ${ }^{117}$ se obtiene la cuota líquida correspondiente a cada hogar. ${ }^{118}$.

Por último y para completar los flujos de transferencias corrientes entre las unidades institucionales residentes, calculamos las transferencias corrientes entre los diferentes tipos de hogares y entre éstos y las IPSFL a partir de la información que proporciona la EPF90-91. Según esta fuente, los gastos de los hogares por transferencias a IPSFL (incluidas las cuotas a las APAs) ascienden a 14.281 millones de pesetas y sus ingresos por transferencias de IPSFL a 51.985 millones de pesetas. Este último dato lo hemos obtenido restando las transferencias regulares pagadas por los hogares a otros hogares al total de transferencias regulares recibidas por los hogares de otros hogares e instituciones ${ }^{119}$.

La subdeclaración de los ingresos en la EPF90-91 provoca que las transferencias que declaran recibir los hogares de otros hogares y de IPSFL sean inferiores a las que declaran pagar a otros hogares. Por ello, hemos calculado las transferencias corrientes entre los distintos grupos de hogares desde la óptica del gasto (358.978 millones de pesetas) y hemos asignado las transferencias realizadas por cada grupo de hoga-

partir de los ingresos brutos. Aunque lo ideal sería emplear los propios datos de la Agencia Tributaria, el carácter confidencial de la información a nivel microeconómico sobre el I.R.P.F. no lo permite.

${ }^{117}$ No hemos considerado el resto de deducciones establecidas en la ley, por no disponer de información o por las dificultades que entrañaban.

${ }^{118}$ El importe agregado de las cuotas líquidas estimadas es muy superior, aproximadamente un 40\%, a la recaudación de las AA.PP. por I.R.P.F. Si bien una parte de dicha sobrevaloración se debe a que no hemos considerado todas las deducciones establecidas en la ley, en su mayor parte se explica por la utilización, en el cálculo de la base imponible, de los ingresos por rendimientos del trabajo por cuenta propia y por rentas del capital armonizados con las cifras de la CNE90. Es muy probable que sean estas dos categorías de rentas las más infravaloradas en las declaraciones de la renta. Una prueba de ello es que cuando estimamos las retenciones por I.R.P.F. del trabajo por cuenta ajena, en el apartado 3.3.2, la diferencia entre los ingresos de las AA.PP por retenciones a cuenta del trabajo asalariado y el resultado de la estimación era mínima.

119 En este cálculo no hemos utilizado las transferencias ocasionales porque los gastos declarados por los hogares en transferencias ocasionales a otros hogares son muy superiores a sus ingresos por transferencias ocasionales de hogares y de instituciones. 
res entre los demás en proporción a los ingresos que declaran recibir por transferencias de hogares e instituciones.

En el cuadro 3.17 recogemos el total de transferencias corrientes recibidas y pagadas por los distintos grupos de hogares desglosadas por sectores de origen y destino. La submatriz completa de transferencias corrientes y rentas de la propiedad y de la empresa está recogida en la submatriz 4.4. del cuadro A.1 del anexo estadístico.

CUADRO 3.17. Transferencias corrientes por grupos hogares

\begin{tabular}{|c|c|c|c|c|c|c|c|c|c|c|c|c|}
\hline \multirow{2}{*}{$\begin{array}{r}\text { Grupos } \\
\text { hogares }\end{array}$} & \multicolumn{6}{|c|}{ Recibidas de } & \multicolumn{6}{|c|}{ Pagadas a } \\
\hline & Hogares & IPSFL & Empresas & AA.PP. & $\mathrm{RDM}$ & Total & Hogares & IPSFL & Empresas & AA.PP. & RDM & Total \\
\hline H.1 & 129 & 19 & 3.758 & 13.352 & 430 & 17.689 & 11.347 & 451 & 3.848 & 18.773 & 1.506 & 35.92 \\
\hline H.2 & 1.248 & 181 & 56.849 & 163.943 & 9.985 & 232.206 & 43.312 & 1.723 & 61.067 & 387.048 & 10.067 & 503.217 \\
\hline Н.3 & 0 & 0 & 1.257 & 2.163 & 352 & 3.772 & 5.011 & 199 & 1.752 & 14.004 & 711 & 21.677 \\
\hline H. 4 & 936 & 136 & 2.193 & 12.176 & 661 & 16.101 & 2.263 & 90 & 1.337 & 4.742 & 450 & 8.88 \\
\hline H.5 & 107 & 16 & 37.828 & 386.758 & 1.572 & 426.281 & 52.522 & 2.089 & 9.694 & 62.670 & 10.413 & 137.388 \\
\hline H.6 & 3.165 & 458 & 36.584 & 394.177 & 4.315 & 438.700 & 17.097 & 680 & 7.223 & 85.288 & 3.030 & 113.318 \\
\hline H.7 & 929 & 135 & 5.431 & 26.824 & 2.120 & 35.438 & 6.845 & 272 & 3.657 & 49.682 & 1.612 & 62.068 \\
\hline H. 8 & 3.012 & 436 & 69.402 & 255.927 & 12.760 & 341.538 & 23.342 & 929 & 68.385 & 417.109 & 7.987 & 517.75 \\
\hline Н.9 & 0 & 0 & 2.721 & 5.478 & 998 & 9.198 & 3.589 & 143 & 3.238 & 35.906 & 453 & 43.330 \\
\hline H.10 & 419 & 61 & 1.620 & 13.576 & 222 & 15.898 & 543 & 22 & 583 & 3.449 & 134 & 4.730 \\
\hline H.11 & 2.335 & 338 & 44.842 & 475.243 & 2.479 & 525.237 & 8.572 & 341 & 9.159 & 40.706 & 2.323 & 61.101 \\
\hline H.12 & 2.234 & 324 & 46.274 & 499.468 & 5.485 & 553.785 & 7.245 & 288 & 8.630 & 90.504 & 1.916 & 108.58 \\
\hline H.13 & 419 & 61 & 14.375 & 74.880 & 3.069 & 92.803 & 6.538 & 260 & 9.492 & 129.967 & 1.840 & 148.097 \\
\hline H.14 & 6.083 & 881 & 80.553 & 341.914 & 15.820 & 445.251 & 18.154 & 722 & 75.098 & 497.997 & 8.058 & 600.030 \\
\hline H.15 & 0 & 0 & 7.603 & 13.320 & 744 & 21.667 & 5.044 & 201 & 8.995 & 68.377 & 1.302 & $83.91 \mathrm{c}$ \\
\hline H.16 & 5.724 & 829 & 1.767 & 14.382 & 3.153 & 25.855 & 1.199 & 48 & 762 & 6.055 & 150 & 8.21 \\
\hline H.17 & 511 & 74 & 34.603 & 344.033 & 2.900 & 382.121 & 4.880 & 194 & 7.800 & 33.137 & 1.529 & 47.540 \\
\hline H.18 & 3.724 & 539 & 60.117 & 675.531 & 4.363 & 744.274 & 9.470 & 377 & 9.181 & 102.066 & 2.337 & $123.43 \mathrm{C}$ \\
\hline H.19 & 4.537 & 657 & 39.813 & 179.644 & 6.893 & 231.543 & 15.623 & 622 & 28.815 & 454.724 & 4.082 & 503.86 \\
\hline H. 20 & 28.588 & 4.140 & 88.583 & 390.142 & 37.032 & 548.486 & 21.642 & 861 & 81.833 & 569.031 & 8.512 & 681.87 \\
\hline Н.21 & 1.178 & 171 & 16.607 & 32.478 & 3.341 & 53.775 & 8.542 & 340 & 19.288 & 167.959 & 2.209 & 198.337 \\
\hline H.22 & 1.599 & 232 & 1.650 & 15.480 & 1.386 & 20.346 & 422 & 17 & 526 & 5.708 & 142 & 6.81 \\
\hline H. 23 & 9.079 & 1.315 & 24.008 & 228.896 & 6.059 & 269.356 & 2.560 & 102 & 6.981 & 29.594 & 898 & 40.13 \\
\hline H. 24 & 10.269 & $\begin{array}{l}1.487 \\
\end{array}$ & 59.476 & 671.899 & 11.817 & 754.948 & 6.194 & 246 & 8.798 & 123.528 & 1.688 & 140.45 \\
\hline H.25 & 21.714 & 3.144 & 114.878 & 586.402 & 39.191 & 765.330 & 38.333 & 1.525 & 80.028 & 1.890 .017 & 10.826 & 2.020 .730 \\
\hline H.26 & 55.996 & 8.109 & 69.010 & 324.720 & 84.170 & 542.006 & 12.329 & 490 & 58.094 & 576.155 & 5.528 & 652.59 \\
\hline H.27 & 9.032 & 1.308 & 53.405 & 129.050 & 56.643 & 249.439 & 18.944 & 754 & 63.049 & 647.248 & 6.492 & 736.486 \\
\hline Н.28 & 35.270 & 5.108 & 9.437 & 55.988 & 24.618 & 130.420 & 1.688 & 67 & 5.826 & 75.177 & 689 & 83.447 \\
\hline Н.29 & 45.623 & $\begin{array}{l}3 \\
3\end{array}$ & 15.460 & 212.737 & 28.005 & 308.432 & 1.288 & 51 & 3.406 & 28.345 & 558 & 33.648 \\
\hline H.30 & 105.115 & 15.222 & 101.797 & 850.080 & 81.571 & 1.153 .785 & 4.441 & 177 & 7.998 & 228.789 & 1.504 & 242.908 \\
\hline Total & 358.978 & 51.985 & 1.101 .899 & 7.390 .661 & 452.157 & 9.355 .679 & 358.978 & 14.281 & 654.542 & 6.843 .752 & 98.947 & 7.970 .500 \\
\hline
\end{tabular}




\subsubsection{Utilización de la renta y otras operaciones}

Una vez asignada y distribuida la renta, la renta disponible que resulta es utilizada por las unidades institucionales para satisfacer necesidades humanas individuales y colectivas. La parte de la renta disponible que no se emplea para satisfacer necesidades finales, el ahorro, se utiliza para adquirir bienes y servicios en el mercado con el fin de acumularlos o utilizarlos en ejercicios venideros en el proceso productivo y para adquirir activos en los mercados financieros. La diferencia entre la renta disponible y las gastos de adquisición de bienes y servicios y de activos financieros se cubre con transferencias de capital y mediante la contracción neta de pasivos. De acuerdo con la secuencia descrita, en este apartado primero describimos la elaboración de la submatriz de gastos de consumo final, que al figurar en la cuenta de bienes y servicios está desglosada por categorías de productos (3.3.4.1 y 3.3.4.2) y a continuación la de las cuentas que reflejan el proceso de acumulación de capital y las variaciones en los activos y pasivos de las unidades institucionales (3.3.4.3).

\subsubsection{Los gastos de consumo final clasificados por funciones PROCOME}

La finalidad del consumo final es satisfacer necesidades y carencias individuales y necesidades colectivas de los miembros de la comunidad, y puede ser financiado a titulo individual (gasto de consumo final de los hogares) o colectivo (servicios suministrados gratuitamente por las AA.PP. con financiación coercitiva o por las IPSFL con financiación voluntaria). Buena parte de los servicios que prestan gratuitamente las AA.PP. (sanidad, educación, servicios sociales,...) y la mayoría de los que suministran las IPSFL satisfacen necesidades efectivas de los hogares, en tanto que otra parte de los mismos (administración general, defensa, justicia, protección del medio ambiente,..) producen beneficios que no pueden atribuirse individualmente. De ahí que el SCN93 distinga entre gastos de consumo final (de hogares, administraciones públicas 
e instituciones privadas sin fines de lucro al servicio de los hogares ${ }^{120}$ ) y consumo final efectivo (de hogares y administraciones públicas ${ }^{121}$ ). En este trabajo hemos optado por considerar únicamente los gastos de consumo final, a efectos de obviar la redistribución de la renta en especie cuyo tratamiento en detalle requeriría un trabajo específico.

La CNE90 estima, por un lado, el consumo final de las AA.PP. o consumo público y, por otro, el consumo privado que incluye los gastos de consumo final de los hogares e instituciones privadas sin fines de lucro y el consumo de bienes y servicios sanitarios financiados públicamente. Por tanto, para determinar los gastos de consumo final de las AA.PP. (8.359.728millones de pesetas) hemos reasignado la última de las partidas señaladas de los hogares a las AA.PP, el montante de dicha partida es de 545.099 millones de pesetas (IGAE, 1993, p.100). Los gastos de consumo final de las IPSFL (238.049 millones de pesetas) los hemos calculado como la diferencia entre el consumo privado de otros servicios no destinados a la venta n.c.o.p.(R.58 de la TIO90) y el consumo de servicios domésticos de los hogares y, por último, hemos obtenido residualmente los gastos de consumo final de los hogares (30.520.229 millones de pesetas).

Para distribuir ahora los gastos de consumo final por grupos de hogares, ajustamos previamente las cifras que proporciona la Encuesta con las de la Contabilidad Nacional ${ }^{122}$ para cada una de las funciones de consumo consideradas en esta última.

\footnotetext{
120 Todos los gastos de adquisición de bienes y servicios realizados por las empresas se contabilizan como consumo intermedio o formación bruta de capital, al considerar que todos ellos tienen como destino el proceso productivo.

${ }^{121}$ El SCN93 supone que todos los gastos de consumo final de las IPSFL son en bienes y servicios individuales, $\mathrm{y}$, por tanto, los contabiliza como consumo final efectivo de los hogares.

${ }^{122}$ La CNE90 desglosa el consumo privado por funciones de consumo PROCOME (tres dígitos para alimentos y dos dígitos para el resto de funciones) y por tipos de productos (R.56 de la TIO90), mientras que la EPF90-91 únicamente lo hace por funciones PROCOME (siete dígitos).
} 
Para ajustar los datos de consumo final de la EPF90-91 ${ }^{123}$ con los que proporciona la CNE90, además de considerar que esta última incluye en el consumo privado los gastos de consumo de las IPSFL y algunas prestaciones sanitarias en especie, también hay que tener en cuenta que la CNE90 y la EPF90-91 no siempre emplean idénticos criterios de registro y valoración para las distintas partidas de consumo final de los hogares $^{124}$. La CNE90 registra el consumo en el momento que se produce la compra del bien o en el momento en el que el hogar recibe la prestación del servicio, y valora los productos de mercado a precios de adquisición, los bienes donados por el resto del mundo a precios de adquisición de bienes similares, el autoconsumo y la remuneración en especie a precios de producción y el servicio domestico por la remuneración de asalariados; en tanto que la EPF90-91 utiliza como norma general de registro el momento en el que se efectúa el pago ${ }^{125}$ y valora los productos de mercado por el total de pagos efectuados (incluidas las correspondientes cargas financieras) y el autoconsumo, el autosuministro y el salario en especie a precio local minorista.

El cuadro 3.18 recoge las estimaciones que ambas fuentes proporcionan del consumo de los hogares desglosadas por funciones PROCOME ${ }^{126}$ y las diferentes par-

\footnotetext{
${ }^{123}$ Dichos gastos están referidos a los hogares residentes en su condición de consumidores y comprenden los flujos monetarios destinados por el hogar y cada uno de sus miembros al pago de determinados bienes y servicios (incluidos en la nomenclatura armonizada de la OSCE) con destino al propio hogar o para ser transferidos gratuitamente a otros hogares o instituciones y el valor de los bienes recibidos en especie en concepto de autosuministro, autoconsumo, salario en especie, comidas gratuitas o bonificadas y alquiler imputado de la vivienda en la que reside el hogar. No se incluyen los gastos de consumo derivados de las actividades de las empresas o explotaciones familiares (INE,1992b, p.21).

124 Frente a la referencia anual de los datos de la CNE, la EPF 90-91 utiliza distintos periodos de observación y, por ende, distintos periodos de referencia temporal, en función del tipo de gasto. El periodo de observación para los gastos de consumo de mobiliario y electrodomésticos es anual (abril 89-marzo 91), para las consultas médicas y los gastos de conservación de la vivienda es trimestral (enero 90-marzo 91), para el consumo de vestido, calzado y calefacción es mensual (marzo 90-marzo91) y, por último, para el consumo de alimentos y bebidas es semanal (abril 90-marzo 91). A pesar de ello, consideramos que la utilización de coeficientes de ajuste temporal supone una digresión excesiva que no modificaría significativamente los resultados.

${ }^{125}$ Las dos excepciones a esta norma general son: a) las compras al contado o a plazos sin recargos efectuadas con tarjeta de compra o crédito, o mediante modalidades especiales de pago (como los pagos periódicos que permiten a los hogares retirar los productos del establecimiento a medida que los necesitan) y b) los bienes procedentes del autoconsumo, autosuministro o salario en especie. Las primeras se consideran consumidas en el momento de su adquisición y los segundos cuando se produce su consumo o regalo, o en el momento en el que acceden al hogar. Ambos criterios coinciden con los de la CNE90.

${ }^{126}$ Las partidas de gastos no desglosables o de gastos no mencionados anteriormente que la EPF90-91 incluye en los distintos grupos de gasto, las hemos agrupado en una única categoría de gastos no desglosables por funciones de consumo PROCOME (1 dígito). Este es el motivo por el que las cifras que figuran en el cuadro 3.18 no coinciden exactamente con las publicadas por el INE.
} 
tidas de ajuste que hemos utilizado para homogeneizar cada una de las funciones de consumo antes de proceder al ajuste de los datos de la EPF90-91 con los de la CNE90. 
CUADRO 3.18. Consumo final de los hogares. De la EPF90-91 a la CNE90

\begin{tabular}{|c|c|c|c|c|c|c|}
\hline \multirow{2}{*}{$\begin{array}{l}\text { Consumo Final } \\
\text { 1. Alimentos, bebidas y tabaco }\end{array}$} & \multirow{2}{*}{\begin{tabular}{|r|} 
EPF90-91 \\
7.011 .199
\end{tabular}} & \multirow{2}{*}{$\begin{array}{l}\text { CNE90 } \\
7.127 .340\end{array}$} & \multicolumn{2}{|c|}{$\begin{array}{l}\text { Partidas de } \\
\text { ajuste }\end{array}$} & \multicolumn{2}{|c|}{$\begin{array}{c}\text { EPF90-91 CNE90 } \\
\text { homogeneizadas }\end{array}$} \\
\hline & & & & & 7.011 .199 & 7.127 .340 \\
\hline 1.1 Alimentos & 5.974 .033 & 6.050 .285 & & & 5.974 .033 & 6.050 .285 \\
\hline 1.1.1 Pan y cereales & 786.224 & 792.122 & & & 786.224 & 792.122 \\
\hline 1.1.2 Carne & 1.817.317 & 1.873 .072 & & & 1.817 .317 & 1.873 .072 \\
\hline 1.1.3 Pescado & 781.683 & 748.644 & & & 781.683 & 748.644 \\
\hline 1.1.4 Leche, queso y huevos & 851.441 & 881.731 & & & 851.441 & 881.731 \\
\hline 1.1.5 Aceites y grasas & 252.585 & 275.239 & & & 252.585 & 275.239 \\
\hline 1.1.6 Frutas y verduras & 1.023 .030 & 989.028 & & & 1.023 .030 & 989.028 \\
\hline 1.1.7 Patatas y otros tubérculos. & 122.133 & 131.002 & & & 122.133 & 131.002 \\
\hline 1.1.8 Azúcar & 42.747 & 50.933 & & & 42.747 & 50.933 \\
\hline 1.1.9 Café, té y cacao & 92.993 & 102.557 & & & 92.993 & 102.557 \\
\hline 1.1.10 Otros productos alimenticios & 203.881 & 205.957 & & & 203.881 & 205.957 \\
\hline 1.2 Bebidas no alcoholicas & 136.279 & 155.245 & & & 136.279 & 155.245 \\
\hline 1.3 Bebidas alcohólicas & 248.602 & 454.649 & & & 248.602 & 454.649 \\
\hline 1.4 Tabacos & 361.820 & 467.161 & & & 361.820 & 467.161 \\
\hline Gastos no desglosables & 290.466 & & & & & \\
\hline 2. Vestido y calzado & 2.704 .154 & 2.908 .105 & & & 2.704 .154 & 2.908 .105 \\
\hline 2.1 Vestido (incluidas reparaciones) & 2.087 .005 & 2.124 .713 & & & 2.087 .005 & 2.124 .713 \\
\hline 2.2 Calzado (incluidas reparaciones) & 501.406 & 783.392 & & & 501.406 & 783.392 \\
\hline Gastos no desglosables & 115.743 & & & & & \\
\hline 3 Vivienda, calefacción y alumbrado & 6446623* & 4.110 .057 & \multirow{4}{*}{ (a) } & \multirow{4}{*}{$\begin{array}{l}-945.043 \\
-945.043\end{array}$} & 5.501 .580 & 4.110 .057 \\
\hline 3.1 Vivienda y consumo de agua & 5674034* & 3.271 .944 & & & 4.728 .991 & 3.271 .944 \\
\hline 3.2 Calefacción y alumbrado & 772.519 & 838.113 & & & \multirow[t]{2}{*}{772.519} & \multirow[t]{2}{*}{838.113} \\
\hline Gastos no desglosables & \multicolumn{2}{|l|}{70} & & & & \\
\hline 4 Muebles y accesorios para el hogar & 1.563 .670 & 2.174 .341 & & & 1.563 .670 & 2.174 .341 \\
\hline 4.1 Muebles, alfombras, accesorios y sus reparaciones & 356.690 & 697.731 & & & 356.690 & 697.731 \\
\hline 4.2 Artículos textiles para el hogar & 148.144 & 294.654 & & & 148.144 & 294.654 \\
\hline 4.3 Aparatos de calefacción y electrodomésticos & 272.485 & 335.208 & & & 272.485 & 335.208 \\
\hline 4.4 Cristalería y vajilla & 129.976 & 137.531 & & & 129.976 & 137.531 \\
\hline 4.5 Bienes y servicios para mantenimiento corriente de la vivienda & 428.582 & 447.243 & & & 428.582 & 447.243 \\
\hline 4.6 Servicio doméstico & 220.143 & 261.974 & & & 220.143 & 261.974 \\
\hline Gastos no desglosables & 7.649 & & & & & \\
\hline 5. Productos y servicios sanitarios & 735.369 & $1277772 *$ & (b) & -545.099 & 735.369 & 732.673 \\
\hline 5.1 Medicamentos y otros productos farmaceúticos & 226.157 & $617484 *$ & $\left(b_{1}\right)$ & -447951 & 294.151 & \\
\hline 5.2 Aparatos y equipo terapeútico & 67.994 & $87490^{*}$ & & & & 257023 \\
\hline $\begin{array}{l}\text { 5.3 Serv. médicos, enfermeras y otros prof.de la medicina } \\
5.4 \text { Atención hospitalaria y conexa }\end{array}$ & $\begin{array}{r}328.909 \\
30.536\end{array}$ & $\begin{array}{l}375415^{*} \\
106836 *\end{array}$ & $\left(b_{2}\right)$ & -97.148 & 359.445 & 385.103 \\
\hline 5.5 Cuota familiar de seguro médico privado & 81.464 & 90.547 & & & 81.464 & 90.547 \\
\hline Gastos no desglosables & 308 & & & & & \\
\hline 6. Transporte y comunicaciones & 3492989* & 4.977 .984 & & -16.101 & 3.476 .888 & 4.977 .984 \\
\hline 6.1 Vehículos para transporte personal & 1.232 .361 & 1.448 .831 & & & & 1.448 .831 \\
\hline 6.2 Gastos de utilización de vehículos & 1.600 .268 & 2.682 .229 & & & & 2.682 .229 \\
\hline 6.3 Servicios de transporte & $323281 *$ & 544.935 & (c) & -16.101 & 307.180 & 544.935 \\
\hline 6.4 Comunicaciones & 333.836 & 301.989 & & & & 301.989 \\
\hline Gastos no desglosables & 3.243 & & & & & \\
\hline 7. Esparcimiento, espectáculos, enseñanza y cultura & 1.738 .784 & 2.145 .336 & & 124.175 & 1.862 .959 & 2.145 .336 \\
\hline 7.1 Artículos de esparcimiento & 638.055 & 771.696 & $\left(d_{1}\right)$ & 24.486 & 662.540 & 771.696 \\
\hline 7.2 Servicios de esparcimiento, espectáculos y cultura & 395.794 & 550.405 & $\left(\mathrm{~d}_{2}\right)$ & 24.486 & 420.280 & 550.405 \\
\hline 7.3 Libros, períodicos y revistas & 259.367 & 244.949 & & & 259.367 & 244.949 \\
\hline 7.4 Enseñanza & 441.908 & 578.266 & (e) & 75.204 & 517.112 & 578.266 \\
\hline Gastos no desglosables & 3.661 & & & & & \\
\hline 8 Otros bienes y servicios & 3.673 .434 & & & 202903 & 3.876 .338 & \\
\hline & & 8.023 .288 & & 238049 & & 7.785.239 \\
\hline 8.1 Cuidado y efectos personales & 505.210 & 462.518 & & & 505.210 & 462.518 \\
\hline 8.2 Otros artículos no mencionados en otra parte & 157.732 & 453.159 & & & 157.732 & 453.159 \\
\hline 8.3 Restaurantes, cafés y hoteles & 2670294* & 5.675 .537 & $\left(\mathrm{e}_{2}\right)$ & -60.481 & 2.609 .813 & 5.675 .537 \\
\hline 8.4 Viajes turísticos, todo incluido & 161.772 & 224.545 & & & 161.772 & 224.545 \\
\hline 8.5 Servicios financieros n.c.o.p. & 2.122 & 59.316 & & & 2.122 & 59.316 \\
\hline 860 & 172992* & & $\left(\mathrm{f}_{1}+\mathrm{f}_{2}-\mathrm{e}_{3}\right)$ & 263.384 & 436.376 & \\
\hline 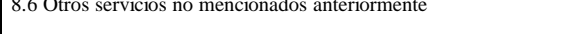 & & $1148213 *$ & (g) & -238.049 & & 910.164 \\
\hline Gastos no desglosables & 3.312 & & & & & \\
\hline
\end{tabular}

Fuente: INE (1992c , 1995b y 1993b) y Sanz (1995). (*): Flujos a homogeneizar.

$\left(\mathrm{a}=\mathrm{a}_{1}+\mathrm{a}_{2}\right)$ Partida de ajuste del consumo de vivienda y agua.

$\left(\mathrm{a}_{1}\right)$ Impuesto sobre bienes inmuebles (98.792 millones pts.).

$\left(\mathrm{a}_{2}\right)$ Gastos de reparación y mantenimiento de la vivienda a cargo del propietario (846.251 millones pts.). 
$\left(b=b_{1}+b_{2}\right.$ )Consumo privado sanitario con financiación pública.

$\left(\mathrm{b}_{1}\right)$ Medicamentos, aparatos y equipos terapéuticos subvencionados.

$\left(\mathrm{b}_{2}\right)$ Servicios sanitarios con financiación pública.

(c) Transporte escolar (16.101 millones pts.).

$\left(d=d_{1}+d_{2}\right)$ Dinero de bolsillo (48.971 millones pts.).

$\left(\mathrm{e}=\mathrm{C}+\mathrm{e}_{1}+\mathrm{e}_{2}-\mathrm{e}_{3}\right)$ Partida de ajuste del consumo de enseñanza.

$\left(\mathrm{e}_{1}\right)$ Comedor y alojamiento escolar (60.481 millones pts.).

$\left(\mathrm{e}_{2}\right)$ APA (4.789 millones pts.).

(e3) Gastos de enseñanza en el extranjero (6.167 millones pts).

( $\mathrm{f}_{1}$ )Consumo de servicios de seguros (235.807 millones pts.).

$\left(\mathrm{f}_{2}\right)$ Gastos de consumo en juegos de azar (32.366 millones pts.).

(g)Consumo privado colectivo de las IPSFL (238.049 millones pts.).

Al comparar los datos de ambas fuente observamos que para los alimentos y las bebidas no alcohólicas (PROCOME 1.1 y 1.2) las estimaciones de ambas fuentes son similares, en tanto que la infravaloración en la EPF90-91 del consumo de bebidas alcohólicas y tabaco (PROCOME 1.3 y 1.4) es considerable, quizá debido a que éstos últimos gastos se anotan en las libretas de gastos individuales de los miembros de los hogares mayores de 14 años y la calidad de registro de este tipo de libretas es bastante inferior a la de las libretas de gastos del hogar. Con relación a los gastos en vestido y calzado (PROCOME 2), la infravaloración de la EPF90-91 es reducida, lo que en cierto modo puede explicarse por la incidencia de la economía sumergida en estos sectores, lo que dificulta su registro por la Contabilidad Nacional.

El consumo de vivienda, calefacción y alumbrado (PROCOME 3) está sobrestimado de forma considerable en la EPF90-91, incluso una vez deducidos el impuesto de bienes inmuebles y los gastos de reparación y mantenimiento de la vivienda efectuados por los propietarios ${ }^{127}$, lo que puede achacarse a la subjetividad del criterio de valoración de los alquileres imputados en la Encuesta, ya comentada en el apartado 3.3.2.2. En relación al consumo de muebles y accesorios para el hogar (PROCOME 4), aunque no existen diferencias de contenido en ninguna de las seis subfunciones que lo integran, la falta de coincidencia en los criterios de registro de las compras a crédito y

\footnotetext{
${ }^{127}$ La CNE90 registra como consumo de vivienda y agua (PROCOME 3.1) los gastos en alquileres brutos (alquileres reales e imputados, tasas pagadas por recogida de basuras y otras tasas y contribuciones especiales, salvo las tasa de alcantarillado que se consideran gastos de consumo de agua), los gastos de reparación y mantenimiento de la vivienda realizados por el inquilino y el consumo de agua. Además de las partidas anteriores, la EPF90-91incluye el impuestos sobre bienes inmuebles y los gastos de reparación y mantenimiento de la vivienda realizados por el propietario, que en términos de Contabilidad Nacional se registrarían, respectivamente, como transferencias corrientes y consumo intermedio. Los gastos en calefacción y alumbrado no presentan ninguna discrepancia relacionada con la delimitación de su contenido.
} 
en el tratamiento de las indemnizaciones por seguros del hogar ${ }^{128}$ provocan que la mayor infravaloración por parte de la EPF90-91 se produzca en el consumo de muebles y artículos textiles para el hogar (PROCOME 4.1 y 4.2).

Una vez descontadas las prestaciones sanitarias en especie, el consumo de productos y servicios sanitarios (PROCOME 5) es similar en ambas fuentes ${ }^{129}$. Por lo que respecta al consumo de transportes y comunicaciones (PROCOME 6), la Encuesta registra los gastos de transporte escolar como consumo de servicios de transporte (PROCOME 6.3) y la Contabilidad Nacional lo hace como consumo de enseñanza (PROCOME 7.4). Una vez descontado el transporte escolar de los servicios de transporte, la mayor infravaloración de la EPF90-91 se produce para los gastos de utilización de vehículos (PROCOME 6.2) que comprenden, entre otras partidas, el mantenimiento y la reparación de vehículos y los servicios de grúa, que no se contabilizan en la EPF90-91 si son pagados por las compañías aseguradoras, y el alquiler de vehículos sin conductor que tampoco recoge la EPF90-91 si corresponde a unidades no residentes $^{130}$.

\footnotetext{
${ }^{128}$ La Contabilidad Nacional registra las indemnizaciones de seguros de accidente, primero, como una transferencia recibida por los hogares de las compañías de seguros y, posteriormente, como un gasto de consumo del hogar para reponer los daños por razón de incendio, robo u otros daños en el material mobiliario; sin embargo, cuando los bienes dañados son repuestos o reparados directamente por la compañía aseguradora la EPF90-91 no las registra como gastos consumo de los hogares. Aunque la EPF90-91 recoge los gastos de los hogares en primas brutas de seguros del hogar (PROCOME 92011.04 y 92011.05), no las hemos utilizado para homogeneizar esta función de consumo porque incluyen la remuneración de los servicios prestados por las entidades de seguros.

129 La CNE90 incluye en el consumo de productos sanitarios (PROCOME 5.1 y 5.2) todos los medicamentos y productos sanitarios adquiridos en farmacia con o sin receta médica y los aparatos y equipo terapéutico adquiridos con o sin subvención, lo que significa que están incluidas las prestaciones sanitarias en especie. Sin embargo, la EPF90-91 tan sólo registra los gastos realizados por los hogares para adquirir productos sanitarios, de ahí el reducido gasto de los pensionistas en esta función de consumo. Con relación a los servicios sanitarios (PROCOME 5.3 y 5.4), la EPF90-91 registra todos los pagos directos de los hogares (incluidos los gastos de adquisición de cheques de sociedades médicas) y la CNE90 incluye, además de los pagos directos de los hogares, parte de los pagos realizados por entidades aseguradoras por la prestación de servicios médicos y de atención hospitalaria o conexa. Por tanto, la CNE contabiliza las prestaciones recibidas a través del INSALUD por los afiliados al régimen general de la Seguridad Social como consumo público y la recibida por los afiliados a administraciones de seguridad social distintas del INSS (MUFACE, ISFAS, MUJEJU,...) como consumo privado. De acuerdo con la clasificación económica funcional de los empleos de las administraciones de seguridad social (IGAE,1993, p.207), el 17,82\% de las prestaciones sanitarias en especie correspondieron a servicios de sanidad y el $82,18 \%$ restante a medicamentos y aparatos y equipos terapéuticos. En cuanto a la cuota familiar de seguro médico, no existen diferencias reseñables entre ambas fuentes

${ }^{130}$ A pesar de que las diferencias entre la Encuesta y la Contabilidad Nacional en el tratamiento de las indemnizaciones por accidente y de las compras a crédito conducen a una infravaloración de los gastos en vehículos para transporte personal en la EPF90-91, en parte éstas se compensan por el diferente método de contabiliza-
} 
En cuanto al consumo de esparcimiento, espectáculos, enseñanza y cultura, dejando a un lado el hecho de que declaramos leer más de lo que leemos, en general la infravaloración de la EPF90-91 no es importante y afecta por igual a las distintas partidas. Si bien es conveniente, antes de proceder al ajuste de los datos, homogeneizar el contenido del consumo de enseñanza (PROCOME 7.4) en la Encuesta con el de la CNE90 para incluir los gastos en transporte escolar (PROCOME 63011.04 y 63021.05), en asociaciones de padres de alumnos (PROCOME 86011.03) y en comedores y alojamientos escolares y de estudiantes (PROCOME 83011.03 a 83011.05, 83021.03 y 83021.04) y descontar los gastos de enseñanzas en el extranjero (PROCOME 74011.69) ${ }^{131}$. Por último, con relación al consumo de otros bienes y servicios (PROCOME 8), las mayores diferencias, una vez homogeneizado el contenido de ambas fuentes ${ }^{132}$, se producen para los gastos en restaurantes, cafés y hoteles, servicios financieros y otros servicios no mencionados anteriormente, lo que puede achacarse, respectivamente, a los problemas de registro de los gastos de turismo y al distinto ámbito poblacional de ambas fuentes ${ }^{133}$, a la dificultad que supone para los hogares conocer y evaluar los pagos que han realizado en concepto de remuneración de servicios de intermediación financiera y al carácter residual de la última de las partidas consideradas.

\footnotetext{
ción de los vehículos usados, mientras que la CNE90 registra su adquisición neta, la EPF90-91 registra todos los pagos realizados.

${ }^{131}$ Hemos considerado que el dinero de bolsillo y regalos en efectivo a miembros del hogar menores de 14 años (PROCOME 92021.01) se utilizan para adquirir artículos o servicios de esparcimiento.

${ }^{132}$ Por una parte, descontamos los gastos en comedores y alojamientos escolares y los gastos de los hogares en asociaciones de padres de alumnos, que en la CNE90 figuran como gastos en enseñanza, de la partidas de restauración (PROCOME 8.3) y de otros servicios no mencionados anteriormente (PROCOME 8.6). Por otra parte, en la partida de otros servicios no mencionados anteriormente de la EPF90-91 incluimos el consumo de servicios de seguros, que calculamos como la diferencia entre el consumo privado de créditos y seguros (R.47 de la TIO90) y el consumo de servicios financieros (PROCOME 8.5), y el consumo de juegos de azar no controlados por las AA.PP (dato estimado en Sanz ,1995). En la misma partida de la CNE90 descontamos el consumo colectivo de las IPSFL. Para distribuir el consumo de servicios de seguro y de juegos no controlados por las AA.PP. entre los hogares utilizamos, respectivamente, sus gastos en primas brutas de seguros y en otros juegos de azar. Ambos figuran en el grupo 9 de gasto de la Encuesta (cuadro 3.19).

133 Por un lado, la EPF90-91 sólo encuesta a las familias que ocupan su vivienda principal en el momento de la entrevista, por lo que difícilmente puede registrar los gastos vacacionales en restaurantes, cafés o similares que tienen un periodo de observación semanal, además cuando dichos gastos lo realizan adultos distintos del sustentador principal se anotan en las libretas individuales de gasto que tienen menor fiabilidad. Por otro lado, la CNE90 registra el consumo final de hogares residentes y no residentes en el territorio económico, y buena parte de los gastos de los turistas se concentran en la partida de restaurantes, cafés y hoteles.
} 
Además de los ocho grupos de gastos en los que la CNE desglosa el consumo privado, la EPF90-91 distingue un grupo adicional de otros gastos no mencionados anteriormente en el que figuran muchas de las partidas que utilizamos para ajustar las estimaciones de la EPF90-91 y la CNE90 (cuadro 3.19). En términos de Contabilidad Nacional una parte de dichos gastos son transferencias corrientes y la otra parte consumo final y así figuran en los cuadros 3.16 y 3.18 .

CUADRO 3.19. Otros gastos no mencionados anteriormente (Grupo9 EPF90-91)

\begin{tabular}{|c|c|c|c|}
\hline \multicolumn{2}{|l|}{ Transferencias corrientes } & \multicolumn{2}{|l|}{ Consumo final } \\
\hline Impuestos sobre circulación y animales y otras tasas & 66.089 & Gastos en otros juegos de azar* & 80.916 \\
\hline Transferencias a otros hogares, regulares y ocasionales & 239.348 & Primas brutas de seguro tipo vida* & 394.263 \\
\hline Remesas a miembros del hogar mayores de 14 años & 119.630 & Primas brutas de seguro de daños & 32.515 \\
\hline Transferencias a instituciones privadas sin fines de lucro & 8.925 & Dinero de bolsillo & 48.971 \\
\hline Gastos en juegos de azar controlados por las AA.PP. & 176.499 & Otros gastos no mencionados y cobros indebidos & 18.712 \\
\hline Total & 610.491 & & 575.376 \\
\hline
\end{tabular}

\subsubsection{Los gastos de consumo final por categorias de productos}

Conocidos los gastos de consumo final de AA.PP., IPSFL y de los distintos grupos de hogares, desglosados éstos últimos por funciones de consumo, el siguiente paso es clasificarlos por categorías de bienes y servicios. La información de la TIO90 permite desglosar los gastos de consumo final de los dos primeros sectores institucionales por tipos de productos, pero para los distintos grupos de hogares es necesario, además de elaborar indicadores de distribución por categorías de bienes y servicios, referir su consumo al criterio de residencia.

Para elaborar los indicadores de distribución del consumo final por categorías de productos, en primer lugar, a partir de las correspondencias entre las clasificaciones PROCOME (7 dígitos) y R.56 de la TIO90, detalladas en el apartado 3.2.4, y de los gastos de consumo final de la EPF90-91 ajustados por funciones de consumo con los 
datos de la CNE90, tal y, como refleja el cuadro 3.19, hemos elaborado el cuadro 3.20 que recoge los gastos de consumo final de los hogares clasificados por funciones de consumo y categorías de productos de la MCSE-90.

CUADRO 3.20. Gastos de consumo final privado por funciones y productos a precios de adquisición (sin ajustar a la TIO90)

\begin{tabular}{|c|c|c|c|c|c|c|c|c|c|}
\hline \multirow{2}{*}{$\begin{array}{l}\text { Productos } \\
\text { (MCSE-90) }\end{array}$} & \multicolumn{8}{|c|}{ Funciones de consumo PROCOME } & \multirow{2}{*}{ Total } \\
\hline & F.1 & F.2 & F.3 & F.4 & F.5 & F.6 & F.7 & F.8 & \\
\hline P.1 & 1.653 .112 & 0 & 35.761 & 0 & 0 & 0 & 29.821 & 0 & 1.718 .693 \\
\hline P. 2 & 0 & 0 & 19.232 & 0 & 0 & 0 & 0 & 0 & 19.232 \\
\hline P.3 & 0 & 0 & 0 & 0 & 0 & 0 & 0 & 0 & 0 \\
\hline P.4 & 0 & 0 & 225.736 & 0 & 0 & 1.630 .693 & 0 & 0 & 1.856 .429 \\
\hline P.5 & 0 & 0 & 27.574 & 0 & 0 & 0 & 0 & 0 & 27.574 \\
\hline P.6 & 0 & 0 & 92.779 & 0 & 0 & 0 & 0 & 0 & 92.779 \\
\hline P.7 & 0 & 0 & 515.423 & 0 & 0 & 0 & 0 & 0 & 515.423 \\
\hline P.8 & 0 & 0 & 14.388 & 0 & 0 & 0 & 0 & 0 & 14.388 \\
\hline P.9 & 0 & 0 & 0 & 0 & 0 & 0 & 0 & 0 & 0 \\
\hline P.10 & 0 & 0 & 0 & 0 & 0 & 0 & 0 & 0 & 0 \\
\hline P.11 & 0 & 0 & 0 & 0 & 0 & 0 & 0 & 0 & 0 \\
\hline P.12 & 0 & 0 & 5.023 & 47.802 & 0 & 0 & 0 & 0 & 52.824 \\
\hline P.13 & 0 & 0 & 2.303 & 357.496 & 125.241 & 17.175 & 50.247 & 243.499 & 795.961 \\
\hline P.14 & 0 & 0 & 0 & 194.482 & 0 & 0 & 8.869 & 35.247 & 238.597 \\
\hline P.15 & 0 & 0 & 0 & 10.302 & 0 & 0 & 0 & 0 & 10.302 \\
\hline P.16 & 0 & 0 & 0 & 4.581 & 62.560 & 0 & 67.698 & 82.469 & 217.307 \\
\hline P.17 & 0 & 0 & 1.241 & 300.887 & 1.015 & 22.816 & 306.411 & 12.528 & 644.899 \\
\hline P.18 & 0 & 0 & 0 & 0 & 0 & 1.491 .555 & 0 & 0 & 1.491 .555 \\
\hline P.19 & 0 & 0 & 0 & 0 & 1.015 & 48.156 & 11.964 & 5.541 & 66.676 \\
\hline P.20 & 1.847 .743 & 0 & 0 & 0 & 0 & 0 & 0 & 0 & 1.847 .743 \\
\hline P.21 & 734.812 & 0 & 0 & 0 & 0 & 0 & 0 & 0 & 734.812 \\
\hline P.22 & 1.812 .166 & 0 & 0 & 0 & 0 & 0 & 40.800 & 0 & 1.852 .966 \\
\hline P.23 & 612.347 & 0 & 0 & 0 & 0 & 0 & 0 & 0 & 612.347 \\
\hline P.24 & 467.161 & 0 & 0 & 0 & 0 & 0 & 0 & 0 & 467.161 \\
\hline P.25 & 0 & 2.037 .448 & 0 & 233.114 & 5.178 & 0 & 1.272 & 11.681 & 2.288 .692 \\
\hline P.26 & 0 & 549.411 & 0 & 0 & 0 & 0 & 0 & 72.735 & 622.147 \\
\hline P.27 & 0 & 0 & 591 & 591.317 & 0 & 0 & 0 & 13.732 & 605.640 \\
\hline P.28 & 0 & 0 & 292 & 43.863 & 62.015 & 0 & 368.719 & 32.058 & 506.948 \\
\hline P.29 & 0 & 226.983 & 0 & 49.303 & 0 & 72.703 & 112.690 & 25.680 & 487.360 \\
\hline P.30 & 0 & 3.962 & 0 & 4.581 & 0 & 0 & 129.772 & 163.021 & 301.337 \\
\hline P.31 & 0 & 0 & 11.636 & 0 & 0 & 0 & 0 & 0 & 11.636 \\
\hline P.32 & 0 & 37.828 & 0 & 60.463 & 0 & 397.834 & 65.028 & 28.931 & 590.083 \\
\hline P.34 & 0 & 0 & 0 & 0 & 0 & 2.554 & 135.854 & 5.675 .537 & 5.813 .945 \\
\hline P.35 & 0 & 0 & 0 & 0 & 0 & 537.496 & 18.006 & 0 & 555.502 \\
\hline P.36 & 0 & 0 & 0 & 0 & 0 & 195.379 & 0 & 224.545 & 419.924 \\
\hline P.37 & 0 & 0 & 0 & 0 & 0 & 301.989 & 0 & 0 & 301.989 \\
\hline P.38 & 0 & 0 & 0 & 0 & 45.274 & 0 & 1.008 & 295.123 & 341.404 \\
\hline P.40 & 0 & 39.929 & 0 & 55 & 0 & 3.956 & 33.232 & 173.022 & 250.193 \\
\hline P.41 & 0 & 0 & 3.001 .654 & 0 & 0 & 196.938 & 0 & 0 & 3.198 .592 \\
\hline P.42 & 0 & 0 & 0 & 0 & 0 & 58.740 & 261.011 & 0 & 319.751 \\
\hline P.43 & 0 & 0 & 0 & 0 & 430.377 & 0 & 0 & 0 & 430.377 \\
\hline P.44 & 0 & 12.544 & 156.426 & 14.121 & 0 & 0 & 427.340 & 689.889 & 1.300 .319 \\
\hline P.45 & 0 & 0 & 0 & 0 & 0 & 0 & 0 & 0 & 0 \\
\hline P.46 & 0 & 0 & 0 & 0 & 0 & 0 & 70.240 & 0 & 70.240 \\
\hline P.47 & 0 & 0 & 0 & 0 & 0 & 0 & 0 & 0 & 0 \\
\hline P.48 & 0 & 0 & 0 & 261.974 & 0 & 0 & 5.356 & 0 & 267.330 \\
\hline Total & 7.127 .340 & 2.908 .105 & 4.110 .057 & 2.174 .341 & 732.673 & 4.977.984 & 2.145 .336 & 7.785 .239 & 31.961 .075 \\
\hline
\end{tabular}


En segundo lugar, dado que en la TIO90, por categorías de productos, el consumo privado está valorado a precios de salida de fábrica, inicialmente y para ajustar los datos obtenidos en el cuadro 3.20 con los de la TIO90 suponemos el mismo margen unitario de distribución para todos los bienes consumidos por los hogares ${ }^{134}$. El cuadro 3.21 recoge el consumo final de los hogares por funciones de consumo y categorías de productos a precios de salida de fábrica. Como puede observarse en dicho cuadro, el consumo privado de la TIO90 es mayor que los gastos de consumo final de los hogares al incluir el consumo final de las IPSFL (238.049 millones de pesetas) y las prestaciones sanitarias en especie (545.099 millones de pesetas). Para transformar las cifras de la TIO90 en términos de gastos de consumo final, hemos descontado el consumo colectivo de las IPSFL del consumo privado de servicios no destinados a la venta n.c.o.p. (P.48), en tanto que en el caso de las prestaciones sanitarias en especie hemos descontado la parte correspondiente a medicamentos valorados a precios de salida de fábrica (287.014 millones de pesetas) del consumo privado de productos químicos (P.13), los márgenes asociados a su distribución (160.837 millones de pesetas) del total de márgenes y la parte correspondiente a servicios sanitarios con financiación pública (97.148 millones de pesetas) del consumo privado de servicios sanitarios destinados a la venta (P.43). Asimismo, para conseguir una equivalencia completa en el consumo privado por categorías de productos, también hemos deducido los márgenes de transporte de los bienes destinados al consumo final de los hogares (409.983 millones de pesetas) del consumo privado de servicios de transporte de la TIO90 (P.35) y los hemos añadido a la fila de márgenes de distribución.

\footnotetext{
${ }^{134}$ El margen unitario de distribución lo obtenemos dividiendo los márgenes de distribución de los bienes destinados al consumo privado interior excluidos los productos sanitarios con financiación pública (6.291.517 y 160.837 millones pts., respectivamente) y los gastos de consumo final de los hogares en productos agrarios e industriales excluidos el agua y la energía eléctrica (17.481.589 millones pts.).
} 
CUADRO 3.21. Gastos de consumo final privado por funciones y productos a precios de salida de fábrica (sin ajustar a la TIO90)

\begin{tabular}{|c|c|c|c|c|c|c|c|c|c|c|c|}
\hline \multirow{3}{*}{$\begin{array}{l}\text { Productos } \\
\text { (MCSE-90) }\end{array}$} & \multirow{2}{*}{\multicolumn{8}{|c|}{ Funciones de consumo PROCOME }} & \multirow{3}{*}{ Total } & \multicolumn{2}{|c|}{ TIO90 } \\
\hline & & & & & & & & & & Consumo & Gastos de \\
\hline & F.1 & F.2 & F.3 & F.4 & F.5 & F.6 & F.7 & F. 8 & & $\begin{array}{c}\text { final } \\
\text { privado }\end{array}$ & $\begin{array}{l}\text { consumo } \\
\text { final }\end{array}$ \\
\hline P.1 & \begin{tabular}{|l|}
1.073 .376 \\
\end{tabular} & 0 & 23.220 & 0 & 0 & 0 & 19.363 & 0 & 1.115 .959 & 737.932 & 737.932 \\
\hline P. 2 & 0 & 0 & 12.487 & 0 & 0 & 0 & 0 & 0 & 12.487 & 24.906 & 24.906 \\
\hline P. 3 & 0 & 0 & 0 & 0 & 0 & 0 & 0 & 0 & 0 & 0 & 0 \\
\hline P. 4 & 0 & 0 & 146.572 & 0 & 0 & 1.058 .820 & 0 & 0 & 1.205 .391 & 938.315 & 938.315 \\
\hline P. 5 & 0 & 0 & 17.904 & 0 & 0 & 0 & 0 & 0 & 17.904 & 26.086 & 26.086 \\
\hline P.6 & 0 & 0 & 92.779 & 0 & 0 & 0 & 0 & 0 & 92.779 & 100.514 & 100.514 \\
\hline P. 7 & 0 & 0 & 515.423 & 0 & 0 & 0 & 0 & 0 & 515.423 & 474.590 & 474.590 \\
\hline P. 8 & 0 & 0 & 9.342 & 0 & 0 & 0 & 0 & 0 & 9.342 & 16.927 & 16.927 \\
\hline P.9 & 0 & 0 & 0 & 0 & 0 & 0 & 0 & 0 & 0 & 0 & 0 \\
\hline P. 10 & 0 & 0 & 0 & 0 & 0 & 0 & 0 & 0 & 0 & 0 & 0 \\
\hline P.11 & 0 & 0 & 0 & 0 & 0 & 0 & 0 & 0 & 0 & 0 & 0 \\
\hline P.12 & 0 & 0 & 3.261 & 31.038 & 0 & 0 & 0 & 0 & 34.299 & 40.691 & 40.691 \\
\hline P.13 & 0 & 0 & 1.495 & 232.125 & 81.320 & 11.152 & 32.626 & 158.106 & 516.823 & 731.554 & 444.440 \\
\hline P.14 & 0 & 0 & 0 & 126.278 & 0 & 0 & 5.759 & 22.886 & 154.923 & 199.339 & 199.339 \\
\hline P. 15 & 0 & 0 & 0 & 6.689 & 0 & 0 & 0 & 0 & 6.689 & 7.388 & 7.388 \\
\hline P.16 & 0 & 0 & 0 & 2.975 & 40.620 & 0 & 43.956 & 53.548 & 141.099 & 97.784 & 97.784 \\
\hline P.17 & 0 & 0 & 806 & 195.368 & 659 & 14.815 & 198.955 & 8.135 & 418.737 & 397.868 & 397.868 \\
\hline P.18 & 0 & 0 & 0 & 0 & 0 & 968.477 & 0 & 0 & 968.477 & 1.111.127 & 1.111.127 \\
\hline P.19 & 0 & 0 & 0 & 0 & 659 & 31.268 & 7.768 & 3.598 & 43.293 & 93.168 & 93.168 \\
\hline P. 20 & 1.199.751 & 0 & 0 & 0 & 0 & 0 & 0 & 0 & 1.199 .751 & 1.360 .454 & 1.360 .454 \\
\hline P.21 & 477.118 & 0 & 0 & 0 & 0 & 0 & 0 & 0 & 477.118 & 618.634 & 618.634 \\
\hline P. 22 & 1.176 .651 & 0 & 0 & 0 & 0 & 0 & 26.492 & 0 & 1.203 .143 & 1.539 .088 & 1.539 .088 \\
\hline P. 23 & 397.601 & 0 & 0 & 0 & 0 & 0 & 0 & 0 & 397.601 & 381.874 & 381.874 \\
\hline P. 24 & 303.331 & 0 & 0 & 0 & 0 & 0 & 0 & 0 & 303.331 & 420.759 & 420.759 \\
\hline P. 25 & & 1.322 .928 & 0 & 151.362 & 3.362 & 0 & 826 & 7.585 & 1.486 .063 & 1.218 .596 & 1.218 .596 \\
\hline P.26 & 0 & 356.736 & 0 & 0 & 0 & 0 & 0 & 47.228 & 403.964 & 354.254 & 354.254 \\
\hline P. 27 & 0 & 0 & 384 & 383.946 & 0 & 0 & 0 & 8.916 & 393.246 & 302.714 & 302.714 \\
\hline P. 28 & 0 & 0 & 190 & 28.480 & 40.267 & 0 & 239.412 & 20.815 & 329.164 & 259.744 & 259.744 \\
\hline P. 29 & 0 & 147.382 & 0 & 32.013 & 0 & 47.207 & 73.170 & 16.674 & 316.446 & 100.934 & 100.934 \\
\hline P. 30 & 0 & 2.573 & 0 & 2.975 & 0 & 0 & 84.262 & 105.851 & 195.660 & 251.044 & 251.044 \\
\hline P.31 & 0 & 0 & 11.636 & 0 & 0 & 0 & 0 & 0 & 11.636 & 92.728 & 92.728 \\
\hline P.32 & 0 & 37.828 & 0 & 60.463 & 0 & 397.834 & 65.028 & 28.931 & 590.083 & 1.149 .405 & 1.149 .405 \\
\hline Márgenes & 2.499.512 & 988.186 & 116.479 & 644.479 & 90.136 & 1.151 .362 & 395.674 & 244.851 & 6.130 .680 & 5.881 .534 & 6.130 .680 \\
\hline P.34 & 0 & 0 & 0 & 0 & 0 & 2.554 & 135.854 & 5.675 .537 & 5.813 .945 & 6.039 .133 & 6.039 .133 \\
\hline P. 35 & 0 & 0 & 0 & 0 & 0 & 537.496 & 18.006 & 0 & 555.502 & 965.485 & 555.502 \\
\hline P.36 & 0 & 0 & 0 & 0 & 0 & 195.379 & 0 & 224.545 & 419.924 & 127.537 & 127.537 \\
\hline P.37 & 0 & 0 & 0 & 0 & 0 & 301.989 & 0 & 0 & 301.989 & 301.990 & 301.990 \\
\hline P.38 & 0 & 0 & 0 & 0 & 45.274 & 0 & 1.008 & 295.123 & 341.404 & 295.123 & 295.123 \\
\hline P. 40 & 0 & 39.929 & 0 & 55 & 0 & 3.956 & 33.232 & 173.022 & 250.193 & 209.005 & 209.005 \\
\hline P.41 & 0 & 0 & 3.001 .654 & 0 & 0 & 196.938 & 0 & 0 & 3.198 .592 & 2.881 .560 & 2.881 .560 \\
\hline P.42 & 0 & 0 & 0 & 0 & 0 & 58.740 & 261.011 & 0 & 319.751 & 378.809 & 378.809 \\
\hline P.43 & 0 & 0 & 0 & 0 & 430.377 & 0 & 0 & 0 & 430.377 & 615.080 & 517.932 \\
\hline P. 44 & 0 & 12.544 & 156.426 & 14.121 & 0 & 0 & 427.340 & 689.889 & 1.300 .319 & 1.439 .040 & 1.439 .040 \\
\hline P. 45 & 0 & 0 & 0 & 0 & 0 & 0 & 0 & 0 & 0 & 0 & 0 \\
\hline P.46 & 0 & 0 & 0 & 0 & 0 & 0 & 70.240 & 0 & 70.240 & 61.487 & 61.487 \\
\hline P.47 & 0 & 0 & 0 & 0 & 0 & 0 & 0 & 0 & 0 & 0 & \\
\hline P.48 & 0 & 0 & 0 & 261.974 & 0 & 0 & 5.356 & 0 & 267.330 & 500.023 & 261.974 \\
\hline Total & 7127340 & 2908105 & 4110057 & 2174341 & 732673 & 4977984 & 2145336 & 7785239 & 31.961 .075 & \begin{tabular}{|l|}
32.744 .223 \\
\end{tabular} & 31.961 .075 \\
\hline
\end{tabular}

Fuente: Elaboración propia e INE(1995b).

En tercer y último lugar ajustamos los gastos de consumo final de los hogares por productos (filas) con los datos de la TIO90 y por funciones de consumo (columnas) con el consumo privado por funciones homogeneizado de la CNE90 que figura en el cuadro 3.18. Dicho ajuste plantea un problema de biproporcionalidad, para cuya 
solución se han desarrollado diversos métodos de ajuste ${ }^{135} \mathrm{y}$, entre ellos, el método RAS, inicialmente propuesto por Stone y Brown (1962), que es el más utilizado en el campo de la contabilidad social y del análisis input-output.

Cuando de la matriz inicial $M$ se conocen con certeza una parte de los valores $(C)$, el método RAS se aplica al resto de valores $(A=M$-C). En este trabajo hemos mantenidos fijos los gastos de los hogares en servicios de transporte, transporte escolar (P.35, F.7) y resto de servicios de transporte (P.35, F.6) que ya estimamos al calcular los márgenes de transporte, y los gastos en servicio doméstico (P.48, F.4) y en servicios financieros (parte de P.38, F.8) ${ }^{136}$, por obtenerse directamente de la CNE90.

El método RAS consiste en multiplicar cada uno de los elementos $a_{\text {ij }}^{0}$ de la matriz $A$ por el coeficiente corrector $x_{\mathrm{i}} / \sum_{\mathrm{i}} a_{\mathrm{ij}}^{0}$, donde $x_{\mathrm{i}}$ son los gastos de consumo final por productos de la TIO90 (cuadro 3.21), y volver a multiplicar el resultado obtenido $a^{1}$ ij por el cociente corrector $y_{\mathrm{j}} / \sum_{\mathrm{j}} a_{\mathrm{ij}}^{1}$, donde $y_{\mathrm{j}}$ son las cifras de consumo privado por funciones homogeneizadas de la CNE90 (cuadro 3.18). Este proceso se repite hasta que todos y cada uno de los coeficientes correctores se aproximen a la unidad. La congruencia del resultado se basa en que se mantienen nulos los elementos que inicialmente son cero.

Tras un proceso iterativo de 96 etapas obtenemos la matriz ajustada $\left(A^{*}\right)$, que al sumarle la matriz de elementos fijos $C$, permite obtener la matriz ajustada de gastos de consumo por productos y funciones $\left(M^{*}\right)$ que figura en el cuadro $3.22^{137}$.

\footnotetext{
135 Mesnard (1989) clasifica los métodos biproporcionales para “ajustar una matriz $S$ (cuyos términos son $s_{i j}$ ) a los márgenes de una matriz $M$ (cuyos términos son $m_{i}$. y $m_{\cdot j}$ ) en orden a obtener una matriz $X$ (con elementos $x_{i j}$ )" en métodos de corrección multiplicativa, de corrección aditiva y biproporcionales sintéticos, grupo éste último en el que está incluido el método RAS. Pulido y Fontela (1993) ofrecen una primera aproximación al método RAS y sus variantes más conocidas. Para una visión más detallada véase (Mun-Heng, 1998).

${ }^{136}$ Del total de gastos de los hogares en crédito y seguro (P.38) correspondientes a la función de otros bienes y servicios (F.8), 295.123 millones pts., mantenemos fijos el consumo de servicios financieros (59.316 millones pts.) y ajustamos los gastos en servicios de seguro, que corresponden a seguros de daños y de vida. Los gastos de consumo en servicios de seguro médico y escolar están comprendidos, respectivamente, en las funciones F.5 y F.7.

${ }^{137}$ Como puede comprobarse en dicho cuadro, aunque en un principio supusimos el mismo margen unitario de distribución para todos los bienes consumidos por los hogares, una vez realizado el ajuste de la matriz de gastos de consumo final existen diferencias notables por funciones de consumo. Los bienes con mayores márge-
} 
CUADRO 3.22. Gastos de consumo privado interior ajustados

\begin{tabular}{|c|c|c|c|c|c|c|c|c|c|}
\hline \multirow{2}{*}{$\begin{array}{l}\text { Productos } \\
\text { (MCSE-90) }\end{array}$} & \multicolumn{8}{|c|}{ Funciones de consumo PROCOME } & \multirow{2}{*}{ Total } \\
\hline & F.1 & F.2 & F.3 & F.4 & F.5 & F.6 & F.7 & F.8 & \\
\hline P.1 & 697.613 & 0 & 25.983 & 0 & 0 & 0 & 14.334 & 0 & 737.930 \\
\hline P. 2 & 0 & 0 & 24.906 & 0 & 0 & 0 & 0 & 0 & 24.906 \\
\hline P.3 & 0 & 0 & 0 & 0 & 0 & 0 & 0 & 0 & 0 \\
\hline P. 4 & 0 & 0 & 161.169 & 0 & 0 & 777.148 & 0 & 0 & 938.317 \\
\hline P.5 & 0 & 0 & 26.086 & 0 & 0 & 0 & 0 & 0 & 26.086 \\
\hline P.6 & 0 & 0 & 100.515 & 0 & 0 & 0 & 0 & 0 & 100.515 \\
\hline P.7 & 0 & 0 & 474.594 & 0 & 0 & 0 & 0 & 0 & 474.594 \\
\hline P.8 & 0 & 0 & 16.927 & 0 & 0 & 0 & 0 & 0 & 16.927 \\
\hline P.9 & 0 & 0 & 0 & 0 & 0 & 0 & 0 & 0 & 0 \\
\hline P.10 & 0 & 0 & 0 & 0 & 0 & 0 & 0 & 0 & 0 \\
\hline P.11 & 0 & 0 & 0 & 0 & 0 & 0 & 0 & 0 & 0 \\
\hline P.12 & 0 & 0 & 5.076 & 35.615 & 0 & 0 & 0 & 0 & 40.691 \\
\hline P.13 & 0 & 0 & 1.896 & 216.982 & 56.073 & 9.439 & 27.369 & 132.681 & 444.439 \\
\hline P.14 & 0 & 0 & 0 & 165.615 & 0 & 0 & 6.778 & 26.946 & 199.339 \\
\hline P.15 & 0 & 0 & 0 & 7.388 & 0 & 0 & 0 & 0 & 7.388 \\
\hline P.16 & 0 & 0 & 0 & 2.415 & 24.324 & 0 & 32.022 & 39.024 & 97.784 \\
\hline P.17 & 0 & 0 & 1.098 & 196.185 & 488 & 13.470 & 179.293 & 7.333 & 397.868 \\
\hline P.18 & 0 & 0 & 0 & 0 & 0 & 1.111 .127 & 0 & 0 & 1.111.127 \\
\hline P.19 & 0 & 0 & 0 & 0 & 1.161 & 67.636 & 16.654 & 7.717 & 93.168 \\
\hline P. 20 & 1.360 .450 & 0 & 0 & 0 & 0 & 0 & 0 & 0 & 1.360 .450 \\
\hline P.21 & 618.632 & 0 & 0 & 0 & 0 & 0 & 0 & 0 & 618.632 \\
\hline P.22 & 1.500 .600 & 0 & 0 & 0 & 0 & 0 & 38.484 & 0 & 1.539 .084 \\
\hline P.23 & 381.873 & 0 & 0 & 0 & 0 & 0 & 0 & 0 & 381.873 \\
\hline P. 24 & 420.758 & 0 & 0 & 0 & 0 & 0 & 0 & 0 & 420.758 \\
\hline P. 25 & 0 & 1.104 .444 & 0 & 107.056 & 1.754 & 0 & 524 & 4.816 & 1.218 .594 \\
\hline P.26 & 0 & 321.846 & 0 & 0 & 0 & 0 & 0 & 32.407 & 354.253 \\
\hline P.27 & 0 & 0 & 402 & 296.138 & 0 & 0 & 0 & 6.174 & 302.714 \\
\hline P.28 & 0 & 0 & 229 & 25.336 & 26.424 & 0 & 191.131 & 16.624 & 259.744 \\
\hline P.29 & 0 & 53.313 & 0 & 9.811 & 0 & 13.099 & 20.123 & 4.588 & 100.934 \\
\hline P.30 & 0 & 4.316 & 0 & 4.227 & 0 & 0 & 107.459 & 135.042 & 251.044 \\
\hline P.31 & 0 & 0 & 92.729 & 0 & 0 & 0 & 0 & 0 & 92.729 \\
\hline P.32 & 0 & 93.368 & 0 & 126.434 & 0 & 753.261 & 122.030 & 54.311 & 1.149 .405 \\
\hline Márgenes & 2.147 .413 & 1.271 .937 & 172.298 & 702.782 & 72.505 & 1.136 .826 & 387.208 & 239.702 & 6.130 .672 \\
\hline P.34 & 0 & 0 & 0 & 0 & 0 & 2.709 & 142.797 & 5.893 .623 & 6.039 .128 \\
\hline P.35 & 0 & 0 & 0 & 0 & 0 & 537.496 & 18.006 & 0 & 555.502 \\
\hline P.36 & 0 & 0 & 0 & 0 & 0 & 59.611 & 0 & 67.926 & 127.537 \\
\hline P.37 & 0 & 0 & 0 & 0 & 0 & 301.990 & 0 & 0 & 301.990 \\
\hline P.38 & 0 & 0 & 0 & 0 & 32.013 & 0 & 867 & 262.243 & 295.123 \\
\hline P. 40 & 0 & 41.753 & 0 & 49 & 0 & 3.173 & 26.420 & 137.610 & 209.005 \\
\hline P.41 & 0 & 0 & 2.760 .683 & 0 & 0 & 120.903 & 0 & 0 & 2.881 .586 \\
\hline P.42 & 0 & 0 & 0 & 0 & 0 & 70.097 & 308.711 & 0 & 378.809 \\
\hline P.43 & 0 & 0 & 0 & 0 & 517.930 & 0 & 0 & 0 & 517.930 \\
\hline P. 44 & 0 & 17.128 & 245.466 & 16.335 & 0 & 0 & 443.640 & 716.473 & 1.439 .041 \\
\hline P. 45 & 0 & 0 & 0 & 0 & 0 & 0 & 0 & 0 & 0 \\
\hline P.46 & 0 & 0 & 0 & 0 & 0 & 0 & 61.487 & 0 & 61.487 \\
\hline P. 47 & 0 & 0 & 0 & 0 & 0 & 0 & 0 & 0 & 0 \\
\hline P.48 & 0 & 0 & 0 & 261.974 & 0 & 0 & 0 & 0 & 261.974 \\
\hline Total & $\begin{array}{l}7.127 .340 \\
\end{array}$ & 2.908 .105 & 4.110 .057 & 2.174 .341 & 732.673 & $\begin{array}{l}4.977 .984 \\
\end{array}$ & $\begin{array}{l}2.145 .336 \\
\end{array}$ & 7.785 .239 & 31.961 .075 \\
\hline $\begin{array}{c}\text { Márgen } \\
\text { unitario de } \\
\text { distribución }\end{array}$ & 0,43 & 0,86 & 0,65 & 0,66 & 0,66 & 0,57 & 0,61 & 0,58 & 0,56 \\
\hline
\end{tabular}

Fuente: Elaboración propia.

Las cifras del cuadro 3.22 están referidas a los gastos de consumo realizados en el territorio económico, por lo que para llegar a los gastos de consumo de los hogares residentes necesitamos descontar los gastos de consumo realizados por los hogares no

nes de distribución son los incluidos en la función de vestido y calzado (PROCOME 2), seguidos de la de muebles y artículos para el hogar (PROCOME 4) y de productos sanitarios (PROCOME 5). 
residentes en el territorio económico y añadir los gastos de los hogares residentes en el resto del mundo.

La única estadística que proporciona información sobre el consumo de los no residentes en el territorio nacional por ramas de actividad es la Tabla intersectorial de la economía turística española, 1992 (TIOT92) que elaboró la Secretaría General de Turismo. Sobre los hogares residentes, la TIOT92 tan sólo informa sobre sus gastos de turismo interior, por lo que no disponemos de información sobre la estructura de los gastos que realizan fuera del territorio económico. De ahí que tengamos que conformarnos con repartir el saldo turístico de la economía española por categorías de bienes y servicios, ${ }^{138}$ de acuerdo con la estructura de los gastos de consumo final de los no residentes en el territorio nacional. Para su posterior distribución por funciones de consumo empleamos la relación entre los gastos de consumo de los hogares por grupos de productos y funciones de consumo que figuran en el cuadro 3.22. Por último, calculamos los gastos de consumo de los hogares residentes por funciones de consumo y categorías de productos (cuadro 3.23) descontando el saldo por turismo de los gastos de consumo privado interior.

La submatriz de gastos de consumo final (submatriz 1.4 del cuadro A.1 del anexo estadístico) la hemos obtenido como resultado de corregir los gastos de consumo declarados por los hogares en la EPF90-91, ajustados previamente con los datos homogeneizados de la CNE90 por funciones de consumo y clasificados por funciones y productos (cuadro 3.21) con los datos que figuran en el cuadro $3.23^{139}$.

\footnotetext{
${ }^{138}$ Aunque la TIOT92 desglosa o agrupa las ramas de actividad de la TIO90 según su relevancia para el turismo, proporciona una tabla de las correspondencias entre ambas clasificaciones.

${ }^{139}$ La utilización de este procedimiento supone, implícitamente, que los gastos no desglosables de los hogares se distribuyen de forma proporcional entre los subgrupos que conforman cada una de las ocho funciones de consumo y que la subdeclaración de gastos de consumo no depende de las características socioeconómicas de los hogares.
} 
CUADRO 3.23. Gastos de consumo de los hogares residentes

\begin{tabular}{|c|c|c|c|c|c|c|c|c|c|c|}
\hline \multirow{2}{*}{$\begin{array}{l}\text { Productos } \\
\text { (MCSE-90) }\end{array}$} & \multicolumn{8}{|c|}{ Funciones de consumo PROCOME } & \multirow{2}{*}{ Total } & \multirow{2}{*}{$\begin{array}{c}\text { Saldo por } \\
\text { turismo }\end{array}$} \\
\hline & F.1 & F.2 & F.3 & F.4 & F.5 & F.6 & F.7 & F.8 & & \\
\hline P.1 & 685.233 & 0 & 25.522 & 0 & 0 & 0 & 14.080 & 0 & 724.835 & 13.097 \\
\hline P. 2 & 0 & 0 & 24.168 & 0 & 0 & 0 & 0 & 0 & 24.168 & 738 \\
\hline P.3 & 0 & 0 & 0 & 0 & 0 & 0 & 0 & 0 & 0 & 0 \\
\hline P. 4 & 0 & 0 & 152.460 & 0 & 0 & 735.153 & 0 & 0 & 887.613 & 50.702 \\
\hline P.5 & 0 & 0 & 25.917 & 0 & 0 & 0 & 0 & 0 & 25.917 & 169 \\
\hline P.6 & 0 & 0 & 100.169 & 0 & 0 & 0 & 0 & 0 & 100.169 & 345 \\
\hline P.7 & 0 & 0 & 468.347 & 0 & 0 & 0 & 0 & 0 & 468.347 & 6.243 \\
\hline P.8 & 0 & 0 & 16.758 & 0 & 0 & 0 & 0 & 0 & 16.758 & 169 \\
\hline P.9 & 0 & 0 & 0 & 0 & 0 & 0 & 0 & 0 & 0 & 0 \\
\hline P.10 & 0 & 0 & 0 & 0 & 0 & 0 & 0 & 0 & 0 & 0 \\
\hline P.11 & 0 & 0 & 0 & 0 & 0 & 0 & 0 & 0 & 0 & 0 \\
\hline P.12 & 0 & 0 & 4.613 & 32.366 & 0 & 0 & 0 & 0 & 36.979 & 3.712 \\
\hline P.13 & 0 & 0 & 1.867 & 213.623 & 55.205 & 9.293 & 26.945 & 130.627 & 437.559 & 6.881 \\
\hline P.14 & 0 & 0 & 0 & 159.871 & 0 & 0 & 6.543 & 26.012 & 192.425 & 6.914 \\
\hline P.15 & 0 & 0 & 0 & 7.281 & 0 & 0 & 0 & 0 & 7.281 & 107 \\
\hline P.16 & 0 & 0 & 0 & 2.258 & 22.746 & 0 & 29.945 & 36.493 & 91.442 & 6.342 \\
\hline P.17 & 0 & 0 & 1.080 & 193.059 & 480 & 13.255 & 176.435 & 7.217 & 391.526 & 6.342 \\
\hline P.18 & 0 & 0 & 0 & 0 & 0 & 1.092 .906 & 0 & 0 & 1.092 .906 & 18.221 \\
\hline P.19 & 0 & 0 & 0 & 0 & 934 & 54.408 & 13.397 & 6.207 & 74.947 & 18.221 \\
\hline P. 20 & 1.341 .003 & 0 & 0 & 0 & 0 & 0 & 0 & 0 & 1.341 .003 & 19.451 \\
\hline P. 21 & 599.183 & 0 & 0 & 0 & 0 & 0 & 0 & 0 & 599.183 & 19.451 \\
\hline P.22 & 1.481 .640 & 0 & 0 & 0 & 0 & 0 & 37.997 & 0 & 1.519 .637 & 19.451 \\
\hline P.23 & 375.894 & 0 & 0 & 0 & 0 & 0 & 0 & 0 & 375.894 & 5.980 \\
\hline P.24 & 414.422 & 0 & 0 & 0 & 0 & 0 & 0 & 0 & 414.422 & 6.337 \\
\hline P. 25 & 0 & 1.071 .963 & 0 & 103.907 & 1.702 & 0 & 509 & 4.674 & 1.182 .755 & 35.841 \\
\hline P.26 & 0 & 311.015 & 0 & 0 & 0 & 0 & 0 & 31.316 & 342.332 & 11.922 \\
\hline P. 27 & 0 & 0 & 389 & 286.677 & 0 & 0 & 0 & 5.977 & 293.043 & 9.671 \\
\hline P.28 & 0 & 0 & 224 & 24.717 & 25.779 & 0 & 186.465 & 16.218 & 253.402 & 6.342 \\
\hline P.29 & 0 & 49.963 & 0 & 9.194 & 0 & 12.276 & 18.859 & 4.299 & 94.592 & 6.342 \\
\hline P.30 & 0 & 4.207 & 0 & 4.120 & 0 & 0 & 104.744 & 131.631 & 244.702 & 6.342 \\
\hline P.31 & 0 & 0 & 91.514 & 0 & 0 & 0 & 0 & 0 & 91.514 & 1.214 \\
\hline P.32 & 0 & 91.494 & 0 & 123.896 & 0 & 738.141 & 119.581 & 53.221 & 1.126 .334 & 23.071 \\
\hline P. 34 & 0 & 0 & 0 & 0 & 0 & 2.418 & 127.489 & 5.261 .822 & 5.391 .728 & 647.405 \\
\hline P.35 & 0 & 0 & 0 & 0 & 0 & 358.086 & 11.996 & 0 & 370.082 & 185.420 \\
\hline P.36 & 0 & 0 & 0 & 0 & 0 & 54.951 & 0 & 62.616 & 117.567 & 9.970 \\
\hline P.37 & 0 & 0 & 0 & 0 & 0 & 295.972 & 0 & 0 & 295.972 & 6.018 \\
\hline P.38 & 0 & 0 & 0 & 0 & 31.518 & 0 & 853 & 258.186 & 290.557 & 4.566 \\
\hline P. 40 & 0 & 41.156 & 0 & 48 & 0 & 3.128 & 26.043 & 135.643 & 206.018 & 2.987 \\
\hline P. 41 & 0 & 0 & 2.675 .104 & 0 & 0 & 117.155 & 0 & 0 & 2.792 .259 & 89.301 \\
\hline P. 42 & 0 & 0 & 0 & 0 & 0 & 70.097 & 308.712 & 0 & 378.809 & 0 \\
\hline P.43 & 0 & 0 & 0 & 0 & 515.482 & 0 & 0 & 0 & 515.482 & 2.450 \\
\hline P. 44 & 0 & 16.710 & 239.472 & 15.936 & 0 & 0 & 432.807 & 698.979 & 1.403 .905 & 35.135 \\
\hline P. 45 & 0 & 0 & 0 & 0 & 0 & 0 & 0 & 0 & 0 & 0 \\
\hline P. 46 & 0 & 0 & 0 & 0 & 0 & 0 & 61.487 & 0 & 61.487 & 0 \\
\hline P. 47 & 0 & 0 & 0 & 0 & 0 & 0 & 0 & 0 & 0 & 0 \\
\hline P.48 & 0 & 0 & 0 & 257.352 & 0 & 0 & 0 & 0 & 257.352 & 4.622 \\
\hline $\begin{array}{l}\text { MÁRGENES DE } \\
\text { DISTRIBUCIÓN }\end{array}$ & 2.097 .203 & 1.242.197 & 168.270 & 686.350 & 70.810 & 1.110 .244 & 378.154 & 234.098 & 5.987 .325 & 143.356 \\
\hline Total & 6.994 .578 & 2.828 .704 & 3.995 .873 & 2.120 .657 & 724.657 & 4.667.484 & 2.083 .040 & 7.105 .236 & 30.520 .229 & 1.440 .846 \\
\hline Saldo por turismo & 132.762 & 79.401 & 114.184 & 53.684 & 8.016 & 310.500 & 62.296 & 680.003 & 1.440 .846 & \\
\hline
\end{tabular}

Fuente: Elaboración propia y SGT (1995). 


\subsubsection{Las operaciones de acumulación}

La renta disponible que las unidades institucionales no emplean para adquirir bienes y servicios de consumo final, o ahorro bruto, junto con el saldo de transferencias de capital determinan la variación del patrimonio (C.5) o los recursos que dichas unidades disponen para acumular activos reales y financieros, si bien para adquirir activos pueden también recurrir a la financiación ajena (C.6). El patrimonio de las unidades institucionales también puede verse alterado por otras variaciones de volumen o valor de los activos; sin embargo, por el momento la información disponible es muy insuficiente para considerar en este trabajo la estimación de los dos últimos flujos mencionados.

Para elaborar las cuentas de variación del patrimonio (C.5) y de variaciones del balance (C.6) hemos agrupado las unidades institucionales residentes en tres sectores: empresas, que incluyen las sociedades no financieras, las instituciones financieras y las empresas de seguro, administraciones públicas y hogares, sector este último en el que están incluidas las IPSFL.

Comenzando por la cuenta de variación del patrimonio, tomamos como ahorro bruto de cada uno de los sectores considerados los saldos de sus respectivas cuentas de asignación, distribución y utilización de renta, por lo que solo necesitamos conocer las transferencias de capital para obtener sus respectivas variaciones patrimoniales. Para desglosar por sectores de origen y destino las transferencias de capital (impuestos sobre el capital, ayudas a la inversión y otras transferencias de capital) hemos considerado que las ayudas y otras transferencias de capital con origen en los hogares y en las empresas tienen como destino los sectores empresas y AA.PP., y que todas las recibidas por el resto del mundo son pagadas por las AA.PP. ${ }^{140}$. Las transferencias de capital con origen y destino en sectores residentes figuran en la submatriz 5.5 del cuadro

\footnotetext{
${ }^{140}$ La distribución por sectores institucionales de las transferencias de capital que hemos obtenido es muy similar a la que figura en la matriz de contabilidad social elaborada por Uriel y otros (1997).
} 
A.1 del anexo estadístico y las transferencias de capital con origen y con destino en el resto del mundo en las submatrices 7.5 y 5.7, respectivamente.

Aunque el ahorro y la variación del patrimonio deben valorarse en términos netos, dadas las deficiencias de información sobre el consumo de capital fijo, en todo momento hemos considerado las variaciones de activos fijos en términos brutos.

En cuanto a las variaciones del balance o de la estructura del patrimonio, la información estadística únicamente permite desglosar las variaciones de los activos no financieros producidos por categorías de productos para el total de la economía, sin que sea posible elaborar una matriz cruzada de formación de capital por productos y sectores institucionales. Dicha información tampoco permite desglosar las variaciones de los activos no financieros no producidos, de los activos financieros y de los pasivos por sectores de origen y destino. Por ello, en la cuenta de variaciones del balance (C.6) hemos sustituido la submatriz de formación bruta de capital (1.6) por una cuenta dummy, y en la submatriz 6.6, que debería recoger las adquisiciones menos cesiones de activos no financieros no producidos, las adquisiciones netas de activos financieros y la contracción neta de pasivos entre sectores residentes, tan sólo hemos incluido las adquisiciones netas de terrenos. Por último, hemos registrado, respectivamente, como ingresos y gastos del sector exterior las variaciones totales en los activos financieros y pasivos de los sectores residentes.

La matriz de contabilidad social completa figura en el cuadro A.1 del anexo estadístico. Por razones de presentación hemos omitido algunas submatrices cuyos elementos son ceros. En el primer epígrafe del capítulo siguiente discutimos algunas presentaciones alternativas de la matriz y analizamos su consistencia. 
CAPÍTULO 4

LA MEDICIÓN DE LA DESIGUALDAD EN EL MARCO DE LA CONTABILIDAD SOCIAL 

La naturaleza desagregada de las matrices de contabilidad social las convierte en un marco ideal para analizar los efectos distributivos de cualquier cambio exógeno, al permitir explicitar los mecanismos de creación y difusión de la renta entre los distintos agentes de una economía. La mayoría de los trabajos previos que han abordado el análisis de la distribución de la renta empleando matrices de contabilidad social realizan un análisis descriptivo de los multiplicadores que, aunque sumamente útil, en numerosas ocasiones no permite obtener una valoración global concluyente sobre los cambios acaecidos en la distribución de la renta o en la desigualdad. En este capítulo tratamos de ir más allá al introducir algunas de las aportaciones más recientes en el campo de la medición de la desigualdad que, si bien no suponen la solución definitiva de los problemas, constituyen al menos un avance en la necesaria tarea de integración de las aproximaciones micro y macro de la actividad económica.

Con carácter previo, en el primer apartado valoramos la consistencia del modelo que hemos utilizado con respecto a las distintas alternativas posibles y en relación con los modelos empleados en estudios previos por otros autores. En el segundo apartado, presentamos el estado actual de la literatura sobre medición de la desigualdad mediante una exposición rigurosa y compacta que, a nuestro juicio, contiene extensiones originales. En el tercer apartado, abordamos la tarea de unir los campos de investigación sobre medición de desigualdad y matrices de contabilidad social a través del empleo de normas frontera que permiten valorar los efectos distributivos producidos por intervenciones exógenas, incluso en aquellos casos en los que las medidas de distribución relativa, tradicionalmente utilizadas en el campo de las matrices de contabilidad social, no conducen a resultados concluyentes. 


\subsection{MOdelización de LA MCSE-90}

Como ya hemos señalado en los capítulos previos, la MCSE-90 es susceptible de diversas modelizaciones alternativas. Básicamente, el diseño de los modelos alternativos que pueden derivarse de una matriz de contabilidad social se concreta a través de la elección del grado de desagregación de los flujos y las unidades, de la selección de las cuentas endógenas y exógenas, y de la especificación de los parámetros que determinan el comportamiento de las unidades endógenas del modelo.

Con el fin de no desviarnos en exceso del objetivo central de este capítulo, que consiste en extender el análisis de los efectos distributivos en el ámbito de las matrices de contabilidad social, hemos optado por trabajar con una sola versión del modelo, una vez valorada su consistencia con respecto a distintas alternativas posibles. Por lo que respecta a la especificación de los parámetros, hemos supuesto que las distintas unidades emplean los recursos de cada una de sus cuentas endógenas en proporciones fijas y que no existe limitación de recursos primarios ${ }^{141}$. En cuanto a la selección de las cuentas exógenas, frente a la opción más común de considerar exógenas las cuentas del sector público y/o del sector exterior, hemos optado por tratar por igual a todos los sectores considerando exógenas las operaciones de acumulación de todos ellos, lo que permite el cálculo de efectos multiplicadores con la mayor amplitud posible ${ }^{142}$. Finalmente, en lo referente al grado de agregación con el que se presenta el modelo, hemos agrupado las cuentas exógenas y hemos eliminado la cuenta de bienes y servicios, opciones ambas que no afectan a los resultados.

\footnotetext{
${ }^{141}$ Como los diseños de las matrices de contabilidad social que se han elaborado son muy diferentes, no es posible adoptar sin más las funciones estimadas para otros trabajos. Una estimación propia con cierto rigor de las funciones de producción, demanda interna y externa, etc., requiere abordar diversas literaturas lo suficientemente desarrolladas como para ser objeto de capítulos específicos e, incluso, de memorias completas distintas a la planteada en este trabajo.

142 En teoría lo ideal sería que los únicos flujos exógenos fueran las variaciones de los activos que no son debidas a operaciones, que por lo general son flujos involuntarios. Sin embargo, la falta de información detallada sobre las variaciones de los activos y pasivos por operaciones, muy especialmente en el caso de las variaciones de los activos fijos, hace que en la práctica nos veamos obligados a considerar exógenas todas las variaciones del patrimonio neto y de la estructura de los balances de los distintos grupos de unidades considerados.
} 


\subsubsection{Agregación de operaciones y reordenación de unidades}

La agregación de las cuentas exógenas no requiere de mayor justificación, ya que, una vez que se conoce su composición, carece de importancia que en el modelo se presenten los flujos exógenos como una suma de vectores o agregados en un único vector. En cuanto a las cuentas endógenas, como puede apreciarse al comparar los multiplicadores de Leontief o Kalecki con el multiplicador agregado keynesiano (véase apartado 2.1.2 de este trabajo) su agregación sin más supondría omitir los efectos derivados de las interrelaciones que se producen entre los flujos y las unidades objeto de agregación. El problema de agregar cuentas sin la consiguiente pérdida explicativa fue resuelto por Leontief (1967) al proponer el método de la doble inversión para comparar tablas input output con diferentes niveles de desagregación sectorial. De forma independiente Pyatt (1989) propuso, en el ámbito más general de las matrices de contabilidad social, el método de apportionment que consiste en eliminar una cuenta, que está representada por una fila y una columna, sumando al resto de elementos de la matriz inicial los correspondientes elementos normalizados de la matriz que resulta al multiplicar los vectores fila y columna de su cruce con el resto de cuentas ${ }^{143}$ (cuadro 4.1).

En los cuadros 4.2 y 4.3 mostramos la MCSE-90 agregada antes y después de eliminar la cuenta de bienes y servicios ${ }^{144}$. Los resultados detallados están recogidos en los cuadros A.1 y A.2 del anexo estadístico.

\footnotetext{
${ }^{143}$ La normalización es simétrica, así al eliminar una cuenta $i$, las filas y columnas de la matriz normalizada $\left(T_{n i}\left(Y_{i}-T_{i i}\right)^{-1} T_{i n}\right)$ son proporcionales, respectivamente, al vector fila $T_{n i} \mathrm{y}$ al vector columna $T_{i n}$.

144 Dado que todos los elementos de la fila P.33 (servicios de comercio) de la cuenta de bienes y servicios son cero, a efectos de poder calcular la inversa de la matriz $\left(\hat{Y}_{m}-T_{m m}\right)^{-1}$ del cuadro 4.1, hemos agregado los servicios comerciales con los márgenes de distribución.
} 
CUADRO 4.1. Eliminación de cuentas en una matriz de contabilidad social

\begin{tabular}{|c|c|c|c|c|c|c|}
\hline $\begin{array}{l}\text { MCS } \\
\text { inicial }\end{array}$ & $\mathrm{T}_{\mathrm{m}}$ & $\mathrm{T}_{\mathrm{m}+1} \quad \ldots \quad \mathrm{T}_{\mathrm{m}+\mathrm{n}}$ & Total & $\begin{array}{c}\text { MCS } \\
\text { reducida }\end{array}$ & $\mathrm{T}_{1}, \ldots, \mathrm{T}_{\mathrm{n}}$ & Total \\
\hline $\mathrm{T}_{\mathrm{m}}$ & $T_{m m}$ & $T_{m n}$ & $Y_{m}$ & & & \\
\hline $\begin{array}{c}\mathrm{T}_{\mathrm{m}+1} \\
\cdots \\
\mathrm{T}_{\mathrm{m}+\mathrm{n}}\end{array}$ & $T_{n m}$ & $T_{n n}$ & $Y_{n}$ & $\begin{array}{l}\mathrm{T}_{1} \\
\cdots \\
\mathrm{T}_{\mathrm{n}}\end{array}$ & $\begin{array}{c}T_{n n}^{*}=T_{n n}+ \\
T_{n m}\left(\hat{Y}_{m}-T_{m m}\right)^{-1} T_{m n}\end{array}$ & $Y_{n}$ \\
\hline Total & $\begin{array}{c}i T_{m m}+i T_{n m} \\
=\left(Y_{m}\right)^{T}\end{array}$ & $i T_{m n}+i T_{n n}=\left(Y_{n}\right)^{T}$ & & Total & $i T_{n, n}^{*}=\left(Y_{n}\right)^{T}$ & \\
\hline
\end{tabular}

Fuente: Pyatt (1989). 
CUADRO 4.2. MCSE-90 adaptada al SCN93

(Presentación agregada en miles de millones de pesetas)

\begin{tabular}{|c|c|c|c|c|c|c|c|c|c|c|c|c|c|c|c|c|c|}
\hline \multirow[t]{2}{*}{$\begin{array}{l}\text { SCN } \\
1993\end{array}$} & \multicolumn{2}{|l|}{$\begin{array}{l}\text { Bienes y } \\
\text { servicios }\end{array}$} & Producción & $\begin{array}{l}\text { Generación } \\
\text { de renta } \\
\text { primaria }\end{array}$ & \multicolumn{4}{|c|}{$\begin{array}{l}\text { Asignación, distribución y } \\
\text { utilización de la renta } \\
\text { (operaciones corrientes) }\end{array}$} & \multicolumn{3}{|c|}{$\begin{array}{c}\text { Variación del } \\
\text { patrimonio } \\
\text { (por operaciones) }\end{array}$} & \multicolumn{4}{|c|}{ Variación del Balance } & RDM & \\
\hline & \multicolumn{2}{|l|}{ C. 0} & C.I & C.II.1 & \multicolumn{4}{|c|}{ Cs.II.2 a II.4 } & \multicolumn{3}{|c|}{ C.III.1.1 } & \multicolumn{4}{|c|}{ C. IV.1.2 (=Cs. III.1.2, III.2) } & C.V & \\
\hline \multirow{3}{*}{ MCSE } & \multicolumn{2}{|c|}{ Productos } & Actividades & $\begin{array}{l}\text { Categorías } \\
\text { de Valor } \\
\text { Añadido }\end{array}$ & \multicolumn{11}{|c|}{ Unidades institucionales residentes } & u.n.r. & \\
\hline & \multicolumn{2}{|l|}{1} & 2 & 3 & \multicolumn{4}{|c|}{4} & \multicolumn{3}{|c|}{5} & \multicolumn{4}{|c|}{6} & 7 & \\
\hline & P.1...P.48 & 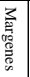 & R.1...R.48 & C1...C.15 & Н.1...H.30 & Emp. & AA.PP. & IPSFL & Hog. & Emp. & AA.PP. & Hog. & Emp. & AA.PP. & \begin{tabular}{|c|}
$\begin{array}{c}\text { Formació } \\
\mathrm{n} \text { bruta de } \\
\text { capital }\end{array}$ \\
\end{tabular} & RDM & Total \\
\hline 票 & & $\begin{array}{c}\tilde{m} \\
\sigma \\
\sigma\end{array}$ & 36.983 & & 24.533 & & 8.199 & 238 & & & & & & & 12.421 & 7.848 & 99.354 \\
\hline Márgenes & 0 & & 1.975 & & 5.987 & & 161 & 0 & & & & & & & 302 & 707 & 9.132 \\
\hline 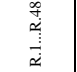 & 85.962 & & & & & & & & & & & & & & & & 85.962 \\
\hline ن̀ & & & 47.004 & & & & & & & & & & & & & 35 & 47.039 \\
\hline 商 & & & & 31.011 & 359 & 4.651 & 7.785 & 52 & & & & & & & & 477 & 44.335 \\
\hline Empresas & & & & 9.740 & 2.832 & 7.433 & 1.366 & & & & & & & & & 766 & 22.138 \\
\hline AA.PP. & 3.142 & & & 6.271 & 6.844 & 2.286 & & & & & & & & & & 388 & 18.930 \\
\hline IPSFL & & & & 16 & 14 & & & & & & & & & & & 0 & 30 \\
\hline Hogares & & & & & 3.666 & 267 & & -260 & 0 & 0 & 114 & & & & & 14 & 3.802 \\
\hline Empresas & & & & & & 6.309 & & & 7 & 0 & 646 & & & & & 81 & 7.043 \\
\hline AA.PP. & & & & & & & 885 & & 117 & 182 & 480 & & & & & 62 & 1.726 \\
\hline Hogares & & & & & & & & & 3.678 & & & & 50 & & & 4.238 & 8.057 \\
\hline Empresas & & & & & & & & & & 6.861 & & & & 0 & & 15.299 & 22.160 \\
\hline AA.PP. & & & & & & & & & & & 470 & & & & & 3.837 & 4.306 \\
\hline FBC & & & & & & & & & & & & 2.784 & 7.505 & 2.434 & & & 12.723 \\
\hline RDM & 10.251 & & & 2 & 99 & 1.192 & 533 & 0 & 0 & 0 & 17 & 5.273 & 14.604 & 1.782 & & & 33.753 \\
\hline Total & 99.354 & & 85.962 & 47.039 & 44.335 & 22.138 & 18.930 & 30 & 3.802 & 7.043 & 1.726 & 8.057 & 22.160 & 4.306 & 12.723 & 33.753 & \\
\hline
\end{tabular}

Fuente: Cuadro A.1 del anexo estadístico. 
CUADRO 4.3. MCSE-90R. Sin cuenta de bienes y servicios

(Presentación agregada en miles de millones de pesetas)

\begin{tabular}{|c|c|c|c|c|c|c|c|c|c|c|c|c|c|c|c|}
\hline & $\begin{array}{c}\text { Bienes y } \\
\text { servicios y } \\
\text { Producción }\end{array}$ & $\begin{array}{c}\text { Generacion } \\
\text { de renta } \\
\text { primaria }\end{array}$ & \multicolumn{4}{|c|}{$\begin{array}{c}\text { Asignación, distribución y } \\
\text { utilización de la renta (operaciones } \\
\text { corrientes) }\end{array}$} & $\begin{array}{r}\mathrm{Va} \\
\mathrm{p} \\
\text { (por }\end{array}$ & $\begin{array}{l}\text { ariación } \\
\text { atrimon } \\
\text { operaci }\end{array}$ & $\begin{array}{l}\text { del } \\
\text { iio } \\
\text { iones) }\end{array}$ & \multicolumn{4}{|c|}{ Variaciones de balance } & RDM & \\
\hline & Actividades & de Valor & \multicolumn{11}{|c|}{ Unidades institucionales residentes } & u.n.r. & \\
\hline & 1 & 2 & \multicolumn{4}{|c|}{3} & \multicolumn{3}{|c|}{4} & \multicolumn{4}{|c|}{5} & 6 & \\
\hline & R.1...R.48 & C1...C.15 & H.1...H.30 & Emp. & AA.PP. & IPSFL & Hog. & Emp. & AA.PP. & Hog. & Emp. & AA.PP. & $\begin{array}{c}\text { Formación } \\
\text { bruta de } \\
\text { capital }\end{array}$ & RDM & TOTAL \\
\hline 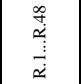 & 32.895 & & 26.979 & 0 & 8.253 & 237 & & & & & & & 10.721 & 6.876 & 85.962 \\
\hline 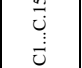 & 47.004 & & & & & & & & & & & & & 35 & 47.039 \\
\hline 孞 & & 31.011 & 359 & 4.651 & 7.785 & 52 & & & & & & & & 477 & 44.335 \\
\hline Empresas & & 9.740 & 2.832 & 7.433 & 1.366 & & & & & & & & & 766 & 22.138 \\
\hline AA.PP. & 1.029 & 6.271 & 8.056 & 2.286 & 18 & & & & & & & & 529 & 741 & 18.930 \\
\hline IPSFL & & 16 & 14 & & & & & & & & & & & 0 & 30 \\
\hline Hogares & & & 3.666 & 267 & & -260 & 0 & & 114 & & & & & 14 & 3.802 \\
\hline Empresas & & & & 6.309 & & & 7 & & & & & & & 81 & 7.043 \\
\hline AA.PP. & & & & & 885 & & 117 & 182 & 480 & & & & & 62 & 1.726 \\
\hline Hogares & & & & & & & 3.678 & & & & 50 & & & 4.238 & 8.057 \\
\hline Empresas & & & & & & & & 6.861 & & & & 0 & & 15.299 & 22.160 \\
\hline AA.PP. & & & & & & & & & 470 & & & & & 3.837 & 4.306 \\
\hline FBC & & & & & & & & & & 2.784 & 7.505 & 2.434 & & & 12.723 \\
\hline RDM & 5.034 & 2 & 2.427 & 1.192 & 621 & 1 & 0 & 0 & 17 & 5.273 & 14.604 & 1.782 & 1.472 & 1.327 & 33.753 \\
\hline TOTAL & 85.962 & 47.039 & 44.335 & 22.138 & 18.930 & 30 & 3.802 & 7.043 & 1.726 & 8.057 & 22.160 & 4.306 & 12.723 & 33.753 & \\
\hline
\end{tabular}

Fuente: Cuadro A2 del anexo estadístico.

La diferencia entre la MCSE-90 inicial y la que resulta de eliminar la cuenta de bienes y servicio radica en que, en ésta ultima, el consumo intermedio, el consumo final, la formación bruta de capital y las exportaciones están reasignados entre los pro- 
ductores residentes (ramas de actividad) y no residentes (importaciones), y las AA.PP (IVA y aranceles) $)^{145}$.

Una vez reducida la MCSE-90, procedemos a su reordenación tal y como figura en los cuadro 4.4.a y 4.4.b. Para ello, en primer lugar, descomponemos las operaciones con el resto del mundo que figuran en la cuenta 6 de la MCSE-90R y presentamos cada una de ellas, junto con las operaciones entre residentes, en la cuenta correspondiente de la sucesión ${ }^{146}$. En segundo lugar, para facilitar el posterior análisis de las cuestiones distributivas, separamos las rentas de la propiedad de las transferencias corrientes y registramos ambas operaciones en términos netos, las primeras junto con el resto de operaciones de distribución primaria de la renta en la submatriz 3.2 y las segundas en la submatriz 3.3 de la cuenta de asignación, distribución y utilización de la renta ${ }^{147}$. Por último, reordenamos los sectores institucionales y los factores de producción, con el fin de disponer las operaciones de tal modo que queden agrupadas las operaciones de distribución primaria y secundaria de la renta de los hogares en una única submatriz (remarcada en los cuadro 4.4.a y 4.4.b). Los datos desagregados de la nueva matriz reducida y reordenada se presentan en los cuadro A.3.a y A.3.b del anexo estadístico.

\footnotetext{
${ }^{145}$ En la práctica la matriz reducida con la que hemos trabajado es ligeramente distinta a la mostrada en el cuadro 4.3, ya que para poder obtener las matrices inversas que requiere la modelización de una matriz de contabilidad social (véase cuadro 2.10 de este trabajo) es necesario eliminar la rama de PISB (R.39), dado que todos los elementos de su fila son ceros. Al eliminar la PISB los recursos de la rama de créditos y seguros (R.38) se reducen en 3.627.250 millones pts., que corresponden al consumo intermedio de la rama de PISB, y paralelamente, el excedente de explotación del sector empresas aumenta en 3.662.185, los ingresos de las AA.PP por impuestos indirectos netos disminuyen en 3.157 millones pts. y las importaciones se reducen en 31.778. Para mantener el equilibrio entre la suma de los elementos por filas y columnas de la MCSE-90R, hemos supuesto que la producción imputada de servicios bancarios es consumo intermedio de la rama R.38, lo que supone una reducción de su excedente de explotación y un aumento de sus gastos en concepto de impuestos indirectos netos y de importaciones. Además para simplificar la descomposición de los multiplicadores (véase cuadro 2.11 de este trabajo) hemos movido el IVA y los aranceles a la submatriz de inputs primarios, creando al efecto una nueva fila y columna.

${ }^{146}$ A efectos de mantener equilibradas todas las cuentas del RDM hemos incluido en la columna de la cuenta de acumulación correspondiente al resto del mundo los saldos que equilibran cada una de ellas.

${ }^{147}$ Consecuentemente, en la submatriz 3.2 los ingresos de los distintos sectores institucionales en concepto de excedente bruto de explotación quedan mermados por el montante de rentas de propiedad pagadas al resto de unidades residentes.
} 
CUADRO 4.4.a. Matriz de contabilidad social reducida y reordenada

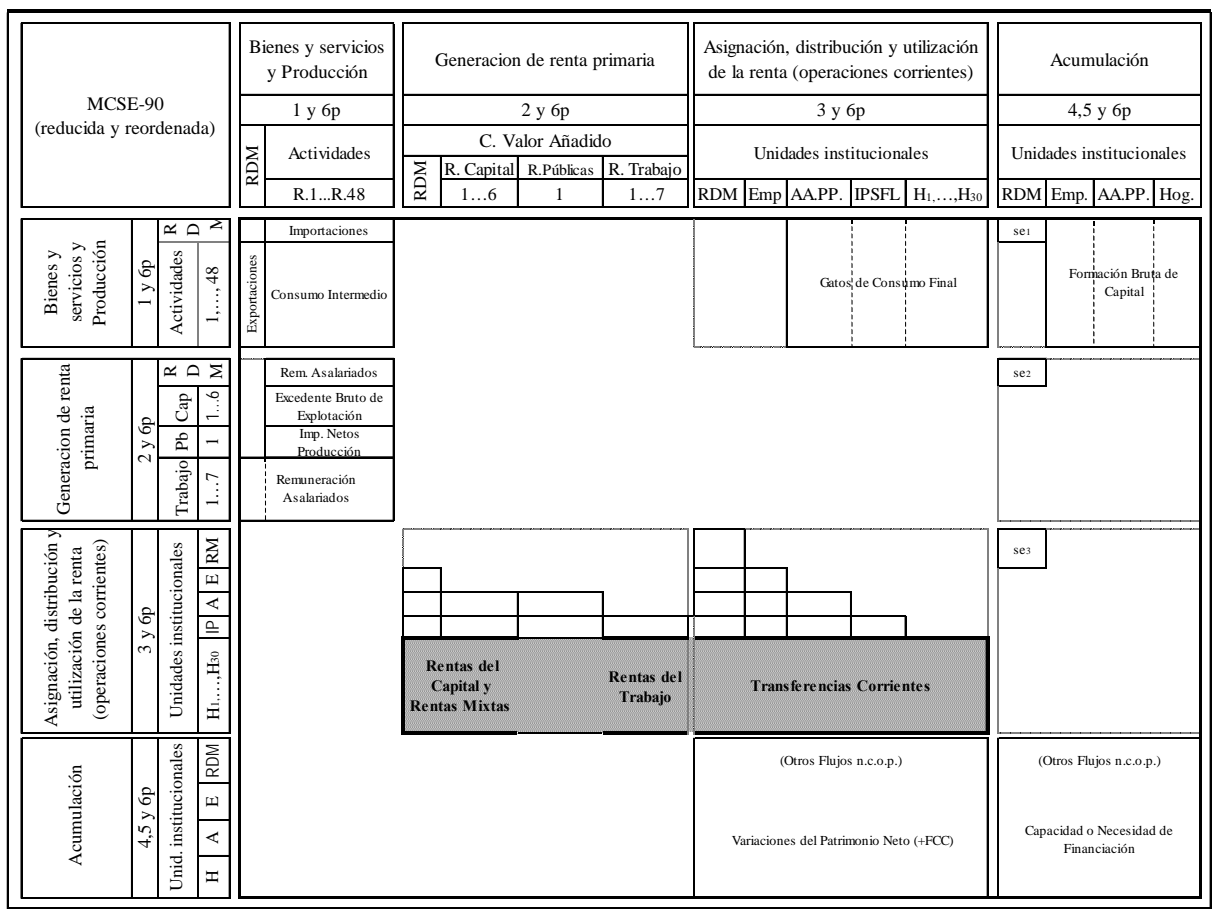

Con respecto a la clasificación de las cuentas de una matriz de contabilidad social en endógenas y exógenas, aunque formalmente es posible utilizar cualquier partición, la decisión del investigador al respecto está condicionada por criterios económicos y limitaciones estadísticas que orientan su elección, en función del objeto de análisis a abordar en cada caso.

Como señalamos con anterioridad, se pueden seleccionar alternativamente como cuentas endógenas, un conjunto de operaciones (v.gr.: operaciones de acumulación versus corrientes), un grupo de unidades (v.gr.: AA.PP. y resto del mundo versus productores y unidades institucionales privadas) o cualquier combinación de operaciones y unidades. Como señalan Reinert y otros (1993) y tendremos ocasión de comprobar en el siguiente apartado, a medida que se reduce el número de cuentas exógenas aumenta la magnitud de los multiplicadores, por lo que lo ideal sería endogeneizar el máximo número posible de cuentas. Sin embargo, debido a la deficiente información 
sobre la composición y variación del patrimonio de los distintos sectores institucionales, especialmente en lo que a sus activos no financieros se refiere, nos hemos visto obligados a considerar exógenas las cuentas de acumulación de todos los sectores institucionales.

CUADRO 4.4.b. MCSE-90RR. Reducida, reordenada y sin PISB (Presentación agregada en miles de millones de pesetas)

\begin{tabular}{|c|c|c|c|c|c|c|c|c|c|c|c|c|c|}
\hline \multirow{3}{*}{ MCSE-90RR } & \multicolumn{2}{|c|}{$\begin{array}{l}\text { Bienes y servios y } \\
\text { Producción }\end{array}$} & \multicolumn{4}{|c|}{ Generacion de renta primaria } & \multicolumn{5}{|c|}{$\begin{array}{l}\text { Asignación, distribución y utilización de la } \\
\text { renta (operaciones corrientes) }\end{array}$} & \multirow{3}{*}{ 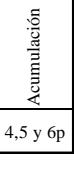 } & \multirow{3}{*}{ Total } \\
\hline & \multicolumn{2}{|c|}{1 y $6 p$} & \multicolumn{4}{|c|}{2 y $6 p$} & \multicolumn{5}{|c|}{3 y $6 p$} & & \\
\hline & RDM & R1...-48 & RDM & R.Capital & R. Públicas & R. Trabajo & RDM & E & A & IP & $\mathrm{H} 1 \ldots \mathrm{H} 30$ & & \\
\hline RDM & 1.327 & 5.034 & & & & & 0 & 0 & 88 & 1 & 2.328 & -540 & 8.238 \\
\hline R1...48 & 6.876 & 29.267 & & & & & 0 & 0 & 8.253 & 237 & 26.979 & 10.721 & 82.334 \\
\hline RDM & 0 & 2 & & & & & & & & & & -487 & -485 \\
\hline R. Capital & 0 & 22.774 & & & & & & & & & & 0 & 22.774 \\
\hline R. Públicas & 0 & 1.974 & & & & & & & & & & 0 & 1.974 \\
\hline R. Trabajo & 35 & 23.282 & & & & & & & & & & 0 & 23.318 \\
\hline RDM & & & & & & & & & & & & 645 & 645 \\
\hline Empresas & & & -414 & 8.593 & & 665 & -13 & & & & & 0 & 8.832 \\
\hline AA.PP. & & & \begin{tabular}{|l|} 
\\
\end{tabular} & -776 & 1.974 & 4.817 & 304 & 1.809 & & & & 529 & 8.561 \\
\hline IPSFL & & & 0 & 16 & 0 & 0 & 0 & 0 & 0 & 0 & & 0 & 16 \\
\hline Н1 ... Н30 & & & 25 & 14.941 & 0 & 17.836 & 353 & 447 & -666 & 38 & 275 & 0 & 33.249 \\
\hline Acumulación & 0 & 0 & 0 & 0 & 0 & 0 & 0 & 6.576 & 885 & -260 & 3.666 & 10.868 & 189.456 \\
\hline Total & 8.238 & 82.334 & -485 & 22.774 & 1.974 & 23.318 & 645 & 8.832 & 8.561 & 16 & 33.249 & 189.456 & \\
\hline
\end{tabular}

Fuente: Cuadros A.3.b del anexo estadístico. 


\subsubsection{Consistencia de los multiplicadores de la MCSE-90}

Los multiplicadores SAM o multiplicadores contables, descritos en el apartado 2.3.1 de este trabajo, miden los efectos de una inyección de renta exógena sobre los distintos subsistemas económicos y sobre el conjunto de la economía, y su estimación permite analizar los instrumentos alternativos disponibles para favorecer el crecimiento económico y reducir la desigualdad. De las múltiples aplicaciones posibles de la MCSE-90, en este apartado calculamos los efectos producidos por variaciones exógenas en los recursos de las ramas de actividad sobre la producción y las rentas de los factores y de los hogares, a efectos de comprobar la consistencia de las distintas modelizaciones posibles.

Para analizar dicha consistencia y valorar tanto los supuestos adoptados como otras alternativas posibles, partimos de la MCSE-90 que figura en el cuadro A.1 del anexo estadístico y la adaptamos, en la medida de lo posible, a la empleada por Ferri y Uriel (2000). Para ello, en primer lugar, agregamos los productos (P.1,..,P.48) y las actividades (R.1,...,R.48) distinguidas en este trabajo en las once categorías consideradas por Ferri y Uriel. En segundo lugar, aunque no es posible establecer una correspondencia entre las clasificaciones de las categorías de valor añadido y de los hogares empleadas en ambos trabajos, para disponer al menos de una matriz de similar tamaño agregamos las rentas no salariales en una única categoría de valor añadido y a los hogares de cada quintil en tres grupos según su principal fuente de renta provenga del trabajo, de rentas de la propiedad o de transferencias. En tercer lugar, asignamos los márgenes comerciales y de transporte a las cuentas de los servicios de comercio y transporte. En cuarto lugar, repartimos el consumo intermedio de la rama de PISB entre las demás ramas de actividad en proporción a sus respectivos consumos intermedios de servicios de créditos y seguros. Finalmente, suponemos exógenos los impuestos netos de subvenciones que gravan la producción y la importación, el consumo y la inversión públicos, y todas la operaciones con el resto del mundo. Además de este primer modelo (Ia), para cuantificar la influencia 
de los modificaciones anteriores, consideramos el modelo (IIa) que reasigna los márgenes comerciales y de transporte a través de la eliminación de la cuenta de márgenes de distribución por el método de apportionment descrito en el apartado anterior; los modelos ( $I b$ y $I I b$ ) que, a diferencia de los dos anteriores, asignan íntegramente el consumo intermedio de la rama de PISB a la rama de créditos y seguros; y por último, los modelos ( $I A, I I A, I B$ y IIB) que se diferencian de los cuatro anteriores en que los multiplicadores se obtienen a partir de la matriz desagregada.

Un primer resultado de interés es que los modelos I y II arrojan idénticos multiplicadores. Tal y como demostró Pyatt (1989) el método de apportionment es consistente con respecto a los multiplicadores. La importancia de este resultado radica en que para analizar, en la práctica, una política concreta se puede reducir desde un principio la matriz de contabilidad social para tener en cuenta, exclusivamente, las cuentas de medios (exógenas) y de fines (endógenas). En el cuadro 4.5 hemos recogido una síntesis de la matrices de multiplicadores que miden los efectos de un aumento unitario en la demanda final exógena de las actividades (agrupadas en 11 ramas) sobre los recursos totales de las ramas, de los factores y de los hogares. Al comparar los resultados que arrojan los distintos modelos considerados, se observa un ligero aumento de los multiplicadores cuando la agregación de las ramas se lleva a cabo una vez invertida la matriz $\left(M_{I B}>M_{I b}\right.$ y $\left.M_{I A}>M_{I a}\right)$, en tanto que el mayor o menor tamaño de los multiplicadores, según se reparta o no la PISB, depende de las ramas consideradas $\left(M_{I A} \sim M_{I B}\right.$ y $\left.M_{I a} \sim M_{I b}\right)$.

En general, los multiplicadores actividades-actividades obtenidos a partir de la matriz de contabilidad social elaborada en este trabajo son inferiores a los que obtienen Ferri y Uriel (2000), aunque las diferencias desparecen al considerar los multiplicadores actividades-hogares. En cualquier caso, la conclusión general que se puede extraer con respecto a los multiplicadores globales es que ninguna de las alternativas produce efectos diferenciales notables. De hecho un aumento unitario de la renta exógena de las ramas de actividad, proporcional al peso de las distintas ramas en el total de recursos (última columna del cuadro 4.5) provoca un aumento de 
los recursos totales de las ramas de actividad entre 3,32 y 3,49 unidades, de la renta primaria entre 1,51 y 1,58 unidades, y de la renta disponible de los hogares entre 1.29 y 1.35 unidades.

CUADRO 4.5. Multiplicadores actividades-actividades, factores y hogares

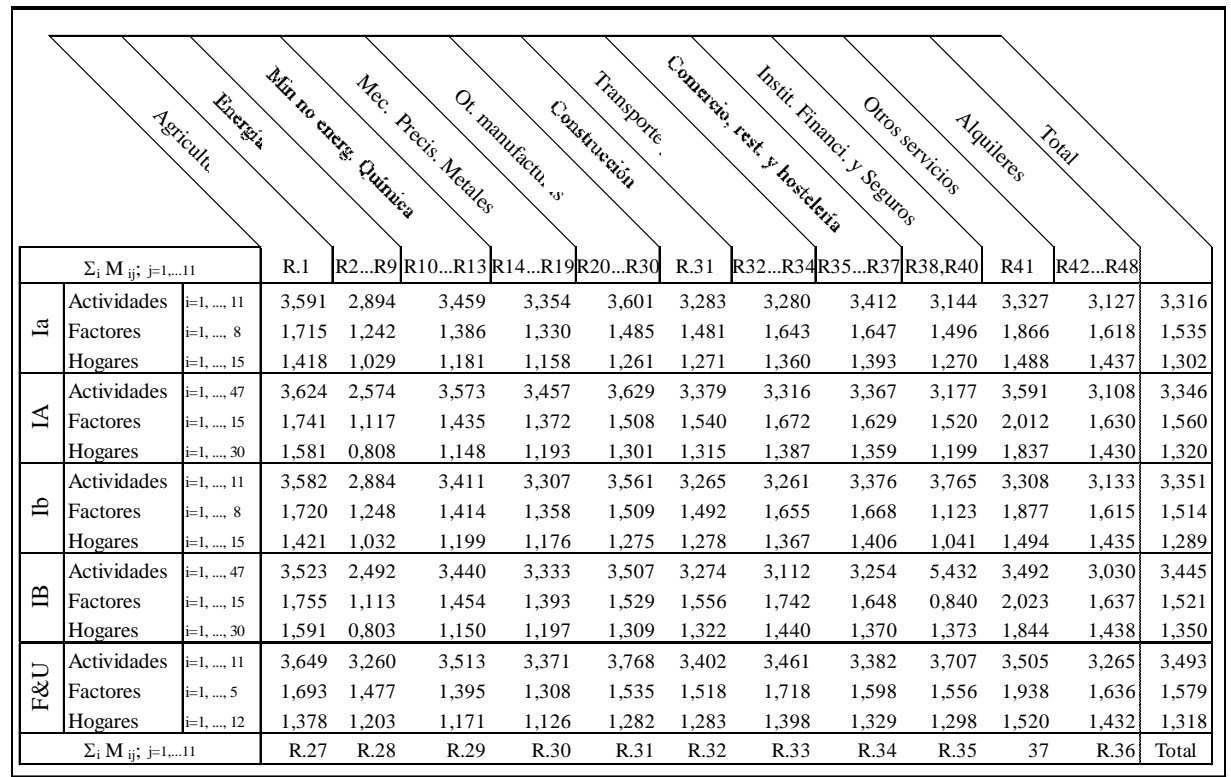

Fuente: Elaborado a partir de los cuadros A1 y A2 del anexo estadístico y de Ferri y Uriel (2000).

Dicha conclusión general se modifica cuando se comparan los multiplicadores unitarios de las distintas ramas de actividad. Las correlaciones entre los multiplicadores que arrojan las distintas versiones del modelo SAM elaborado a partir de la MCSE90 (cuadro 4.6) muestran, por un lado, una mayor consistencia del modelo cuando la

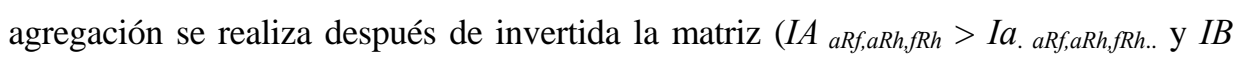
$\left.a R f, a R h . f R h .>\mathrm{Ib}{ }_{a R f, a R h, f R h . .)}\right)$, por otro, que la consistencia del modelo es similar tanto si reparte la PISB entre todas las ramas de actividad (parte superior derecha del cuadro 4.6) como si se elimina la cuenta de PISB (parte inferior izquierda del cuadro 4.6), siempre que en este último caso se excluya la rama de créditos y seguros $\left(I a_{a} R I b_{a}\right.$ $\left.\cong I \mathrm{~A}_{a} R \mathrm{IBa} \cong 1 ; I a_{f} R I b_{f} \cong I A_{f} R I B_{f} \cong 1 ; I a_{h} R I b_{h} \cong I A_{h} R I B_{h} \cong 1\right)$. En todas las versiones del modelo, la matriz de contabilidad social elaborada en este trabajo aparentemente muestra una mayor consistencia entre los distintos multiplicadores (actividades-
Comentario: El coeficiente de correlación nos muestra la relación entre dos conjuntos ordenados. Es el cociente entre la covarianza y el producto de las desviaciones tipicas. $R_{x y}=\frac{\operatorname{cov}(x, y)}{\sigma(x) \sigma(y)}=\frac{(1 / n) \sum_{i}\left(x_{i}-\bar{x}\right.}{\sqrt{(1 / n) \sum_{i}\left(x_{i}-\bar{x}\right)^{2}} \sqrt{(1}}$ 
actividades, actividades-factores y actividades-hogares) que la empleada por Uriel y Ferri (2000), si bien los ratios entre los recursos totales, las rentas primarias y la renta disponible de los hogares no necesariamente tienen que ser similares para las distintas ramas.

CUADRO 4.6. Correlaciones entre las distintas series de multiplicadores

\begin{tabular}{|c|c|c|c|c|c|c|c|c|c|c|c|c|c|c|c|c|c|}
\hline & \multicolumn{15}{|c|}{11 Ramas de actividad } \\
\hline & & & \multicolumn{3}{|c|}{ Ia } & \multicolumn{3}{|c|}{ IA } & \multicolumn{3}{|c|}{$\mathrm{Ib}$} & \multicolumn{3}{|c|}{ IB } & \multicolumn{3}{|c|}{$\mathrm{F} \& \mathrm{U}$} \\
\hline & & & A & $\mathrm{F}$ & $\mathrm{H}$ & A & $\mathrm{F}$ & $\mathrm{H}$ & A & $\mathrm{F}$ & $\mathrm{H}$ & A & $\mathrm{F}$ & $\mathrm{H}$ & A & $\mathrm{F}$ & $\mathrm{H}$ \\
\hline \multirow{15}{*}{ 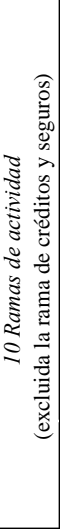 } & \multirow{3}{*}{$\approx$} & Actividades & & 0,35 & 0,35 & 0,925 & 0,42 & 0,480 & 0,622 & 0,457 & 0,455 & 0,115 & 0,489 & 0,433 & 0,617 & 0,060 & 0,042 \\
\hline & & Factores & 0,345 & & 0,96 & 0,480 & 0,97 & 0,945 & 0,274 & 0,847 & 0,866 & 0,129 & 0,745 & 0,948 & 0,230 & 0,909 & 0,922 \\
\hline & & Hogares & 0,353 & 0,96 & & 0,480 & 0,94 & 0,925 & 0,287 & 0,813 & 0,890 & 0,141 & 0,716 & 0,929 & 0,172 & 0,812 & 0,893 \\
\hline & \multirow{3}{*}{$\llbracket$} & Actividades & 0,925 & 0,47 & 0,47 & & 0,60 & 0,654 & 0,634 & 0,511 & 0,520 & 0,239 & 0,560 & 0,626 & 0,586 & 0,186 & 0,173 \\
\hline & & Factores & 0,423 & 0,97 & 0,94 & 0,608 & & 0,981 & 0,339 & 0,824 & 0,843 & 0,196 & 0,756 & 0,985 & 0,285 & 0,852 & 0,862 \\
\hline & & Hogares & 0,460 & 0,94 & 0,92 & 0,644 & 0,98 & 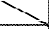 & 0,309 & 0,852 & 0,873 & 0,123 & 0,802 & 0,980 & 0,264 & 0,801 & 0,821 \\
\hline & \multirow{3}{*}{$=$} & Actividades & 0,997 & 0,39 & 0,40 & 0,922 & 0,46 & 0,500 & & $-0,066$ & 0,002 & 0,838 & $-0,132$ & 0,424 & 0,886 & 0,053 & 0,051 \\
\hline & & Factores & 0,381 & 0,99 & 0,96 & 0,511 & 0,97 & 0,952 & 0,424 & & 0,971 & $-0,368$ & 0,976 & 0,754 & $-0,032$ & 0,748 & 0,750 \\
\hline & & Hogares & 0,382 & 0,96 & 0,99 & 0,507 & 0,94 & 0,933 & 0,428 & 0,964 & & $-0,283$ & 0,937 & 0,790 & $-0,039$ & 0,711 & 0,774 \\
\hline & \multirow{3}{*}{ 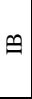 } & Actividades & 0,920 & 0,48 & 0,48 & 0,994 & 0,61 & 0,659 & 0,919 & 0,516 & 0,517 & & $-0,455$ & 0,296 & 0,679 & 0,035 & 0,041 \\
\hline & & Factores & 0,434 & 0,97 & 0,93 & 0,617 & 0,99 & 0,977 & 0,470 & 0,976 & 0,943 & 0,614 & & 0,684 & $-0,079$ & 0,636 & 0,637 \\
\hline & & Hogares & 0,459 & 0,95 & 0,93 & 0,642 & 0,98 & 0,999 & 0,499 & 0,958 & 0,938 & 0,652 & 0,985 & 7 & 0,354 & 0,809 & 0,831 \\
\hline & \multirow{3}{*}{$\mid \begin{array}{l}2 \\
\not \\
1\end{array}$} & Actividades & 0,856 & 0,29 & 0,22 & 0,755 & 0,34 & 0,378 & 0,862 & 0,315 & 0,244 & 0,746 & 0,360 & 0,380 & & 0,153 & 0,088 \\
\hline & & Factores & 0,049 & 0,90 & 0,81 & 0,181 & 0,85 & 0,805 & 0,098 & 0,896 & 0,801 & 0,185 & 0,845 & 0,812 & 0,194 & & 0,963 \\
\hline & & Hogares & 0,033 & 0,92 & 0,89 & 0,170 & 0,86 & 0,826 & 0,089 & 0,905 & 0,880 & 0,179 & 0,854 & 0,833 & 0,117 & 0,963 & \\
\hline
\end{tabular}

Fuente: Elaborado a partir de los cuadros A1 y A2 del anexo estadístico y de Ferri y Uriel (2000).

En cualquier caso, una de las ventajas de la matriz de contabilidad social que presentamos en este trabajo radica en su desagregación, lo que permite un análisis más detallado tanto de los medios como de los fines. Así por ejemplo, para valorar qué sectores ejercen mayor influencia sobre las rentas de determinados tipos de hogares, las clasificaciones más desagregadas tanto de las actividades como de los hogares permiten definir políticas más precisas, tanto a la hora de elegir los hogares sobre los que se pretende influir, como las actividades sobre las que se va actuar. Como muestra el cuadro 4.7.a, el tamaño de los multiplicadores difiere considerablemente entre las distintas ramas que componen cada uno de los once grupos de actividades consideradas en el cuadro 4.5. Asimismo, la MCSE-90 presenta por vez primera una clasificación de los hogares no sólo por categorías sociales sino también por niveles de renta, lo que supone un argumento en su favor de cara al análisis de los efectos distributivos 
en el marco de la contabilidad social que, en definitiva, constituye la finalidad última de este trabajo. Como tendremos ocasión de comprobar en el siguiente apartado, cualquier criterio de clasificación de los hogares alternativo al de su nivel de renta, aunque pueda ser de gran utilidad para diseñar políticas indirectas sobre aspectos específicos de la desigualdad, únicamente permite una valoración parcial del problema. Además como muestra el cuadro 4.7b, la consistencia entre los distintos modelos alternativos que se derivan de la MCSE-90 aumenta de forma apreciable al incrementar la desagregación de las ramas de actividad, de los factores de producción y de los grupos de hogares, lo que minimiza las posibles distorsiones asociadas a la elección de uno u otro modelo.

CUADRO 4.7.a. Multiplicadores actividades-actividades, factores y hogares Modelos IA y IB (47 ramas)

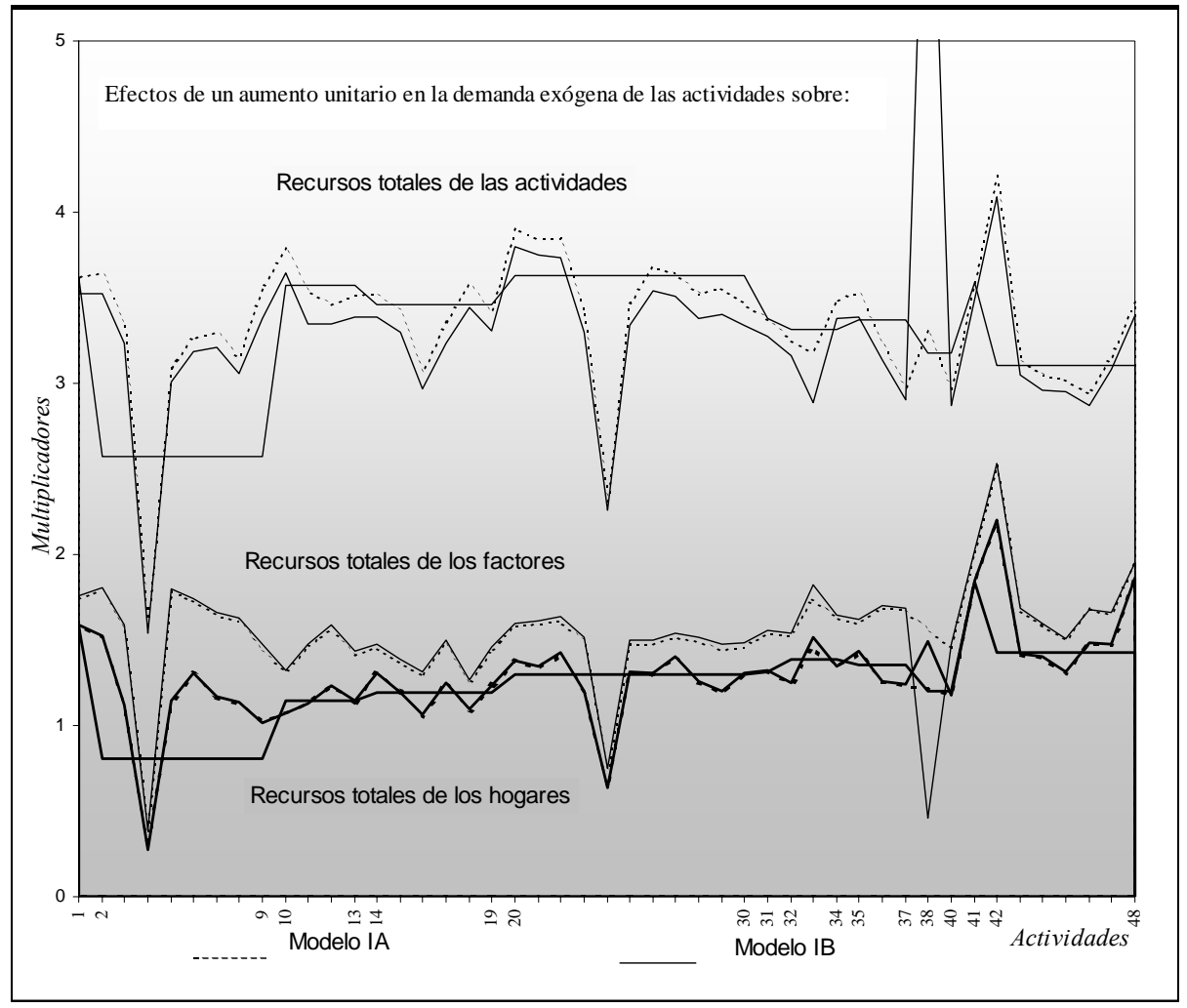

Fuente: Elaborado a partir del cuadro A2 del anexo estadístico. 
CUADRO 4.7.b. Correlaciones entre los multiplicadores IA-IB

\begin{tabular}{|c|c|c|c|c|c|c|c|c|}
\hline & \multicolumn{6}{|c|}{47 Ramas de actividad } \\
\hline & & & \multicolumn{3}{|c|}{ Sin PISB } & \multicolumn{3}{|c|}{ Con PISB repartida } \\
\hline & & & A & $\mathrm{F}$ & $\mathrm{H}$ & A & $\mathrm{F}$ & $\mathrm{H}$ \\
\hline \multirow{6}{*}{ 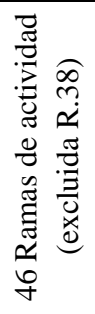 } & \multirow{3}{*}{$\begin{array}{l}n \\
\omega \\
\tilde{a} \\
\approx \\
\omega\end{array}$} & Actividades & & 0,641 & 0,666 & 0,572 & 0,580 & 0,656 \\
\hline & & Factores & 0,641 & & 0,918 & 0,388 & 0,876 & 0,914 \\
\hline & & Hogares & 0,666 & 0,919 & & 0,369 & 0,824 & 0,990 \\
\hline & \multirow{3}{*}{ 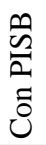 } & Actividades & 0,996 & 0,652 & 0,677 & & $-0,044$ & 0,475 \\
\hline & & Factores & 0,650 & 0,999 & 0,918 & 0,657 & & 0,755 \\
\hline & & Hogares & 0,661 & 0,919 & 1,000 & 0,670 & 0,919 & \\
\hline
\end{tabular}

Fuente: Elaborado a partir del cuadro A2 del anexo estadístico.

Un último aspecto a considerar es el de la importancia de la elección de las operaciones y unidades exógenas sobre los efectos multiplicadores. Como muestra el cuadro 4.8.a, a medida que aumenta el número de cuentas endógenas se amplían los efectos multiplicadores. Más allá de este resultado que es obvio, en el cuadro 4.8.a se puede apreciar cómo el grado de endogeneización del modelo también influye sobre el tamaño de los multiplicadores relativos. De ahí que finalmente hayamos optado por el modelo más desagregado posible que considera endógenas las cuentas corrientes de todas las unidades y exógenas las cuentas de acumulación, por no disponer para estas últimas de información suficiente sobre su reparto por sectores institucionales. En cuanto al tratamiento de la PISB, hemos optado por no repartirla entre las ramas de actividad según sus respectivos consumos intermedios de créditos y seguros por carecer de justificación firme frente a otros criterios alternativos y porque dicho reparto no mejora la consistencia de los modelos (cuadro 4.8.b), siempre y cuando se excluya del análisis la rama de créditos y seguros (R.38). En otras palabras, hemos optado por una única gran distorsión explícita frente a la alternativa de introducir 47 pequeñas distorsiones implícitas. 
CUADRO 4.8.a. Multiplicadores actividades-actividades y hogares (47 ramas)

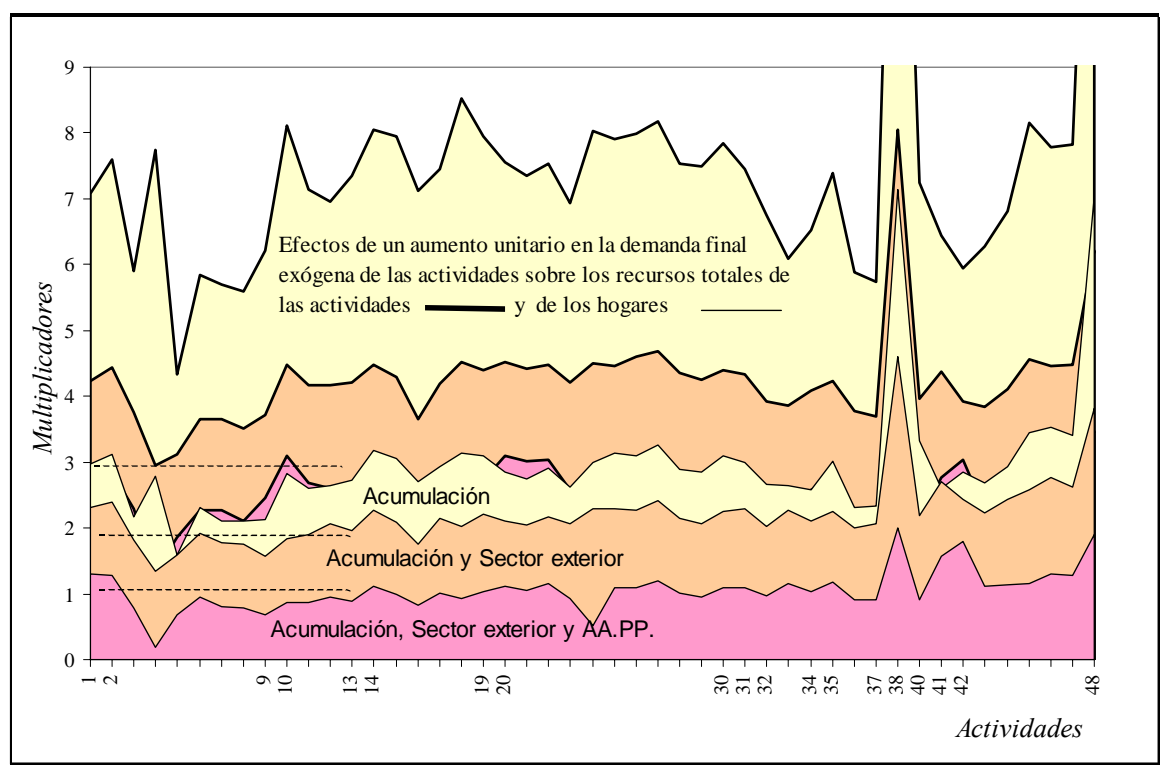

Fuente: Elaborado a partir del cuadro A2 del anexo estadístico.

CUADRO 4.8.b. Correlaciones entre los multiplicadores actividades-actividades,

factores y hogares (47 ramas)

\begin{tabular}{|c|c|c|c|c|c|c|c|c|c|c|c|c|c|c|}
\hline & \multicolumn{12}{|c|}{$\begin{array}{c}\text { PISB repartida en proporción a los consumos intermedios de las ramas de } \\
\text { servicios de créditos y seguros ( } 47 \text { ramas de actividad) }\end{array}$} \\
\hline & & & \multicolumn{12}{|c|}{ Cuentas endógenas } \\
\hline & & & \multicolumn{3}{|c|}{$\mathrm{I}, \mathrm{II}, \mathrm{III}(\mathrm{H})$} & \multicolumn{3}{|c|}{ I,II,III(H,I,S) } & \multicolumn{3}{|c|}{$\mathrm{I}, \mathrm{II}, \mathrm{III}(\mathrm{H}, \mathrm{I}, \mathrm{S}, \mathrm{A})$} & \multicolumn{3}{|c|}{ I,IIyIII* } \\
\hline & & & A & $\mathrm{F}$ & $\mathrm{H}$ & $1 \mathrm{~A}$ & $1 \mathrm{~F}$ & $1 \mathrm{H}$ & $2 \mathrm{~A}$ & $2 \mathrm{~F}$ & $2 \mathrm{H}$ & $3 \mathrm{~A}$ & $3 \mathrm{~F}$ & $3 \mathrm{H}$ \\
\hline \multirow{12}{*}{ 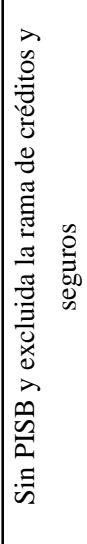 } & \multirow{3}{*}{ 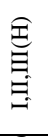 } & A & & 0 , & 0,65 & 0,93 & 0,30 & 0,53 & 0,70 & 0,15 & 0,34 & 0,38 & 0,19 & 0,30 \\
\hline & & F & 0,70 & & 0,92 & 0,53 & 0,90 & 0,94 & 0,59 & 0,75 & 0,85 & 0,28 & 0,36 & 0,47 \\
\hline & & $\mathrm{H}$ & 0,83 & 0,95 & & 0,65 & 0,76 & 0,93 & 0,61 & 0,58 & 0,78 & 0,35 & 0,36 & 0,50 \\
\hline & \multirow{3}{*}{ 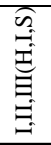 } & $1 \mathrm{~A}$ & 0,94 & 0,71 & 0,79 & & 0,51 & 0,66 & 0,81 & 0,34 & 0,49 & 0,54 & 0,39 & 0,48 \\
\hline & & $1 \mathrm{~F}$ & 0,45 & 0,88 & 0,75 & 0,62 & & 0,93 & 0,62 & 0,86 & 0,89 & 0,44 & 0,56 & 0,63 \\
\hline & & $1 \mathrm{H}$ & 0,67 & 0,94 & 0,92 & 0,77 & 0,93 & & 0,63 & 0,71 & 0,84 & 0,42 & 0,47 & 0,59 \\
\hline & \multirow[t]{3}{*}{4} & $2 \mathrm{~A}$ & 0,85 & 0,77 & 0,81 & 0,86 & 0,64 & 0,72 & & 0,74 & 0,80 & 0,84 & 0,78 & 0,81 \\
\hline & & $2 \mathrm{~F}$ & 0,53 & 0,85 & 0,76 & 0,60 & 0,84 & 0,78 & 0,86 & & 0,96 & 0,67 & 0,79 & 0,81 \\
\hline & & $2 \mathrm{H}$ & 0,68 & 0,91 & 0,88 & 0,70 & 0,83 & 0,86 & 0,91 & 0,97 & & 0,69 & 0,78 & 0,83 \\
\hline & \multirow[t]{3}{*}{$\stackrel{\hbar=}{=}$} & $3 \mathrm{~A}$ & 0,66 & 0,57 & 0,65 & 0,71 & 0,53 & 0,58 & 0,92 & 0,81 & 0,84 & & 0,96 & 0,95 \\
\hline & & $3 \mathrm{~F}$ & 0,55 & 0,60 & 0,63 & 0,62 & 0,61 & 0,61 & 0,88 & 0,88 & 0,87 & 0,98 & & t. \\
\hline & & $3 \mathrm{H}$ & 0,62 & 0,68 & 0,72 & 0,68 & 0,66 & 0,69 & 0,90 & 0,89 & 0,91 & 0,98 & 0,99 & \\
\hline
\end{tabular}

Fuente: Elaborado a partir del cuadro A2 del anexo estadístico. I: Cuenta de producción (actividades), II: Cuenta de generación de renta (factores), IIII: Cuenta de asignación, distribución y utilización de la renta (hogares, instituciones privadas sin fines de lucro, sociedades y AA.PP) y III*: incluye las operaciones corrientes con el resto del mundo. 


\subsection{MEDICIÓN DE LA DESIGUALDAD. TEORÍA}

La desigualdad es un concepto impreciso que ha sido objeto de estudio por muy diversas disciplinas. En el campo de la economía confluyen los esfuerzos realizados para desarrollar, por una parte, modelos teóricos a partir de las premisas que sobre diversos principios éticos y de comportamiento aportan la filosofía y la psicología y, por otra, modelos aplicados al análisis de realidades concretas mediante la utilización de las técnicas estadísticas disponibles.

Dado el actual estado de compromiso entre los desarrollos de la teoría y las limitaciones de la estadística, la economía utiliza los precios de mercado para agregar un sinfín de relaciones heterogéneas y poder representar de forma inteligible una realidad compleja. Aunque los precios de mercado no reflejan el "verdadero" valor de las relaciones económicas porque el mercado tiene una laguna (el reparto inicial de las dotaciones o sistema de derechos de propiedad) y tres fallos (indivisibilidad, inapropiabilidad e incertidumbre), se acepta que dicha métrica es la menos mala de las conocidas y aplicables.

Supongamos que en un futuro no lejano fuésemos capaces de arbitrar sin excesivos costes sistemas de derechos de propiedad divisibles, apropiables y ciertos, la cuestión que todavía permanecería abierta sería: ¿qué sistema de derechos de propiedad elegimos?. Las dos respuestas extremas a esta pregunta las aportan la filosofía del derecho natural (Hobbes,1651) que defiende el respeto a las dotaciones individuales y el contrato social (Rousseau,1763) que aboga por los mismos derechos para todos como miembros de una única sociedad. Ambas posturas tienen también una fundamentación económica basada en argumentos positivos que pretenden excluir los juicios de valor. Así, por una parte, los defensores del derecho natural (Nozick,1974) argumentan que si no se garantiza la propiedad individual sobre las dotaciones, desaparece el incentivo para aprovechar eficientemente los recursos disponibles. Por tanto, su defensa del no reparto se basa en la idea de que el bienestar es fruto del esfuerzo individual. Por otra parte, la defensa del reparto de Marx se basa 
en que el grueso del bienestar se obtiene en sociedad a través de la especialización y el intercambio, lo que hace necesario un consenso sobre su reparto para evitar el conflicto que impediría capturar dichos beneficios potenciales.

En suma, tenemos que la desigualdad genera conflicto y su corrección ineficiencia. A partir de las dos posturas extremas enunciadas con anterioridad, la economía trata de avanzar hacia algún punto de encuentro, utilizando como único instrumento las mejoras paretianas, o cambios hacia situaciones en las que alguien mejora sin que nadie empeore. A partir del ejemplo de Musgrave (1983), supongamos dos individuos con capacidades o dotaciones altas (Rico) y bajas (Pobre) que les permiten obtener unos ingresos de 60 y 20 unidades monetarias, respectivamente. Si se redistribuye una porción pequeña de renta (3 unidades) de $\mathrm{R}$ hacia $\mathrm{P}$ es posible que $\mathrm{R}$ se esfuerce para mantener su nivel de renta sacrificando parte de su ocio $\left(\mathrm{A}^{\prime}=60\right.$ y $\left.\mathrm{B}^{\prime}=23\right)$ y se produzca una mejora paretiana; pero si la renta se redistribuyera hasta alcanzar la igualdad, lo más probable sería que tanto $\mathrm{P}$ como R se esforzaran menos y que el producto total a repartir se redujera considerablemente $(60+20 \rightarrow 25+25)$. Siguiendo a Ralws (1971), P estaría dispuesto a consentir una participación en la renta inferior a la de R si con ello mejorara su situación en términos absolutos (A"=42 y B"'=35). En otras palabras, los puntos $(60,23)$ y $(42,35)$ son óptimos de Pareto (situaciones en las que ninguno puede mejorar sin que el otro empeore) y constituyen, por tanto, las dos las soluciones económicas dependiendo de si el problema se plantea partiendo de la filosofía del derecho natural (Hobbes) o del contrato social (Rousseau). 


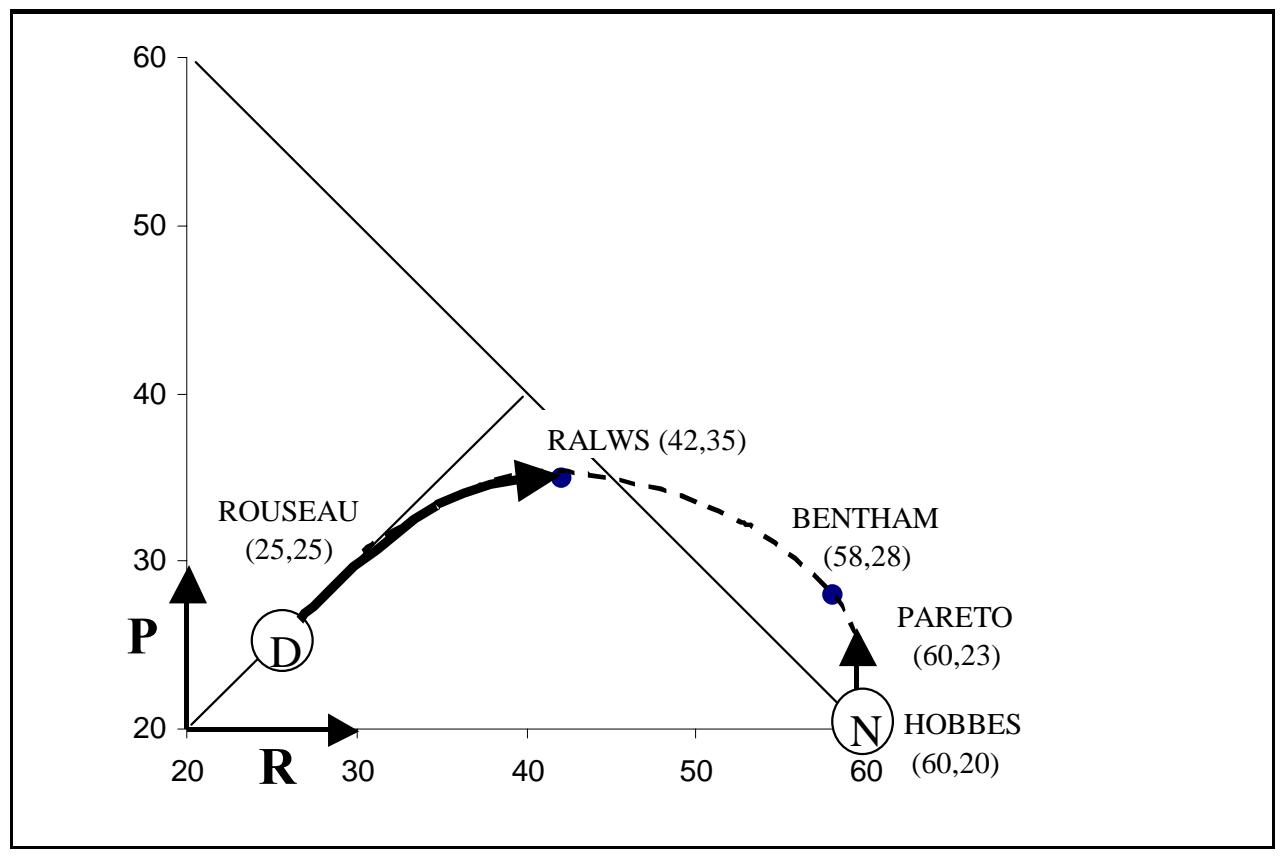

Para encontrar soluciones entre Ralws y Pareto (tramo de línea quebrada) en las pizarras suponemos habitualmente que las utilidades se pueden medir y que son comparables, lo que permite maximizar la utilidad total (Bentham, 1789). De hecho, el objetivo de maximizar el PIB o la renta total de una economía constituye un sucedáneo de la solución anterior. Dado que no sabemos medir ni comparar utilidades, se considera que todas las unidades monetarias producen la misma utilidad sin importar de dónde vienen ni a quién se dirigen. Como veremos a continuación, dicha solución incorpora una norma concreta que no es sino una más de entre otras muchas posibles. Hacer explícita la norma que se utiliza en cada caso es, en definitiva, el argumento central de este capítulo. 


\subsubsection{El espacio de las distribuciones. Representaciones geométricas}

El término matriz lo utilizó Sylvester en 1850 para designar una disposición rectangular de números, en 1855 Cayley mostró la posibilidad de expresar una transformación lineal mediante notación matricial y del trabajo de Hamilton de 1853 surgió el concepto de espacio vectorial. Ya en el siglo XX los matemáticos comenzaron a centrar su atención en las transformaciones lineales de espacios vectoriales, más que en la matrices que las representan (E. Britannica, pp. 262 y 634).

El conjunto de subconjuntos de $n$ rentas ordenadas constituye un espacio vectorial $n$-dimensional sobre el cuerpo de los números reales $U_{\mathrm{n}}(R)$, sus elementos se denominan vectores $\{\mathrm{V}\}$ y siempre que su dimensión sea menor o igual que tres tienen una interpretación geométrica. En el cuadro 4.10 representamos el vector de coordenadas de la renta disponible de los hogares españoles $(X)$ en un espacio bidimensional $\left(U_{2}\right)$, empleando bases diferentes. La figura de la izquierda está construida con los datos que se obtienen directamente de la Encuesta de Presupuestos Familiares de 1990-91 $\left(X_{H}^{\prime}\right)$ y con los datos de la Encuesta ajustados a la Contabilidad Nacional $\left(X_{H}\right)$, tal y como hemos descrito en el capítulo anterior. En ambos casos hemos utilizado los hogares como base $(H)$. En la figura de la derecha hemos representado los datos ajustados con la CNE90 empleando como base los individuos $\left(X_{I}\right)$ y la escala de equivalencia de la $\operatorname{OCDE}\left(X_{E}\right)$.

Las matrices de transición desde la base $H$ hacia las bases $I$ y $E$ son matrices diagonales cuyos elementos dependen del numero de miembros del hogar $\left(n_{\mathrm{i}}\right)$ y de la proporción de menores de 14 años $\left(b_{\mathrm{i}}\right): X_{\mathrm{I}}=A^{(\mathrm{H}, \mathrm{l})} X_{H}$ y $X_{\mathrm{E}}=A^{(\mathrm{H}, \mathrm{E})} X_{H}$, donde $A_{\mathrm{ii}}{ }^{(\mathrm{H}, \mathrm{I})}=\left(n_{\mathrm{i}}\right)^{-1}$ y $A_{\mathrm{ii}}^{(\mathrm{H}, \mathrm{E})}=\left\{1+0.7\left[\left(1-\mathrm{b}_{\mathrm{i}}\right) \mathrm{n}_{\mathrm{i}}-1\right]+0.5 \mathrm{~b}_{\mathrm{i}} \mathrm{n}_{\mathrm{i}}\right\}^{-1}$. 
CUADRO 4.10. Distribuciones (pobres-ricos) en diferentes bases

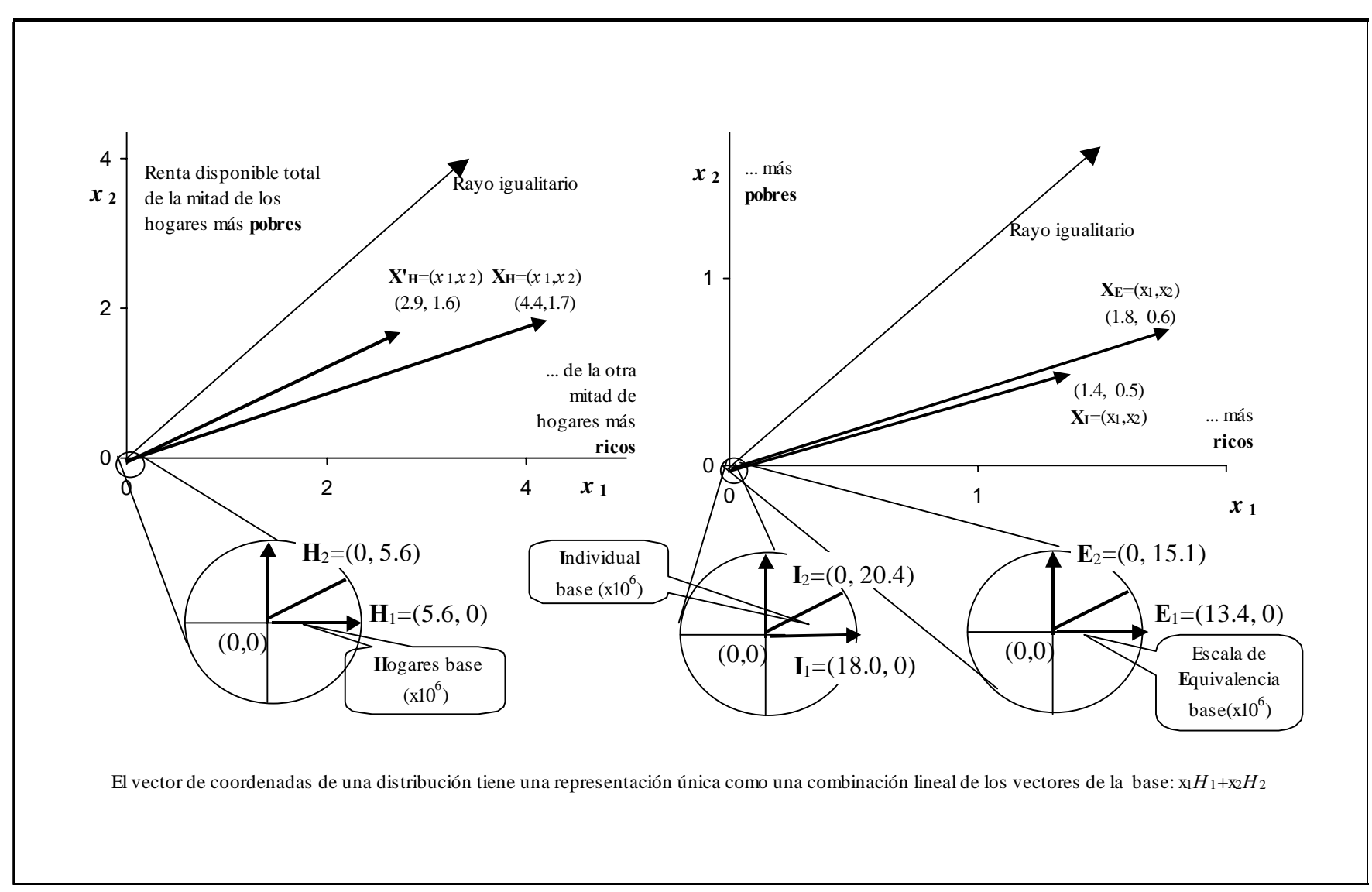


El cuadro 4.11 recoge la distribución de los tres tipos de renta de los hogares, que figuran en la submatriz resaltada de los cuadros 4.4.a y 4.4.b: trabajo (W), capital y renta mixta $(\mathrm{Y})$ y transferencias $(\mathrm{Z})$. En la figura de la izquierda, las distribuciones están ordenadas por el nivel de renta de los hogares y en la de la derecha, según su localización geográfica. El hecho de que en la figura de la izquierda las distribuciones de los tres tipos de renta considerados estén más próximas al rayo igualitario que en la figura de la derecha, se debe a que al clasificar a los hogares de acuerdo con su región de residencia tan sólo se recogen aspectos parciales de la desigualdad. Resultados similares se obtienen al aplicar otros criterios de clasificación de los hogares tales como su actividad económica, edad, sexo, etc.

Aunque el cuadro 4.11 ya plantea algunas cuestiones relevantes sobre desigualdad, para tratar otros aspectos también importantes, como son su descomposición por grupos o la sensibilidad posicional de las transferencias, es necesario utilizar espacios vectoriales de al menos tres dimensiones. En el cuadro 4.12 hemos representado de nuevo la distribución de la renta disponible y de las rentas del trabajo, del capital y de las transferencias corrientes, pero en un espacio tridimensional en el que los hogares están clasificados según su renta en pobres, medios y ricos. La imagen de la izquierda refleja perfectamente la dificultad de apreciar la mayor o menor desigualdad de varias distribuciones cuando la renta total a repartir no coincide. Sin embargo, en la imagen derecha se puede apreciar cómo la representación de distribuciones de participaciones en la renta simplifica bastantes cuestiones, aunque algunas otras como cuánto más desiguales son las rentas de la propiedad que las del trabajo o bajo qué supuestos las transferencias reducen la desigualdad, todavía siguen sin respuesta. 
CUADRO 4.11. Descomposición factorial de distribuciones

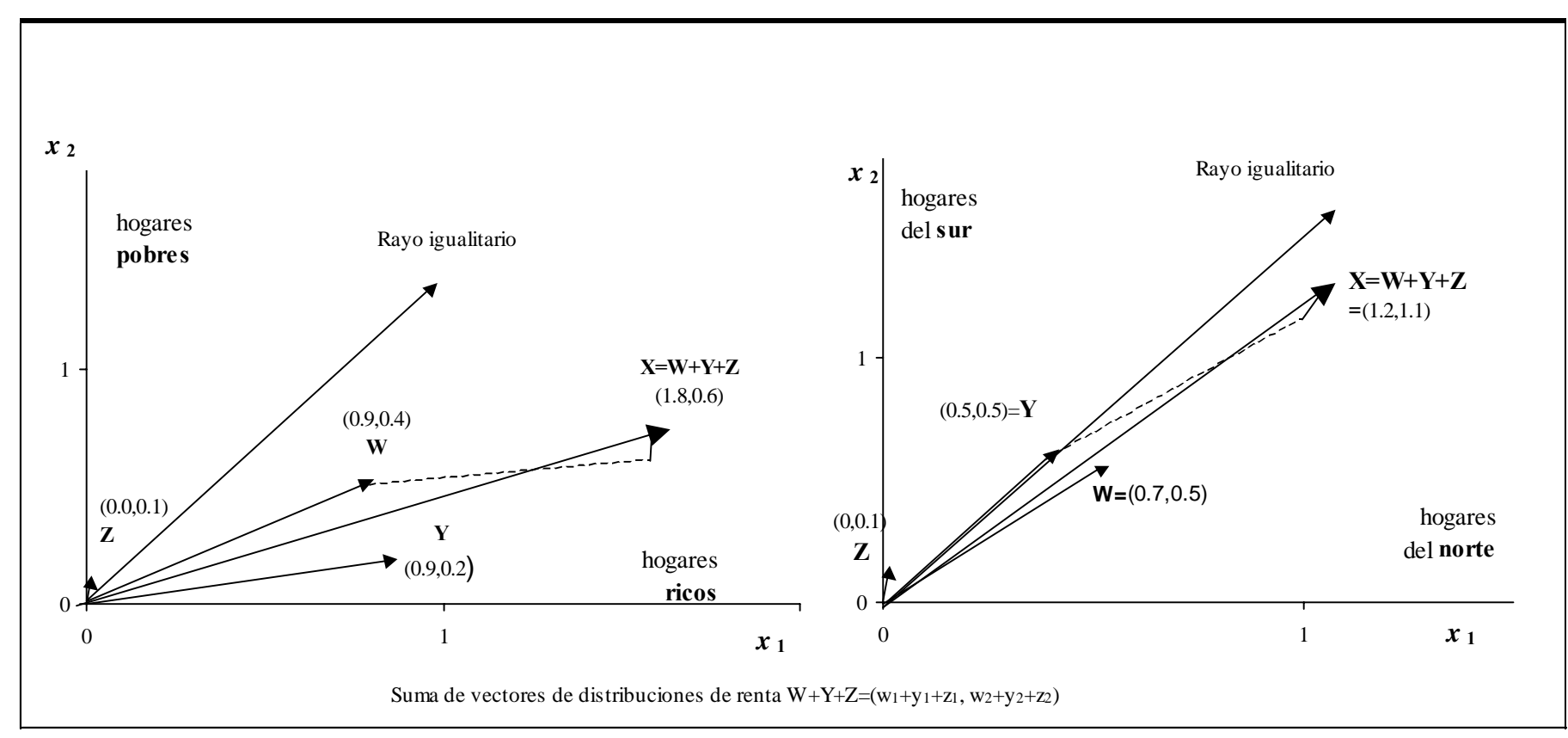


CUADRO 4.12. Distribuciones tridimensionales (valores absolutos y participaciones)

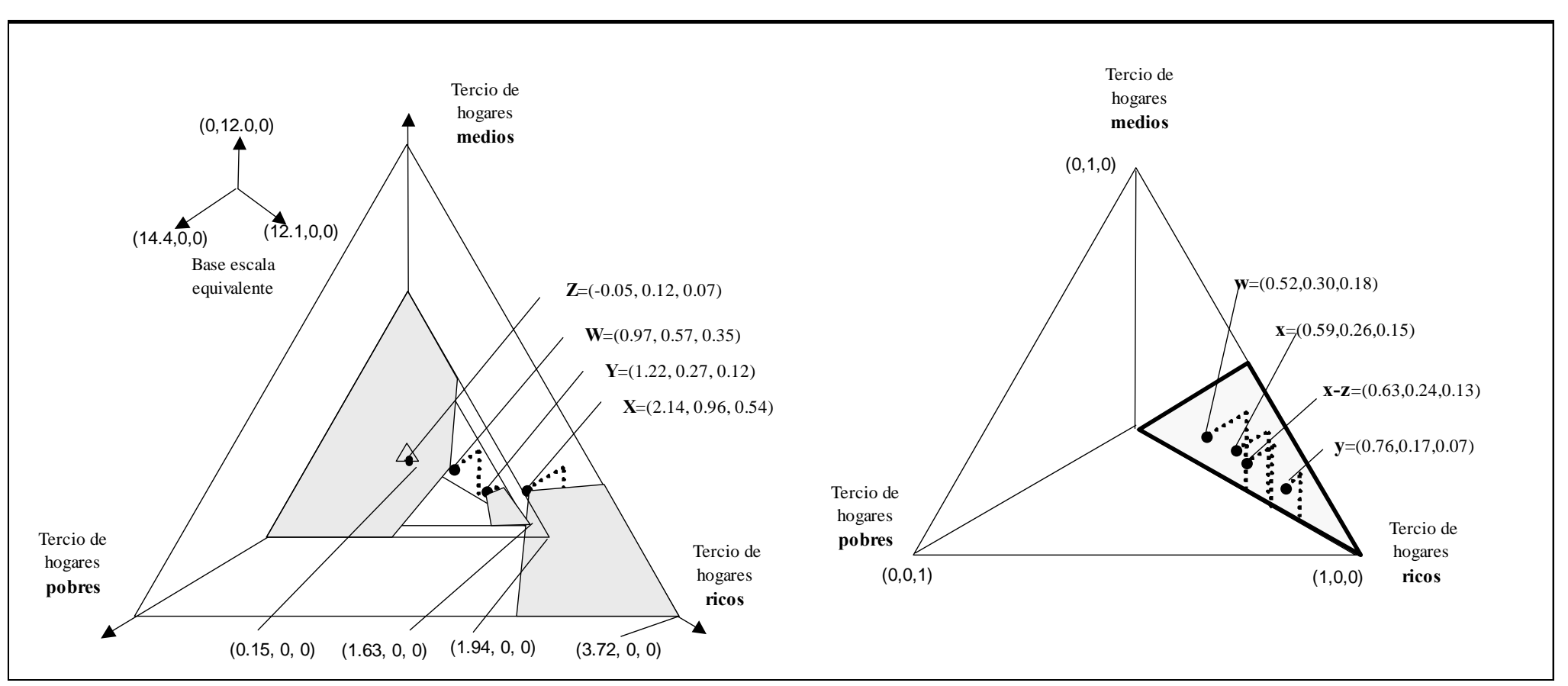


Debido a la imposibilidad de representar gráficamente más de tres dimensiones, cuando se considera un numero elevado de unidades, como por ejemplo los más de 21.000 hogares de la Encuesta de Presupuestos Familiares, y los datos se vuelcan sin más sobre el plano se obtiene la imagen superior izquierda del cuadro 4.13, y como puede apreciarse difícilmente puede emitirse a partir de la misma ningún juicio, en términos de equidad, sobre la distribución de la renta.

El análisis de la equidad o del bienestar de una población lleva aparejada la necesidad de efectuar un conjunto de juicios de valor sobre la distribución de las características de dicha población. Dicha distribución se puede representar matricialmente como $\left[x_{i j}\right]$, donde $i(1, \ldots n)$ son los individuos de la población y $j(1, \ldots, m)$ sus características relevantes, cada una de las cuáles puede medirse a través de una variable o de una combinación de variables. En el caso de que estemos interesados en una única característica, (por ejemplo, la renta), podemos establecer una relación funcional del tipo $x_{i}=F\left(x_{i}\right)$, (v.gr.: $x_{i}=x_{i} / n_{i}{ }^{\theta}$, donde $j$ representa la característica renta del hogar, $n$ el numero de miembros del hogar y $0 \leq \theta \leq 1$ es un parámetro que recoge los rendimientos crecientes del capital doméstico) y representar la distribución de la característica representativa de las $i$ unidades de análisis a través del vector $x=\left(x_{1}, \ldots, x_{i}, \ldots, x_{n}\right)$. La presentación ordenada de los elementos del vector facilita enormemente la tarea de comparar distintas distribuciones.

Una de las representaciones más intuitivas de una distribución consiste en hacer desfilar la población ordenada por su altura, que está determinada por el valor de la variable objeto de análisis. La figura superior derecha del cuadro 4.13 muestra un caso típico en el que la atención de los espectadores es capturada por los enanos y gigantes con los que se inicia y cierra respectivamente el desfile. Su eje horizontal representa la proporción de población que ha desfilado y su eje vertical la altura del último incorporado, medida a través de su renta por adulto equivalente. La función cuantílica $(Q)$ que se obtiene refleja el techo de renta $(x)$ de la proporción de población $(q)$ más pobre. 

CUADRO 4.13. Proyecciones sobre el plano
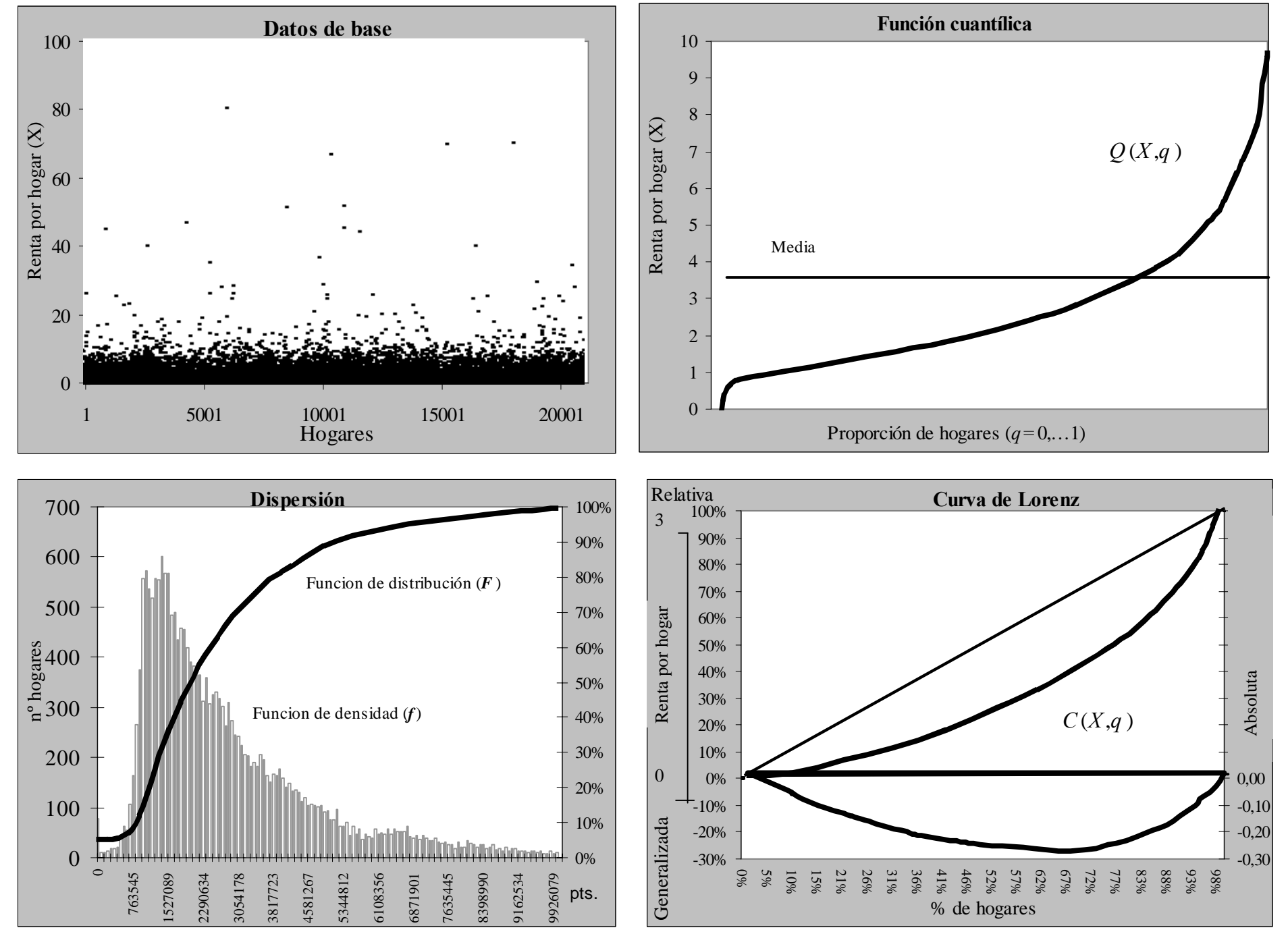
Esta última representación se puede invertir para obtener la función de distribución $(F)$, imagen inferior izquierda del cuadro 4.13, que representa la proporción de población $(q)$ cuya renta es igual o inferior a un determinado valor $(x)$. La variación de la función de distribución viene dada por la función de densidad ( $f$ ), que refleja la proporción de población $(q)$ con un nivel de renta dado $(x)$ (imagen inferior izquierda del cuadro 4.13).

Las relaciones entre las funciones anteriores pueden formalizarse del siguiente modo:

$$
\begin{gathered}
F(x)=\int f(x) d x \\
Q(F, q)=\{x: F(x)=q\} \quad \text { o } \quad Q(F ; q)=\inf \{x \mid F(x) \geq q\}=x_{q}
\end{gathered}
$$

Las funciones de distribución, sus inversas $Q$, o derivadas $f$, constituyen formas alternativas de representar una misma distribución y permiten interpretar las ideas en el campo del análisis de la desigualdad en términos de conceptos desarrollados en el campo de la estadística.

Otro modo de representar la distribución $\left(x_{1}, x_{2}, \ldots, x_{n}\right)$, es a través de funciones que recogen la renta acumulada por la proporción de población $(q)$ más pobre. Dicha modalidad incluye la curva de Lorenz que es una de las representaciones con más tradición en el análisis de la desigualdad. Aunque no existe una terminología universalmente aceptada, se puede diferenciar entre la función acumulativa o curva de Lorenz generalizada $(C)$, la función de desviaciones relativas acumuladas o curva de Lorenz relativa $(L)$ y la función de desviaciones absolutas acumuladas o curva de Lorenz absoluta $(A)$. Dichas curvas están representadas en la parte inferior izquierda del cuadro 4.13.

$$
C(F, q)=\int_{\underline{x}}^{Q(F, q)} x d F(x)=q[\mu(F, q)]
$$




$$
\begin{gathered}
L(F, q)=\frac{C(F, q)}{\mu(F)}=q \frac{\mu(F, q)}{\mu(F, l)} \\
A(F, q)=C(F, q)-q \mu(F)=q[\mu(F, q)-\mu(F, 1)]
\end{gathered}
$$

Recientemente Cowell (2000) ha revisado el alcance de las representaciones anteriores a efectos de comparar el grado de desigualdad de varias distribuciones. De forma sucinta, el criterio de dominación de primer orden, $Q(X, q) \geq Q(Y, q)$ permite afirmar que "el bienestar de $X$ no es menor que el de $Y$ " cuando el bienestar agrega utilidades individuales que sólo dependen (positivamente) de la propia renta, en tanto que puede aplicarse el criterio de dominación de segundo orden, $C(X, q) \geq C(Y, q)$, cuando las funciones de utilidad, además, son cóncavas. Sin embargo, "en la práctica, nos encontramos a menudo con que ambos criterios no son concluyentes" y entonces "las alternativas consisten en... imponer restricciones adicionales a las funciones de bienestar o elaborar índices concretos de desigualdad que no sean ambiguos”.

\subsubsection{Espacios normados y medidas de desigualdad. Medidas de distancia}

Toda medida de desigualdad, o función de bienestar, está relacionada con alguna norma o métrica en el espacio de las distribuciones.

Dado un espacio vectorial real $U$, la aplicación $\|\cdot\| \rightarrow \Re$ es una norma si y sólo si $\forall X, Y \in U$ :
1) $\|\mathrm{X}\| \geq 0$
2) $\|\mathrm{X}\|=0 \Leftrightarrow \mathrm{X}=[0]$
3) $\|\alpha \mathrm{X}\|=\mid \alpha\|\mathrm{X}\|$
4) $\|\mathrm{X}+\mathrm{Y}\| \leq\|\mathrm{X}\|+\|\mathrm{Y}\|$

$\mathrm{Al}$ par $(U,\|\cdot\|)$ se le denomina espacio normado. 
Algunas normas clásicas son la norma uno: $\left\|\left(X_{1}, \ldots, X_{\mathrm{n}}\right)\right\|_{1}=\Sigma\left|X_{\mathrm{i}}\right|$ y la norma dos o euclidiana: $\left\|\left(X_{1}, \ldots, X_{\mathrm{n}}\right)\right\|_{2}=\left(\Sigma X_{\mathrm{i}}^{2}\right)^{1 / 2}$.

La aplicación $d: V \times V \rightarrow \mathfrak{R}$ es una métrica o distancia si y sólo si $\forall X, Y, Z \in V$ :

$$
\begin{aligned}
& \text { 1) } d(X, Y) \geq 0 \\
& \text { 2) } d(X, Y)=0 \Leftrightarrow X=Y \\
& \text { 3) } d(X, Y)=d(Y, X) \\
& \text { 4) } d(X, Y) \leq d(X, Z)+d(Y, Z)
\end{aligned}
$$

Al par $(V, d)$ se le denomina espacio métrico. Dado un espacio normado, la aplicación definida por $d(X, Y)=\|X-Y\|$ es una distancia.

A partir de los conceptos anteriores, como muestra la ecuación 4.6, podemos expresar la desigualdad como la distancia normalizada entre cualquier vector distributivo $X \in \mathfrak{R}^{\mathrm{n}}+$ y su proyección sobre el rayo igualitario $\bar{X}$. Para evitar traslaciones del origen hemos supuesto rentas positivas y hemos restringido la condición 3 de norma a: $\alpha>0$. El parámetro $d$ indica la sensibilidad del índice a la distancia entre el lugar de la distribución en el que se produce la transferencia y la renta media.

$$
I_{d}=\left(\frac{\sum_{i=1}^{n}\left|X_{i}-\bar{X}\right|^{d}}{\sum_{I=1}^{n} \bar{X}_{i}^{d}}\right)^{1 / d}=\frac{\|X-\bar{X}\|_{d}}{\|\bar{X}\|_{d}}=\frac{d_{d}(X, \bar{X})}{\|\bar{X}\|_{d}}, \quad I_{d} \in\left(0,\left[\frac{(n-1)^{d}+(n-1)}{n}\right]^{1 / d}\right)
$$

Como recoge la ecuación 4.7, los índices de desigualdad anteriores, a su vez, pueden reformularse en términos del vector de participaciones en la renta $(x)$ y del tamaño de la población $(n)$.

$$
I_{d}=n^{\frac{d-1}{d}}\left(\sum_{i=1}^{n}\left|x_{i}-\bar{x}_{i}\right|^{d}\right)^{1 / d}=n^{\frac{d-1}{d}}\|x-\bar{x}\|_{d}=n^{\frac{d-1}{d}} d_{d}(x, \bar{x})
$$


Las medidas estadísticas de dispersión como la desviación media relativa $(D M R)$ o el coeficiente de variación $(C V)$ constituyen casos particulares de las familias de índices de desigualdad recogidas por las ecuaciones 4.6 y 4.7 y están asociados, respectivamente, al empleo de las normas uno y dos

$$
\begin{aligned}
D M R & =\frac{\sum\left|X_{i}-\bar{X}_{i}\right|}{\sum_{i=1}^{n} \bar{X}_{i}}=\|x-\bar{x}\|_{1}=d_{1}(x, \bar{x}), \quad D M R \quad \in[0,2(n-1) / n] \\
C V & =\sqrt{\frac{\sum_{I=1}^{n}\left(X_{i}-\bar{X}_{i}\right)^{2}}{\sum_{i=1}^{n} \bar{X}_{i}^{2}}}=n^{1 / 2}\|x-\bar{x}\|_{2}=n^{1 / 2} d_{2}(x, \bar{x}), \quad C V \in\left[0,(n-1)^{1 / 2}\right]
\end{aligned}
$$

Las dos medidas de distancia anteriores satisfacen dos propiedades de gran utilidad para el análisis de la desigualdad por razones técnicas y normativas: anonimidad o simetría, $I_{\mathrm{d}}(P X)=I_{\mathrm{d}}(X)$, donde $P$ es una matriz de permutación que tiene un uno en cada fila y columna y el resto de sus elementos son ceros, e independencia de la escala $\mathrm{u}$ homogeneidad de grado cero: $I_{\mathrm{d}}(X)=I_{\mathrm{d}}(t X) \mid t>0$. Por tanto, al normalizar las distancias, el índice depende únicamente de las participaciones en la renta.

Las figuras recogidas en el cuadro 4.14 representan, en el cono $\mathfrak{R}^{3}$, las curvas de nivel $\left(I_{\mathrm{d}}(X)=\bar{c}\right)$ para las métricas uno $(R M D)$ y dos $(C V)$. La independencia de la escala nos permite centrar el análisis en el triángulo equilátero $\|X\|_{1}=1$ delimitado por los puntos $(1,0,0),(0,1,0)$ y $(0,0,1)$. Dado que no importa quien esté representado en cada eje (anonimidad), podemos elegir cualquiera de las seis áreas simétricas que integran el triángulo anterior como, por ejemplo, la delimitada por los puntos (1/3, 1/3, $1 / 3),(1 / 2,1 / 2,0)$ y $(1,0,0)$. 
CUADRO 4.14. Curvas de nivel y medidas de distancia

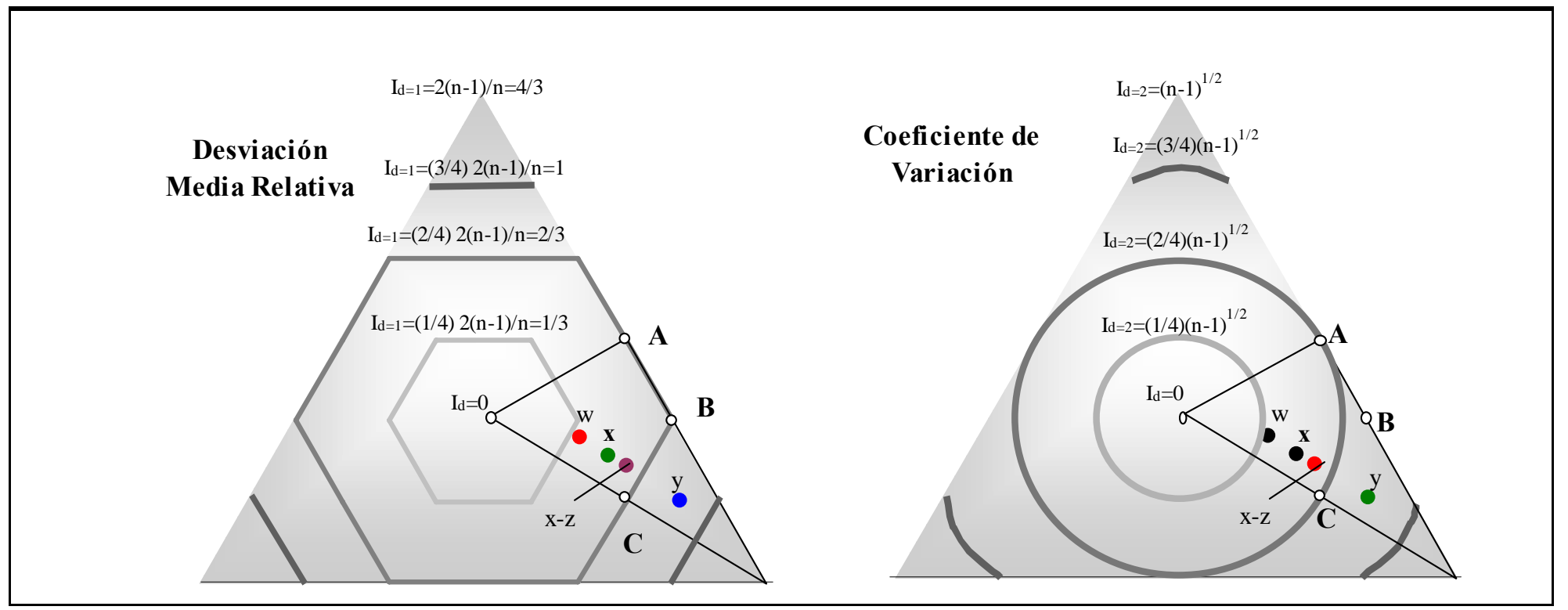


Cuando se emplea la desviación media relativa, figura izquierda del cuadro 4.14, las transferencias de ricos a pobres sólo reducen la desigualdad si cruzan la renta media. Así distribuciones diferentes en términos de desigualdad, como $A=(1 / 2,1 / 2,0)$, $\mathrm{B}=(2 / 3,1 / 3,0)$ y $C=(2 / 3,1 / 6,1 / 6)$, tienen la misma $D M R: 2 / 3$. En otras palabras, la desviación media relativa no satisface la propiedad de estricta $S$-Convexidad o principio de transferencias de Pigou-Dalton: $I(B X)<I(X)$, donde $B \neq P$ es una matriz biestocástica $\left(B_{\mathrm{ij}} \geq 0\right.$ y $\left.\Sigma_{\mathrm{j}} B_{\mathrm{ij}}=\Sigma_{\mathrm{i}} \cdot B_{\mathrm{ij}}=1\right)$ o un producto de matrices que representan transferencias de ricos a pobres (Dasgupta, Sen y Starrett, 1973 y Rothschild y Stiglizt, 1973).

El coeficiente de variación, aunque sí satisface el principio de transferencias, no evita otra objeción común con la medida anterior: su sensibilidad posicional simétrica con respecto de la renta media. Como puede observarse en la figura de la derecha del cuadro 4.14, las transferencias desde $B$ hacia $A$ o hacia $C$ reducen la desigualdad en la misma cuantía.

\subsubsection{Sensibilidad posicional. Medidas lineales y no lineales}

Para incorporar sensibilidad posicional monotónica a los índices de desigualdad, hay que definir la desigualdad como una diferencia de normas, en lugar de como una norma de diferencias. La ecuación 4.10 muestra la pertenencia del índice de Atkinson (1970) a este grupo de medidas de desigualdad. Dichas medidas dependen de un parámetro $(\varepsilon)$ que puede ser interpretado en términos de aversión al riesgo (ex-ante) o de altruismo (ex-post). Si $\varepsilon$ es positivo, cuanto mayor sea su valor mayor será la sensibilidad del índice a las transferencias en la parte superior de la distribución y, por el contrario, si $\varepsilon$ es negativo, a medida que disminuye su valor aumenta la sensibilidad del índice a las transferencias en la parte inferior de la distribución.

$$
A_{1-\varepsilon}=1-\left[\frac{1}{n} \sum_{i=1}^{n}\left(\frac{X_{i}}{\bar{X}_{i}}\right)^{\varepsilon}\right]^{\frac{1}{\varepsilon}}=1-\frac{\|X\|_{\varepsilon}}{\|\bar{X}\|_{\varepsilon}}=n^{\frac{\varepsilon-1}{\varepsilon}}\left(\|\bar{x}\|_{\varepsilon}-\|x\|_{\varepsilon}\right), \quad A_{1-\varepsilon} \in\left(0,1-n^{\frac{\varepsilon-1}{\varepsilon}}\right)
$$


Como refleja la ecuación 4.11, los índices de desigualdad descritos en la ecuación 4.10, a su vez pueden transformarse para incorporar propiedades adicionales. Por ejemplo, cuando se requiere la propiedad de descomposición por subgrupos de población en dos únicos términos que dependan, exclusivamente, de la desigualdad, la media y el tamaño de los subgrupos, es necesario recurrir al índice de entropía generalizada, que incluye como casos particulares el índice de Theil y la desviación media de los logaritmos para $\varepsilon=1$ y $\varepsilon=0$, respectivamente (Cowell,1977; Shorrocks, 1984).

$$
\begin{gathered}
E_{\varepsilon}=\frac{\left(1-A_{1-\varepsilon}\right)^{\varepsilon}-1}{\varepsilon^{2}-\varepsilon}=\frac{1}{n\left(\varepsilon^{2}-\varepsilon\right)} \sum_{i=1}^{n}\left[\left(\frac{X_{i}}{\bar{X}_{i}}\right)^{\varepsilon}-1\right]= \\
=\frac{n^{\varepsilon-1}}{\varepsilon^{2}-\varepsilon} \sum_{i=1}^{n}\left[\left(\|x\|_{\varepsilon}\right)^{\varepsilon}-\left(\|\bar{x}\|_{\varepsilon}\right)^{\varepsilon}\right], \\
E \in\left(0, \frac{n^{\varepsilon-1}-1}{\left.\varepsilon^{2}-\varepsilon\right)}\right)
\end{gathered}
$$

El índice anterior puede rescribirse en términos de desigualdades inter $(B)$ e intra $(W)$ grupos del siguiente modo:

$$
E_{\varepsilon}=E_{\varepsilon}^{B}+\sum_{g=1}^{G} w_{g} E_{\varepsilon g}^{W}, \quad w_{g}=\left(\frac{n_{g}}{n}\right)^{1-\varepsilon} x_{g}^{\varepsilon}
$$

En el cuadro 4.15 extendemos los resultados de Blackorby y Donaldson, (1978), Davies y Hoy (1994) y Champernowne y Cowell (1998) al mostrar, proyectadas sobre el plano $\|x\|_{1}=1$, las curvas de nivel para el índice de Entropía $\left(E_{\varepsilon}(x)=\bar{c}\right)$ y para el índice de Atkinson $\left(A_{1-\varepsilon}(x)=1-\left[\bar{c}\left(\varepsilon^{2}-\varepsilon\right)+1\right]^{1 / \varepsilon}\right)$. El punto $\boldsymbol{x}$ representa las proporciones de renta equivalente correspondientes al tercio de hogares más ricos $x_{1}$, a la clase media $x_{2} \mathrm{y}$ al tercio de hogares más pobre $x_{3}$. Al comparar la distribución $\boldsymbol{x}$ con cualquier otra distribución $y$ nos encontraremos necesariamente con una de las tres alternativas representadas en el cuadro 4.15, donde $L$ es una matriz biestocástica que representa una sucesión de transferencias de ricos a pobres (progresivas) y $L^{-1}$ es la inversa de una matriz biestocástica que representa una sucesión de transferencias de pobres a ricos (regresivas). 
CUADRO 4.15. Medidas de desigualdad no lineales con diferentes parámetros de aversión.

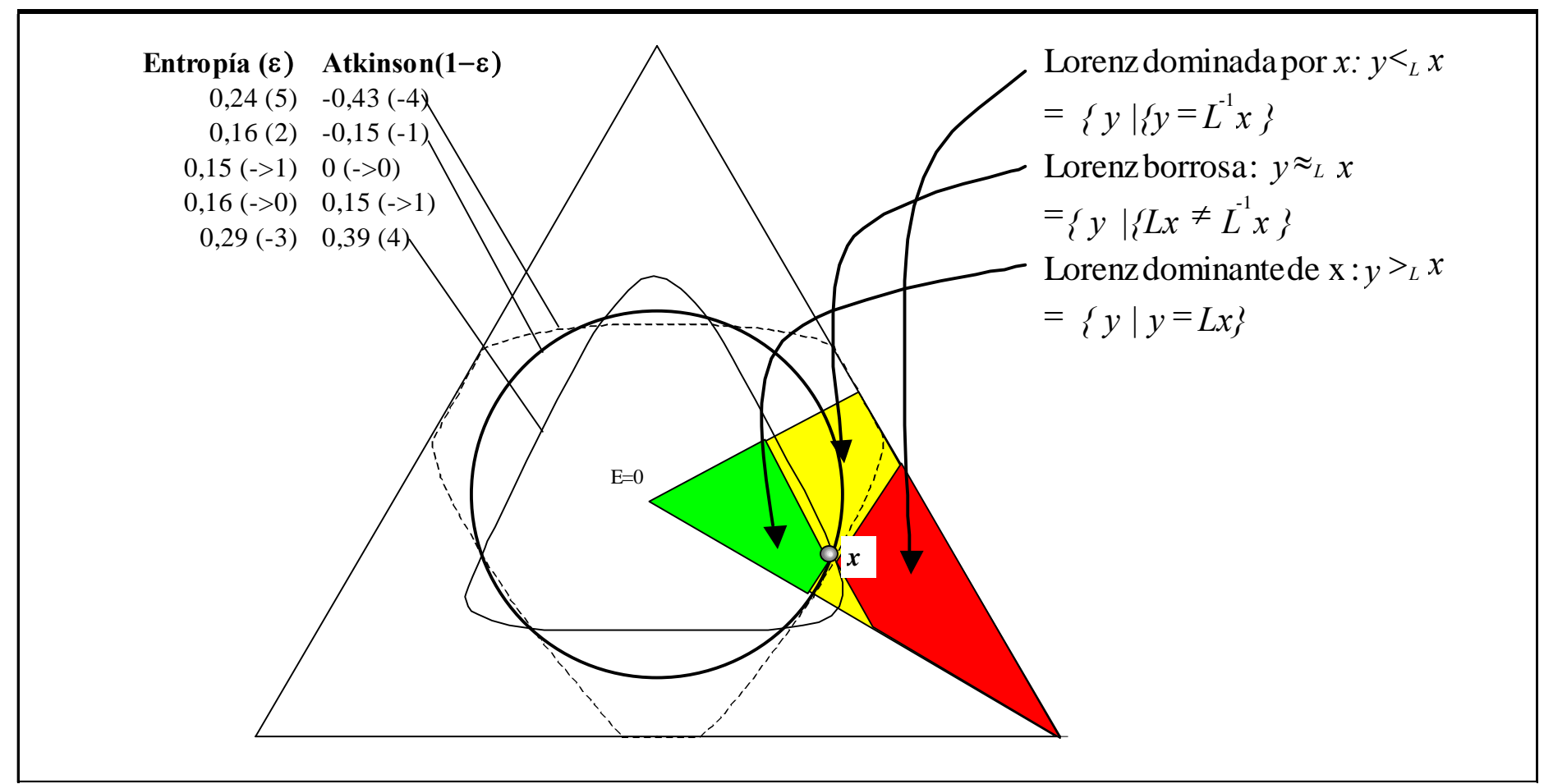


Hasta ahora hemos venido utilizando normas no lineales del tipo $\|x\|_{\varepsilon}=\Sigma\left(x_{\mathrm{i}}^{\varepsilon}\right)^{1 / \varepsilon}$, sin embargo también cabe la posibilidad de emplear normas lineales en las rentas como $\|x\|_{\theta}=\Sigma i{ }^{\theta} x_{\mathrm{i}}$. Si se utiliza esta última norma se obtiene la familia de índices de la ecuación 4.13, que incluye el índice de Gini como un caso particular para $\theta=1$. La ecuación 4.14 la hemos obtenido a partir de la ecuación 2.8.3 de Sen (1973), reordenando $x_{1} \leq \ldots \leq x_{\mathrm{n}}$ y teniendo en cuenta que $\Sigma i=(\mathrm{n}+1) \mathrm{n} / 2$. La proyección sobre el plano $\|x\|_{1}=1$ de las curvas de nivel para el conjunto anterior de índices de desigualdad lineales figura en el cuadro 4.16. Al igual que en los cuadros anteriores, el punto $\boldsymbol{x}$ representa las proporciones de renta equivalente correspondientes al tercio de hogares más ricos $x_{1}$, medios $x_{2}$ y más pobres $x_{3}$.

CUADRO 4.16. Curvas de nivel de medidas de desigualdad lineales

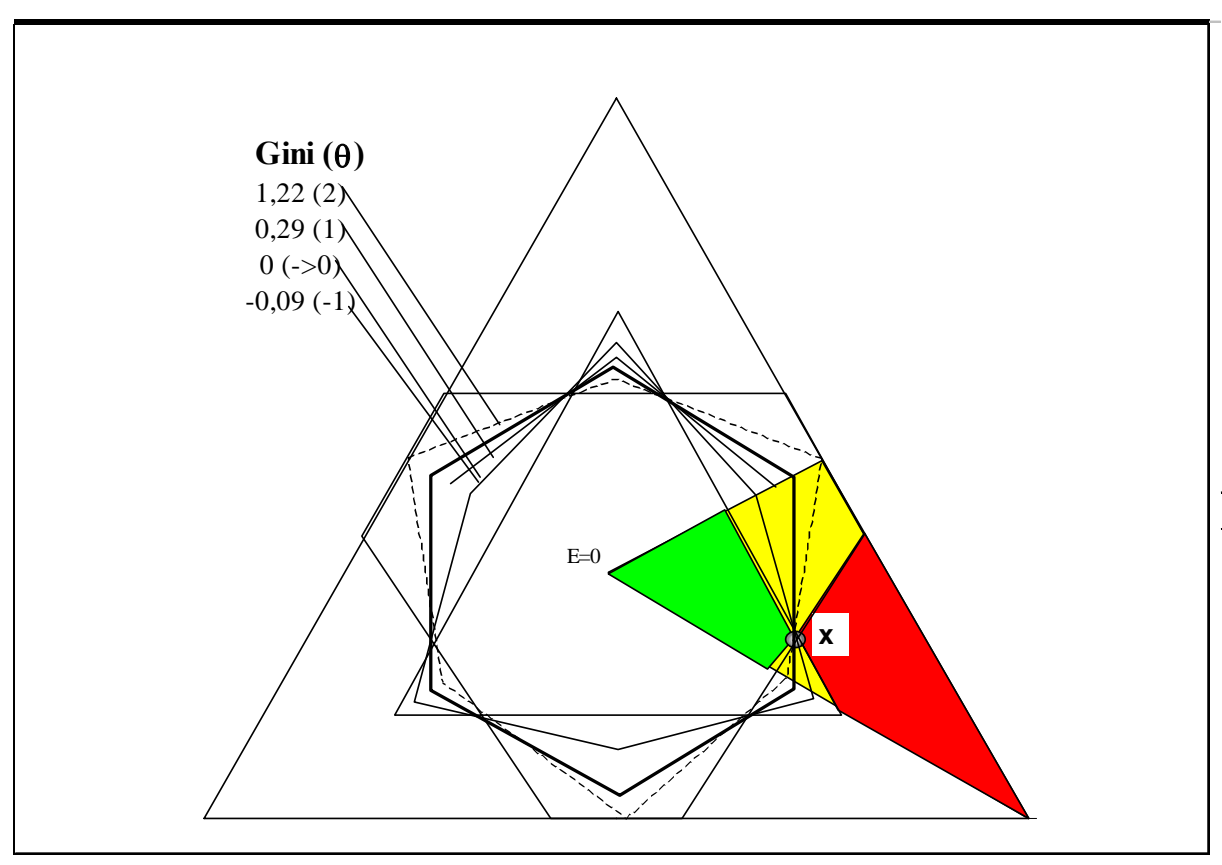




$$
\begin{gathered}
G_{\theta}=\frac{2}{n}\left(\sum_{i=1}^{n} i^{\theta} x_{i}-\sum_{i=1}^{n} i^{\theta} \bar{x}_{i}\right), \quad G \in\left(0,2 \frac{n^{\theta+1}-\sum_{i} i^{\theta}}{n^{2}}\right) \\
G=\frac{n+1}{n}-\frac{2}{n} \sum_{i=1}^{n}(n+1-i) \frac{X_{i}}{n \bar{X}_{i}}=-\frac{n+1}{n}+\sum_{i=1}^{n} \frac{2 i}{n} x_{i}=\frac{2}{n}\left(\sum_{i=1}^{n} i x_{i}-\sum_{i=1}^{n} i \bar{x}_{i}\right)
\end{gathered}
$$

Del análisis anterior (cuadros 4.15 y 4.16) cabe concluir que la ordenación de las distribuciones borrosas en el sentido de Lorenz depende de la norma subyacente en el índice utilizado para medir la desigualdad. Por ejemplo, si suponemos una norma Ralws ( $\varepsilon=-\infty$ ), entonces toda distribución Lorenz borrosa que se encuentre por encima (debajo) de $\boldsymbol{x}$ es menos (más) desigual que $x$, en otras palabras, es dominante de (dominada por) $x$.

$$
\begin{gathered}
\|y\|_{\infty}=\|x\|_{\infty} \Leftrightarrow y_{3}=x_{3}, \\
\|y\|_{\infty}>\|x\|_{\infty} \Leftrightarrow y_{3}>x_{3},
\end{gathered}
$$

donde $y_{3}$ y $x_{3}$ representan a los hogares con menos renta de cada distribución.

Por el contrario, si suponemos ex-ante personas ambiciosas y amantes del riesgo o ex-post que prevalece el interés de los más acomodados $(\varepsilon=\infty)$, entonces toda distribución Lorenz borrosa que se encuentre por encima (debajo) de $\boldsymbol{x}$ es menos (más) preferida que $\boldsymbol{x}$

$$
\begin{aligned}
& \|y\|_{-\infty}=\|x\|_{-\infty} \Leftrightarrow y_{1}=x_{1}, \\
& \|y\|_{-\infty}<\|x\|_{-\infty} \Leftrightarrow y_{1}<x_{1},
\end{aligned}
$$

donde $y_{1}$ y $x_{1}$ representan a los hogares con más renta de cada distribución.

Obviamente, cabe la posibilidad de adoptar múltiples supuestos intermedios entre los dos anteriores y utilizar, por ejemplo, el índice de Gini, que en el cuadro 4.16 
está representado por el hexágono equilátero que divide en dos partes iguales el área de distribuciones borrosas en el sentido de Lorenz, o el coeficiente de variación, representado en el cuadro 4.15 por el círculo que también divide aproximadamente, en dos partes iguales el área de las distribuciones borrosas.

Si bien los resultados anteriores son a primera vista bastante desalentadores, su interpretación también puede realizarse de un modo mucho más constructivo: en general para comparar dos distribuciones $x$ e $y$, para las que $\|x\|_{1}=\|y\|_{1}=1$, cabe definir una familia de normas $\|\cdot\|_{\varepsilon}$ tal que:

- $\forall \varepsilon, x>y$ en el sentido de Lorenz: $I_{\varepsilon}\left(\|x\|_{\varepsilon}\right)<I_{\varepsilon}\left(\|y\|_{\varepsilon}\right)$, o que

- $\forall \varepsilon, x<y$ en el sentido de Lorenz: $I_{\varepsilon}\left(\|x\|_{\varepsilon}\right)>I_{\varepsilon}\left(\|y\|_{\varepsilon}\right)$, o al menos

- $\exists$ un único valor de $\varepsilon$ tal que $I_{\varepsilon}\left(\|x\|_{\varepsilon}\right)=I_{\varepsilon}\left(\|y\|_{\varepsilon}\right)$.

En otras palabras, cuando se comparan dos distribuciones borrosas en el sentido de Lorenz, aunque no pueda establecerse de un modo indiscutible cuál es más o menos desigual, al menos sí es posible explicitar la norma frontera que delimita las dos alternativas posibles. Más aún, a nuestro juicio, toda política reivindicada como igualitaria debería explicitar los límites dentro de los cuáles dicha reivindicación resulta cierta, con el fin de que los demás puedan asumirla o no de acuerdo con sus propios juicios de valor. 


\subsection{Medición de la desigualdad. Práctica}

A pesar del explosivo desarrollo de la literatura sobre medición de la desigualdad durante las últimas décadas y de su extensa aplicación a diversos campos de la economía (Silber, 2001; Atkinson y Bourguignon, 2000 y Sen y Foster, 1997), dichos desarrollos apenas han comenzado a introducirse en el campo de las matrices de contabilidad social (Young y Huang 1977 y Decaluwé y otros 1999).

Con el fin de avanzar por la senda abierta por los dos trabajos anteriores en el campo de la contabilidad social, el grueso de este apartado está dedicado a la aplicación de los desarrollos teóricos descritos en el apartado anterior, para evaluar los efectos sobre la desigualdad de variaciones en los flujos exógenos del modelo SAM que se deriva de la matriz de contabilidad social elaborada en este trabajo y que ya describimos en el apartado 4.1.2.

\subsubsection{Medidas de distribución relativa}

Tradicionalmente en el campo de las matrices de contabilidad social el análisis de los efectos distributivos provocados por cambios en las rentas exógenas (inversión pública o privada, consumo público o transferencias corrientes) se ha limitado al cálculo de medidas de distribución relativas basadas en los multiplicadores que de ellas se derivan.

Como señalamos en el apartado 2.2.3, los multiplicadores correspondientes a cada grupo de hogares ponderados por la participación en la renta total de cada uno de ellos permiten analizar los efectos de un aumento unitario de un flujo exógeno concreto sobre la participación en la renta de cada grupo de hogares (ecuación 2.14). Y desde un punto de vista más general, la suma ponderada de las filas de la matriz de multiplicadores permite analizar los efectos distributivos provocados por cambios exógenos más amplios. Por ejemplo, se puede simular el impacto de una variación unitaria insesgada en la formación bruta de capital de origen interior, empleando la ecuación 
2.15, a efectos de identificar los grupos de hogares que mejoran o empeoran su participación en la renta total.

El cuadro 4.17 permite apreciar cómo un aumento unitario insesgado de la acumulación de las ramas de actividad produce una ligera reducción de la desigualdad, ya que aumenta la participación en la renta del quintil de hogares más pobre $\left(\xi_{\mathrm{i}}>1\right)$ y se reduce la del quintil más rico $\left(\xi_{\mathrm{i}}<1\right)$. El resultado anterior se debe a que el efecto progresivo de la inversión en bienes procedentes de la industria transformadora y de la construcción (ramas R.10 a R.31 de la MCSE-90) predomina sobre los efectos regresivos de la inversión en productos primarios y terciarios.

CUADRO 4.17. Efectos distributivos de un crecimiento unitario de la inversión

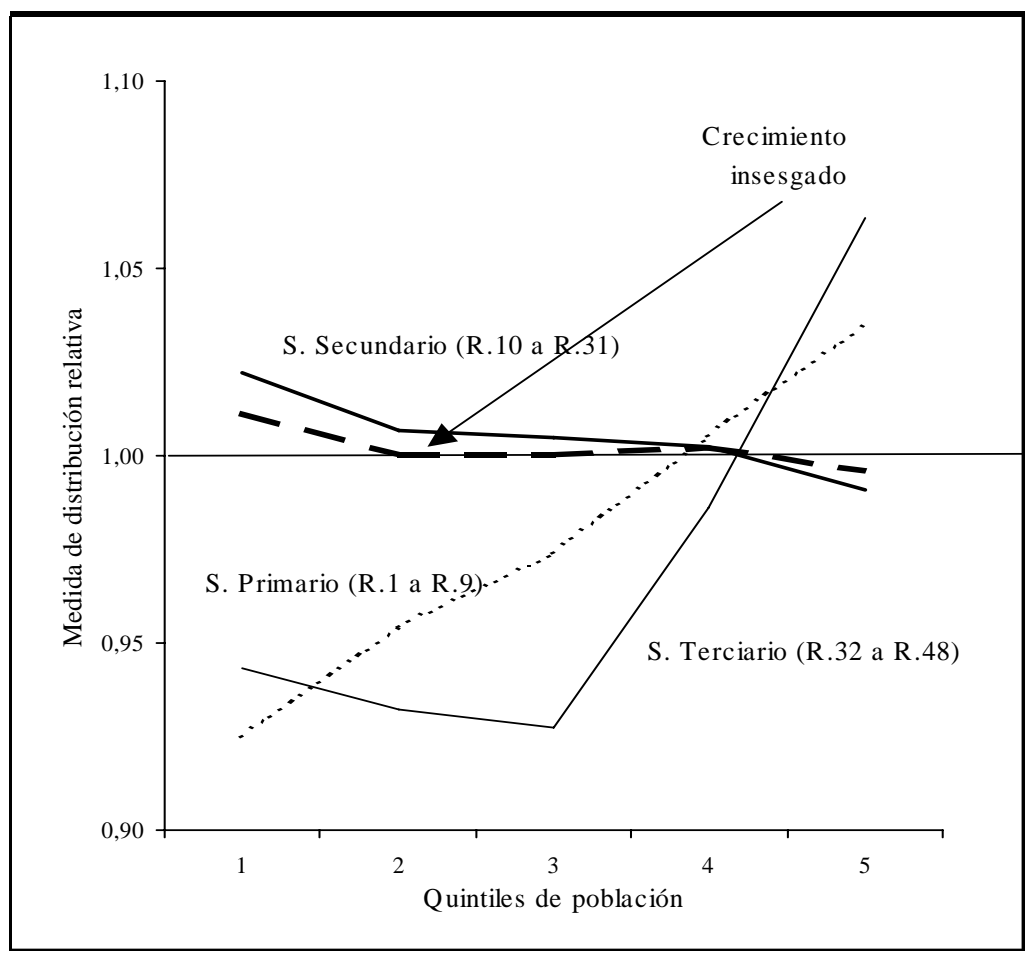

Como las funciones de distribución relativa de la inversión en productos primarios, industriales y de servicios sólo se cruzan una vez con la función de distribu- 
ción relativa correspondiente a un crecimiento neutral de la inversión, la progresividad del crecimiento de la inversión en productos industriales y la regresividad del crecimiento de la inversión en productos primarios y terciarios constituyen resultados concluyentes en términos de dominancia según el criterio de Lorenz. Sin embargo, dicho criterio resulta insuficiente para determinar si el crecimiento de la inversión en productos primarios es más o menos regresivo que el de la inversión en productos terciarios. Si nos fijamos en la parte baja de la distribución, la inversión en productos terciarios es menos regresiva que la inversión en productos primarios, en tanto que si nos fijamos en la parte alta de la distribución sucede lo contrario.

Como refleja el cuadro 4.18, al aplicar criterios de dominación de primer grado, los efectos de un crecimiento unitario de la inversión sobre la distribución de la renta de los hogares son concluyentes para la mayoría de productos, ya que sus funciones de distribución relativa son monótonas. En otros casos, aunque dichas funciones muestren máximos o mínimos interiores, sus efectos sobre la distribución de la renta siguen siendo concluyentes al aplicar criterios de dominación de segundo grado, dado que sólo cortan una vez a la función de distribución relativa correspondiente a un crecimiento neutral de los flujos exógenos. Sin embargo, como puede apreciarse en las dos figuras de la parte inferior del cuadro 4.18, también encontramos casos para los que los criterios de dominación anteriores resultan insuficientes para determinar su carácter progresivo o regresivo, o dilucidar cuáles son más o menos progresivos o regresivos. Por tanto, las medidas de distribución relativas no siempre permiten llegar a resultados concluyentes sobre los efectos de variaciones en determinados flujos exógenos y, además, resultan insuficientes para ordenar los flujos exógenos (los medios) en función de su progresividad. Para llevar a cabo dicha ordenación, en el apartado siguiente calculamos normas frontera. 
CUADRO 4.18. Efectos distributivos de un crecimiento unitario de la inversión
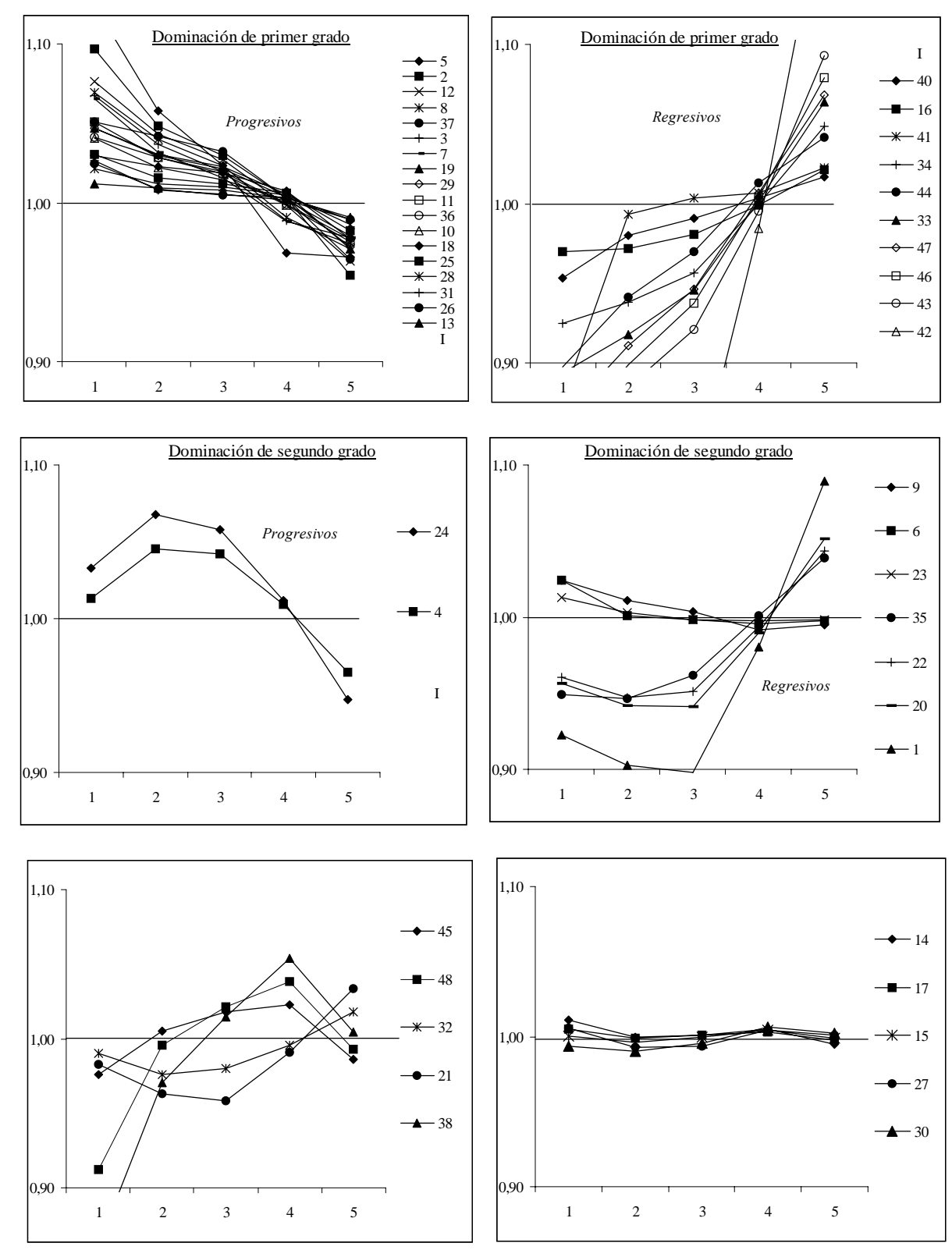


\subsubsection{Medición de la desigualdad y cálculo de normas frontera}

En el cuadro 4.19 presentamos las cifras sobre la desigualdad de la distribución de la renta disponible equivalente de los hogares españoles en 1990, medida por el índice de entropía generalizada $(E)$, y su descomposición por grupos de hogares clasificados, por una parte, según su principal fuente de renta y, por otra, de acuerdo con su nivel de renta equivalente ${ }^{148}$. Las normas de desigualdad que hemos elegido representan algunas de las medidas no lineales de uso más común como son el coeficiente de variación ( $\varepsilon=2$ ), el índice de Theil ( $\varepsilon=1$ ), la desviación media de los logaritmos ( $\varepsilon=0)$ y los índices de entropía ordinalmente equivalentes a los de Atkinson, sensibles a las transferencias en la parte alta de la distribución $(\varepsilon=5)$ y en su parte baja ( $\varepsilon$ $=-3)$.

El resultado más destacable es la enorme sensibilidad de las cifras de desigualdad con respecto a la norma aplicada. La utilización de parámetros relativamente elevados ( $\varepsilon=5$ ó $\varepsilon=-3$ ) da lugar a valores ciertamente exagerados de los índices de desigualdad. Cuando se utilizan parámetros más moderados $(0<\varepsilon<2)$, aunque algunos resultados que se obtienen, como la menor desigualdad en la distribución de las rentas del trabajo y de las pensiones, son bastante robustos, otros son ambiguos. Así para valores de $\varepsilon$ próximos a cero y a uno, las rentas peor distribuidas son las rentas de la propiedad, sin embargo cuando $\varepsilon$ es igual a dos, son las rentas del trabajo por cuenta propia y otras transferencias las que presentan un mayor índice de desigualdad. Asimismo, mientras que la desigualdad en las rentas del trabajo cualificado y sin cualificar es muy similar cuando el valor del parámetro tiende a cero, para un valor de $\varepsilon$ igual a dos la desigualdad en las rentas del trabajo no cualificadas dobla la de las rentas cualificadas.

\footnotetext{
${ }^{148}$ Para descomponer los índices de desigualdad por grupos de hogares hemos utilizado la ecuación 4.12.
} 

CUADRO 4.19. Índice de entropía generalizada

\begin{tabular}{|c|c|c|c|c|c|c|c|c|}
\hline \multicolumn{9}{|c|}{ a) Renta bruta disponible equivalente de los hogares clasificados según su principal fuente de renta } \\
\hline Principal fuente de renta & $(\varepsilon=5)$ & $(\varepsilon=2)$ & $(\varepsilon \cong 1)$ & $(\varepsilon \cong 0)$ & $(\varepsilon=-3)$ & $X_{\mathrm{g}} / X(\%)$ & $n_{g} / \mathrm{n}(\%)$ & $\bar{X}_{\mathrm{g}} / \bar{X}(\%)$ \\
\hline Trabajo por cuenta propia & 160635,42 & 1,20 & 0,23 & 0,17 & 1165,98 & 30,03 & 18,87 & 159,17 \\
\hline Trabajo por cuenta ajena no cualificado & 444,69 & 0,32 & 0,17 & 0,14 & 42,14 & 37,99 & 48,07 & 79,02 \\
\hline Trabajo por cuenta ajena cualificado & 5,80 & 0,18 & 0,14 & 0,14 & 39,68 & 11,07 & 7,11 & 155,74 \\
\hline Rentas de la propiedad & 8,48 & 0,49 & 0,38 & 0,42 & 175,24 & 1,85 & 1,51 & 122,28 \\
\hline Pensiones & 392,48 & 0,38 & 0,16 & 0,13 & 2282,19 & 7,20 & 10,60 & 67,97 \\
\hline Otras transferencias & 22032,75 & 1,21 & 0,31 & 0,22 & 19780,79 & 11,86 & 13,84 & 85,68 \\
\hline "Intra" & 1534,83 & 0,38 & 0,18 & 0,16 & 5683,54 & & & \\
\hline "Inter" & 0,09 & 0,06 & 0,06 & 0,05 & 0,05 & & & \\
\hline Total & 1534,92 & 0,44 & 0,24 & 0,21 & 5683,59 & 100 & 100 & \\
\hline b) Renta bruta disponil & equivalen & de $\operatorname{los}$ & gares $c l$ & ificados & por nive & les de re & enta & \\
\hline Quintiles $(*)$ & $(\varepsilon=5)$ & $(\varepsilon=2)$ & $(\varepsilon \cong 1)$ & $(\varepsilon \cong 0)$ & $(\varepsilon=-3)$ & $X_{\mathrm{g}} / X(\%)$ & $n_{g} / \mathrm{n}(\%)$ & $\bar{X}_{\mathrm{g}} / \bar{X}(\%)$ \\
\hline Bajo & 0,024 & 0,028 & 0,033 & 0,044 & 1517,254 & 8,94 & 22,74 & 0,39 \\
\hline Medio-Bajo & 0,004 & 0,004 & 0,004 & 0,004 & 0,004 & 12,32 & 20,21 & 0,61 \\
\hline Medio & 0,003 & 0,003 & 0,003 & 0,003 & 0,003 & 15,26 & 18,83 & 0,81 \\
\hline Medio-Alto & 0,006 & 0,006 & 0,006 & 0,006 & 0,006 & 21,57 & 19,37 & 1,11 \\
\hline Alto & 149,987 & 0,252 & 0,121 & 0,087 & 0,073 & 41,90 & 18,85 & 2,22 \\
\hline "Intra" & 1534,44 & 0,24 & 0,06 & 0,03 & 5683,24 & & & \\
\hline "Inter" & 0,48 & 0,20 & 0,18 & 0,18 & 0,35 & & & \\
\hline Total & 1534,92 & 0,44 & 0,24 & 0,21 & 5683,59 & 100 & 100 & \\
\hline
\end{tabular}


Centrándonos ahora en el cuadro 4.19.a, resulta menos sorprendente la escasa influencia de la desigualdad entre los distintos grupos de hogares (inter) cuando éstos se clasifican de acuerdo con su principal fuente de renta. Como señalamos al comentar la representación de las rentas del trabajo, del capital y las transferencias de los hogares en un espacio bidimensional (cuadro 4.11), los criterios de clasificación de los hogares distintos al de su nivel de renta tan sólo recogen aspectos parciales de la desigualdad. De ahí que cuando se carece de datos individualizados, o su obtención es costosa, y este es el caso de las matrices de contabilidad social, el uso de categorías sociales no resulte la alternativa más adecuada para el estudio de la desigualdad, en la medida que la mayor parte de la desigualdad se concentra dentro de cada una de las categorías distinguidas.

Los resultados son bien distintos cuando los hogares se agrupan por nivel de renta. Como muestran las últimas filas del cuadro 4.19.b, la desigualdad entre los distintos grupos de hogares prevalece sobre la desigualdad dentro de cada uno de los grupos, al menos para valores de $\varepsilon$ próximos a cero y a uno.

El que este último resultado no se mantenga para el resto de valores positivos o negativos de $\varepsilon$ se debe a que, como muestra el cuadro 4.20, los quintiles de los extremos predominan en la medición de la desigualdad global. Cuando se emplea el índice de Theil ( $\varepsilon=1$ ), o la desviación media de los logaritmos $(\varepsilon=0)$, los pesos de agregación de las desigualdades intra-grupos suman la unidad ( $w$ g, en la ecuación 4.12). Precisamente, esta es una de las razones que explican el amplio uso del índice de Theil. No obstante, puede observarse que incluso para valores moderados de $\varepsilon$ los pesos asignados a los diferentes quintiles varían de forma considerable. 
CUADRO 4.20. Pesos de agregación de las desigualdades intra-grupos

\begin{tabular}{|l|ccrrl|}
\hline Quintiles & $(\varepsilon=5)$ & $(\varepsilon=2)$ & $(\varepsilon \cong 1)$ & $(\varepsilon \cong 0)$ & $(\varepsilon=-3)$ \\
\hline Bajo & 0,002 & 0,035 & 0,089 & 0,227 & 3,746 \\
Medio-Bajo & 0,017 & 0,075 & 0,123 & 0,202 & 0,892 \\
Medio & 0,066 & 0,124 & 0,153 & 0,188 & 0,354 \\
Medio-Alto & 0,332 & 0,240 & 0,216 & 0,194 & 0,140 \\
Alto & 10,230 & 0,931 & 0,419 & 0,189 & 0,017 \\
\hline Suma & 10,648 & 1,405 & 1 & 1 & 5,149 \\
\hline
\end{tabular}

Al final de la sección anterior mostramos que cuando se analizan sin más las variaciones en las participaciones de los distintos grupos de hogares en la renta total, no es posible concluir sobre si un crecimiento exógeno unitario de la inversión en productos primarios empeora más o menos la distribución de la renta que el de la inversión en productos terciarios. Si se observa ahora el cuadro 4.21, en el que hemos medido la desigualdad entre los grupos de hogares, clasificados por su nivel de renta, para diferentes parámetros de aversión, se puede comprobar que los resultados, en esta ocasión, sí son bastante concluyentes. Un crecimiento exógeno de la inversión dirigido hacia los productos del sector primario es más regresivo que el dirigido hacia los productos del sector terciario, para valores de $\varepsilon$ menores que 3,95.

Del mismo modo se pueden calcular las normas frontera que permiten ordenar cualquier grupo de ramas productivas para las que no resulten concluyentes las medidas de distribución relativa. Así para las ramas de actividad incluidas en la esquina inferior izquierda del cuadro 4.18 (R.21, R.32, R.38, R.45 y R.48) y que representamos en el cuadro 4.22, se puede comprobar que un crecimiento exógeno de la inversión en productos de las ramas R.38 y R.48 sólo puede considerarse más regresivo que el de la inversión en productos de las ramas R.21 y R.32 si se asumen valores de $\varepsilon$ positivos y elevados, es decir, muy sensibles con lo que les sucede a los hogares de mayor renta. 


$\begin{array}{rl}\varepsilon>1,85 & I(38)>I(48)>I(21)>I(32)>I(45) \\ 1,85>\varepsilon>0,85 & I(38)>I(21)>I(48)>I(32)>I(45) \\ 0,85>\varepsilon>0,25 & I(38)>I(21)>I(32)>I(48)>I(45) \\ 0,25>\varepsilon>-1 & I(21)>I(38)>I(32)>I(48)>I(45) \\ -1>\varepsilon & I(21)>I(32)>I(38)>I(48)>I(45)\end{array}$

CUADRO 4.21. Cálculo de normas frontera. (3 Ramas de actividad)

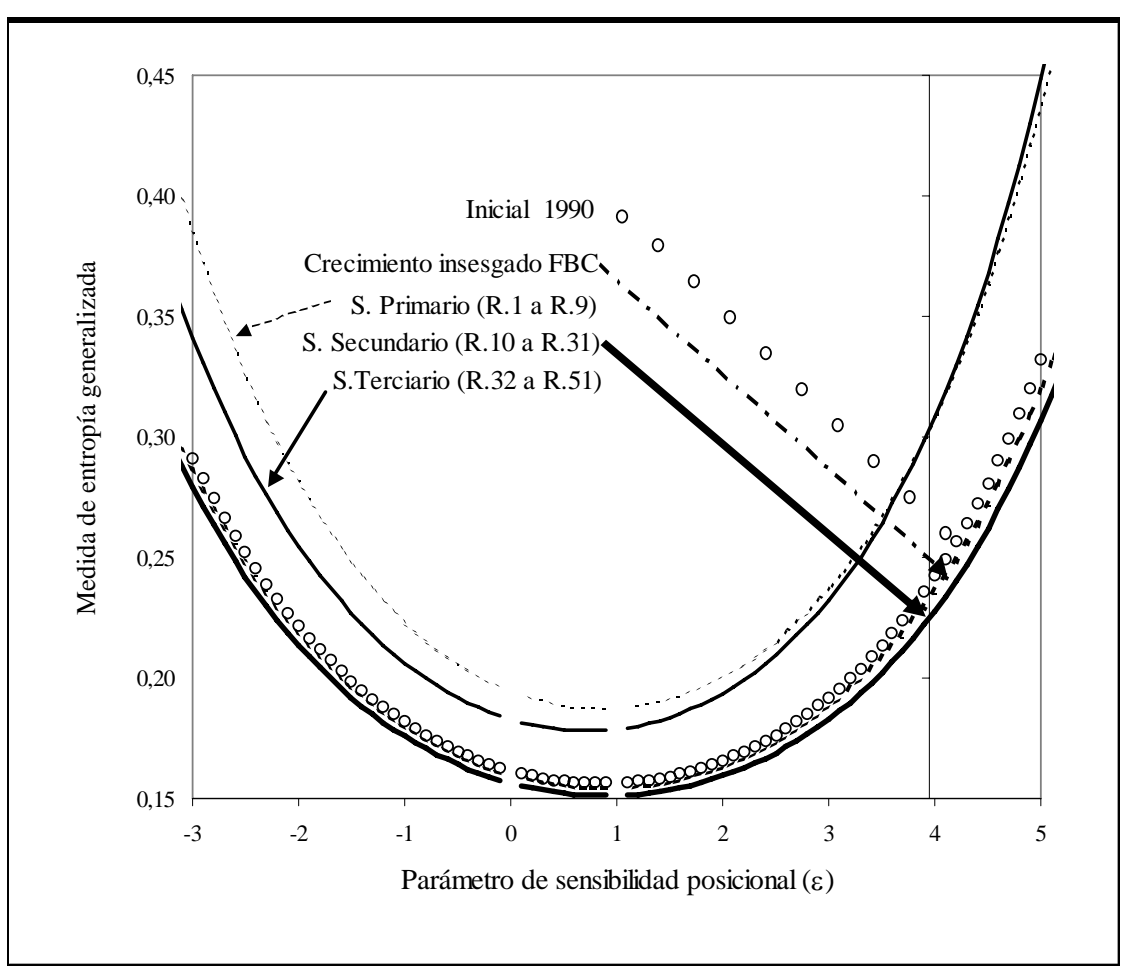




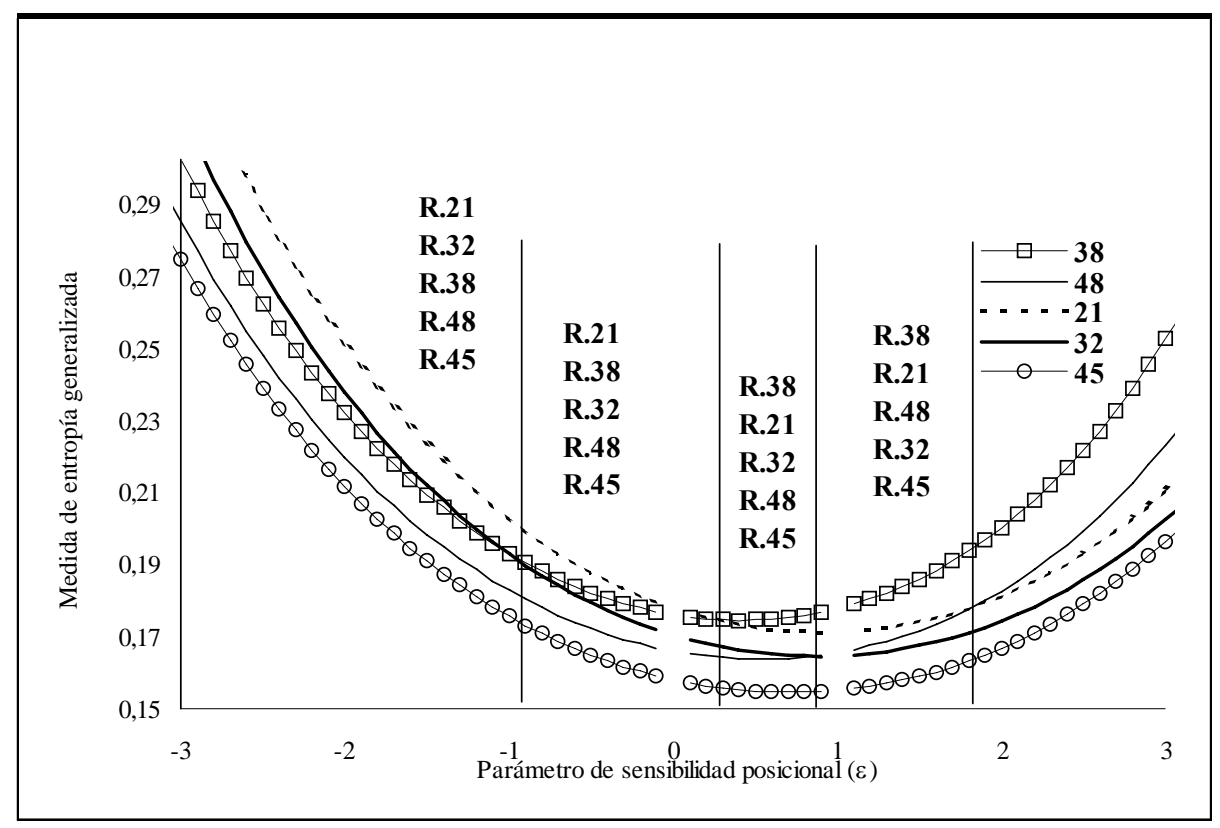

Como señalan Champernowne y Cowell (1998), “carece de interés la elección de valores positivos elevados de $\varepsilon$... (sensibles con) lo que les sucede a los ricos. -dado que- Una razón para preocuparse por la desigualdad es la injusticia de las rentas extremadamente bajas...”.

Por supuesto que no existe a priori ningún tipo de consenso sobre la norma concreta a utilizar en cada caso. Ahora bien, a nuestro juicio, tal dificultad, más que una excusa para mantener el empleo de normas $a d$ hoc, como la norma uno a la que no le importa ni quién es el receptor ni de dónde proviene la renta, es un incentivo para proseguir en la investigación y avanzar hacia un consenso que resulta necesario.

En la medida que se produzcan futuros avances en la especificación de un espacio de las distribuciones, las propuestas de este trabajo adquirirán su pleno significado. Las matrices de contabilidad social y los modelos generales computables equilibrados son herramientas muy apropiadas para calcular los efectos distributivos bajo 
diferentes normas. Los votantes, por supuesto, apoyan o combaten cualquier política $(P)$ a favor de la igualdad de acuerdo con sus propios intereses, pero también teniendo en cuenta sus criterios de justicia distributiva. En el modelo que utilizamos en este trabajo, los votantes de izquierda o de derecha en el sentido de Kolm (1976) mantendrán posturas enfrentadas sólo si existe algún $\varepsilon$ tal que:

$$
I_{\varepsilon}\left(x^{\prime}\right)=I_{\varepsilon}(x)
$$

donde: $\boldsymbol{x}^{\prime}=(1-A)^{-1}(B+P) /\left\|X^{\prime}\right\|_{1}, \mathrm{y} \quad \boldsymbol{x}=(1-A)^{-1}(B) /\|X\|_{1}$

En suma, para que los votantes puedan realizar elecciones consistentes, los programas políticos no deben conformarse con enunciar sus efectos positivos sobre la equidad, sino que deben explicitar la norma en la que basan sus alegatos. 
CONCLUSIONES 

Cuando emprendimos este trabajo no existía la red, o al menos no estaba a nuestro alcance. Al iniciar la redacción de estas conclusiones el buscador yahoo! muestra más de 4000 entradas al introducir el término System of National Accounts, más de 1600 cuando se introduce el término Social Accounting Matrix y miles de entradas más cuando introducimos términos como Income Distribution o Inequality.

Hace menos de una década la modelización aplicada se incluía en las enseñanzas de postgrado y, más concretamente, en los cursos de métodos de investigación, como parte de una especialización que algunos consideraban matemática, compleja, abstracta y algo oscura (Naudé, 1994). Por otra parte, la Contabilidad Nacional a duras penas conseguía abrirse hueco en los capítulos introductorios de la macroeconomía, como extensión de la estadística descriptiva o como parte de las fuentes para el estudio de la economía nacional (IARIW, 1998). A nuestro juicio, contabilidad y modelización forman parte de un todo indisoluble con distintos niveles de complejidad y diversos ámbitos de especialización. En concreto, nos hemos centrado en el proceso de elaboración de una matriz de contabilidad social plenamente adaptada a las versión más actual del Sistema de Cuentas Nacionales y en la introducción de algunas propuestas sobre la medición de los efectos distributivos producidos por cambios en los flujos exógenos de dicha matriz de contabilidad social.

Aunque la contabilidad social moderna surgió en acreditados centros académicos para proporcionar modelos de planificación para las economías desarrolladas en pleno periodo bélico (Meade y Stone, 1941), la modelización basada en los Sistemas de Cuentas fue relegada con el tiempo al campo, menos respetado en algunos ámbitos académicos, de la economía del desarrollo (Pyatt y Round, 1985). Las laboriosas construcciones de Johansen (1960) o Harberger (1962) no encajaban del todo en la depurada formalización teórica de Arrow y Debreu (1954), hasta que la computación del equilibrio (Scarf, 1967, Shoven y Whalley, 1972) abrió definitivamente el camino a una extensa literatura en la que las matrices de contabilidad social constituyen su base empírica (Kehoe, 1996). 
En el primer capítulo de este trabajo hemos tratado de mostrar que la tarea desarrollada por los arquitectos y los obreros de los Sistemas de Cuentas Nacionales, desde la aparición de la aritmética política hace ya más de tres siglos hasta la creación del Grupo de Trabajo sobre Cuentas Nacionales de las Secretarías de los organismos internacionales más influyentes (UN, BM, FMI, OCDE, UE) con ocasión de la elaboración del nuevo Sistema de Cuentas Nacionales de 1993, ha constituido una permanente labor de adaptación a las exigencias de cada momento.

De los diseños censales con fines contributivos que respondían a las necesidades financieras de los primeros estados, se pasó a la contabilidad de la demanda (cuentas en forma de T) al requerirse la intervención de dichos estados para aliviar las crisis económicas, en tanto que la contabilidad de la oferta (tablas input-output) comenzó a aplicarse a medida que les fueron atribuidas competencias en el ámbito de la regulación industrial. La creciente preocupación por la equidad inter e intra-generacional explica el desarrollo actual de la contabilidad matricial y de la contabilidad de balances.

Por una parte, el desarrollo de la contabilidad matricial permite integrar en el Sistema otras fuentes de información estadística, fundamentalmente en el ámbito de las operaciones de distribución y financieras de los hogares, lo que facilita la valoración conjunta de los aspectos relacionados con la eficiencia y la equidad. Por otra parte, el inventario periódico de los activos de un país permite evaluar los distintos tipos de crecimiento según el uso realizado de cada uno de los componentes del patrimonio $\mathrm{y}$, sobre todo, el de aquellos que son irreproducibles y pueden poner en peligro la sostenibilidad del crecimiento.

En definitiva, se trata de un sistema vivo que cuenta con un mecanismo de revisión y actualización permanente, en el que no sólo participan las oficinas estadísticas internacionales y nacionales, sino que además dispone de foros de discusión abiertos a la participación de todos aquellos que puedan sugerir ideas para su perfeccionamiento. Los críticos ya no tienen disculpa, pueden aportar sus alternativas sin más límite que el 
que siempre ha marcado la evolución de los Sistemas de Cuentas y que no es otro que el compromiso entre los avances de la teoría y las limitaciones de la estadística.

Por lo que respecta a la Contabilidad Nacional de España, hemos advertido un claro paralelismo entre la evolución del Sistema de Cuentas y el de la propia economía española: atraso inicial, loables intentos particulares por introducir los avances acaecidos fuera de nuestras fronteras, aislamiento y oficialismo, apertura y apoyo de los organismos internacionales, desarrollo y esfuerzo para adaptarse e incorporarse a los estándares de los sistemas estadísticos más avanzados y, finalmente, incorporación al sistema estadístico de la Unión Europea.

En el segundo capítulo hemos intentado mostrar que el gran atractivo de la presentación matricial de un Sistema de Cuentas reside en que incorpora la ley fundamental de la economía: todo recurso esta vinculado a un empleo y viceversa. La incorporación explícita de la ley de Walras a los Sistemas de Cuentas Nacionales ha dado fin a muchas controversias (Robinson, 2001).

Los modelos de equilibrio general aplicados son ciertamente bastante más complejos que un modelo Heckserch-Ohlin con dos países, dos bienes y dos factores, no por ello dicho modelo 2x2x2 deja de ser un modelo de equilibrio general. Las matrices de contabilidad social son asimismo extremadamente más complejas que, por ejemplo, la matriz (5x5) empleada en el Instituto de Estadística y Economía de Oxford para iniciar a los alumnos en la computación de los modelos de equilibrio general (Naudé, 1994). De hecho la matriz de contabilidad social adosada en la contraportada final del SCN93, a pesar de ser una matriz agregada para una economía ficticia, ha tenido que ser plegada varias veces para su distribución impresa. En otras palabras, las matrices de contabilidad social son tan complejas como el propio Sistema de Cuentas y, en definitiva, como la economía que pretenden representar. 
Las ventajas de la presentación matricial residen en su enorme flexibilidad e inmediata modelización:

- Una fila cualquiera (y su correspondiente columna) puede desagregarse en varias filas (y columnas), para profundizar en el análisis micro de un grupo de operaciones o de unidades concretas.

- Varias filas y columnas pueden agregarse para dar una visón macro de una parcela amplia de la actividad económica o incluso del conjunto de la economía.

- Cada matriz de contabilidad social es susceptible de numerosas modelizaciones alternativas en función de las operaciones y unidades que se consideren endógenas y exógenas, y del grado de especificación de los comportamientos endógenos.

- Los efectos multiplicadores de los cambios exógenos pueden ser calculados globalmente o detallados mediante una sucesión de matrices que muestren el proceso a través del cuál los efectos se acumulan.

- Una matriz desagregada puede presentarse reducida para mostrar sólo los medios y los fines objeto de cada análisis concreto, sin desaprovechar el resto de la información, mediante el reparto adecuado de las filas y columnas omitidas.

En el tercer capítulo hemos elaborado una matriz de contabilidad social para España. Al abordar esta fase del trabajo nos enfrentamos a dos dilemas. El primero de ellos, si adoptábamos, o no, alguna de las matrices de contabilidad social ya elaboradas por otros autores para nuestro país. Las únicas matrices de contabilidad social disponibles estaban referidas a 1980 y la única disponible, hoy en día, para 1990 no apareció hasta el año 1997. Aun así nos cuestionamos la conveniencia de proseguir la elaboración de una matriz de contabilidad social propia. El principal motivo que finalmente nos decantó a favor de llevar a cabo dicha tarea, más allá del ejercicio útil que supone 
para la formación de un doctorando (Allen, 1998, p. 8), fue básicamente el que la información publicada es rígida y no permite aprovechar la enorme flexibilidad de las matrices de contabilidad social.

El segundo de los dilemas fue el de plantear la matriz de contabilidad social “de arriba hacia abajo” o de "abajo hacia arriba”. La primera aproximación consiste en partir de los agregados de la Contabilidad Nacional e introducir la información detallada de aquellos aspectos de especial interés para posibles aplicaciones posteriores, en tanto que la segunda consiste en recopilar toda la información de base disponible para ajustarla finalmente a los agregados oficiales. Como bien ha resumido recientemente Ferrari (2001), desde un punto de vista teórico la primera presenta problemas de rigidez en la compilación, desaprovechamiento de información y simplificaciones y errores, en tanto que la segunda permite superar buena parte de los problemas anteriores y constituye la vía correcta para integrar la matriz de contabilidad social en el Sistema de Cuentas; sin embargo, desde un punto de vista operativo la realidad estadística aconseja una aproximación mixta que integre ambos métodos.

La ardua y compleja tarea de elaborar la matriz de contabilidad social se ha visto acrecentada porque las distintas fuentes estadísticas necesarias para su construcción utilizan diferentes clasificaciones. Así, por ejemplo, la ausencia de una tabla de correspondencias entre las clasificaciones PROCOME y CNAE, aparentemente un detalle sin importancia, ha sido uno de los principales escollos en el proceso de elaboración de la matriz presentada en este trabajo (Anexo: programa SAS). Consideramos que la introducción por parte del INE de pequeños cambios en el diseño de las clasificaciones de la Encuesta de Presupuestos Familiares, a efectos de armonizarlas con las empleadas por los Sistemas de Cuentas Nacionales, contribuirían de forma notable y sin excesivo coste a aumentar la utilidad de la información que en ella se recoge.

Las principales aportaciones de la matriz de contabilidad social elaborada en este trabajo en relación con otras disponibles hasta el momento, pueden resumirse del siguiente modo: 
- Una descripción precisa del proceso de elaboración de cada una de las matrices que la componen, así como de las fuentes y de las bases de datos empleadas.

- Una mayor desagregación de las clasificaciones, tanto de las operaciones como de las unidades.

- Anexos detallados, tanto de las matrices desagregadas como del software empleado para compilar los datos de consumo final de los hogares.

- Su adaptación plena al SCN93/SEC95, tanto en lo que se refiere a los aspectos metodológicos, como a la sucesión de cuentas.

- Varios diseños alternativos tanto en lo que respecta a su tamaño, como en lo que concierne a la selección de las unidades y de las operaciones endógenas y exógenas.

- El tratamiento endógeno de las operaciones de bienes y servicios y de distribución con el resto del mundo.

- La desagregación de la actividad de los hogares por niveles de renta, requisito éste indispensable para poder evaluar globalmente los efectos distributivos.

En el capítulo 4 examinamos, en primer lugar, la consistencia de la matriz elaborada en relación con otras existentes y con sus posibles diseños alternativos. Una vez elegida la matriz a aplicar, en segundo lugar, tratamos de integrar los avances más recientes en el campo de la medición de la desigualdad en el marco de la contabilidad social. Paradójicamente, aunque una de las principales motivaciones del surgimiento de las matrices de contabilidad social es la inclusión de las actividades redistributivas en el Sistema de Cuentas, su tratamiento formal deja bastante que desear.

El reconocimiento de que no existe una correlación teórica predeterminada entre el crecimiento y la desigualdad (Vicente y Borge, 2000) y la evidencia más reciente sobre la evolución de la distribución de la renta, tanto a escala mundial (Milanovic, 1999), como en el seno de cada país (Deninguer y Squire, 1998), conlleva la necesidad, cada vez más evidente, de introducir indicadores explícitos sobre la evolución 
global de la distribución de la renta en la contabilidad regular de los países. Con dicha finalidad hemos realizado una revisión de la literatura sobre medición de la desigualdad y sugerimos algunas propuestas que aplicamos empleando la matriz de contabilidad social obtenida en el capítulo anterior. A nuestro juicio las principales aportaciones del trabajo al respecto son (Rubio y Vicente, 2000a,b):

En cuanto a los aspectos teóricos,

- El empleo novedoso del concepto de norma para englobar las distintas familias de índices de desigualdad, tanto lineales como no lineales. Hasta donde conocemos, no existe ningún precedente explícito al respecto.

- El empleo de diagramas tridimensionales para mostrar las propiedades de los distintos índices. En lo que conocemos, no existe tratamiento previo al respecto de la familia de Gini, ni un tratamiento gráfico explícito de las relaciones obvias entre las familias de índices lineales y no lineales.

En cuanto a los aspectos prácticos,

- La conclusión de que dada una política cualquiera, aunque no siempre sea posible alcanzar un consenso sobre su carácter progresivo o regresivo, al menos sí cabe la posibilidad de explicitar la norma frontera a partir de la cuál puede defenderse una u otra postura.

Llegados a este punto tenemos la sensación de que más que concluir un trabajo lo que hemos hecho es adentrarnos tímidamente en un vasto programa de investigación, plagado de enormes desafíos. Ni que decir tiene que las conclusiones de este trabajo son cuando menos provisionales.

De acuerdo con la teoría de las capacidades de Sen (1992), un primer desafío al respecto es la estimación de cuentas de patrimonio para los hogares, que incluyan tan- 
to el capital físico como el capital humano. Los juicios sobre la distribución de los flujos (renta) pierden sentido sin no se dispone de una valoración previa de la distribución de los stocks (capital), pues es obvio que el carácter progresivo o regresivo de un vector de renta $(3,1)$ depende de si el vector de capital inicial es $(10,20)$ ó $(20,10)$. El no haber considerado dicha cuestión en este trabajo obedece únicamente a que dichas cuentas de patrimonio aún no están disponibles.

Un segundo reto al respecto es la elaboración de bases alternativas de los espacios distributivos en los que pueda diseñarse la política económica. La equidad de un determinado vector de distribución de renta no es la misma si el tamaño de los hogares es diferente, si alguno de sus miembros padece alguna discapacidad o si su principal fuente de renta procede de herencias o monopolios, como pone de manifiesto la teoría de los derechos de Nozick (1974).

Más difícil, pero no por ello menos necesaria, es la introducción de límites superiores e inferiores dentro de los cuáles los dilemas justicia-libertad o eficienciaequidad resulte procedente. De acuerdo con Rawls (1971), el límite inferior debe ser un vector que tenga todos sus elementos por encima de algún mínimo racional y el límite superior podría superar el rayo igualitario. 
REFERENCIAS BIBLIOGRÁFICAS 

Abad, A.M., A. Cristóbal, y E.M. Quilis (2000): "El análisis de la coyuntura en el Instituto Nacional de Estadística”, Informe para el proyecto Tools and Practices For Business Cycle Analysis in National Statistical Institutes of EU (BUSY), WP4: Methods for Oficial Statistics.

Abadía, A. (1979): “Un modelo para simulación de políticas redistributivas”, Investigaciones Económicas, 9, 41-62.

Abadía, A., O. Fanjul y J. Borrell (1981): Un modelo dinámico multisectorial de crecimiento económico, empleo y distribución de la renta, Fundación Empresa Pública, Serie E, 5.

Abrego, L. y C. Perroni (1998): “Free- Riding, Carbon Treaties and Trade Wards: the Role of Domestic Environmental Policies”, CSGR Working Paper, 09/98.

Adelman, I. y S. Robinson (1978): Income Distribution Policy in Developing Countries: A Case Study of Corea, Oxford University Press, London.

Adelman, J., P. Berck y D. Vujovic (1991): "Using Social Accounting Matrices to Account for Distortions in Non-market Economies”, Economic Systems Research, 3 (3), 269-298.

Ahluwalia, M. y F. Lysy (1979): "Welfare Effects of Demand Management Policies: Impact Multipliers under Alternative Models Structures”, Journal of Policy Modeling, 1 (3), 317-342.

Alcaide, A. (1967): “Las tablas input-output de la economía española en 1962”, Información Comercial Española, 401, 17-45.

Alcaide, A., G. Begue, J. Fdez-Castañeda y A. Santos Blanco (1958): La estructura de la economía española. Tabla input-output”, Instituto de Estudios Políticos, Madrid.

Alcaide, J. (1989): “La distribución de la renta española en la década de los ochenta”, Documentos de Trabajo, Fundación FIES, 38/1989.

Allen, R. (1998): "Why Produce a SAM?”, 51st Course on National Accounts, Munich Center, cap. 12.9 .

Alvarez, C., L. Ayala, I. Iriondo, R. Martinez, J.I. Palacio, y J. Ruiz-Huerta (1996): La distribución funcional y personal de la renta en España. Un análisis de sus relaciones, Colección Estudios, 30, CES, Madrid.

Amman, H.M., D.A. Kendrick y J. Rust (eds.) (1996): Handbook of Computational Economics, North Holland, Amsterdam.

Andrés, J. y J. García (1991): “Una interpretación de las diferencias salariales entre sectores”, Investigaciones Económicas, XV (1), 143-167.

Archambault, E. (1982): Comptabilité Nationale, $2^{\text {a }}$ ed., Economica, París.

Archambault, E. (1997): "Mesurer le secteur sans but lucratif en France dans un cadre de comparaison internationale”, en Archambault y Boëda (eds.) (1997), 311-326.

Archambault, E. y M. Boëda (eds.) (1997): Comptabilité Nationale. Dévelopments récents, Economica, Paris.

Arrow, K. J. y G. Debreu (1954): “Existence of Equilibrium for a Competitive Economy”, Econometrica, 22, 265-290.

Atkinson, A.B. (1970): “On the Measurement of Inequality”, Journal of Economic Theory, 2, 244-263.

Atkinson, A.B. y F. Bourguignon (eds.) (2000): Handbook of Income Distribution, North Holland.

Atkinson, A.B. y F. Bourguignon (2000): "Introduction: Income Distribution and Economics", en Atkinson y Bourguignon (eds.).

Banco de España (1984): Cuentas financieras de la economía española 1972-1982. Madrid.

Banco de España (1999): "Principales cambios incorporados en la Contabilidad Nacional de España, base 1995”, Boletín Económico del Banco de España, septiembre, 41-54.

Banco de España (2000): "Presentación de las cuentas financieras de la economía española. SEC/95. Serie 1995-1999”, Boletín Económico del Banco de España, mayo, 43-61.

Barna, T. (1975): "Quesnay's Tableau in Modern Guise", Economic Journal, 85, 485-496.

Batey, P.W.J. y M.J. Weeks (1989): The Effects of Household Desegregation in Extended InputOutput Models”, en Miller y otros (1989), 119-133.

Bentham, J. (1789): Introduction of the Principles of Morals and Legislation, ed. de 1823 en www.la.utexas.edu/labyrinth/ipml/index.html, [Acceso 14/11/2001].

Bentham, J. (1948): The Principles of Morals and Legislation, Macmillan, New York.

Bergman, L. (1990): “The Development of Computable General Equilibrium Modeling”, en L. Bergman y otros (1990), 3-32.

Bergman, L., D.W. Jorgenson y E. Zalai (1990): General Equilibrium Modeling and Economic Policy Analysis, Basic Blackwell, Cambridge.

Blackorby, C. y D. Donaldson (1978): "Measures of Relative Equality and Their Meaning in Terms of Social Welfare”, Journal of Economic Theory, 18, 59-80.

Boisguillebert, Pier le Pesant (1695): Le Détail de la France, 1675, en Economistes Financiers du XVIIIme Siècle, ed. Eugène Daire, Paris, 1843.

Bosch, A.; C. Escribano. y I. Sanchez.(1989): Evolución de las desigualdades y la pobreza en España. Estudio basado en las Encuestas de Presupuestos Familiares 1973-74 y 1980-81, INE, Madrid.

Bottiroli, M. y R. Targetti (1988): "The Distribution of Personal Income at the Sectoral Level in Italy: A SAM Model”, Journal of Policy Modeling, 10 (3), 453-468. 
Bovenberg, A.L., J.J. Graafland y R.A. De Mooij (1998): “Tax Reform and the Dutch Labor Market: An Applied General Equilibrium Approach”, Working Papers, 6693, National Bureau of Economic Research.

Cardenete, M.A. (1998): “Una Matriz de Contabilidad Social para la economía andaluza: 1990”, Revista de Estudios Regionales, 52, 137-153.

Cardenete, M.A. y F. Sancho (2000): “Impact Assessment Using a Social Accounting Matrix”, paper presentado en $13^{\text {th }}$ International Conference on Input-Output Techniques, 21-25/8, Macerata, Italia.

Caricchia, A., F. Battellini y A. Coli (1997): "La matrice de comptabilité sociale el les comptes satellites comme instruments d'intégration des statistiques économiques et sociales", en Archambault y Boëda (1997), 275-299.

Chalmers, G. (1802): An Estimation of the Comparative Strenth of Great Britain, J. Stockdale, London.

Champernowne, D.G. y F.A. Cowell (1998): Inequality and Income Distribution, Cambridge University Press, Cambridge.

Clark, C. (1932): The National Income 1924-1931, Macmillan, London.

Cohen, S.I (1989): "The Multiplier Analyses in Social Accounting and Input-Output Frameworks: Evidence for Several Countries”, en Miller y otros (1989), 79-99.

Cohen, S.I. y J.M.C. Tuyl (1991): "Growth and Equity Effects of Changing Demographic Structures in the Netherlands", Economic Modeling, 13, January, 3-15.

Collado J.C. y D.W. Roland-Holst (1993): "Distribución de la renta e integración en la CE de la economía española. Una perspectiva de contabilidad social”, Economía Industrial, marzo/abril, 137-147.

Consejo de Economía Nacional (1945): La renta nacional de España. Planteamiento general del problema. Estimaciones indirectas y primeras cifras, vol. I, Madrid.

Consejo de Economía Nacional (1947): “ La riqueza de España en 1913-1935”, en CEN: La renta nacional de España, vol. II, Madrid, 55-168.

Consejo de Economía Nacional (1956): La renta nacional de España en 1955, Madrid.

Consejo de las CC.EE (1996), Reglamento (CE) 2223/96 de 25 de junio de 1996, relativo al Sistema Europeo de Cuentas Nacionales y Regionales de la Comunidad, DOCE (L310) de 30/11/96.

Cowell, F.A. (1977): Measuring Inequality (1 $1^{\mathrm{a}}$ ed.), Philip Allan, Oxford. ( $2^{\mathrm{a}}$ ed. 1995).

Cowell, F.A. (2000): "Measurement of Inequality”, en Atkinson y Bourguignon (eds.), cap. 2.

Cristóbal, A. (1999): “Análisis de la coyuntura y Contabilidad Nacional Trimestral”, Boletín Trimestral de Coyuntura del INE, marzo, 85-107.

Curbelo, J.L. (1986): "Una introducción a las matrices de contabilidad social y a su uso en la planificación del desarrollo regional”, Estudios Territoriales, 22, 147-155.

Curbelo, J.L. (1987): “Modelo económico de desarrollo endógeno para Andalucía (MEDEA)”, Revista de Estudios Andaluces, 7.

Curbelo, J.L.(1988): “Crecimiento y equidad en una economía regional estancada: el caso de Andalucía. (Un análisis en el marco de las matrices de contabilidad social)”, Investigaciones Económicas, XII (3), 501-518.

Dagum, C. (1999): “Linking the Functional and Personal Distributions of Income”, en J.Silber: Handbook on Income Inequality Measurement, Kluwer Academic Publishers, Boston, 101-132.

Dasgupta, P.S., A. Sen y D.A. Starrett (1973): "Notes on the Measurement of Inequality", Journal of Economic Theory, 6, 180-187.

Davar E. (2000): "Leontief and Walras: Input-Output and Reality", paper presentado en $13^{\text {th }}$ International Conference on Input-Output Techniques, 21/8-25/8, Macerata, Italia.

Davenant, C. (1698): Discourses on the Public Revenues and on the Trade of England, 2 vols., London.

Davies, J.B. y H. Hoy (1994): "The Normative Significance of Using Third-Degree Stochastic Dominance in Comparing Income Distribution”, Journal of Economic Theory, 64, 520-530.

Decaluwé, B., J.C. Dumont y P.L. Savard (1999): "Mesurer la Pauvreté et les Inégalités dans un Modèle d’Équilibre Général Calculable", Cahiers de Recherche, Université Laval, 99-120.

Decaluwé, B., P. L. Savard y E. Thorbecke (1999): "Poverty Analysis within a General Equilibrium Model”, Cahiers de Recherche, Université Laval, 99-06.

Deforny, J. (1982): “Une aproache structurale pour l'analyse input-output: un premier bilan”, Economie Appliquée, 35 (1/2), Paris.

Defourny, J. y E. Thorbecke (1984): "Structural Path Analysis and Multiplier Decomposition within a Social Accounting Matrix Framework”, The Economic Journal, 94, 1-36.

Deninger, K. y L. Squire (1998): “New Way of Looking at Old Issues: Asset Inequality and Growth”, Journal of Development Economics, LVII, 259-287.

Dervis, K.; J. De Melo y S. Robinson (1982): General Equilibrium Models for Development Policy. World Bank and Cambridge University Press.

Dixon, P.B. y B.R. Parmenter (1996): “Computable General Equilibrium Modelling for Policy Analysis and Forecasting”, en Amman y otros (1996), 3-85.

Dixon, P.B. y M.T. Rimmer (2000): “An Overview of Monash”, III Annual Conference of Global Economics Analysis, June 27-30, Melbourne, aparecerá en Monash: A disaggregated dynamic model of the Australian economy, (http://monash.edu.au/policy/conf2000.htm). 
Dixon, P.B., B.R. Parmenter, J.Sutton y D.P. Vincent (1982): ORANI: A Multisectoral Model of the Australian Economy, North-Holland, Amsterdam.

Duffie, D. y H. Sonnenshein (1989): “Arrow and General Equilibrium Theory”, Journal of Economic Literature, XXVII (June), 565-598.

Encyclopaedia Britannica (1987): “'Linear algebra”, 262-267; “Matrix theory”, 634-638, 15th ed.

Encyclopaedia Britannica Online: "Optimización”, //members.eb.com/bol/topic?eu=115359\&sctn=3\&pm=1 [Acceso 11/01/2000].

Eurostat (1980): European System of Integrated Economic Accounts, ESA, Second Edition 1979, Luxembourg.

Eurostat (1996): Sistema Europeo de Cuentas, SEC 1995, Luxemburgo.

Eurostat, INE (1986): Sistema Europeo de Cuentas Económicas Integradas (SEC) $2^{a}$ Edición, INE, Madrid.

Ferrari, G. (2001): “Social Accounting Matrices (SAM): Upward and Downward Estimation”, 53rd session of the ISI (International Statistical Institute), 22-29 August, Seul.

Ferri, J. y E. Uriel (2000): "Multiplicadores contables y análisis estructural en la matriz de contabilidad social. Una aplicación al caso español”, Investigaciones Económicas, 24 (2), 419-453.

Fuentes Quintana, E. (1954): "Las estimaciones de la renta nacional en España”, en Contabilidad Nacional de España", tomo I, Madrid 1954, reimpreso en J. Velarde (1969): Lecturas de economía española, Gredos S.A., Madrid, 135-160.

Fundación BBV (1998). El "stock" de capital en España y su distribución territorial, 5 vol., Fundación BBV, Bilbao.

Galbraith, J.K. (1989): Historia de la economía, Ariel, Barcelona, cap.XV y XVI, 211-240.

Gazon, J. (1976): Transmission de l'influence économique. Une approache structurale, Collection de l'IME, 13, Sirey, París.

Gazon, J. (1979): "Une nouvelle méthodologie: l'approache structurale de l’influence économique”, Economie Appliquée, 32 (2/3), 301-337.

Gazon, J. y M. Nihon (1976): “La dominance économique dans la structure de production belge et ses implications pour une politique de relance”, Research Paper, 76002, CREDEL, Univ. Liège.

Gómez, A. (1999): "Efectos de los impuestos a través de un modelo de equilibrio general aplicado para la economía española”, Papeles de Trabajo del IEF, 4/99.

Gómez, A. (2000): "Extensiones de la matriz de contabilidad social de España”, Documento de Trabajo, Departamento de Economía, Universidad Pública de Navarra, D.T. 0006.

Gómez Orbaneja, A. (1943): "La valoración de la Renta Nacional de España. Crítica de las evaluaciones realizadas", Moneda y Crédito, 7, 34-42.

Goodwing, R.M. (1949): “The Multiplier as Matrix”, Economic Journal, 59 (236), 537-55.

Graafland, J.J. y R.A. Mooij (1998): “Analysing Fiscal Policy in The Netherlands: Simulations with a Revised MIMIC”, CPB Research Memorandum, 140 CPB, The Hague.

Groves, R.M. (1986): Survey Error and Survey Cost, John Wiley and Sons, New York.

Hanson, K.A. y S. Robinson (1991): "Data, Linkages and Models: US National Income and Products Accounts in the Framework of a Social Accounting Matriz", Economic Systems Research, 3(3), 215232.

Harberger, A. C. (1962): “The Incidence of the Corporate Income Tax”, Journal of Political Economy, 70, 215-240.

Hemberg, P. (1955): “Informe preliminar sobre la renta interior de España”, Revista de Economía Política, VI(2), 114-171.

Hill, P. (1999): “Foreword”, en N.D. Ruggles y R. Ruggles (1999).

Hobbes, T. (1651): Leviathan, en http://www.knuten.liu.se/ bjoch509/works/hobbes/leviathan.txt.

Hudson, E.A. y D.W. Jorgenson (1978): "Energy Prices and US Economy 1972-76”, Natural Resources Journal, 18 (4), 877-897.

Hull, C. (1900): "Pettys's Place in the History of Economic Theory", Quarterly Journal of Economics, en http://socserv2.socsci.mcmaster.ca/ econ/ugcm/3ll3/petty/hull.html [Acceso 11/07/2001].

IEF (1969): La Contabilidad Nacional de España 1954-1964, Madrid.

IARIW (1998): The Role of National Accounting in Teaching Economics, IAIRW Conference, 23-29 August Cambridge, UK.

IETC (1993): Los transportes y las comunicaciones. Anuario de 1992, MOPTMA, Madrid.

IGAE (1993): Las Cuentas de las Administraciones Públicas. Año 1990, Ministerio de Economía y Hacienda, Madrid.

INE (1967): La Contabilidad Nacional de España. Año 1965 y avance de 1966, Madrid.

INE (1968): Contabilidad Nacional de España. Años 1965, 1966 y avance de 1967, Madrid.

INE (1969): Contabilidad Nacional de España. Años 1965, 1966, 1967 y avance de 1968, Madrid.

INE (1970): Contabilidad Nacional de España. Años 1964 a 1968 y avance de 1969, Madrid.

INE (1971): Contabilidad Nacional de España. Años 1964 a 1969 y avance de 1970, Madrid.

INE (1972): Contabilidad Nacional de España. Años 1964 a 1970 y avance de 1971, Madrid.

INE (1973): Contabilidad Nacional de España. Años 1964 a 1971 y avance de 1972, Madrid. 
INE (1976a): Contabilidad Nacional de España. Años 1970-71-72-73 y avance de 1974, Madrid.

INE (1976b): Clasificación Nacional de Actividades Económicas 1974, Madrid.

INE (1977): Contabilidad Nacional de España. Años 1970-1974, 1975 provisional y avance de 1976, Madrid.

INE (1978): Contabilidad Nacional de España. Años 1970-1975, 1976 provisional. y avance de 1977, Madrid.

INE (1979): Contabilidad Nacional de España. Base 1970. Años 1964-1976,1977 provisional y avance de 1978, Madrid.

INE (1980): Contabilidad Nacional de España. Base 1970. Años 1970-1977, 1978 provisional y avance de 1979, Madrid.

INE (1981): Contabilidad Nacional de España. Base 1970.Años 1970-77,1978 y1979 provisional y avance de1980, Madrid.

INE (1982): Contabilidad Nacional de España. Base 1970. Años 1970-1979, 1980 provisional y avance de 1981, Madrid.

INE (1983): Contabilidad Nacional de España. Base 1970. Años 1970-1979, 1981 provisional y avance de 1982, Madrid.

INE (1984): Contabilidad Nacional de España. Base 1970. Años 1980-1981, 1982 provisional y avance de 1983, Madrid.

INE (1986a): Contabilidad Nacional de España. Base 1980. Cuentas Nacionales y tabla input-output, Madrid.

INE (1986b): Contabilidad Nacional de España. Base 1980. Serie 1980-1983 definitivos, 1984 provisional y 1985 avance, Madrid.

INE (1987): Contabilidad Nacional de España. Base 1980. Serie 1980-1984 definitivos, 1985 provisional y 1986 avance, Madrid.

INE (1988): Contabilidad Nacional de España. Base 1980. Serie 1980-1985 definitivos, 1986 provisional y 1987 avance. Serie homogénea de los principales agregados macroeconómicos 1970-1986. Base 1980, Madrid.

INE (1990a): Contabilidad Nacional de España. Base 1985. Cuentas Nacionales y tabla input-output, Madrid

INE (1990b): La condición socioeconómica en la Encuesta de Población Activa, Madrid.

INE (1990c): Encuestas de Población Activa de 1990, ficheros de datos.

INE (1991a): Contabilidad Nacional de España. Base 1985. Serie contable 1985-1989 y Tabla InputOutput de 1986, Madrid.

INE (1991b): Contabilidad Nacional de España. Base 1985. Serie contable 1985-1990 y Tabla InputOutput de 1987, Madrid.

INE (1992a): Contabilidad Nacional de España. Serie enlazada 1964-1991. Base 1986, Madrid.

INE (1992b): Encuesta de Presupuestos Familiares. 1990/91. Metodología, Madrid.

INE (1992c): Encuesta de Presupuestos Familiares. 1990/91, ficheros de microdatos.

INE (1993a): Contabilidad Nacional de España. Base 1986. Serie contable 1985-1991 y Tabla InputOutput de 1988, Madrid.

INE (1993b): Clasificación Nacional de Actividades Económicas 1993 (CNAE-93), Madrid.

INE (1994): Contabilidad Nacional de España. Base 1986. Serie contable 1985-1992 y Tabla InputOutput de 1989, Madrid.

INE (1995a): Contabilidad Nacional de España. Base 1986. Serie contable 1985-1993 y Tabla InputOutput de 1990, Madrid.

INE(1995b): Contabilidad Nacional de España. Base 1986. Serie contable 1985-1993 y Tabla InputOutput de 1990, publicación electrónica.

INE (1995c): Anuario Estadístico de España de 1994, Madrid.

INE (1996a): Contabilidad Nacional de España. Base 1986. Serie contable 1989-1994, Madrid.

INE (1996b): Clasificación Nacional de Productos por Actividades 1996 (CNPA-96), Madrid.

INE (1997a): Contabilidad Nacional de España. Base 1986. Serie contable 1990-1995, Madrid.

INE (1997b): Contabilidad Nacional de España. Base 1986. Serie contable 1991-1996, Madrid.

INE (1998): Contabilidad Nacional de España. Base 1986. Serie contable 1992-1997, Madrid.

INE (2001): Contabilidad Nacional de España. Base 1995. Serie contable 1995-1999. Tablas de origen $y$ destino 1996, Madrid.

INE, Eurostat (1986): Sistema Europeo de Cuentas Económicas Integradas S.E.C. 1983, 2ª ed. (1979), Madrid.

INE, SGCN (1999): “Contabilidad Nacional de España. Base 1995”, Boletín Trimestral de Coyuntura, 72 (junio), 65-86.

Johansen, L. (1960): A Multisectoral Study of Economic Growth, North-Holland, Amsterdam.

Karadag, M. y T. Westaway (1999): "A SAM-Based Computable General Equilibrium Model of the Turkish Economy”, Economic Research Paper, 99/18, Departament of Economics, U. Loughborough. 
Kehoe, T. (1996): “Social Accounting Matrices and Applied General Equilibrium Models”, Federal Reserve Bank of Minneapolis, Working Papers, 563.

Kehoe, T., A. Manresa, P.J. Noyola, C. Polo, F. Sancho y J. Serra (1986): “A Social Accounting System for Spain”, Working Paper 63.86, Departamento de Economía e Historia Económica de la UAB.

Kehoe,T., A. Manresa, C. Polo y F. Sancho (1988): "Una Matriz de Contabilidad Social de la economía española”, Estadística Española, 30 (117), 5-33.

Kehoe,T., A. Manresa, C. Polo y F. Sancho (1989): "Un análisis de equilibrio general de la reforma fiscal de 1986 en España”, Investigaciones Económicas, XIII (3), 337-385.

Kehoe,T., P.J. Noyola, A. Manresa, C. Polo y F. Sancho (1988): "A General Equilibrium Analysis of the 1986 Tax Reform in Spain”, European Economic Review, 32 (2/3), 334-342.

Kendrick J.W. (1979): "Cuentas de renta nacional y producto nacional", en D.L. Shills (dir.): Enciclopedia Internacional de las Ciencias Sociales, Aguilar, vol. 6, 281-293.

Kendrick, J.W. ed. (1995a): The New System of National Accounts, Kluwer Academic Publishers, Boston, Dordrecht, London.

Kendrick, J.W. (1995b): “Introduction and Overview”, en Kendrick (1995a), 1-23.

Keuning, S. (1991): "Proposal for a Social Accounting Matrix which Fits into the Next System of National Accounts", Economic Systems Research, 3 (3), 233-248.

Keuning, S. (1994): “The SAM and Beyond: Open SESAME”, Economic Systems Research, 6(1), 2150.

Keuning, S. (1995): "Productivity Changes and Shifts in the Income Distribution”, Economic Systems Research, 7 (3), 453-468.

Keuning, S. (1996): Accounting for Economic Development and Social Change, IOS Press, Amsterdam.

Keuning, S. (1998): “A Powerful Link between Economic Theory and Practice: National Accounting”, Review of Income and Wealth, 44 (3), 437-446.

Keuning, S. y W.A. Ruijter (1988): "Guidelines to the Construction of a Social Accounting Matrix", Review of Income and Wealth, 34, (1),71-101.

Keynes, J.M. (1936): The General Theory of Employment, Interest and Money, Collected Writings, vol.7 (1973), en cepa.newschool.edu/het/essays/keynes/gtcont.htm, [Acceso 6/01/2001].

King, G. (1696): Natural and Political Observations and Conclusions upon the State \& Condition of England. Reprinted in King, 1936, Two Tracts, Johns Hopkins University Press, Baltimore.

Kolm, S.C. (1976): “Unequal Inequalities I”, Journal of Economic Theory 12, 416-442.

Khorshid, M. (1991): “ A Social-accounting-matrix-based Long-term Model for a Gulf Cooperation Council Country: the Kuwaiti Case”, Economic Systems Research, 3 (3), 299-314.

Kurz, H.; E. Dietzenbacher y C. Lager eds. (1998): Input-Output Analysis (vol.I), Edward Elgar Publishing, Cheltenham.

Kuznets, S. (1955): "Economic Growth and Income Inequality”, American Economic Review, 45(1), $1-28$.

Lantner, R. (1974): Théorie de la dominance économique, Dunod, París.

Leontief, W. (1928): "Die Wirstchaft als Kreislauf”, Archiv für Sozialwissenschaft und Sozialpolitik, v. 60, 577-623, traducido al inglés (1991): "The Economy as a Circular Flow”, Structural Change and Economic Dynamics, v 2(1), 181-212, y reimpreso en Kurz y otros (1998), 68-99.

Leontief, W (1936): "Quantitative Input and Output Relations in the Economic System of the United States", Review of Economic Statistics, XVIII (3), August, 105-125.

Leontief, W. (1941): The Structure of American Economy, 1919-1939: An Empirical Application of Equilibrium Analysis, Intern. Arts and Sciences Press, White Plains, New York.

Leontief, W. (1966): Input-Output Economics, Oxford University Press, New York.

Leontief, W.(1967): “An Alternative to Aggregation in Input-Output Analysis and National Accounts", Review of Economic and Statistics, 49, 412-421, reimpreso en W. Leontief (1986): Input-Output Economics, Oxford University Press, Oxford.

Leontief, W (1987): “Input-Output Analysis”, The New Palgrave, vol.2, 860-864.

Llop, M. y A. Manresa (1999): “Análisis de la economía de Cataluña (1994) a través de una Matriz de Contabilidad Social”, Estadistica Española, 41 (144), 241-268.

Manresa, A., C. Polo y F. Sancho (1988): "Una evaluación de los efectos del IVA mediante un modelo de producción y gasto de coeficientes fijos”, Revista Española de Economía, 5 (1/2),45-64.

Manresa, A., F. Sancho y J.M. Vergara (1998): “Measuring Commodities’ Commodity Content”, Economic Systems Research, 10 (4), 357-365.

Markusen,J. y T.F. Rutherford (1985): "General Equilibrium Modeling with MPSGE. Some Examples for Self-Study", http://www.gams.com/solvers/mpsge/marcusen.htm, [Acceso 11/01/2001].

Marshall, A. (1890): The Principles of Economics, en cepa.newschool.edu/het/profiles/marshall, [Acceso 15/11/2001].

Marx, K. (1885,1894). El Capital, Vol. II El proceso de circulación del capital, Parte III La reproducción y circulación del capital social agregado, capítulos XX "Reproducción simple” y XXI “Acumulación y reproducción a escala ampliada”; Vol. III El proceso de producción capitalista en su conjun- 
to, Parte VII Las rentas y sus fuentes, capítulo XLIX “Sobre el análisis del proceso de producción”, en //csf.colorado.edu/mirrors/marxists.org/archive/marx/works/ [Acceso 12/7/2001].

Mayeres, Y. (1999): "The Distributional Impacts of Policies for the Control of Transport Externalities. An Applied General Equilibrium Model”, Working Papers, 1999.8, Fondazione Enrico Mattei.

Meade , J. E. y R. Stone (1941): "The Construction of Tables of National Income, Expenditure, Savings and Investment”, Economic Journal, 51, 216-233.

Mesnard, L. De (1989): "Note about the Theoretical Foundations of Biproportional Methods”, Ninth International Conference on Input-Output Techniques, Keszthely, September.

Miguel, F. de, A. Manresa y J. Ramajo (1998): "Matriz de contabilidad social y multiplicadores contables: una aplicación para Extremadura”, Estadística Española, 40, (143), 195-232.

Milanovic, B. (1999): "True World Income Distribution, 1988 and 1993. First calculations, Based on Household Surveys Alone”. World Bank, Country Economics Departament. Papers, 2244.

Mill, J.S (1848): Principles of Political Economy, en www.utm.edu/research/iep/m/milljs.htm\#, [Acceso 22/11/2001].

Miller, R.E., K.R. Polenske y A.Z. Rose (eds.) (1989): Frontiers of Input-Output Analysis, Oxford University Press, Oxford.

Ministerio de Economía y Hacienda (2000): Avance de la actuación presupuestaria del Estado en 1999, Madrid.

Ministerio de Hacienda (1959): La Contabilidad Nacional de España. Años 1954, 1955 y 1956, SGT, Madrid.

Ministerio de Hacienda (1960): La Contabilidad Nacional de España en 1957, SGT, Madrid.

Ministerio de Hacienda (1964a): La Contabilidad Nacional de España. Años 1954 a 1960. SGT, Madrid.

Ministerio de Hacienda (1964b): La Contabilidad Nacional de España en 1961 y 1962, multicopiado, SGT, Madrid.

Ministerio de Hacienda (1965a): La Contabilidad Nacional de España. Año 1963, multicopiado, SGT, Madrid.

Ministerio de Hacienda (1965b): Avance de la Contabilidad Nacional de España. Año 1964 (cifras provisionales), multicopiado, SGT, Madrid.

Miyazawa, K. (1976): Input-Output Analysis and the Structure of Income Distribution, Springer-Verlag, Berlín.

Miyazawa, K y S. Masegi (1963): "Interindustry Analysis and the Structure of Income Distribution”, Metroeconomica, XV (2-3), 89-103.

MOPTMA (1993): Anuario Estadístico de 1992, Madrid.

MTSS (1992): "Protección social”, Anuario de Estadísticas Laborales de 1991, 655-880.

Mun-Heng, T. (1998): "The RAS Approach in Updating Input-Output Matrices: An Instrumental Variable Interpretation and Analysis of Structural Change”, Economic Systems Research, 10 (1), 63-78.

Muñoz, C. (1989): Introducción a la economía aplicada. Cuentas nacionales, tablas input-output y balanza de pagos, Espasa Calpe, Madrid.

Muñoz, C. (2000): Las cuentas de la nación. Introducción a la economía aplicada, Colección Civitas, Madrid.

Musgrave, R.A. (1983): Hacienda pública, teórica y aplicada, $2^{\mathrm{a}}$ ed., Instituto de Estudios Fiscales, Madrid.

Naredo, J.M. (1997): "Le inmobilier et les plus-values en Espagne. Réflexion théorique et résultats pratiques”, en E. Archambault y M. Boëda (eds.), 35-48.

Naudé, W. (1994): “Teaching Applied General Equilibrium Modelling”. Computers in Higher Education Review, CHEER, The virtual edition, 8,3.

Neumann, J.v. (1937): “A Model of General Economic Equilibrium”, traducido en Review of Economic Studies, XIII, 1945, 1-9; en Kurz y otros eds. (1998), 133-141.

Ng, L.S. (1974): An Income Distribution and Employment Consistency Model of the Philippines, Ph. D. dissertation, University of Bristol.

Nozick, R.(1974): Anarchy, State and Utopia, Blackwell, Oxford.

OCDE (1997a): Differences between SNA 93 and ESA 95. STD/NA/RD(97)15.

OCDE (1997b): Meeting of National Accounts Experts, 3-6 June, Paris, STD/NA(97)1-STD/NA(97)32 y STD/NA/RD(97)1 - STD/NA/RD(97)18.

OCDE (1998): Meeting of National Accounts Experts, 22-25 September, Paris, STD/NA(98)1STD/NA(98)34 y STD/NA/RD(98)1 - STD/NA/RD(98)10.

OCDE (1999): Meeting of National Accounts Experts, 21-24 September, Paris, STD/NA(99)17STD/NA(99)35; STD/NA(99)37-STD/NA(99)55 y STD/NA/RD(99)1- STD/NA/RD(99)4 у STD/NA/RD(99)6.

OCDE (2000): Meeting of National Accounts Experts, 26-29 September, Paris, STD/NA(00)1STD/NA(00)39 y STD/NA/(00)RD01.

OCDE (2001): "Draft Agenda" of Meeting of National Accounts Experts, 9-12 October, en www.oecd.org/std/nameet.htm. 
OCEE (1950): A Simplified System of National Accounts, OCEE, Paris.

OCEE (1952): A Standardised System of National Accounts, OCEE, Paris.

Organización Sindical Española (1962): Tabla Input-Output de la economía española. 1958. Madrid.

Organización Sindical Española (1966-1967): Tablas Input-Output de la economía española, vol. I y II, Madrid.

OSCE (1972): European System of Integrated Economic Account, ESA, Brusels.

Pareto, V. (1897): Cours d'Économie Politique, Rouge, Lausanne.

Peacock, A.T. y J. Wiseman (1961): The Growth of Public Expenditures in The United Kingdom, NBER, Princeton University.

Petty, W. (1665): Verburn Saplenti (or Account or the Wealth and Expences of England, and the Method of raising Taxes in the most Equal Manner), written in 1665, printed 1691, http://www.eumed.net/cursecon/economistas/Petty.htm. [Acceso 18/10/2001].

Petty, W. (1676): Political Arithmetick, en http://socserv2.socsci.mcmaster.ca/ econ/ugcm/ 3ll3/petty/poliarith.html, [Acceso 18/10/2001].

Philips, A. (1955): "The Tableau Economic as a Simple Leontief Model", Quarterly Journal of Economics, 69(1), 137-144.

Piggott, J. y J. Whalley (1977): “General Equilibrium Investigation of U.K. Tax-Subsidy Policy: Progress Report”, en Artis y Nobay (ed.): Studies in Modern Economic Analysis, Blackwell, Oxford, 259-299.

Piggott, J. y J. Whalley (1985): “Economic Effects of U. K. Tax-Subsidy Policies: A General Equilibrium Appraisal”, en J. Piggott y J. Whalley (eds.): New Developments in Applied General Equilibrium Analysis, Cambridge University Press, New York.

Pigou, A.C. (1923): Essays in Applied Economics.

Plaza Prieto, J. (1975): “La renta nacional”, en J. Plaza Prieto: Estructura Económica de España en el siglo XVIII, Confederación Española de Cajas de Ahorro, Madrid, 493-598.

Polo, C. y F. Sancho (1990a): "Efectos económicos de una reducción de las cuotas empresariales a la Seguridad Social”, Investigaciones Económicas, XIV(3), 407-424.

Polo, C. y F. Sancho (1990b): “An Analysis of Spain’s Integration in the EEC”, Working Paper, 140.90, Departamento de Economía, UAB.

Polo, C. y F. Sancho (1992): “Updating the SAM of the Spanish Economy to 1987 data”, Mimeo, UAB, citado en Collado y Roland-Holst (1993).

Polo, C. y F. Sancho (1993): "Insights or Forecasts? An Evaluation of a Computable General Equilibrium Model of Spain”, Journal of Forecasting, 12, 437-448.

Polo, C., D.W. Roland-Holst y F. Sancho (1990): "Distribución de la renta en un modelo SAM de la economía española”, Estadística Española, 32 (125), 537-567.

Polo, C., D.W. Roland-Holst y F. Sancho (1991a): "Descomposición de multiplicadores en un modelo multisectorial: una aplicación al caso español”, Investigaciones Económicas, XV (1), 53-69.

Polo, C., D.W. Roland-Holst y F. Sancho (1991b): "Análisis de la influencia económica en un modelo multisectorial”, Investigaciones Económicas, Suplemento, 125-129.

Pulido, A. y E. Fontela (1993): Análisis Input-Ouput. Modelos, datos y aplicaciones, Pirámide, Madrid.

Pyatt, G. (1985): “Commodity Balances and National Accounts: A SAM Perspective”, Review of Income and Wealth, 31 (2), 155-169.

Pyatt, G. (1988): “A SAM Approach to Modeling”, Journal of Policy Modeling, 10 (3), 327-352.

Pyatt, G. (1989): “The Method of Apportionment and Accounting Multipliers", Journal of Policy Modeling, $11(1), 111-130$.

Pyatt, G. (1991a): “Fundamentals of Social Accounting”, Economic Systems Research, 3 (3), 315-341.

Pyatt, G. (1991b): "SAMs, The SNA y National Accounting Capabilities", Review of Income and Wealth, 37 (2), 177-198.

Pyatt, G. (1994): "Modelling Commodity Balances. A Derivation of de Stone Model”, Economic Systems Research, 6 (1), 5-20.

Pyatt, G. (1999): "Some Relationships between T-Accounts, Input-Output Tables and Social Accounting Matrices”, Economic Systems Research, 11(4), 365-387.

Pyatt, G y J.I. Round (1979): “Accounting and Fixed Price Multipliers in a Social Accounting Matrix Framework”, The Economic Journal, 89, 850-873.

Pyatt, G. y J.I. Round (1985): Social Accounting Matrices. A Basis for Planning, World Bank, Washington D.C.

Pyatt, G. y otros (1972): Employment and Income Policies for Iran: Methodology for Macroeconomics Projections, International Labour Office, Geneva.

Pyatt, G. y E. Thorbecke (1976): Planning Techniques for a Better Future, International Labour Office, Geneva.

Quesnay, F. (1766): “Analyse de la formule arithmétique du TABLEAU ÉCONOMIQUE de la distribution des dépenses annualles d'une Nation agricole”, Journal de l'agriculture, du comerse \& des finances, T.II, $3^{\mathrm{a}}$ p., junio, 11-41, en http://ecn.bris.ac.uk/het/quesnay/Tab1766.html [Acceso $12 / 7 / 2001]$. 
Quesnay, F. (1972): Tableau Économique, editado y traducido por M. KuczynskI y R.L. Meek, Macmillan, London, Kelley, New York.

Rawls, J. (1971): A Theory of Justice, Harvard University Press, Cambridge.

Reinert, K.A. y Roland-Holst, D.W. (1992): “ A Detailed Social Accounting Matrix for the USA, 1988”, Economic Systems Research, 4 (2), 173-187.

Reinert, K.A., D.W. Roland Holst y C.R. Shiells (1993): "Social Accounts and the Structure of the North American Economy”, Economic Systems Research, 5 (3), 295-326.

Reininga, T. (2000): "Social Accounting Matrices and Data Construction for the Age-model of The Netherlands Bureau of Economic Analysis", paper prepared for $26^{\text {th }}$ General Conference IARIW , 29/08-2/09, Krakow.

Ricardo, D. (1817): “Preface”, On the Principles of Political Economy and Taxation, ed. de 1821 en www.econlib.org/library/Ricardo, [Acceso 8/11/2001].

Robinson, S. (2001): “Ongoing Issues of Integrating Macro Models and CGE Models”, Policy Modeling for European and Global Issues. ULB, 5-7 July, Brussels.

Robinson, S. y D.W. Roland-Host (1988): "Macroeconomic Structure and Computable General Equilibrium Models”, Journal of Policy Modeling , 10, 353-375.

Rodríguez López, J. (1977): "Producto y renta nacionales de España: Conceptos, fuentes estadísticas y evolución”, en P. Schwartz (1977), 593-646.

Rodríguez Romero, L. (1988): “Comentarios”, Estadística Española, 30 (117), 41-44.

Roland-Host, D.W. y F. Sancho (1992): "Relative Income Determination in the United States: A Social Accounting Perspective”, Review of Income and Wealth, 38 (3), 311-327.

Roland-Host, D.W. y F. Sancho (1995): "Modeling Prices in a SAM Structure”, The Review of Economics and Statistics, 77 (2), 361-371.

Romero Jordan, D. (1996): "La distribución del rendimiento neto de la explotación de los empresarios en la EPF90-91", Papeles de Trabajo, núm.8/96, Instituto de Estudios Fiscales.

Rose, A. y W. Miernyk (1989): "Input-Output Analysis: The First Fifty Years”, Economic Systems Research, 1 (2), 229-271.

Rothschild, M. y J.E. Stiglitz (1973): “Some Further Results on the Measurement of Inequality”, Journal of Economic Theory, 6, 188-203.

Round, J.I. (1985):"'Decomposing Multipliers for Economic Systems Involving Regional and World Trade", The Economic Journal, June, 383-399.

Rousseau, J. (1763): The Social Contract, traducido por M. Cranston (1968), Penguin Books, Baltimore.

Rowlatt, A., S. Holloway, H. Haworth y N. Stuttard (2000): "Preparing Social Accounting Matrices and Labour Accounts for The United Kingdom. The First Steps”, paper prepared for $26^{\text {th }}$ General Conference IARIW, 29/08-2/09, Krakow.

Rubio, M.T. (1995): “Matrices de Contabilidad Social” en Rubio, M.T. y J.A. Salvador: Análisis inputoutput. Aplicaciones para Castilla y León, Consejería de Economía y Hacienda, Junta de Castilla y León, Valladolid, 15-80.

Rubio, M.T. y J. Vicente (2000a): “SAM Multipliers and Inequality Measurement”, IARIW Conference, 29/8-2/9, Krakow.

Rubio, M.T. y J. Vicente (2000b): "Integrating Micro and Macro Using Boundary Norms of Inequality”, Fighting Poverty and Inequality Workshop, 25 de noviembre, Barcelona.

Ruggles, R. (1995): “The United Nations System of National Accounts and the Integration of Micro and Macro Data”, en Kendrick (1995a), 387-421.

Ruggles, R. y N. Ruggles (1986): "The Integration of Macro and Micro Data for the Household Sector", Review of Income and Wealth, 32 (3), 245-276.

Ruggles, N. y R. Ruggles (1999): National Accounting and Economic Policy, Edward Elgar Publishing, Cheltenham.

Ruiz-Castillo, J. (1987): La medición de la pobreza y la desigualdad en España, 1980-81, Servicio de Estudios del Banco de España, Estudios Económicos, 42, Banco de España, Madrid.

Ruiz-Huerta, J. y R.Martinez (1994): “ La pobreza en España: ¿Qué nos muestran las EPF ?” Documentación Social, 96, 15-111.

Rutherford, T. y S. Paltsev (1999): “ From an Input-Output Table to a General Equilibrium Model: Assessing the Excess Burden of Indirect Taxes in Russia”, Academic Paper, 08/99, U. Colorado.

Samuelson, P.A. (1983): Economía ,11ª ed., Mc Graw-Hill, Madrid, Apéndice Cap. 42, 918-932.

Samuelson, P.A. y W.D. Nordhaus (1996): Economía, 15ª ed., Mc Graw-Hill, Madrid.

Sanz, B. (1995): "La articulación micro-macro en el sector hogares: de la Encuesta de Presupuestos Familiares a la Contabilidad Nacional”, Papeles de Trabajo, 27/95, Instituto de Estudios Fiscales.

Say, J. B. (1803): A Treatise on Political Economy or the Production, Distribution and Consumption or Wealth, en sosci.mcmaster.ca/ econ/ugcm/3||3/Say, [Acceso 9/ 11/2001].

Scarf, H. E. (1967): “On the Computation of Equilibrium Prices”, en W. J. Fellner (ed.): Ten Economic Studies in the Tradition of Irving Fischer, Wiley , New York, 207-230.

Schumpeter, J.A. (1942): Capitalism, Socialism and Democracy, Harped \&Brothers, New York. Citado en J. A. Shumpeter (1983): 10 Grandes economistas de Marx a Keynes , Alianza Editorial, Madrid. 
Schwartz, P. (1977): El producto nacional de España en el siglo XX, Instituto Estudios Fiscales, Madrid. Secretaría General de Turismo (1995): Tabla intersectorial de la economía turística española 1992, Instituto de Estudios Turísticos del Ministerio de Comercio y Turismo, Madrid.

Sen, A. (1973): On Economic Inequality Reexamined, Oxford University Press.

Sen, A. (1992): Inequality Reexamined, Clarendon Press, Oxford.

Sen, A. y J.E. Foster (1997): On Economic Inequality, $2^{\mathrm{a}}$ ed., Clarendon Press, Oxford.

Shorrocks, A.F.(1984): “Inequality Decomposition by Population Subgroups”, Econometrica, 52, 13691385.

Shoven, J. y J. Whalley (1972): “A General Equilibrium Calculation of the Effects of Differential Taxation of Income from Capital in the US”, Journal of Public Economics, 1, 475-490.

Shoven, J. y J. Whalley (1974): "On the Computation of Competitive Equilibrium in International Markets with Tariffs", Journal of International Economics, 4, 341-354.

Shoven, J. y J. Whalley (1984): “Applied General-Equilibrium Models of Taxation and International Trade: An Introduction and Survey", Journal of Economic Literature, XXII, September, 1007-1051.

Silber, J. (ed.) (2001): Handbook on Income Inequality Measurement, Kluwer Academic Publishers, London.

Skountzos, T. (1988): "Social Accounting Multipliers in a Developing Economy: The Case of Greece", Economics of Planning, 22, (1/2), 57-71.

Smith, A. (1776): An Inquiry into the Nature and Causes of the Wealth Nations, Edinburgh, en www.adamsmith.org.uk.smith. [Acceso 9/11/2001].

Sraffa (1960): Production of Commodities by Means of Commodities, Cambridge University Press, Cambridge.

Stone (General ed.) Cambridge University, Department of Applied Economic: (1962-1974): A Programmm for Growth, Vols. I-XII, Chapman and Hall, London. Vol.I: A computable model of economic growth; Vol.II: A social accounting matrix for 1960; Vol.III: Input-Output relationships 19541966.

Stone, R. (1985): "The Desegregation of the Household Sector in the National Accounts", en Pyatt y Round eds. (1985), 145-185, version actualizada y ampliada de un trabajo previo presentado con el mismo titulo en (1978): World Bank Conference on Social Accounting Methods in Development Planning, Cambridge, UK,16-21 April.

Stone, R. (1997): “The Accounts of Society”, Nobel Memorial Lecture, reimpreso en The American Economic Review, 87 (6), 17-29.

Stone, R. y G. Croft-Murray (1959): Social Accounting and Economic Models, Bowes \& Bowes, London.

Stone, R. y A. Brown (1962) : A Computable Model of Economic Growth, vol.1, Chapman and Hall, Londres.

Taylor , L. y otros (1980): Models of Growth and Redistribution for Brazil, Oxford University Press, London.

Thorbecke, E. (1985): “The Social Accounting Matrix and Consistency-Type Planning Models”, en Pyatt y Round (1985), 207-256.

Thorbecke, E. (2000): "The Use of Social Accounting Matrices in Modeling", paper prepared for $26^{\text {th }}$ General Conference IARIW, 29/08-2/09, Krakow.

Thorbecke, E. y J. Sengupta, (1972): A Consistency Framework for Employment Output and Income Distribution Projections Applied to Colombia", World Bank, Washington.

Torres, M. y otros (1958): La Contabilidad Nacional de España (Cuentas y cuadros de 1954), Facultad de Ciencias Políticas y Económicas e Instituto "Sancho de Moncada", Madrid.

Torres,M. (Dir.), V. Andrés, J.L. Sampedro, E. Fuentes, A. Alcaide, J. Álcaide, J. Fdez-Castañeda, A. Santos y J. Velarde, (1960): Relaciones estructurales y desarrollo económico, Organización Sindical, Madrid

United Nations (1947): Measurement of National Income and the Construction of Social Accounts, Studies and Reports on Statistical Methods, 7, Geneva.

United Nations (1950): National Income Statistics, 1938-1948, United Nations Publication, New York.

United Nations (1953): A System of National Accounts and Supporting Tables, Studies in Methods, Series F, 2, New York.

United Nations (1958): Yearbook of National Accounts Statistics, New York.

United Nations (1968): A System of National Accounts, Studies in Methods, Series. F, 2 (rev.3), New York.

United Nations (1986a): “Organization of the SNA Review”, ESA/STAT/AC.28/2, 17/3.

United Nations (1986b): "Conceptual Framework of the Revised SNA”, ESA/STAT/AC.28/3, 9/2.

United Nations (1999) : "Informe del grupo de tareas sobre cuentas nacionales", Consejo Económico y Social, Comisión Estadística, 30º periodo de sesiones, 1-5/ marzo/1999, E/CN.3/1999/2.

United Nations (2000a) : "Informe del grupo de tareas sobre cuentas nacionales", Consejo Económico y Social, Comisión Estadística, $31^{\circ}$ periodo de sesiones, 29/2-3/3/2000, E/CN.3/2000/2. 
United Nations (2000b): "Evaluación de los hitos de la aplicación del Sistema de Cuentas Nacionales por los estados miembros”, Consejo Económico y Social, Comisión Estadística, E/CN.3/2000/3

United Nations (2001): "Informe del grupo de tareas sobre cuentas nacionales", Consejo Económico y Social, Comisión Estadística, 32 ${ }^{\circ}$ período de sesiones, 6/3-9/3/2000, E/CN.3/2001/7.

United Nations, CEC, IMF, OECD y WB (1993): A System of National Accounts 1993, Brussels/Luxembourg, New York, Washington, D.C.

Universidad Comercial de Deusto (1971): Riqueza Nacional de España, Apéndice. Distribución provincial, actualización y comentarios, Bilbao.

UNSO (1964): National Accounting Practices in Sixty Countries: A Supplement to the Yearbook of the National Accounts Statistics, Studies in Methods, Series F, 11, New York.

UNSO (1972): "Draft System of Statistics on the Distribution of Income, Consumption and Accumulation", Statistical Commission Agendum Paper, United Nations, New York.

UNSO (1975): Towards a System of Social and Demographic Statistics, Series F, 18, United Nations, New York.

UNSO (1977): Provisional Guidelines on Statistics of the Distribution of Income, Consumption and Accumulation of Households, Studies and Methods, Series M, 61, United Nations, New York.

Uriel, E. (1986): Enlace entre los Sistemas de Contabilidad Nacional CNE-58 y CNE-70, IEF, Monografía 47, Madrid.

Uriel, E. (1989): "Elaboración alternativa de una matriz de contabilidad social para la economía española" Quaderns de Treball, 153, 1-42.

Uriel, E., P. Beneito, J. Ferri y M.L. Molto (1997): Matriz de contabilidad social de España 1990 (MCS-90), INE e IVIE, Madrid.

Van Bochove, C.A. y H.K. Van Tuinen (1986): "Revision of the System of National Accounts: the Case for Flexibility", Review of Income and Wealth, 32 (2), 127-154.

Vauban, Sébastien le Preste (1707): Project d'une Dîme Royale, en Economistes Financiers du XVIIIme Siècle, ed. Eugène Daire, Paris, 1843.

Velarde, J. (1957): “Consideraciones sobre la Contabilidad Nacional de España”, Anales de Economía, XVII (65), reimpreso en J. Velarde (1969): Lecturas de economía española, Gredos S.A., Madrid, 161-172.

Velarde, J. (1968): “Crítica de las distintas estimaciones efectuadas sobre la riqueza nacional de España”, en U. C. de Deusto: La riqueza Nacional de España, vol. I, Bilbao, 265-323.

Vicente, J. y E. Decimavilla (1998): "El sistema estadístico de la Unión Europea. Desarrollos recientes”, en I. Vega (coord.): La integración Económica Europea: curso básico, Lex Nova, Valladolid.

Vicente, J. y L. Borge (2000): "Development and Inequality. Inverted and Uninverted U-shapes”, Applied Economic Letters, 7, 497-500.

Walras, L. (1874-77): Eléments d'économie politique pure, 4th ed. Lausanne: L.CORBAZ, 1874-77, traducido al inglés por W. JAFFÉ(1954): Elements of pure economics, Allen \&Unwin, London.

Yang, Y. y Y. Huang (1997): “ The Impact of Trade Liberalisation on Income Distribution in China”, Economics Division Working Papers, 97/1, Research School of Pacific and Asian Studies.

Zalai, E. (1998): "Computable Equilibrium Modelling and Application to Economies in Transition", Discussion Papers 98/04, Centre for Economic Reform and Transformation, Heriot Watt University.

Zenios, S.A. (1996): "Modeling Languages in Computational Economics: GAMS”, en H.M. Amman, D.A. Kendrick y J. Rust (eds.), 471-488. 
ANEXOS 



\section{ANEXO ESTADÍSTICO}

Cuadro A.1. Matriz de Contabilidad Social de España (MCSE-90).

Cuadro A.2. MCSE-90R. Sin cuenta de bienes y servicios

Cuadro A.3.a. MCSE-90RR. Reducida, reordenada y con PISB repartida.

Cuadro A.3.b. MCSE-90RR. Reducida, reordenada y sin PISB. 



\section{PROGRAMA SAS}

El programa informático que presentamos a continuación es el programa estadístico SAS que hemos utilizado para convertir la clasificación PROCOME (7 dígitos) de los gastos de consumo de los hogares de la EPF90-91 en la clasificación de productos que utilizamos en la MCSE-90. Salvo para algunas categorías que están agregadas, esta última coincide con la clasificación R.56 de la TIO90.

Los códigos hacen referencia a los códigos de recogida de campo de la EPF90-91, cuyas correspondencias una a una con la clasificación PROCOME (7 dígitos) figuran en INE (1992b, Anexo I: Clasificación de los gastos de consumo). La utilización de los códigos de recogida de campo se debe únicamente a que en el fichero tipo 2 de gastos del hogar que nos proporcionó el INE existía un error con los códigos PROCOME.

Por último, los distintos tipos de gasto (gasto 1, gasto 2,....gasto 57) hacen referencia a los códigos de la clasificación R.56 de la TIO90. A los grupos de productos de la TIO90 que están agregados en una categoría de productos de la MCSE-90 les hemos asignado el mismo código de gasto:

Productos de las ramas R.2, R.3 y R. 4 de la TIO90: gasto 2.

Productos de las ramas R.14, R.15, R.16 y R.17 de la TIO90: gasto 15.

Productos de las ramas R.33 y R.34 de la TIO90: gasto 34.

Productos de las ramas R.41, R.42, R.43 y R.44 de la TIO90: gasto 41 


\section{PROGRAMA SAS}

data a; set di.gasto90;

proc sort;by norden;

data di.consumo; set a;

by norden;

if first.norden then gasto $1=0$;

if first.norden then gasto $2=0$;

if first.norden then gasto $6=0$;

if first.norden then gasto $7=0$;

if first.norden then gasto8 $=0$;

if first.norden then gasto $9=0$;

if first.norden then gasto $15=0$;

if first.norden then gasto $18=0$;

if first.norden then gasto $19=0$;

if first.norden then gasto $20=0$;

if first.norden then gasto $21=0$;

if first.norden then gasto $22=0$;

if first.norden then gasto23 $=0$;

if first.norden then gasto $24=0$;

if first.norden then gasto $25=0$;

if first.norden then gasto $26=0$;

if first.norden then gasto $27=0$;

if first.norden then gasto $28=0$;

if first.norden then gasto $29=0$;

if first.norden then gasto $30=0$;

if first.norden then gasto $31=0$;

if first.norden then gasto $32=0$;

if first.norden then gasto $34=0$;

if first.norden then gasto $35=0$;

if first.norden then gasto36 $=0$;

if first.norden then gasto $37=0$;

if first.norden then gasto $38=0$;

if first.norden then gasto $40=0$;

if first.norden then gasto $41=0$;

if first.norden then gasto $45=0$;

if first.norden then gasto $46=0$;

if first.norden then gasto $47=0$;

if first.norden then gasto $49=0$;

if first.norden then gasto $50=0$;

if first.norden then gasto $51=0$;

if first.norden then gasto $52=0$;

if first.norden then gasto53 $=0$;

if first.norden then gasto55 $=0$;

if first.norden then gasto $57=0$;

if first.norden then $\mathrm{psv}=0$;

if first.norden then $\mathrm{ps}=0$;

if first.norden then th $=0$;

if first.norden then resto $1=0$; 
if first.norden then resto $2=0$;

if first.norden then resto $3=0$;

if first.norden then resto $4=0$;

if first.norden then resto $5=0$;

if first.norden then resto $6=0$;

if first.norden then resto $7=0$;

if first.norden then resto $8=0$;

if first.norden then resto $9=0$;

if first.norden then imptos $=0$;

if first.norden then alqimpt $=0$;

if $100100<=$ codigo $<=102399$ then gasto $27+$ gasto; if $102400<=$ codigo $<=104999$ then gasto $25+$ gasto; if $105000<=$ codigo $<=105099$ then gasto27+gasto; if $105100<=$ codigo $<=105299$ then gasto25+gasto; if $105300<=$ codigo $<=105499$ then gasto $27+$ gasto; if $105500<=$ codigo $<=105599$ then gasto25+gasto; if $105600<=$ codigo $<=105699$ then gasto $27+$ gasto; if $105700<=$ codigo $<=105799$ then gasto25+gasto; if $105800<=$ codigo $<=106399$ then gasto25+gasto; if $106400<=$ codigo $<=108899$ then gasto $1+$ gasto; if $108900<=$ codigo $<=109099$ then gasto27+gasto; if $109100<=$ codigo $<=109899$ then gasto $1+$ gasto; if $109900<=$ codigo $<=111399$ then gasto27+gasto; if $111400<=$ codigo $<=111499$ then gasto $1+$ gasto/2; if $111400<=$ codigo $<=111499$ then gasto26+gasto/2; if $111500<=$ codigo $<=113399$ then gasto26+gasto; if $113400<=$ codigo $<=113499$ then gasto1+gasto; if $113500<=$ codigo $<=113599$ then gasto27+gasto; if $113600<=$ codigo $<=113699$ then gasto26+gasto; if $113700<=$ codigo $<=113799$ then gasto27+gasto; if $113800<=$ codigo $<=114199$ then gasto $27+$ gasto; if $114200<=$ codigo $<=114399$ then gasto $25+$ gasto; if $114400<=$ codigo $<=114499$ then gasto27+gasto; if $114500<=$ codigo $<=116799$ then gasto1+gasto; if $116800<=$ codigo $<=116899$ then gasto27+gasto; if $116900<=$ codigo $<=117999$ then gasto27+gasto; if $118000<=$ codigo $<=121199$ then gasto $1+$ gasto; if $121200<=$ codigo $<=121799$ then gasto27+gasto; if $121800<=$ codigo $<=121899$ then gasto $1+$ gasto; if $121900<=$ codigo $<=123299$ then gasto27+gasto; if $123300<=$ codigo $<=123399$ then gasto26+gasto; if $123400<=$ codigo $<=124099$ then gasto27+gasto; if $124100<=$ codigo $<=124199$ then gasto28+gasto; if $124200<=$ codigo $<=124399$ then gasto $27+$ gasto; if $124500<=$ codigo $<=125799$ then gasto28+gasto; if $125800<=$ codigo $<=125899$ then gasto28+gasto; if $125900<=$ codigo $<=126299$ then gasto29+gasto;

if $200100<=$ codigo $<=206799$ then gasto30+gasto; 
if $206800<=$ codigo $<=206899$ then gasto30+gasto/3; if $206800<=$ codigo $<=206899$ then gasto31+gasto/3; if $206800<=$ codigo $<=206899$ then gasto35+gasto/3; if $206900<=$ codigo $<=206999$ then gasto30+gasto/2; if $206900<=$ codigo $<=206999$ then gasto31+gasto/2; if $207000<=$ codigo $<=207099$ then gasto30+gasto; if $207100<=$ codigo $<=207199$ then gasto30+gasto/3; if $207100<=$ codigo $<=207199$ then gasto35+gasto/3; if $207100<=$ codigo $<=207199$ then gasto36+gasto/3; if $207200<=$ codigo $<=207299$ then gasto30+gasto; if $207300<=$ codigo $<=207399$ then gasto $49+$ gasto; if $207400<=$ codigo $<=207499$ then gasto38+gasto/2; if $207400<=$ codigo $<=207499$ then gasto57+gasto/2; if $207500<=$ codigo $<=207699$ then gasto53+gasto; if $207800<=$ codigo $<=207899$ then gasto31+gasto; if $207900<=$ codigo $<=208199$ then gasto35+gasto; if $208200<=$ codigo $<=208399$ then gasto31+gasto; if $208400<=$ codigo $<=208699$ then gasto35+gasto; if $208700<=$ codigo $<=208899$ then gasto31+gasto; if $208900<=$ codigo $<=209199$ then gasto35+gasto; if $209200<=$ codigo $<=209399$ then gasto38+gasto;

if $300100<=$ codigo $<=300899$ then gasto50+gasto; if 303095=codigo then gasto50+gasto; if 300999=codigo then gasto53+gasto; if 301097=codigo then gasto50+gasto; if 301195=codigo then gasto53+gasto; if $301200<=$ codigo $<=301499$ then gasto50+gasto; if $301500<=$ codigo $<=301699$ then gasto53+gasto; if 301715=codigo then gasto50+gasto; if $301800<=$ codigo $<=301999$ then gasto53+gasto; if $302000<=$ codigo $<=302099$ then gasto50+gasto; if $302100<=$ codigo $<=302299$ then gasto53+gasto; if $302300<=$ codigo $<=302399$ then gasto50+gasto; if $302400<=$ codigo $<=302599$ then gasto53+gasto; if $302600<=$ codigo $<=302699$ then gasto50+gasto; if $302700<=$ codigo $<=302899$ then gasto53+gasto; if $302900<=$ codigo $<=302999$ then gasto50+gasto; if $303100<=$ codigo $<=303199$ then gasto50+gasto; if $303200<=$ codigo $<=303699$ then gasto53+gasto; if $305500<=$ codigo $<=305699$ then gasto $18+$ gasto/2; if $305500<=$ codigo $<=305699$ then gasto37+gasto/2; if $305700<=$ codigo $<=305899$ then gasto34+gasto/2; if $305700<=$ codigo $<=305899$ then gasto37+gasto/2; if $305900<=$ codigo $<=306000$ then gasto $22+$ gasto $/ 2$; if $305900<=$ codigo $<=306000$ then gasto37+gasto/2; if $306100<=$ codigo $<=306499$ then gasto $15+$ gasto/2; if $306100<=$ codigo $<=306499$ then gasto37+gasto/2; if $306500<=$ codigo $<=306599$ then gasto32+gasto/2; if $306500<=$ codigo $<=306599$ then gasto37+gasto/2; 
if $306600<=$ codigo $<=306699$ then gasto37+gasto; if $306700<=$ codigo $<=306799$ then gasto37+gasto/2; if $306700<=$ codigo $<=306799$ then gasto32+gasto/2; if $306800<=$ codigo $<=306899$ then gasto37+gasto; if $306900<=$ codigo $<=306999$ then gasto37+gasto/2; if $306900<=$ codigo $<=306999$ then gasto32+gasto/2; if $307000<=$ codigo $<=307099$ then gasto37+gasto; if $307100<=$ codigo $<=307299$ then gasto53+gasto; if $307300<=$ codigo $<=308099$ then gasto8+gasto; if $308100<=$ codigo $<=308299$ then gasto9+gasto; if $308300<=$ codigo $<=308399$ then gasto $10+$ gasto; if $308400<=$ codigo $<=308499$ then gasto7+gasto; if $308500<=$ codigo $<=308599$ then gasto $10+$ gasto; if $308600<=$ codigo $<=308699$ then gasto $7+$ gasto; if $308700<=$ codigo $<=309699$ then gasto6+gasto; if $309700<=$ codigo $<=309799$ then gasto2+gasto; if $309800<=$ codigo $<=309899$ then gasto $1+$ gasto; if $309900<=$ codigo $<=309999$ then gasto $2+$ gasto/3; if $309900<=$ codigo $<=309999$ then gasto3+gasto/3; if $309900<=$ codigo $<=309999$ then gasto $4+$ gasto/3; if $310000<=$ codigo $<=310099$ then gasto2+gasto; if $310100<=$ codigo $<=310199$ then gasto $1+$ gasto; if $310200<=$ codigo $<=310299$ then gasto $2+$ gasto/3; if $310200<=$ codigo $<=310299$ then gasto $3+$ gasto/3; if $310200<=$ codigo $<=310299$ then gasto $4+$ gasto/3; if $310300<=$ codigo $<=310499$ then gasto6+gasto;

if $400100<=$ codigo $<=400699$ then gasto $19+$ gasto; if $400700<=$ codigo $<=401299$ then gasto32+gasto; if $401400<=$ codigo $<=401499$ then gasto19+gasto/2; if $401400<=$ codigo $<=401499$ then gasto32+gasto/2; if $401500<=$ codigo $<=401699$ then gasto32+gasto; if $401700<=$ codigo $<=401799$ then gasto19+gasto/3; if $401700<=$ codigo $<=401799$ then gasto32+gasto/3; if $401700<=$ codigo $<=401799$ then gasto35+gasto/3; if $401900<=$ codigo $<=402099$ then gasto32+gasto; if $402200<=$ codigo $<=402299$ then gasto32+gasto; if $402300<=$ codigo $<=402399$ then gasto30 + gasto/3; if $402300<=$ codigo $<=402399$ then gasto19+gasto/3; if $402300<=$ codigo $<=402399$ then gasto35+gasto/3; if $402400<=$ codigo $<=402499$ then gasto32+gasto/3; if $402400<=$ codigo $<=402499$ then gasto $19+$ gasto/3; if $402400<=$ codigo $<=402499$ then gasto35+gasto/3; if $402500<=$ codigo $<=402599$ then gasto16+gasto/8; if $402500<=$ codigo $<=402599$ then gasto $19+$ gasto/8; if $402500<=$ codigo $<=402599$ then gasto30+gasto/8; if $402500<=$ codigo $<=402599$ then gasto36 + gasto/8; if $402500<=$ codigo $<=402599$ then gasto53+gasto/8; if $402500<=$ codigo $<=402599$ then gasto $21+$ gasto $/ 8$; if $402500<=$ codigo $<=402599$ then gasto32+gasto/8; 
if $402500<=$ codigo $<=402599$ then gasto35+gasto/8; if $402600<=$ codigo $<=402699$ then gasto30+gasto; if $402700<=$ codigo $<=402799$ then gasto35+gasto; if $402800<=$ codigo $<=402899$ then gasto38+gasto; if $402900<=$ codigo $<=402999$ then gasto19+gasto/3; if $402900<=$ codigo $<=402999$ then gasto30+gasto/3; if $402900<=$ codigo $<=402999$ then gasto35+gasto/3; if $403000<=$ codigo $<=403099$ then gasto $19+$ gasto; if $403100<=$ codigo $<=403999$ then gasto30+gasto; if $404000<=$ codigo $<=404099$ then gasto $19+$ gasto/3; if $404000<=$ codigo $<=404099$ then gasto35+gasto/3; if $404000<=$ codigo $<=404099$ then gasto30+gasto/3; if $404100<=$ codigo $<=404199$ then gasto $15+$ gasto/4; if $404100<=$ codigo $<=404199$ then gasto $16+$ gasto/4; if $404100<=$ codigo $<=404199$ then gasto19+gasto/4; if $404100<=$ codigo $<=404199$ then gasto32+gasto/4; if $404200<=$ codigo $<=404299$ then gasto38+gasto; if $404400<=$ codigo $<=405099$ then gasto22+gasto; if $405100<=$ codigo $<=405299$ then gasto $19+$ gasto; if $405300<=$ codigo $<=405699$ then gasto22+gasto; if $405700<=$ codigo $<=405799$ then gasto $19+$ gasto; if $405800<=$ codigo $<=405999$ then gasto $22+$ gasto; if $406000<=$ codigo $<=406099$ then gasto19+gasto; if $406100<=$ codigo $<=406199$ then gasto $22+$ gasto; if $406200<=$ codigo $<=406299$ then gasto $22+$ gasto; if $406300<=$ codigo $<=406399$ then gasto20+gasto; if $406400<=$ codigo $<=406899$ then gasto $22+$ gasto; if $406900<=$ codigo $<=406999$ then gasto20+gasto/2; if $406900<=$ codigo $<=406999$ then gasto $19+$ gasto/ 2 ; if $407000<=$ codigo $<=407299$ then gasto22+gasto/2; if $407000<=$ codigo $<=407299$ then gasto38+gasto/2; if $407300<=$ codigo $<=407399$ then gasto $15+$ gasto; if $407400<=$ codigo $<=407499$ then gasto $15+$ gasto/2; if $407400<=$ codigo $<=407499$ then gasto $16+$ gasto/2; if $407500<=$ codigo $<=407599$ then gasto $15+$ gasto/4; if $407500<=$ codigo $<=407599$ then gasto16+gasto/4; if $407500<=$ codigo $<=407599$ then gasto19+gasto/4; if $407500<=$ codigo $<=407599$ then gasto35+gasto/4; if $407600<=$ codigo $<=408199$ then gasto $19+$ gasto; if $408200<=$ codigo $<=408299$ then gasto19+gasto/2; if $408200<=$ codigo $<=408299$ then gasto35+gasto/2; if $408300<=$ codigo $<=408399$ then gasto $19+$ gasto; if $408400<=$ codigo $<=408599$ then gasto22+gasto; if $408600<=$ codigo $<=408699$ then gasto38+gasto; if $408800<=$ codigo $<=409599$ then gasto $18+$ gasto; if $409600<=$ codigo $<=409699$ then gasto35+gasto; if $409700<=$ codigo $<=409899$ then gasto18+gasto; if $409900<=$ codigo $<=409999$ then gasto34+gasto; if $410000<=$ codigo $<=410099$ then gasto $19+$ gasto; if $410100<=$ codigo $<=410199$ then gasto34+gasto; 
if $410200<=$ codigo $<=410299$ then gasto34+gasto/2; if $410200<=$ codigo $<=410299$ then gasto35+gasto/2; if $410300<=$ codigo $<=410399$ then gasto32+gasto/2; if $410300<=$ codigo $<=410399$ then gasto35+gasto/2; if $410400<=$ codigo $<=410499$ then gasto32+gasto/4; if $410400<=$ codigo $<=410499$ then gasto35+gasto/4; if $410400<=$ codigo $<=410499$ then gasto $18+$ gasto/4; if $410400<=$ codigo $<=410499$ then gasto $19+$ gasto/4; if $410500<=$ codigo $<=410599$ then gasto $19+$ gasto; if $410600<=$ codigo $<=410899$ then gasto53+gasto; if $410900<=$ codigo $<=410999$ then gasto $49+$ gasto/2; if $410900<=$ codigo $<=410999$ then gasto53+gasto/2; if $411000<=$ codigo $<=411399$ then gasto57+gasto;

if $500100<=$ codigo $<=500799$ then gasto $18+$ gasto; if $500800<=$ codigo $<=500899$ then gasto18+gasto/3; if $500800<=$ codigo $<=500899$ then gasto $21+$ gasto/3; if $500800<=$ codigo $<=500899$ then gasto30+gasto/3; if $500900<=$ codigo $<=500999$ then gasto34+gasto; if $501000<=$ codigo $<=501099$ then gasto34+gasto; if $501100<=$ codigo $<=501699$ then gasto $21+$ gasto; if $501700<=$ codigo $<=501899$ then gasto $21+$ gasto/3; if $501700<=$ codigo $<=501899$ then gasto22+gasto/3; if $501700<=$ codigo $<=501899$ then gasto $24+$ gasto/3; if $501900<=$ codigo $<=503499$ then gasto52+gasto; if $503500<=$ codigo $<=503999$ then gasto52+gasto; if $504000<=$ codigo $<=504099$ then gasto $47+$ gasto/2; if $504000<=$ codigo $<=504099$ then gasto52+gasto/2;

if $600100<=$ codigo $<=600299$ then gasto23+gasto; if $600300<=$ codigo $<=600499$ then gasto23+gasto; if $600500<=$ codigo $<=600599$ then gasto23+gasto/2; if $600500<=$ codigo $<=600599$ then gasto $24+$ gasto/2; if $600600<=$ codigo $<=600699$ then gasto35+gasto; if $600700<=$ codigo $<=600799$ then gasto $22+$ gasto; if $600800<=$ codigo $<=600899$ then gasto23+gasto; if $600900<=$ codigo $<=600999$ then gasto25+gasto; if $601000<=$ codigo $<=601099$ then gasto23+gasto/2; if $601000<=$ codigo $<=601099$ then gasto24+gasto/2; if $601100<=$ codigo $<=601899$ then gasto38+gasto; if $601900<=$ codigo $<=602299$ then gasto6+gasto; if $602300<=$ codigo $<=602399$ then gasto $18+$ gasto; if $602400<=$ codigo $<=602499$ then gasto51+gasto; if $602500<=$ codigo $<=602599$ then gasto50+gasto; if $602600<=$ codigo $<=602699$ then gasto $45+$ gasto; if $602700<=$ codigo $<=602799$ then gasto $45+$ gasto; if $602800<=$ codigo $<=602899$ then gasto $49+$ gasto; if $603000<=$ codigo $<=603299$ then gasto $41+$ gasto; if $603300<=$ codigo $<=603399$ then gasto $41+$ gasto; if $603400<=$ codigo $<=603599$ then gasto41+gasto; 
if $603600<=$ codigo $<=603999$ then gasto $41+$ gasto; if $604000<=$ codigo $<=604099$ then gasto $41+$ gasto; if $604100<=$ codigo $<=604299$ then gasto $41+$ gasto; if $604300<=$ codigo $<=604399$ then gasto $41+$ gasto/2; if $604300<=$ codigo $<=604399$ then gasto $40+$ gasto/2; if $604400<=$ codigo $<=604499$ then gasto $41+$ gasto; if $604500<=$ codigo $<=604599$ then gasto $45+$ gasto; if $604600<=$ codigo $<=604799$ then gasto $46+$ gasto; if $604800<=$ codigo $<=605399$ then gasto $46+$ gasto;

if $700131<=$ codigo $<=700435$ then gasto22+gasto; if $700532<=$ codigo $<=700738$ then gasto22+gasto; if 700836=codigo then gasto36+gasto; if $701531<=$ codigo $<=701639$ then gasto21+gasto; if $701737=$ codigo then gasto36+gasto; if $701835<=$ codigo $<=701933$ then gasto21+gasto; if $702031=$ codigo then gasto19+gasto/2; if $702031=$ codigo then gasto22+gasto/2; if $702139=$ codigo then gasto $1+$ gasto/3; if $702139=$ codigo then gasto24+gasto/3; if $702139=$ codigo then gasto36+gasto/3; if $700934<=$ codigo $<=701434$ then gasto $22+$ gasto; if $702209=$ codigo then gasto22+gasto; if $702307<=$ codigo $<=702405$ then gasto18+gasto/2; if $702307<=$ codigo $<=702405$ then gasto $22+$ gasto/2; if $702502=$ codigo then gasto22+gasto; if $702600=$ codigo then gasto22+gasto/2; if $702600=$ codigo then gasto $18+$ gasto/2; if $702736=$ codigo then gasto30+gasto/3; if $702736=$ codigo then gasto19+gasto/3; if $702736=$ codigo then gasto35+gasto/3; if $702834=$ codigo then gasto36+gasto/3; if $702834=$ codigo then gasto35+gasto/3; if 702834=codigo then gasto19+gasto/3; if 702911=codigo then gasto19+gasto; if $703019=$ codigo then gasto35+gasto/2; if $703019=$ codigo then gasto36+gasto/2; if $703117<=$ codigo $<=703616$ then gasto35+gasto/2; if $703117<=$ codigo $<=703616$ then gasto36+gasto/2; if $703714=$ codigo then gasto34+gasto/2; if $703714=$ codigo then gasto36+gasto/2; if $703805=$ codigo then gasto36+gasto; if $703910=$ codigo then gasto34+gasto/2; if $703910=$ codigo then gasto $18+$ gasto/2; if $704018=$ codigo then gasto $1+$ gasto/2; if $704018=$ codigo then gasto35+gasto/2; if $704121=$ codigo then gasto1+gasto; if $704207=$ codigo then gasto27+gasto; if $704312<=$ codigo $<=704517$ then gasto38+gasto; if 704608=codigo then gasto53+gasto; 
if $704706=$ codigo then gasto53+gasto/2; if $704706=$ codigo then gasto57+gasto/2; if $704804<=$ codigo $<=705000$ then gasto53+gasto; if $705120=$ codigo then gasto53+gasto $/ 2$; if $705120=$ codigo then gasto $57+$ gasto/2; if $705206=$ codigo then gasto53+gasto; if 705304=codigo then gasto53+gasto/2; if 705304=codigo then gasto57+gasto/2; if $705402=$ codigo then gasto $40+$ gasto/2; if $705402=$ codigo then gasto53+gasto/2; if $705509<=$ codigo $<=705629$ then gasto53+gasto/2; if $705509<=$ codigo $<=705629$ then gasto57+gasto/2; if $705712=$ codigo then gasto $49+$ gasto; if $705810=$ codigo then gasto53+gasto; if 705901=codigo then gasto49+gasto; if 706021=codigo then gasto49+gasto/2; if 706021=codigo then gasto53+gasto/2; if $706100<=$ codigo $<=706199$ then gasto53+gasto; if $706200<=$ codigo $<=706299$ then gasto53+gasto/2; if $706200<=$ codigo $<=706299$ then gasto36 + gasto/2; if $706300<=$ codigo $<=706399$ then gasto53+gasto; if $706400<=$ codigo $<=706899$ then gasto34+gasto; if $706900<=$ codigo $<=707099$ then gasto55+gasto; if $707100<=$ codigo $<=707599$ then gasto51+gasto; if $707600<=$ codigo $<=707699$ then gasto34+gasto; if $707700<=$ codigo $<=708299$ then gasto51+gasto; if $708300<=$ codigo $<=708699$ then gasto34+gasto; if $708700<=$ codigo $<=708999$ then gasto51+gasto; if $709000<=$ codigo $<=709199$ then gasto34+gasto; if $709200<=$ codigo $<=709299$ then gasto55+gasto; if $709300<=$ codigo $<=709499$ then gasto51+gasto; if $709500<=$ codigo $<=709599$ then gasto55+gasto; if $709600<=$ codigo $<=709699$ then gasto51+gasto; if $709700<=$ codigo $<=709899$ then gasto34+gasto; if $709900<=$ codigo $<=710199$ then gasto51+gasto; if $710200<=$ codigo $<=710399$ then gasto34+gasto; if $710400<=$ codigo $<=710699$ then gasto51+gasto; if $710700<=$ codigo $<=710899$ then gasto34+gasto; if $710900<=$ codigo $<=710999$ then gasto55+gasto; if $711000<=$ codigo $<=711199$ then gasto51+gasto; if $711200<=$ codigo $<=711799$ then gasto55+gasto; if $711800<=$ codigo $<=711899$ then gasto51+gasto; if $711900<=$ codigo $<=712099$ then gasto34+gasto; if $712100<=$ codigo $<=712399$ then gasto55+gasto; if $712400<=$ codigo $<=712499$ then gasto51+gasto; if $712500<=$ codigo $<=712699$ then gasto34+gasto; if $712700<=$ codigo $<=712999$ then gasto1+gasto; if $713000<=$ codigo $<=713199$ then gasto34+gasto; if $713200<=$ codigo $<=713299$ then gasto51+gasto; if $713300<=$ codigo $<=713399$ then gasto34+gasto; 
if $713400<=$ codigo $<=713499$ then gasto51+gasto; if $713500<=$ codigo $<=713599$ then gasto34+gasto; if $713600<=$ codigo $<=713699$ then gasto36+gasto/4; if $713600<=$ codigo $<=713699$ then gasto34+gasto/4; if $713600<=$ codigo $<=713699$ then gasto35+gasto/4; if $713600<=$ codigo $<=713699$ then gasto18+gasto/4; if $713800<=$ codigo $<=713899$ then gasto $47+$ gasto; if $714000<=$ codigo $<=714599$ then gasto55+gasto;

if $800100<=$ codigo $<=800499$ then gasto53+gasto; if $800500<=$ codigo $<=800599$ then gasto19+gasto/2; if $800500<=$ codigo $<=800599$ then gasto $22+$ gasto/2; if $800600<=$ codigo $<=800699$ then gasto35+gasto; if $800700<=$ codigo $<=800799$ then gasto $22+$ gasto/2; if $800700<=$ codigo $<=800799$ then gasto35+gasto/2; if $800800<=$ codigo $<=800999$ then gasto32+gasto/2; if $800800<=$ codigo $<=800999$ then gasto35+gasto/2; if $801000<=$ codigo $<=801099$ then gasto19+gasto/5; if $801000<=$ codigo $<=801099$ then gasto32+gasto/5; if $801000<=$ codigo $<=801099$ then gasto35+gasto/5; if $801000<=$ codigo $<=801099$ then gasto22+gasto/5; if $801000<=$ codigo $<=801099$ then gasto36 + gasto/5; if $801100<=$ codigo $<=801199$ then gasto38+gasto/2; if $801100<=$ codigo $<=801199$ then gasto22+gasto/2; if $801200<=$ codigo $<=801599$ then gasto $18+$ gasto; if $801600<=$ codigo $<=801699$ then gasto19+gasto; if $801700<=$ codigo $<=802399$ then gasto18+gasto; if $802400<=$ codigo $<=802499$ then gasto36+gasto; if $802500<=$ codigo $<=802599$ then gasto $21+$ gasto; if $802600<=$ codigo $<=802699$ then gasto36+gasto; if $802700<=$ codigo $<=802799$ then gasto38+gasto; if $802800<=$ codigo $<=802999$ then gasto31+gasto; if $803000<=$ codigo $<=803099$ then gasto $21+$ gasto; if $803100<=$ codigo $<=803199$ then gasto38+gasto/3; if $803100<=$ codigo $<=803199$ then gasto21+gasto/3; if $803100<=$ codigo $<=803199$ then gasto31+gasto/3; if $803200<=$ codigo $<=803299$ then gasto36 + gasto; if $803300<=$ codigo $<=803399$ then gasto $24+$ gasto; if $803400<=$ codigo $<=803499$ then gasto $22+$ gasto/2; if $803400<=$ codigo $<=803499$ then gasto35+gasto/2; if $803500<=$ codigo $<=803599$ then gasto30+gasto; if $803600<=$ codigo $<=803699$ then gasto19+gasto; if $803700<=$ codigo $<=803799$ then gasto38+gasto/3; if $803700<=$ codigo $<=803799$ then gasto22+gasto/3; if $803700<=$ codigo $<=803799$ then gasto36+gasto/3; if $803800<=$ codigo $<=803899$ then gasto34+gasto; if $803900<=$ codigo $<=803999$ then gasto $19+$ gasto/5; if $803900<=$ codigo $<=803999$ then gasto $21+$ gasto/5; if $803900<=$ codigo $<=803999$ then gasto32+gasto/5; if $803900<=$ codigo $<=803999$ then gasto35+gasto/5; 
if $803900<=$ codigo $<=803999$ then gasto36 + gasto/5; if $804000<=$ codigo $<=804199$ then gasto $40+$ gasto; if $804200<=$ codigo $<=804499$ then gasto $40+$ gasto; if $804500<=$ codigo $<=806099$ then gasto $40+$ gasto; if $806100<=$ codigo $<=806299$ then gasto $40+$ gasto; if $806300<=$ codigo $<=806499$ then gasto $40+$ gasto; if $806500<=$ codigo $<=806599$ then gasto $40+$ gasto; if $806600<=$ codigo $<=806699$ then gasto $45+$ gasto; if $806700<=$ codigo $<=806799$ then gasto $47+$ gasto; if $806800<=$ codigo $<=806999$ then gasto $49+$ gasto; if $807000<=$ codigo $<=807099$ then gasto57+gasto; if $807100<=$ codigo $<=807199$ then gasto57+gasto/6; if $807100<=$ codigo $<=807199$ then gasto53+gasto/6; if $807100<=$ codigo $<=807199$ then gasto $47+$ gasto/6; if $807100<=$ codigo $<=807199$ then gasto32+gasto/6; if $807100<=$ codigo $<=807199$ then gasto15+gasto/6; if $807100<=$ codigo $<=807199$ then gasto1+gasto/6; if $807200<=$ codigo $<=807299$ then gasto53+gasto;

keep gasto1 gasto2 gasto6-gasto9 gasto15 gasto18-gasto32 gasto34 gasto35-gasto38 gasto40 gsto 41 gasto46 gasto47 gasto49-gasto53gasto55 gasto57 psv ps th resto1-resto9 imptos alqimpt fpobla norden;

if last.norden then output; 